\title{
National Profile on Commercially Generated Low-Level Radioactive Mixed Waste
}

Manuscript Completed: August 1992

Date Published: December 1992

Prepared by

J. A. Klein, J. E. Mrochek, R. L. Jolley, I. W. Osborne-Lee, A. A. Francis, T. Wright

Oak Ridge National Laboratory

Managed by Martin Marietta Energy Systems, Inc.

Oak Ridge National Laboratory

Oak Ridge, TN 37831-6285

Prepared for

Division of Low-Level Waste Management and Decommissioning

Office of Nuclear Material Safety and Safeguards

U.S. Nuclear Regulatory Commission

Washington, DC 20555

NRC FIN L1647

and

State and Regional Programs Branch

Office of Solid Waste

U.S. Environmental Protection Agency

Washington, DC 20460 


\begin{abstract}
This report details the findings and conclusions drawn from a survey undertaken as part of a joint U.S. Nuclear Regulatory Commission and U.S. Environmental Protection Agency-sponsored project entitled "National Profile on Commercially Generated Low-Level Radioactive Mixed Waste." The overall objective of the work was to compile a national profile on the volumes, characteristics, and treatability of commercially generated low-level mixed waste for 1990 by five major facility categories-academic, industrial, medical, and NRC-/Agreement State-licensed government facilities and nuclear utilities. Included in this report are descriptions of the methodology used to collect and collate the data, the procedures used to estimate the mixed waste generation rate for commercial facilities in the United States in 1990, and the identification of available treatment technologies to meet applicable EPA treatment standards (40 CFR Part 268) and, if possible, to render the hazardous component of specific mixed waste streams nonhazardous. The report also contains information on existing and potential commercial waste treatment facilities that may provide treatment for specific waste streams identified in the national survey. The report does not include any aspect of the Department of Energy's (DOE's) management of mixed waste and generally does not address wastes from remedial action activities.
\end{abstract}




\section{Contents}

$\underline{\text { Page }}$

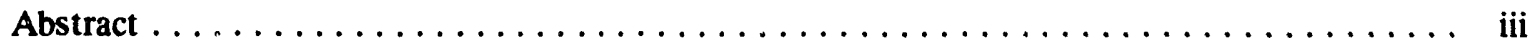

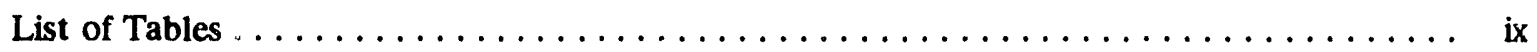

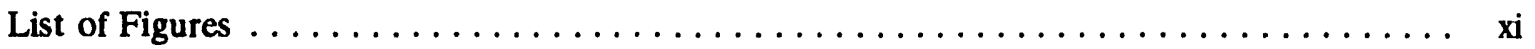

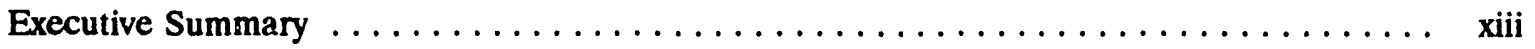

Abbreviations $\ldots \ldots \ldots \ldots \ldots \ldots \ldots \ldots \ldots \ldots \ldots \ldots \ldots \ldots \ldots \ldots \ldots \ldots \ldots \ldots \ldots$

Acknowledgments $\ldots \ldots \ldots \ldots \ldots \ldots \ldots \ldots \ldots \ldots \ldots \ldots \ldots \ldots \ldots \ldots \ldots \ldots \ldots \ldots$

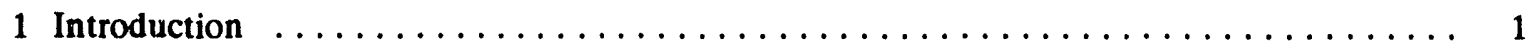

1.1 Objective of the National Profile $\ldots \ldots \ldots \ldots \ldots \ldots \ldots \ldots \ldots \ldots \ldots \ldots \ldots$

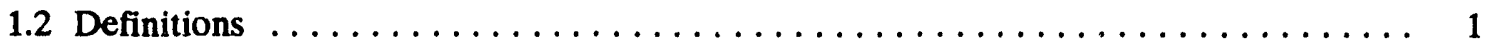

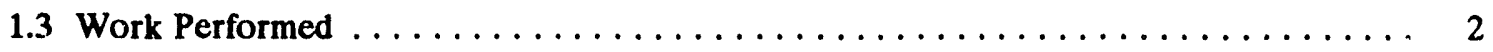

1.3.1 Evaluation of Available Mixed Waste Information $\ldots \ldots \ldots \ldots \ldots \ldots \ldots$

1.3.2 Evaluation of Adequacy of Existing Information $\ldots \ldots \ldots \ldots \ldots \ldots \ldots$

1.3.3 Data Collection Plan ........................... 4

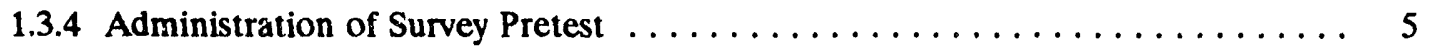

1.4 Generation of Mixed Waste Profile $\ldots \ldots \ldots \ldots \ldots \ldots \ldots \ldots \ldots \ldots \ldots \ldots$

2 Review of Relevant Regulations Affecting the Mixed Waste Profile $\ldots \ldots \ldots \ldots$

2.1 Regulation of Low-Level Radioactive Waste $\ldots \ldots \ldots \ldots \ldots \ldots \ldots \ldots \ldots \ldots$

2.2 Regulation of Hazardous Waste $\ldots \ldots \ldots \ldots \ldots \ldots \ldots \ldots \ldots \ldots \ldots$

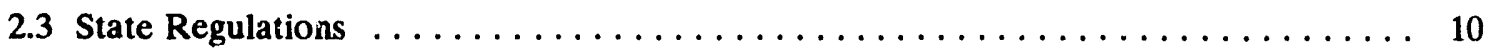

2.3.1 Low-Level Radioactive Waste in Agreement States . . . . . . . . . . . . . 10

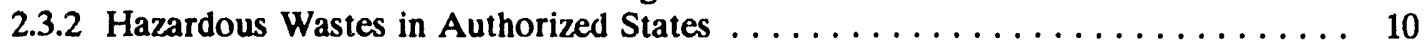

2.3.3 Authorization for Mixed Waste $\ldots \ldots \ldots \ldots \ldots \ldots \ldots \ldots \ldots \ldots \ldots \ldots \ldots$

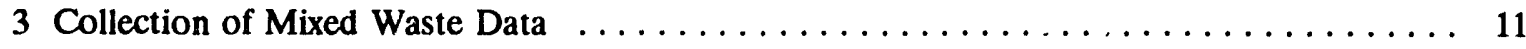

3.1 Objective $\ldots \ldots \ldots \ldots \ldots \ldots \ldots \ldots \ldots \ldots \ldots \ldots \ldots \ldots \ldots \ldots \ldots \ldots \ldots \ldots \ldots$

3.2 Collection Methods $\ldots \ldots \ldots \ldots \ldots \ldots \ldots \ldots \ldots \ldots \ldots \ldots \ldots \ldots \ldots \ldots \ldots$

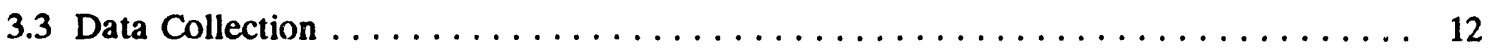

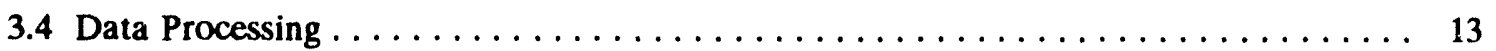




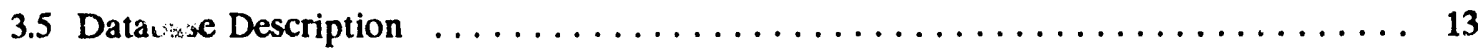

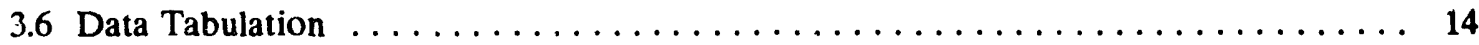

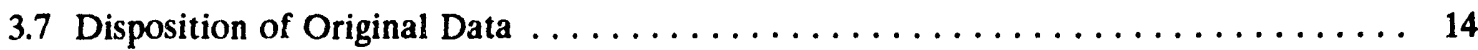

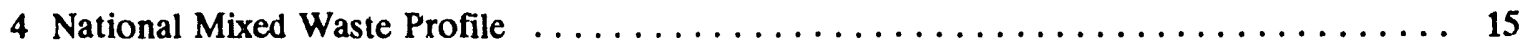

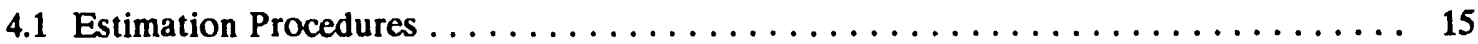

4.1.1 Survey Design Objectives $\ldots \ldots \ldots \ldots \ldots \ldots \ldots \ldots \ldots \ldots \ldots \ldots \ldots \ldots \ldots \ldots \ldots \ldots, 15$

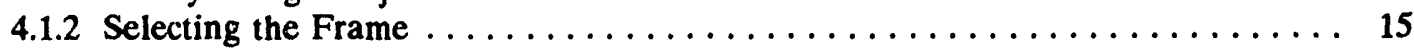

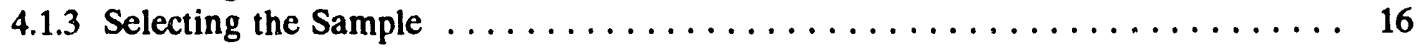

4.1.4 Weighting of Sample Data and Estimation of Total Volumes ........... 16

4.1.5 Expected Accuracy and Precision of Survey Results . . . . . . . . . . . 17

4.1.6 Approximate $95 \%$ Confidence Intervals $\ldots \ldots \ldots \ldots \ldots \ldots \ldots \ldots \ldots \ldots$

4.1.7 Limitations of Survey Design $\ldots \ldots \ldots \ldots \ldots \ldots \ldots \ldots \ldots \ldots \ldots \ldots \ldots$

4.2 Description of the National Commercial Mixed Waste Profile $\ldots \ldots \ldots \ldots \ldots \ldots 19$

4.2.1 Facility Categorization ............................ 19

4.2.2 Low-Level Radioactive Waste (LLRW) Stream Descriptions . . . . . . . . . . 19

4.2.3 Estimated Mixed Waste Generation Rates by Facility Category . . . . . . . 20

4.2.4 Stored Mixed Wastes by Category $\ldots \ldots \ldots \ldots \ldots \ldots \ldots \ldots \ldots \ldots \ldots \ldots$

4.2.5 Mixed Waste That Currently Cannot Be Treated $\ldots \ldots \ldots \ldots \ldots \ldots \ldots .21$

4.2.6 Types of Mixed Wastes Reported ....................... 21

4.2.7 Estimated Mixed Waste Generated by Compacts and Unaligned States . . . . . . 22

4.2.8 Detailed Profile Description by Individual Category .............. 22

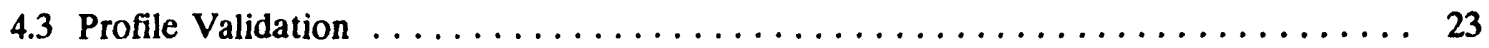

4.3.1 Comparison with Manifest Data on Low-Level Radioactive Waste (LLRW) . . . 23

4.3.2 Comparison with Existing Data on Mixed Waste Generation .......... 23

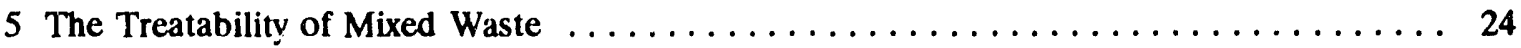

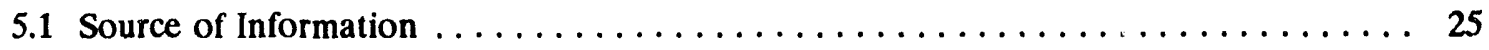

5.2 Characteristics of Mixed Waste $\ldots \ldots \ldots \ldots \ldots \ldots \ldots \ldots \ldots \ldots \ldots \ldots \ldots \ldots \ldots \ldots \ldots \ldots \ldots, 25$

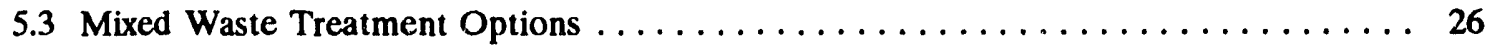

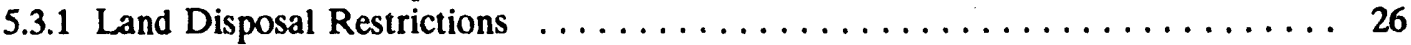

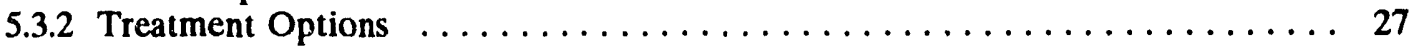

5.3.3 Selection of Recommended Treatment .................... 27

5.4 The Demand for Treatment Services $\ldots \ldots \ldots \ldots \ldots \ldots \ldots \ldots \ldots \ldots \ldots \ldots \ldots$

5.5 Profiles of Mixed Waste Treatment Industries $\ldots \ldots \ldots \ldots \ldots \ldots \ldots \ldots \ldots \ldots, \ldots \ldots$

5.5 .1 Overview of Existing Treatment Capability .................. 31

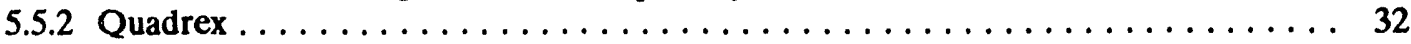

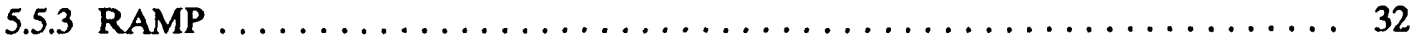

5.5.4 NSSI/Recovery Services, Inc. $\ldots \ldots \ldots \ldots \ldots \ldots \ldots \ldots \ldots \ldots \ldots \ldots \ldots$

NUREG/CR-5938 vi 
5.5.5 Diversified Scientific Services, Inc. $\ldots \ldots \ldots \ldots \ldots \ldots \ldots \ldots \ldots \ldots \ldots \ldots \ldots$

5.6 Potential Mixed Waste Treatment Facilities $\ldots \ldots \ldots \ldots \ldots \ldots \ldots \ldots \ldots \ldots \ldots \ldots$

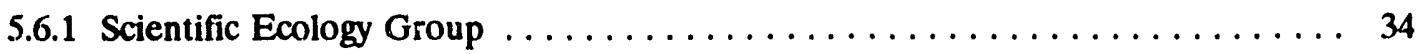

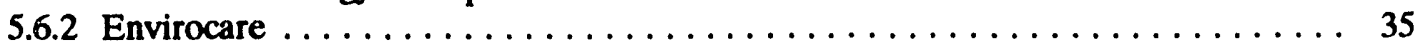

5.7 Comparison of Treatment Availability Versus Demand $\ldots \ldots \ldots \ldots \ldots \ldots \ldots \ldots$

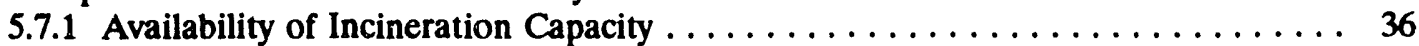

5.7 .2 Availability of Stabilization Capacity $\ldots \ldots \ldots \ldots \ldots \ldots \ldots \ldots \ldots \ldots \ldots \ldots \ldots \ldots$

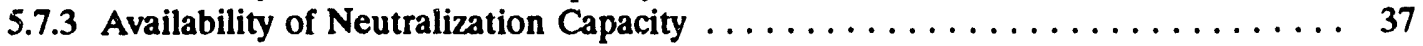

5.7.4 Availability of Capacity for Distillation/Oxidation of Organics . . . . . . . . 37

5.7.5 Availability of Capacity for Decontamination/Macroencapsulation of Lead . . . . 37

5.7.6 Availability of Capacity for Chemical Reduction of Chromium Wastes . . . . . . 37

5.7.7 Thermal Recovery of Mercury and Lead .................... 37

5.7.8 Summary of Current Waste Treatability Capacity $\ldots \ldots \ldots \ldots \ldots \ldots \ldots \ldots$

5.7.9 Estimated Future Treatability Capacity . . . . . . . . . . . . . . . 39

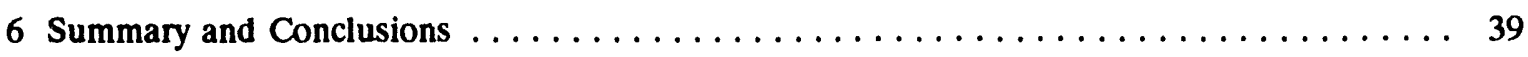

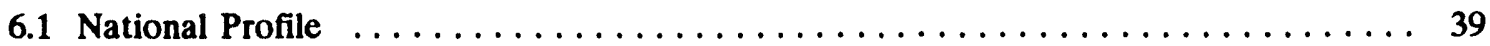

6.2 The Treatability of Mixed Waste $\ldots \ldots \ldots \ldots \ldots \ldots \ldots \ldots \ldots \ldots \ldots \ldots \ldots \ldots$

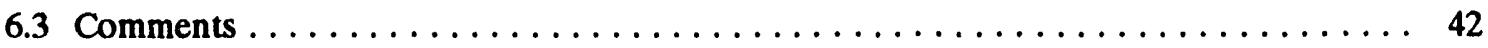

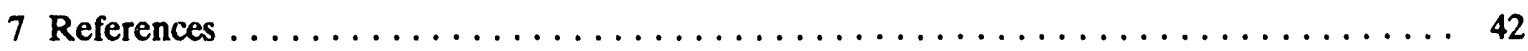

APPENDIX A: STUDY DESIGN SPECIFICATIONS

APPENDIX B: SURVEY PACKAGE - NATIONAL PROFILE ON MIXED WASTE (INCLUDING MIXED WASTE QUESTIONNAIRE)

APPENDIX C: FIELD STRUCTURE MIXED WASTE DATABASE

APPENDIX D: DETAILED “AS REPORTED” DATA TABLES

APPENDIX E: ESTIMATION PROCEDURES

APPENDIX F: RECOMMENDATION FOR CHANGES TO SURVEY QUESTIONNAIRE

APPENDIX G: PERMITS AND LICENSES FOR COMPANIES TREATING MIXED WASTE

APPENDIX H: OPEN LITERATURE CITATIONS FOR SELECTED MIXED WASTE TREATMENT TECHNOLOGIES 


\section{List of Tables}

Page

4.1 Mixed waste survey - Operational statistics $\ldots \ldots \ldots \ldots \ldots \ldots \ldots \ldots \ldots \ldots$

4.2 Licensee facility categories and number of survey respondents $\ldots \ldots \ldots \ldots \ldots \ldots$

4.3 National Mixed Waste Profile - Generation rate in $1990 \ldots \ldots \ldots \ldots \ldots \ldots \ldots$

4.4 National Mixed Waste Profile - Amount in storage as of $12 / 31 / 90 \ldots \ldots \ldots \ldots \ldots$

4.5 National Mixed Waste Profile - Waste generated in 1990 that currently cannot be treated 48

4.6 National Mixed Waste Profile - Generation rate in 1990 - By hazardous waste stream 49

4.7 National Mixed Waste Profile - Amount in storage as of 12/31/90 -

By hazardous waste stream $\ldots \ldots \ldots \ldots \ldots \ldots \ldots \ldots \ldots \ldots \ldots \ldots \ldots$

4.8 National Mixed Waste Profile - Waste generated in 1990 that currently cannot be treated By hazardous waste stream $\ldots \ldots \ldots \ldots \ldots \ldots \ldots \ldots \ldots \ldots \ldots \ldots \ldots \ldots$

4.9 State composition of the nine compacts as of early $1992 \ldots \ldots \ldots \ldots \ldots \ldots \ldots$

4.10 Mixed waste generated in 1990 - By facility category and compact/state - Weighted . . 53

4.11 Facility mixed waste profile - Academic - Weighted $\ldots \ldots \ldots \ldots \ldots \ldots \ldots$

4.12 Facility mixed waste profile - Government - Weighted $\ldots \ldots \ldots \ldots \ldots \ldots \ldots$. 55

4.13 Facility mixed waste profile - Industrial - Weighted $\ldots \ldots \ldots \ldots \ldots \ldots \ldots$

4.14 Facility mixed waste profile - Medical - Weighted $\ldots \ldots \ldots \ldots \ldots \ldots \ldots \ldots$

4.15 Facility mixed waste profile - Nuclear utilities - Weighted $\ldots \ldots \ldots \ldots \ldots \ldots$. 58

4.16 Facility mixed waste profile - All facilities - Weighted $\ldots \ldots \ldots \ldots \ldots \ldots \ldots$

4.17 Compact/State generation of LLRW - generation and/or disposal in $1990 \ldots \ldots \ldots 60$

4.18 Compact/State generation of mixed waste - Generation rate in $1990 \ldots \ldots \ldots \ldots 61$

5.1 Mixed waste volume generation and storage in the United States for calendar year 199062

5.2 Mixed waste treatment alternatives - available options $\ldots \ldots \ldots \ldots \ldots \ldots \ldots$

5.3 Treatment demand summary by waste category $\ldots \ldots \ldots \ldots \ldots \ldots \ldots \ldots$

5.4 Current and potential future commercial industries treating mixed wastes $\ldots \ldots \ldots 68$ 


\section{List of Figures}

Page

$4.1 \quad$ Types of mixed waste streams - By facility category $\ldots \ldots \ldots \ldots \ldots \ldots \ldots \ldots$

4.2 Mixed waste generation in 1990 by facility category - Weighted $\ldots \ldots \ldots \ldots \ldots$

4.3 Mixed waste generation in 1990 - By hazardous stream - Weighted $\ldots \ldots \ldots \ldots$

4.4 Mixed waste in storage as of $12 / 31 / 90$ - By facility category - Weighted $\ldots \ldots \ldots 74$

4.5 Mixed waste in storage as of 12/31/90 - By hazardous waste stream - Weighted .... 75

5.1 Mixed waste generation in 1990 by hazardous waste stream (weighted) without liquid

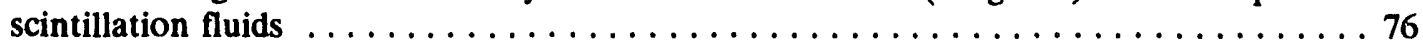

5.2 Commercial treatment capacity by vendor and treatment technology $\ldots \ldots \ldots \ldots 77$

5.3 Treatability of mixed waste - availability of services versus demand $\ldots \ldots \ldots \ldots$ 


\section{Executive Summary}

This report details the findings and conclusions drawn from a survey undertaken as part of a joint U.S. Nuclear Regulatory Commission and U.S. Environmental Protection Agency-sponsced project entitled "National Profile on Commercially Generated Low-Level Radioactive Mixed Waste." The overall objective of the work was to compile a national profile on the volumes, characteristics, and treatability of commercially generated low-level mixed waste for 1990 by five major facility categories-academic, industrial, medical, and NRC-/Agreement State-licensed government facilities and nuclear utilities. Included in this report are descriptions of the methodology used to collect and collate the data, the procedures used to estimate the mixed waste generation rate for commercial facilities in the United States in 1990, and the identification of available treatment technologies to meet applicable EPA treatment standards (40 CFR Part 268) and, if possible, to render the hazardous component of specific mixed waste streams nonhazardous. The report also contains information on existing and potential commercial waste treatment facilities that may provide treatment for specific waste streams identified in the national survey. The report does not include any aspect of the Department of Energy's (DOE's) management of mixed waste and generally does not address wastes from remedial action activities.

The national survey consisted of a series of steps which included: (1) selecting a total number of facilities to be sampled, based on an expected $25 \%$ nonresponse rate and a $10 \%$ relative standard error; (2) sending out a detailed questionnaire to a number of randomly selected facilities; (3) accumulating and compiling the responses in an appropriate format and database; (4) estimating the national generation rates based on multiplying the "raw" mixed waste generation data by weighting factors to correct for the fraction of the facilities in each group that were sent questionnaires. The final sample sizes were selected to achieve a relative standard error of $10 \%$ to provide a conservative survey design and to provide a measure of protection for uncorrectable factors such as incorrect and missing data.

The survey target population (survey frame) included a total of 2,936 facilities. The random sample selected from the target population consisted of 1,323 facilities. Data from 1,016 completed mixed waste survey questionnaires, including 21 facilities that reported they were out of business (77\% response rate), received by Oak Ridge National Laboratory indicate that approximately 81,000 it $^{3}$ of low-level radioactive mixed waste was generated in the United States in 1990 by those facilities surveyed. Approximately $63 \%$ of this reported volume was liquid scintillation fluids (LSF).

Using the weighting factors described previously to generate a statistically valid estimate of the 'national' profile, the survey estimates that approximately $140,000 \mathrm{ft}^{3}$ of commercial low-levil radioactive mixed waste was generated nationally in 1990 and that nearly $72 \%$ was LSF. Ir. addition, an estimated $75,000 \mathrm{ft}^{3}$ of commercial low-level mixed waste was in storage for various reasons as of December 31,1990 . The industrial category was estimated to be the largest generator and also the largest accumulator of mixed waste. Industrial facilities generated over $36 \%$ of the mixed waste generated in 1990 and accounted for $57 \%$ of the mixed waste in storage as of December 1, 1990. Data received from $97 \%$ of the operating nuclear utilities in the country indicated that they generated less than $10 \%$ of the estimated total 1990 generation rate for commercial mixed waste.

Although Compact/State and Hazardous Waste Stream data are presented, it should be emphasized that the profile was generated to be statistically valid only at the national level and only for the major facility categories. It is estimated that the overall accuracy of the projected 
commercial mixed waste generation rates and waste in storage are well within the objective of the study that was to be, at the $\mathbf{9 5 \%}$ confidence level, within a factor of 2 . Estimations of commercial mixed waste generation and storage at the state or regional level may be less reliable, mainly due to fewer samples in these substrata.

The survey sets upper and lower bounds on the volume of mixed waste that is untreatable under current technologies by making the simplifying assumption that LSF, oil, organic (not halogenated), and corrosive mixed wastes are treatable. Deducting the wastes that are assumed to be treatable from the estimated national total mixed waste generation rate leaves about $18,500 \mathrm{ft}^{3}$ of mixed waste that is untreatable. Thus, with this as an upper bound and the estimated $5,000 \mathrm{ft}^{3}$ of reported currently untreatable mixed waste as the lower bound, the untreatable mixed waste ranges from 3.5 to $13.3 \%$ of the estimated 1990 national generation rate of $140,000 \mathrm{ft}^{3}$. Please note, however, that the capacity to treat all of the so-called "treatable" mixed waste may not be available.

A broad spectrum of commercially generated low-level radioactive mixed waste streams are generated by the facilities surveyed including LSFs, halogenated and unhalogenated organics, wastes contaminated with toxic metals, and acidic and basic corrosives. These mixed wastes present a need for specific waste treatment services, including incineration, stabilization, chemical treatment, and recovery/reuse processes. Four commercial companies, NSSI (Houston, TX), DSSI (Kingston, TN), Quadrex (Gainesville, FL), and RAMP (Denver, CO), currently offer treatment services for mixed waste. Two other companies, SEG (Oak Ridge, TN) and Envirocare (Salt Lake City, UT), may offer mixed waste treatment services in the near future. Comparing estimated demand for commercial mixed waste treatment services (1990 generation rate plus total mixed waste in storage at the end of 1990) with available treatment capacity in specific mixed waste categories indicated that sufficient capacity seems to exist for more than $95 \%$ of all mixed waste except chlorinated fluorocarbons (CFCs), lead shielding and other waste contaminated with solid lead, and mercury-contaminated equipment and debris. The shortfall in commercial mixed waste treatment capacity amounts to about $12,000 \mathrm{ft}^{3}$. Currently operating commercial treatment facilities may be able to handle nearly all of the commercial mixed waste generated, based on 1990 generation data, but significant additional capacity must be developed to address the total demand which consists of not only the annual generation rate but also the mixed waste in storage at the end of 1990. In addition, this comparison does not include current and future demands that the noncommercial generators (i.e., the DOE) will have for commercial mixed waste treatment services. DOE's demand for commercial mixed waste treatment may affect the availability of these services to commercial generators. 


\section{Abbreviations}

ACURI

AEA

BDAT

CFC

Cd

Cor

DOE

EEI

EPA

$\mathrm{Hg}$

HSWA

IDB

LDR

LLRW

LLRWPAA

LSF

NEPA

Org-Cl

Org-Fl

Org-Other

OENL

MW

NARM

NRC

$\mathrm{Pb}$ RCRA .............. Resource Conservation and Recovery Act of 1976, as Amended

TCC . Host State Technical Coordinating Committee for Low-Level Radioactive Waste Disposal

Appalachian Compact Users of Radioactive Isotopes Atomic Energy Act of 1954, as Amended Best Demonstrated Available Technology Cadmium and Cadmium-containing Materials Chromium and Chromium-containing Materials U.S. Department of Energy Edison Electric Institute .. U.S. Environmental Protection Agency Mercury and Mercury-containing Materials Hazardous and Solid Waste Amendments of 1984 Integrated Data Base Land Disposal Restrictions (40 CFR Part 268) Low-Level Radioactive Waste Act of 1985, as Amended Liquid Scintillation Fluid National Environmental Policy Act of 1969 Chlorinated Organics Fluorinated Organics Organics Other Than Those Specifically Identified Oak Ridge National Laboratory Low-Level Radioactive Mixed Waste Naturally Occurring or Accelerator-Produced Radioactive Material
$\ldots \ldots \ldots \ldots \ldots \ldots$.S. Nuclear Regulatory Commission Naturally Occurring or Accelerator-Produced Radioactive Material
$\ldots \ldots \ldots \ldots \ldots$. . . . . Nuclear Regulatory Commission 


\section{Acknowledgnents}

We would like to take this opportunity to express our appreciation to individuals without whom the completion of this project would not have been possible. These included University of

Tennessee Environmental Law students - Shari Tayloe, Julie Martin, Kevin Townsel, Greg Oakley, and Larry Wallace for making the hundreds of follow-up telephone calls persuading facilities to respond to the survey; ORNL Biomedical and Environmental Information Analysis staff members - Mary Francis for database construction, organization and supervision, Karen Weaver and Cynthia Seiber for data entry, Mychal Manie for computer programming, and Gerry Danford for document tracking and quality assurance checking.

In addition, we would like to acknowledge the cooperation of members of Appalachian Compact Users of Radioactive Isotopes (ACURI) and its executive secretary, John Vincenti, for agreeing to participate in the pretest of the national survey. The Edison Electric Institute (EEI) is recognized for urging its members to complete their survey forms. In addition, the following compacts and states allowed us access to unpublished information they had on mixed waste generation in their compact or state: Appalachian Compact, Massachusetts, New York, Southeastern Compact, Southwestern Compact, and Texas. The ORNL study team would especially like to acknowledge the vital input of Chad Glenn of the Nuclear Regulatory Commission and Jared Flood of the Environmental Protection Agency who initially were the primary sponsor contacts involved with this program. 


\section{NATIONAL PROFILE ON COMMERCIALLY GENERATED LOW-LEVEL RADIOACTIVE MIXED WASTE}

\section{Introduction}

\subsection{Objective of the National Profile}

The objective of this U.S. Nuclear Regulatory Commission- (NRC-) and U.S. Environmental Protection Agency- (EPA-) sponsored project was to compile a national profile on the volumes, characteristics, and treatability of commercially generated low-level radioactive mixed waste. The information collected and assembled in this project may be used by NRC, EPA, and the states to make decisions regarding the management and disposal of commercially generated mixed waste. The project did not enc', apass mixed waste generated by the government [i.e., Department of Energy (DOE)] since $16:$ is iverse of mixed waste had been previously estimated by DOE. This project did not specifically attempt to address cleanup wastes from remedial action activities although information obtained from generators performing these activities was not excluded.

\subsection{Definitions}

For the purposes of this project, mixed waste is defined as "waste that satisfies the definition of low-level radioactive waste (LLRW) in the Low-Level Radioactive Waste Policy Amendments Act of 1985 (LLRWPAA) and contains hazardous waste that (1) is listed as hazardous waste in Subpart D of 40 CFR Part 261 or (2) causes the LLRW to exhibit any of the hazardous waste characteristics identified in Subpart C of $\mathbf{4 0}$ CFR Part 261."

The LLRWPAA defines LLRW as "radioactive material that (a) is not high-level radioactive waste, spent nuclear fuel, or byproduct material as defined in section 11e. (2) of the Atomic Energy Act of 1954 (AEA) i.e., uranium or thorium mill tailings and (b) NRC classifies as LLRW consistent with existing law and in accordance with (a)."

In addition, the following were included in the definition of hazardous waste for the purposes of the National Profile: 
- Oils and oil sludges. These wastes are included in the survey because they may be considered hazardous under the RCRA for the "Toxicity Characteristic" or may be listed as hazardous or may be characteristically hazardous under state law."

- Other wastes regulated as "hazardous wastes" solely under state law, but not under the Federal RCRA d nition of hazardous waste.

Commercially generated low-level radioactive mixed waste, for the purposes of the National Profile, includes all mixed waste generated by NRC- or Agreement State-licensed facilities that would normally send any LLRW to one of the three existing LLRW disposal facilities. This definition would, therefore, include all generators of mixed waste except the DOE facilities.

Mixed waste generators include NRC- and Agreement State-licensed nuclear facilities and have been defined for this study to be nuclear utilities, medical, academic, industrial, and NRC/Agreement State-licensed government facilities. Individual generators chose the generator category that best described their mixed waste activities when completing the questionnaire. The term "nuclear utility" is equivalent to "nuclear power plant," "power plant," and "nuclear reactor facility" in this report. The "industrial" category includes facilities such as manufacturing, research and development, decontamination and waste reduction, sealed source users, waste brokers, nuclear fuel cycle other than reactors, and commercial radiopharmacies.

\subsection{Work Performed}

The project consisted of the following eight tasks:

1. Evaluation of existing available informatior on mixed waste from past surveys conducted by host states, compacts or other parties; summarizing the results; and identifying the lessons learned from past survey reports.

2. Determination of the adequacy of these existing data to estimate and project the volumes, characteristics and treatability of commercially generated mixed waste on a national level.

3. Development of a plan to collect and analyze mixed waste data and the development of a pretest questionnaire.

4. Administation of the pretest, production of the final questionnaire, and completion of the overall survey design.

5. Collection and analyses of mixed waste data.

'EPA recently published a final decision not to list used oil as a hazardous waste in 57 FR 21524, May 20, 1992. 
6. Compilation of a national mixed waste profile.

7. Identification of available treatment 'echnologies to meet applicable EPA treatment standards for Land Disposal Restricted (LDR) wastes and, if possible, to eliminate th 2 hazardous component of specific inixed waste streams.

8. Documentation of the study results in an NRC NUREG report.

\subsubsection{Evaluation of Available Mixed Waste Information}

Available information on the volumes, characteristics, and treatability of mixed waste were compiled and evaluated. This included:

- A literature search to identify and obtain pertinent sources of ... ted waste information. Such information included mixed waste survey reports and survey forms prepared by states, compacts, or other parties. Some information was also obtuined from studies in progress and from projects that are, as yet, unpublished.

- An evaluation of current and projected mixed waste inver the radiological and chemical characteristics of the mixed waste, and the treatability of the various types of mixed waste to meet Resource Conservation and Recovery Act (RCRA) requirements. An effort was made to distinguish between currently available treatment technologies, newly developed technologies, or technologies that may be available in the near future.

- Identification of the assumptions underlying the projections made in past surveys, such as a state's decision to include certain wasie (e.g., waste oils) as hazardous waste under RCRA and how these assumptions affected the results of the study.

- An assessment of the potential that mixed waste streams or volumes that were misreported or overlooked, based on the National Profile development team's knowledge of the operations and activities within the commercial nuclear industry. This assessment addressed the potential for significant volumes of mixed waste being unaccounted for because they were reported under a designation that precludes consideration [such as waste reported as an "asset" (e.g., lead to be reused as shielding)].

- An evaluation of previous mixed waste surveys to determine their applicability to the development of a national mixed waste survey. This included contacting individuals who have conducted past surveys.

Based on the available information at the time this study was initiated (late 1990), the projected (1993-1995) national generation rate for mixed waste was estimated to be $\sim 43,000 \mathrm{ft}^{3}$ per year. A number of factors were determined to have an impact on the accuracy of the reported 
data. These issues included the validity of voluntary surveys, whether waste oils and liquid scintilla'ion fluids were included as mixed waste, the variation in the way individuals filled out the questionnaires, the variation in interpretations of the raw data provided by the surveyed facilities, the variations in time frames for completing the various surveys, the differences in presentation and interpretation of definitions, the different opinions on whether a particular stream is waste or an asset, the uncertainty in when a material becomes a waste, the variations in laws defining mixed waste, and the importance that individual facilities assigned to filling out the survey form accurately.

\subsubsection{Evaluation of Adequacy of Existing Information}

To determine if the existing data were adequate to estimate and project the volumes, characteristics, and treatability of mixed waste at the national level, the data parameters and an information configuration appropriate for a mixed waste profile were prepared. Existing data were then analyzed individually by compact and/or state to determine their ability to meet these requirements.

This evaluation indicated that the differences in the questions asked, the variation in the definitions and instructions provided, and the attention shown to completing the various questionnaires led to major difficulties in reconciling the data from the various surveys. Thus, it was recommended that a new survey reaching a wide selection of potential mixed waste generators be conducted. Because a great deal of current mixed waste data already existed, although in a wide variety of forms and in varying quality, it was also recommended that the existing data be acquired, where available, summarized, and compared with the results of a new survey.

A national mixed waste generation rate of $51,000 \mathrm{ft}^{3}$ per year was estimated as the lower baseline for those compacts/states reporting mixed waste generation. See Sect. 4.3.2, Table 4.18 for more information on this projection.

\subsubsection{Data Collection Plan}

The object of Task 3 was to develop a detailed plan necessary to collect and analyze the mixed waste data for the compilation of the national mixed waste profile. Included in the plan is a statement of the task's objectives, specification of the survey design, and a description of the mixed waste database that was to be developed. The specific parameters for the data collection plan were developed as follows:

- The national mixed waste volumes were to be determined within a factor of 2 for both 1990 annual mixed waste generation rates and the total quantity of mixed waste in storage at the end of 1990 . 
- The factor of 2 also applied to mixed waste volumes for each of the major facility categories. The major categories consisted of nuclear utilities, medical, industrial, academic institutions, and NRC-/Agreement State-licensed government facilities.

- The radiological characteristics were to include the Low-Level Radioactive Waste (LLRW) Class (A, B, C, etc.), as defined in 10 CFR 61.55, and a listing of the major nuclides present.

- The hazardous waste characteristics were to include the EPA waste codes (D, F, K, P, or $U$ series) and a common name descriptor.

- Information was to be acquired to determine the relationship between mixed waste stream generation and any plans the facility had for reducing or eliminating that waste stream.

- Information was to be acquired on how the various mixed waste streams are presently being treated, stored, and/or disposid of.

The study design specifications were provided by David C. Cox \& Associates and are included as Appendix A. A detailed description of the data collection methods employed and the final mixed waste profile are presented later in this report.

\subsubsection{Administration of the Survey Pretest}

Twenty facilities belonging to the Appalachian Compact Users of Radioactive Isotopes (ACURI), the association of radioactive licensees within the Appalachian Compact, agreed to cooperate in the initial test phase of the national mixed waste survey. These 20 facilities comprised a broad mix of both large and small facilities within each of the major facility categories. Oak Ridge National Laboratory (ORNL) mailed pretest survey forms to each of the facilities on August 16, 1991, and made follow-up visits to 9 facilities. Other than the strong support that the ACURI, through its executive secretary and its board of directors, extended to the mixed waste profile effort and the individual contacts with each of the facilities, administration of the pretest followed the same methodology used for the actual survey.

Based on the data collected, the comments received during actual site visits to ACURI member facilities, and the various discussions among the mixed waste profile team members, the pretest survey questionnaire was modified to enhance its usefulness. The final survey questionnaire is included as Appendix B. 


\subsection{Generation of the Mixed Waste Profile}

A major component of this project consisted of collecting the mixed waste data necessary to compile a national profile on mixed waste characteristics, volumes, and treatability. Detailed descriptions of the data collection methodology are presented in Sect. 3. A compilation and presentation of the national mixed waste profile including estimation procedures, profile description, major facility category and hazardous stream presentations, and a discussion of the usefulness and limitations to the profile are detailed in Sect. 4.

Another important part of this study was the identification of existing treatment capacity for specific mixed wastes reported in the survey. Various types of treatment technologies are evaluated such as incineration, compaction, solidification, vitrification, including other methods that could meet applicable EPA treatment standards and, if possible, render hazardous wastes nonhazardous. Organizations that currently have the capability to treat mixed waste and those that may have future mixed waste treatment capabilities were also reported as part of the analysis.

\section{Review of Relevant Regulations Affecting the Mixed Waste Frofile}

Low-level radioactive mixed waste is regulated under a dual framework created by Congress. The NRC (or NRC Agreement States) and EPA (or EPA authorized states) independently regulate different components of the same waste. The AEA of 1954, as amended, the Energy Reorganization Act of 1974 , as amended, and other statutes provide authority to NRC to regulate the possession and use of special nuclear material (fissile materials), source unaterial (the raw materials of nuclear energy), and byproduct material (fission and activation products and uranil " mill tailings and associated processing wastes). NRC has the primary responsibility for regulating nuclear power and nonpower reactors, academic institutions, health care facilities, commercial facilities, and Federal facilities such as Veterans Administration hospitals, the National Institutes of Health, and the National Institute of Standards and Technology that use source, special nuclear, or byproduct material. Section 274 of the AEA allows for the discontinuance of certain regulatory authority by NRC and assumption of this authority by the states. States may assume authority for licensing and regulating byproduct materials, mill tailings, source material, and small quantities (less than $350 \mathrm{~g}$ ) of special nuclear material. An agreement between the Governor of the State and NRC allows states to assume this authority - hence the term "Agreement State."

EPA regulates the hazardous component of low-level radioactive mixed waste under RCRA. The EPA's authority to regulate the hazardous component of mixed waste was first clarified in 
"EPA Clarification of RCRA Applicability to Mixed Waste" (51 FR 24505, July 3, 1986) and was subsequently addressed in "DOE Clarification of the Definition of Byproduct Material"

52 FR 15937, May 1, 1987). The former provided EPA's legal interpretation of the source, special nuclear, and byproduct material exclusion to the definition of solid waste found in RCRA Section 1004(27) and required authorized states to obtain authorization for mixed waste. The latter, referring only to byproduct material, indicated that only the actual radionuclides, not the entire waste stream, are considered to be byproduct material; therefore, EPA retains authority to regulate the hazardous portion of the waste stream under RCRA.

\subsection{Regulation of Low-Level Radioactive Waste}

Source, special nuclear, and byproduct material are subject to regulation under the AEA. NRC or NRC Agreement States generally administer the AEA for commercial and non-DOE Federal facilities while DOE regulates radioactive materials at DOE facilities. NRC is responsible for licensing and regulating nuclear facilities and materials and for conducting research in support of the licensing and regulatory process. Activities must be conducted in accordance with the National Environmental Policy Act (NEPA) of 1969, as amended. NRC responsibilities include protecting the public health and safety, protecting the environment, and safeguarding nuclear materials in the interest of national security. Agency functions are performed through: (1) standards setting and rulemaking; (2) technical reviews and studies; (3) conduct of public hearings; (4) issuance of licenses; (5) inspection, investigation, and enforcement; and (6) research (see "Regulating the Disposal of Low-Level Radioactive Waste, A Guide to the Nuclear Regulatory Commission's 10 CFR Part 61").

Some radioactive materials such as naturally occurring or accelerator-produced radioactive material (NARM) are not subject to regulation under the AEA and, therefore, are not subject to regulation by NRC. However, NRC does have authority for limited types of NARM, including source material (uranium and thorium) and uranium and thorium mill tailings and associated wastes. NARM waste is currently not identified as hazardous under RCRA; however, it could be because it was not specifically excluded from regulation under RCRA as were other radioactive materials. NARM regulation is primarily a state responsibility, at present, if the State chooses to exercise it.

Low-level radioactive waste is defined in the LLRWPAA to mean radioactive material subject to NRC regulation that is not high-level waste, spent nuclear fuel, or byproduct mill tailings and waste, which NRC classifies as low-level radioactive waste. The NRC radioactive waste classification methodology (10 CFR Part 61) is a systems approach to control the potential 
dose to people from the disposed waste. The components of the system include the site characteristics, the design and operation of the site, the institutional controls, the waste form, and intruder barriers. The quantity and type of radionuclides permitted for disposal in each class are based on combinations of these various components and on concentrations of radioactive materials that are expected to be in the wastes and that are important for disposal. Three classes are established for routine near-surface disposal: Class A, Class B, and Class C.

Low-level radioactive waste contains short-lived and long-lived radionuclides. Three important time intervals are relied on in setting the waste classification limits. One is the length of time the government will actively control access to the site (100 years). The second is the minimum stability of the waste form ( 300 years). The third is the expected lifetime of angineered barriers or assured burial depth (for intruder protection) and the time when total failure of the wasia form is assumed to occur (500 years). Concentrations of short-lived radionuclides permitted in the waste are higher than concentrations of long-lived radionuclides, because the short-lived nuclides will significantly decay during the 100 years of assumed institutional controls. Shorterlived nuclides will also significantly decay during the 300 -year design lifetime of stabilized wastes. The limits are further set so that at the end of the 100-year institutional control period, no active site controls or maintenance are needed, and so that at the end of 500 years, no reliance on engineered features or waste form are neeted for intruder protection. The limits specified for both short- and long-lived radionuclides ensure that the performance objectives will be met. Details of the concentration limits that define waste form classification as either A, B, o: C are contained in 10 CFR 61.55 .

Any class of radioactive waste that contains a hazardous waste as defined in RCRA is considered mixed waste. The radioactive component of commercial mixed waste is generally lowlevel radioactive waste and is the only area of concern for this study.

\subsection{Regulation of Hazardous Waste}

RCRA and HSWA set the regulatory framework for hazardous waste. Subtitle C of RCRA established the regulation of hazardous waste from generation through its ultimate disposal ("cradle-to-grave"). RCRA defines solid waste as "any garbage, refuse, sludge from a waste treatment plant, water supply treatment plant, or air pollution control facility and other discarded material, including solid, liquid, semisolid, or contained gaseous material resulting from industrial, commercial, mining, and agricultural operations, and from community activities". Solid waste, however, does not include "source, special nuclear, or byproduct material as defined by the Atomic Energy Act of 1954..." [RCRA Section 1004(27)]. As indicated above, EPA, NRC, and DOE 
interpret the exception for source, special nuclear, or byproduct material as referring only to the radioactive component of the waste, and not to the entire waste mixture. Thus, AEA regulations apply only to the radioactive components and, if the waste contains RCRA hazardous waste components, the waste also becomes subject to regulation under RCRA.

HSWA amended RCRA significantly. A key element of HSWA is the I DR program which restricts the land disposal of hazardous wastes, including mixed wastes, unless a waste meets EPA treatment standards or a "no-migration" determination has been made for a specific site. The LDRs initially applied to waste listed or identified as of November 8, 1984, under RCRA. They now also cover several hazardous wastes listed after November 8,1984 , for which treatment standards have been developed. Treatment standards exist for hazardous waste that contains solvents (FO01 to FO05) dioxins (FO20 to FO23 and FO26 to F028) and California list wastes (halogenated wastes, certain metal-bearing wastes, polychlorinated biphenyls, cyanide, and corrosive wastes). EPA deferred issuing treatment standards for most radioactive waste mixed with scheduled hazardous waste (i.e., all wastes listed as of November 8, 1984, which are described in the First, Second, and Third Third rules; 53 FR 31137, August 17, 1988; 54 FR 26594, June 23, 1989; and 55 FR 22520, June 1, 1990) and that are not solvents or dioxins, or California list waste until the promulgation of the last scheduled LDR rule on May 8, 1990 (the Third Third rule). After May 8, 1990, all mixed wastes 'alling into the above categories of waste were restricted from land disposal. However, for all mixed waste described in the First, Second, and Third Third rule, EPA granted a two-year national capacity variance based on the lack of treatability capacity. This variance (which expired on May 8, 1992) delayed the imposition of the LDR treatment requirements for land disposal of mixed waste until the expiration date. Storage of these restricted wastes is also prohibited after May 8, 1392 (with a very few exceptions) unless storage is for the sole purpose of accumulating sufficient quantities in a tank or container to facilitate proper recovery, treatment, or disposal of the waste (see 40 CFR 268.50 , the storage prohibition). Under the LDR, the RCRA-regulated hazardous portion of mixed waste must meet the appropriate treatment standards for all applicable waste codes before land disposal (in the absence of a "no-migration" determination). Mixed waste for which adequate treatment capacity is not available must be stored in accordance with all RCRA storage requirements until treatment capacity becomes available (although such storage may constitute a violation of the LDR storage prohibition) or a site-specific variance from the treatment standard (40 CFR 268.44) is granted. Currently, a capacity variance is in effect for mixed waste that contains certain newly listed wastes (57 FR 37194, August 18, 1992) and debris and soil contaminated with mixed waste (57 FR 47772, October 20, 1992). 


\subsection{State Regulations}

RCRA allows for the delegation of authority of the Federal regulatory program to the states. The AEA allows for the discontinuance of certain regulatory authority by NRC and assumption of this authority by the states. NRC-granted Agreement State status and EPAauthorized RCRA state programs implement the regulatory programs. In certain cases, state regulations may include provisions more stringent than the applicable Federal regulations.

\subsubsection{Low-Level Radioactive Waste in Agreement States}

Twenty-nine states have signed agreements with NRC (under Subsection 274b of the AEA), enabling the various "Agreement" States to regulate the use of source, special nuclear (limited quantities), and byproduct material within their boundaries. This applies to all radioactive material except that from nuclear utilities and fuel cycle facilities (regulated by NRC) and DOE facilities (regulated by DOE). Each "Agreement" provides that the state will use its best efforts to maintain continuing compatibility with the NRC's regulatory programs. States that plan to licunse new disposal sites must adopt most of the provisions of 10 CFR Part 61 to maintain compatibility. All Agreement States must adopt the manifest system in 10 CFR Part 20 to cover waste generators in the state. NRC maintains a continuing relationship with each Agreement State to ensure continued compatibility; however, states are independent regulatory authorities under the agreement. In making licensing decisions, states may take local conditions such as weather or public opinion into account as long as the program remains compatible and adequate to protect the public health and safety.

\subsubsection{Hazardous Wastes in Authorized States}

The Federal RCRA program was developed to be implemented primarily by the states, with EPA oversight. A state must develop a program that is equivalent to, no less stringent than, and consistent with the Federal program. State programs may be more stringent than their Federal counterpart. Once authorized, the state has primary responsibility for implementation and enforcement of RCRA requirements within its boundaries. Authorized state programs operate in lieu of the Federal RCRA program, although EPA retains oversight and residual enforcement authority. EPA administers the Federal RCRA program in unauthorized states. In addition, EPA administers HSW 1 requirements (e.g., LDRs) in all states until they are authorized for these provisions.

A state authorized for the RCRA program may choose to define additional wastes as hazardous under its state hazardous waste program. Maryland, for example, even includes radioactive materials on its hazardous waste lists. 


\subsubsection{Authorization for Mixed Waste}

EPA has formally clarified its position that the hazardous component of mixed waste is subject to RCRA regulation (see 51 FR 24504, July 3, 1986). In the notice, EPA called for authorized states to revise their authorized programs and incorporate the authority to regulate the hazardous components of mixed waste. States authorized for the base program (pre-HSWA) were -illowed a maximum of 2 years from the promulgation of the notice to incorporate the mixed waste authority (i.e., until July 3, 1988). The July 1988 deadline was extended one year. As of September 30,1992, authorization for mixed waste authority has been given to 31 states and 1 territory (Guam). In those states that are authorized for RCR.A's base program but which have not received mixed waste authority, mixed waste is not subject to RCRA hazardous waste regulations, including the land disposal restrictions until the state is authorized for mixed waste.

At present there are 15 states (Alabama, Arizona, Delaware, Maine, Maryland, Massachusetts, Missouri, Montana, New Hampshire, New Jersey, Pennsylvania, Rhode Island, Vermont, Virginia, and West Virginia) authorized for base RCRA but not authorized for mixed waste. According to a recent EPA guidance document Federal restrictions for mixed waste disposal are not applicable in these states. In fact, mixed waste may not even be defined or regulated as hazardous waste in these states. However, it does appear that facilities in most of those states in this category treat mixed waste as if it was regulated under RCRA. In those states that are not authorized for RCRA's base program and in states authorized for mixed wastes, the RCRA land disposal restrictions are in effect. ${ }^{b}$

\section{Collection of Mixed Waste Data}

\subsection{Objective}

The primary objective of the joint NRC- and EPA-sponsored project under Tasks 5 and 6 was to collect and analyze the data reported on the survey questionnaire (see Appendix B). The data collected supported the development of the national mixed waste profile.

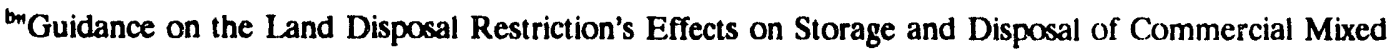
Waste," Office of Solid Waste and Emergency Response (OSWER) Directive No. 9555.00-01, September 1990.
} 


\subsection{Collection Methods}

A pre'iminary letter (drafted and cosigned by NRC and EPA and included in Appendix B) was mailed to all the compacts and their member states, to each of the unaligned states, and also to all NRC licensees. The letter informed them of the purpose of the survey and requested their aid in helping to ensure that the compilation of the national survey would be a meaningful and credible undertaking. In addition, a number of industry groups volunteered to support and disseminate information on the survey.

Based on the study design specifications detailed in Appendix A, 1,323 facilities were randomly selected, from among 2,936 facilities with a high potential to generate mixed waste, to receive mixed waste surveys. These facilities were sent the mixed waste questionnaire in early November 1991. A formal survey monitoring procedure was established that included a survey questionnaire return trackin's system and a system that allowed for follow-up call documentation.

By the end of December 1991, only 190 surveys had been returned. At that time, a series of phone calls began, by trained data collection specialists, to those facilities that had not yet returned their surveys. These calls were implemented to encourage the facilities to participate in the survey, to offer any assistance required to fill out the survey or, if necessary, to acquire any survey information over the telephone. Generally, the latter approach was used only for those facilities that indicated they generated little or no mixed waste. Initial procedures called for five telephone attempts to contact a cognizant person responsible for completing the questionnaire. In a number of cases, additional telephone contacts were attempted before a data collection specialist discontinued his or her effort to obtain a survey response from a specific facility.

By the end of April 1992, ORNL had received 995 questionnaires. An additional 21 facilities were determined to no longer be in business. Survey respondents and those facilities that were no longer in business accounted for the approximately $77 \%$ return-resolution rate (completed surveys/questionnaires sent out).

\subsection{Data Collection}

As questionnaires were received at ORNL, they were noted on the master list of surveyed facilities. All data were initially checked by a principal investigator for obvious errors and inconsistencies, misinterpretation of instructions, incomplete data, and clarifications. In general, all data from the survey questionnaires were included in the database. A number of exceptions to this procedure occurred when facilities inadvertently left out a waste code, description, or stream number. Obvious errors were corrected where appropriate. Responses that required clarification were followed up with a telephone call to the responding facilities. Minor inconsistences and/or 
gaps in information were not usually corrected due to the large number of questionnaires that were returned to ORNL.

One major exception to the above procedure occurred during the survey. One facility reported that it generated three waste streams with a total of over $2,000,000 \mathrm{ft}^{3}$ of liquid mixed waste generated in 1990 . Checking with this facility confirmed that these entries were valid. However, it was decided not to include these three waste streams in the database because (1) they appeared to be generated from a one-time event which is not likely to be repeated; (2) the facility has petitioned the state to have the streams delisted and, if successful, they would no longer be considered mixed waste; and (3) inclusion of these streams would invalidate the statistical interpretation of the mixed waste database and prevent its usefulness as a predictive tool for the nation as a whole. This response, however, indicates a large potential variability in the generation rate of mixed waste by specific facilities.

\subsection{Data Processing}

An initial data cleaning process identified and categorized the major mixed waste streams [e.g., liquid scintillation fluids (LSFs), oil, lead, etc.). Any unclassified waste streams were entered into an "unassigned" category until further classification. Daily activity reports were printed and proofread. Trend analysis was also employed as a data integrity check after the data were cntered in to the database. This entailed the listing of records that did not fit the norm for selected criteria. The abnormal records were then compared with the data in the original questionnaires and either confirmed or corrected. Variations of reports, using a variety of category breakouts, were made and compared to ensure congruity in the totals. "Smart" algorithms were used to seek out orphaned data records that did not match valid facility or stream identification numbers. This aided in the double-checking for data entry errors. Original questionnaires were retained for future reference.

\subsection{Database Description}

An analysis of the questionnaire indicated that several relational data files were necessary to include all of the available data while maintaining data integrity. The personal computer-based commercial software, FoxPro, was selected as the database program because of its versatility. The data from each questionnaire were organized into nine subfiles based on the format of the questionnaire and linked together through the use of an identification code (IDNUMBER) unique for each queried facility. This organizational structure provides for the separation of exact and 
range data and enables the data to be used independently in summations and statistical calculations. Comment fields were included throughout the database for additional information that may be needed to clarify the data. The database contains the responses from 1,016 facilities that use a total file length of about 15 MB. Specific descriptions and contents of the data subfiles and definitions of the fields within the subfiles are given in Appendix $\mathrm{C}$.

\subsection{Data Tabulation}

The reports generated were tabulated using several classification schemes. The main tabulation was based on how the facility identified itself. Other classifications used the "GROUPID" field (LSF, oil, organic, etc.) to subdivide the waste streams in the tabulations. An "Other" category was added to the Waste Stream classification to account for two types of wastes-those containing multiple types or mixtures of hazardous wastes and unique waste streams such as lead contained in a "freon" mixture. Table D.11, Appendix D, lists all the "Other" mixed wastes that were reported as being generated in 1990. Classification by compact (group of states) was also done, with the nonaligned states tallied individually.

\subsection{Disposition of Original Data}

Mixed Waste Survey participants were ensured of the greatest confidentiality possible. The joint letter from the sponsors (see Appendix B), NRC and EPA, indicated the data were not being collected for any enforcement purposes. ORNL was directed NOT to provide the identities of any of the survey respondents to NRC or EPA "unless a future development involving the protection of the public health and safety and the environment," warrants it. "Except as outlined above, data and results from the survey will only be provided to NRC, EPA or other groups or individuals, as approved in writing by the NRC Office of Nuclear Material Safety and Safeguards (NMSS) Project Manager, in an aggregated format, stripped of any specific licensee identifiers." "At the conclusion of this project, ORNL will retain all raw data that contains facility identification information (e.g., completed survey forms, follow-up call notes and records, records of interviews with specific facilities, etc.) regardless of the form of the record (e.g. hard copy, computer disk, etc.) for 7 years. Seven years after completion of this project, ORNL will destroy this information." 


\section{National Mixed Waste Profile}

\subsection{Estimation Procedures}

\subsubsection{Survey Design Objectives}

The objective of this project was to compile a profile of national commercial mixed waste volumes to within a factor of 2 (with $95 \%$ confidence limits) for both 1990 annual mixed waste generation rates and, if possible, the total quantity of mixed waste in storage at the end of 1990. This factor of 2 also applied to mixed waste generation rates for each of the major facility categories. The categories include nuclear utilities, medical, academic, industrial facilities, and NRC/Agreement State-licensed government facilities. Based on these objectives and the necessity of limiting the survey of facilities to a manageable level, limitations were placed on the numbers and characteristics of those facilities chosen to receive the survey questionnaire.

\subsubsection{Selecting the Frame}

Those facilities that were deemed suitable for investigation in this study were facilities having the potential to generate low-level mixed waste. Four different strata were used to identify these facilities and are defined as follows:

- ORNL List. This stratum is a list of $\mathbf{4 4 4}$ facilities which was compiled by ORNL. It includes all nuclear utilities and other facilities which have been designated by ORNL as likely generators of mixed waste. Possible reasons for the inclusion of particular facilities in this stratum were their appearance on a list in a governor's certification (pursuant to the LLRWPAA of 1985 as amended, certification by the governor of the intent of the state to safely manage LLRW generated within its borders) or on a compact/state survey as having generated, or having the potential to generate, mixed waste.

- Shipper's List. This stratum contains all 1990 shippers of LLRW (to any of the three commercial burial grounds) who do not already appear on the ORNL list.

- NRC Potential Mixed Waste Generators with EPA Permits. This list includes those facilities having NRC licenses and Material License Program Codes which have a high potential for generating mixed waste and have an EPA Permit to treat, store, or dispose of hazardous waste, or have an EPA identification number. The codes defined as having high potential for mixed waste generation are shown in Table 1, Appendix A.

- NRC Potential Mixed Waste Generators without EPA Permits. Same as above but without an EPA permit. 
The likelihood that any given facility generates mixed waste depends on the actual processes and materials in use at the facility. After duplicate names were removed from the lists described above, approximately 2,936 facilities were finally estimated to be in the 4 strata. These are defined as the overall universe or entire population of interest.

Two groups of potential mixed waste generators were not included in the survey target population. The first are those that have NRC licenses and Material License Codes which were determined not to have a high potential for generating mixed waste because of the nature of the licensed activity, such as private doctor's offices. The second are those facilities in NRC Agreement States and not on the ORNL list or the shipper's list. The first group was not included in the survey target population because of a low potential for generating mixed waste and its size (or, 6,000 facilities). The second group was not included because of a low potential for mixed waste generation, the lack of facility names and addresses, and for its large size $(\sim 16,000)$. The size of a group was, however, a secondary factor in both of these exclusions.

\subsubsection{Selecting the Sample}

Based on the objectives of the study as outlined previously, a sample size determination was made using the number of facilities in each of the population substrata, estimates for the means and variances or the total volume of mixed waste within each of the substrata, and the accuracy requirements of the survey. Estimates for the means and variances were based on several compact surveys completed prior to this study. The actual detailed discussion of the final sample size for each substratum is discussed in Appendix A.

Potential generators of commercial mixed waste were grouped into 17 substrata (groups), as shown in Exhibit 5 of Appendix A, based on the type of facility (nuclear utility, medical, academic, industrial facilities, or NRC/Agreement State-licensed government facilities) and whether they were on the ORNL List, the Shipper's List (excluding those on the ORNL List), or NRC licensees either with or without EPA permits. From each substratum and independently of the other strata, a simple random sample of facilities was selected. For nine of the substrata, all facilities within the substrata were selected for the sample.

As indicated in Table E.6 of Appendix $E$, the overall sample size was $n=1,323$ facilities selected from an estimated overall universe of approximate size $\mathrm{N}_{-}=2,936$ facilities. Details on the precision requirements for determination of sample size are given in Appendixes $A$ and $E$.

\subsubsection{Weighting of Sample Data and Estimation of Total Volumes}

Each respondent facility was assigned to only 1 of the 17 substrata as indicated in Sect. 4.1.3. The sampling weight for an individual respondent depended on the substratum in which it was originally assigned. This weighting factor was computed by dividing the estimated number of 
facilities in its assigned substratum by the number of sample respondents, including the number of sample facilities that reported that they were out of business. For example, of 165 academic facilities on the Shipper's List and not on the ORNL List, 111 survey responses were received, and no faciiities were found to be "out of business." Thus, the sample weight for this substratum is computed to be $165 / 111=1.4865$. The other sampling weights used are given in Table E.7 of Appendix $E$ and range from a low of 1.026 to a high of 31.5. In other words, these numbers indicate that each response from these facilities represent anywhere from 1.03 to 31.5 other facilities in the same substratum.

The estimate of a total volume, $\hat{T}_{D}$, of a particular waste for any specific collection of facilities, $D$, in the entire universe was computed as follows. First, each sample respondent included in the specific collection of facilities (D) was identified. The reported waste volume for each sample respondent belonging to collection $D$ was then multiplied by the appropriate sampling weight. The sum of all such products for sample respondents from $D$ gave the estimated

total volume, $\hat{T}_{\mathrm{D}}$. The collection of samples, $\mathrm{D}$, can be any collection desired such as all industrial, medical in state "X", etc. More details on estimation and the computation of selected standard errors (s.e.) are given in Appendix E.

\subsubsection{Expected Accuracy and Precision of Survey Results}

As discussed in Sect. 3.3 of Appendix A, the sample sizes for each of the 17 substrata were determined with the goal of achieving a relative standard error (r.s.e.) of $10 \%$ for the national estimate of the total volume of waste generated. While the final sample sizes selected greatly exceeded sample sizes necessary to provide estimates within the desired accuracy factor of 2 (as described in Appendix A), the selected sample sizes provide a significant factor of conservatism in the survey design and allow for nonsampling error. This nonsampling error reflects how accurately the completed questionnaire represents reality and is not related to the statistics involved in choosing the sample size or to the number returning the questionnaire. The estimated r.s.e., for sampling error only, that were realized are given below:

\begin{tabular}{lrl}
\multicolumn{1}{c}{ Category } & \multicolumn{2}{c}{$\begin{array}{c}\text { Estimated relative } \\
\text { standard error }\end{array}$} \\
\hline Academic & $10.5 \%$ & $(=3,055 / 28,982)$ \\
Government & $22.6 \%$ & $(=5,978 / 26,500)$ \\
Industrial & $22.6 \%$ & $(=11,414 / 50,430)$ \\
Medical & $14.7 \%$ & $(=2,928 / 19,904)$ \\
Nuclear utilities & $5.2 \%$ & $(=703 / 13,625)$ \\
& & \\
\hline National & $9.7 \%$ & $(=13,579 / 139,441)$
\end{tabular}


Note that each estimated r.s.e. given above is obtained from Table 4.3 by dividing the estimated s.e. by the estimated total volume generated. Four of the five r.s.e. exceeded the desired goal of $10 \%$ (only a goal used in estimating sample size); however, the r.s.e. for the estimated total commercial mixed waste generated in the country $(9.7 \%)$ is almost eriual to the desired goal. [Computed as the square root of the sum of the individual group variances (the square of the indicated s.e.) divided by the estimated total volume of mixed waste generated.] Based on the conservative sampling design of the survey as discussed above, the final results obtained at the national level are well within desired accuracy of a factor of 2 for both sampling and nonsampling errors.

\subsubsection{Approximate 95\% Confidence Intervals}

Using the notation of Sect. 4.1.4, s.e. $\hat{T}_{D}$ is the estimated s.e. of the estimator $\hat{T}_{D}$. Assuming that the estimator $\hat{\mathrm{T}}_{\mathrm{D}}$ has a normal distribution, an approximate $95 \%$ confidence interval for $\widehat{T}_{D}$ is given by:

$$
\hat{T}_{D} \pm 1.96\left[\sec \left(\hat{T_{D}}\right)\right]
$$

Approximate $95 \%$ confidence intervals for the total volume generated in the United States and for the total generated waste for each major category are given below:

\begin{tabular}{lc}
\multicolumn{1}{c}{ Category } & $\begin{array}{c}\text { Approximate 95\% } \\
\text { confidence interval }\end{array}$ \\
\hline Academic & $22,994-34,970$ \\
Government & $14,775-38,209$ \\
Industrial & $28,059-72,801$ \\
Medical & $14,165-25,643$ \\
Nuclear utilities & $12,247-15,003$ \\
\hline \multicolumn{1}{c}{ National } & $112,818-166,048$
\end{tabular}

From the above data, one may conclude that "we are approximately $95 \%$ confident that the actual total national volume of commercial mixed waste generated in 1990 is between $113,000 \mathrm{ft}^{3}$ and $166,000 \mathrm{ft}^{3}$." Similarly, it can be said that "we are approximately $95 \%$ confident that the actual total volume of commercial mixed waste generated in 1990 by academic facilities is between $23,000 \mathrm{ft}^{3}$ and $35,000 \mathrm{ft}^{3} . "$ 


\subsubsection{Limitations of Survey Design}

As discussed in Appendix A, the sampling plan (including sample sizes) was designed to provide conservative estimates of the total volumes of mixed waste at the national level for each of the five facility categories. Reliability of the estimates at these levels are reflected in Table 4.3 and Sects. 4.1.5 and 4.1.6.

Estimates of mixed waste volumes calculated at the compact/state level are far less reliable, mainly due to fewer samples in these substrata. For this reason, estimates of mired waste volumes and generation rates for individual states and compacts should be used with great caution.

\subsection{Description of the National Commercial Mixed Waste Profile}

The National Profile on Commercial Mixed Waste is a statistically based estimation of the 1990 generation rates and volumes of commercially generated mixed waste. The amounts of mixed waste generated in 1990 and in storage as of December 31, 1990, for the National Profile was estimated by examining the responses to 1,323 questionnaires (see Appendix B) which were sent to a broad spectrum of potential generators of mixed waste on November 1, 1991. The responses of 1,016 facilities (77\% response rate) were entered into a 1,016 by $15 \mathrm{~KB}$ (a total of $15 \mathrm{MB}$ ) database from which the National Profile was estimated employing weighting factors described in Sect. 4.1.4.

\subsubsection{Facility Categorization}

Five broad categories of generators of mixed waste were established which included academic, industrial, medical, NRC/state-licensed government facilities, and nuclear utilities. These were then subdivided by size, functionality, type of business and, if applicable, type of reactor. Illustrated in Table 4.2 are the five generalized categories as they were subdivided showing the number of questionnaire responses received in each subcategory.

In addition to categorization, the questionnaire asked the respondents to indicate their EPA facility classification, if possible. A total of 616 responses were obtained to this query. Large quantity generator status ( $>1,000 \mathrm{~kg} / \mathrm{month})$ was indicated by 216 facilities and small quantity generator status (100 to $1,000 \mathrm{~kg} /$ month) was designated by 186 facilities. Also, 82 facilities reported that they were conditionally exempt small quantity generators ( $<100 \mathrm{~kg} /$ month), and 132 facilities indicated they had no EPA classification.

\subsubsection{Low-Level Radioactive Waste (LLRW) Stream Descriptions}

Section B of the questionnaire (see Appendix B) requested information on the amount of class A, B, or C LLRW shipped either to a broker or directly to one of the three burial sites 
(Hanford, WA; Beatty, NV; Barnwell, SC). The amount of LLRW reported by the respondents is discussed in Sect. 4.3. Also requested were data on LLRW stream number, a coded number indicating the type of LLRW from a listing of 26 different potential waste streams shown in Attachment 1 of the questionnaire (Appendix B, p. 1-1 and 1-2) and a waste stream name together with the generating practice yielding the waste stream. The same information was also requested on stored waste. The responses to the LLRW stream number and name request were not provided by all facilities. Some respondents reported in detail on this information while others often neglected it entirely or were very cursory in their responses.

\subsubsection{Estimated Mixed Waste Generation Rates by Facility Category}

The results of the National Profile are presented in Table 4.3. Column 1 of Table 4.3 details the total mixed waste generated during 1990 by facility category as reported by the 1,016 respondents to the survey questionnaire. Note that the generation volumes reported by the academic, industrial, and NRC/Agreement State-licensed government categories were approximately equivalent and equaled $71 \%$ of the generated mixed waste reported for 1990 . However, the weighted data in column 2, representing the estimated national generation rate for each category, indicate a somewhat different picture. The previous three categories are projected to have generated nearly $76 \%\left(106,000 \mathrm{ft}^{3}\right)$ of the total mixed waste; however, the industrial category is projected to have produced more than $36 \%\left(50,000 \mathrm{ft}^{3}\right)$ of the total $140,000 \mathrm{ft}^{3}$ in the United States in 1990. The large differences between "as reported" data and projected generation rate are due to the large number of facilities in the survey frame in the industrial category coupled with a relatively small sample size within critical groups (see Sect. 4.1.4 for a discussion on weighting factors). It is interesting to note in Table 4.3 that the estimated total generation of mixed wastes by nuclear utilities is $<10 \%\left(\sim 14,000 \mathrm{ft}^{3}\right)$ of the total commercial mixed wastes generated in the United States.

\subsubsection{Stored Mixed Wastes by Category}

Amounts of mixed waste stored as of December 31, 1990, listed by category, are depicted in Table 4.4. Facilities returning the questionnaire reported $44,000 \mathrm{ft}^{3}$ in storage as of December 31, 1990. Applying the weighting factors developed in Tasks 5 and 6 yields a national volume of $75,000 \mathrm{ft}^{3}$.

On an "as reported" basis, nuclear utilities have the largest amount of mixed waste in

storage. However, the estimated amount in storage for the industrial category, after application of weighting factors, is nearly twice the amount estimated for nuclear utilities. This is because the weighting factors for the latter category are very close to 1 since all of these facilities were contacted and the response rate was over $97 \%$ (76 of 78). Not all of the stored mixed waste 
reported was untreatable. In fact, some of it was awaiting accumulation of sufficient quantities before being shipped to off-site treatment facilities (e.g., liquid scintillation wastes). It should be noted that treatment and storage data in Tables 4.11 through 4.16 are not necessarily horizontially additive since waste in either category may have been generated prior to 1990 .

\subsubsection{Mixed Waste That Currently Cannot Be Treated}

Mixed waste that currently cannot be treated represents waste that may be difficult, or even impossible, to dispose of because of a lack of acceptable treatment capability or disposal capacity. Two categories, NRC/Agreement State-licensed government and nuclear utilities appear to have the largest amount of untreatable waste [69\% of the reported and $59 \%$ of the projected total (about 4,800 $\mathrm{ft}^{3}$ ) of these wastes] as shown in Table 4.5. Chlorinated fluorocarbons (CFC), reported by nuclear utilities, account for over $23 \%\left(866 \mathrm{ft}^{3}\right)$ of the "reported" mixed waste designated as untreatable with present technology and about $18 \%\left(889 \mathrm{ft}^{3}\right)$ of the estimated wastes requiring ultimate disposal. The generation of these wastes should be decreasing rapidly as substitute materials are used and laundries serving nuclear utilities rapidly shift to aqueous-based clothes washing facilities. Not all respondents to the mixed waste questionnaire reported on their treatment options, and some of their untreatable waste may have gone directly into storage. Therefore, the estimate of $4,838 \mathrm{ft}^{3}$ reported in Table 4.5 may be an underestimate of the total amount of untreatable mixed waste generated in 1990.

Upper and lower bounds can be set on the volume of mixed waste that currently is untreatable. Assuming that LSF, oils, organics (not halogenated), and corrosive wastes are treatable under currently available technologies and deducting them from the estimated national total mixed waste generation rate leaves $\sim 18,500 \mathrm{ft}^{3}$ of untreatable mixed waste. Thus, with this as an upper bound and the $\sim 5,000 \mathrm{ft}^{3}$ mentioned above as a lower bound, the untreatable mixed wastes range from 3.5 to $13.3 \%$ of the estimated 1990 national generation rate of about $139,000 \mathrm{ft}^{3}$. Please note, however, that the capacity to treat all so-called "treatable" mixed waste in this report may not be available.

\subsubsection{Types of Mixed Wastes Reported}

In excess of $62 \%$ of the mixed wastes reported as generated during 1990 consisted of LSF wastes. After application of the statistical weighting factors (see Sect. 4.1.4), the scintillation fluid wastes were estimated at nearly $72 \%$ of the total projected generation of commercial mixed wastes in the United States. In contrast, the estimated generation rates for waste streams such as mercury-containing or cadmium-containing streams are very small as indicated in Table 4.6. Illustrated in Fig. 4.1 is a summary of the various types of waste streams reported as generated by 
the five major facility categories. In addition, a mixed waste stream of appreciable size, not shown in Fig. 4.1, is a stream labeled as "Other" in Table 4.6. This waste stream, representing $7.5 \%$ of the projected mixed waste generation, has multiple hazardous components and cannot be delineated as a single waste stream. A detailed breakout of the contents of this "Other" category is contained in Table D.11 of Appendix D.

Table 4.7 is a detailed breakdown of the amounts of the various types of mixed waste in storage as of December 31, 1990. (This is the same breakdown of waste types as shown in Table 4.6.) It depicts significant quantities of cadmium-containing wastes (35\% of projected waste in storage) being stored by industrial facilities and CFC-containing wastes being stored by the nuclear utilities (11\% of projected waste in storage).

Table 4.8 details the amounts, by waste-stream type, of mixed wastes designated as untreatable by currently available technologies. The two major waste streams in this category are used scintillation fluids and the "Other" types of mixed wastes (21.6\% and $22.9 \%$, respectively). The scintillation fluids réported here are considered untreatable because they contain isotopes that cannot be burned either on- or off-site due to license restrictions on the available combustion units.

\subsubsection{Estimated Mixed Waste Generated by Compacts and Unaligned States}

In order to implement the Low-Level Radioactive Waste Policy Act of 1980, 43 states organized themselves into nine compacts primarily to consolidate their disposal efforts for LLRW. These nine compacts and their member states are listed in Table 4.9. The remaining seven states, the District of Columbia, and Puerto Rico are not aligned with other states and are, essentially, "on their own" to responsibly dispose of LLRW and mixed waste. Listed in Table 4.10 are the categorized estimated generation rates for mixed waste tabulated by compact and unaligned state (including the District of Columbia and Puerto Rico). In interpreting the data shown in this table, please review Sects. 4.1.6 and 4.1.7 regarding the statistical validity and cautions in interpreting these survey data. To aid the reader in assessing Table 4.10, the number of respondents from each compact and unaligned state is also shown. Of interest is the fact that the Appalachian Compact appears to be the largest generator of mixed waste among all the compacts and unaligned states.

\subsubsection{Detailed Profile Description by Individual Category}

Depicted in Tables 4.11 through 4.15 are detailed listings of estimated waste generation rates by waste type, treatment (on-site, off-site), amount destined for ultimate disposal, and amount in storage for each of the five categories. Depicted in Table 4.16 are similar data for the entire survey (not broken down into categories). 


\subsection{Profile Validation}

\subsubsection{Comparipon with Manifest Data on Low-Level Radioactive Waste (LLRW)}

Very accurate data exist on the shipments of LLRW to the three burial sites in the states of Washington, Nevada, and South Carolina and are based on actual manifests of shipments received at these sites. Comparisons of the LLRW shipped by the various facilities (responses to B-1 in the Questionnaire, Appendix B) with the manifested waste received at the three burial grounds provide a measure of validation concerning the completeness of the survey. The Integrated Data Base (IDB) Program at ORNL, an official DOE database on national radioactive waste, publishes annual data on shipments of LLRW to the three burial grounds. Illustrated in column one of Table 4.17 are the total 1990 LLRW shipments to the three burial grounds listed by compact (nine) and unaligned states (eight and the District of Columbia). Listed in column two of this table are the total volumes of LLRW reported as shipped off site in 1990 by the respondents to the National Profile questionnaire by compact and unaligned state. Generally, many of these shipments from individual facilities will pass through a broker who will treat, combine, or otherwise compact individual packages prior to shipment to a burial ground. Therefore, one might expect the raw totals at the originating point (as shown in column two of Table 4.17) to be somewhat higher than those listed from the manifests at the three burial sites. As indicated in the table, the total LLRW as reported by the respondents is only $1.3 \%$ less than that determined from records at the three burial sites for the IDB report. Applying the statistical weighting factors, based on number in the frame and the number of responses in the various categories, yields the projected total shipments of LLRW on a national basis. This total is $\mathbf{3 8 \%}$ greater than that reported in the IDB annual report. You will note in comparing numbers for individual compacts, that in some instances the weighted numbers for LLRW are in reasonable agreement with those listed in the IDB report (e.g., for the Southwestern and Southeast Compacts). In other instances, for example the Appalachian and Midwest Compacts, the weighted data are much higher than listed in the IDB report. Such differences may illustrate the fact that because this survey was designed as a national survey caution must be employed in interpreting the data in ways other than those for which the survey was designed. However, the comparison of actual and estimated low-level radioactive waste, from Table 4.17, indicates that the responses to this survey represent a fairly complete sampling of potential mixed waste generators across the United States.

\subsubsection{Comparison with Existing Data on Mixed Waste Generation}

Illustrated in Table 4.18 is a summary of existing mixed waste generation data gleaned from various 1990-1991 sources including Governor's Certifications compact/state low-level waste surveys and compact/state mixed waste surveys. These data are compared to unweighted and 
weighted generation data as determined from the ORNL survey for the National Profile of Mixed Waste. These older data, in general, represent conditions existing during 1989. However, because of their inconsistencies, it was decided that a new national survey, having a defensible statistical basis, should be performed. The most complete data on mixed waste generation found prior to undertaking the National Survey were from the Southwest Compact; reasonable agreement is found between the 1990 projected generation rate of $16,515 \mathrm{ft}^{3}$ and the 1989 rate of $21,156 \mathrm{ft}^{3}$ as determined by a survey of potential mixed waste generators in that compact. Good agreement is also noted for the unaligned state of New York. However, with the exceptions of the Southwest Compact and the two unaligned states of New York and Texas, the current survey data show much higher generation rates for mixed waste than was indicated by the existing data for 1989 . This may be due to inconsistencies found between previous surveys in locating and questioning of potential mixed waste generators. In addition, previous mixed waste surveys were primarily focused on the generation and shipment of LLRW rather than on mixed waste management.

\section{The Treatability of Mixed Waste}

The objective of Task 7 was the identification of existing treatment capability for specific mixed waste streams identified in Sect. 4.2 and Appendix D. Various types of treatment technologies such as incineration, compaction, solidification, vitrification, or other methods that could meet EPA treatment standards and, if possible, to render hazarclous wastes nonhazardous were evaluated. Organizations that currently have the capability to treat low-level radioactive mixed waste, as well as the services these organizations can provide for the treatment of mixed waste, are also identified. For the purposes of the National Profile, an organization is considered to have a treatment capability for mixed waste if that organization has a process that:

1. has been technically demonstrated;

2. has the necessary permits or approvals; and

3. has sufficient approved operating capacity so as to enable a generator to anticipate treatment of his/her waste in a reasonable time frame.

Waste streams, generated nationwide as identified in Sections 4.2 and Appendix D, along with best demonstrated available technologies (BDAT) for their treatment, were examined. This section matches these treatment technologies with each waste stream and also describes treatment services available nationwide for low-level radioactive mixed wastes. A comparison is made of the 
availability of treatment services with the demands indicated by mixed waste generation rates and inventories based on the national profile.

\subsection{Source of Information}

The categories, characteristics, and amounts of mixed waste used in Sect. 5 are based on waste volumes outlined in Sect. 4.2 and Appendix D. Volume distributions by waste category are derived from the database of information provided by a collection of 1,016 completed surveys to the questionnaire (see Appendix B). Further details about the database are contained in Appendix C.

\subsection{Characteristics of Mixed Waste}

Commercial low-level radioactive mixed waste in the United States consists of a variety of waste streams from a range of sources. Generators of mixed waste include facilities in the government, academic, and industrial sectors, as well as nuclear utilities and medical facilities. Mixed waste generation in the United States for 1990 is estimated at about $140,000 \mathrm{ft}^{3}$ (see Sect. 4.2). The mixed waste generated in 1990 covered a broad spectrum of waste types. Table 5.1. shows these categories, along with the volumes generated, amounts stored, primary hazardous constituents, prevalent isotopes, and sources for mixed waste generated in the U.S. in 1990. The distributions of volume and storage by waste category are depicted in Figures 4.3 and 4.5 , respectively. The waste types observed are consistent with mixed waste streams identified in other studies. ${ }^{1.3}$

The LSF category is by far the largest mixed waste generation category, comprising nearly $72 \%$ of the total estimated volume. Although the largest, in terms of generated volume, the LSF category does not, in general, currently pose a significant treatability problem, nor is it expected to in the future because of the adequate amount of commercial treatment capacity that currently exists and the increasing use of substitute materials. The largest volumes of waste in storage as of December 31, 1990, are cadmium and LSF (see Fig. 4.5). Some LSF wastes undergo substantial radioactive decay in storage (e.g., waste containing ${ }^{125} \mathrm{I},{ }^{32} \mathrm{P}$, or ${ }^{35} \mathrm{~S}$ ) reducing or eliminating the radiological hazard, but most LSF in storage is being accumulated for future shipment and/or treatment.

Waste categories (Table 5.1) fall into four general classes - those with organic constituents, those with hazardous metals, aqueous corrosives, and an "Other" category containing complex mixtures and those wastes for which the hazardous constituent could not be determined from available data. The organics class is broken down to include LSFs, various organohalides, and a category to include the balance of organic constituents not covered by the other categories. 
Similarly, the metals class is subdivided into categories for cadmium-, chromium-, lead-, and mercury-contaminated wastes.

In addition to the large quantity of LSFs discussed previously, organic chemicals found in mixed waste include chloroform, trichloroethane, methylene chloride, waste oils, CFCs, and other chlorinated organics used in research or as pesticides. CFCs are derived from dry cleaning, refrigeration, and other industrial operations. Waste oils are derived from vacuum pumps, other equipment and maintenance operations.

Mixed waste containing metals are generated through decontamination of lead used as shielding, from batteries, paint wastes, and lead-containing research solutions. Metal-bearing wastes also result from the use of chromium as a corrosion inhibitor in nuclear power reactors, as a cleaning agent, and as a waste treatment agent for ion-exchange resins. Other sources are cadmium-containing reactor control rods and grit blast. Mercury-contaminated equipment and debris, as well as mercury from laboratory experiments, are also sources of metal-contaminated mixed waste.

Aqueous corrosive mixed wastes are generated from a wide range of industrial and laboratory operations. These are primarily acids (over $90 \%$ ); however, bases also make up a small percentage of this category. "Other" sources of mixed waste include biological wastes, incinerator ash, filter bags, and trash (see Appendix D, Table D.11).

\subsection{Mixed Waste Treatment Options}

\subsubsection{Land Disposal Restrictions}

EPA regulations, known as the LDR, prohibit the disposal of hazardous waste (including mixed waste) unless the wastes are treated to EPA standards in 40 CFR 268 Subpart D or unless a variance or extension to an LDR effective date is granted. Hence mixed waste must be treated to the applicable treatment standard before land disposal is permitted. In general, EPA treatment standards for specific wastes are either expressed as concentration levels or treatment technologies. EPA's approach for developing treatment standards was established using BDAT. Mixed wastes are subject to the established treatment standards for the hazardous portion of the waste except for four categories of mixed waste that have a specified treatment technology as their treatment standard (radioactive lead solids, radioactive elemental mercury, radioactive hydraulic oil contaminated with mercury, and certain radioactive high-level wastes). Please note that the

\footnotetext{
'The definition of mixed waste does not, generally, include biological waste. However, biological waste containing mixed waste would be considered as mixed waste. The "biological" category in this study includes waste reported by its source as mixed waste, with a description clearty designating the biological nature of the waste.
} 
BDAT, used to set treatment levels, does not necessarily have to be the technology used to meet a treatment standard unless the treatment standard is expressed as a specific technology. ${ }^{\mathrm{d}}$

\subsubsection{Treatment Options}

The treatment options evaluated for each mixed waste category are listed in Table 5.2. One or more individual treatments or sequences of treatments were identified for each waste category. Where the waste category contains two or more distinct streams, a treatment or treatment sequence is identified for each waste stream. The table also shows the hazardous constituents in each waste stream, the EPA waste code, the BDAT for treatment of the waste stream, as identified by the EPA, and the EPA treatment standard for the stream. Potential treatment schemes for each waste stream are shown under the column "Treatment Alternatives." These alternatives represent approaches that are considered as possibly feasible based on the capability of the technology to achieve the required treatment standard. The column entitled "Treatment Considerations" contains useful information pertaining to the treatment or to the waste stream. The last column, "Recommended Treatment," shows the treatment (or sequence) selected as the recommended treatment in this study. It must be stressed that, using a specific technology to meet treatment standards is mandatory when, and only when, the standard is a specified technology.

The treatment options appearing in Table 5.2 were evaluated based on information derived from several sources, including 40 CFR Part 268, and several reports. ${ }^{1.5}$ The range of treatment options considered was compiled from these references, drawing on those technologies that have been demonstrated as meeting the EPA requirements for streams similar, as indicated by available stream property data, to those in this study (Table 5.2). For each stream, the recommended treatment was selected using the following criteria. The treatment must (1) satisfy regulatory requirements, (2) be economically feasible, and (3) be likely to become available within about a year, if not already offered commercially. It also needs to be noted that the options were evaluated on the basis of the hazardous waste and its hazardous constituents only. The radiological properties of the mixed waste stream and the present and future availability of any option to treat mixed waste may call into question the viability of the recommended treatment.

\subsubsection{Selection of Recommended Treatment}

Treatment, handling, and packaging requirements for the radioactive components of mixed waste depend on a knowledge of radionuclide identities and concentrations in the waste as well as the physical form of the waste, the radioactive waste class (i.e., Class A, B, or C), and the chemical form. For RCRA-regulated wastes, treatment requirements depend on a knowledge of the EPA

\footnotetext{
dFor further information on the LDRs, please refer to OSWER Directive 9555.00-01, "Guidance on the Land Disposal Restrictions' Effects on Storage and Disposal of Commercial Mixed Waste," September 1990.
} 
waste codes provided in 40 CFR Part 261 and the EPA treatment standards if the waste is determined to be LDR under 40 CFR Part 268.

Once classified by EPA waste code, physical form, radionuclide, and NRC waste class, the treatment for each waste can be identified. Minimum waste form and stability requirements for radioactive waste are specified in 10 CFR Part 61 . Certain mixed wastes fit into special waste groups (e.g., certain high-level radioactive waste, contaminated lead solids, or mercury) with treatment standards as specified technologies.

EPA waste codes, EPA treatment standards, and concentration levels of contaminants (for wastes with treatment standards that are specified as concentration levels) were the key factors in categorizing waste streams for treatment selection. These data and information on waste forms were obtained from the survey. It must be noted that the data used in this study vary widely in the amount and quality of information available for each waste stream. In particular, individual radionuclide concentrations for wastes with multiple isotopes were usually not obtainable from the completed survey questionnaires. In addition, EPA codes were not consistently provided by the generator. Since determining EPA code or codes that apply to a waste requires considerable knowledge of RCRA regulations, it is also likely that some of the EPA codes provided are not entirely accurate or complete. For these reasons, some EPA codes have been inferred from the stream description.

The recommended treatments seiected for mixed waste in this work are shown in the last column of Table 5.2. In selecting a treatment for a given waste, EPA standards were first consulted. The existence of a standard specified as a technology, such as macroencapsulation for lead shielding, leaves no option. The specified treatment technology must be selected unless a variance from a treatment standard is granted pursuant to 40 CFR 268.44. In other cases, possible treatment options for the waste were compiled from prior studies, ${ }^{1.5}$ using alternatives previously developed for similar wastes. Final selection was made giving preference to the BDAT and current availability but also taking into account economic feasibility and likelihood of future availability.

Incineration is recommended for most of the wastes in the onganics class, including LSFs, oils, chlorinated organics, and fluorinated organics. Incineration is the BDAT for all of the organic mixed waste in this study, except for waste oils, for which a BDAT has not been established and which is not a Federally listed hazardous waste. However, it may be possible to

\footnotetext{
'EPA has decided not to list used oil destined for disposal as hazardous waste, considering the existing regulations and controls to be adequate to ensure that used oil does not pose a threat to public health and the environment. However, used oil may still be declared a hazardous waste if if exhibits a tooic characteristic. States have the right to impose additional controls, some of which have done so in their decision to designate used oil as a hazardous waste.
} 
increase the percent incinerated through judicious blending with other incinerable organics. The corrosive nature of incinerator emissions from highly halogenated CFCs make incineration less feasible, since facility emission limits are likely to be exceeded. Incineration was selected for only $5 \%$ of CFCs. The treatment selected for the remaining $95 \%$ of CFCs is distillation, followed by chemical oxidation. The "Other organics" category consists mostly of materials for which the BDAT is incineration or deactivation (which may include incineration).

The metals class requires a more diverse set of treatments than the organics class. Cadmium-contaminated waste may be st:bilized in cement or glass. Chromium wastes, consisting mainly of chromium-contaminated solutions, can be chemically reduced, followed by precipitation, filtration, and stabilization. Neutralization of the filtrate following precipitation may be required. Three types of lead-contaminated wastes required different treatment sequences. Lead shielding that cannot be decontaminated and reused must be macroencapsulated. Lead-bearing solutions should be precipitated filtered and the precipitate stabilized. Again, neutralization of the filtrate following precipitation may be required. Lead batteries, not prevalent in the study $\left(0.5 \mathrm{ft}^{3}\right)$, may require thermal recovery of the lead. The mercury category consisted of two types of streams: (1) aqueous solutions, which may be precipitated and stabilized, and (2) equipment and debris contaminated with undetermined levels of mercury, for which the treatment required is ther.nal recovery. However, based on the radiological properties of these wastes and the present and future availability of facilities that offer thermal recovery, this treatment may not be a viable option.

The selected treatment for "Aqueous Corrosives," consisting primarily (greater than 90\%) of inorganic acids and bases, is neutralization. Incineration, however, is also a feasible option for aqueous streams burned in combination with high-heat-value streams.

The "Other" class is more difficult to assign treatments to, since wastes in this class have multiple or unusual contaminants. Wastes have been grouped (and numbered) within this class to the extent possible, and treatment options were identific! based on the limited information available, as indicated in the "Treatment Alternatives" column. The metal-contaminated organic sludges (group 1) could be treated by distillation to recover solvents and followed by oxidation and stabilization of the residue. Incinerator ash (group 2), metal alloys (group 3), and sealed sources (group 8 ) are good candidates for stabilization. The aqueous, metal-bearing solutions (group 4) in

\footnotetext{
'Only monochloromonofluorocarbons are assumed to be acceptable for incineration.

The conservative assumption that the mercury level is high for these waster is made since the actual level is not known. For low mercury contamination levels (below $260 \mathrm{mg} / \mathrm{kg} \mathrm{Hg}$ ), the BDAT selected would be to acid leach, then axidize, followed by dewatering. If elemental mercury is present, the treatment standard is amalgamation.
} 
this class are more complicated than those in the metals class above, but it should be possible to treat them the same way, although with more difficulty, using precipitation, filtration, and stabilization, with possible neutralization of the filtrate. Treatment selections for groups 5-6 are not possible, given the data available.

\subsection{The Demand for Treatment Services}

Table 5.3 summarizes some of the results of Table 5.2, presenting estimates of the demand, in cubic feet, for treatment services by the different waste types encountered in this study. Some waste categories require more than one technology. The demand shown in Table 5.3 is defined as the sum of the 1990 annual generation rate for the waste and the amount of waste in storage at the end of 1990. ${ }^{b}$ In other words, this quantity represents the amount of capacity that would have to be provided to treat the annual waste generated and eliminate the 1990 inventory in one year. This demand figure is chosen in light of the strong regulatory incentive against storage of mixed waste.

The total demand for the different treatments is slown scross the bottom row of Table 5.3, above the solid bar. Incineration, by far, is in greastest domand at 142,74: $\mathrm{ft}^{3}$ for orgaaic and other materials. Stabilization is second $h^{i}$ hest at $42,514 \mathrm{it}^{3}$. Next in demand is a sequence to distill and oxidize organic sludges, in the amount of $17,486 \mathrm{ft}^{3}$. Neutralization, macroencapsulation, and chemical reduction are next in demanc, estimated at $13,847 \mathrm{ft}^{3}, 4,124 \mathrm{ft}^{3}$, and $2,885 \mathrm{ft}^{3}$, respectively. The demand for thermai recovery hor mercury and lead acid hatteries is estimated at $366 \mathrm{ft}^{3}$. Lead decontamination could have a demand $r=$ to $4,124 \mathrm{ft}^{3}$.

\footnotetext{
"The demand for storage has been determined using the same diatribution of demand within each waste category as was obtained for generation. This assumption could result in underestimation of the demand for certain problematic wastes. 


\subsection{Profiles of Mixed Waste Treatment Industries}

\subsubsection{Overview of Existing Treatment Capability}

Facilities for treatment of mixed waste have been developed at research laboratories, such as those operated by the DOE, and within the commercial sector. Examination of existing (see Table 5.4) and future capability for treatment of commercial low-level radioactive mixed waste follows. DOE capabilities and facilities for treating mixed waste are not discussed in this report. In a recent Federal Register notice regarding a case-by-case request by DOE to extend the LDR effective date for some of its mixed wastes, a discussion is provided on DOE's use of commercially available mixed waste treatment capacity. The feasibility and extent of DOE's possible use of commercial mixed waste treatment capacity is beyond the scope of this report. However, because of the large volume of mixed waste DOE generates annually, and has generated in the past, relative to commercially generated mixed waste, the possible use of commercial treatment capacity by DOE must be noted because it may impact the availability of commercial mixed waste services to the commercial mixed waste generators that is being discussed in this report.

Four commercial facilities currently treat LSF, the largest volume of mixed waste generated (Table 5.1). The Quadrex ${ }^{k}$ Corporation facility, located in Gainesville, Florida, can process up to about 4,500 drums per month or nearly $400,000 \mathrm{ft}^{3}$ annually. Diversified Scientific Services, Inc. (DSSI), located in Kingston, Tennessee, provides incineration capacity of up to $130,000 \mathrm{ft}^{3}$ year for LSFs and bulk organics. Another LSF treatment facility, operated by RAMP Industries and located in Denver, Colorado, provides incineration and other treatments, up to $25,000 \mathrm{ft}^{3} /$ year. NSSI/Recovery Services, Inc. (NSSI), located in Houston, Texas, accepts LSF materials and has substantial capacity ( $\sim 750,000 \mathrm{ft}^{3}$ annually) for bulking auld storage prior to off-site incineration. NSSI has storage for over $33,000 \mathrm{ft}^{3}$ of drummed wastes.

The pertinent operating license(s) and/or permit(s) should be consulted to determine the facility's treatment process or processes and the acceptable wastes. Appendix $G$ contains portions of the radioactive materials and hazardous waste permits indicating radioactive and hazardous constituents that may be accepted for each commercial mixed waste treatment facility.

\footnotetext{
'Vendor capacities are basod on information provided by the vendors via personal communication in June 1992. Thin

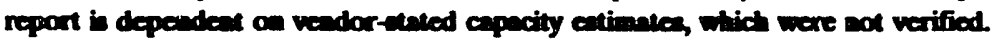

MHazardous Waste Management System: Land Disposal Restrictions (LDR); DOE Mixed Wastes Extension Application," Federal Register, Vol. 57, No. 101, Tuesday, May 26, 1992.

Mention of specific products and/or manufacturers in this document implies neither endorsement, preference, nor disapproval by the U.S. Government or any of its agencies or contractors.
} 


\subsubsection{Quadrex}

The Quadrex Corporation accepts only scintillation liquid, which is bulked by crushing to extract liquid from the vials and stored for accumulation prior to treatment off-site. The liquid, considered a hazardous waste in the state of Florida, is mainly burned off-site for energy recovery at cement kilns.

Quadrex is a TSD facility that fuel blends LSF and holds a Part B storage permit for LSF from the Florida Department of Environmental Regulation (FDER). Quadrex also has a radioactive materials license with the state of Florida which limits storage of radioactive materials to $180 \mathrm{~d}$. The license includes standards for ${ }^{14} \mathrm{C}$ and tritium, allowing disposal of these isotopes as nonradioactive material, provided the activities of ${ }^{14} \mathrm{C}$ and tritium are below $0.05 \mu \mathrm{Ci} / \mathrm{g}$. A list of isotopes acceptable by Quadrex may be found in Appendix G. Quadrex is limited to 100 mCi/year for all isotopes other than ${ }^{14} \mathrm{C}$ and tritium in the material it processes for incineration. Because of this limit, some LSF waste with higher-than-normal activity is sent to NSSI for processing. NRC and Florida regulations allow the disposal of ${ }^{14} \mathrm{C}$ and tritium in $\mathrm{LSF}$ in concentrations $<0.05 \mu \mathrm{Ci} / \mathrm{g}$ without regard to its radioactivity (i.e., as a nonradioactive waste).

Quadrex is considering expanding the type of mixed waste it will accept for processing. The additional wastes that Quadrex is planning to treat are radioactively contaminated solvents similar to LSFs and radioactively contaminated oil. This additional treatment capability will require FDER approval of requests for amendment to Quadrex's treatment, storage, and disposal (TSD) permit.

\subsubsection{RAMP}

RAMP Industries processes both mixed waste and low-level radioactive waste. The mixed waste currently comprises 10 to $15 \%$ of its business. Mixed wastes accepted by RAMP include those containing only spent solvent wastes (F-series) and ignitable (D001) hazardous wastes. The F-series wastes include mostly halogenated and nonhalogenated organic solvents. Mixed wastes are bulked using a crusher/shredder to remove liquid from the vials, and stored for accumulation prior to treatment off-site. Classified as a hazardous waste in the state of Colorado, the LSF wastes are transferred locally to Chemical Waste Management, Inc., for recovery of toluene and other solvents by solvent extraction. The remaining liquid is considered nonradioactive and is transported to a permitted hazardous waste cement kiln for use as an energy recovery RAMP performs other treatment of mixed waste including compaction, neutralization, stabilization in cement, and solidification, but is limited by the hazardous waste codes of the wastes it can accept (see Appendix G). 
RAMP is a TSD facility with interim status and has submitted an application for a Part B Permit to the Colorado Department of Health's (CDH) Waste Management Division. RAMP also holds a radioactive materials license, administered by the Radiation Control Division of $\mathrm{CDH}$, for its radioactive waste operations.

\subsubsection{NSSI/Recovery Services, Inc.}

NSSI/Recovery Services, Inc. (NSSI) is a radioactive waste storage and processing facility that holds a radioactive materials license as well as a Part B Permit to store and process wastes. NSSI operates a multi-process treatment facility for radioactive and mixed waste. NSSI is currently accepting mixed waste that contains hazardous waste classified as D-series (characteristic) waste; F-, P-, and U-series (listed) waste in lab pack form; and all F-series (listed spent solvent) waste except F004 (spent non-halogenated solvents) and F006 (electroplating sludges). Wastes received by NSSI may be processed in the following ways:

- store and/or repackage wastes and accumulate them for off-site disposal,

- process and store wastes to prepare them for off-site disposal,

- process mixed waste to remove hazardous characteristics, and

- recycle wastes as fuels or as other beneficial products.

Liquid wastes received in bulk containers are tested for their compatibility and then transferred to appropriate tanks for storage and processing. Waste characteristics determine the types of processes and sequence to which they are subjected. Treatment processes allowed by their RCRA permit include chemical fixation to stabilize waste for land disposal, chemical oxidation/reduction to destroy hazardous organics, activated carbon which removes organic contaminants by adsorption onto solids, neutralization, and precipitation. Mechanical separation is used to sort lab packs. Decanting is used to separate liquids of varying densities. Solvent recovery segregates and consolidates solvents for recycling, and evaporation is used to dry sludge. LSFs and other similar organics are considered nonradioactive and are transferred off-site to a fuel broker, Gibraltar Corporation, for use as cement kiln fuel at a number of locations throughout Texas.

NSSI currently treats and stores radioactive wastes under its Radioactive Materials License administered by the Texas Department of Health. The license includes standards for ${ }^{14} \mathrm{C}$ and tritium that are similar to Florida's standards, allowing disposal of LSF containing these isotopes as nonradioactive material (i.e., as hazardous waste only) provided the activities of ${ }^{14} \mathrm{C}$ and tritium are below $0.05 \mu \mathrm{Ci} / \mathrm{g}$. The mixed waste that NSSI can accept are governed by the allowable 
hazardous components as specified in its RCRA Part B Permit on file with the Texas Water Commission. NSSI is RCRA permitted to store and treat the hazardous wastes from an extensive list (see Appendix G) but is not allowed to dispose of mixed waste on-site. Chemical and radiological waste profiles are required by NSSI for all types of wastes it receives.

\subsubsection{Diversified Scientific Services, Inc.}

Diversified Scientific Services Incorporated (DSSI) has a boiler facility operating under RCRA interim status to treat mixed waste containing caiegory F001 to F005 (spent solvents) and characteristic solvents. The facility includes a cogeneration plant, the boiler for which provides heat for steam turbines to generate electric power. Complete combustion is promoted by injection of ignitable fluid waste into the boiler by means of an atomizer, or mechanical spray device, leaving very little ash residue. Stack gases pass through a scrubber, baghouse, and High Efficiency Particulate Air (HEPA) filter to remove particulates and are monitored for radioactive particles. This waste fuel boiler has been operational since 1991 and is operating under a state interimstatus-boiler permit. Other materials, such as plastic or glass scintillation vials are recycled for beneficial reuse.

The DSSI facility accepts primarily LSF and other ignitable solvents, such as halogenated organics. DSSI has a RCRA Part B Permit which allows storage of mixed waste for radioactive decay, and a radiological byproduct materials license, which limits the quantity of isotopes (see Appendix $G$ ) that may be on-site at any given time.

\subsection{Potential Mixed Waste Treatment Facilities}

\subsubsection{Scientific Ecology Group}

Scientific Ecology Group (SEG) is likely to begin accepting certain types of mixed waste in the next 2 years. Located in Oak Ridge, Tennessee, SEG provides radioactive waste management services including incineration and is submitting an application for a RCRA Part B Permit in order to process mixed waste.

SEG currently operates a multi-process facility for treatment of low-level radioactive waste. Wastes are sorted and segregated depending on the homogeneity of the waste shipment received. A solidification unit exists for sludges and slurries. Oil, and other wastes that are non-RCRA hazardous wastes, can be treated as LLRW (non-mixed) in Tennessee. Wastes with a halide content exceeding $5 \%$ by weight, however, cannot be incinerated at SEG since the off-gas filtration equipment cannot handle high concentrations of acid gases. The incinerator operates at 900 to $1,600 \mathrm{lb} / \mathrm{h}$ of solid waste and can simultaneously burn $30 \mathrm{gal} / \mathrm{h}$ of radioactive, nonhazardous waste oil. The SEG incinerator includes a secondary chamber with a 3-s gas residence time and a 
temperature of $2,200^{\circ} \mathrm{F}$ to achieve a $99.9999 \%$ destruction and removal efficiency (DRE) of volatile organics.

The SEG incinerator is equipped with a baghouse and dual HEPA filters for particulate removal and a wet scrubber for acid gas removal. SEG expects to achieve a volume reduction through incineration of over 100:1 for mixed waste, similar to that currently realized with combustible radioactive waste.

SEG currently has a radioactive materials license from the Tennessee Department of Health and Environment. This license restricts possession of radioactive materials to a period of $180 \mathrm{~d}$, precluding storage of mixed waste for decay as part of its treatment process. SEG has prepared and is submitting an application for a RCRA Part B Permit to allow incineration of mixed waste and hopes to have this permit within 2 years.

In the future, the facility will be capable of processing mixed waste if SEG obtains a RCRA Part B Permit. Much of the organic mixed waste could be incinerated in the SEG incinerator, which is patterned after a Studsvik unit in Sweden used for incinerating radioactive waste. SEG is developing a vitrification system that will glassify the incinerator ash into glass blocks that should be capable of passing all characteristic tests used for defining hazardous wastes.

\subsubsection{Envirocare}

Envirocare of Utah, Inc., operates a low-activity radioactive and mixed waste disposal (burial) facility and is planning to offer mixed waste treatment in the future. Envirocare has already received a RCRA Part B Permit from the Utah Division of Solid and Hazardous Waste, allowing the receipt, storage, and disposal of low-activity wastes which are both radioactive and hazardous at its South Clive facility. With its Part B Permit, Envirocare may store and dispose of solid-phase mixed waste (see Appendix G for specific limits).

\subsection{Comparison of Treatment Capacity Versus Demand}

Treatment services offered by companies in the commercial sector, along with their estimated annual treatment capacities, are shown in Table 5.4. Figure 5.2 presents the combined capacity, by treatment technology, for the four companies that currently have the capability to treat mixed waste. For the waste streams reported in the Mixed Waste Profile, the information available on hazardous constituent concentration levels, on a stream by stream basis, is limited. For this reason, comparison of hazardous constituent concentrations with specific acceptance criteria for each treatment facility cannot be made. Rather, the capacity available currently to treat each waste category is compared to the demand, with the goal of finding where capacity needs to be developed for mixed waste treatment. Figure 5.3 shows a comparison of the demands 
listed in Table 5.3 with commercial treatment capacities that are currently available. Demand is defined as 1990 generation rate plus material in storage at the end of 1990. This is a conservative estimate of needed capacity because some of the waste in storage is being accumulated for treatment on-site or for shipment to off-site treatment facilities. Drawing on the data in Tables 5.3 and 5.4, the following observation can be made.

\subsubsection{Availability of Incineration Capacity}

2. LSF - The four industries, NSSI (capacity $750,000 \mathrm{ft}^{3}$ ), Quadrex (capacity $400,000 \mathrm{ft}^{3}$ ), DSSI (capacity 130,000 $\mathrm{ft}^{3}$ ), and RAMP (capacity 25,000 $\mathrm{ft}^{3}$ ), together provide 1.28 million $\mathrm{ft}^{3}$ of annual capacity to treat LSF. This amounts to nearly 13 times the amount generated annually $\left(100,196 \mathrm{ft}^{3}\right)$ and can easily accommodate the stored LSF as well. Most, but not all, LSF are acceptable depending on radionuclide content.

b. Waste Oil - Waste oil destined for disposal and not exhibiting a hazardous characteristic is not considered as mixed waste by EPA and can currently be incinerated without a RCRA permit. The 5,259 $\mathrm{ft}^{3}$ generated annually could be accepted by any of the four industries offering LSF treatment, and the radioactive waste oil could also be accepted by SEG, provided the waste oil stream is tested and no listed or characteristic hazardous waste component is present.

c. Halogenated Organics - RAMP accepts organohalides, with concentration limitations, and processes them for incineration. Chlorinated organics, fluorinated organics, and low-halogen CFCs may be incinerated, based on current practice. CFCs with high halogen content, however, are not accepted for incineration. The $2,704 \mathrm{ft}^{3}$ of incinerable organohalides (2,504 $\mathrm{ft}^{3}$ of chlorinated organics and $5 \%$ of $3,998 \mathrm{ft}^{3}$ of chlorinated fluorocarbons) generated annually could be accepted by RAMP for incineration.

d. Other Organics - These wastes, generated at a rate of $9,697 \mathrm{ft}^{3}$ /year, are primarily D001, F003, and F005 wastes for which incineration is the selected treatment. This type of waste could be accepted by RAMP, with a capacity of $25,000 \mathrm{ft}^{3} /$ year (incineration).

a Lead penetration sealants and oils - Penetration sealants and oils contaminated with lead, generated at a rate of $29 \mathrm{ft}^{3} / y e a r$, are not accepted for incineration by any of the existing commercial facilities. The demand for treatment of this waste is estimated to be small (78 $\mathrm{ft}^{3}$ or $1 \%$ of $7,782 \mathrm{ft}^{3}$ of lead wastes). 


\subsubsection{Availability of Stabilization Capacity}

Stabilization of solid mixed waste is provided by RAMP and NSSI. Their joint capacities of 112,000 and $5,000 \mathrm{ft}^{3} /$ year, respectively, exceed the total estimated demand $\left(42,514 \mathrm{ft}^{3} /\right.$ year $)$ for stabilization. Hence, metal-contaminated solutions can be treated by these two companies, with the major capacity being provided by NSSI.

\subsubsection{Availability of Neutralization Capacity}

NSSI (capacity 10,000 $\mathrm{ft}^{3} /$ year) and RAMP (capacity 6,000 $\mathrm{ft}^{3} /$ year) provide a total capacity for neutralization of aqueous corrosives of $16,000 \mathrm{ft}^{3} / \mathrm{year}$, enough to accommodate the demand $\left(13,847 \mathrm{ft}^{3}\right)$ for this waste class.

\subsubsection{Availability of Capacity for Distillation/Oxidation of Organics}

CFCs with high halogen content and metal-contaminated organic sludges present a problem for most commercial vendors. NSSI can treat such wastes by distillation to recover organics and then oxidation with stabilization of the residue. NSSI's capacity to treat organic sludges in this way is estimated at $10,000 \mathrm{ft}^{3}$ /year. This capacity would accommodate the estimated generation rate for CFCs with high halogen content $\left(3,800 \mathrm{ft}^{3} /\right.$ year or $95 \%$ of $3,998 \mathrm{ft}^{3} /$ year of chlorinated fluorocarbons) and CFC sludges from the Other Hazardous Materials category $\left(3,500 \mathrm{ft}^{3} /\right.$ year or $33 \%$ of $10,613 \mathrm{ft}^{3}$ /year of other hazardous materials) with some reserve capacity. However, NSSI's capacity would fall short of the demand $\left(17,486 \mathrm{ft}^{3}\right)$ by about $7,500 \mathrm{ft}^{3}$.

\subsubsection{Availability of Capacity for Decontamination/Macroencapsulation of Lead}

Decontamination of solid lead such as radiation shielding, provided the radioactivity is limited to the surface, is provided by NSSI. Macroencapsulation or stabilization of lead, sealed sources, and some other materials is available from NSSI, provided that waste handling does not require hot cell work based on exposure rate. The capacity of $300 \mathrm{lb} / \mathrm{d}$ for decontamination or macroencapsulation of lead $\left(\sim 100 \mathrm{ft}^{3} /\right.$ year $)$ is substantially less than the annual generation rate $\left(1,528 \mathrm{ft}^{3} /\right.$ year or $53 \%$ of $2,883 \mathrm{ft}^{3}$ /year of lead) and falls short of the demand $\left(4,124 \mathrm{ft}^{3}\right)$ by about $4,000 \mathrm{ft}^{3}$.

\subsubsection{Availability of Capacity for Chemical Reduction of Chromium Wastes}

NSSI has the capability for chemical reduction of wastes contaminated with chromic acid and chromates, with a capacity of $10,000 \mathrm{ft}^{3 / y e a r}$. This capacity exceeds the estimated demand of $2,885 \mathrm{ft}^{3} /$ year.

\subsubsection{Thermal Recovery of Mercury and Lead}

No commercial services are offered for treatment of mercury-contaminated waste, generated at $49 \mathrm{ft}^{3} /$ year (or $11 \%$ of $442 \mathrm{ft}^{3} /$ year of mercury); or $\mathrm{fnr}$ lead batteries, generated at less than 
$1 \mathrm{ft}^{3} /$ year (from mixed waste database), for which thermal recovery is indicated as a treatment standard. These are small streams (estimated demand is $366 \mathrm{ft}^{3} /$ year) for which no commercial treatment alternatives exist. Thermal recovery is the EPA treatment standard for D008 lead characteristic hazardous waste from lead acid batteries and for D009 nonelemental mercurycontaminated materials. However, thermal recovery for these mixed wastes may not be a viable option because of their radioactive component.

\subsubsection{Summary of Current Waste Treatability Capacity}

The estimated demand for treatment services is summarized in Table 5.3 by waste category. These were compared with the treatment capabilities of commercial industries presented in Table 5.4. The findings of this comparison are illustrated in Fig. 5.3 and are summarized below. It should be emphasized that some of the conclusions reached here may be based on one-time generations of unique mixed waste streams; therefore, caution should be exercised in extrapolating these results to present or future treatment needs.

There appears to be adequate incineration capacity available to meet the demand for LSF, waste oil, chlorinated and fluorinated organics, and other organics, except for CFCs. Enough capacity exists to treat CFCs generated annually by distillation and oxidation, but additional capacity, estimated at 7,500 $\mathrm{ft}^{3}$, would be needed to treat CFCs generated and in storage at the end of 1990. Sufficient capacity exists to stabilize metal-bearing solutions, metal alloys, and sealed sources. There is adequate existing capacity available for precipitation, neutralization, and chemical reduction, but capacity is needed for decontamination and macroencapsulation of lead shielding (about 4,000 $\mathrm{ft}^{3}$ ) and to treat other wastes contaminated with solid lead and mercury $\left(366 \mathrm{ft}^{3}\right)$ by thermal recovery.

The volume of wastes requiring added capacity to match their generation rate is estimated at about $1,600 \mathrm{ft}^{3}$ annually. The total unmet demand is estimated at about $12,000 \mathrm{ft}^{3}$ (storage and generation over a 1 -year period).'

It should be clearly understood that the facility capacities presented in this report represent information as provided by the companies themselves. These capacities are, to some degree, theoretical as they have never actually been demonstrated, and they do not take into account any mitigating factors that may affect actual capacity. Such factors may include the need for pretreatment or unusual physical preparation, including unanticipated chemical analyses. Also, the timing of treatment campaigns and any required downtime between campaigns may affect

\footnotetext{
'It is important to note that estimated capacities to treat mixed waste have been provided by the vendors that offer these services. Some overestimation or underestimation may have occurred since most of the needed treatment diversity is provided by only two vendors, with the majority of the capacity provided by only one. It may be impractical for NSSI to provide all of the capacity that it has estimated.
} 
throughput. Additional factors that may limit total capacity are the resource and manpower limitations that operating parallel processing lines may impose on those facilities providing multiple treatment options. Finally, as mentioned previously, DOE's possible use of commercial facilities may affect their availability for use by the commercial sector.

\subsubsection{Estimated Future Treatment Capacity}

Over the next 5 years, as many as two additional facilities could be permitted for the treatment of liquid mixed waste, including technologies other than incineration. Currently, four facilities can accept LSFs; this may increase to five if SEG receives its Part B Permit. Existing facilities have expanded the list of wastes they can accept or are in the process of doing so. Hence, the capacity for treating mixed waste appears to be increasing.

NSSI considers itself a piiot operation and is willing to develop and test new technologies. New processes to be developed at NSSI, or at other facilities, could employ one or more of the promising advanced technologies. Technologies that may have application to treatment of mixed waste include supercritical water oxidation, ultraviolet (UV) light/oxidation, wet air oxidation, and solvent extraction ${ }^{2}$. New technologies such as these may be demonstrated in the near future. $A$ detailed listing of new and emerging technologies for mixed waste treatment is provided in Appendix $\mathrm{H}$.

\section{Summary and Conclusions}

\subsection{National Profile...}

The survey of potential commercial mixed waste generators in the United States consisted of a series of well-defined steps that included: (1) selecting a total number of facilities to be sampled, basing the number on an anticipated $25 \%$ nonresponse rate and a $10 \%$ desired relative standard error; (2) sending out a detailed questionnaire (Appendix B) to a number [determined in (1)] of randomly selected facilities; (3) accumulating and compiling the responses, in an appropriate format, into a database; and (4) estimating the national commercial mixed waste generation rates based on multiplying the "raw" data by weighting factors to correct for the fact that only a fraction of the facilities in each group were sent questionnaires.

The survey target population (survey frame) included a total of 2,936 facilities after duplicates were eliminated. A random sample of 1,323 facilities was selected from this target population. Data from 1,016 completed mixed waste survey questionnaires (including 21 facilities which were determined to be no longer in business, a $77 \%$ response rate) received by ORNL 
indicated that $\sim 81,000 \mathrm{ft}^{3}$ of commercially generated low-level radioactive mixed waste was generated in the United States in 1990 by those surveyed. Approximately $63 \%$ of this reported volume was liquid scintillation fluid.

Using weighting factors to generate a statistically valid estimate of the 'national' mixed waste profile, it is estimated that $\sim 140,000 \mathrm{ft}^{3}$ of low-level radioactive mixed waste were generated nationally in 1990 of which nearly $72 \%$ was LSFs. In addition, an estimated $75,000 \mathrm{ft}^{3}$ of mixed waste was in storage for various reasons as of December 31, 1990. The industrial category was estimated to be the largest generator and accumulator of mixed waste, with over $36 \%$ of the b seration and nearly $57 \%$ of the storage, of the total mixed waste in the United States in 1990. Data received from $97 \%$ of the operating nuclear utilities (some may have multiple reactors) in the country indicated that they accounted for $<10 \%$ of the estimated total 1990 generation rate and $-29 \%$ of the estimated mixed waste in storage.

Upper and lower bounds were set on the volume of mixed waste that is currently untreatable by making the assumption that LSF, oil, organic (not halogenated), and corrosive waste are treatable under current technologies. Deducting the wastes that are assumed to be treatable from the estimated national total mixed waste generation rate leaves $\sim 18,500 \mathrm{ft}^{3}$ of untreatable commercial low-level mixed waste. Thus, with this as an upper bound and the estimated $-5,000 \mathrm{ft}^{3}$ of currently untreatable mixed waste (see Sect. 4.2.5) as the lower bound, the untreatable mixed wastes range from 3.5 to $13.3 \%$ of the estimated 1990 national generation rate of $140,000 \mathrm{ft}^{3}$.

Although Compact/State and Hazardous Waste Stream data are presented, it should be emphasized that the profile was generated to be statistically valid only at the national level and only for the major facility categories. It is estimated that the overall accuracy of the projected mixed waste generation rates and waste in storage are well within the objective of the study which was to be, at the $95 \%$ confidence level, within a factor of $\underline{2}$. Estimates of mixed waste volumes calculated at the state level may be less reliable, mainly due to fewer samples in these substrata.

\subsection{The Treatability of Mixed Waste}

A broad spectrum of mixed wastes were generated by the facilities surveyed in the National Profile, including liquid scintillation fluids, organohalides and other organics, wastes contaminated with toxic metals, corrosives, and other hazardous materials. A considerable inventory of mixed waste existed in storage as of December 31, 1990. These mixed wastes present a need for specific treatment services, including incineration, stabilization, chemical treatment, and recovery/reuse technologies. Four companies - NSSI (Houston, TX), DSSI (Kingston, TN), Quadrex 
(Gainesville, FL), and RAMP (Denver, CO) - currently offer mixed waste treatment services for a limited spectrum of mixed waste. Two others, SEG (Oak Ridge, TN) and Envirocare (Salt Lake City, UT), may offer mixed waste treatment in the near future. A comparison has been made between the available treatment capacity and expected demands due to estimated mixed waste generation in 1990 plus mixed waste in storage at the end of 1990 . Based on the estimated demand for treatment services for each waste generation category, in comparison with treatment capabilities of the industries identified in this report, sufficient treatment capacity appears to exist for all mixed waste categories except chlorinated fluorocarbons, lead shielding and other waste contaminated with solid lead, and mercury-contaminated equipment and debris. Sufficient capacity to treat all mixed waste requiring macroencapsulation is also not available. The capacity shortfall amounts to $\sim 12,000 \mathrm{ft}^{3}$. Currently operating commercial treatment facilities may be able to handle nearly all of the commercial mixed waste generated, based on the reported 1990 generation data, but to address the total demand (computed as 1990 generation plus storage as of the end of 1990), some significant additional capacity must be developed to treat mixed waste already in storage.

Finally, it must be emphasized that the DOE generation and inventory of mixed waste and any DOE capabilities and DOE facilities for treating mixed waste (either commercial and/or DOE mixed waste) are beyond the scope of this study. Current and future demands that DOE will have for commercial mixed waste treatment services are also not covered in this study. (See 57 FR 22024, May 26, 1992, for information on DOE's efforts to contract for commercial mixed waste treatment services.) Thus any effect of DOE's current or future procurement of commercial mixed waste treatment services was not factored into th. ommercial low-level radioactive mixed waste treatment capacity determinations presented in this report.

A range of 5,000 to $18,500 \mathrm{ft}^{3}$ of untreatable mixed waste was estimated from the 1990 generation and storage data resulting from the survey questionnaire results. More specifically, Table 5.3 of Sect. 5, estimates the untreatable volume of mixed waste at $11,954 \mathrm{ft}^{3}$ after comparing treatment capacities with treatment demands in 7 waste categories. Given that some $75,000 \mathrm{ft}^{3}$ of mixed waste was estimated to be in storage as of December 31, 1992, the question arises: Why does so much mixed waste remain untreated? Although, some of the waste may only be in storage for accumulation prior to future treatment/disposal, possible reasons for other waste not being treated, based on discussions with survey participants, include:

- Generators believe that treatment facilities may be overestimating their capabilities, capacities, and possession of required permits. 
- Small mixed waste generating facilities may not be aware of the identity or capabilities of commercial facilities that can treat mixed waste.

- Mixed waste generators may be knowledegable about the identity of treatment facilities but may have insufficient information to match their waste with the acceptance criteria of the treatment facilities.

- Generating facilities may not want to relinquish control over their waste without proper/legal assurances that may be difficult/impossible to obtain.

- Various regulations, as well as their interpretation by the individual states, make the legal landscape complex for mixed waste generators.

- Inexperience or limited experience with the management of mixed waste may cause generators to take longer to make required decisions to contact and contract with a company to treat their mixed waste.

- Waste may, indeed, be treatable to the extent noted in this report, and generating facilities are sending mixed waste to the treatment facilities, but resource (both manpower and funds) limitations make the transfer slow, costly, and sometimes institurionally difficult.

\subsection{Comments}

Comments and suggestions are to be directed to:

D. A. Orlando

Division of Low-Level Waste Management and Decommissioning

Office of Nuclear Material Safety and Safeguards

U.S. Nuclear Regulatory Commission

Washington, DC 20555

Phone: (301) 504-2566
S. Jones

State and Regional Programs Branch Office of Solid Waste U.S. Environmental Protection Agency Washington, DC 20460

Phone: (703) 308-8762

\section{References}

1. "Hazardous Waste/Mixed Waste Disposal Facility-Recommended Treatments and Related Waste Management Issues," WSRC-RY-90-1143, November 1990.

2. "Final Conceptual Mixed Waste Management Plan," A report to California Department of Health Services and the states of the Southwestern Compact, by Ebasco Environmental, December 1989. 
3. Kirner, N., G. Faison, and C. Owens, "Mixed Waste Management Options," DOE/LLW-134, December 1991.

4. "Final Best Demonstrated Available Technology Background Document for K031, K084, K101, K102, Characteristic Arsenic Wastes (D004), Characteristic Selenium Wastes (D010), and $P$ and $U$ Wastes Containing Arsenic and Selenium Listing Constituents, Volume 1," PB90-234014, May 1990.

5. "Final Best Demonstrated Available Technology Background Document for Characteristic Ignitable Wastes (D001), Characteristic Corrosive Wastes (D002), Characteristic Reactive Wastes (D003), and P and U Wastes Containing Reactive Listing Constituents, Volume 2," PB90-234022, May 1990.

6. "Regulating the Disposal of Low-Level Radioactive Waste, A Guide to the Nuclear Regulatory Commission's 10 CFR Part 61," Office of Nuclear Material Safety and Safeguards, U.S. Nuclear Regulatory Commission, August 1989. 


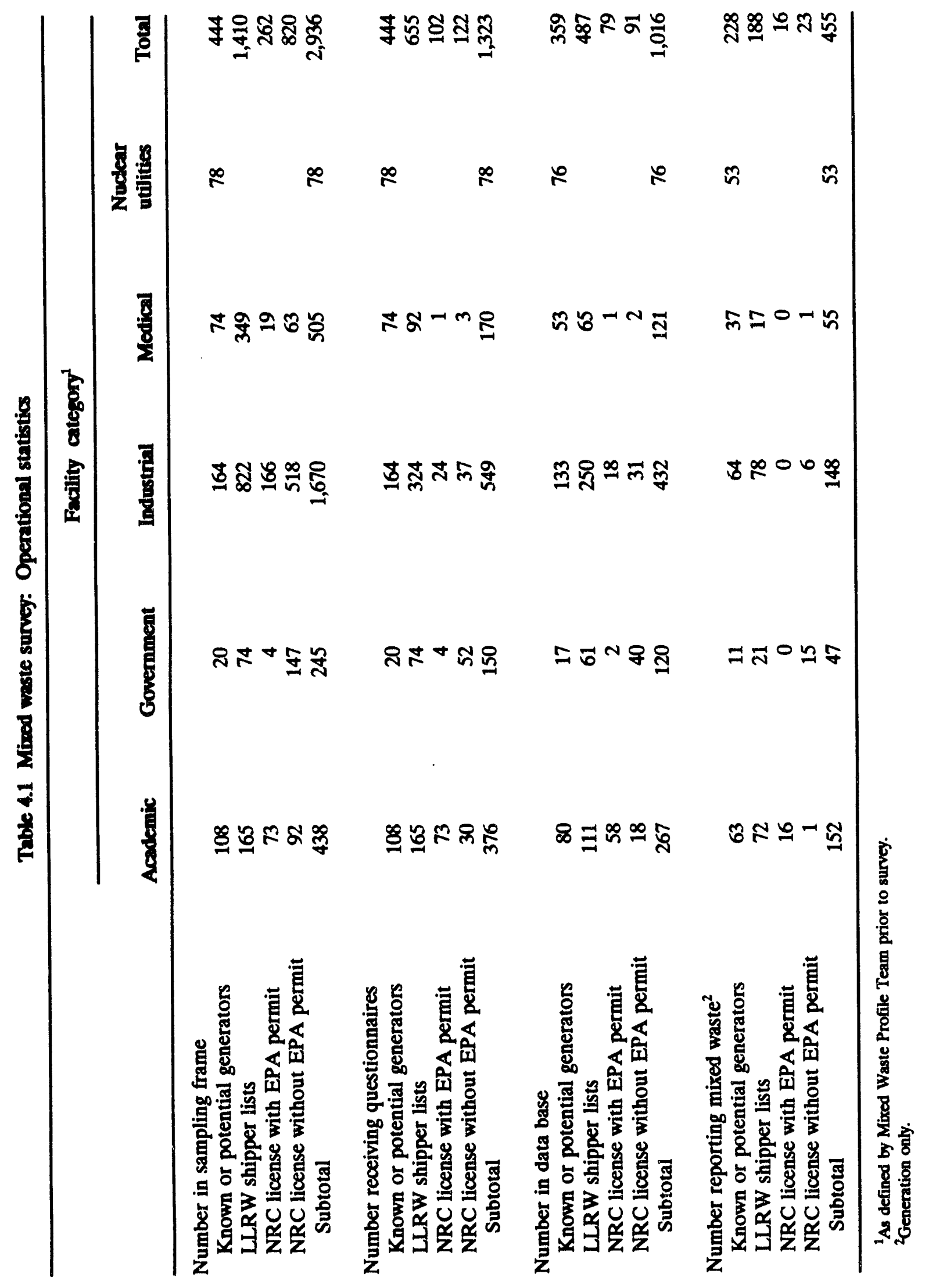


Table 4.2 Licensee facility categories and number of survey respondents

Facility ategory

Number of respondents

Nuclear reactor facility

Boiling Water Reactor

30

Pressurized Water Reactor

Research \& test reactors

Medical (non-federal)

Hospital

$<250$ beds

250-750 beds

$>750$ beds

24

Unassigned hospital

Medical college/hospital 28

Laboratory $\quad 24$

Research $\quad 37$

Unassigned medical $\quad 9$

Academic

$<10,000$ students $\quad 121$

$10,000-20,000$ students $\quad 54$

$>20,000$ students $\quad 47$

Unassigned academic $\quad 34$

Industrial

Manufacturing

$<50$ employees

17

50-200 employees $\quad 28$

$>200$ employees $\quad 40$

Unassigned manufacturing $\quad 3$

Research \& development $\quad 146$

Decontamination \& waste reduction $\quad 14$

Sealed source/gauge/instrument user $\quad 11$

Waste broker/processor $\quad 6$

Nuclear fuel cycle (nonreactor) 1

Commercial radiopharmacy $\quad 6$

$\begin{array}{ll}\text { Unassigned industrial } & 125\end{array}$

Government

Federal

Hospital $\quad 20$

Research \& development $\quad 45$

Military $\quad 23$

$\begin{array}{ll}\text { Unassigned federal } & 13\end{array}$

$\begin{array}{ll}\text { State } & 21\end{array}$

$\begin{array}{ll}\text { Other government } & 12\end{array}$

$\begin{array}{lr}\text { TOTAL } & 1,016\end{array}$

${ }^{1}$ As defined by respondents. Facility categories were, in some cases, different than the original assignment shown in Table 4.1. 
Table 4.3 National Mired Waste Profile

[Generation rate in 1990 ( $\mathrm{ft}^{3}$ /year)]

\begin{tabular}{lccc}
\hline & As reported $^{1}$ & Weighted $^{2}$ & $\begin{array}{c}\text { Estimated standard } \\
\text { error }^{\mathbf{2}}\end{array}$ \\
\hline Academic & 20,420 & 28,982 & 3,055 \\
Government & 18,324 & 26,500 & 5,978 \\
Industrial & 19,055 & 50,430 & 11,414 \\
Medical & 10,151 & 19,904 & 2,928 \\
Nuclear utilities & 13,276 & 13,625 & 703 \\
\multicolumn{1}{c}{ TOTAL } & 81,226 & 139,441 & 13,579 \\
\hline
\end{tabular}

\footnotetext{
In As reported" values are shown for comparison purposes only and are not to be considered as the national mixed waste profile. "As reported" represents mixed waste reported by the 1,016 respondents to the survey questionnaire.

${ }^{2 n}$ Weighted" represents the estimated mixed waste generation rate after correction of the "As reported" data for nonresponses and facilities not queried during the survey.

3"Estimated standard error" is calculated as described in Appendix E.
}

Table 4.4 National Mired Waste Profile [Amount in storage as of 12/31/90 $\left.\left(\mathrm{ft}^{3}\right)\right]^{1}$

\begin{tabular}{lcc}
\hline & As reported $^{2}$ & Wcightod $^{3}$ \\
\hline Academic & 3,874 & 5,447 \\
Government & 1,692 & 2,788 \\
Industrial & 16,078 & 42,281 \\
Medical & 1,158 & 2,227 \\
Nuclear utilities & 21,403 & 21,984 \\
\multicolumn{1}{c}{ TOTAL } & 44,205 & 74,727 \\
\hline
\end{tabular}

\footnotetext{
${ }^{1}$ This is not the amount requiring disposal. Some of this waste was being accumulated for treatment.

${ }^{2 n}$ As reported" values are shown for comparison purposes only and are not to be considered as the national mixed waste profile. "As reported" represents mixed waste reported by the 1,016 respondents to the survey questionnaire.

"Weighted" represents the estimated mixed waste generation rate after correction of the "As reported" data for nonresponses and facilities not queried during the survey.
} 
Table 4.5 National Mired Waste Profile

[Waste generated in 1990 that currently cannot be treated ( $\left.\mathrm{ft}^{3}\right)$ ]

\begin{tabular}{lcc}
\hline & As reported & Weighted $^{2}$ \\
\cline { 2 - 3 } Academic & 253 & 353 \\
Government & 1,183 & 1,455 \\
Industrial & 370 & 834 \\
Medical & 493 & 726 \\
Nuclear utilities & 1,432 & 1,470 \\
\multicolumn{1}{c}{ TOTAL } & 3,731 & 4,838 \\
\hline
\end{tabular}

In As reported" values are shown for comparison purposes only and are not to be considered as the national mixed waste profile. "As reported" represents mixed waste reported by the 1,016 respondents to the survey questionnaire.

2"Weighted" represents the estimated mixed waste generation rate after correction of the "As reported" data for nonresponses and facilities not queried during the survey. 


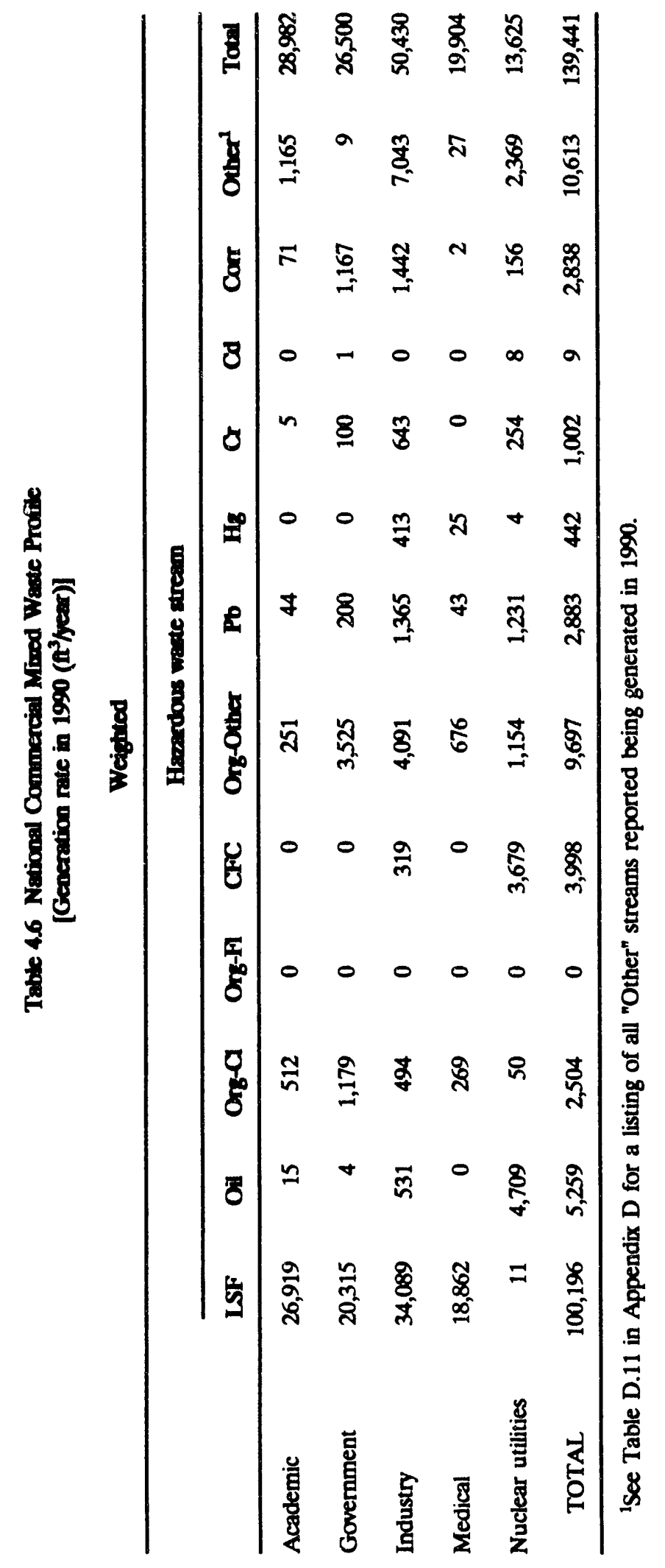




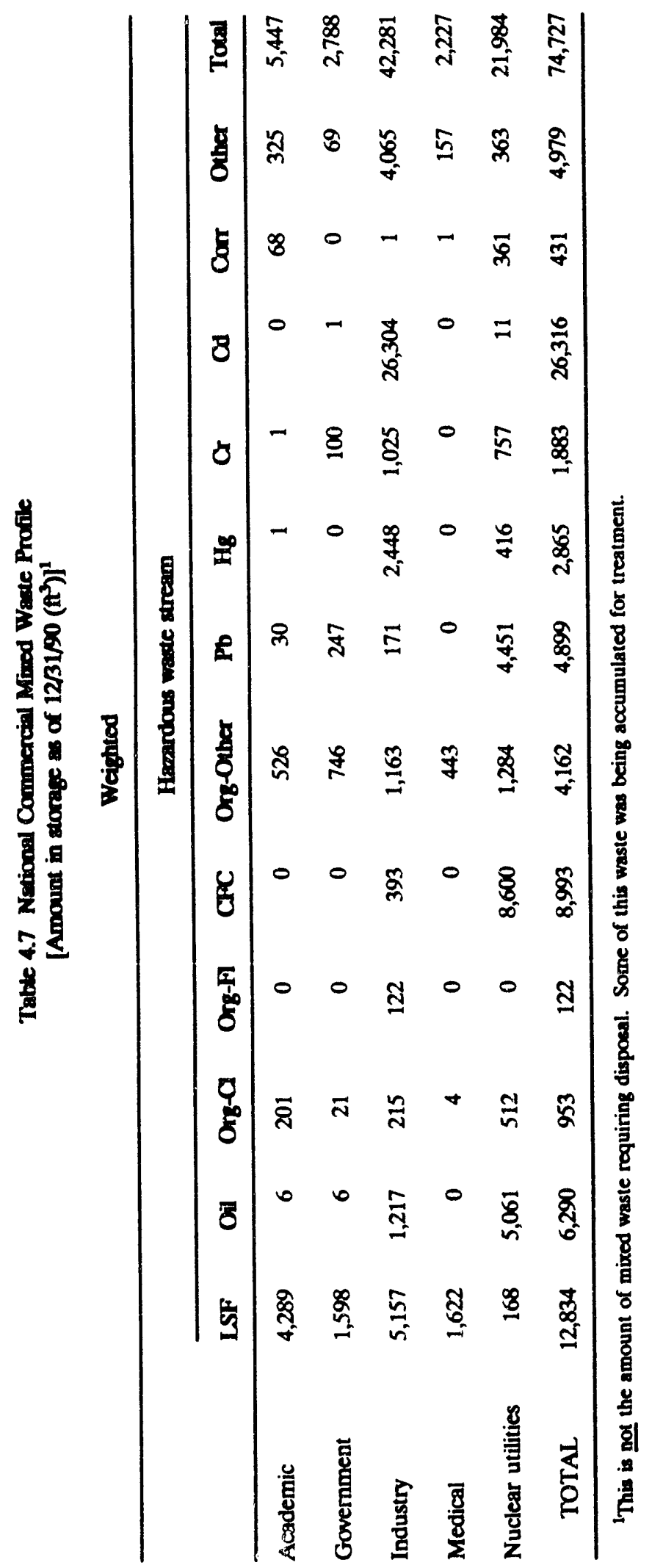




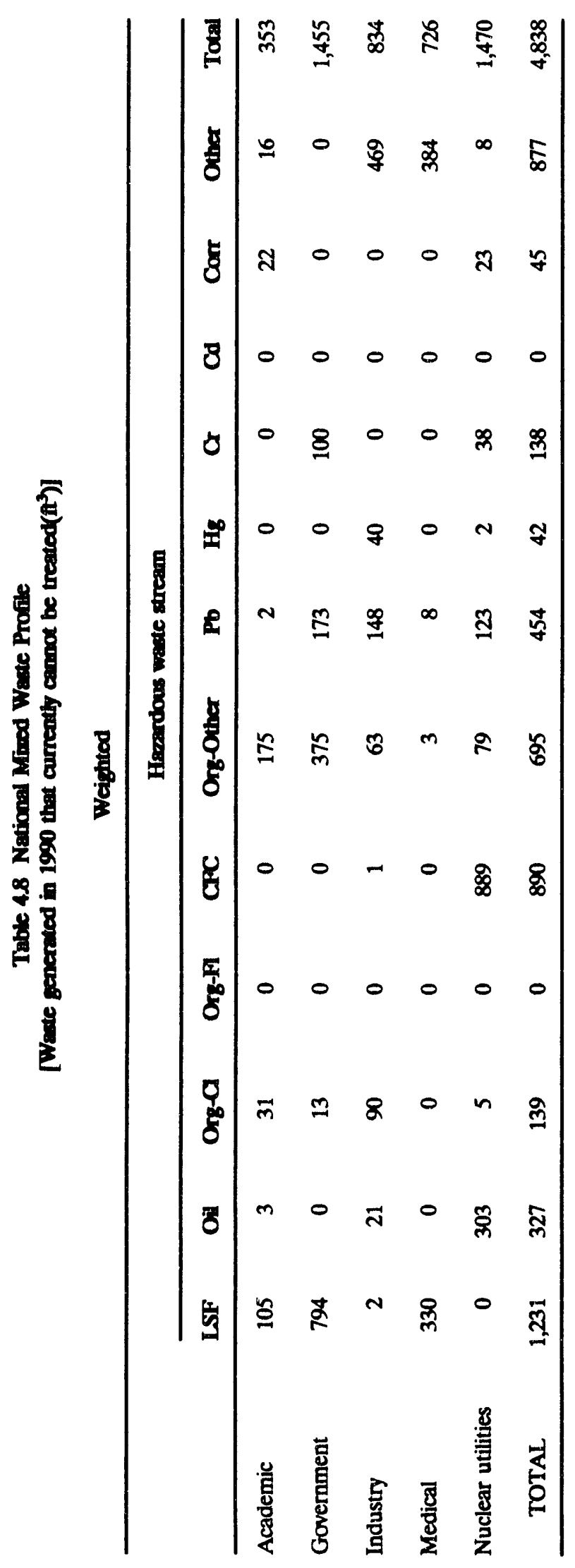


Table 4.9 State composition of the nine compacts ( 20 of early 1992)

\begin{tabular}{|c|c|}
\hline Compect & States \\
\hline Northeast & $\begin{array}{l}\text { Connecticut } \\
\text { New Jersey }\end{array}$ \\
\hline Appalachian & $\begin{array}{l}\text { Pennsylvania } \\
\text { West Virginia } \\
\text { Maryland } \\
\text { Delaware }\end{array}$ \\
\hline Southeast & $\begin{array}{l}\text { Alabama } \\
\text { Florida } \\
\text { Georgia } \\
\text { Mississippi } \\
\text { North Carolina } \\
\text { South Carolina } \\
\text { Tennessee } \\
\text { Virginia }\end{array}$ \\
\hline Central States & $\begin{array}{l}\text { Arkansas } \\
\text { Kansas } \\
\text { Louisiana } \\
\text { Netraska } \\
\text { Oklahoma }\end{array}$ \\
\hline Midwest & $\begin{array}{l}\text { Michigan }{ }^{1} \\
\text { Indiana } \\
\text { Iowa } \\
\text { Minnesota } \\
\text { Missouri } \\
\text { Ohio } \\
\text { Wisconsin }\end{array}$ \\
\hline Central Midwest & $\begin{array}{l}\text { Illinois } \\
\text { Kentucky }\end{array}$ \\
\hline Rocky Mountain & $\begin{array}{l}\text { Colorado } \\
\text { Nevada } \\
\text { New Mexico } \\
\text { Wyoming }\end{array}$ \\
\hline Southwest & $\begin{array}{l}\text { Arizona } \\
\text { California } \\
\text { South Dakota } \\
\text { North Dakota }\end{array}$ \\
\hline Northwest & $\begin{array}{l}\text { Idaho } \\
\text { Washington } \\
\text { Oregon } \\
\text { Utah } \\
\text { Alaska } \\
\text { Hawaii } \\
\text { Montana }\end{array}$ \\
\hline
\end{tabular}

${ }^{1}$ Michigan is included as a member of the Midwest Compact for the purposes of this

Wyoming is included as a member of the Rocky Mountain Compact for the purposes of this study. 


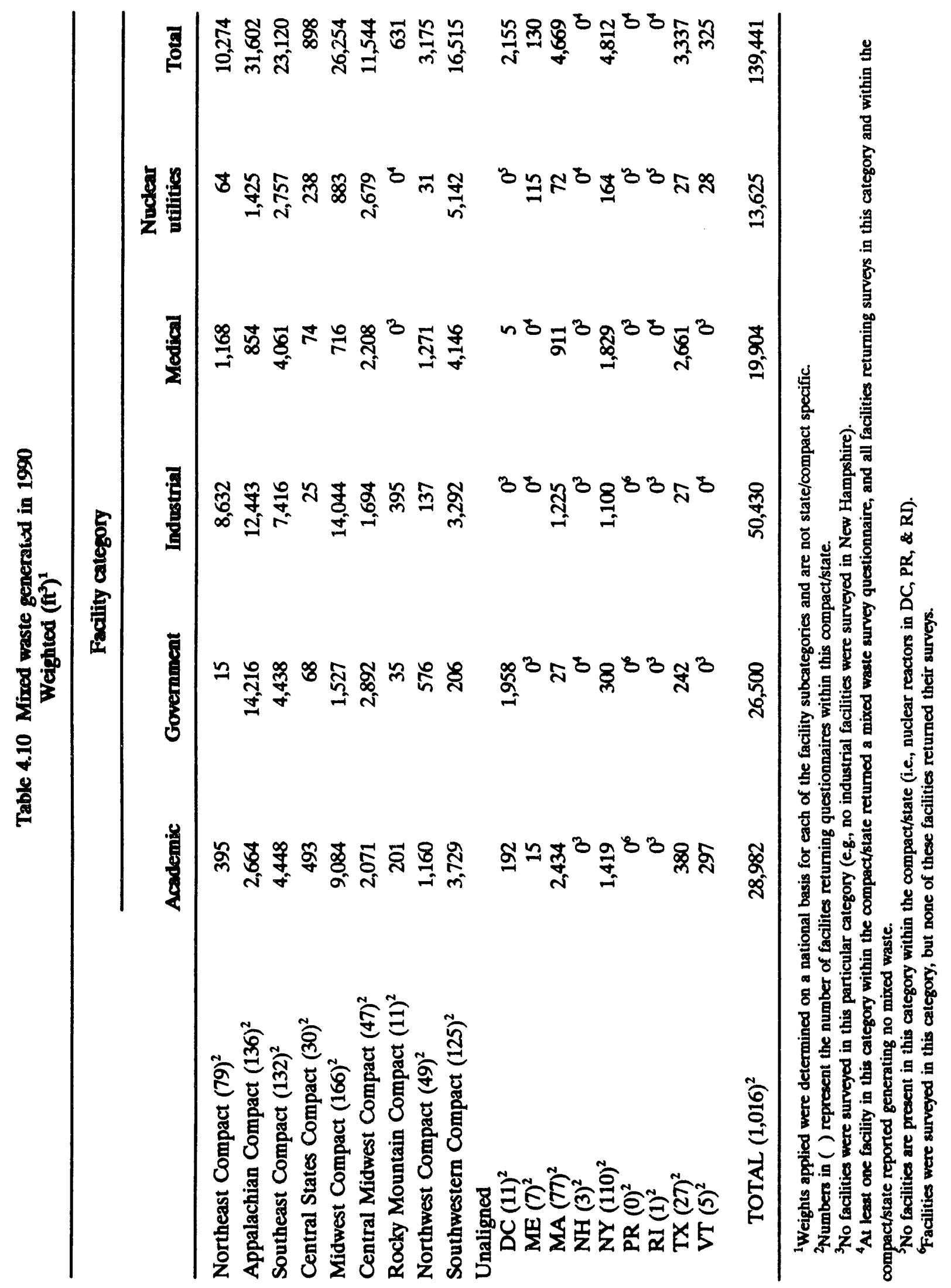




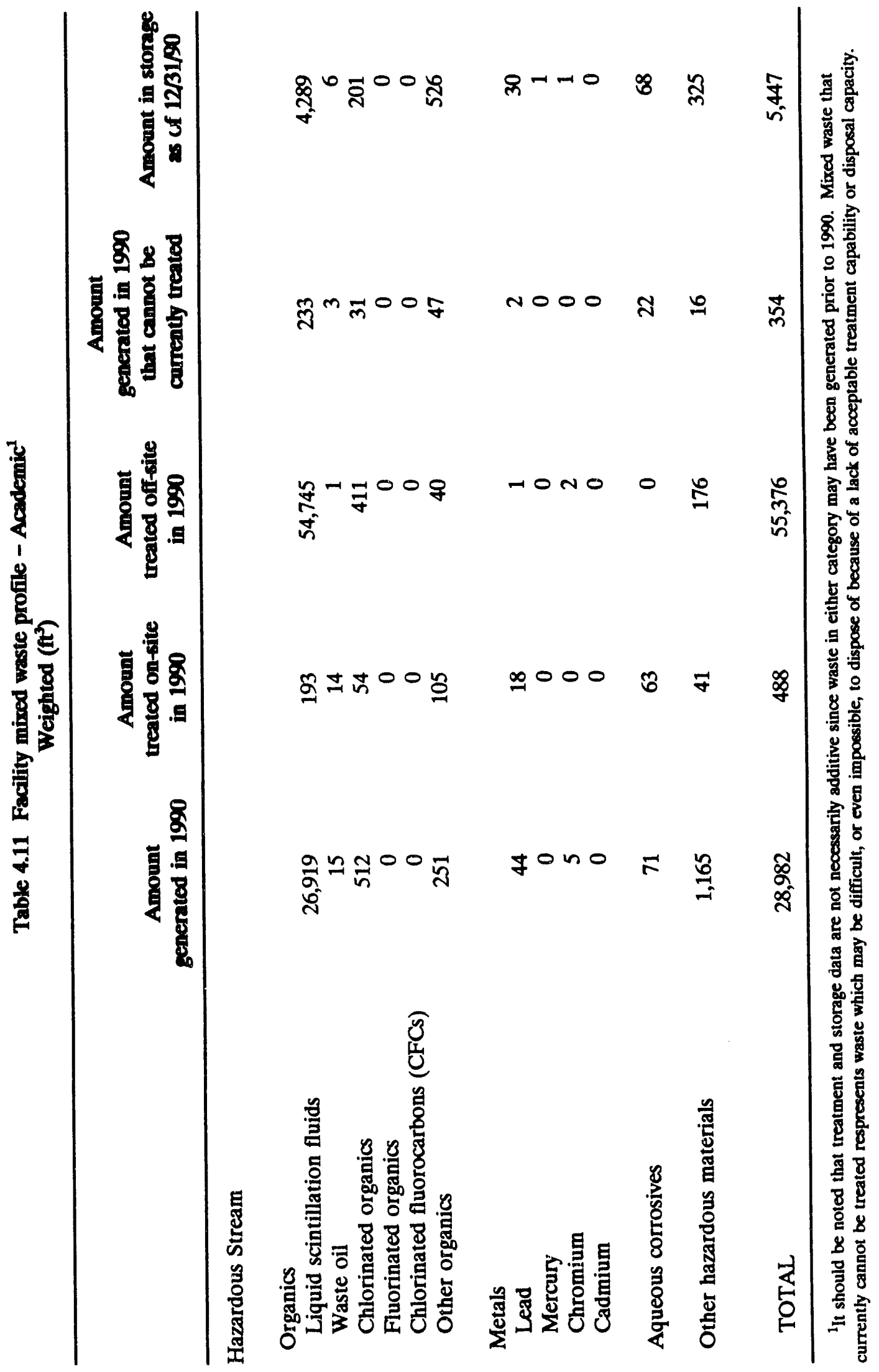




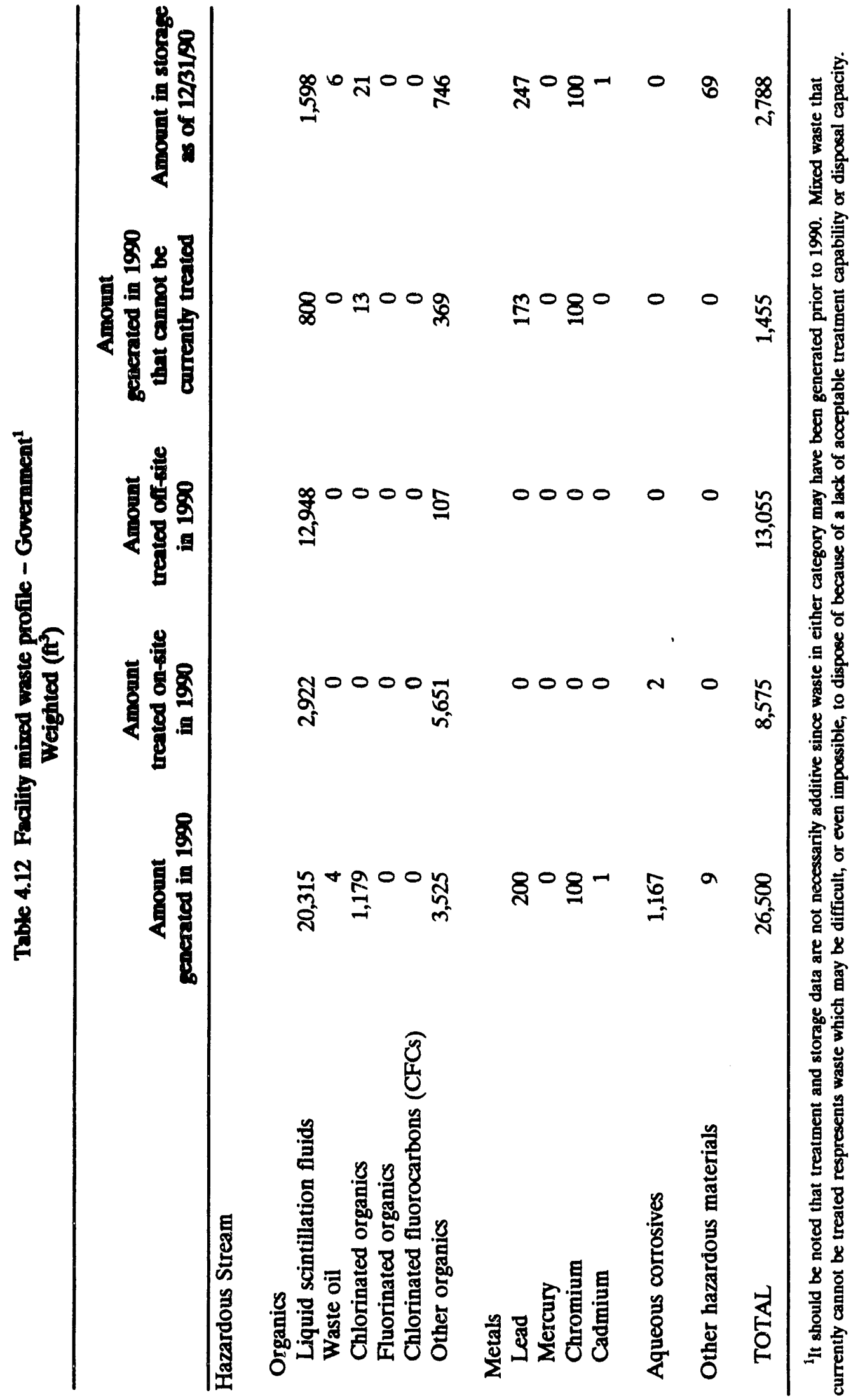




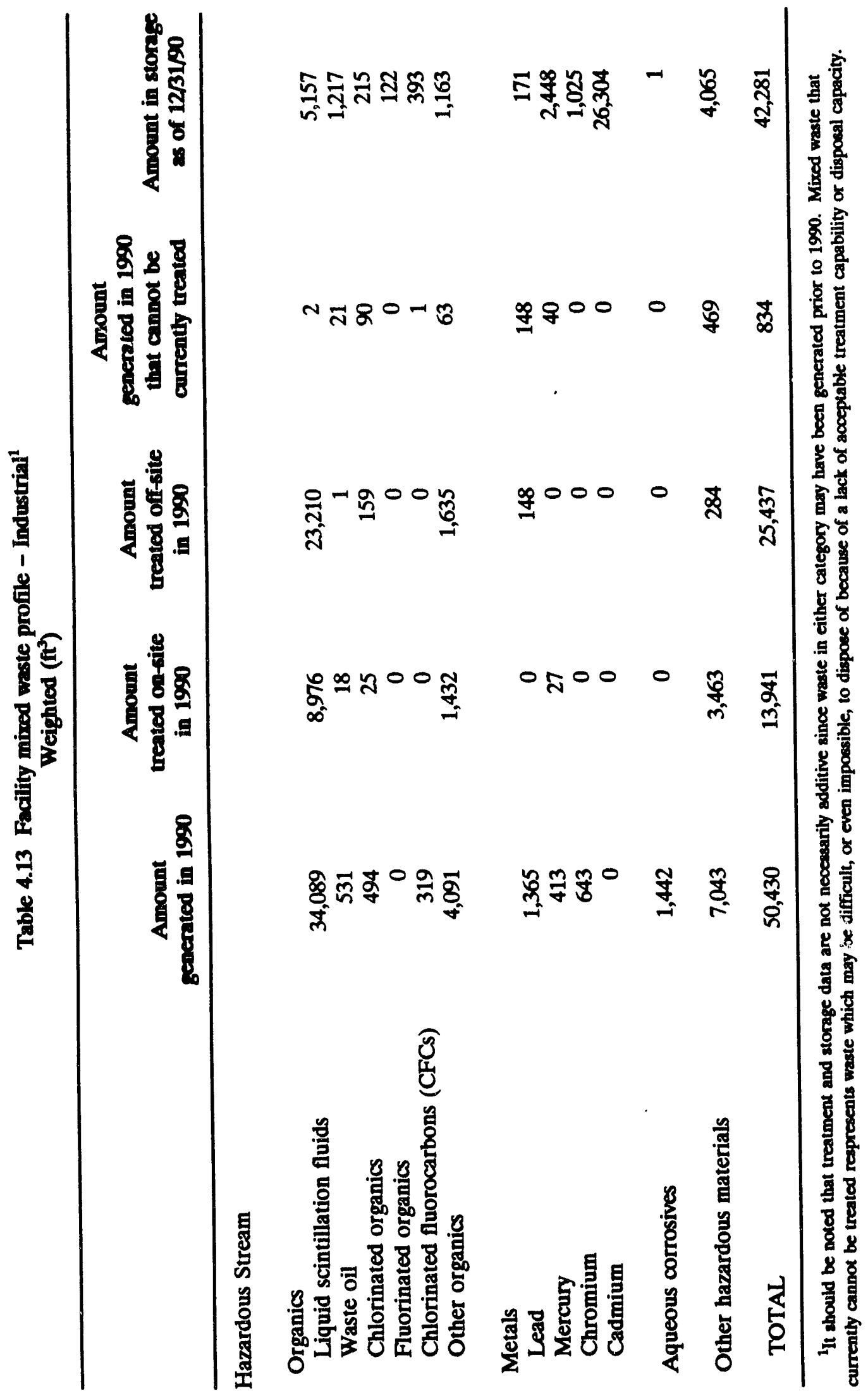




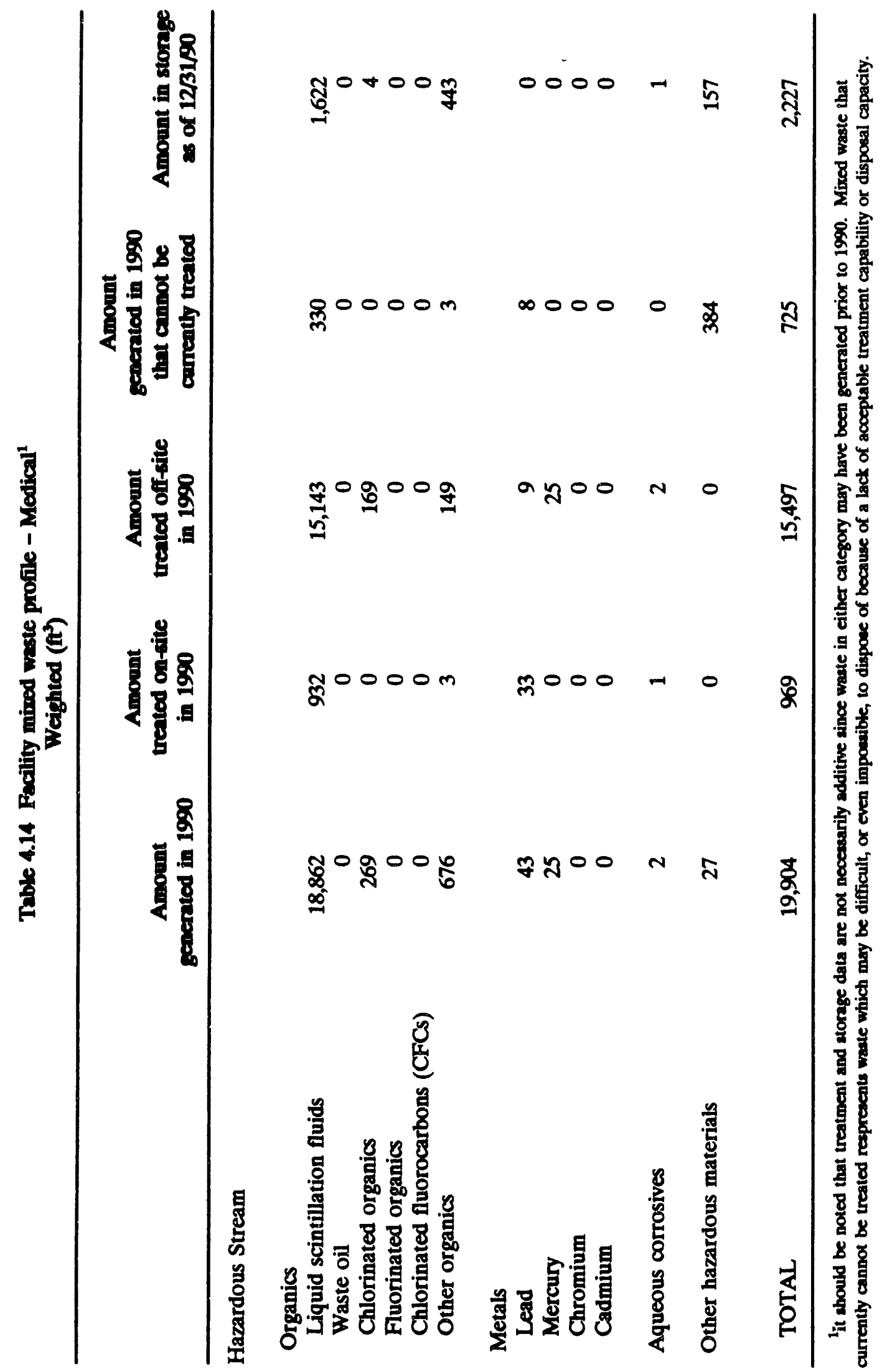




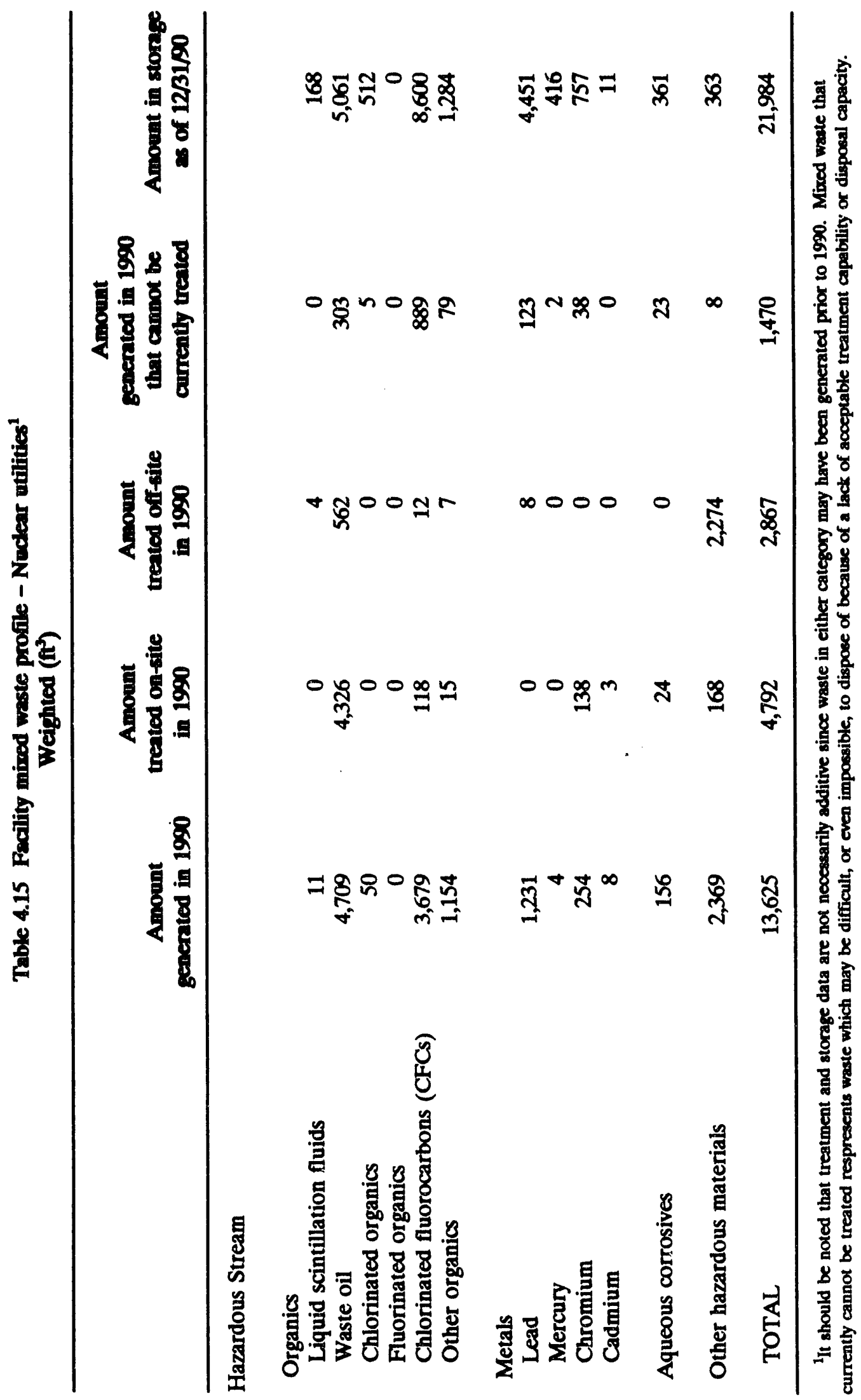




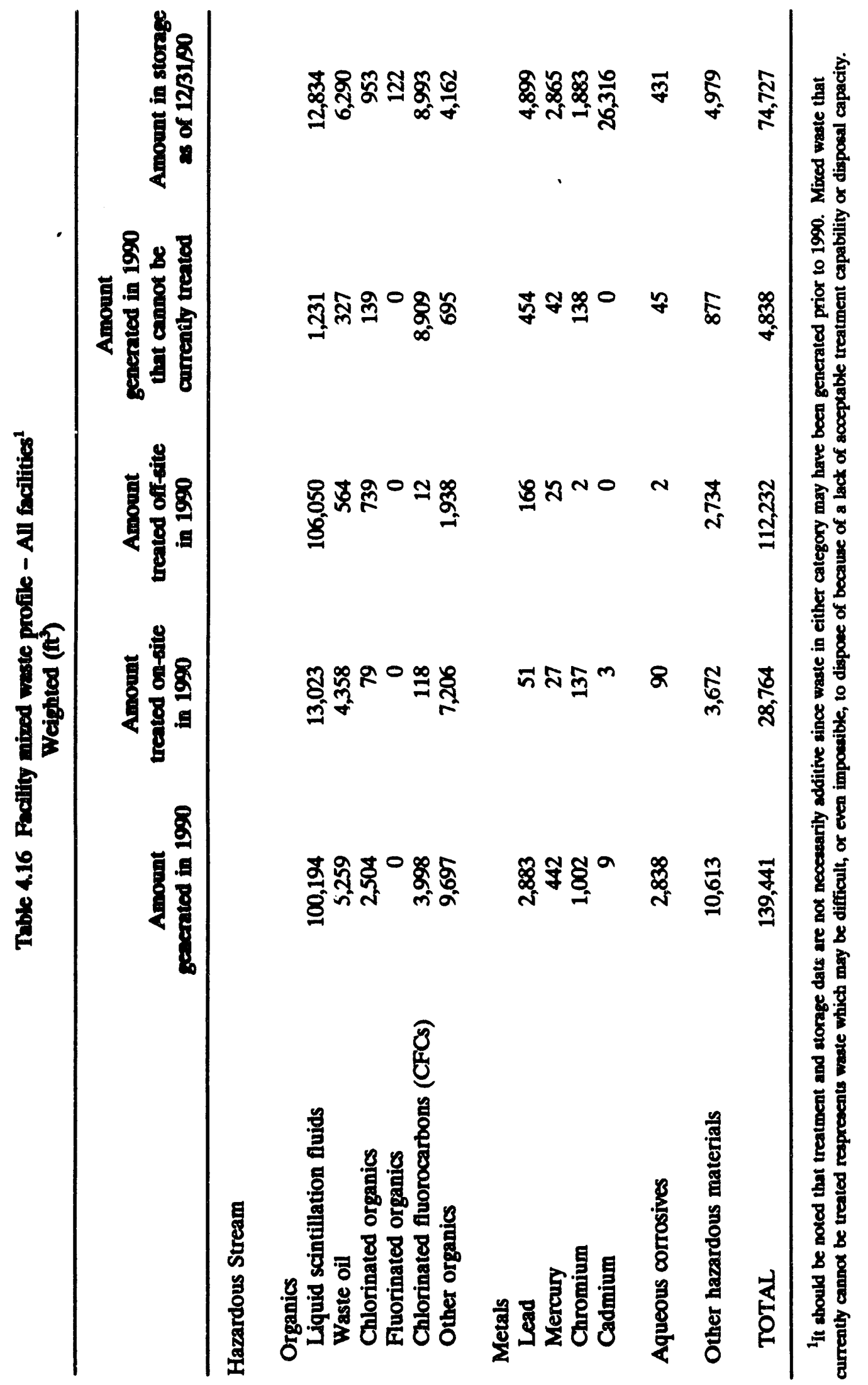


Twble 4.17 Compact/atate gemeration of LLRW

(Generation and/or dispoen in 1990)

(ft)

\begin{tabular}{|c|c|c|c|}
\hline & \multirow{2}{*}{$\underset{\text { disposed }^{1}}{\text { LLRW }}$} & \multicolumn{2}{|c|}{ LLRW generated ${ }^{2}$} \\
\hline & & As reported & Weighted \\
\hline Northeast Compact & 87,019 & 78,202 & 140,757 \\
\hline Appalachian Compact & 119,579 & 212,120 & 359,347 \\
\hline Southeast Compact & 333,488 & 266,507 & 296,971 \\
\hline Central States Compact & 58,377 & 35,885 & 37,730 \\
\hline Midwest Compact & 123,393 & 202,502 & 263,854 \\
\hline Central Midwest Compact & 102,981 & 91,862 & 107,609 \\
\hline Rocky Mountain Compact & 4,484 & 4,835 & 7,014 \\
\hline Northwest Compact & 95,918 & 65,373 & 154,653 \\
\hline Southwestern Compact & 84,934 & 65,744 & 80,638 \\
\hline \multicolumn{4}{|l|}{ Unaligned } \\
\hline DC & 530 & 1,373 & 3,762 \\
\hline ME & 7,840 & 19,393 & 19,904 \\
\hline $\mathbf{M A}$ & 40,613 & 27,673 & 34,576 \\
\hline NH & 177 & 992 & 1,167 \\
\hline NY & 71,303 & 42,496 & 51,986 \\
\hline PR & 0 & 0 & 0 \\
\hline RI & 177 & $\mathbf{0}$ & 0 \\
\hline TX & 9,217 & 9,711 & 13,411 \\
\hline VT & 0 & 174 & 259 \\
\hline TOTAL & $1,140,030$ & $1,124,842$ & $1,573,638$ \\
\hline
\end{tabular}

${ }_{1}$ Invegrated Data Base for 1991: U.S. Spent Fuel and Radioactive Waste Invensories, Projections, and Characteristics, DOE/RW-0006, Rev. 7, October 1991. Bewed on material provided by BG\&G, Idaho to be published by the Low-Level Waste Management Program. IDB annual report data are beeed on actual "as receivad" manifeat data from the three commencial burial grounda.

${ }^{2}$ National Mbred Wate Profile data are wates shipped by LLRW generaton and do not reflect any volume reduction activities by treaters or broken prior to burial. 
Table 4.18 Compect/state generation of mired waste [Generation rate in $1990\left(\mathrm{t}^{3}\right.$ /year)]

\begin{tabular}{|c|c|c|c|}
\hline & $\begin{array}{l}\text { Previous } \\
\text { estimnte }^{1}\end{array}$ & $\begin{array}{c}\text { Mised Waste Profile } \\
\text { as reported }\end{array}$ & $\begin{array}{c}\text { Mired Waste Profile } \\
\text { weighted }\end{array}$ \\
\hline Northeast Compact & 3,010 & 1,782 & 10,274 \\
\hline Appalachian Compact & 1,876 & 18,881 & 31,602 \\
\hline Southeast Compact & 5,340 & 18,356 & 23,120 \\
\hline Central States Compact & 185 & 688 & 898 \\
\hline Midwest Compact & 2,772 & 12,482 & 26,254 \\
\hline Central Midwest Compact & 2,183 & 6,338 & 11,544 \\
\hline Rocky Mountain Compact & $\mathbf{0}$ & 264 & 631 \\
\hline Northwest Compact & 173 & 1,706 & 3,175 \\
\hline Southwestern Compact & 21,156 & 12,261 & 16,515 \\
\hline \multicolumn{4}{|l|}{ Unaligned } \\
\hline DC & 422 & 677 & 2,155 \\
\hline ME & $\mathbf{0}$ & 122 & 130 \\
\hline MA & 1,636 & 2,995 & 4,669 \\
\hline NH & 0 & 0 & 0 \\
\hline NY & 4,535 & 3,075 & 4,812 \\
\hline PR & $\mathbf{0}$ & $\mathbf{0}$ & 0 \\
\hline $\mathbf{R I}$ & $\mathbf{0}$ & 0 & 0 \\
\hline TX & 7,520 & 1,373 & 3,337 \\
\hline VT & $\mathbf{0}$ & 227 & 325 \\
\hline TOTAL & 50,808 & 81,227 & 139,441 \\
\hline
\end{tabular}

${ }^{1}$ National Profile on Commercially Generated Low-Level Racioactive Mixed Waste, Technical Letter Report for Task Two, March 31, 1991. Taak Two Report generation data were derivod from a wide variety of rources, including Governor Certifications, Compact/State Low-Level Waste Surveys, and Compact/State Mixed Waste Specific Surveys. Data quality, currentness, and match to National Mixed Waste Profile varied widely. CAUTHON - Diroct comparisons should not be made between individual compact atatc number. 


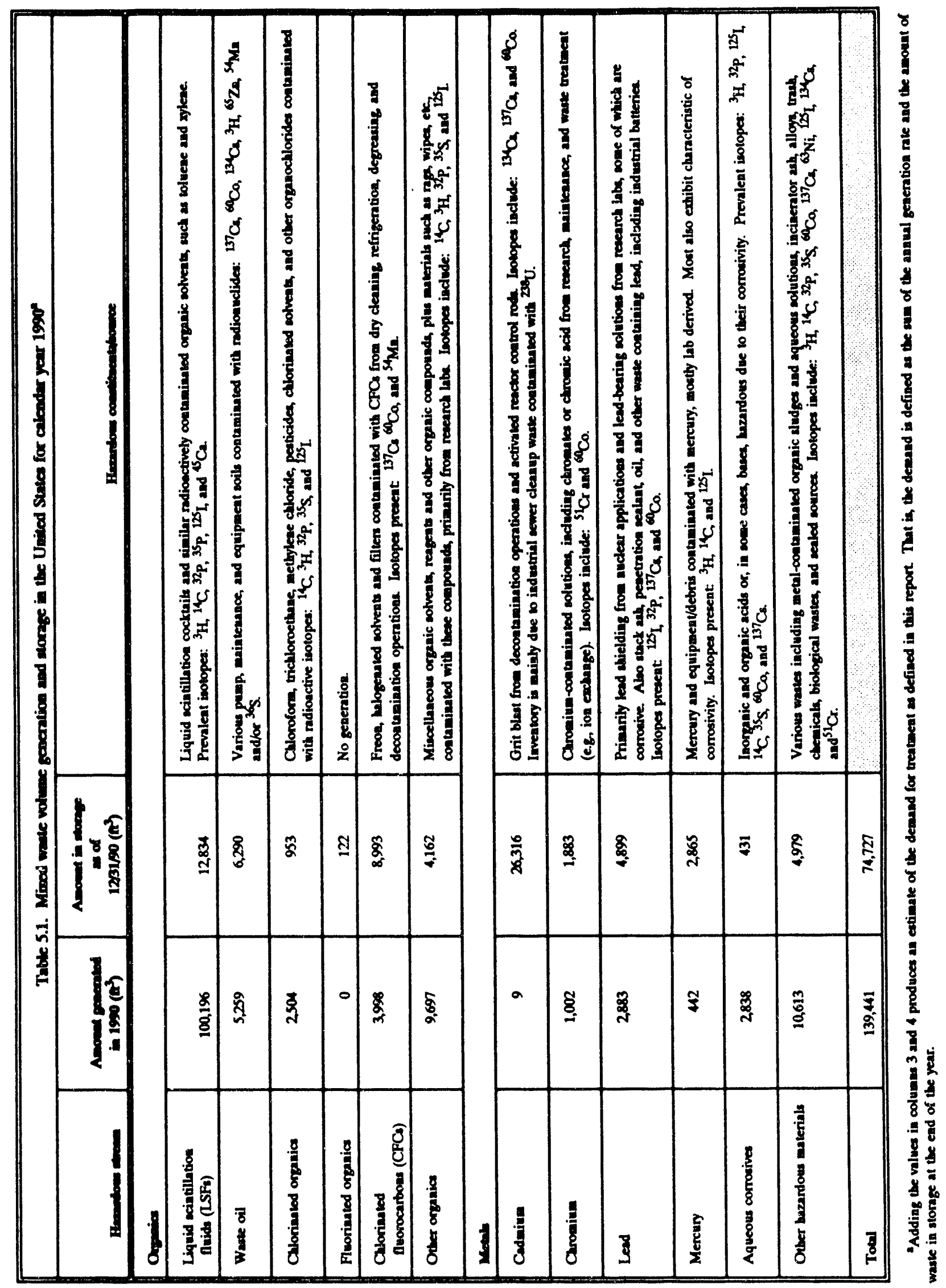




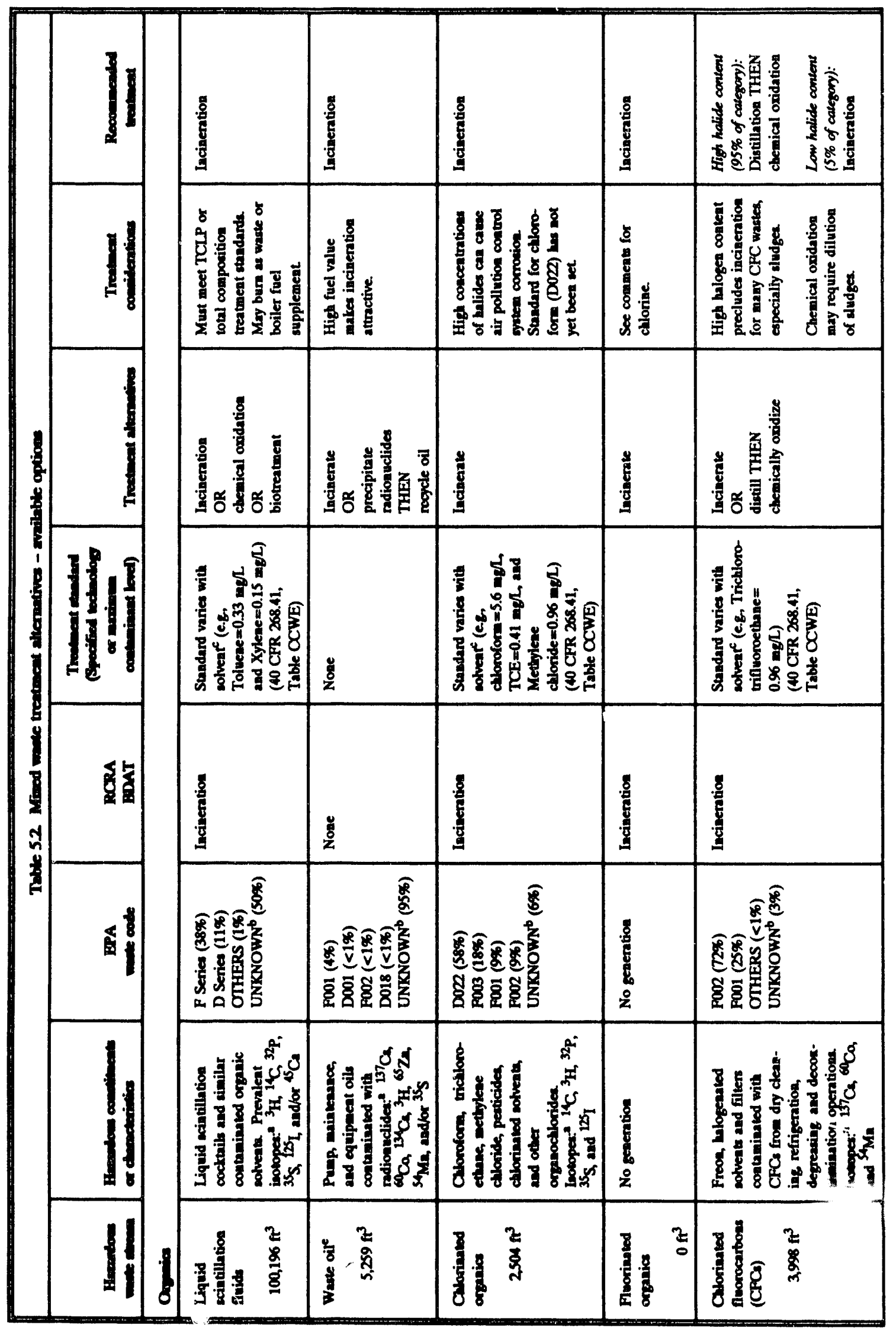




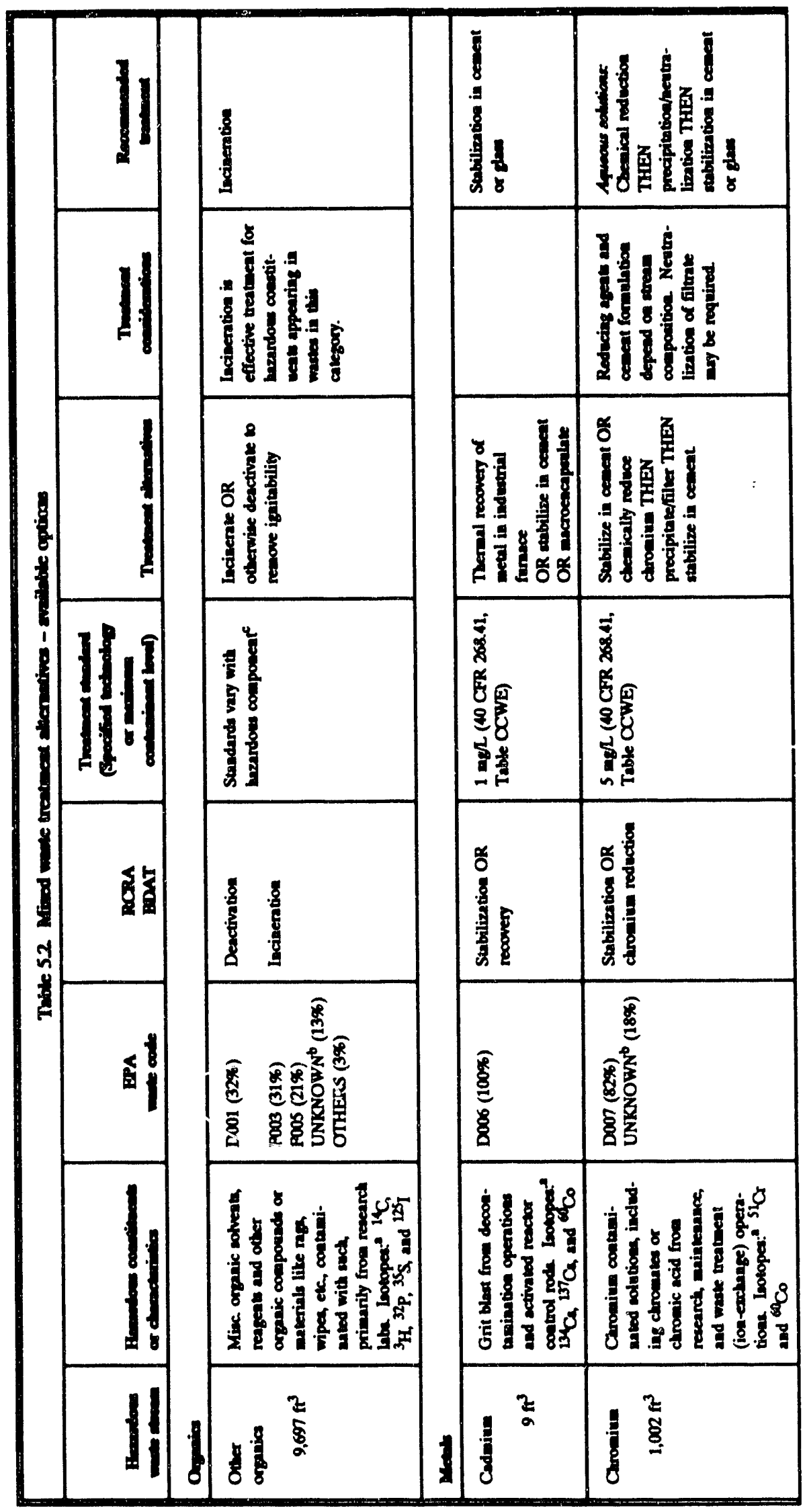




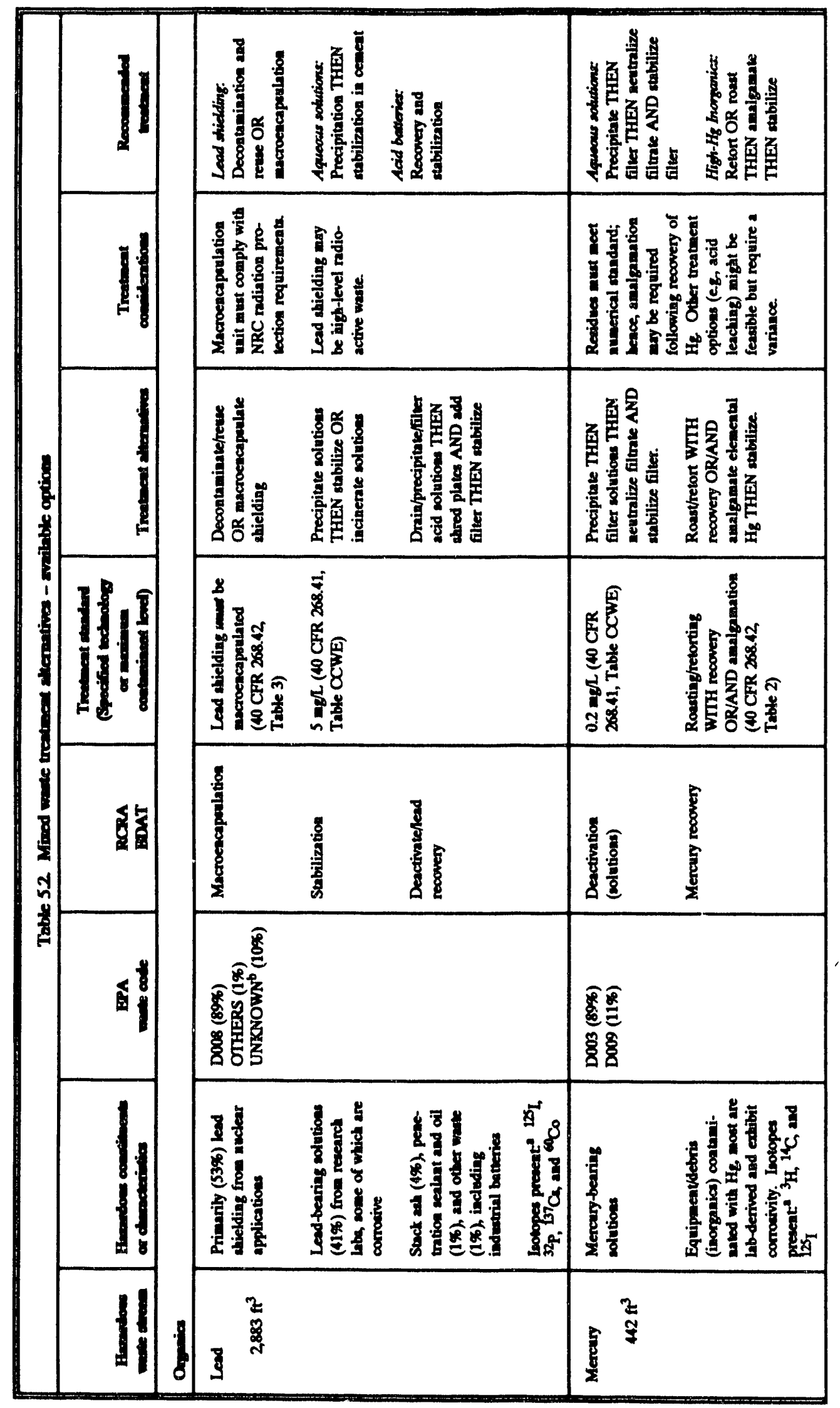



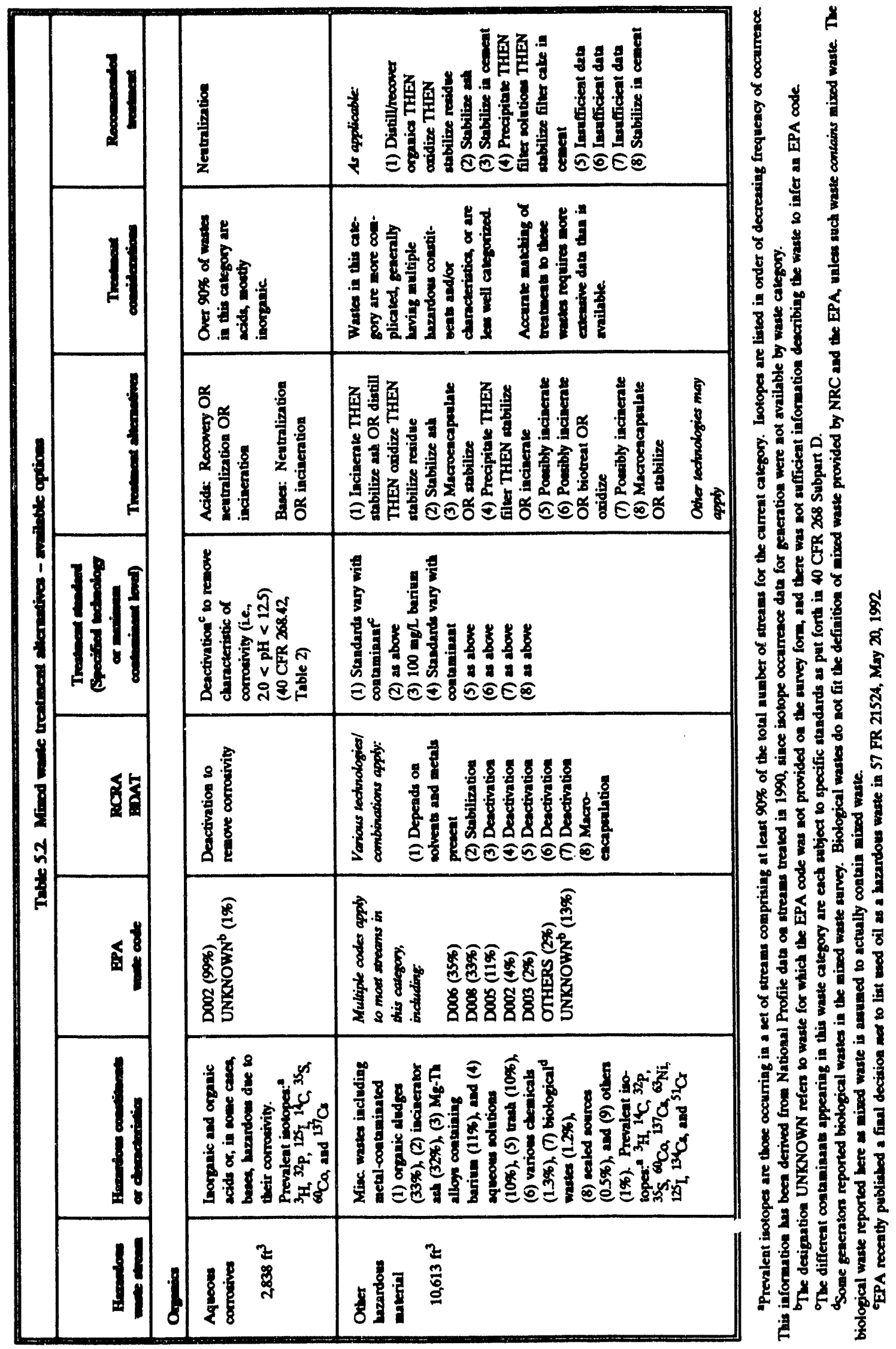


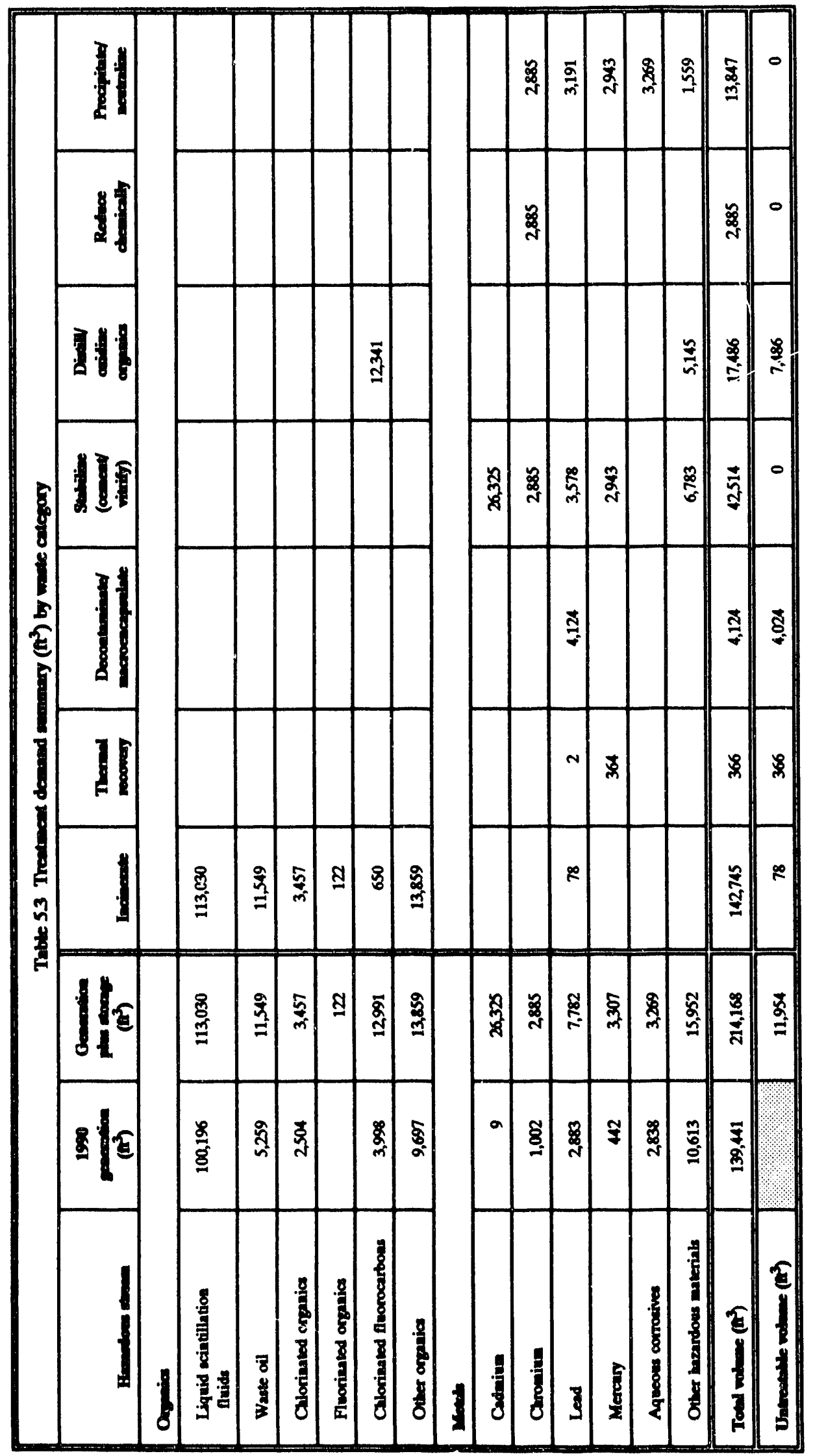




\begin{tabular}{|c|c|c|c|c|c|}
\hline$F$ & 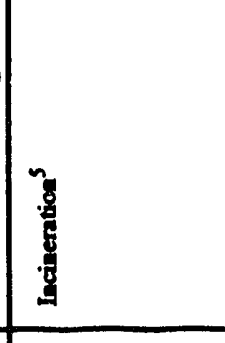 & 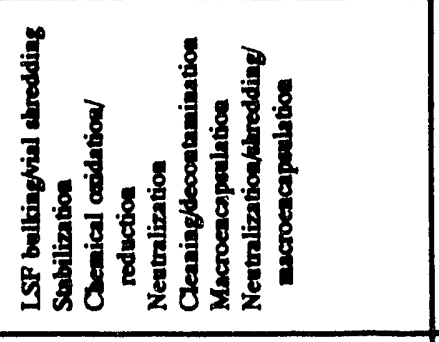 & 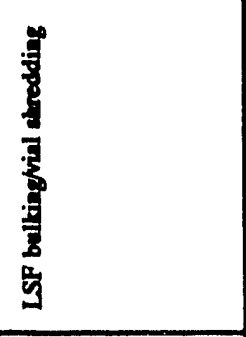 & 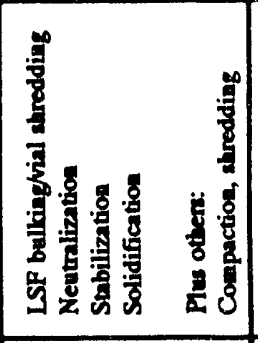 & 量 \\
\hline & 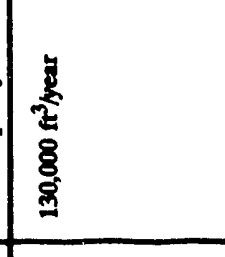 & 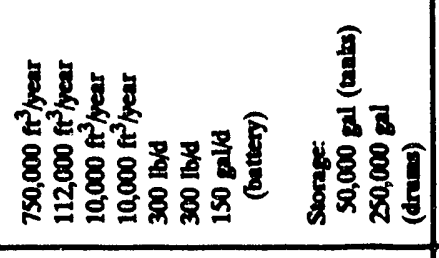 & 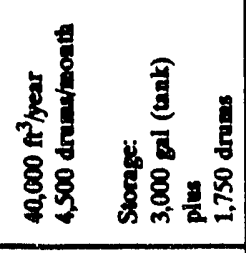 & 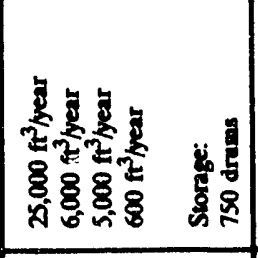 & 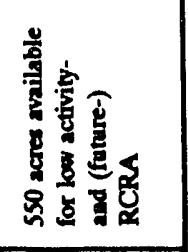 \\
\hline & 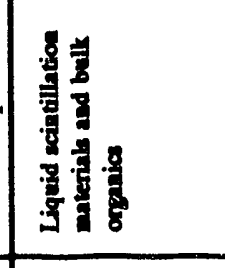 & 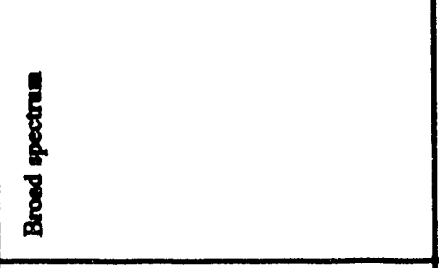 & 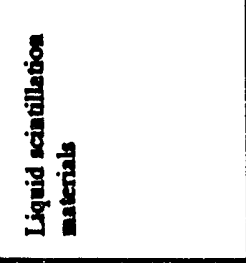 & 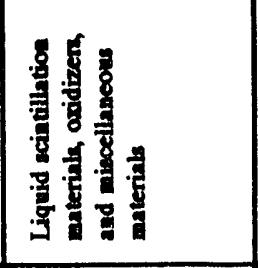 & 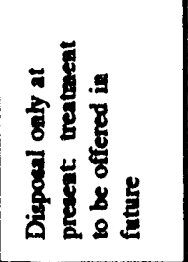 \\
\hline & 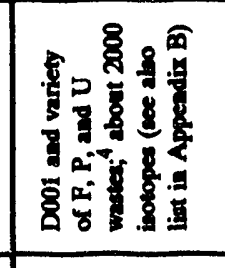 & 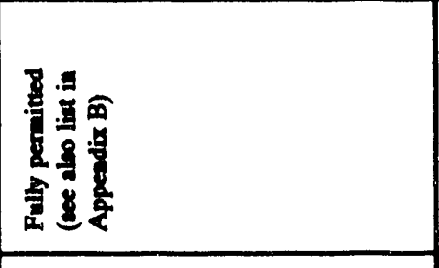 & 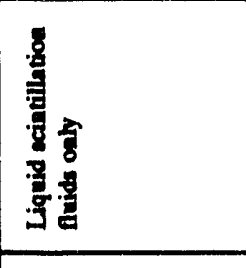 & 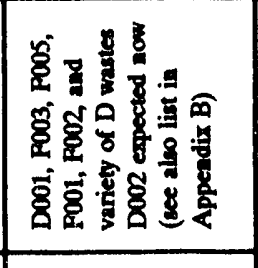 & 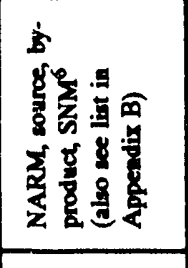 \\
\hline & 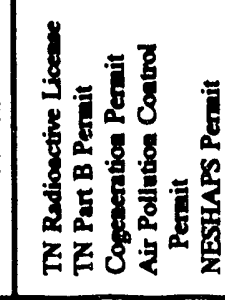 & 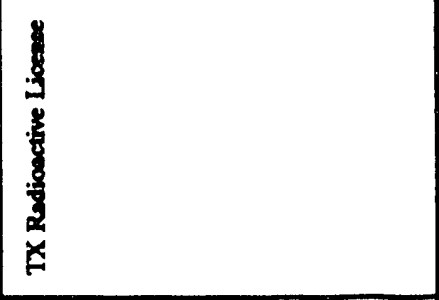 & 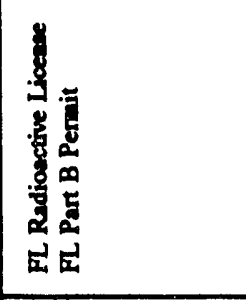 & 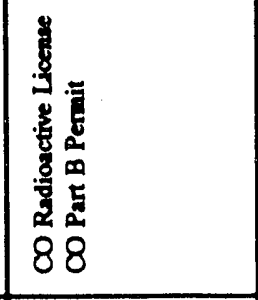 & 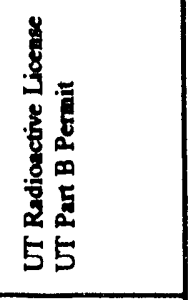 \\
\hline & 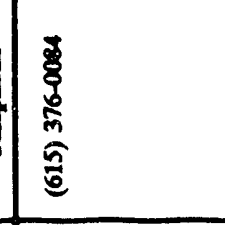 & 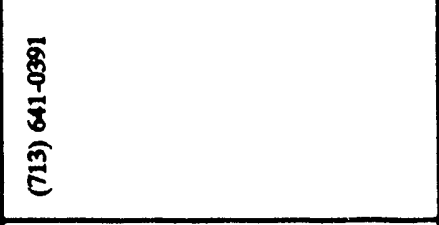 & 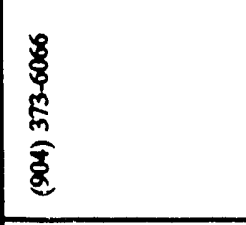 & 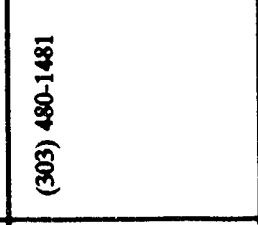 & 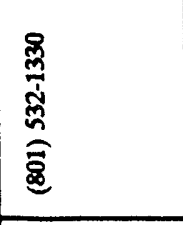 \\
\hline & $\begin{array}{l}85 \\
8 \\
8 \\
\end{array}$ & 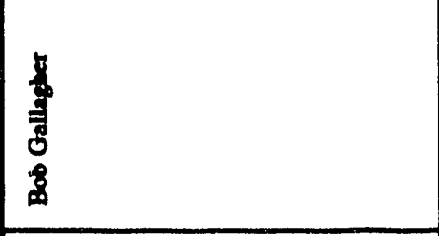 & 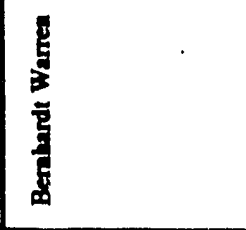 & $\begin{array}{l}3 \\
5 \\
\end{array}$ & $\begin{array}{l}\frac{2}{8} \\
\frac{9}{2} \\
5 \\
5\end{array}$ \\
\hline & 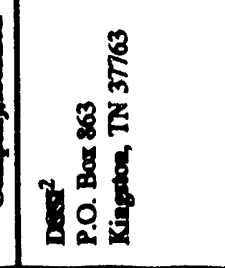 & 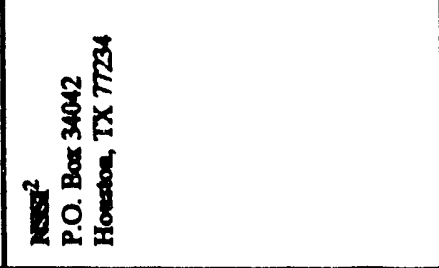 & 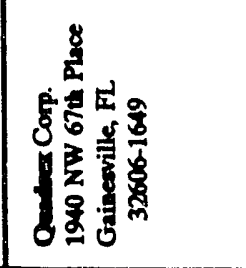 & 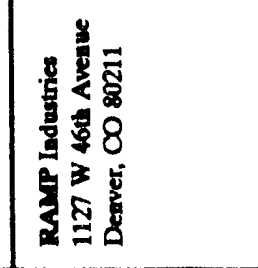 & 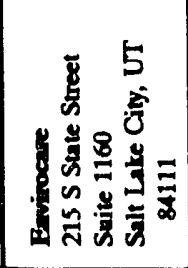 \\
\hline
\end{tabular}




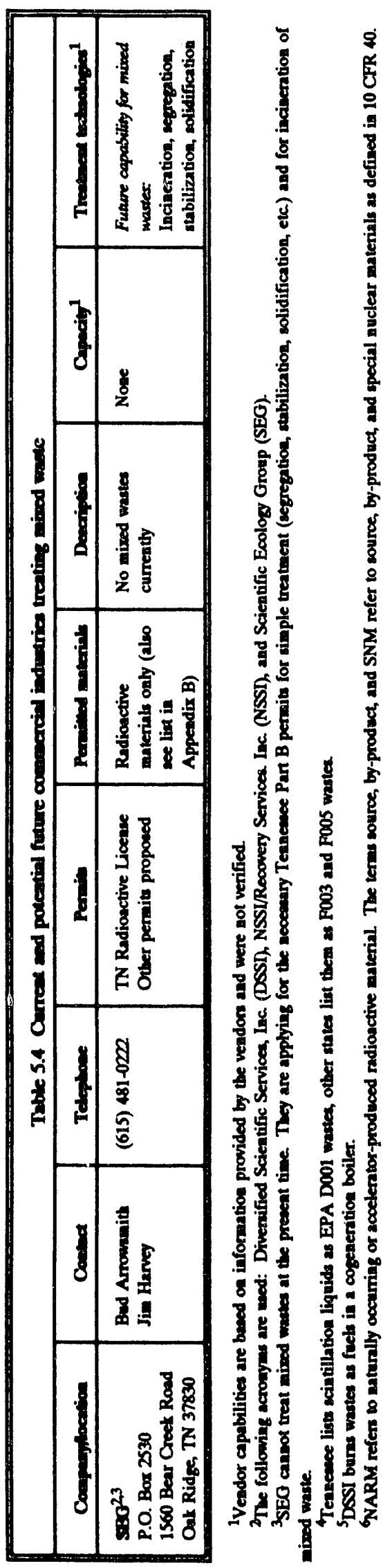




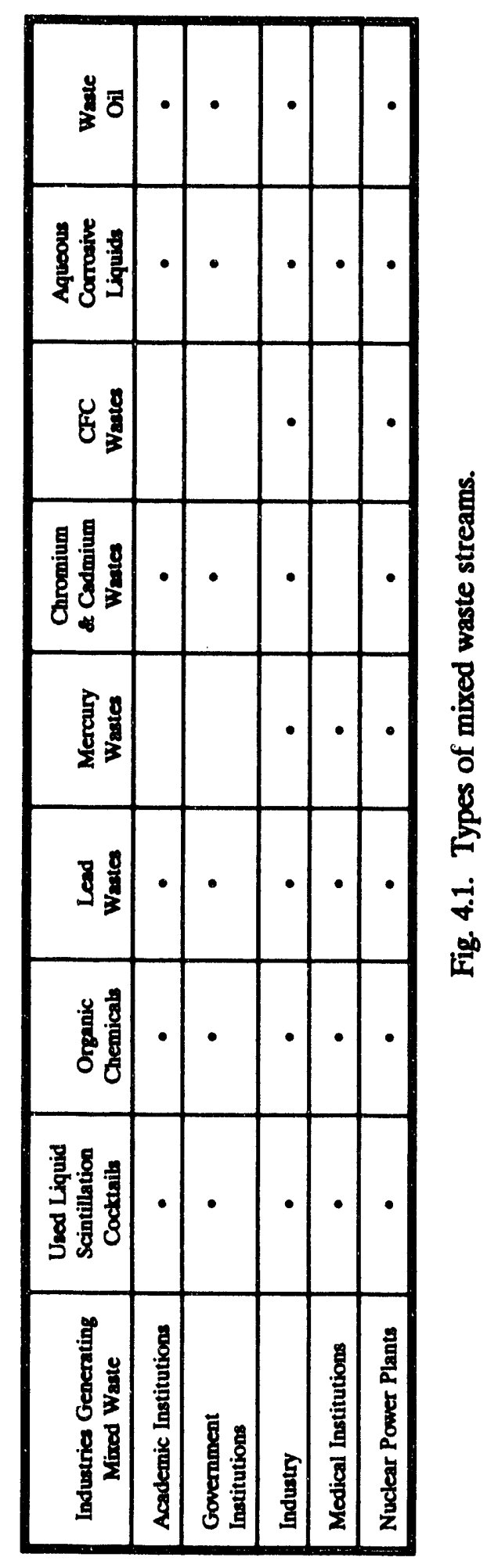




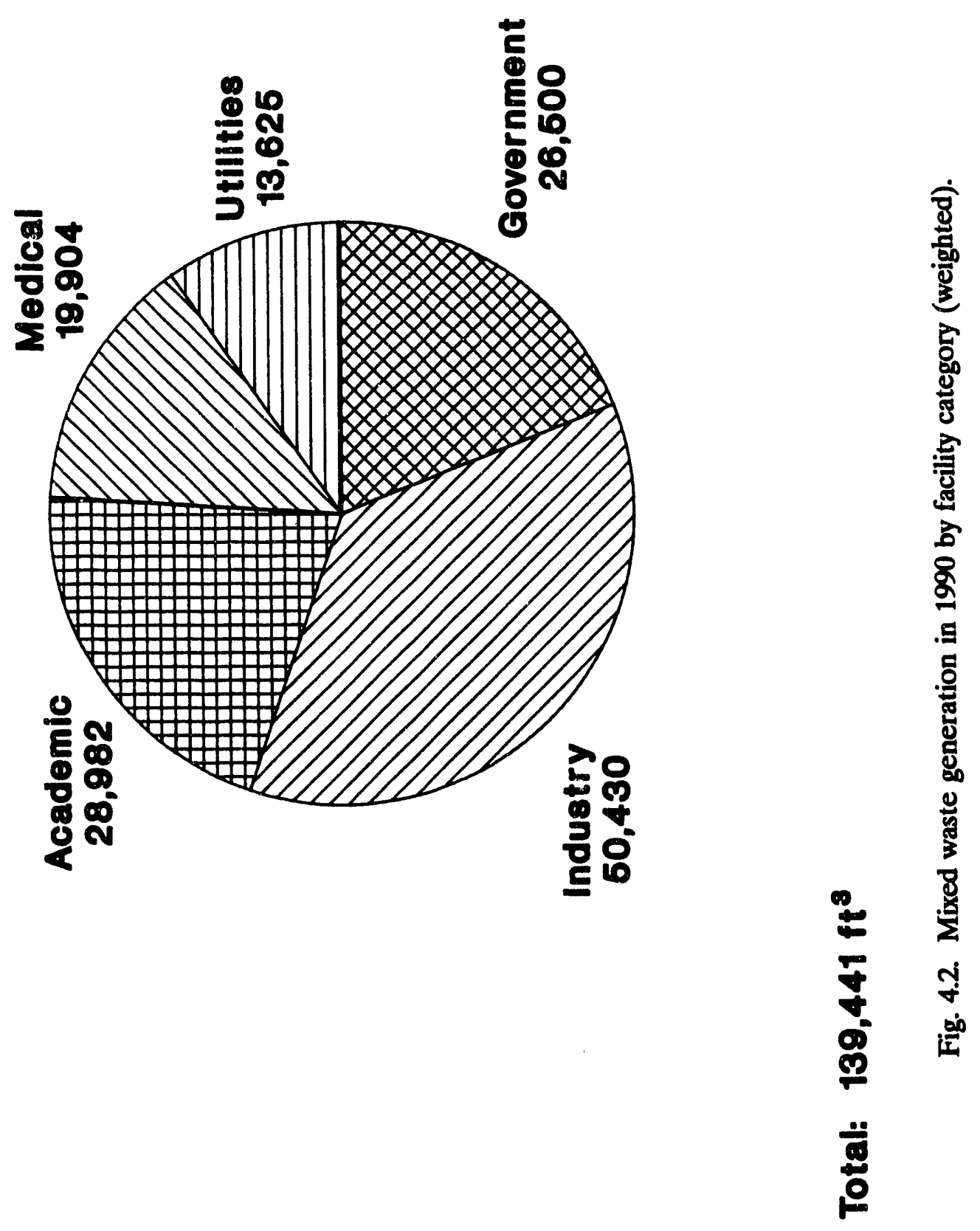



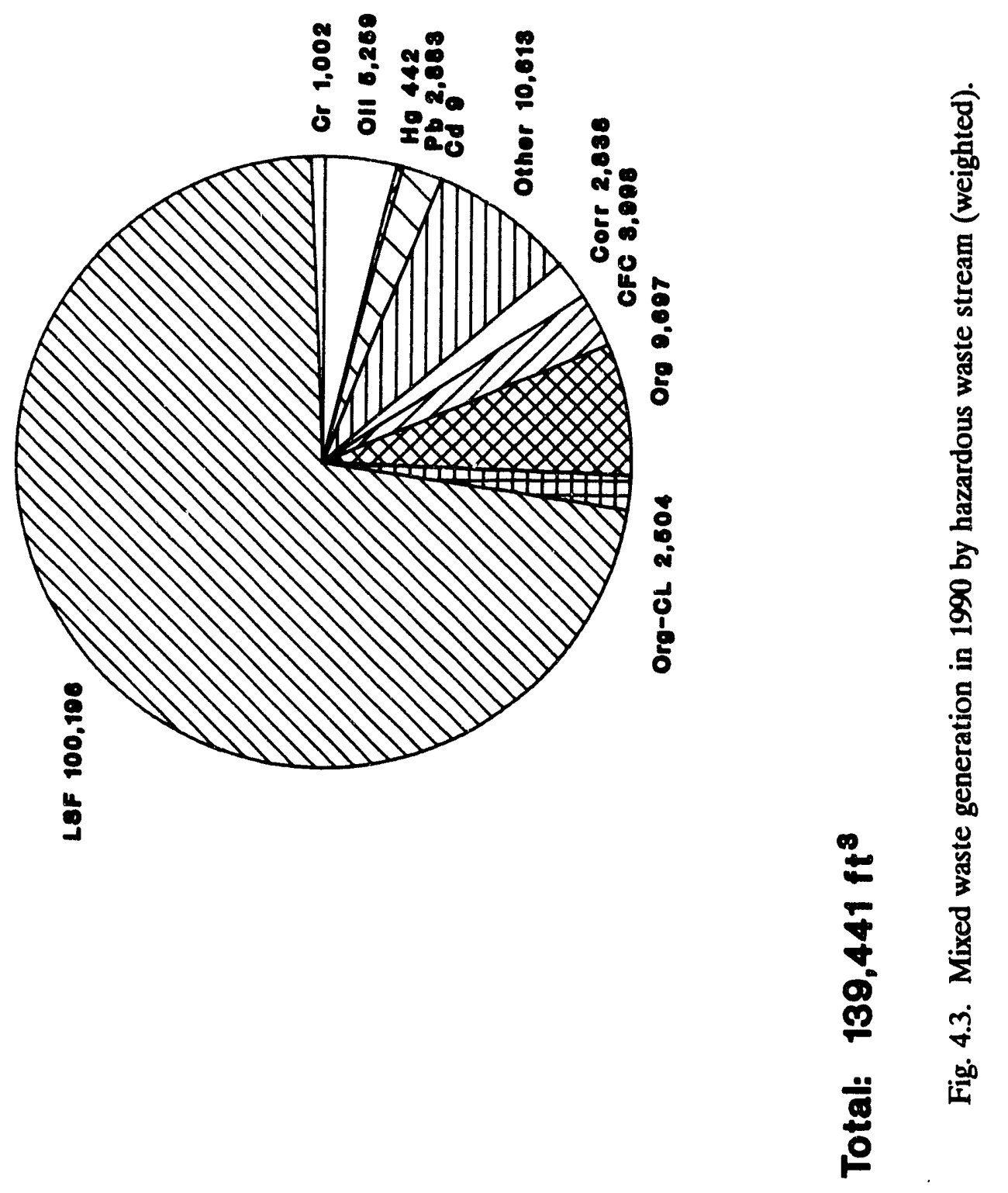


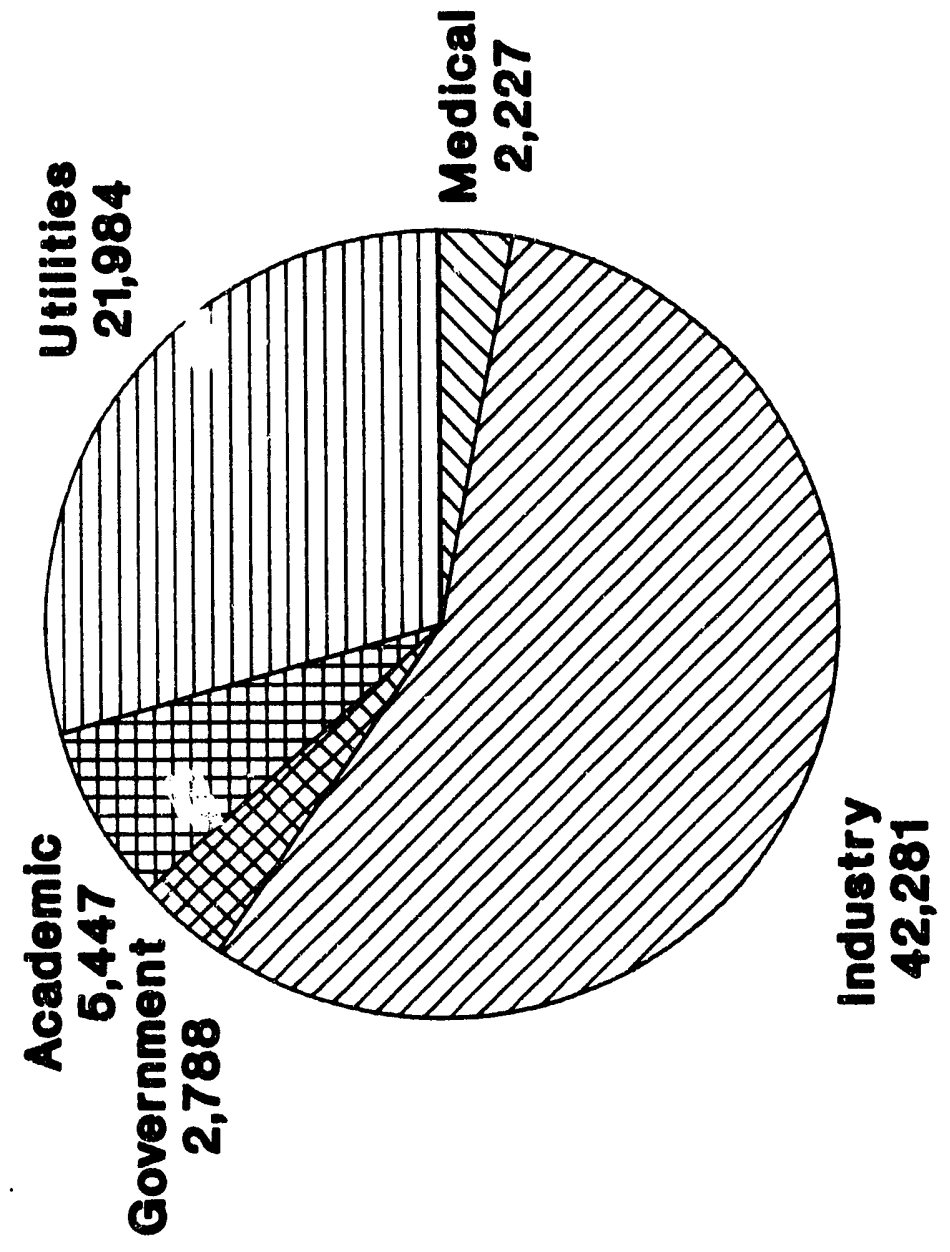

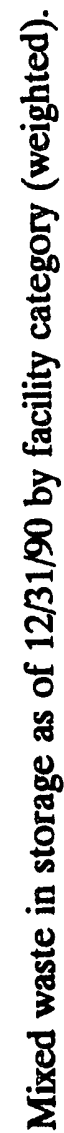

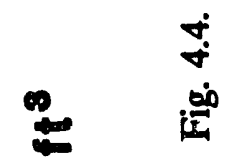

N

$N$

$N$

总 


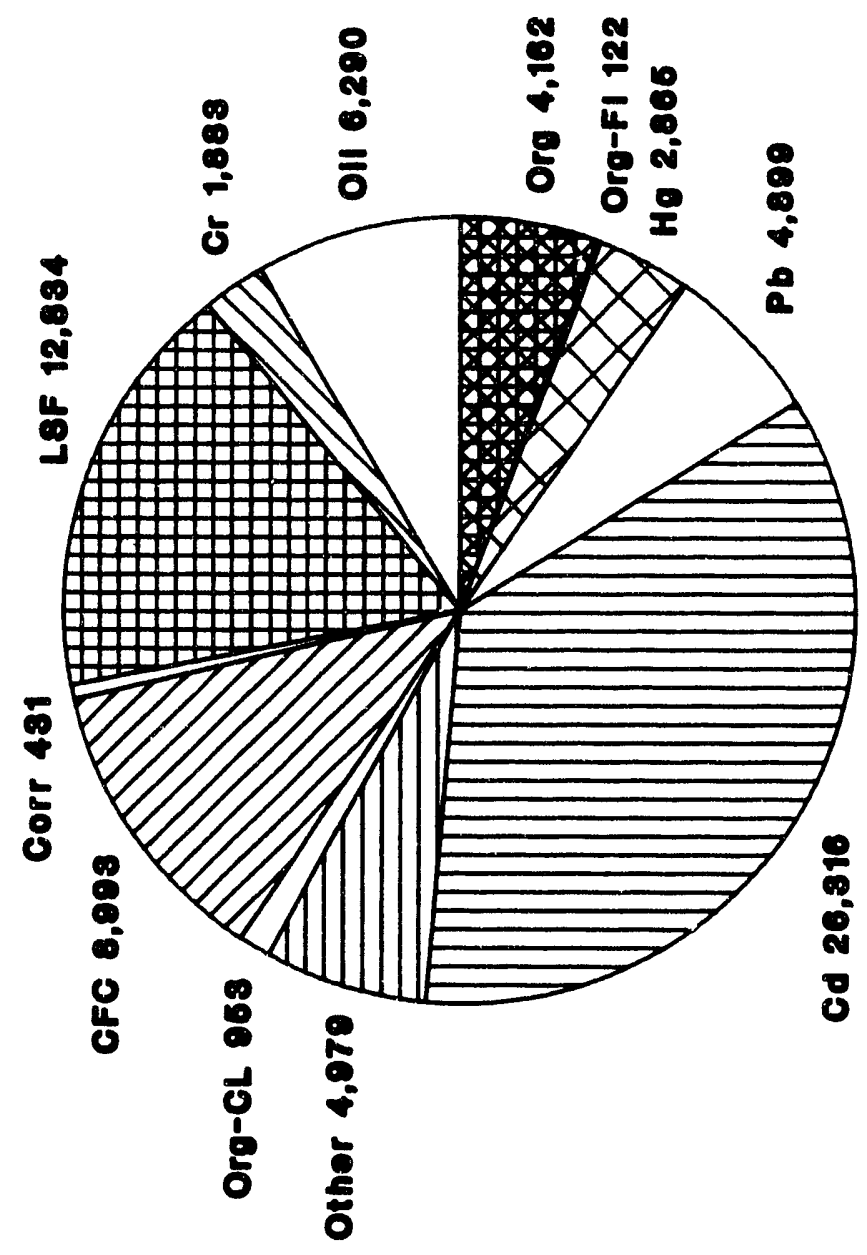




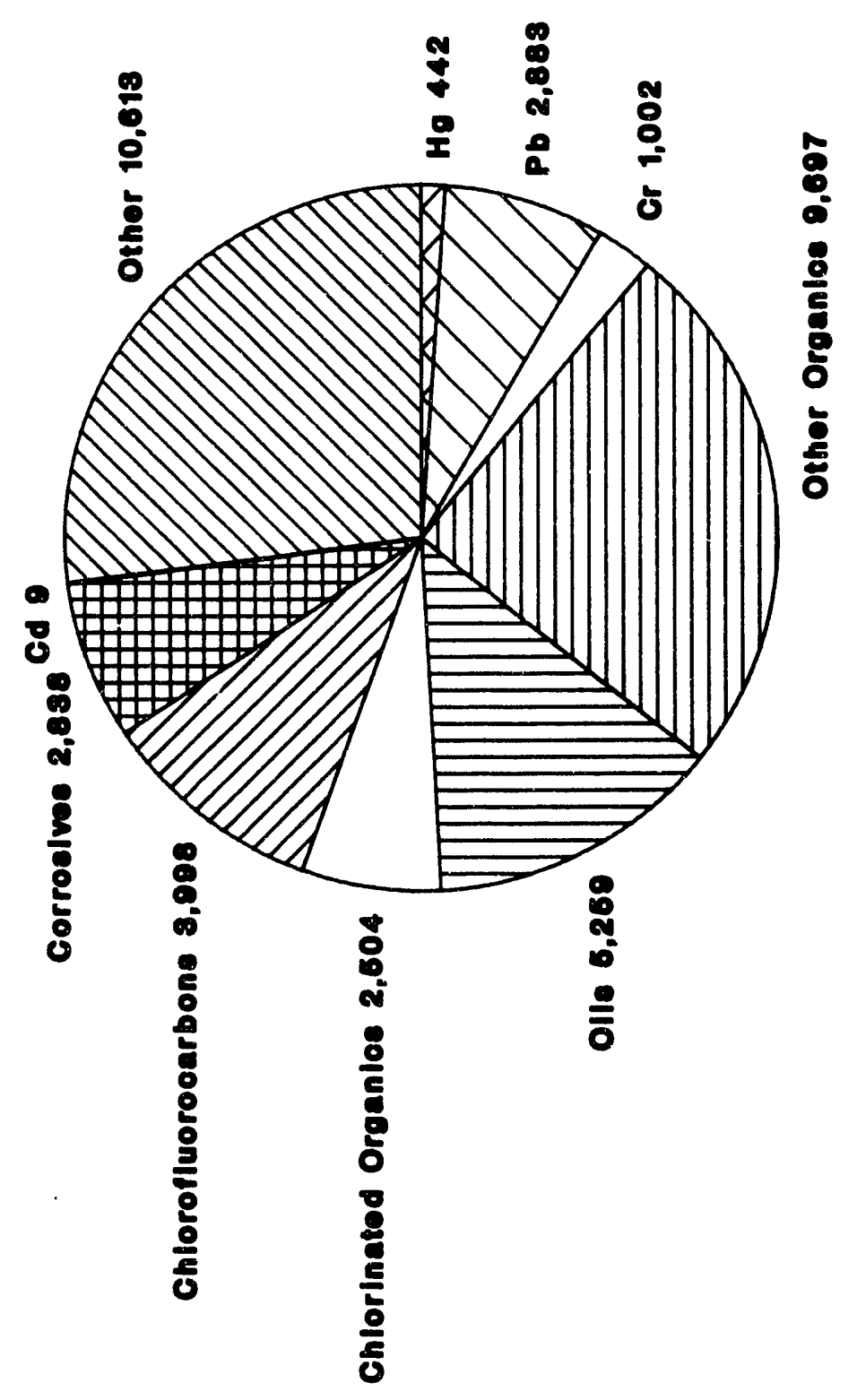

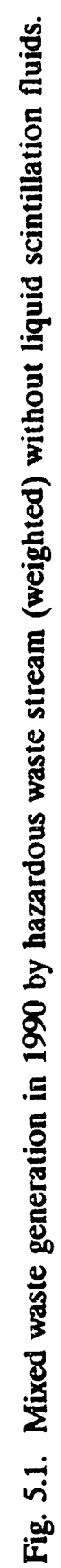




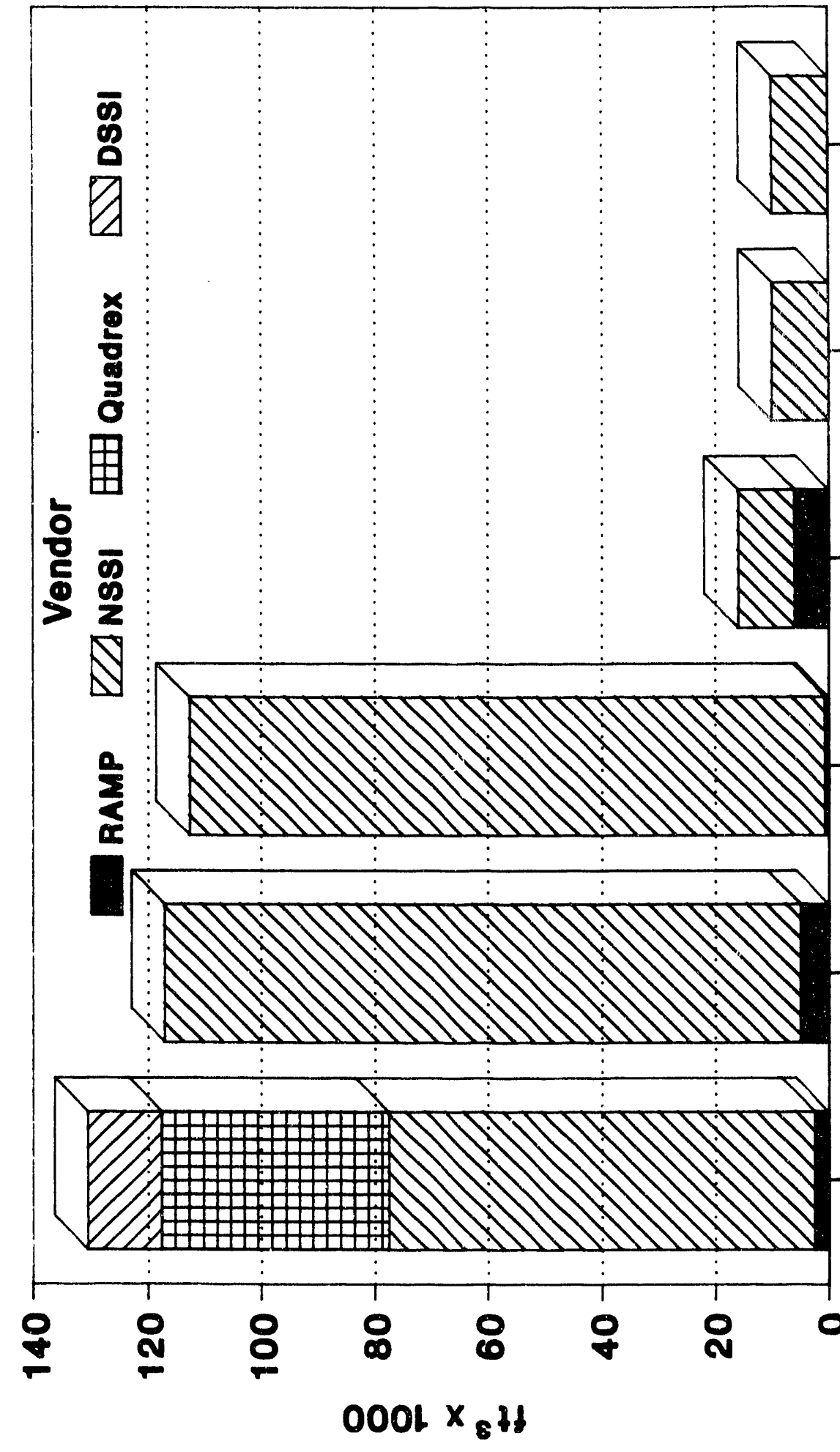




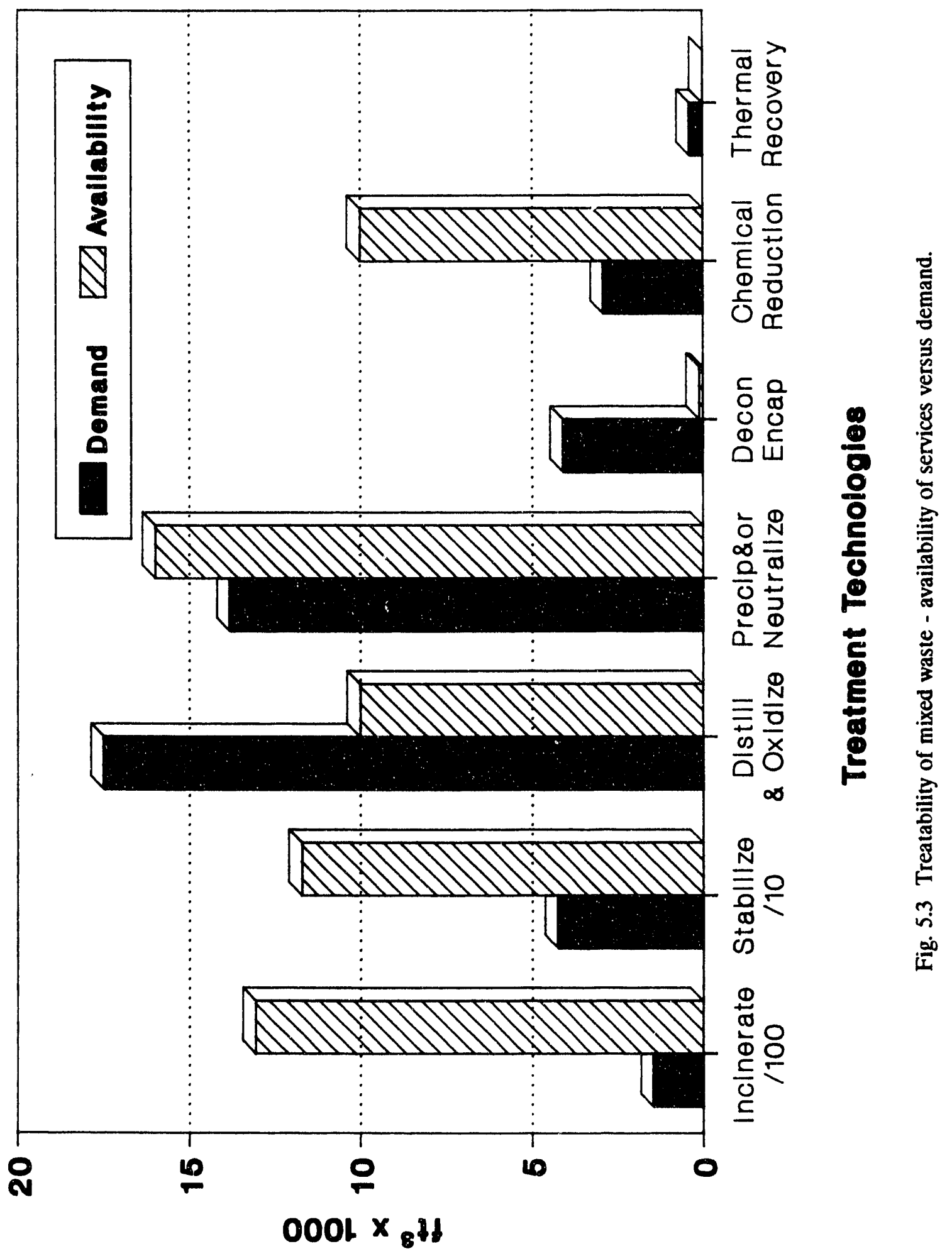




\section{APPENDIX A}

\section{STUDY DESIGN SPECIFICATIONS}




\section{NATIONAL PROPILE OF MIXED WA8TE GENBRATORB \\ BURVEY DEBIGN DOCUNENT}

October 2, 1991

Prepared by:

Arnold Greenland

David C. Cox \& Associates

1620 22nd street, N.W.

Washington, DC 20008

\section{Prepared for:}

U.S. Environmental Protection Agency

Permits and State Programs Division Office of Solid Waste

U.S. Nuclear Regulatory Commission Decommissioning and Regulatory issues Branch

Division of Low-Level Waste Management and Decommissioning

Under Contract No. 68-D0-0099, Task 1-8

Exposure Evaluation Division

office of Toxic Substarices

EPA Project officer: Edith sterrett

EPA Task Managsx: Richard Iashier

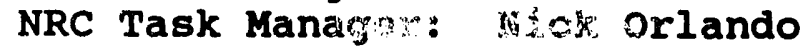


This document presents the statistical design of a national survey of commercially generated mixed waste. The objective of the survey is to compile a profile, both at the national level and by certain broad classes of establishments, of the volumes, characteristics and treatability of commercially generated and stored mixed waste. Because of the technical nature of the definition of mixed waste, the reader is directed to the "Technical Letter Report for Task Three" developed by Oak Ridge National Laboratory (ORNL) for a full definition. In brief, mixed waste is material which is both Low-Level Radioactive Waste (LIRW) under the Atomic Energy Act and its amendments and a hazardous waste under the Resource Conservation and Recovery Act (RCRA).

The key goals of this document are:

- to characterize the target population;

- to write down the specifics of a sampling plan;

- to describe the details of the data collection plan;

- to describe plans for dealing with survey and sampling errors: and

- to lay the foundation for the estimation process which will follow the data collection process.

The sections which follow will address each of the goals in turn.

\section{Characterization of the Target population}

The unit of investigation for this study is defined as an establishment in the United states which has a potential to generate mixed waste. Since an establishment could have mixed waste on its site only if it was licensed by either the NRC or one of the Agreement states to produce, handle or dispose of radioactive waste, we can certainly restrict the target population to such establishments. It is reasonable to suggest also that we further limit the target population to establishments which also have permits or interim status under RCRA. We do not actually employ this limitation because it is possible that an establishment generates mixed waste, for example the emission of a hazardous substance from a piece of equipment on the premises, but is not required to have a permit under RCRA.

Many of the establishments having licenses from the NRC or an Agreement state could not, by the nature of their business, be generators of mixed waste. For example, from the NRC list of approximately 8,000 establishments, only about 1,750 could reasonably generate mixed waste. This group was determined by including only those establishments on the list which have a 
Material License Program Code which is, according to the judgment of cognizant technical personnel, associated with an establishment that could possibly generate mixed waste. The Material License Program codes contain information about the details of the type of radioactive material which the NRC licensee can handle. These codes are included as one of the data items in the data base of NRC licensees which was provided by the NRC. Table 1 contains the specific Material License Program Codes which were included in the definition of the population.

Although an analogous data file to that used for NRC Iicensed states will not be obtained for the Agreement states, the definition for the target population remains "all establishments on either the NRC or Agreemert states lists which, because of the nature of their business, have a chance of generating, either by design or by accident, any mixed waste." We will describe this population as the "potential generators of mixed waste."

Within the population of potential generators of mixed waste, there will be wide variation regarding the likelihood of generating mixed waste. In particular, utilities which are operating nuclear power plants are very likely candidates to generate such wastes because of the volumes of LLRW which are generated on such sites. Therefore it is beneficial to break down the full set of establishments into smaller groups from which to select the sample. Since estimating the volume of mixed waste is the primary goal of the survey, groups which have greater potential to generate substantial volumes will be more likely to be included in the survey. The approach to this segmentation of the sample will be discussed in the next section under "Stratification" of the sample.

\section{Sampling Plan}

This section will discuss several components of the design of the survey. They include:

- stratification;

- sample size determination;

- sampling frame; and

- sampling procedure.

\section{1 stratification}

There are two basic reasons for stratification. The first is to fulfill the requirement for producing estimates within subgroups called estimation cells of the population at a predetermined level of accuracy. This requirement is present in the Mixed Waste survey as it is required to make accurate estimates for each of the following five types of establishments:

- Utilities

- Medical facilities

- Academic institutions 
TABLE 1. Material Iloense Program Codes Included

\begin{tabular}{|c|c|}
\hline CODE & DESCRRPITON \\
\hline 01100 & Academic Type A Broad \\
\hline 01110 & Academic Type B Broad \\
\hline 01120 & Academic Type C Broad \\
\hline 02110 & Medical Institution Broad \\
\hline 02410 & In-Vitro Testing Laboratories \\
\hline 02500 & Nuclear Pharmacies \\
\hline 02511 & Medical Product Distribution - 32.72 \\
\hline 02512 & Medical Product Distribution - 32.73 \\
\hline 02513 & Medical Product Distribution - 32.74 \\
\hline 03110 & Well Logging Byproduct / SNM Tracer \& Sealed Sources \\
\hline 03112 & Well Logging Byproduct Only - Tracers Only \\
\hline 03113 & Field Flooding Studies \\
\hline 03211 & Man and Dist Type Broad A \\
\hline 03212 & Man and Dist Type Broad B \\
\hline 03213 & Man and Dist Type Broad C \\
\hline 03214 & Man and Dist Other \\
\hline 03218 & Nuclear Laundry \\
\hline 03220 & Leak Test Service Only \\
\hline 03221 & Inst Cal Ser Only - Source $<100$ Curies \\
\hline 03222 & Inst Cal Ser Only - Source > 100 Curies \\
\hline 03223 & Leak Test and Inst Cai Ser Only - Source $<100$ Curies \\
\hline 03224 & Leak Test and Inst Cal Ser Only - Source > 100 Curies \\
\hline 03225 & Other Services \\
\hline 03231 & Waste Disposal (Burial) \\
\hline 03232 & Waste Disposal Service Prepackaged Only \\
\hline 03233 & Waste Disposal Service Incineration \\
\hline 03234 & Waste Disposal Service Processing and/or Repackaging \\
\hline 03610 & $\mathbf{R}$ and D Type Broad A \\
\hline 03611 & $R$ and D Type Broad B \\
\hline 03612 & R and D Type Broad C \\
\hline 03613 & R and D Broad - Multisite - Multiregional \\
\hline 03620 & $\mathbf{R}$ and $\mathbf{D}$ Other \\
\hline 11100 & Mills \\
\hline 11200 & Source Material Other < 150 Kilograms \\
\hline 11220 & Source Material Military Munitions Testing \\
\hline 11300 & Source Material Other > 150 Kilograms \\
\hline 11400 & Uranium Hexafluoride Production Plants \\
\hline 11500 & Solutions Testing \\
\hline 11700 & Rare Earth Extraction and Processing \\
\hline 11800 & Source Material \\
\hline 21130 & Hot Cell Operations \\
\hline 21210 & Uranium Fuel Processing Plants \\
\hline 21240 & Uranium Fuel R\&D and Pilot Plants \\
\hline 21310 & Critical Mass Material - Universities \\
\hline 21320 & Critical Mass Material - Other Than Universities \\
\hline 22110 & SNM Plutonium - Unsealed $<$ Critical Mass \\
\hline 22111 & SNM U-235 and/or U-233 Unsealed < Critica! Mass \\
\hline 22150 & SNM Plutonium-Sealed Sources $<$ A Critical Mass \\
\hline 22151 & SNM U-235 and/or U-233 Sealed Sources < A Critical Mass \\
\hline 22162 & Pacemaker Byproduct and/or SNM Man and Dist \\
\hline 23100 & Fresh Fuel Al Reactor Sites \\
\hline 25100 & Transport-Private Carriage \\
\hline
\end{tabular}


- Industrial establishments

- Government facilities.

This list requires some clarifications. First, the group defined as "Utilities" includes only those establishments which are nuclear power plants. Other utilities would fall under the more general industrial category. Medical facilities include hospitals, medical laboratories, medical school hospitals and doctors' offices. Government hospitals, such as Veterans Administration hospitals, are classified as Medical establishments rather than being included in the Government category. Academic institutions include all levels of such institutions, but also some academically affiliated research facilities. The Industrial category includes all other private companies and institutions, including research and development institutions.

The second reason to introduce stratification into a survey design is to optimize the accuracy of the estimates ultimately produced. This is accomplished by selecting subgroups within the population which are similar with respect to their characteristics and with respect to the quantities being estimated. We refer to these subgroups as substrata. One example of such a group of establishments is a list which was developed by Oak Ridge National Laboratory (ORNL) from an earlier stage of this study which contains "likely" generators of mixed waste. This list contains many major generators of mixed waste including all utilities holding NRC licenses. Because establishments on this list are considered to represent a large portios of all mixed waste generated in the country, the list will be jncluded in the survey in its entirety as a separate substratum.

Another example of a critical substratum of establishments is the set of all shippers of LLRW who do not already appear on the ORNL list. Because this group of establishments already ships LLRW, they are considered to be much more likely to be generators of mixed waste than other groups in the population. Experts consulted regarding this group also suggested that the amount of mixed waste generated by these establishments will vary widely. This can be interpreted to mean that the standard deviation, a statistical measure of the variability of a set of numbers, for this substratum will be larger than other groups.

Sampling practice dictates that survey resources should be concentrated in those segments of the population in which the variability of the key estimates (total volume of mixed waste in this case) is the highest. Following that practice will accomplish two important goals. First it will result in overall estimates of the total mixed waste which are more accurate. Second it will use the financial resources of the survey project in the most cost effective manner by concentrating the survey among establishments which are most likely to provide the NRC and EPA with useful information.

Exhibit 1 incorporates the two types of stratification discussed above to reveaj. a breakdown of the population of interest into the primary estimation cells (shown as rows in Exhibit 1) and, 


\begin{tabular}{|c|c|c|c|c|c|c|c|}
\hline & \multirow[b]{3}{*}{$\begin{array}{l}\text { ORNL } \\
\text { List }\end{array}$} & \multirow{3}{*}{$\begin{array}{l}\text { Shipper's } \\
\text { List } \\
\text { Excluding } \\
\text { ORNL List }\end{array}$} & \multicolumn{4}{|c|}{$\begin{array}{c}\text { Other Potentlal Mixed Waste } \\
\text { Generators }\end{array}$} & \multirow[b]{3}{*}{ Total } \\
\hline & & & \multicolumn{2}{|c|}{ NRC } & \multicolumn{2}{|c|}{$\begin{array}{l}\text { Agreement } \\
\text { States }\end{array}$} & \\
\hline & & & $\begin{array}{c}\text { With } \\
\text { EPA } \\
\text { Pormits }\end{array}$ & $\begin{array}{l}\text { Whout } \\
\text { EPA } \\
\text { Permits }\end{array}$ & $\begin{array}{l}\text { With } \\
\text { EPA } \\
\text { Permits }\end{array}$ & $\begin{array}{l}\text { Whout } \\
\text { EPA } \\
\text { Permits }\end{array}$ & \\
\hline Utilities & 67 & - & - & - & $=$ & & 67 \\
\hline Medical & 53 & 369 & 19 & 87 & $40^{*}$ & $170^{*}$ & 738 \\
\hline Academic & 77 & 207 & 79 & 136 & $160^{*}$ & $270 *$ & $929 *$ \\
\hline Industrial & 105 & 922 & 167 & 549 & $330 *$ & $1,100^{\star}$ & $3,173^{\star}$ \\
\hline Government & 16 & 83 & 5 & 156 & $10^{\star}$ & $310 *$ & 580 \\
\hline TOTAL & 318 & 1,581 & 270 & 928 & $540^{*}$ & $1,850 *$ & $5,487 \star$ \\
\hline
\end{tabular}

- denotes estimate

Exhibit 1. Breakdown of the number of establishments in the population of interest.

within that, by substrata (shown as columns in Exhibit) which are introduced to increase efficiency of estimates. The substratification cells defined in that exhibit are the following:

- Oak Ridge National Laboratory (ORNL) Iist. This substratum is a list of 318 names which was compiled by ORNL. They include all nuclear power plants and other waste generators who, for one eason or another, have been designated likely generators of MW. The list contains both NRC and Agreement state licensees.

- 8hippers Iist Excluding the ORNI 11et. This substratum contains all shippers of LIRW who do not already appear on the ORNL list. Outside of the ORNL list, this group is considered to be the next most likely group to generate mixed waste. This list contains both NRC and Agreement State licensecs.

- Other NRC Potential Mixed Naste coneratora. This substratum is defined in two steps. It starts with the group of establishments having NRC licenses and Material License Program Codes which are considered to be "potential" generators of mixed waste (using the codes in Table 1). The group is further broken down into those with and without EPA Permite to treat, store, dispose or generate hazardous waste.

- Other Agreement state Potential uixed waste cenerators. This substratum is analogous to the NRC ca" sgory above. 
Altholyh there is no list which categorizes these establishments by material license codes (like the NRC list), they are defined as part of the population for completeness. All numbers shown in Exhibit 1 which have an asterisk beside them are estimates and not exact counts as are the other columns in the Exhibit. They were obtained by doubling the numbers shown in the columns marked "NRC" and rounding off to the nearest factor of 10 . This method of estimation was used because the total number of Agreement state licensees is approximately 16,000 as compared to 8,000 licensees for the NRC. Thus a factor of 2 was considered reasonable.

The estimates for Other Agreement States Potential Mixed Waste Generators is included in Exhibit 1 to provide a complete picture of the target population. However, after some discussion with NRC technical personnel and the other participants in $i$ is research project, it was decided not to include this group in the sampling frame for the survey. Preliminary investigation revealed that information on establishments in Agreement states, in a form analogous to that obtained for NRC establishments, does exist. Further, that information is usually in machine readable form, though with different data formats and having different sets of data fields available. However, to obtain this information it would have required submitting a request, in writing, to each of the 28 Agreement states and allowing approximately 45 days for their responses. It was a management decision, supported by technical input from the project team, that the cost of obtaining and processing this information far outweighed the expected benefit that would accrue from having it.

The latter conclusion was reached based upon the opinion of experts in the nuclear industry that most of the volume of mixed waste would be concentrated in the more easily available lists. It was also suggested that the "Other NRC Potential Mixed waste Generators," i.e., those not on the ORNL or Shipper's lists, would be similar to the "Other Agreement state Potential Mixed Waste Generators." Therefore, the experts' opinion about the relative importance of the group not available on the ORNL and shippers lists could be tested with the group of NRC establishments which are included in the sample. If there turns out to be a substantial component of MW found to be generated in the NRC group which is outside of both the ORNL and Shippers Lists, then a model can be built to accommodate that portion of the population on the Agreement state side.

Since no sampling will be done from the two segments of the target population shown in Exhibit 1 under "Other Potential Mixed Waste Generators, Agreement States," they will be excluded from the formal survey process. Therefore these two segments will not be shown in subsequent exhibits. Similarly, the formulation and use of the model, mentioned in the previous paragraph, is considered to be outside the scope of the survey and is not considered further in this design document. 


\section{2 sample size}

A sample size determination is made using several key facts about the population and the study goals. Those include the number of units (establishments with potential for generating mixed waste) which are in each of the population strata, estimates for the means and variances of the total volume of mixed waste within each stratum, and the accuracy requirements of the survey.

For the purposes of the sample size estimation, one must formulate a reasonable target for control of sampling error. In surveys, this quantity is often expressed using the concept of relative standard error of the estimate, which is defined as the standard error of the estimate produced by the survey divided by that estimate, and for this survey we based our estimates on a target relative standard error of $10 \%$.

It is useful to explain this concept with an example. If, after collecting the data for this survey, a standard error of 10,000 cubic feet of mixed waste is obtained as associated with an estimate of the total mixed waste generated nationally of 100,000 cubic feet, the relative standard error would be 10\%. This figure must be carefully interpreted. Usually, researchers measure the "error" in an estimate by quoting probabilistically based intervals around the estimate which are called confidence intervals. A $95 \%$ confidence interval about the above example estimate would be approximately two standard errors, or 20,000 cubic feet of mixed waste.

All error requirements quoted in this document will be stated in terms of relative standard errors. However, they must be transformed into target confidence intervals to be consistent with the stated error requirements of the survey. The overall accuracy requirement set by the sponsors of this project is to be within a factor of two of the actual volume of mixed waste both nationally and within each of the five estimation cells. This requirement results in an asymmetric interval about each estimate which is half the estimate on the lower side and twice the estimate on the upper side. As described above, the relative standard error of $10 \%$ of the estimate results in a 958 confidence interval of roughly twice that size or 208 of the estimate. This component of error is that which is due to sampling error (the exror introduced because a sample was taken rather than a census). The stated overall accuracy requirement on the lower and upper sides, therefore, leaves room for what is termed "non-sampling" errors. Although one can quantify the size of the sampling error, there is no similar way to quantify the size of the non-sampling error. It is a matter of subjective judgement that the level of the non-sampling error can be contained within the bounds just defined. As will be discussed below, it is generally accepted that sample sizes be defined using methods which quantify sampling error, and that nonsampling error be minimized by using established practices for questionnaire design and testing, and careful attention to all details of survey operations. 


\begin{tabular}{||c|c|c|}
\hline & $\begin{array}{c}\text { Subgroup } \\
\text { Mean }\end{array}$ & $\begin{array}{c}\text { Subgroup } \\
\text { Standard Doviation }\end{array}$ \\
\hline Utilities & 76 & 140 \\
\hline Medical & 78 & 85 \\
\hline Academic & 107 & 402 \\
\hline Industrial & 15 & 34 \\
\hline Government & $15^{\circ}$ & $34^{\circ}$ \\
\hline
\end{tabular}

'denotes estimate

Exhibit 2. Estimates of Population Means and standard Deviations in cubic feet.

Consider first the table of means and standard deviations which is shown as Exhibit 2. The two columns of this exhibit contain the means and standard deviations obtained from a small "subgroup" of six states. This information was included in an earlier Technical Letter Report produced by the Oak Ridge National Laboratory for this project. Although the volumes of mixed waste included in this subgroup represent different surveys with different selection criteria, they are the best data we have from which to make mean and standard deviation estimates for the total volume. These numbers are used as a basis for the sample size calculations which are described below. Since the six-state data did not have information about Government establishment.s, the mean and standard deviation for that group were estimated as being similar to the Industrial sector.

The means and standard deviations for the substrata are assumed to be constant multipliers of the figures shown in Exhibit 2. They differ from the base figures because experts in this field indicate that these groups have very different likelihoods of generating mixed waste. The multipliers of the base mean and standard deviation figures in Exhibit 2 used in producing sample size estimates are the following:

$\begin{array}{ll}\text { ORNL List } & 1.00 \\ \text { Shipper's Lists } & 1.10 \\ \text { Other NFC with EPA Permit } & 0.40 \\ \text { Other NRC without EPA Permit } & 0.20\end{array}$

For example, the estimated means and standard deviations for the Academic substratum are tabulated in Exhibit 3 . When the estimates for the mean generated mixed waste for all estimation cells by substrata are combined, a estimate for total mixed waste generated within the sampling frame of the survey is 103,275 cubic feet. A very crude estimate of 100,000 cubic feet of mixed waste was provided by experts in the nuclear industry. Since these figures are roughly consistent, the basic assumptions for the means and 


\begin{tabular}{|l|c|c|}
\hline Substratum & Mean & Standard Deviation \\
\hline ORNL List & 107 & 402 \\
\hline Shippers List & 117.7 & 442.2 \\
\hline $\begin{array}{l}\text { Other NRC with EPA } \\
\text { Permit }\end{array}$ & 42.8 & 160.8 \\
\hline $\begin{array}{l}\text { Other NRC without EPA } \\
\text { Permits }\end{array}$ & 21.4 & 80.4 \\
\hline
\end{tabular}

\section{Exhibit 3. Mean and standard deviation estimates for mixed waste generated (in units of cublo feet) for the Acadomic sector.}

standard deviations are considered to be validated.

Using the means and standard deviations just described, we employed Neyman allocation methods to compute a sample size for each of the estimation cells separately. Each estimation cell was handled separately because the error requirements are defined to hold independently for each of these cells. It is clear that meeting the error requirements separately for each of the estimation cells, will ensure the same or better accuracy for estimates related to the combined population.

For completeness, the details of the sample size calculation for the medical estimation cell will be provided here. The sample size calculations for the other estimation cells are similar. Consider the table shown as Exhibit 4. The first four columns in the table correspond to each of the substrata, excluding tise "Other Agreement State Potential Generators," within this estimation cell. The rows of the table contain the key information required to perform the sample size computation. The first row contains the total number of establishments in each of the substrata, denoted $N_{h}$ to indicate population size in substratum $h$. The second row shows estimates for the mean mixed waste in the substrata derived from Exhibit 2. The next row is derived by multiplying the values in the prior two rows, to produce estimates for the total mixed waste in each substratum, $T_{h}$. These estimates are clearly very crude. If the amounts of mixed waste by substratum were known accurately, there would be no need to do a survey. However, for the purposes of sample size estimation and allocation, such estimates are needed. The next row contains an estimate for the standard deviation of the mixed waste in each substratum derived from Exhibit 2 using the adjustment factors for substrata and illustrated in Exhibit 3.

These numbers are combined using standard formulas to produce preliminary estimates of the total sample size required for each estimation cell. Since, the ORNL group had been designated a certainty sector early in this discussion, they are not included in the sample size calculation. This explains the need for the last column of the table. This column contains sums over those columns 


\begin{tabular}{|c|c|c|c|c|c|c|}
\hline & \multirow[b]{3}{*}{$\begin{array}{l}\text { ORNL } \\
\text { List" }\end{array}$} & \multirow{3}{*}{$\begin{array}{l}\text { Shipper's } \\
\text { List } \\
\text { Excluding } \\
\text { ORNL List }\end{array}$} & \multirow{2}{*}{\multicolumn{2}{|c|}{$\begin{array}{c}\begin{array}{c}\text { Other Potentlal } \\
\text { Mixed Waste } \\
\text { Generators }\end{array} \\
\text { NRC }\end{array}$}} & \multirow[b]{3}{*}{ Total } & \multirow[b]{3}{*}{$\begin{array}{l}\text { Total for } \\
\text { Noncertainty } \\
\text { Strata }\end{array}$} \\
\hline & & & & & & \\
\hline & & & $\begin{array}{l}\text { With } \\
\text { EPA } \\
\text { Permit }\end{array}$ & $\begin{array}{l}\text { Without } \\
\text { EPA } \\
\text { Permit }\end{array}$ & & \\
\hline $\begin{array}{l}\text { Number of } \\
\text { Establishments } \\
\left(N_{n}\right)\end{array}$ & 53 & 369 & 19 & 87 & 528 & 475 \\
\hline $\begin{array}{l}\text { Estimated } \\
\text { Mean Mlxed } \\
\text { Waste in } \mathrm{t}^{3}\end{array}$ & 78 & 85.8 & 31.2 & 15.6 & & \\
\hline $\begin{array}{l}\text { Estimated } \\
\text { Total Mixed } \\
\text { Waste in } \mathrm{f}^{3} \\
\left(T_{n}\right) \\
\end{array}$ & 4,134 & $31,660.2$ & 592.8 & $1,357.2$ & $37,744.2$ & $33,610.2$ \\
\hline $\begin{array}{l}\text { Estimated } \\
\text { Standard } \\
\text { Doviation in } \mathrm{ft}^{3} \\
\left(\mathcal{S}_{n}\right) \\
\end{array}$ & 85 & 93.5 & 34 & 17 & & \\
\hline SAMPLE SIZE & 53 & 73 & 1 & 3 & 130 & 77 \\
\hline
\end{tabular}

- denotes certainty substratum

Exhibit 4. Example of sample size calculation for the Medical estimation cell.

which are not certainty sectors.

The formula used to determine total sample size for the noncertainty cells is the following ${ }^{9}$ :

$$
n=\frac{\left(\sum N_{h} s_{h}\right)^{2}}{V+\sum N_{h} s_{h}^{2}}
$$

where $V$ is the estimate for the variance of the total mixed waste for this estimation cell. In this equation, the sum is taken over only those columns in the table which are not certainty sectors, and is found in Exhibit 4 in the very last column of the Exhibit.

'Cochran, w. G., Sampling Techniques, Third Edition, John Wiley and Sons, New York, 1977 (equation 5.50 on page 106). 
$V$ is jetermined using a target relative standard error of $10 \%$. As discuss above, the relative standard error is a commonly used quantity $1 \%$ expressing errors in survey estimates. A $95 \%$ confidence 1 . ferval would be approxirately plus or minus $20 \%$ of the estimate. $\quad V$ is computed as follovs:

$$
V=\left(0.10 \times \sum T_{h}\right)^{2} \text {. }
$$

This latter sum is taken over all columns including the certainty substratum. This is because the accuracy requirement is for the entire estimation cell and not just a subset of it.

The last step of the sample size computation process is to allocate the sample size just computed for the estimation cell as a whole to the individual strata. The certainty sectors are determined already, so the allocation is to the remaining strata. The formula used to allocate, following the Neyman allocation method, is the following:

$$
n_{h}=n\left(\frac{N_{h} s_{h}}{\sum N_{h} s_{h}}\right) .
$$

The sum in this equation is over only the non-certainty sectors.

Exhibit 5 contains the results of the preliminary sample size calculation for all of the estimation cells combined. These estimates are preliminary because they are not yet adjusted for expected nonresponse and other constraints that will be discussed below. As Exhibit 5 demonstrates, Neyman allocation tends to concentrate the sample in those segments of the population in which the estimated volume of mixed waste is the highest and, at the same

\begin{tabular}{|c|c|c|c|c|c|}
\hline & \multirow[t]{3}{*}{$\begin{array}{c}\text { ORNL } \\
\text { List }\end{array}$} & \multirow{3}{*}{$\begin{array}{l}\text { Shippers } \\
\text { List } \\
\text { Excheding } \\
\text { ORNll List }\end{array}$} & \multirow{2}{*}{\multicolumn{2}{|c|}{$\begin{array}{c}\begin{array}{c}\text { Other Potential Mixed } \\
\text { Waste Generators }\end{array} \\
\text { NRC } \\
\end{array}$}} & \multirow[t]{3}{*}{ TOTAL } \\
\hline & & & & & \\
\hline & & & $\begin{array}{c}\text { With EPA } \\
\text { Permit }\end{array}$ & $\begin{array}{l}\text { Without } \\
\text { EPA permit }\end{array}$ & \\
\hline Utilfities & 67 & - & - & - & 67 \\
\hline Medical & 53 & 73 & 1 & 3 & 130 \\
\hline Academic & 77 & 180 & 25 & 22 & 304 \\
\hline Industrial & 105 & 273 & 18 & 30 & 426 \\
\hline Govemment & 16 & 78 & 2 & 27 & 123 \\
\hline TOTAL & 318 & 604 & 46 & 82 & 1,050 \\
\hline
\end{tabular}
time, the variability in that volume is also the highest.

Exhlbit 5. Preliminary ample sige allocation. 
Exhibit 6 contains estimates of the sample sizes for the survey revised to take into corsideration the impact of nonresponse on the ultimate set of completed interviews. Nonresponse has two effects. One is that it lowers the number of available cases to be used for estimation, thus lowering the accuracy of the estimates. Second, since those who participate essentially select themselves for participation or not, there could be a subtle bias in the estimates representing the difference between those who choose to respond to the survey versus those who choose not to respond. Since we expect a 758 response rate, the numbers in Exhibit 6 were obtained from Exhibit 5, by multiplying each estimate from noncertainty cells by 1.333 , the nonresponse adjustment factor (NRAF). This sample size adjustment can compensate for the fact that the number of cases who respond would be too low, but it cannot compensate for nonresponse bias. We must assume here that the group of responders are similar to the non-responders with respect to volumes of mixed waste generated, so that a nonresponse adjustment is possible. Also, we work to control the impact of non-sampling bias by careful survey operation. This will be discussed further below.

Exhibit 7 contains the final sample size estimates for the survey. These numbers are obtained from Exhibit 6 using the natural constraint that the sample size cannot exceed the total number of establishments in the population from Exhibit 1. This constraint affected the Academic row for the Shipper's column where the NRAF adjusted number of 240 cases was limited to 207 . When the remaining 33 cases were allocated to the other two NRC columns, the number of cases in the Academic group having EPA permits was so close to the population total of 79 , it was decided to select all such cases for the sample. This increased the sample for that estimation cell from 379 in Exhibit 6 to 407 in Exhibit 7 .

\begin{tabular}{|c|c|c|c|c|c|}
\hline & \multirow[t]{3}{*}{$\underset{\text { List }}{\text { ORNL }}$} & \multirow{3}{*}{$\begin{array}{l}\text { Shipper's } \\
\text { List } \\
\text { Exchuding } \\
\text { ORNL List }\end{array}$} & \multirow{2}{*}{\multicolumn{2}{|c|}{$\begin{array}{c}\begin{array}{c}\text { Other Potential Mixed } \\
\text { Waste Generators }\end{array} \\
\text { NRC } \\
\end{array}$}} & \multirow[t]{3}{*}{ TOTAL } \\
\hline & & & & & \\
\hline & & & $\begin{array}{l}\text { With EPA } \\
\text { Permit }\end{array}$ & $\begin{array}{l}\text { Without } \\
\text { EPA permit }\end{array}$ & \\
\hline Utilities & 67 & - & - & - & 67 \\
\hline Medical & 53 & 97 & 1 & 5 & 155 \\
\hline Academic & 77 & 240 & 33 & 29 & 379 \\
\hline Industrial & 105 & 364 & 24 & 40 & 533 \\
\hline Govemment & 16 & 104 & 3 & 36 & 159 \\
\hline TOTAL & 318 & 805 & 61 & 109 & 1,293 \\
\hline
\end{tabular}

Exhibit 6. sample sise allocation including adjustment for nonresponse. 
Modifications were also made in the Government estimation cell. The NRAF adjusted number appearing in Exhibit 6 of 104 cases for the Shipper's column exceeded the total of 83 cases available. Therefore, all 83 cases were included for sampling in that group, and the 21 other cases were allocated proportionately to the two NRC columns. These combined modifications resulted in a total sample of 1,321 cases, allocated to the various estimation cells and substrata as shown in Exhibit 7 .

\subsection{Sample size sensitivity}

The sample size computations described in the prior section rely upon many assumptions and preliminary estimates. Should these assumptions be shown to be inaccurate, through the experience of the actual survey, the survey accuracy could be different than projected. The sample size estimates presented here were made using information supplied and reviewed by experts in the nuclear industry. The information was considered to be the best available short of actually doing the survey.

Exhibit 8 shows how sample size estimates change as the assumed relative standard errors (RSEs) change. The Exhibit contains sample size allocations for each of the five estimation cells and the total population. Two different assumptions for the RSE, $15 \%$ and 20\%, are shown. As was mentioned earlier, all of the estimates contained in Exhibits 3 through 7 were obtained assuming a $10 \%$ RSE for the survey estimates. Within each of the two alternative accuracy assumptions in Exhibit 8 , sample sizes are given for both the base sample estimate (analogous to Exhibit 5) and the final allocation which incorporates the adjustment for non-

\begin{tabular}{|c|c|c|c|c|c|}
\hline & \multirow[t]{3}{*}{$\begin{array}{c}\text { ORNL } \\
\text { List }\end{array}$} & \multirow{3}{*}{$\begin{array}{l}\text { Shipper's } \\
\text { List } \\
\text { Excluding } \\
\text { ORNL List }\end{array}$} & \multirow{2}{*}{\multicolumn{2}{|c|}{$\begin{array}{c}\begin{array}{c}\text { Other Potential Mixed } \\
\text { Waste Generators }\end{array} \\
\text { NRC }\end{array}$}} & \multirow[t]{3}{*}{ TOTAL } \\
\hline & & & & & \\
\hline & & & $\begin{array}{l}\text { With EPA } \\
\text { Permit }\end{array}$ & $\begin{array}{l}\text { Whout EPA } \\
\text { permit }\end{array}$ & \\
\hline Utilities & $67^{\circ}$ & - & - & - & 67 \\
\hline Medical & $53^{\circ}$ & 97 & 1 & 4 & 155 \\
\hline Academic & $77^{*}$ & $207^{*}$ & $79^{\circ}$ & 44 & 407 \\
\hline Industrial & $105^{\circ}$ & 364 & 24 & 40 & 533 \\
\hline Government & $16^{\circ}$ & $83^{\circ}$ & $5^{\circ}$ & 55 & 159 \\
\hline TOTAL & 318 & 751 & 109 & 143 & 1,321 \\
\hline
\end{tabular}

- denotes a certainty cell (all population units are sampled)

Exhiblt 7. Final sample ise allocation. 


\begin{tabular}{||l|c|c|c|c|}
\hline \multirow{2}{*}{} & \multicolumn{2}{|c|}{ 15\% Rol Std Error } & \multicolumn{2}{c|}{ 20\% Rol Std Error } \\
\cline { 2 - 5 } & $\begin{array}{c}\text { Base Sample } \\
\text { Size }\end{array}$ & $\begin{array}{c}\text { Adjusted } \\
\text { Sample Size }\end{array}$ & $\begin{array}{c}\text { Base Sample } \\
\text { Size }\end{array}$ & $\begin{array}{c}\text { Adjusted } \\
\text { Sample Size }\end{array}$ \\
\hline Utilities & 67 & 67 & 67 & 67 \\
\hline Medical & 92 & 105 & 75 & 82 \\
\hline Academic & 248 & 304 & 205 & 248 \\
\hline Industrial & 270 & 325 & 205 & 238 \\
\hline Government & 96 & 123 & 75 & 94 \\
\hline TOTAL & 773 & 924 & 627 & 729 \\
\hline
\end{tabular}

Exhibit 8. sample sise estimates associated with alternative assumptions for target relative standard errors of estimates.

response (analogous to Exhibit 7). It is clear from Exhibit 8 that sample sizes are effected dramatically by the assumption regarding RSE. The final non-response adjusted sample size estimate from Exhibit 7 is 1,321 as compared to 924 for $15 \%$ RSE and 729 for $20 \%$ RSE.

The project team decided to use a $10 \%$ RSE assumption for this survey for several reasons. First of all, that assumption is conservative. Since any number of the other assumptions made to produce the sample size estimates could be flawed, for example the means and standard deviations shown in Exhibit 2 or the assumed response rate, it is prudent to opt for a larger sample size. Second, an RSE of $10 \%$ yields a $95 \%$ confidence interval on the survey estimates of plus or minus $20 \%$ of those estimates. Since the non-sampling error is controlled only by careful design of the questionnaire and operation of the data collection process, there was a desire to allow sufficient room for non-sampling error to still stay within the management requirement of estimating total mixed waste to within a factor of two. A third reason for this assumption is that it was the judgement of those on the project team that sufficient financial resources were available to solicit the full 1,321 questionnaires, including the provision to do adequate follow-up of respondents.

Exhibit 8 is included in this report to fully document the discussions of the project team in setting the survey design assumptions for the project. 


\subsection{Sampling frame}

The sampling frame is intended to be a complete physical list of the entire target population for this study. In practice, obtaining such lists, either in computer readable form or in a hard copy list, is often difficult; and this particular survey is not an exception to this rule. The definition of the target population is all "potential generators of mixed waste." The word potential was added to the definition to exclude establishments which, because of the nature of their operations, could not generate mixed waste. Work was done with the NRC list to exclude such establishments using Material License Program Codes.

The set of lists that were available for use as all or part of the sampling frame include the following:

- The Oak Ridge List of Iikely u Generators (the ORNL Iist). This list currently shows 318 establishments including all nuclear power plants. The list was formulated during the preliminary work done by ORNL on this project and was augmented slightly during the frame construction phase. It represents a group of establishments which are very likely to generate mixed waste. Since obtaining estimates for total MW generated is the main goal of this survey, this list will be included in the survey in its entirely. The list may be eventually augmented with names from two other compacts to which requests for such information was made. If the names become available at some future date, they will be matched against other substrata and added to the ORNL segment of the population and sampled with certainty.

- The 8hipper's Ists. These are actually three separate lists of establishments which ship LIRW to one the three sites licensed to handle such waste, one each in the states of South Carolina, Washington, and Nevada. Computer readable lists for sites shipping to south Carolina and washington were obtained from state authorities. A hard copy list of 31 establishments was obtained from Nevada state authorities and typed manually into a computer file. The three lists were merged and matched via computer to obtain one shipper's list.

- The MR? Iicensee Data Base. This list contains a complete accounting of all NRC Licensees, and as such is the most complete source for the population of mixed waste generators for NRC states. However, since it is believed that most of the roughly 8,000 licensees would not be potential mixed waste generators, the other lists mentioned above were matcied against the NRC list so that a more efficiert sampling scheme could be implemented. Also, there is information on the NRC data base (namely, the Material License Program Code) which allowed the 8,000 cases on that file to be reduced to 1,748 potential mixed waste generators. As mentioned earlier, Table 1 of this document contains the complete list of codes included in 
the population. From this point forward, reference to the NRC list will mean the list of 1,748 potential generators.

- The Agreement state Ilcensees. As discussed above, it was not considered cost-effective to obtain and process lists of Agreement state licensees. Therefore, they are not included in the sampling frame for this survey except as they appear on either the ORNL or Shippers lists.

- Hazardous Waste Data Management 8ystom (HWDS) and Resource Conservation and Recovery Information 8ysten (RCRI8) . These data bases contain information about establishments which have permits to treat, store or dispose of hazardous waste under RCRA as well as generators of hazardous waste. The HWDMS is an older data base which is being replaced by RCRIS. At the time frame development was done, only eight states were available in the RCRIS format, the remainder being obtained from HWDMS. In either case, information relating to name, address, phone number, etc. was available. These files were available in computer readable form and, counting generators, included some 300,000 establishments.

In accordance with the sampling stratification described above, the following approach to creating a sampling frame for this survey was implemented. First, all NRC establishments on the ORNL list and the Shipper's Lists were matched against the NRC data base. Agreement State establishments on the ORNL list were crossed with those on the Shipper's Lists. All cases were, therefore, put into one the following unique groups:

(1) the ORNL list;

(2) the Shipper's Lists (excluding any cases on the ORNL list); and

(3) the potential generators on the NRC list which are not on either the shipper's lists or the ORNL list.

More details on the methodology for building the sampling frame will be given in the next section.

\subsection{Sampling procedure}

Central to the sampling procedure is that each case included in the survey be selected with known probability. Such a sample is called a "probability sample." Without a probability sample, it is not possible to produce estimates of total volumes or other estimates from the survey which can be properly weighted and summed so as to represent the entire population of interest. Therefore, operational activities relating to the sample selection endeavored to preserve the probabilities of selection.

First, the sampling frame was created. As described above, each establishment (unit of sample selection for the survey) was 
matched against the other lists to ensura that it appeared in one and only one sector.

The matching and merging proceeded as follows. The first step in this process was to put all files into a consistent computer format, identifying key fields which were in common (name, address, city, state, zip code, and contact person). Next, the three shipper's lists (in two stages) were matched to produce one large shipper's list. This combined shippers list was, then, matched against the ORNL list. When matches were discovered, the two records were collapsed into one record (retaining all information from both sources including which file the record was on). The next phase of the matching used the NRC list (suitably limited to 1,748 establishments as discussed earlier in this document). The cases which did not match to either the ORNL or (combined) shipper's list were assumed to belong to the "Other NRC Potential Mixed Waste Generators" segment of the population. The final matching step compared the NRC group with a combined version of the EPA HWDMS and RCRIS files to place each establishment in the substratum to which it belonged.

All matching was done by name. As this method of matching is not foolproof, it is expected that some duplicates still remain on the frame. The name matching algorithm worked as follows. Two files at a time were matched (as discussed in the previous paragraph). Both files were sorted by state and zip code. Any two records with the same state and $z$ ip code which had the first 5 letters of their name in common were shown as a "potential" match. This method produced many more "potential" matches than "actual" matchis. The list of "potential" matches was reviewed visually to identiry the actual matches. As all statistical work was done using the PC/SAS statistical package, the combining of records was done using a full screen data base editor included in that package.

It sl.juld also be mentioned that the allocation of cases in the frame to the five estimation groups (utilities, medical, academic, industrial and Government) could not be done by computer, since no codes indicating which group establishments were in was available on the data bases. Therefore it had to be done by hand using the names on the files. The allocation of establishments was done using the definitions described earlier in this document and reviewed by a second individual at David Cox \& Associates. They were, then, sent for review to the technical staff at ORNL. ORNL's comments were incorporated in the final allocation of establishments to estimation cells.

The second major component of sample selection is to select a simple random sample within each of the strata according to the sample size numbers shown in Exhibit 7 . In this case the method used was to assign each case in the sampling frame a random number, using the pseudo-random number generator included with the PC/SAS system. Within each of the sampling cells, the cases were sorted by random number and the initial number of cases (matching the number to be sampled from Exhibit 7) was selected as being in the 
sample. This is equivalent to selecting a simple random sample within each sampling cell.

\section{Data collection methodology}

This data collection methodology selected for use in this survey is a mailed out survey with telephone follow-up. The survey forms will be mailed out and respondents will be allowed approximately four weeks to respond before a telephone follow-up will be made.

The follow-up call will consist of two parts. The first part will be a reminder to fill out the survey form. The second part will be an offer either to collect the information over the phone at the time of the call or to schedule a call in the future to collect the information by phone. Should those who promise to send the questionnaire in by mail not fulfill this promise within four weeks of the first call, a second call will be made to collect the data or schedule the collection by phone. Such a protocol has been shown to achieve a resporise rate that approaches 758 of the cases selected.

\section{Assessing and controlling errors}

One of the most critical aspects to designing a survey is preparation for errors. The two main categories of error which creep into surveys (whether censuses or samples) are sampling and non-sampling errors. The former refers to the error in estimates which occurs because not all of the cases in the population were used in making the estimate. This is the type of error which can be handled the easiest. Statistical methodology has been developed to the point where such errors are easily quantifiable and estimates of the impact of such errors can be made. In particular for this survey, based upor assumptions of the type used in the section on sample size computation, a sufficient number of sample units has been selected to yield a relative standard error of each estimate of total mixed waste within each estimation cell of 108 of the estimate for the total in that cell. This error requirement corresponds to a $95 \%$ confidence interval equal to plus or minus $20 \%$ of those estimates.

The other type of error, non-sampling error, is much more difficult to estimate or control. It includes:

1. Nonresponse bias.

2. Frame bias.

3. Response bias (lying, misunderstanding, answering different question).

The first of these, non-response bias, was discussed briefly above. This type of error exists because not all of the cases selected initially are willing to participate in the survey. The usual approach to handing this error is to carefully arrange the survey 
instrument and plan the operations of the survey to minimize the existence of this type of problem; however, additional cases have been included in this sample to accommodate a response rate of $75 \%$. If the survey experiences a response rate lower than 758 , the number of cases in the resulting survey database may be fewer than is required to produce the planned level of accuracy.

A second very important way to improve response relates to how the respondent is contacted and whether he can be convinced that it is in the establishment's best interest to respond. Therefore, trade organizations and other industry groups that could have an influence on response have been contacted to provide supporting letters to be either mailed separately to the sampled establishments or included as an attachment to the main mailout.

Frame bias may result when the sampling frame does not match the target population exactly. The problem in this survey would be when cases which are potential generators of mixed waste are excluded from the frame. In that event, estimates for volumes generated could be either over- or under-estimated. other frame problems include errors in the information on the lists (e.g., wrong address in a mail survey), duplicate entries on the file, definition of a unit on the frame not matching the definition in the target population (e.g., different uses of the term, "establishment"). The procedures described above for creating the frame were intende $s$ produce the best sampling frame that could be obtained; however, if there are still frame duplicates, it is expected that those which are included in the sample will be found during data collection and noted at that time. During the data analysis step, those for which duplicates were found will be incorporated in an adjustment of the sample weights.

The issue of response bias relates to whether the respondents correctly answer the questions intended. There was some concern that the respondents may not be fully cognizant of the definition of mixed waste and could claim that they do not generate mixed waste (a situation that could exclude them from the survey) when in fact they do.

The impact of response bias is best mitigated by very careful design of the survey instrument. Much care has been taken to ensure that all of the key data items will be included in the survey and that subjective responses are minimized. Also, a survey pretest of approximately 20 establishments which are affiliated with the Appalachian Compact Users of Radioactive Isotopes (ACURI) is in process at this writing. All information relating to the survey instrument obtained from the pretest will be incorporated in the final survey instrument.

\section{Estimation}

Estimates of total mixed waste generated and other quantities collected in the survey will be produced for each estimation cell. All survey estimators will be weighted using data recording the 
probability of selection which will be attached to each respondent's data record at the time of the creation of the sample. If there were no frame problems, nonresponses, or other incomplete responses during the data collection process, the weights that would be used at the analysis phase would be equal to the reciprocal of the probability of selection. However, since the majority of surveys experience some of the problems mentioned, we expect that weight ad, ustments, mainly for nonresponse, duplicates, and out of scope cases, will be required. Estimates of totals (for example the total mixed waste generated) will take the following form:

$$
\hat{Y}=\sum_{1, f, k} Y_{1, j, k} * W G T_{1, j, k} * N R A F_{1, j}
$$

where $y_{i, j, k}$ is the response of the $k t h$ establishment in the $j$ th stratum " $j$ th column in Exhibit 1) of estimation cell $i$ (the ith row in Exhibit 1). WGT is the initial sampling weight associated with the establishment, and the NRAF (to be explicitly defined below) is the stratum's unit non-response adjustment factor.

The WGT for each stratum is defined as the reciprocal of the probability of selection. This number is the quotient of corresponding cells in Exhibit 1 to those in Exhibit 7 (the population number divided by the sample number). For example, for the Medical estimation cell and the Shippers substratum, the total number of cases in the population (from Exhibit 1) is 369. The sample for that cell (from Exhibit 7) is 97 . Therefore, the probability of selection is $97 / 369=0.26287$ and the corresponding initial weight, WGT, is $1 / 0.26287=3.8041$.

The NRAF is computed as follows:

$$
N R A F_{1, f}=\frac{\sum_{v 1 a b 10} W G T_{1, f, k}}{\sum_{\text {ueable }} W G T_{1, j, k}}
$$

where the term "viable" in the formula indicates that the sum should include all units (k) in stratum $f$ and estimation cell $i$ which are in scope for the survey. This would only exclude establishments which were found at the time of data collection to be duplicates, out of business, or otherwise outside of the scope of the survey. The term "usable" refers to all establishments (k) in stratum $j$ and estimation cell $i$ which completed the survey.

Estimates of means or proportions can also be obtained from the survey using standard formulas. A mean would be computed as 
follows:

$$
\bar{Y}=\frac{\sum_{1, f, k} y_{1, f, k} * W G T_{1, f, k} * N R A F_{1, J}}{\sum_{1, f, k} W\left(, T_{1, f, k} * N R A F_{1, f}\right.}
$$

The proportion of establishments having some characteristic can be computed using the same formula as the mean where the value $Y_{j, j k}$ is interpreted as a 1 or 0 depending on whether the characteristic is present or not.

The final comment regarding estimation relates to estimation of sampling errors. It is generally accepted as good practice in sample surveys to compute sampling errors related to estimates produced. It is planned that such errors will to computed for at least the major estimates of the survey. These include the total volume of mixed waste generated and stored nationally and by major type of establishment. For this survey it is plarned to select one of the following three commonly used methods to compute sampling errors:

- balanced half sample replication;

- jackknife; or

- Taylor series approximation.

As a detailed discussion of these methods is beyond the scope of this design document, we provide a reference to the book by wolter. 1

${ }^{1}$ Wolter, K. M. (1985). Introduction to Variance Estimation, SpringerVerlag, New York. 


\section{APPENDIX B}

SURVEY PACKAGE - NATIONAL PROFILE ON MIXED WASTE (INCLUDING MIXED WASTE QUESTIONNAIRE) 


\section{Recipients of the National Profile on Mixed Waste Questionnaire}

As described in the following notice, Oak Ridge National Laboratory (ORNL) is participating in a project to develop a national profile on the volumes, characteristics, and treatability of commercially generated low-level radioactive mixed waste. This project is being sponsored by the U.S. Nuclear Regulatory Commission (NRC) and the U.S. Environmental Protection Agency (EPA). ORNL is requesting your participation in the development of this profile, by completing the attached questionnaire, as your facility may possibly generate mixed waste. We recognize that a number of facilities that are being asked to participate in this survey may also have participated in recent Siate or regional surveys. ORNL evaluated many of these surveys as part of our development of the national profile. ORNL determined that while they contain much useful information, results of previous surveys are not adequate to develop a national profile because of differing survey objectives, survey methods, and time frames.

It is important for questionnaire recipients to realize that the data from this profile will be useful to States as they plan and develop low-level radioactive waste disposal capacity as mandated in the Low-Level Radioactive Waste Policy Amendments Act of 1985. This information is not being collected for enforcement purposes by NRC or EPA. In order to make the information available to States in a timely manner, ORNL is requesting that you complete and return the survey form no later than December 2, 1991. Please complete and return the applicable portion of the survey form regardless of whether or not you generate mixed waste.

A self-addressed postcard has been included in the survey package. Your return of this card will indicate that you have received the survey package and have designated an individual to complete the questionnaire. This individual will also serve as a point of contact for any questions ORNL may have about your answers.

We appreciate your support in this important national project. If you have any questions, please feel free to telephone collect:

$\begin{array}{ll}\text { John Mrochek } & (615) 574-6840 \\ \text { Jerry Klein } & (615) 576-6823 \\ \text { Andy Francis } & (615) 576-8456\end{array}$

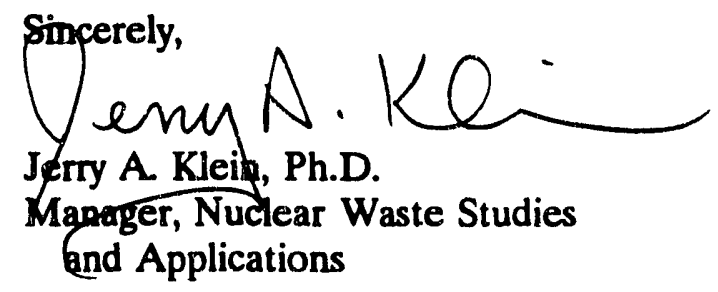

Enclosures 


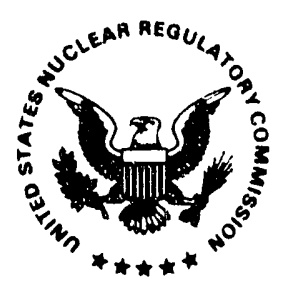

UNITED STATES

NUCLEAR REGULATORY COMMISSION

WASHINGTON, D. C. 20555

AUG 79991

TO NRC LICENSEES, RCRA STATE PROGRAM DIRECTORS, AND OTHER INTÉRESTED PARTIES

SUBJECT: ANNOUNCING PLANS FOR MIXED WASTE SURVEY

The purpose of this notice is to inform you of an upcoming survey and to request your support in making this effort a success. The U.S. Nuclear Regulatory Commission (NRC) and the U.S. Environmental Protection Agency (EPA) are conducting a voluntary survey to collect information to develop a national profile on the volumes, characteristics, and treatability of commercially generated mixed waste. Mixed waste is waste that contains a radioactive component subject to the Atomic Energy Act (AEA) and a hazardous component subject to the Resource Conservation and Recovery Act (RCRA). The Office of Management and Budget has approved the agencies' plan to survey some 1200 respondents. Since this survey will be limited to approximately 1200 respondents, not every licensee who receives this letter will receive a survey questionnaire. We hope to be in a position to begin the actual survey by September 1991. The results of the survey will be published in the Spring of 1992.

This project was undertaken by the two agencies at the request of the Host State Technical Coordinating Committee (TCC). In May 1990, a letter was sent to NRC Chairman Kenneth M. Carr and EPA Administrator William K. Reilly, by the TCC, requesting the development of a national profile on the volumes and characteristics of commercially generated mixed waste. The stated intent of the national profile should be "... to provide needed information to States and compact officials, private developers, and Federal agencies to assist in the planning and development of treatment and disposal facilities for mixed waste." As a result of this letter and consultations between NRC, EPA, and the Department of Energy (DOE), a contract was awarded to Oak Ridge National Laboratory (ORNL), to initiate work on this study.

This study began with an evaluation of past state, compact, and industry survey data to determine if these data are adequate for compiling a national mixed waste profile. At the conclusion of this initial phase, ORNL found that there was much useful existing information, but that the many different survey objectives and survey methods used, as well as the different timeframes involved in earlier surveys, argue against sole reliance on the existing data. ORNL recommended that a new survey be undertaken, and the two agencies adopted this recommendation.

The survey results are expected to help meet the current information needs of NRC, EPA, States and compact officials, and private developers. This information is expected to: (1) provide States and compacts with information to assist in planning and developing adequate disposal capacity for low-level radioactive waste, including mixed waste, as mandated by the Low-Level Radioactive Waste Policy Amendments Act; (2) provide private developers with a clearer idea of the characteristics and volumes of mixed waste and the technical capability and capacity needed to treat this waste; and (3) provide a reliable national data base on the volumes, characteristics, and treatability of commercial mixed waste. This data may also serve as a basis for possible Federal actions to effectively manage and regulate the treatment and disposal of mixed waste. 
The agencies' intent in conducting this survey is to collect accurate and complete information on mixed waste for the reasons outlined above. The data are not being collected for any enforcement purpose. Survey responses will be submitted to and retained by ORNL. Survey results will be provided to NRC and EPA, stripped of any facility identification. Also, any survey results pubilished by NRC or EPA would not identify individual facilities.

States, compact officials, and generators of low-level radioactive waste are asked to support and cooperate with this survey to help ensure that compilation of a national profile will be a meaningful and credible undertaking. The agencies' goal is to achieve at least a 75-percent response rate for this survey. Agreement State cooperation and support are especially needed to ensure that the survey provides a truly national profile. Therefore, NRC and EPA are particularly seeking the aid of Agreement State officials to facilitate making contact with Agreement State licensees. Because of the time-sensicive nature of the project, and our need to compile a national data base, we plan to make direct contact with Agreement State licensees in distributing the survey questionnaire. If this should pose a problem with any Agreement States, please contact Mr. Vandy Miller, Assistant Director for State Agreements Programs, NRC, on 301-492-0326. Any questions about the survey itself should be directed to Chad Glenn, NRC, on 301-492-0567, or Richard LaShier, EPA, on 202-382-2228.

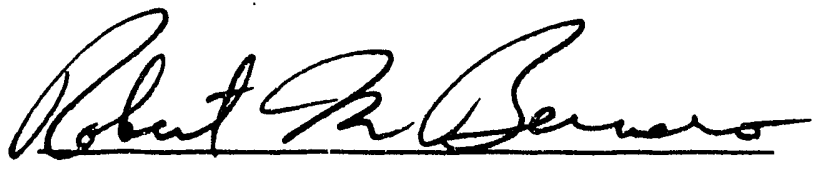

Robert M. Bernero, Director Office of Nuclear Material Safety and Safeguards

U.S. Nuclear Regulatory Commission

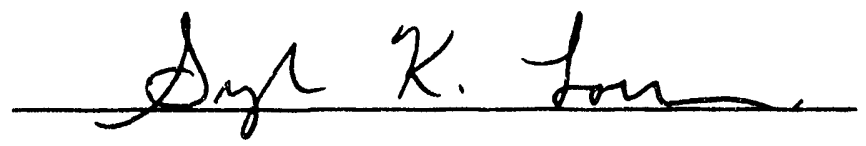

Sylvia K. Lowrance, Director Office of Solid Waste U.S. Environmental Protection Agency
UNITED STATES

NUCLEAR REGULATORY COMMISSION

WASHINGTON, D.C. 20555

OFFICIAL BUSINESS

PENALTY FOR PRIVATE USE, $\$ 300$
FInet CLABs MAll postage fele palo uanne

Penmer No. or 


\title{
QUESTIONNAIRE:
}

\section{NATIONAL PROFLLE ON MDXED WASTE}

\author{
by
}

Oak Ridge National Laboratory

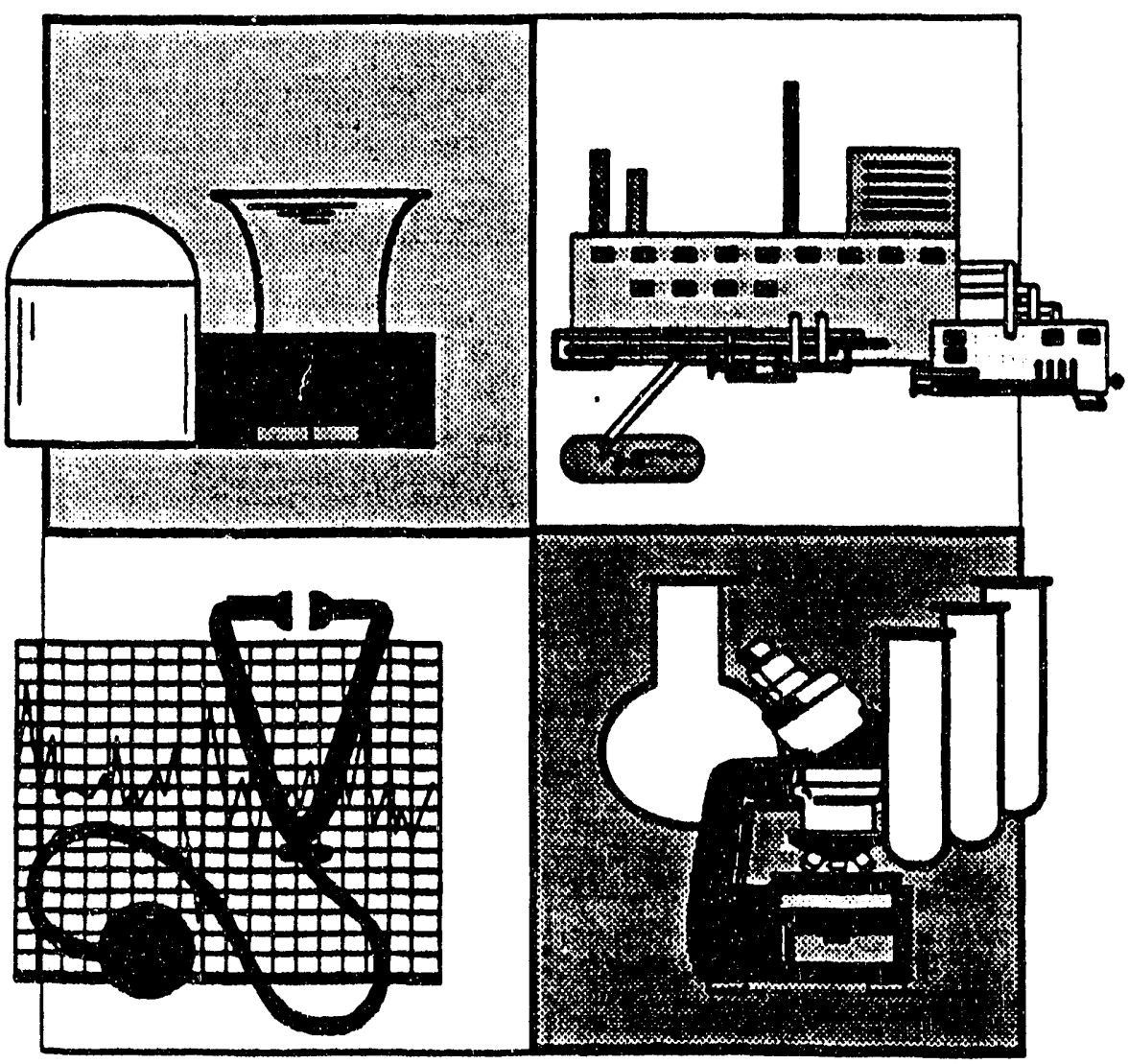

NOTTCE-Public reporting burden for this collection of information is eatimated to average 2 hours per response, including the time for reviowing instructions, searching existing date cources, gathering and maintaining the data neoded, and completing and reviewing the collection of information. Send comments regarding this burden eatimate or any other aspect of this collection of information, including suggestions for reducing this bunden, wo the Information and Records Management Branch (MNBB-7714) U. S. Nuclear Regulatory Commission. Washington, DC 2055s; and to the Office of Information and Regulatory Aftairs, Office of Management and Budget. Papenwork Reduction Project, M3150-0161, Waahington, DC 20503. 


\title{
QUESTIONNAIRE:
}

\section{NATIONAL PROFILE ON MIXED WASTE}

\author{
by
}

Chemical Technology Division

Oak Ridge National Laboratory

\author{
Prepared for the \\ U.S. Nuclear Regulatory Commission \\ and \\ U.S. Environmental Protection Agency \\ Prepared by the \\ OAK RIDGE NATIONAL LABORATORY \\ Oak Ridge, Tennessee 37831 \\ managed by \\ MARTIN MARIETTA ENERGY SYSTEMS, INC. \\ for the \\ U.S. DEPARTMENT OF ENERGY \\ under contract No. DE-AC05-84-OR21400
}




\section{QUESTIONNAIRE INSTRUCTIONS}

\section{Definitions:}

WASTE - For purposes of this study, waste is defined as a material not able to be recycled which must be treated, stored, disposed on-site, or shipped offsite for disposal/storage. This definition is meant to include waste oils or other materials which may be designated as "alternate fuels" and subsequently burned onsite or offsite.

\section{IOW-LEVEI}

RADIOACTIVE

WASTE - Low-level-radioactive waste (LLRW) is radioactive waste that (a) is not high-level radioactive waste, spent nuclear fuel, or byproduct material as defined in section 11e. (2) of the Atomic Energy Act (i.e. uranium or thorium mill tailings) and (b) the NR.C classifies as LLRW consistent with existing law and in accordance with (a).

SOLID

WASTE - The Resource Conservation and Recovery Act (RCRA) defines solid waste as "any garbage, refuse, sludge from a waste treatment plant, water supply treatment plant, or air pollution control facility and other discarded material, including solid, liquid, semisolid, or contained gaseous material resulting from industrial, commercial, mining, and agricultural operations, and from community activities," but does not include "source, special nuclear, or byproduct material as defined by the Atomic Energy Act of 1954...." [RCRA Section 1004(27)]. EPA, NRC, and DOE interpret the exception for source, special nuclear, or byproduct material as referring only to the radionuclide component, and not to the entire waste mixture. [Low-Level Mixed Waste A RCRA Perspective for NRC Licensees, EPA/530-SW-90-057].

\section{HAZARDOUS}

WASTE - $\quad$ A hazardous waste is defined in RCRA as "...a solid waste, or combination of solid wastes, which because of its quantity, concentration, or physical, chemical, or infectious characteristics may..." pose a "substantial present or potential hazard to human health or the environment when improperly...managed." [RCRA Section 1004(5)]. A solid waste is a hazardous waste if it is a "listed" waste or exhibits a hazardous characteristic as outlined in 40 CFR Part 261 Subpart D or C. RCRAauthorized states may declare other materials as hazardous.

\section{MIXED}

WASTE - For purposes of this project, mixed waste (MW) is defined as "waste that satisfies the definition of LLRW in the LLRW Policy Amendments Act of 1985 (LLRWPAA) and contains hazardous waste that (1) is listed as hazardous waste in Subpart D of $\mathbf{4 0}$ CFR Part 261 or (2) causes the LLRW to exhibit any of the hazardous waste characteristics identified in Subpart C of 40 CFR Part 261". In addition, the following are included in the definition of hazardous wastes for the purpose of this study: Oils and sludges, and other wastes classified as hazardous by a RCRA-authorized state. 


\section{A. General Information}

- Facility Information - Name is the facility name as shown on the NRC/Agreement State license or the name as shown on official facility stationary.

- Facility Category - Please select the single, best match to your facility's category. If the choice is between two possibilities, select the one most representative of your mixed waste.

- Standard Industrial Classification (SIC) Number - Bureau of Commerce publication

- NRC/Agreement State license number - Self explanatory.

- EPA identification number - Self explanatory. Please note that the size of facility referred to under EPA facility classification is in terms of totol hazandous waste generated including mixed waste.

- Name and title...- Self explanatory.

B. Low-Level Radioactive Waste (LLRW) - Please enter the total, "as-shipped" volume (in cubic feet) of LLRW shipped either to a broker or to a disposal site during 1990 in each of the three radioactive waste classifications and the Total volume of LLRW shipped.

Attachment 1 contains a list of 25 potential LLRW streams which, in the case of Biological, Waste Oils, Lead-, Paint-, and Mercury-Containing Wastes are further subcategorized. If none of these categories fit your waste stream, the last one (No. 226) can be used together with your own description of the stream. A sub-categorized waste stream should be reported as a 4-digit number with the last digit representing the subcategory; ali others should be reported as their 3-digit numbers. However, the Waste Stream Numbers which are not sub-categorized may be augmented with a 4th digit to indicate the presence of a hazardous "characteristic" in that waste according to the following rule: 1 - indicating flammable; 2 - indicating reactive; 3 - indicating corrosive; and 4 - indicating toxic (e.g., 2163 would indicate a corrosive mineral extraction waste).

Note that Question B-2 requests information on generated LLRW and Question B-3 requests information on stored LLRW. Use the defining 3- or 4-digit numbers from Attachment 1 for both questions. Please use the selected waste stream numbers throughout the remainder of the questionnaire for those same generated or stored waste streams. Use the single, most descriptive name for that waste stream as shown in Attachment 1 (this is the only place where it should appear in the Questionnaire). Use your best judgement in describing the Generating Practice which results in the indicated generated or stored waste; some examples are listed in Questions B-2 and B-3.

Some respondents may immediately categorize a waste as a mixed waste without ever classifying it as a LLRW; in such a case, the respondent may wish to bypass Questions B-2, B-3, and Section C, starting immediately with Section D. However, please do 
enter a descriptive stream number from Attachment 1 . If additional pages are required to complete the requested information, please reproduce additional copies of the needed pages from this Questionnaire.

\section{Hazardous Waste (HW)}

Section $C$ is designed to lead you through the regulations to determine if any of your generated or stored LLRW wastes contain a hazardous material which would cause the waste to be a mixed waste. Those facilities located in RCRA-authorized states should review the applicable state regulations for definitions of other hazardous materials declared by their state authorities. Follow the procedure (outlined in Figure C-1) for each generated (B-2) and stored (B-3) LLRW to identify the generated or stored mixed wastes.

D. Mixed Waste (MW)

Complete the information requested for Generated Mixed Waste in Questions D-1, D-2, and D-3. Detailed instructions are included with each question.

\section{E. Stored Mixed Waste}

Complete the information requested for Stored Mixed Waste in Questions E-1 and E-2. Detailed instructions are included with each question.

\section{F. Mixed Waste Minimization}

Please describe, in narrative style, the methods your facility is employing to minimize the generation of mixed waste.

Please remember that the intent of this survey is to gather complete and accurate information on mixed waste management and is not intended for enforcement purposes. The data reported by you will be used to assist Federal and State regulatory agencies, compact officials, and private developers in making important decisions on mixed waste management and disposal practices for many years. Your cooperation in this survey is greatly appreciated.

Please complete the Questionnaire as accurately as possible within four weeks after receipt and return it in the enclosed envelope to:

OAK RIDGE NATIONAL LABORATORY

ATTN: Dr. J. A. Klein

Nuclear Waste Studies and Applications

P. O. Box 2008, MS-6495

105 Mitchell Road

Oak Ridge, TN 37831-6495

IF YOU HAVE ANY QUESTIONS ABOUT COMPLETING THIS QUESTIONNAIRE, please call collect (615)574-6823, (615)574-6840 or (615)576-8456; M-F, 8:00 AM to 4:30 PM, EST. 


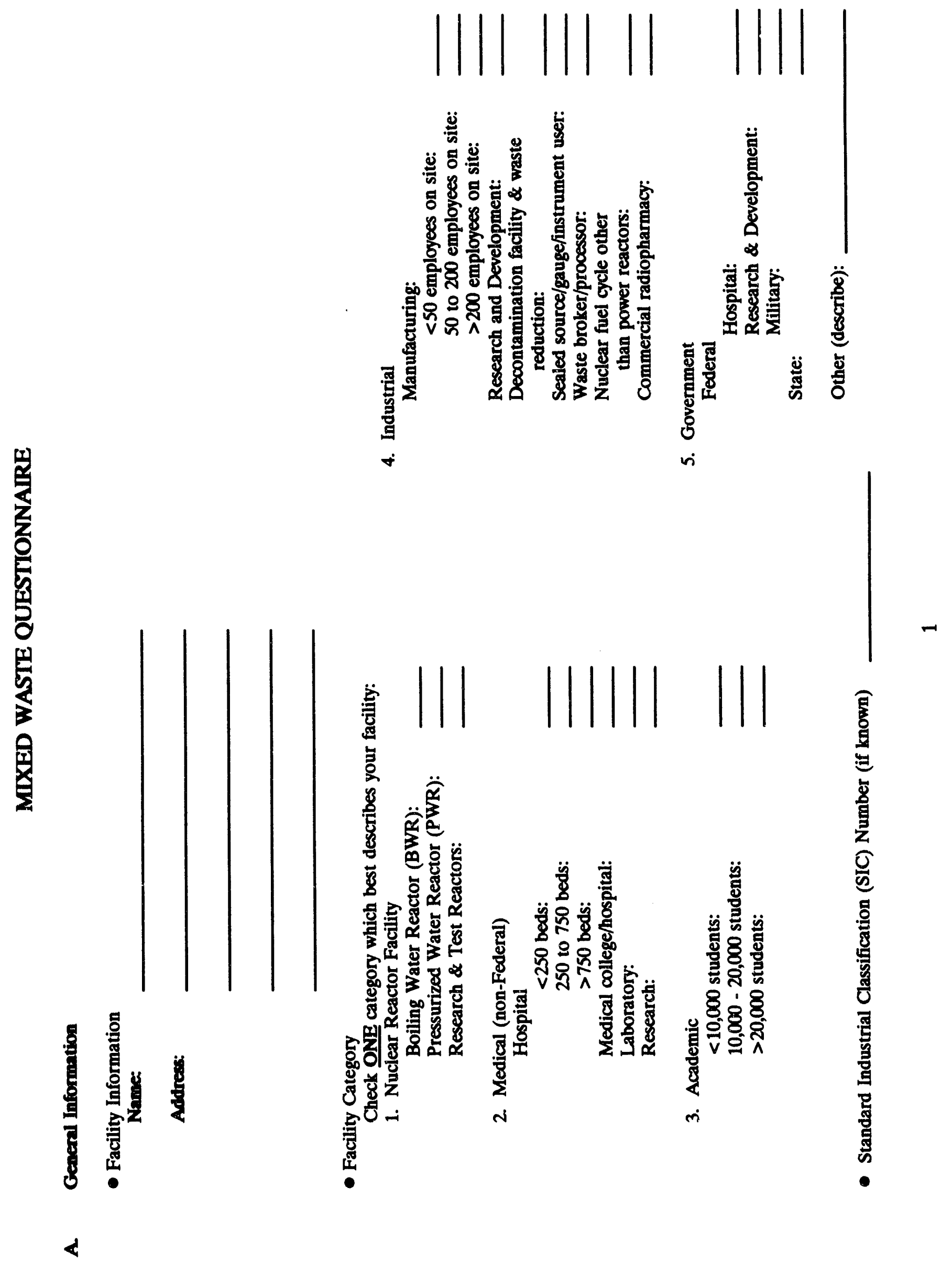




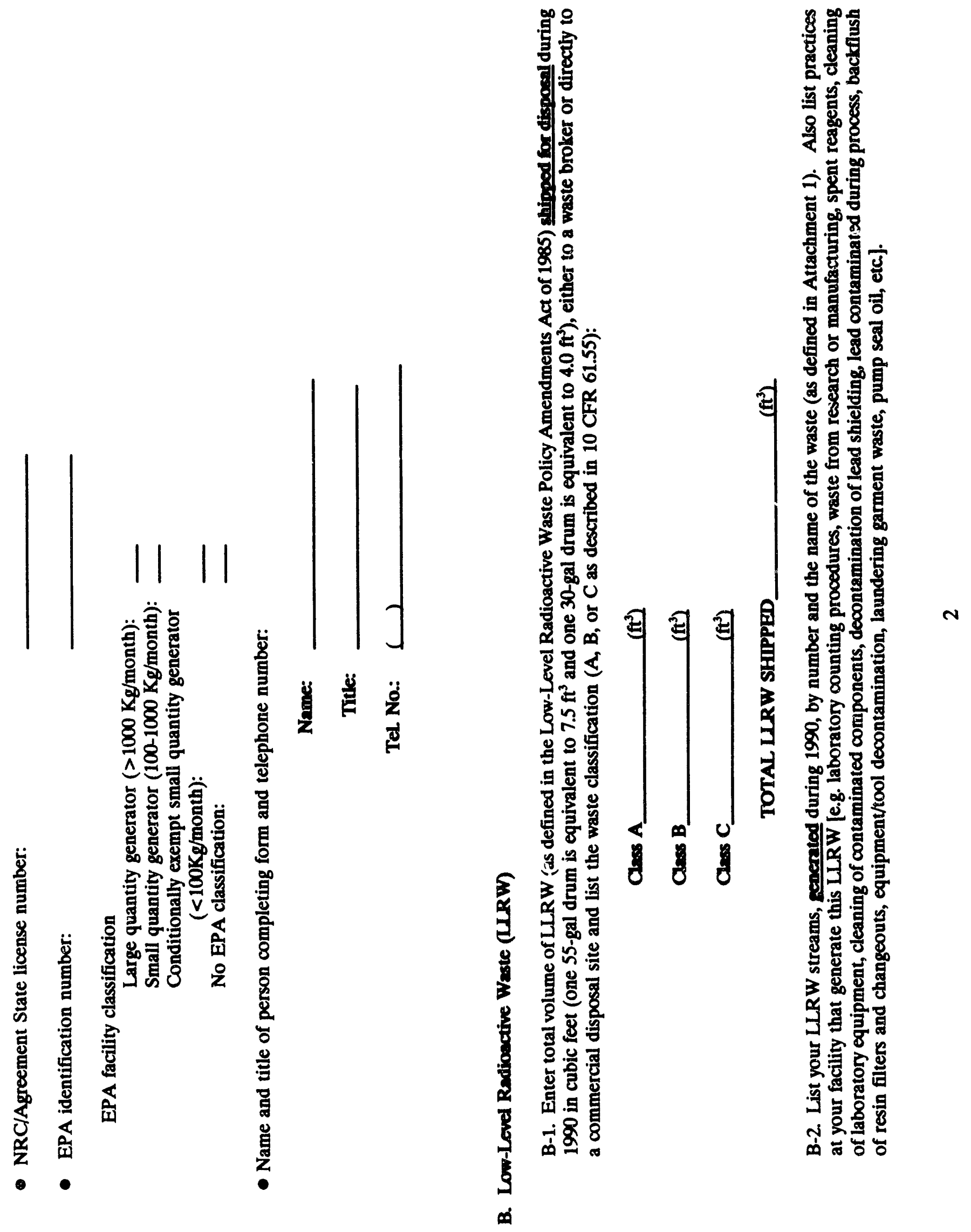




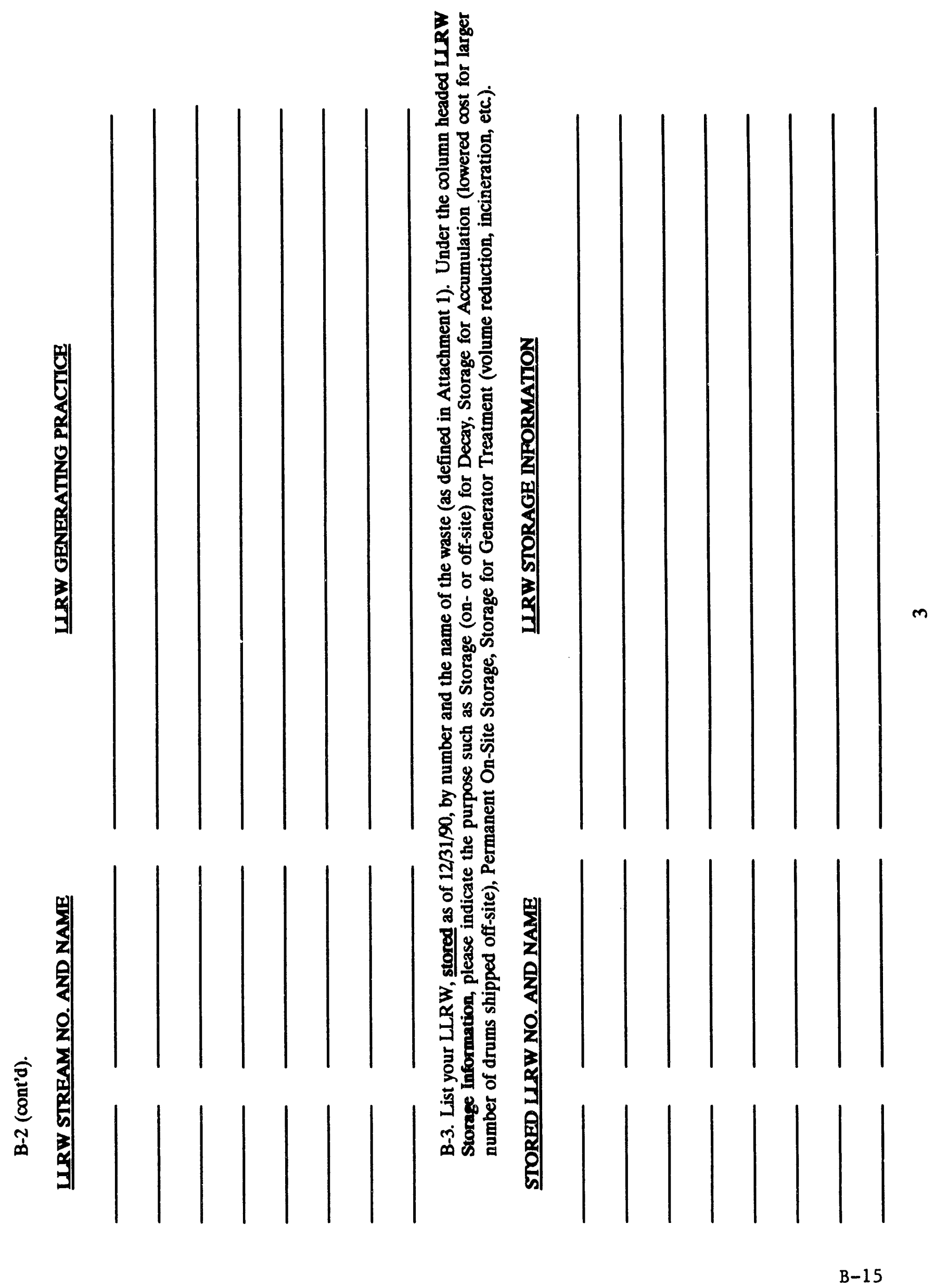




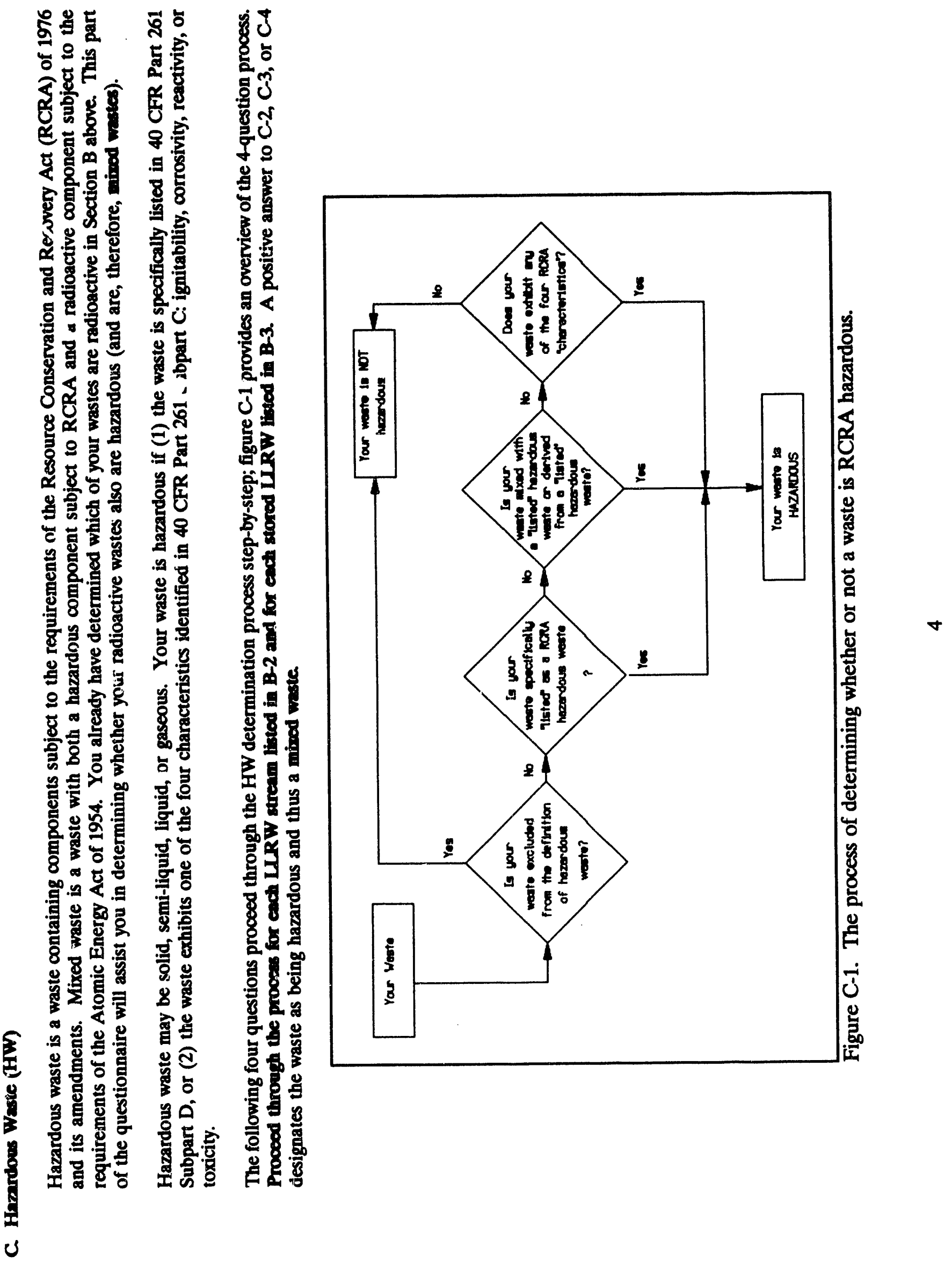




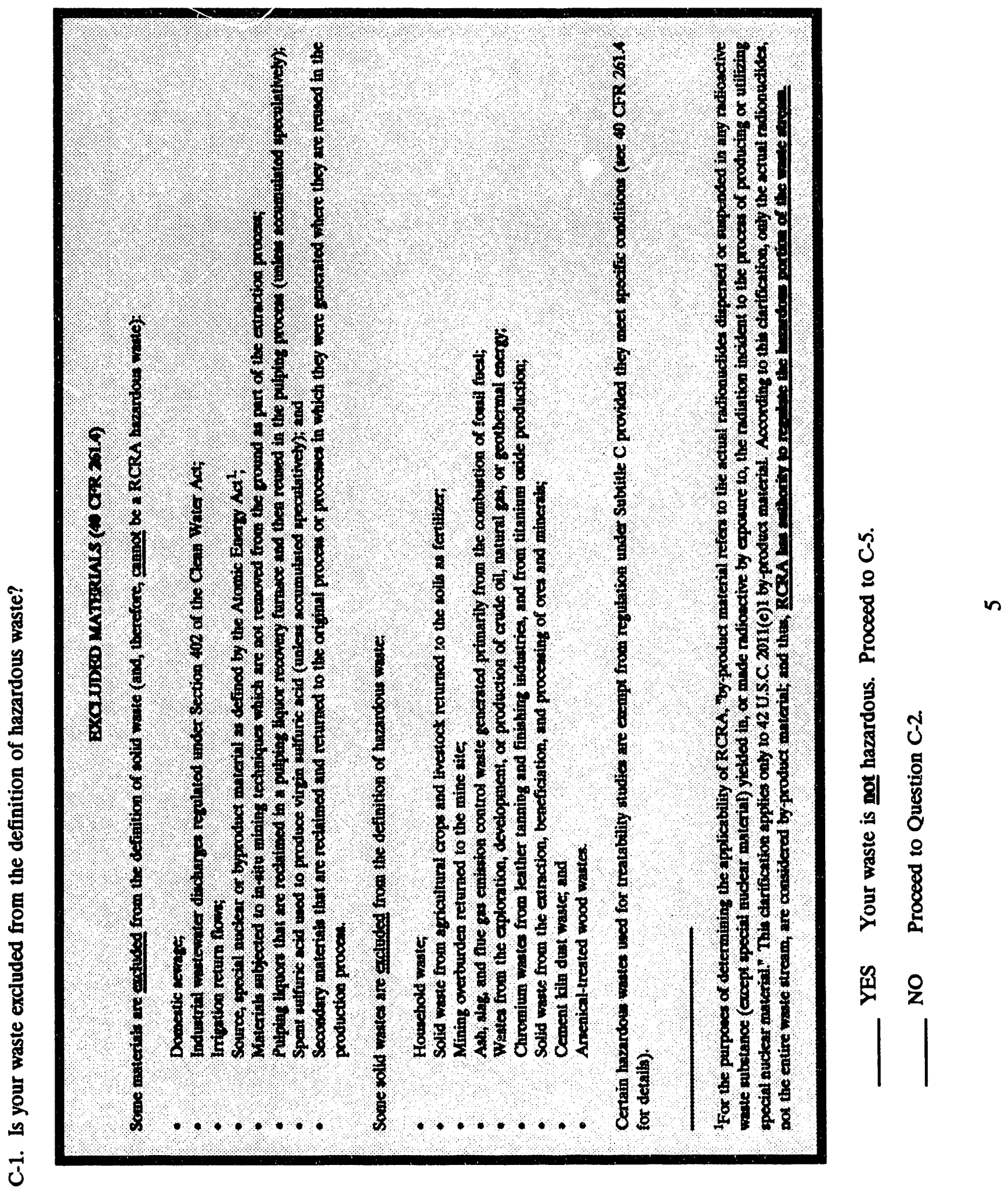




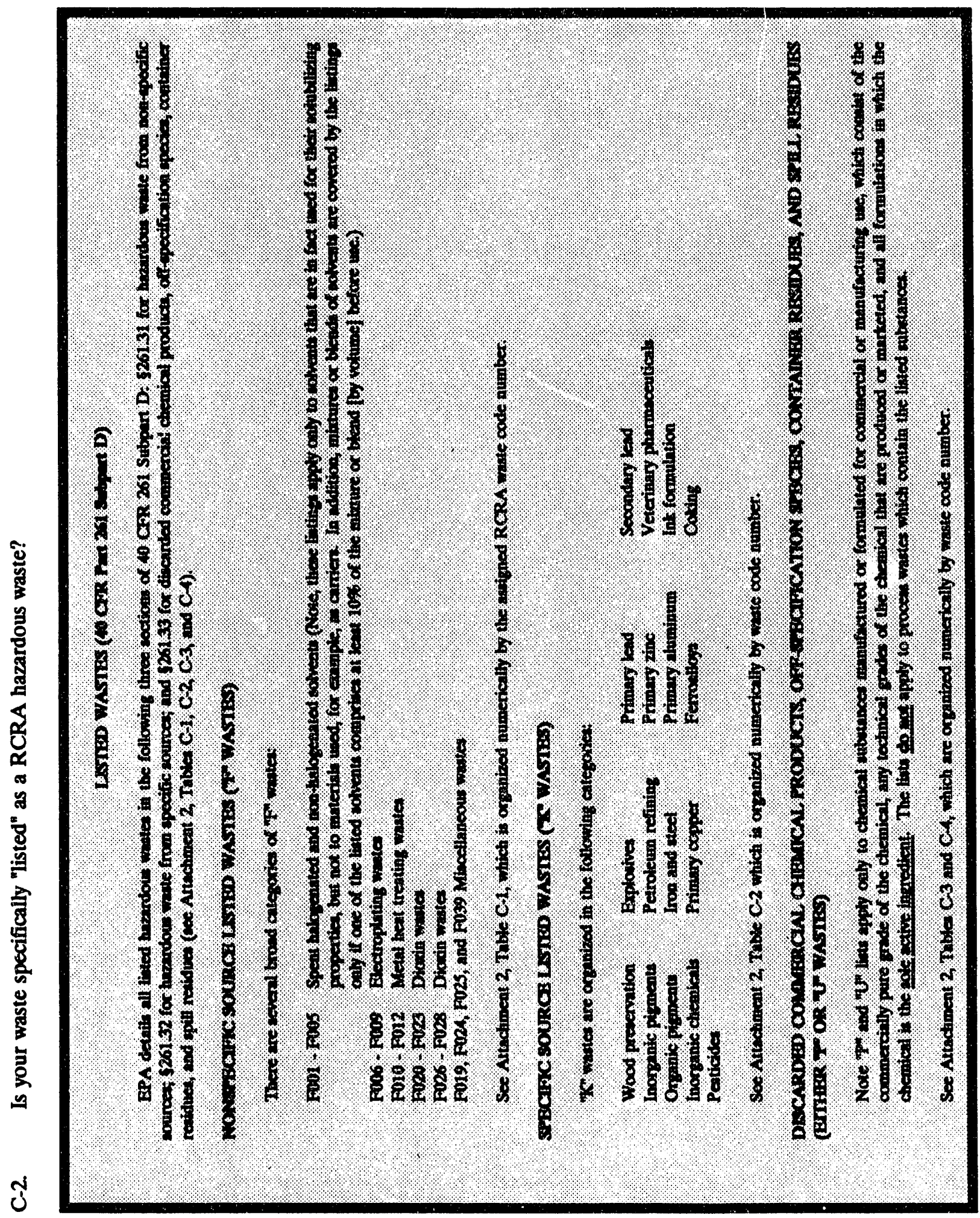




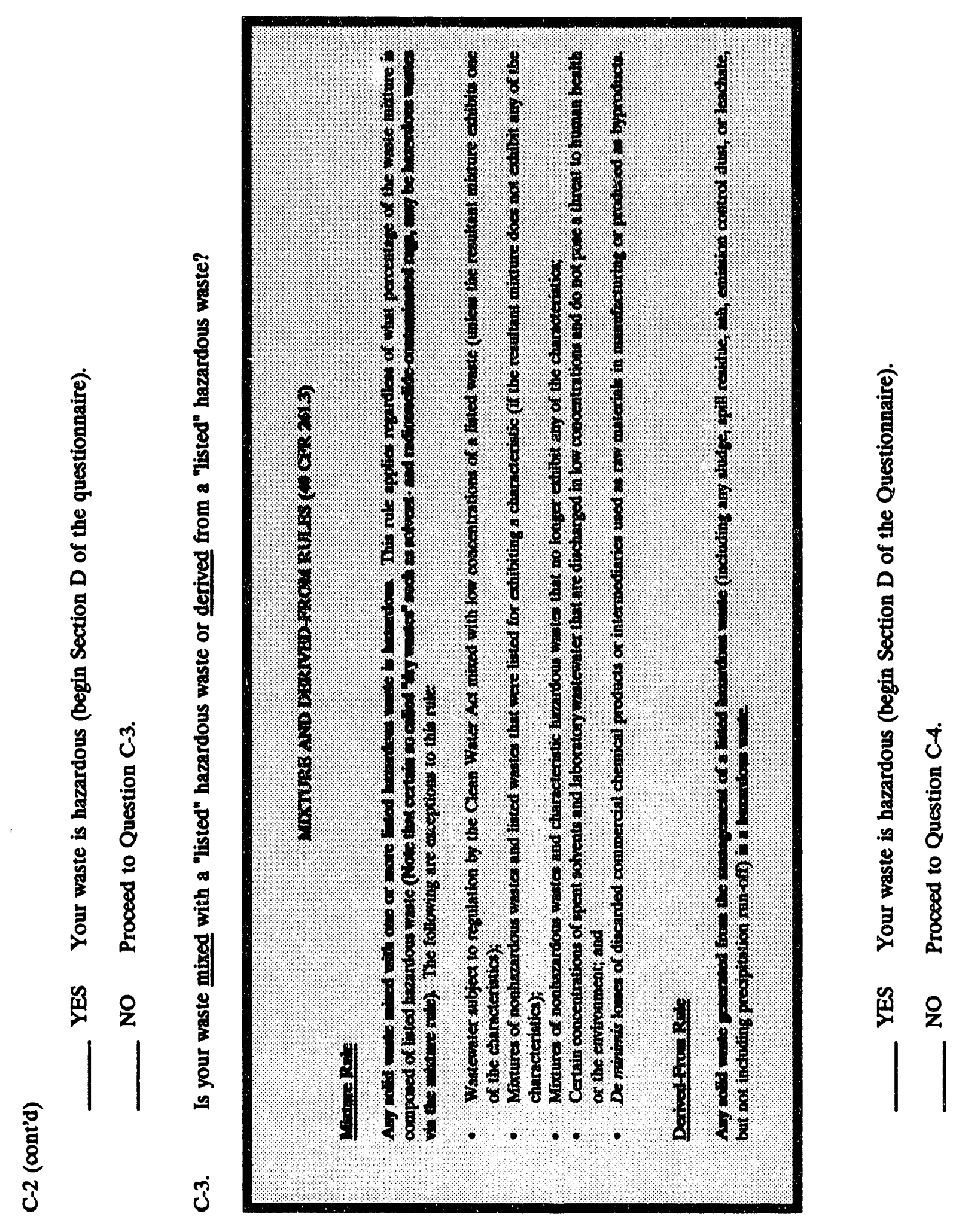




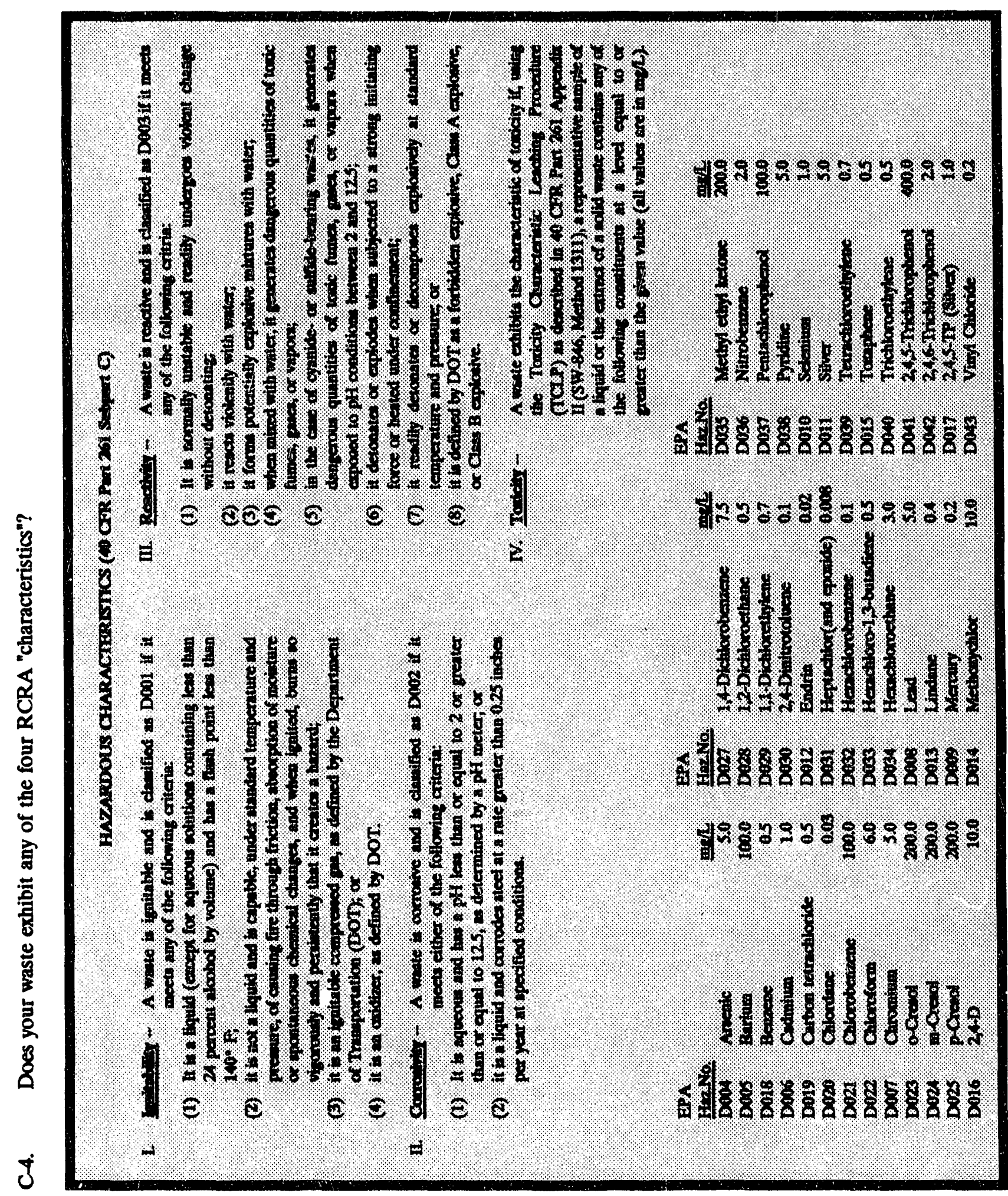


छृ

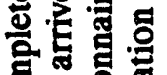

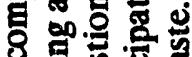

8 .

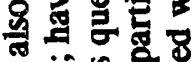

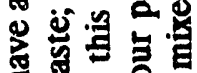

고요용

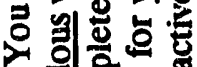

읠용

곽 8 융

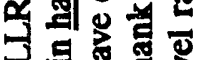

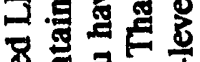

호음

8 용응

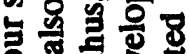

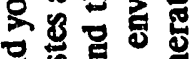

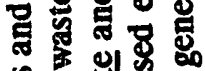

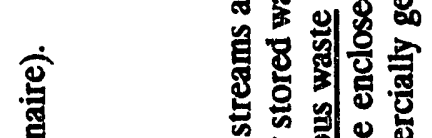

3 의월

뜬

컹 되융

논

当

ㅇํ용

ค 9 ช

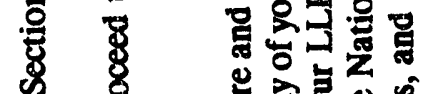

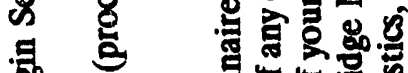

舟

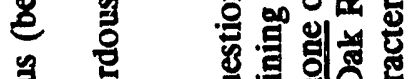

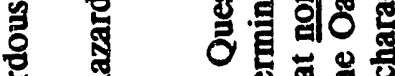

고

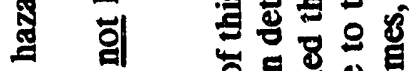

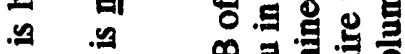

ษ

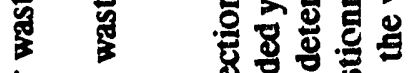

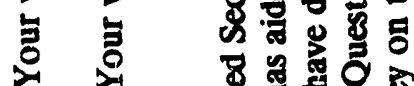

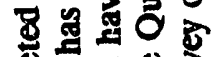

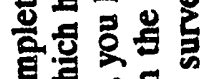

近

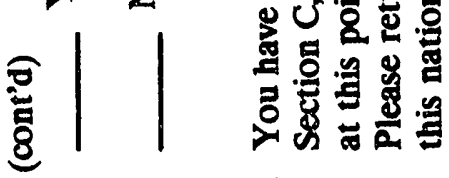

is

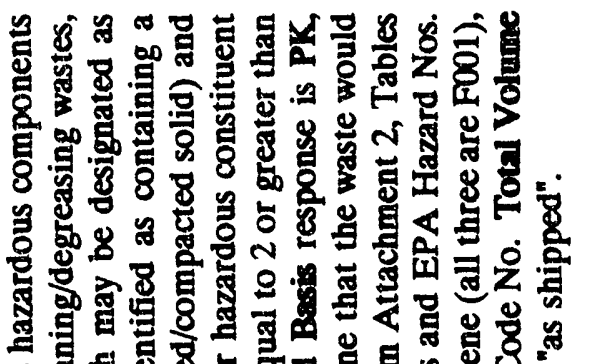

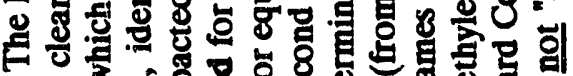

次

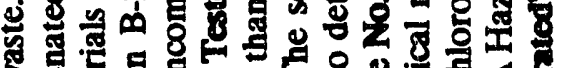

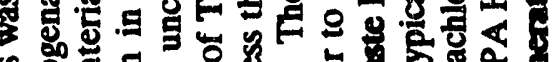

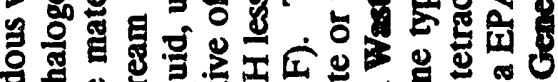

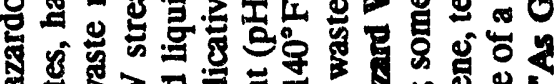

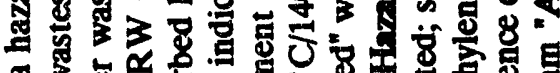

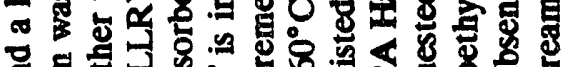

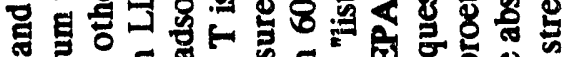

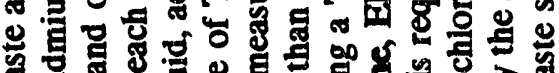

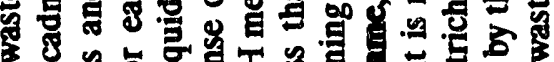

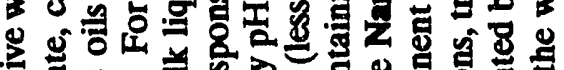

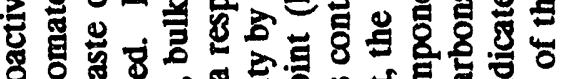

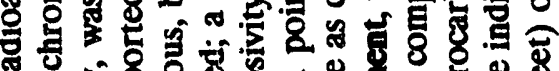

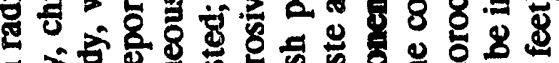

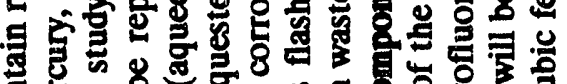

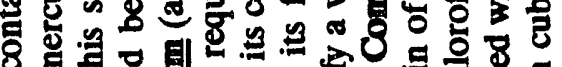

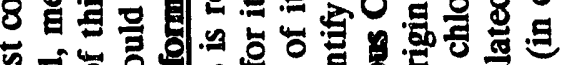

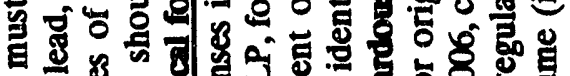

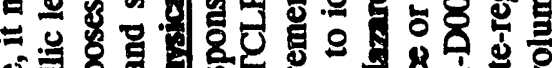

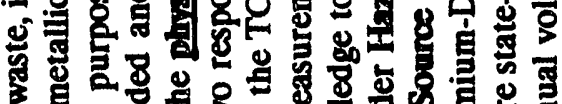

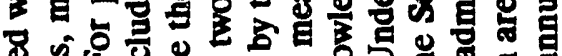

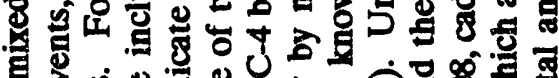

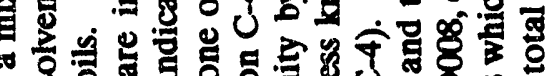
\%

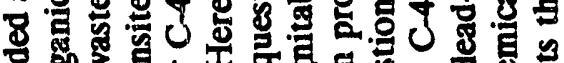

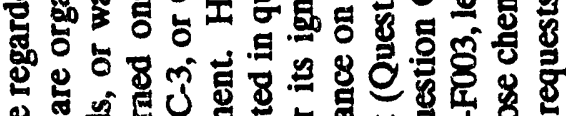

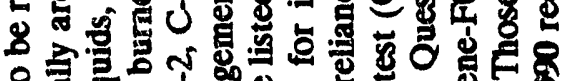

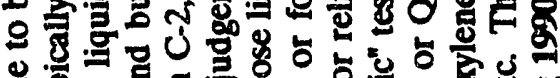

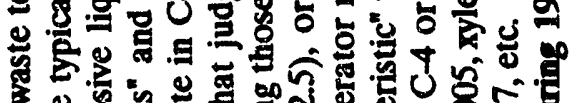

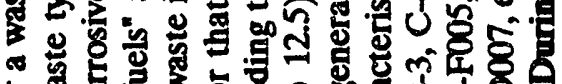

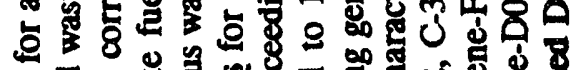

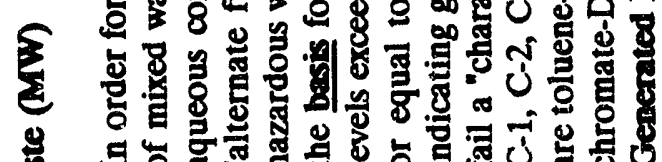

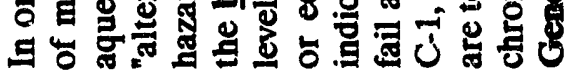
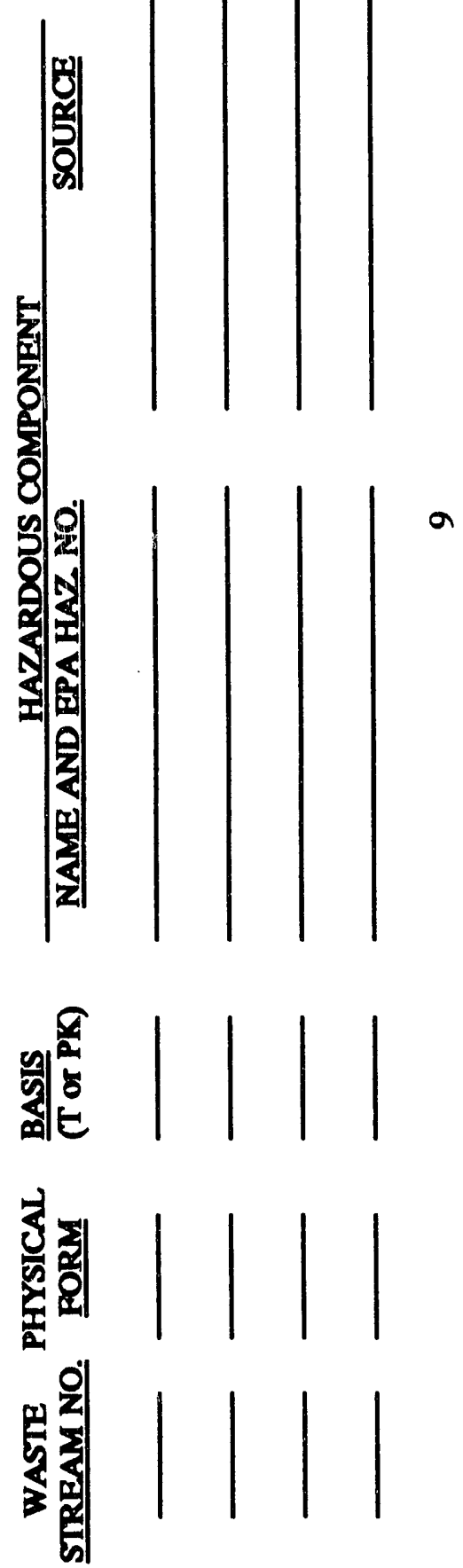


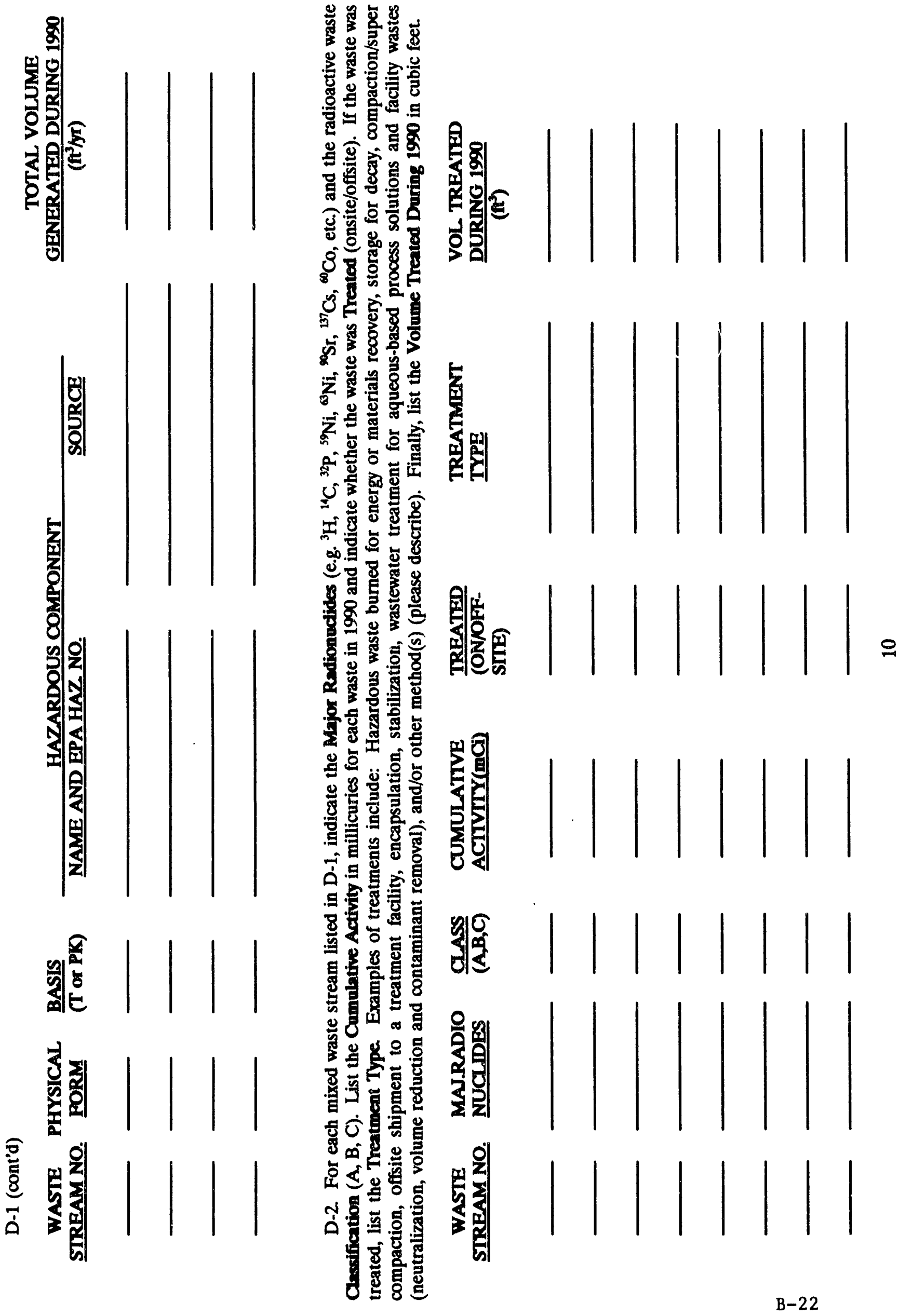




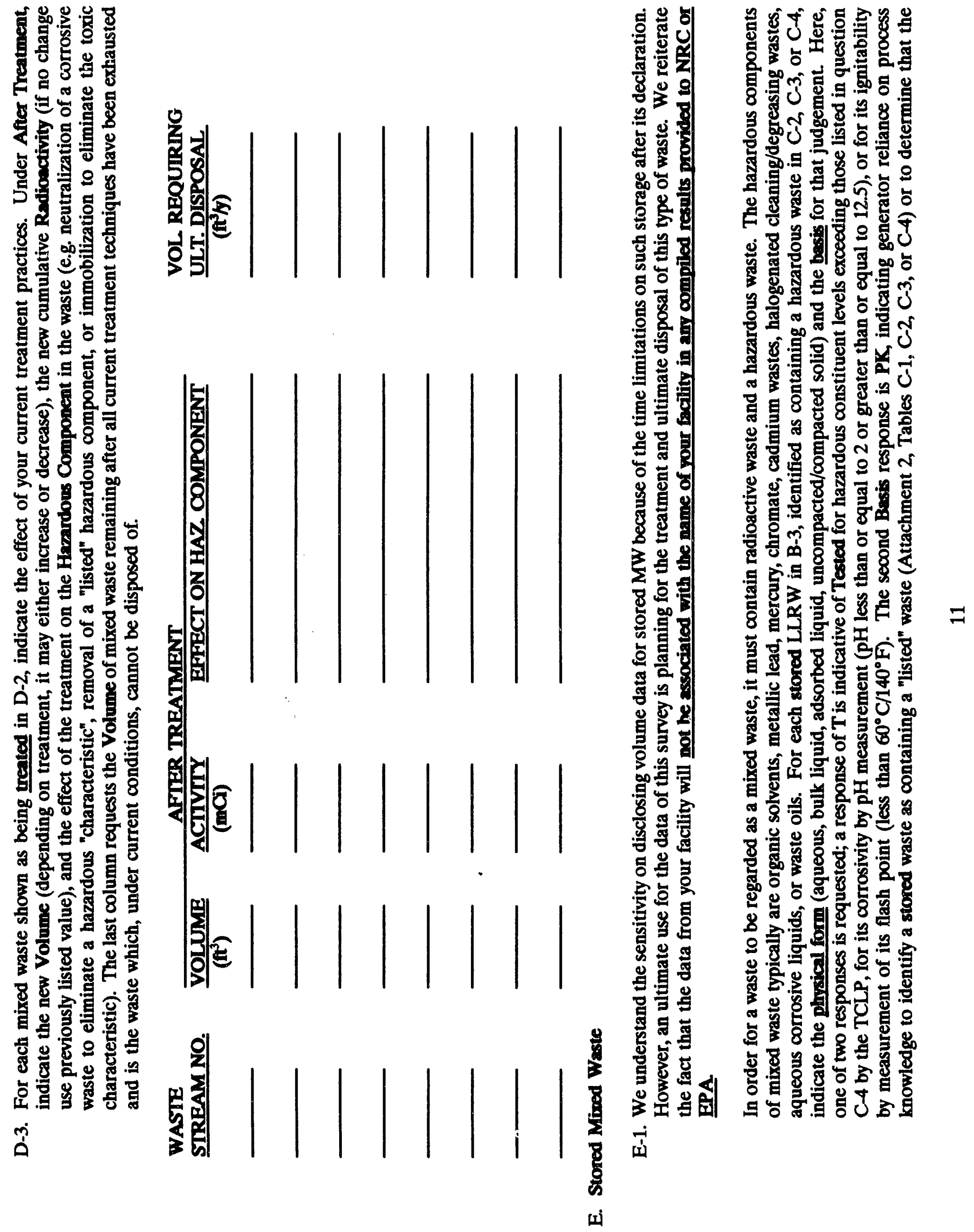




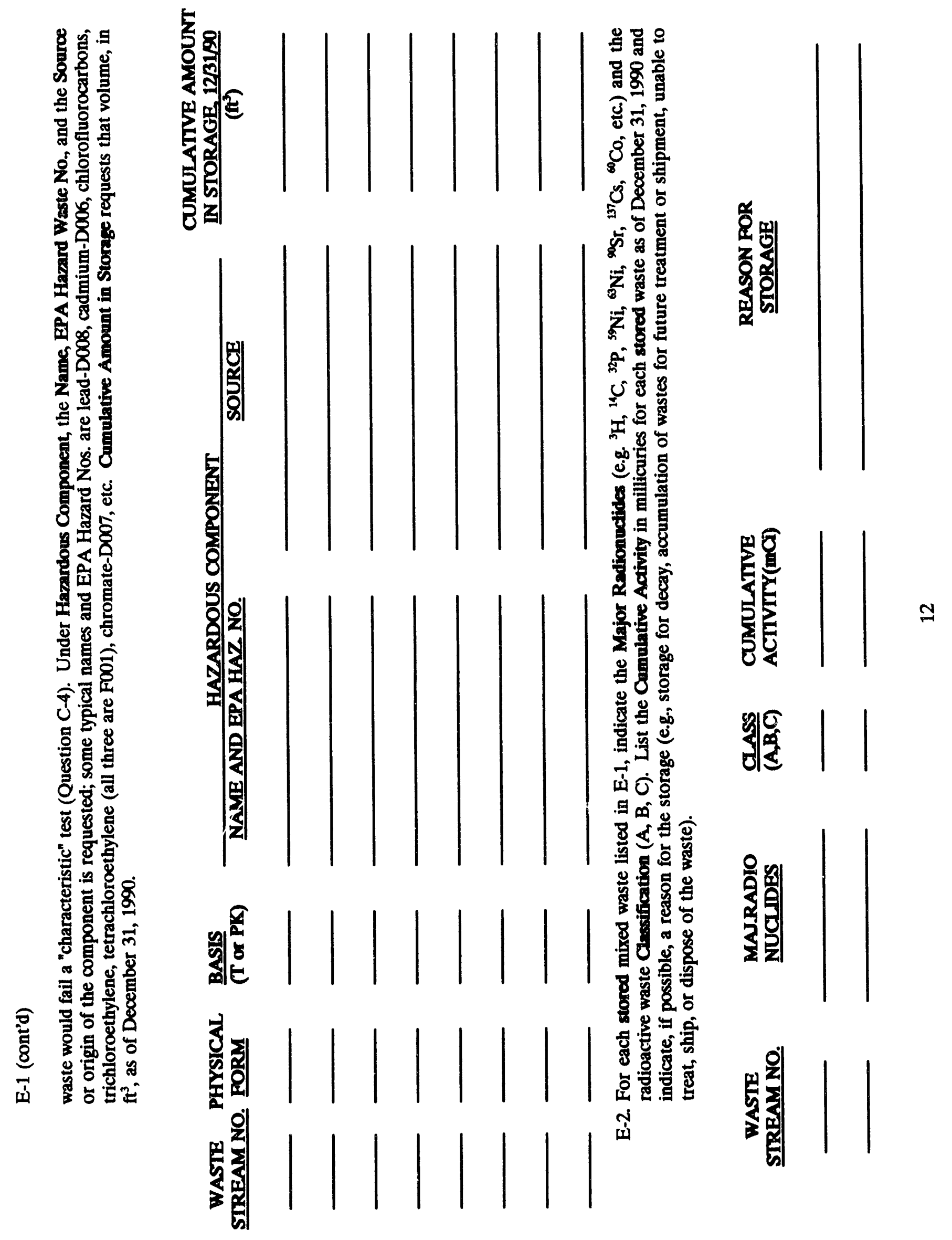




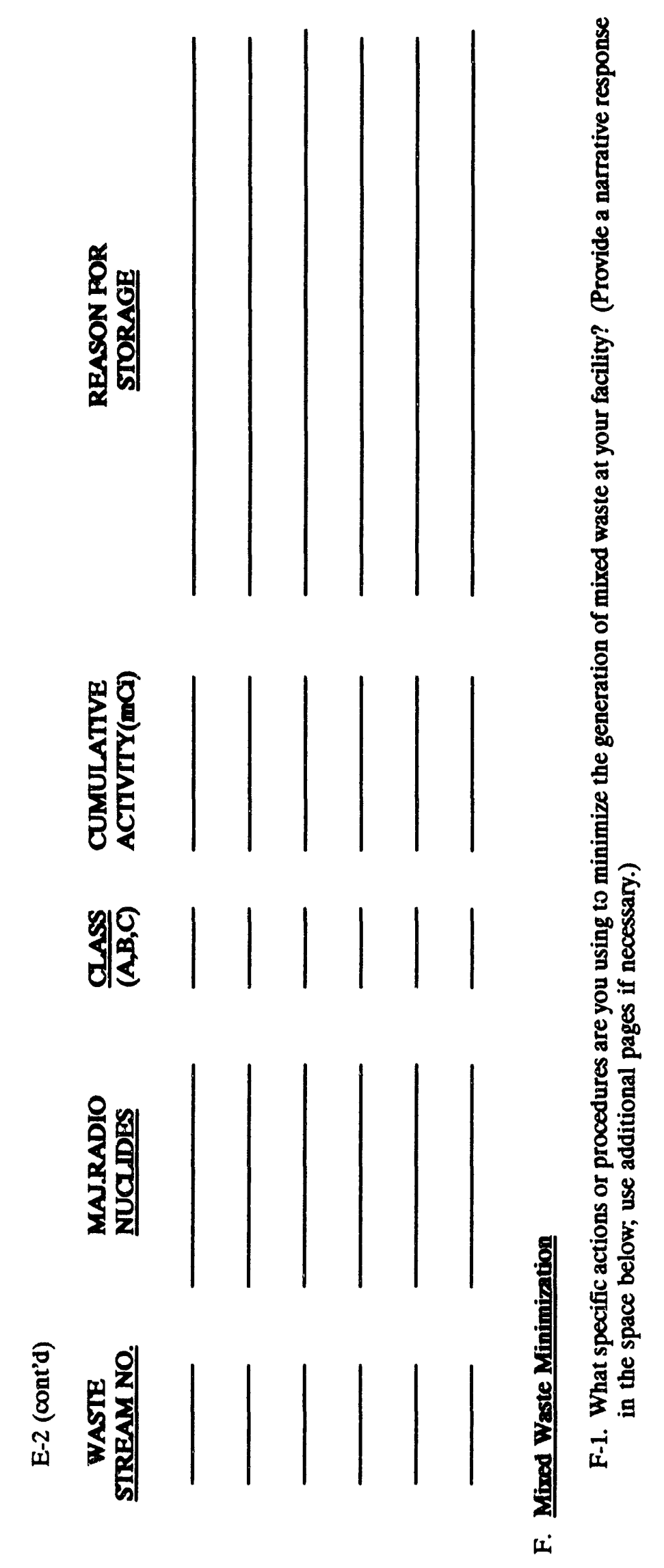




\section{ATTACHMENT 1}

Indicate your radioactive waste streams in Sections $B$ and $C$ and the Tables of Sections D and E by entering their code numbers from the following list. Enter a 3-digit number for those categories which are not subcategorized, but enter a 4-digit number for a waste stream identity which is sub-categorized, e.g. lead blankets would be identified as 2231 (sub-category 1 under lead). Any of the other Waste Stream Numbers which are not subcategorized may be augmented to indicate the presence of a hazardous "characteristic" in that waste by the addition of a 4th digit as follows: 1 - indicating flammable; 2 - indicating reactive; 3 - indicating corrosive; and 4 - indicating toxic (e.g. 2173 would indicate a corrosive mineral extraction waste).

\section{Weste Stream}

No.

201

202

203

204

205

206

207

208

209

210

211

212

213

214

215

216

217

218

219

220

221

222

223

\section{Waste Stream Name}

Biological Waste (Non-infectious)

1. Animal carcasses containing ${ }^{14} \mathrm{C}$ and or tritium

2. Animal carcasses containing radioisotopes other than ${ }^{14} \mathrm{C}$ or tritium

3. Other biological waste

Trash and or Solid Waste (not lead) - non-compacted

Trash and or Solid Waste (not lead) - compacted

Filter Media - Dewatered

Filter Media - Solidified

Filters, Mechanical

Gaseous Sources

Incinerator Ash or Residuals

Ion Exchange Resins - Dewatered

Ion Exchange Resins - Solidified

Irradiated Reactor or Pool Components

Liquids Aqueous - Absorbed

Liquids Aqueous - Solidified

Liquids Organic - (Solvents, Chlorinated Solvents, etc.)

Liquids Scintillation, containing ${ }^{14} \mathrm{C}$ and/or tritium - (fluids or vials) ${ }^{1}$

Liquids Scintillation, containing radioisotopes other than ${ }^{14} \mathrm{C}$ and tritium - (fluids or vials)

Mineral Extraction Waste

Uranium Sludges

Radioactive Sealed Sources, Devices, or Gauges

Solidified Evaporator Bottoms/Concentrates/Sump Sludge

Vitrified Ash or Resins

Waste Oils (Seal Oils from pumps for example)

1. Solvent-contaminated waste oil

2. Waste oil free from solvent contamination

Lead-Containing Waste

1. Blankets

2. Sheeting

3. Shielding

4. Batteries

5. Aqueous liquids

6. Organic liquids

7. Lead-contaminated equipment

8. Lead-contaminated trash

9. Other

${ }^{1}$ Scintillation cocktails that contain 0.05 microcuries/g of medium or less of ${ }^{3} \mathrm{H}$ or ${ }^{14} \mathrm{C}$ destined for incineration or disposal shall still be counted as mixed waste for purposes of this survey. 
Waste Stream

No.

224

225

226

\section{Waste Stream Name}

Mercury-Containing Waste

1. Elemental mercury

2. Hydraulic oil

3. Solids

4. Liquids

5. Other

Paint

1. Water-based

2. Oil-based

3. Epoxy-based

4. Lead-based

Other - (Specify) 


\section{ATTACHMENT 2}

Table C-1. Hazardous wastes from non-specific sources*

Industry and EPA

bazardous waste No.
Hazardous waste
Generic:

F001

F002

F003

F004

F005

F006

F007

F008
The following spent halogenated solvents used in degreasing: Tetrachloroethylene, trichloroethylene, methylene chloride, 1,1,1-trichloroethane, carbon tetrachloride, and chlorinated fluorocarbons; all spent solvent mixtures/blends used in degreasing containing, before use, a total of ten percent or more (by volume) of one or more of the above halogenated solvents or those solvents listed in F0O2, F004, and FOO5; and still bottoms from the recovery of these spent soivents and spent solvent mixtures.

The following spent halogenated solvents: Tetrachloroethylene, methylene chloride, trichloroethylene, 1,1,1-trichlofoethane, chlorobenzene, 1,1,2-trichloro-1,2,2trifluoroethance, ortho-dichlorobenzene, trichlorofluoromethane, and 1,1,2trichloroethane; all spent solvent mixtures/blends containing, before use, a total of ten percent or more (by volume) of one or more of the above halogenated solvents or those listed in FOO1, FOO4, or FOOS; and still bottoms from the recovery of these spent solvents and spent solvent mixtures.

The following spent non-halogenated solvents: Xylene, acetone, ethyl acetate, ethyl benzene, ethyl ether, methyl isobutyl ketone, n-butyl alcohol, cycloheranone, and methanol; all spent solvent mixtures/blends containing, before use, only the above spent non-halogenated solvents; and all spent solvent mixtures/blends containing, before use, one or more of the above non-halogenated solvents and a total of ten percent or more (by volume) of one or more of those solvents listed in F001, FOO2, FOO4, and F0O5; and still bottoms from the recovery of these spent solvents and spent solvent mixtures.

The following spent non-halogenated solvents: Cresols and cresylic acid, and nitrobenzene; all spent solvent mixtures/blends containing, before use, a total of ten percent or more (by volume) of one or more of the above non-halogenated solvents or those solvents listed in FOO1, FOO2, and FOO5; and still bottoms from the recovery of these spent sotvents and spent solvent mixtures.

The following spent non-halogenated solvents: Toluene, methyl ethyl ketone, carbon disulfide, isobutanol, pyridine, benzene, 2-ethoyethanol, and 2-nitropropane; all spent sotvent mixtures/blends containing, before use, a total of ten percent or more (by volume) of one or more of the above non-halogenated solvents or those solvents listed in FOO1, FOO2, or FOO4; and still bottoms from the recovery of these spent soivents and spent solvent mixtures.

Wastewater treatment sludges from electroplating operations except from the following processes: (1) Sulfuric acid anodizing of aluminum; (2) tin plating on carbon steel; (3) zinc plating (segregated basis) on carbon steel; (4) aluminum or zinc-aluminum plating on carbon steel; (5) cleaning/stripping associated with tin, zinc, and aluminum plating on carbon steel; and (6) chemical etching and milling of aluminum.

Spent cyanide plating bath solutions from electroplating operations.

Plating bath residues from the bottom of plating baths from electroplating operations where cyanides are used in the process. 
Table C-1. (continued)

Industry and EPA

hazardous waste No.
Hazardous waste
F009

F010

F011

F012

F019

F020

F021

F022

F023

F024

F025
Spent stripping and cleaning bath solutions from electroplating operations where cyanides are used in the process.

Quenching bath residues from oil baths from metal heat treating operations where cyanides are used in the process.

Spent cyanide solutions from salt bath pot cleaning from metal heat treating operations.

Quenching wastewater treatment sludges from metal heat treating operations where cyanides are used in the process.

Wastewater treatment sludges from the chemical conversion coating of aluminum except from zirconium phosphating in aluminum can washing when such phosphating is an exclusive conversion coating process.

Wastes (except wastewater and spent carbon from hydrogen chloride purification) from the production or manufacturing use (as a reactant, chemical intermediate, or component in a formulating process) of tri- or tetrachlorophend, or of intermediates used to produce their pesticide derivatives. (This listing does not include wastes from the production of Hexachlorophene from highly purified 2,4,5-trichlorophenol.)

Wastes (except wastewater and spent carbon from hydrogen chloride purification) from the production or manufacturing use (as a reactant, chemical intermediate, or component in a formulating process) of pentachlorophenol, or of intermediates used to produce its derivatives.

Wastes (except wastewater and spent carbon from hydrogen chloride purification) from the manufacturing use (as a reactant, chemical intermediate, or component in a formulating process) of tetra-, penta-, or hexachlorobenzenes under alkaline conditions.

Wastes (except wastewater and spent carbon from bydrogen chloride purification) from the production of materials on equipment previousty used for the production or manufacturing use (as reactant, chemical intermediate, or component in a formulating process) of tri- and tetrachlorophenos. (This listing does not include wastes from equipment used onty for the production or use of Hexachlorophene from highly purified 2,4,5-trichlorophenol.)

Process wastes, including but not limited to, distillation residues, beavy ends, tars, and reactor clean-out wastes, from the production of certain chlorinated aliphatic hydrocarbons by free radical catalyzed processes. These chlorinated aliphatic hydrocarbons are those having carbon chain lengths ranging from one to and including five, with varying amounts and positions of chlorine substitution. (This listing does not include wastewaters, wastewater treatment sludges, spent catalysts, and wastes listed in $\$ 261.31$ or $\$ 261.32$.)

Condensed light ends, spent filters and filter aids, and spent desiccant wastes from the production of certain chlorinated aliphatic mydrocarbons, by free radical catalyzed processes. These chlorinated aliphatic hydrocarbons are those having carbon chain lengths ranging from one to and including five, with varying amounts and positions of chlorine substitution. 
Table C-1. (continued)

Industry and EPA

hazardous waste No.
Hazardous waste
F026

F027

F028

F039
Wastes (except wastewater and spent carbon from hydrogen chloride purification) from the production of materials on equipment previously used for the manufacturing use (as a reactant, chemical intermediate, or component in a formulating process) of tetra-, penta-, or hesachlorobenzene under alkaline conditions.

Discarded unused formulations containing tri-, tetra, or pentachlorophenol or discarded unused formulations containing compounds derived from these chlorophenols. (This listing does not include formulations containing Hexachlorophene synthesized from prepuritied 2,4,5-trichlorophenol as the sole component.)

Residues resulting from the incineration or thermal treatment of soil contaminated with EPA Hazardous Waste Nos. FO20, FO21, FO22, FO23, FO26, and FO27.

Leachate resulting from the treatment, storage, or disposal of wastes classified by more than one waste code under Subpart D, or from a mixture of wastes classified under Subparts C and D of this part. [Leachate resulting from the management of ore or more of the following EPA Hazardous Wastes and no other hazaróous wastes retains its hazardous waste code(s): FO20, F021, FO22, FO23, FO26, F027, and/or F028.]

*From 40 CFR 261.31. 
Table C-2. Hazardous wastes from specific sources*

Industry and EPA hazardous waste No.

Hazardous waste

Wood preservation:

K001

Bottom sediment sludge from the treatment of wastewaters from wood preserving processes that use creosote and/or pentachlorophenol.

Inorganic pigments:

K002

K003

K004

Wastewater treatment sludge from the production of chrome yellow and orange pigments.

K005

Wastewater treatment sludge from the production of molybdate orange pigments.

Wastewater treatment sludge from the production of zinc yellow pigments.

Wastewater treatment sludge from the production of chrome green pigments.

K006

K007

K008

Wastewater treatment sludge from the production of chrome coide green pigments (anhydrous and hydrated).

Wastewater treatment sludge from the production of iron blue pigments.

Oven residue from the production of chrome oxide green pigments.

Organic chemicals:

K009

Distillation bottoms from the production of acetaldehyde from ethylene.

K010

Distillation side cuts from the production of acetaldehyde from ethylene.

K011

Bottom stream from the wastewater stripper in the production of acrylonitrile.

K013

Bottom stream from the acetonitrile column in the production of acrylonitrile.

K014

Bottoms from the acetonitrile purification column in the production of acrylonitrile.

K015

Still bottoms from the distillation of benzyl chloride.

K016

Heavy ends or distillation residues from the production of carbon tetrachloride.

K017

K018

Heavy ends (still bottoms) from the purification column in the production of epichlorohydrin.

K019

K020

K021

Heavy ends from the fractionation column in ethyl chloride production.

Heavy ends from the distillation of ethylene dichloride in ethylene dichloride production.

Heavy ends from the distillation of vinyl chloride in vinyl chloride monomer production.

Aqueous spent antimony catalyst waste from fluoromethanes production.

K022

Distillation bottom tars from the production of phenol/acetone from cumene. 
Table C-2. (continued)

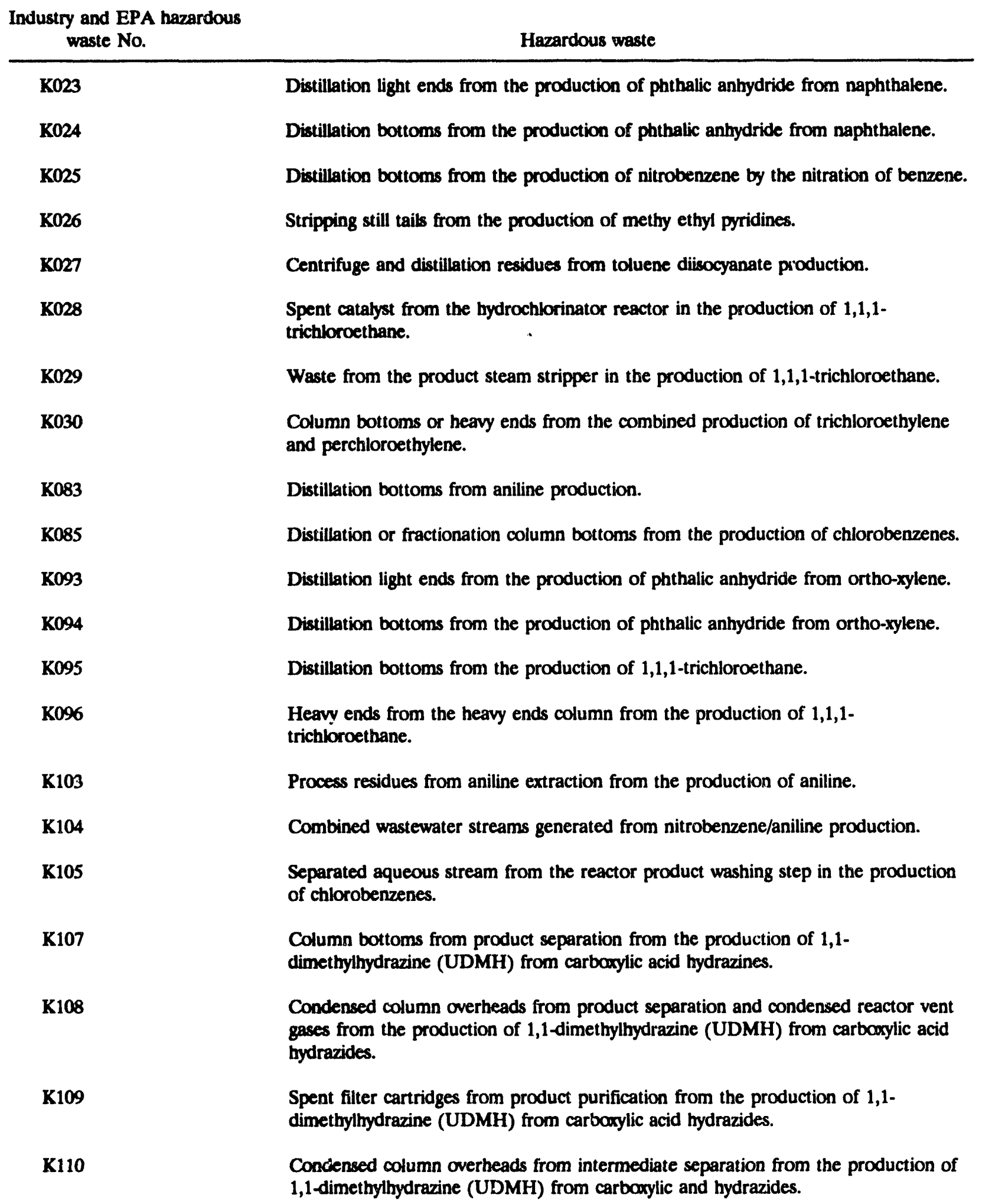


Table C-2. (continued)

Industry and EPA hazardous waste No.

Hazardous waste

K111

K112

K113

K114

K115

K116

K117

K118

K136

Inorganic chemicals:

K071

K073

K106

Pesticides:

K031

K032

K033

K034

K035
Product washwaters from the production of dinitrotoluene via nitration of toluene.

Reaction by-product water from the drying column in the production of toluenediamine via hydrogenation of dinitrotoluene.

Condensed liquid light ends from the purification of toluenediamine in the production of toluenediamine via hydrogenation of dinitrotoluene.

Vicinals from the purification of toluenediamine in the production of toluenediamine via hydrogenation of dinitrotoluene.

Heavy ends from the purification of toluenediamine in the production of toluenediamine via hydrogenation of dinitrotoluene.

Organic condensate from the solvent recovery column in the production of toluene diisocyanate via phosgenation of toluenediamine.

Wastewater from the reactor vent gas scrubber in the production of ethylene dibromide via bromination of ethene.

Spent adsorbent solids from purification of ethylene dibromide in the production of ethylene dibromide via bromination of ethene.

Still bottoms from the purification of ethylene dibromide in the production of ethylene dibromide via bromination of ethene.

Brine purification muds from the mercury cell process in chlorine production, where separately prepurified brine is not used.

Chlorinated hydrocarbon waste from the purification step of the diaphragm cell process using graphite anodes in chlorine production.

Wastewater treatment sludge from the mercury cell process in chlorine production.

By-product salts generated in the production of MSMA and cacodylic acid.

Wastewater treatment sludge from the production of chlordane.

Wastewater and scrub water from the chlorination of cyclopentadiene in the production of chlordane.

Filter solids from the filtration of hexachlorocyclopentadiene in the production of chlordane.

Wastewater treatment sludges generated in the production of creosote. 
Table C-2. (continued)

Industry and EPA hazardous waste No.

Hazardous waste

K036

K037

K038

K039

K040

K041

K042

K043

K097

K098

K099

K123

K124

K125

K126

K131

K132

Explosives:

K044

K045

K046
Still bottoms from toluene reclamation distillation in the production of disulfoton.

Wastewater treatment sludges from the production of disulfoton.

Wastewater from the washing and stripping of phorate production.

Filter cake from the filtration of diethylphosphorodithioic acid in the production of phorate.

Wastewater treatment sludge from the production of phorate.

Wastewater treatment sludge from the production of toxaphene.

Heavy ends or distillation residues from the distillation of tetrachlorobenzene in the production of 2,4,5-T.

2,6-Dichlorophenol waste from the production of 2,4-D.

Vacuum stripper discharge from the chlordane chlorinator in the production of chlordane.

Untreated process wastewater from the production of toxaphene.

Untreated wastewater from the production of 2,4-D.

Process wastewater (including supernates, filtrates, and washwaters) from the production of ethylenebisdithiocarbamic acid and its salts.

Reactor vent scrubber water from the production of ethylenebisdithiocarbamic acid and its salts.

Filtration, evaporation, and centrifugation solids from the production of ethylenebisdithiocarbamic acid and its salts.

Baghouse dust and floor sweepings in milling and packaging operations from the production or formulation of ethylenebisdithiocarbamic acid and its salts.

Wastewater from the reactor and spent sulfuric acid from the acid dryer from the production of methyl bromide.

Spent absorbent and wastewater separator solids from the production of methy! bromide.

Wastewater treatment sludges from the manufacturing and processing of explosives.

Spent carbon from the treatment of wastewater containing explosives.

Wastewater treatment sludges from the manufacturing, formulation and loading of lead-based initiating compounds. 
Table C-2. (continued)

Industry and EPA hazardous waste No.

Hazardous waste

$$
\text { K047 }
$$

Petroleum refining: K048

K049

K050

K051

K052

Iron and steel:

K061

K062

Primary copper: K064

Primary lead: K065

Primary zinc: K066

Primary aluminum: K088

Ferroalloys:

K090

K091

Secondary lead:

K069
Pink/red water from TNT operations.

Dissolved air flotation (DAF) float from the petroleum refining industry.

Slop oil emulsion solids from the petroleum refining industry.

Heat exchanger bundle cleaning sludge from the petroleum refining industry.

API separator sludge from the petroleum refining industry.

Tank bottoms (leaded) from the petroleum refining industry.

Emission control dust/sludge from the primary production of steel in electric furnaces.

Spent pickle liquor generated by steel finishing operations of facilities within the iron and steel industry (SIC Codes 331 and 332).

Acid plant blowdown slurry/sludge resulting from the thickening of blowdown slurry from primary copper production.

Surface impoundment solids contained in and dredged from surface impoundments at primary lead smelting facilities.

Sludge from treatment of process wastewater and/or acid plant blowdown from primary zinc production.

Spent potliners from primary aluminum reduction.

Emission control dust or sludge from ferrochromiumsilicon production.

Emission control dust or sludge from ferrochromium production.

Emission control dust/sludge from secondary lead smelting. 
Table C-2. (continued)

Industry and EPA hazardous waste No.

Hazardous waste

K100

Waste leaching solution from acid leaching of emission control dust/sludge from secondary lead smelting.

Veterinary pharmaceuticals: K084

Wastewater treatment sludges generated during the production of veterinary pharmaceuticals from arsenic or organo-arsenic compounds.

K101

Diatillation tar residues from the diatillation of aniline-based compounds in the production of veterinary pharmaceuticals from arsenic or organo-arsenic compounds.

K102 Residue from the use of activated carbon for decolorization in the production of veterinary pharmaceuticals from arsenic or organo-arsenic compounds.

Inix formulation:

K086

Solvent washes and sludges, caustic washes and sludges, or water washes and sludges from cleaning tubs and equipment used in the formulation of ink from pigments, driers, soaps, and stabilizers containing chromium and lead.

Coking:

K060

Ammonia still lime sludge from coking operations.

K087

Decanter tank tar sludge from coking operations.

"From 40 CFR 261.32. 
Table C-3. Discarded commercial chemical products*

(Acute hazardous wastes)

\begin{tabular}{|c|c|}
\hline $\begin{array}{l}\text { Hazardous } \\
\text { Waste No. }\end{array}$ & Substance \\
\hline $\mathrm{P} 023$ & Acetaldehyde, chloro- \\
\hline $\mathrm{POO2}$ & Acetamide, $\mathrm{N}$-(aminothicxomethyl)- \\
\hline P057 & Acetamide, 2-fluoro- \\
\hline P058 & Acetic acid, fluoro-, sodium salt \\
\hline POO2 & 1-Acetyl-2-thiourea \\
\hline $\mathrm{POO3}$ & Acrolein \\
\hline P070 & Aldicarb \\
\hline P004 & Aldrin \\
\hline P005 & Altyl alcohol \\
\hline P006 & Aluminum phosphide \\
\hline P007 & 5-(Aminomethyl)-3-iscoxazolol \\
\hline P008 & 4-Aminopyridine \\
\hline P009 & Ammonium picrate \\
\hline P119 & Ammonium vanadate \\
\hline P099 & Argentate(1-), bis(cyano-C)-, potassium \\
\hline P010 & Arsenic acid $\mathrm{H}_{3} \mathrm{AsO}_{4}$ \\
\hline P012 & Arsenic oxide $\mathrm{As}_{2} \mathrm{O}_{3}$ \\
\hline P011 & Arsenic oxide $\mathrm{As}_{2} \mathrm{O}_{5}$ \\
\hline P011 & Arsenic pentoxide \\
\hline P012 & Arsenic tricoride \\
\hline P038 & Arsine, diethyl- \\
\hline P036 & Arsonous dichloride, phenyl- \\
\hline P054 & Aziridine \\
\hline P067 & Aziridine, 2-methyl- \\
\hline P013 & Barium cyanide \\
\hline
\end{tabular}


Table C-3. (continued)

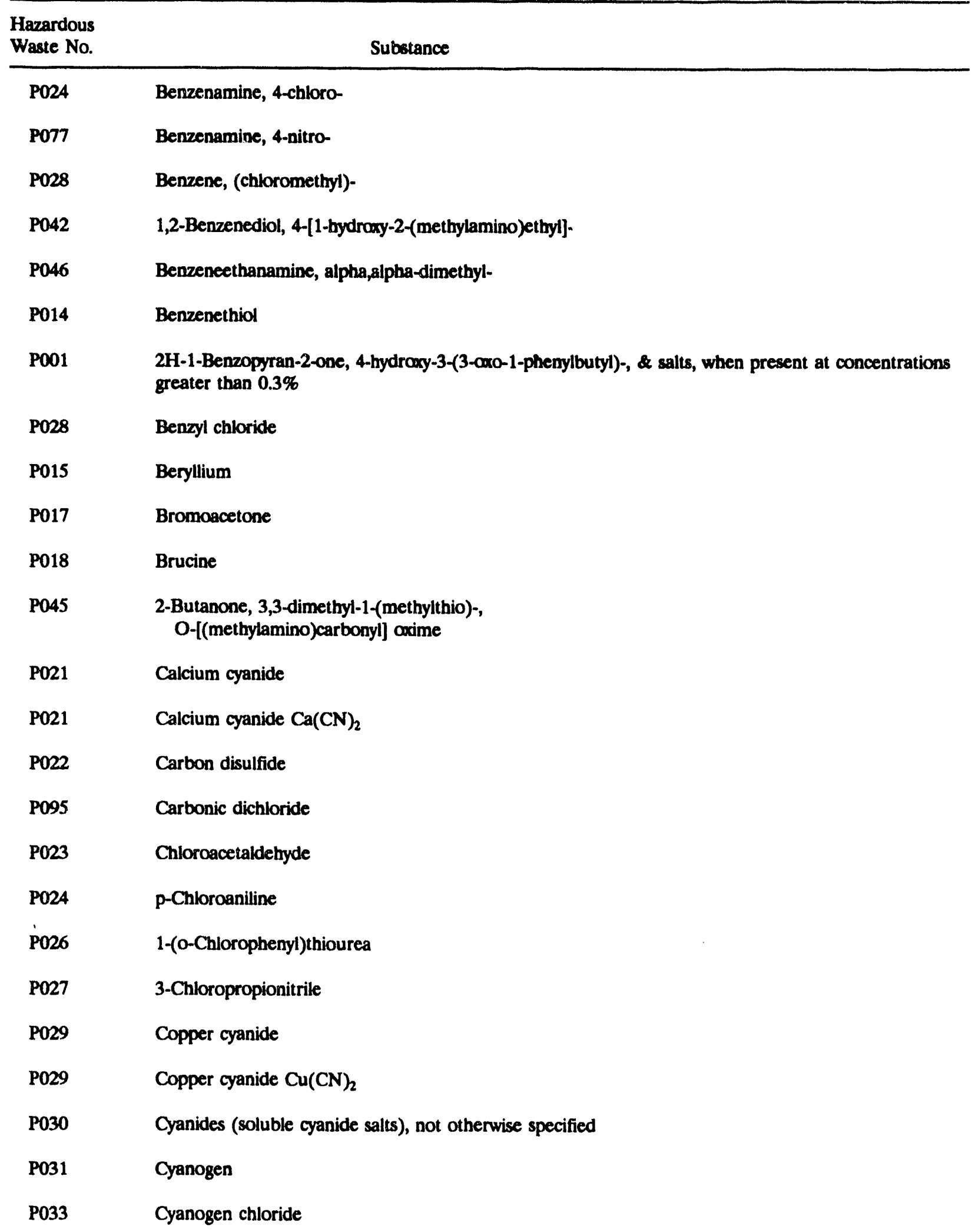


Table C-3. (continued)

\begin{tabular}{|c|c|}
\hline $\begin{array}{l}\text { Hazardous } \\
\text { Waste No. }\end{array}$ & Substance \\
\hline P033 & Cyanogen chloride $\mathrm{CNCl}$ \\
\hline P034 & 2-Cyclohexyl-4, 6-dinitrophenol \\
\hline P016 & Dichloromethyl ether \\
\hline P036 & Dichlorophenylarsine \\
\hline P037 & Dieldrin \\
\hline P038 & Diethylarsine \\
\hline P041 & Diethyl-p-nitrophenyl phosphate \\
\hline P040 & O,O-Diethyl O-pyrazinyl phosphorothioate \\
\hline $\mathbf{P 0 4 3}$ & Diisopropylfluorophosphate (DFP) \\
\hline P004 & $\begin{array}{l}\text { 1,4,5,8-Dimethanonaphthalene, 1,2,3,4,10,10-hexachloro-1,4,4a,5,8,8a-hexahydro-, } \\
\text { (1alpha,4alpha,4abeta,5alpha,8alpha,8abeta)- }\end{array}$ \\
\hline $\mathbf{P 0 6 0}$ & $\begin{array}{l}\text { 1,4,5,8-Dimethanonaphthalene, 1,2,3,4,10,10-hexachloro-1,4,4a,5,8,8a-hexahydro-, } \\
\text { (1alpha,4alpha,4abeta,5beta,8beta,8abeta)- }\end{array}$ \\
\hline P037 & $\begin{array}{l}\text { 2,7:3,6-Dimethanonaphth[2,3-b]oxirene, 3,4,5,6,9,9-hexachloro-1a,2,2a,3,6,6a,7,7a-octahydro-, } \\
\text { (1aalpha,2beta,2aalpha,3beta,6beta,6aalpha,7beta,7aalpha)- }\end{array}$ \\
\hline P051 & $\begin{array}{l}\text { 2,7:3,6-Dimethanonaphth[2,3-b]oxirene, 3,4,5,6,9,9-hexachloro-1a,2,2a,3,6,6a,7,7a-octahydro-, } \\
\text { (1aalpha,2beta,2abeta,3alpha,6alpha,6abeta,7beta,7aalpha)- \& metabolites }\end{array}$ \\
\hline $\mathbf{P 0 4 4}$ & Dimethoate \\
\hline P046 & alpha,alpha-Dimethylphenethylamine \\
\hline P047 & 4,6-Dinitro-0-cresol \& salts \\
\hline P048 & 2,4-Dinitrophenol \\
\hline $\mathbf{P 0 2 0}$ & Dinoseb \\
\hline P085 & Diphosphoramide, octamethyl- \\
\hline $\mathbf{P} 111$ & Diphosphoric acid, tetraethyl ester \\
\hline P039 & Disulfoton \\
\hline P049 & Dithiobiuret \\
\hline P050 & Endosulfan \\
\hline P088 & Endothall \\
\hline
\end{tabular}


Table C-3. (continued)

\begin{tabular}{|c|c|}
\hline $\begin{array}{l}\text { Hazardous } \\
\text { Waste No. }\end{array}$ & Substance \\
\hline P051 & Endrin \\
\hline P051 & Endrin \& metabolites \\
\hline P042 & Epinephrine \\
\hline P031 & Ethanedinitrile \\
\hline P066 & $\begin{array}{l}\text { Ethanimidothioic acid, } \\
\mathrm{N}-[[(\text { methylamino }) \text { carbonyl }] \text { oxy }]-, \text { methyl ester }\end{array}$ \\
\hline P101 & Ethyl cyanide \\
\hline P054 & Ethyleneimine \\
\hline P097 & Famphur \\
\hline P056 & Fluorine \\
\hline P057 & Fluoroacetamide \\
\hline P058 & Fluoroacetic acid, sodium salt \\
\hline PO65 & Fulminic acid, mercury $(2+)$ salt \\
\hline P059 & Heptachlor \\
\hline P062 & Hexaethyl tetraphosphate \\
\hline P116 & Hydrazinecarbothioamide \\
\hline P068 & Hydrazine, methyl- \\
\hline P063 & Hydrocyanic acid \\
\hline $\mathrm{P} 063$ & Hydrogen cyanide \\
\hline P096 & Hydrogen phosphide \\
\hline P060 & Isodrin \\
\hline P007 & $3(2 \mathrm{H})$-Isoxazolone, 5-(aminomethyl)- \\
\hline P092 & Mercury, (acetato-O)phenyl- \\
\hline P065 & Mercury fulminate \\
\hline P082 & Methanamine, N-methyl-N-nitroso- \\
\hline P064 & Methane, isocyanato- \\
\hline
\end{tabular}


Table C-3. (continued)

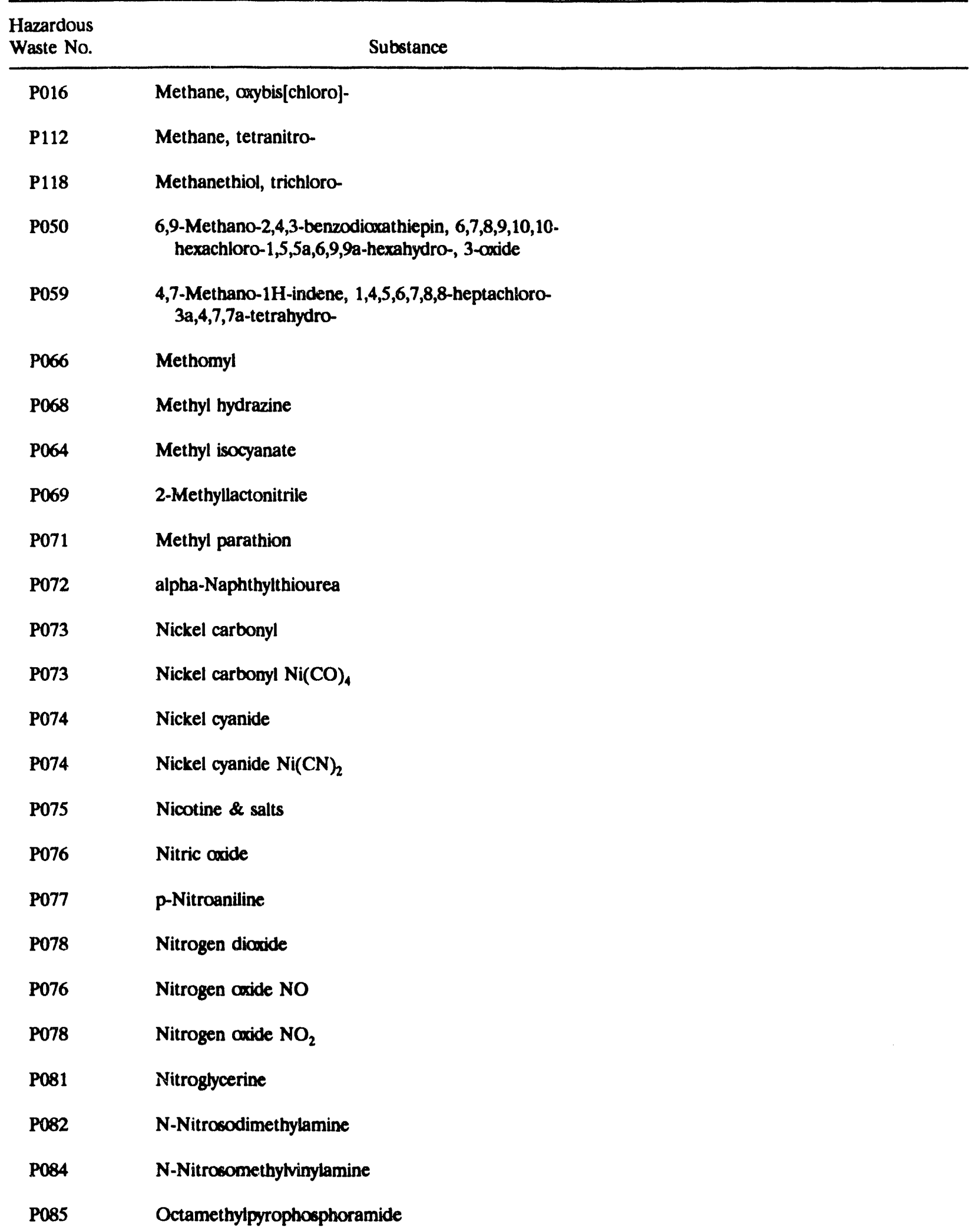


Table C-3. (continued)

\begin{tabular}{|c|c|}
\hline $\begin{array}{l}\text { Hazardous } \\
\text { Waste No. }\end{array}$ & Substance \\
\hline P087 & Osmium oride $\mathrm{O}_{3} \mathrm{O}_{4}$ \\
\hline P087 & Osmium tetroxide \\
\hline P088 & 7-Oxabicyclo $[2,2,1]$ beptane-2,3-dicarboxylic acid \\
\hline P089 & Parathion \\
\hline P034 & Phenol, 2-cyclohexyl-4,6-dinitro- \\
\hline P048 & Phenol, 2,4-dinitro- \\
\hline P047 & Phenol, 2-methyl-4,6-dinitro-, \& salts \\
\hline P020 & Phenol, 2-(1-methylpropyl)-4, 6-dinitro- \\
\hline P009 & Pbenol, 2,4,6-trinitro-, ammonium salt \\
\hline P092 & Phenyimercury acetate \\
\hline P093 & Phenylt hiourea \\
\hline P094 & Phorate \\
\hline P095 & Phosgene \\
\hline P096 & Phosphine \\
\hline P041 & Phosphoric acid, diethyl 4-nitrophenyl ester \\
\hline P039 & $\begin{array}{l}\text { Phosphorodithioic acid, O,O-diethyl } \\
\text { S-[2-(ethylthio)ethyl] ester }\end{array}$ \\
\hline P094 & $\begin{array}{l}\text { Phosphorodithioic acid, O,O-diethyl } \\
\text { S-[(ethylthio)methyl] ester }\end{array}$ \\
\hline P044 & Phosphorodithioic acid, 0,0-dimethyl S-[2-(methylamino)-2-oxoethyl] ester \\
\hline P043 & Phosphorofluoridic acid, bis(1-methylethyl) ester \\
\hline P089 & Phosphorothioic acid, 0,O-diethyl O-(4-nitrophenyl) ester \\
\hline P040 & Phosphorothioic acid, 0,O-diethyl O-pyrazinyl ester \\
\hline P097 & $\begin{array}{l}\text { Phosphorothioic acid, } \\
\text { O-[4-[(dimethylamino)sulfonyl]phenyl] 0,0-dimethyl ester }\end{array}$ \\
\hline P071 & Phosphorothioic acid, O,O-dimethyl O-(4-nitrophenyl) ester \\
\hline P110 & Plumbane, tetraethyl- \\
\hline
\end{tabular}


Table C-3. (continued)

\begin{tabular}{|c|c|}
\hline $\begin{array}{l}\text { Hazardous } \\
\text { Waste No. }\end{array}$ & Substance \\
\hline P098 & Potassium cyanide \\
\hline P098 & Potassium cyanide $\mathrm{KCN}$ \\
\hline P099 & Potassium silver cyanide \\
\hline P070 & $\begin{array}{l}\text { Propanal, 2-methyl-2-(methylthio)- } \\
\text { O-[(methylamino)carbonyl }] \text { oxime }\end{array}$ \\
\hline P101 & Propanenitrile \\
\hline P027 & Propanenitrile, 3-chloro- \\
\hline P069 & Propanenitrile, 2-hydroxy-2-methyl- \\
\hline P081 & 1,2,3-Propanetriol, trinitrate \\
\hline P017 & 2-Propanone, 1-bromo- \\
\hline P102 & Propargyl alcohol \\
\hline P003 & 2-Propenal \\
\hline P005 & 2-Propen-1-oi \\
\hline P067 & 1,2-Propylenimine \\
\hline P102 & 2-Propyn-1-ol \\
\hline P008 & 4-Pyridinamine \\
\hline P075 & Pyridine, 3-(1-methyl-2-pyrrolidinyl)-, (S), \& salts \\
\hline P114 & Selenious acid, dithallium $(1+)$ salt \\
\hline P103 & Selenourea \\
\hline P104 & Silver cyanide \\
\hline P104 & Silver cyanide $\mathrm{AgCN}$ \\
\hline P105 & Sodium azide \\
\hline P106 & Sodium cyanide \\
\hline P106 & Sodium cyanide $\mathrm{NaCN}$ \\
\hline P107 & Strontium sulfide SrS \\
\hline P108 & Strychnidin-10-one, \& salts \\
\hline
\end{tabular}

Hazardous 
Table C-3. (continued)

\begin{tabular}{|c|c|}
\hline $\begin{array}{l}\text { Hazardous } \\
\text { Waste No. }\end{array}$ & Substance \\
\hline P018 & Strychnidin-10-one, 2,3-dimethoory- \\
\hline P108 & Strychnine, \& salts \\
\hline P115 & Sulfuric acid, dithallium $(1+)$ salt \\
\hline P109 & Tetraethyldithiopyrophosphate \\
\hline P110 & Tetracthyl lead \\
\hline P111 & Tetracthyl pyrophosphate \\
\hline P112 & Tetranitromethane \\
\hline PO62 & Tetraphosphoric acid, bexaethyl ester \\
\hline P113 & Thallic ouide \\
\hline P113 & Thallium coride $\mathrm{Tl}_{2} \mathrm{O}_{3}$ \\
\hline P114 & Thallium(l) selenite \\
\hline P115 & Thallium(l) sulfate \\
\hline P109 & Thiodiphosphoric acid, tetraethyl ester \\
\hline P045 & Thiofanox \\
\hline P049 & Thioimidodicarbonic diamide $\left[\left(\mathrm{H}_{2} \mathrm{~N}\right) \mathrm{C}(\mathrm{S})\right]_{2} \mathrm{NH}$ \\
\hline P014 & Thiophenol \\
\hline P116 & Thiosemicarbazide \\
\hline P026 & Thiourea, (2-chlorophenyl)- \\
\hline P072 & Thiourea, 1-naphthalenyl- \\
\hline P093 & Thiourea, phenyl- \\
\hline P123 & Tocosphene \\
\hline P118 & Trichloromethanethiol \\
\hline P119 & Vanadic acid, ammonium salt \\
\hline P120 & Vanadium oride $\mathrm{V}_{2} \mathrm{O}_{3}$ \\
\hline P120 & Vanadium pentaxide \\
\hline P084 & Vinylamine, N-methyl-N-nitroso- \\
\hline
\end{tabular}


Table C-3. (continued)

\begin{tabular}{ll}
$\begin{array}{l}\text { Hazardous } \\
\text { Waste No. }\end{array}$ & \multicolumn{1}{c}{ Substance } \\
\hline P001 & Warfarin, \& salts, when present at concentrations greater than $0.3 \%$ \\
P121 & Zinc cyanide \\
P121 & Zinc cyanide $\mathrm{Zn}(\mathrm{CN})_{2}$ \\
P122 & Zinc phosphide $\mathrm{Zn}_{3} \mathrm{P}_{2}$, when present at concentrations greater than 10\% \\
\hline
\end{tabular}

*From 40 CFR 261.33. 
Table C-4. Discarded commercial chemical products*

(Toxic wastes)

\begin{tabular}{|c|c|}
\hline $\begin{array}{l}\text { Hazardous } \\
\text { Waste No. }\end{array}$ & Substance \\
\hline U001 & Acetaldehyde \\
\hline U034 & Acetaldebyde, trichloro- \\
\hline U187 & Acetamide, N-(4-ethouyphenyl). \\
\hline U005 & Acetamide, N-9H-fluoren-2-yl- \\
\hline U240 & Acetic acid, (2,4-dichlorophenoxy)-, salts \& esters \\
\hline U112 & Acetic acid ethyl ester \\
\hline U144 & Acetic acid, lead $(2+)$ salt \\
\hline U214 & Acetic acid, thallium $(1+)$ salt \\
\hline See: F027 & Acetic acid (2,4,5-trichlorophenoxy)- \\
\hline U002 & Acetone \\
\hline U003 & Acetonitrile \\
\hline U004 & Acetophenone \\
\hline U005 & 2-Acetylaminofluorene \\
\hline U006 & Acetyl chloride \\
\hline U007 & Acrylamide \\
\hline U008 & Acrylic acid \\
\hline U009 & Acrylonitrile \\
\hline v011 & Amitrole \\
\hline U012 & Aniline \\
\hline U136 & Arsenic acid, dimethyl- \\
\hline U014 & Auramine \\
\hline U015 & Azaserine \\
\hline U010 & $\begin{array}{l}\text { Azirino }[21,31: 3,4] \text { pyrrolo[1,2-a]indole-4,7-dione, 6-amino-8-[[(aminocarbonyl)oxy]methyl]- } \\
\text { 1,1a,2,8,8a,8b-hexahydro-8a-methoxy-5-methyl-, [1aS-(1aalpha, 8beta,8aalpha,8balpha)]-- }\end{array}$ \\
\hline U157 & Benz[j]aceanthrylene, 1,2-dihydro-3-methyl- \\
\hline
\end{tabular}


Table C-4. (continued)

\begin{tabular}{|c|c|}
\hline $\begin{array}{l}\text { Hazardous } \\
\text { Waste No. }\end{array}$ & Substance \\
\hline U016 & Benz[c]acridine \\
\hline U017 & Benzal chloride \\
\hline U192 & Benzamide, 3,5-dichloro-N-(1,1-dimethyl-2-propynyl)- \\
\hline U018 & Benz[a]anthracene \\
\hline U094 & Benz[a]anthracene, 7,12-dimethyl- \\
\hline U012 & Benzenamine \\
\hline U014 & Benzenamine, 4,4'-carbonimidoylbis[N,N-dimethyl]- \\
\hline U049 & Benzenamine, 4-chloro-2-methyl-, hydrochloride \\
\hline U093 & Benzenamine, N,N-dimethyl-4-(phenylazo)- \\
\hline U328 & Benzenamine, 2-methyl- \\
\hline U353 & Benzenamine, 4-methyl- \\
\hline U158 & Benzenamine, 4,4'-methylenebis[2-chloro]- \\
\hline U222 & Benzenamine, 2-methyl-, hydrochloride \\
\hline U181 & Benzenamine, 2-methyl-5-nitro- \\
\hline U019 & Benzene \\
\hline U038 & Benzeneacetic acid, 4-chloro-alpha-(4-chlorophenyl)-alpha-hydraxy-, ethyl ester \\
\hline U030 & Benzene, 1-bromo-4-phenoxy- \\
\hline U035 & Benzenebutanoic acid, 4-[bis(2-chloroethyl)amino]- \\
\hline U037 & Benzene, chloro- \\
\hline U221 & Benezenediamine, ar-methyl- \\
\hline U028 & 1,2-Benzenedicarboxylic acid, bis(2-ethylhexyl) ester \\
\hline U069 & 1,2-Benzenedicarboxylic acid, dibutyl ester \\
\hline U088 & 1,2-Benzenedicarbcusylic acid, diethyl ester \\
\hline U102 & 1,2-Benzenedicarboxylic acid, dimethyl ester \\
\hline U107 & 1,2-Benzenedicarboxylic acid, dioctyl ester \\
\hline U070 & Benzene, 1,2-dichloro- \\
\hline
\end{tabular}


Table C-4. (continued)

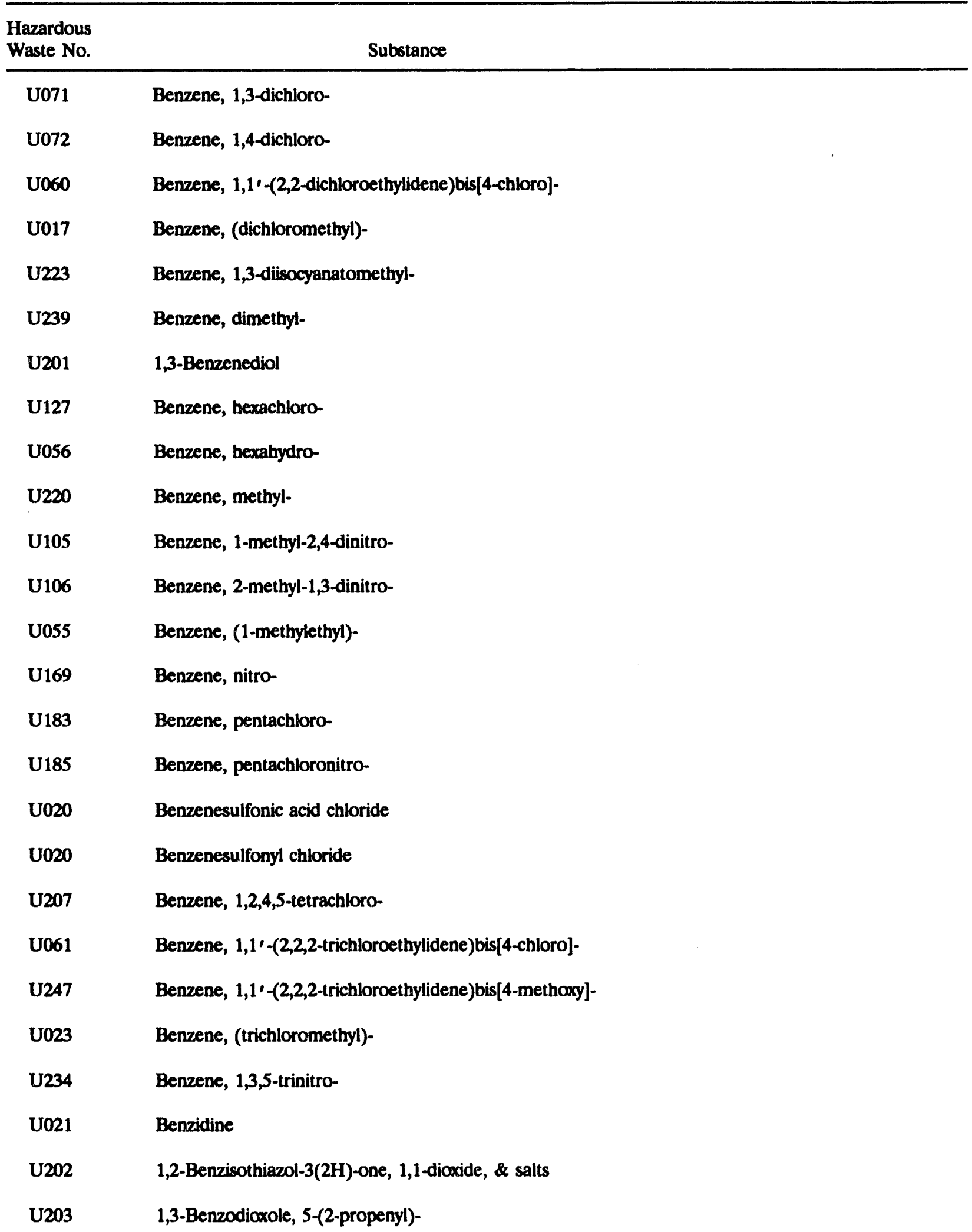


Table C-4. (continued)

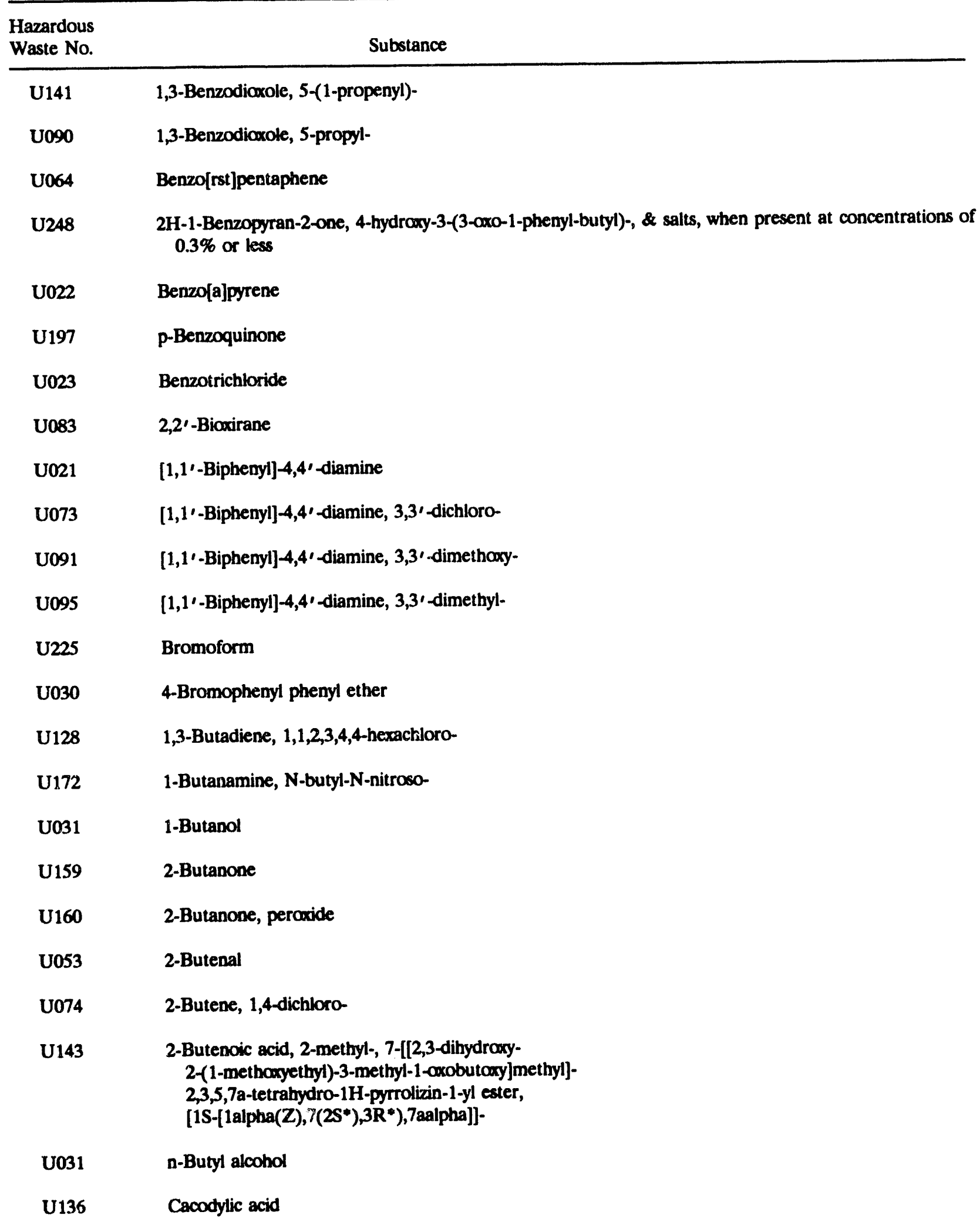


Table C-4. (continued)

\begin{tabular}{|c|c|}
\hline $\begin{array}{l}\text { Hazardous } \\
\text { Waste No. }\end{array}$ & Substance \\
\hline U032 & Calcium chromate \\
\hline U238 & Carbamic acid, ethyl ester \\
\hline U178 & Carbamic acid, methylnitroso-, ethyl ester \\
\hline U097 & Carbamic chloride, dimethyl- \\
\hline U114 & $\begin{array}{l}\text { Carbamodithioic acid, 1,2-ethanediylbis-, } \\
\text { salts \& caters }\end{array}$ \\
\hline U062 & Carbamothioic acid, bis(1-methylethyl)-, S-(2,3-dichloro-2-propenyl) ester \\
\hline U215 & Carbonic acid, dithallium $(1+)$ salt \\
\hline U033 & Carbonic difluoride \\
\hline U156 & Carbonochloridic acid, methyl ester \\
\hline U033 & Carbon cxyfluoride \\
\hline U211 & Carbon tetrachloride \\
\hline U034 & Chloral \\
\hline U035 & Chlorambucil \\
\hline U036 & Chlordane, alpha \& gamma isomers \\
\hline U026 & Chlornaphazin \\
\hline U037 & Chlorobenzene \\
\hline U038 & Chlorobenzilate \\
\hline U039 & p-Chloro-m-cresol \\
\hline U042 & 2-Chloroethyl vinyl ether \\
\hline U044 & Chloroform \\
\hline U046 & Chloromethyl methyl ether \\
\hline U047 & beta-Chloronaphthalene \\
\hline U048 & o-Chlorophenol \\
\hline U049 & 4-Chloro-0-toluidine, hydrochloride \\
\hline U032 & Chromic acid $\mathrm{H}_{2} \mathrm{CrO}_{4}$, calcium salt \\
\hline
\end{tabular}


Table C-4. (continued)

\begin{tabular}{|c|c|}
\hline $\begin{array}{l}\text { Hazardous } \\
\text { Waste No. }\end{array}$ & Substance \\
\hline U050 & Chrysene \\
\hline U051 & Creosote \\
\hline U052 & Cresol (Cresylic acid) \\
\hline U053 & Crotonakdehyde \\
\hline U055 & Cumene \\
\hline U246 & Cyanogen bromide $(\mathrm{CN}) \mathrm{Br}$ \\
\hline U197 & 2,5-Cyclohexadiene-1,4-dione \\
\hline U056 & Cyclohexane \\
\hline U129 & $\begin{array}{l}\text { Cyclohexane, 1,2,3,4,5,6-hexachloro-, } \\
\text { (1alpha,2alpha,3beta,4alpha,5alpha,6beta)- }\end{array}$ \\
\hline U057 & Cyclohexanone \\
\hline U130 & 1,3-Cyclopentadiene, 1,2,3,4,5,5-hexachloro- \\
\hline U058 & Cyclophosphamide \\
\hline $\mathrm{U} 240$ & 2,4-D, salts \& esters \\
\hline U059 & Daunomycin \\
\hline U060 & DDD \\
\hline UO61 & DDT \\
\hline U062 & Diallate \\
\hline U063 & Dibenz $[a, h]$ anthracene \\
\hline U064 & Dibenzo[a,i]pyrene \\
\hline U066 & 1,2-Dibromo-3-chloropropane \\
\hline U069 & Dibutyl phthalate \\
\hline U070 & o-Dichlorobenzene \\
\hline U071 & m-Dichłorobenzene \\
\hline U072 & p-Dichlorobenzene \\
\hline U073 & 3,3'-Dichlorobenzidine \\
\hline
\end{tabular}


Table C-4. (continued)

\begin{tabular}{|c|c|}
\hline $\begin{array}{l}\text { Hazardous } \\
\text { Waste No. }\end{array}$ & Substance \\
\hline U074 & 1,4-Dichloro-2-butene \\
\hline U075 & Dichlorodifluoromethane \\
\hline U078 & 1,1-Dichloroethylene \\
\hline U079 & 1,2-Dichloroethylene \\
\hline U025 & Dichloroethyl ether \\
\hline U027 & Dichloroisopropyl ether \\
\hline U024 & Dichloromethory ethane \\
\hline U081 & 2,4-Dichlorophenol \\
\hline $\mathrm{v082}$ & 2,6-Dichlorophenol \\
\hline U084 & 1,3-Dichloropropene \\
\hline U085 & 1,2:3,4-Diepoxybutane \\
\hline J108 & 1,4-Diethyleneaxide \\
\hline U028 & Diethylhexyl phthalate \\
\hline U086 & $\mathrm{N}, \mathbf{N}$ '-Diethylhydrazine \\
\hline U087 & O,O-Diethyl S-methyl dithiophosphate \\
\hline U088 & Diethyl phthalate \\
\hline U089 & Diethylstilbesterol \\
\hline U090 & Dihydrosafrole \\
\hline U091 & 3,3'-Dimethorybenzidine \\
\hline U092 & Dimethylamine \\
\hline U093 & p-Dimethylaminoazobenzene \\
\hline U094 & 7,12-Dimethylbenz[a]anthracene \\
\hline U095 & 3,3'-Dimethylbenzidine \\
\hline U096 & alpha,alpha-Dimethylbenzylhydroperoxide \\
\hline U097 & Dimethylcarbamoyl chloride \\
\hline U098 & 1,1-Dimethylhydrazine \\
\hline
\end{tabular}


Table C-4. (continued)

\begin{tabular}{|c|c|}
\hline $\begin{array}{l}\text { Hazardous } \\
\text { Waste No. }\end{array}$ & Substance \\
\hline U099 & 1,2-Dimethylhydrazine \\
\hline U101 & 2,4-Dimethylphenol \\
\hline U102 & Dimethyl phthalate \\
\hline U103 & Dimethyl sulfate \\
\hline U105 & 2,4-Dinitrotoluene \\
\hline U106 & 2,6-Dinitrotoluene \\
\hline U107 & Di-n-octyl phthalate \\
\hline U108 & 1,4-Dioxane \\
\hline U109 & 1,2-Diphenylhydrazine \\
\hline U110 & Dipropylamine \\
\hline U111 & Di-n-propylnitrosamine \\
\hline U041 & Epichlorohydrin \\
\hline U001 & Ethanal \\
\hline U174 & Ethanamine, N-ethyl-N-nitroso- \\
\hline U155 & 1,2-Ethanediamine, N,N-dimethyl-N'-2-pyridinyl-N'-(2-thienylmethyl)- \\
\hline U067 & Ethane, 1,2-dibromo- \\
\hline U076 & Ethane, 1,1-dichloro- \\
\hline U077 & Ethane, 1,2-dichloro- \\
\hline U131 & Ethane, hexachloro \\
\hline U024 & Ethane, 1,1'-[methylenebis(oxy)]bis[2-chloro]- \\
\hline U117 & Ethane, $1,1^{\prime}$-axybis-(1) \\
\hline U025 & Ethane, 1,1'-axybis[2-chloro]- \\
\hline U184 & Ethane, pentachloro- \\
\hline U208 & Ethane, 1,1,1,2-tetrachloro- \\
\hline U209 & Ethane, 1,1,2,2-tetrachloro- \\
\hline U218 & Ethanethioamide \\
\hline
\end{tabular}


Table C-4. (continued)

\begin{tabular}{|c|c|}
\hline $\begin{array}{l}\text { Hazardous } \\
\text { Waste No. }\end{array}$ & Substance \\
\hline U226 & Ethane, 1,1,1-trichloro- \\
\hline U227 & Ethane, 1,1,2-trichloro- \\
\hline U359 & Ethanol, 2-ethory- \\
\hline U173 & Ethanol, 2,2'-(nitrosoimino)bis- \\
\hline U004 & Ethanone, 1-phenyl- \\
\hline U043 & Ethene, chloro- \\
\hline U042 & Ethene, (2-chloroethouy)- \\
\hline U078 & Ethene, 1,1-dichloro- \\
\hline U079 & Ethene, 1,2-dichloro- \\
\hline U210 & Ethene, tetrachloro- \\
\hline U228 & Ethene, trichloro- \\
\hline $\mathrm{U} 1: 2$ & Ethyl acetate \\
\hline U113 & Ethyl acrylate \\
\hline U238 & Ethyl carbamate (urethane) \\
\hline U117 & Ethyl ether \\
\hline U114 & Ethylenebisdithiocarbamic acid, salts \& esters \\
\hline U067 & Ethylene dibromide \\
\hline U077 & Ethylene dichloride \\
\hline U359 & Ethylene glycol monoethyl ether \\
\hline U115 & Ethylene coride \\
\hline U116 & Ethylenethiourea \\
\hline v076 & Ethylidene dichloride \\
\hline U118 & Ethyl methacrylate \\
\hline U119 & Ethyl methanesulfonate \\
\hline U120 & Fluoranthene \\
\hline U122 & Formaldehyde \\
\hline
\end{tabular}


Table C-4. (continued)

\begin{tabular}{|c|c|}
\hline $\begin{array}{l}\text { Hazardous } \\
\text { Waste No. }\end{array}$ & Substance \\
\hline U123 & Formic acid \\
\hline U124 & Furan \\
\hline U125 & 2-Furancarboxaldehyde \\
\hline U147 & 2,5-Furandione \\
\hline U213 & Furan, tetrahydro- \\
\hline U125 & Furfural \\
\hline U124 & Furfuran \\
\hline U206 & Glucopyranose, 2-decxy-2-(3-methyl-3-nitrosoureido)-, D- \\
\hline U206 & $\begin{array}{l}\text { D-Glucose, 2-deoxy-2-[[(methylnitrosoamino)- } \\
\text { carbonyl]amino]- }\end{array}$ \\
\hline U126 & Glycidylaldehyde \\
\hline U163 & Guanidine, $N$-methyl-N'-nitro-N-nitroso- \\
\hline U127 & Hexachlorobenzene \\
\hline U128 & Hexachlorobutadiene \\
\hline U130 & Hexachlorocyclopentadiene \\
\hline U131 & Hexachloroethane \\
\hline U132 & Hexachlorophene \\
\hline U243 & Hexachloropropene \\
\hline U133 & Hydrazine \\
\hline U086 & Hydrazine, 1,2-diethyl- \\
\hline U098 & Hydrazine, 1,1-dimethyl- \\
\hline U099 & Hydrazine, 1,2-dimethyl- \\
\hline U109 & Hydrazine, 1,2-diphenyl- \\
\hline U134 & Hydrofluoric acid \\
\hline U134 & Hydrogen fluoride \\
\hline U135 & Hydrogen sulfide \\
\hline
\end{tabular}


Table C-4. (continued)

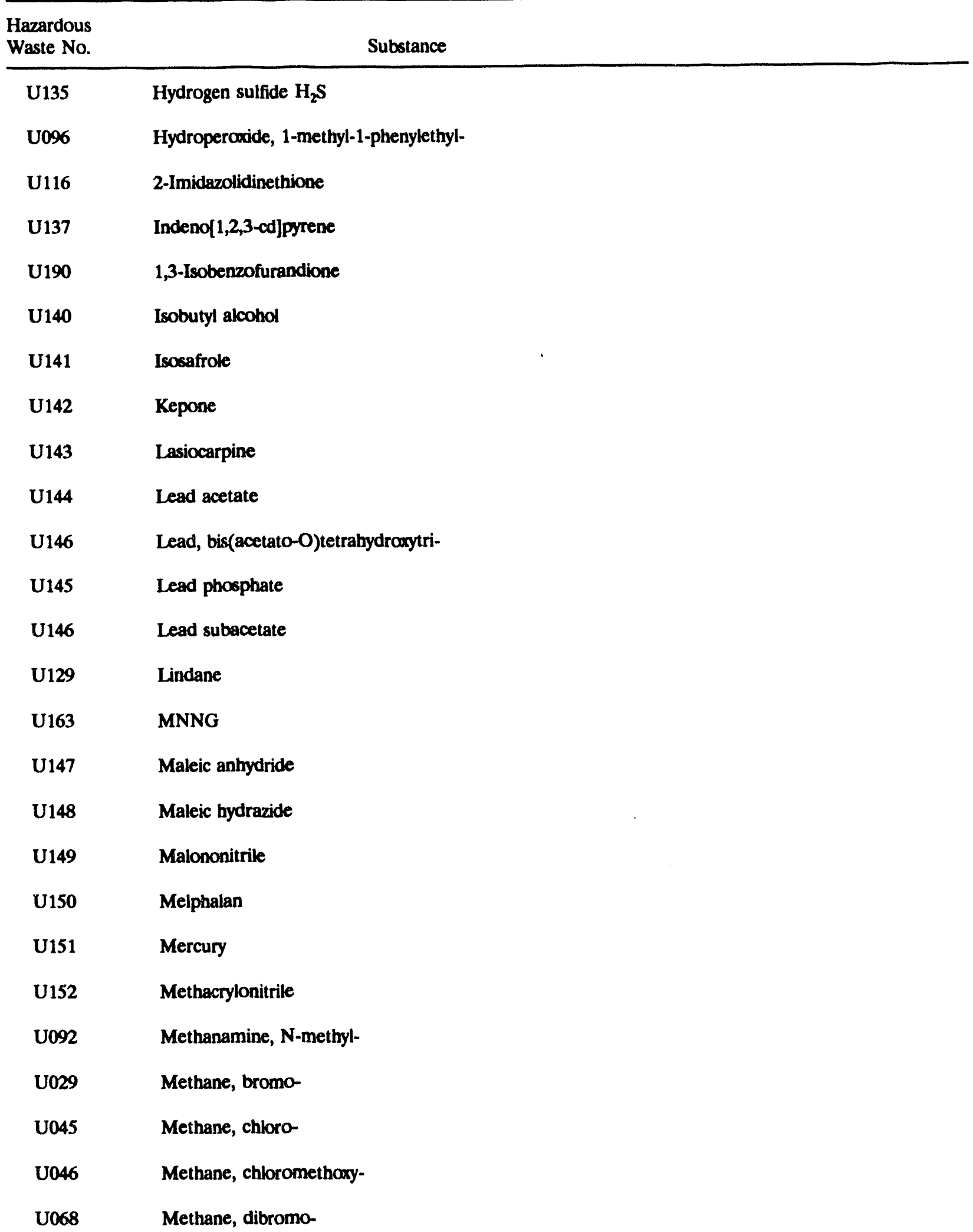


Table C-4. (continued)

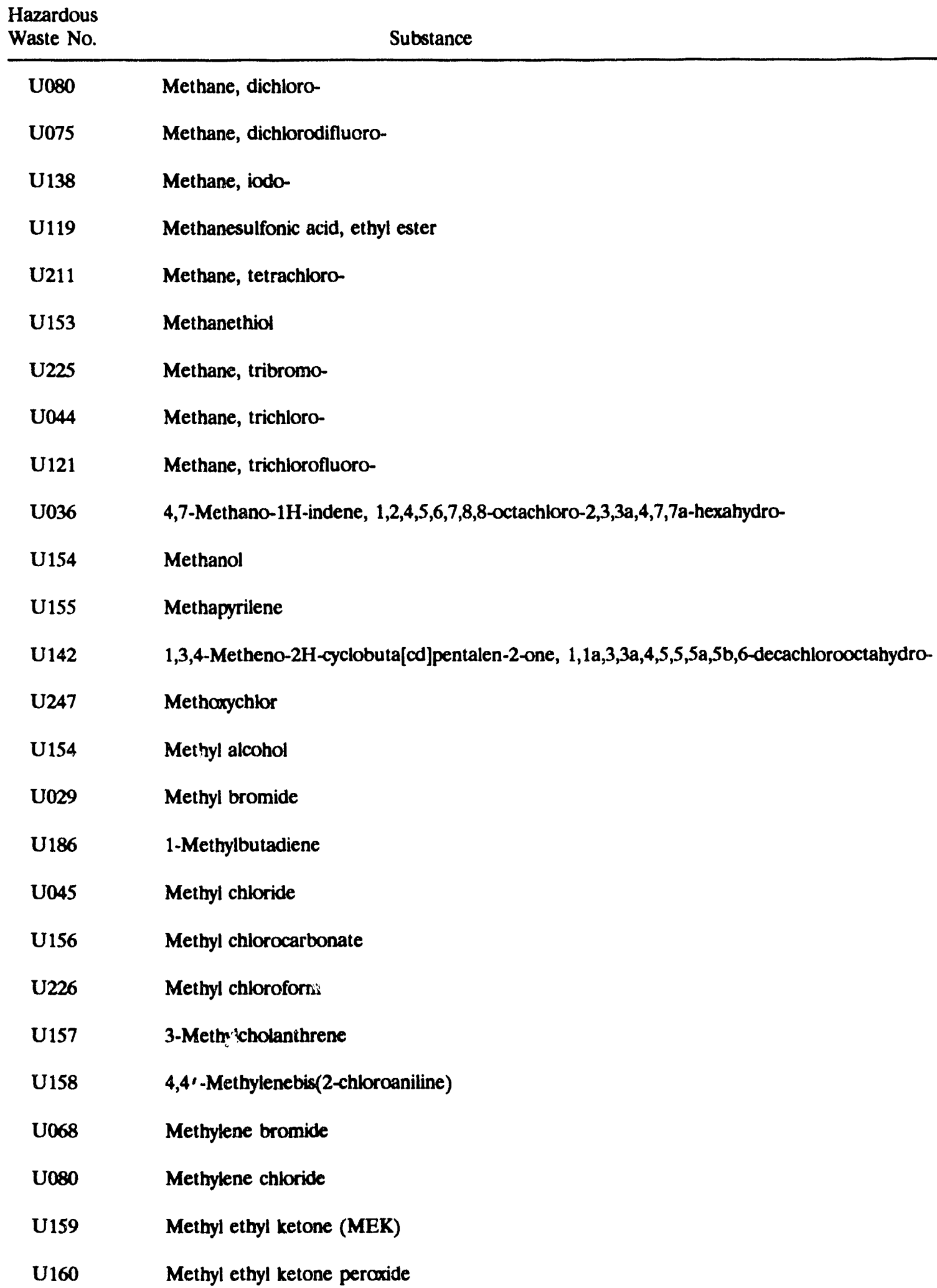


Table C-4. (continued)

\begin{tabular}{|c|c|}
\hline $\begin{array}{l}\text { Havardous } \\
\text { Waste No. }\end{array}$ & Substance \\
\hline U138 & Methyl iodide \\
\hline U161 & Methyl isobutyl ketone \\
\hline U162 & Methyl methactylate \\
\hline U161 & 4-Methyl-2-pentanone \\
\hline U164 & Methylthiouracil \\
\hline U010 & Mitomycin C \\
\hline U059 & $\begin{array}{l}\text { 5,12-Naphthacenedione, 8-acetyl-10-[(3-amino-2,3,6-tridecuy }) \text {-alpha-L-tyxo-bexopyrancoyl)ouxy]- } \\
7,8,9,10 \text {-tetrahydro-6,8,11-tribydrowy-1-methoury-, (8S-cis)- }\end{array}$ \\
\hline U167 & 1-Naphthalenamine \\
\hline U168 & 2-Naphthalenamine \\
\hline U026 & Naphthalenamine, N,N'-bis(2-chloroethyl)- \\
\hline U165 & Naphthalene \\
\hline U047 & Naphthalene, 2-chloro- \\
\hline U166 & 1,4-Naphthalenedione \\
\hline U236 & $\begin{array}{l}\text { 2,7-Naphthalenedisulfonic acid, } 3,3{ }^{\prime}-[(3,3 \prime- \\
\text { dimethyl[1,1'-biphenyl }]-4,4^{\prime} \text {-diyl)bis(azo)bis[5-amino-4-hydroxy]-, tetrasodium salt }\end{array}$ \\
\hline U166 & 1,4-Naphthoquinone \\
\hline U167 & alpha-Naphthylamine \\
\hline U168 & beta-Naphthylamine \\
\hline U217 & Nitric acid, thallium $(1+)$ salt \\
\hline U169 & Nitrobenzene \\
\hline U170 & p-Nitrophenol \\
\hline U171 & 2-Nitropropane \\
\hline U172 & N-Nitrosodi-n-butylamine \\
\hline $\mathbf{U 1 7 3}$ & N-Nitrosodiethanclamine \\
\hline U174 & N-Nitroeodiethylamine \\
\hline U176 & N-Nitroso-N-ethylurea \\
\hline
\end{tabular}


Table C-4. (continued)

\begin{tabular}{|c|c|}
\hline $\begin{array}{l}\text { Hazardous } \\
\text { Waste No. }\end{array}$ & Substance \\
\hline U177 & $\mathrm{N}$-Nitroso-N-methylurea \\
\hline U178 & N-Nitroso-N-metbylurethane \\
\hline U179 & N-Nitrosopiperidine \\
\hline U180 & N-Nitrosopytrolidine \\
\hline U181 & 5-Nitro-o-toluidine \\
\hline U193 & 1,2-Oxathiolane, 2,2-dioxide \\
\hline U058 & $\begin{array}{l}\text { 2H-1,3,2-Oxazaphosphorin-2-amine, } \\
\text { N,N-bis(2-chloroethyl)tetrahydro-, 2-oxide }\end{array}$ \\
\hline U115 & Oxirane \\
\hline U126 & Oxiranecarboxyaldehyde \\
\hline U041 & Oxirane, (chloromethyl)- \\
\hline U182 & Paraldehyde \\
\hline U183 & Pentachlorobenzene \\
\hline U184 & Pentachloroethane \\
\hline U185 & Pentachloronitrobenzene (PCNB) \\
\hline See: F027 & Pentachlorophenol \\
\hline U161 & Pentanol, 4-methyl- \\
\hline U186 & 1,3-Pentadiene \\
\hline U187 & Phenscetin \\
\hline U188 & Pbenol \\
\hline U048 & Phenol, 2-chloro- \\
\hline U039 & Pbenol, 4-chloro-3-methyl- \\
\hline v081 & Phend, 2,4-dichloro- \\
\hline U082 & Phenol, 2,6-dichloro- \\
\hline U089 & Phenol, 4,4'-(1,2-diethyl-1,2-ethenediyl $)$ bis \\
\hline U101 & Phenol, 2-4-dimethyl- \\
\hline
\end{tabular}


Table C-4. (continued)

\begin{tabular}{|c|c|}
\hline $\begin{array}{l}\text { Hazardous } \\
\text { Waste No. }\end{array}$ & Substance \\
\hline U052 & Phenol, methyl- \\
\hline U132 & Phenol, 2,2' -methylenebis[3,4,6-trichloro]- \\
\hline U170 & Phenol, 4-nitro- \\
\hline See: F027 & Phenol, pentachloro- \\
\hline See: F027 & Phenol, 2,3,4,6-tetrachloro- \\
\hline See: F027 & Phenol, 2,4,5-trichloro- \\
\hline See: F027 & Phenol, 2,4,6-trichloro- \\
\hline U150 & L-Phenylalanine, 4-[bis(2-chloroethyl)amino]- \\
\hline U145 & Phosphoric acid, lead(2t) salt $(2: 3)$ \\
\hline U087 & Phosphorodithioic acid, O,O-diethyl S-methyl ester \\
\hline U189 & Phosphorus sulfide \\
\hline U190 & Phthalic anhydride \\
\hline U191 & 2-Picoline \\
\hline U179 & Piperidine, 1-nitroso- \\
\hline U192 & Pronamide \\
\hline U194 & 1-Propanamine \\
\hline U111 & 1-Propanamine, N-nitroso-N-propyl- \\
\hline U110 & 1-Propanamine, N-propyl- \\
\hline U066 & Propane, 1,2-dibromo-3-chloro- \\
\hline U083 & Propane, 1,2-dichloro- \\
\hline U149 & Propanedinitrile \\
\hline U171 & Propane, 2-nitro- \\
\hline U027 & Propane, 2,2'-axybis[2-chloro]- \\
\hline
\end{tabular}


Table C-4. (continued)

\begin{tabular}{|c|c|}
\hline $\begin{array}{l}\text { Hazardous } \\
\text { Waste No. }\end{array}$ & Substance \\
\hline U193 & 1,3-Propane sultone \\
\hline See: F027 & Propanoic acid, 2-(2,4,5-trichlorophenoxy)- \\
\hline U235 & 1-Propanol, 2,3-dibromo-, phosphate (3:1) \\
\hline U140 & 1-Propanol, 2-methyl- \\
\hline U002 & 2-Propanone \\
\hline U007 & 2-Propenamide \\
\hline U084 & 1-Propene, 1,3-dichloro- \\
\hline U243 & 1-Propene, 1,1,2,3,3,3-hexachloro- \\
\hline U009 & 2-Propenenitrile \\
\hline U152 & 2-Propenenitrile, 2-methyl- \\
\hline U008 & 2-Propenoic acid \\
\hline U113 & 2-Propenoic acid, ethyl ester \\
\hline U118 & 2-Propenoic acid, 2-methyl-, ethyl ester \\
\hline U162 & 2-Propenoic acid, 2-methyl-, methyl ester \\
\hline U194 & n-Propylamine \\
\hline U083 & Propylene dichloride \\
\hline U148 & 3,6-Pyridazinedione, 1,2-dihydro- \\
\hline U196 & Pyridine \\
\hline U191 & Pyridine, 2-methyl- \\
\hline U237 & $\begin{array}{l}\text { 2,4-(1H,3H)-Pyrimidinedione, 5-[bis(2- } \\
\text { chloroethyl)amino]- }\end{array}$ \\
\hline U164 & $4(1 \mathrm{H})$-Pyrimidinone, 2,3-dihydro-6-methyl-2-thioxo- \\
\hline U180 & Pyrrolidine, 1-nitroso- \\
\hline U200 & Reserpine \\
\hline U201 & Resorcinol \\
\hline $\mathrm{U} 202$ & Saccharin, \& salts \\
\hline
\end{tabular}


Table C-4. (continued)

\begin{tabular}{|c|c|}
\hline $\begin{array}{l}\text { Hazardous } \\
\text { Waste No. }\end{array}$ & Substance \\
\hline U203 & Safrole \\
\hline U204 & Selenious acid \\
\hline U204 & Selenium diouide \\
\hline U205 & Selenium sulfide \\
\hline U205 & Selenium sulfide $\mathrm{SeS}_{2}$ \\
\hline U015 & L-Serine, diazoacetate (ester) \\
\hline See: F027 & Silvex $(2,4,5-T P)$ \\
\hline U206 & Streptozotocin \\
\hline U103 & Sulfuric acid, dimethyl ester \\
\hline U189 & Sulfur phosphide \\
\hline See: F027 & $2,4,5-\mathrm{T}$ \\
\hline U207 & 1,2,4,5-Tetrachlorobenzene \\
\hline U208 & 1,1,1,2-Tetrachloroethane \\
\hline U209 & 1,1,2,2-Tetrachloroethane \\
\hline U210 & Tetrachloroethylene \\
\hline See: F027 & 2,3,4,6-Tetrachlorophenol \\
\hline U213 & Tetrahydrofuran \\
\hline U214 & Thallium(I) acetate \\
\hline U215 & Thallium(l) carbonate \\
\hline U216 & Thallium(l) chloride \\
\hline U216 & Thallium chloride $\mathrm{TCl}$ \\
\hline U217 & Thallium(l) nitrate \\
\hline U218 & Thioacetamide \\
\hline U153 & Thiomethanol \\
\hline
\end{tabular}


Table C-4. (continued)

\begin{tabular}{|c|c|}
\hline $\begin{array}{l}\text { Hazardous } \\
\text { Waste No. }\end{array}$ & Substance \\
\hline U244 & Thioperoxydicarbonic diamide $\left[\left(\mathrm{H}_{2} \mathrm{~N}\right) \mathrm{C}(\mathrm{S})\right]_{2} \mathrm{~S}_{2}$, tetramethyl- \\
\hline U219 & Thiourea \\
\hline U244 & Thiram \\
\hline $\mathrm{U} 220$ & Toluene \\
\hline U221 & Toluenediamine \\
\hline U223 & Toluene diisocyanate \\
\hline U328 & a-Toluidine \\
\hline U353 & p-Toluidine \\
\hline U222 & o-Toluidine hydrochloride \\
\hline U011 & 1H-1,2,4-Triazol-3-amine \\
\hline U227 & 1,1,2-Trichloroethane \\
\hline U228 & Trichloroethylene \\
\hline U121 & Trichloromonofluoromethane \\
\hline See: F027 & 2,4,5-Trichlorophenol \\
\hline See: F027 & 2,4,6-Trichlorophenoi \\
\hline U234 & 1,3,5-Trinitrobenzene \\
\hline U182 & 1,3,5-Trioxane, 2,4,6-trimethyl- \\
\hline U235 & Tris(2,3-dibromopropyl) phosphate \\
\hline U236 & Trypan blue \\
\hline U237 & Uracil mustard \\
\hline U176 & Urea, N-ethyl-N-nitroso- \\
\hline U177 & Urea, N-methyl-N-nitroso- \\
\hline U043 & Vinyl chloride \\
\hline U248 & Warfarin, \& salts, when present at concentrations of $0.3 \%$ or less \\
\hline U239 & Xylene \\
\hline
\end{tabular}


Table C-4. (continued)

Hazardous
Waste No.

U200
Substance

Yohimban-16-carboxylic acid, 11,17-dimethoxy-18-[(3,4,5-trinzethorybenzoyl)axy]-, methyl ester, (3beta,16beta,17alpha,18beta,20alpha)-

U249

Zinc phosphide $\mathrm{Zn}_{3} \mathrm{P}_{z}$ when present at concentrations of $10 \%$ or less

*From 40 CFR 261.33. 


\section{APPENDIX C}

FIELD STRUCIURE MIXED WASTE DATABASE 


\section{NATIONAL PROFILE ON MIXED WASTE .DATA BASE}

The data base for the National Profile on Mixed Waste resides in the PC-based FoxPro software. The data from each questionnaire is organized in several relational files. The files are connected by a common identification number to provide integrity of data and allow reports to be generated from all data files. The files are based on the format of the questionnaire, i.e. file FACILITY.DBF contains data found in section A, file LLRW.DBF data found in section B-1, etc. Keeping exact and range data separated while retaining both allows these data to be used in summations and other statistical calculations as described. Mixtures of hazardous chemicals are organized in subfiles and available under the names of the components of the mixtures. Unlimited comment fields provide additional information to clarify data. The descriptions of the files and their fields are as follows. 


\title{
Subfile Description
}

\author{
FILE ID: FACILITY.DBF
}

FILE NAME: Mixed Waste facility file (Section A of the questionnaire)

DESCRIPTION:

This file organizes identification information and includes the name and address of the facility returning the questionnaire, the name and title of the individual completing the questionnaire along with numbers identifying the facility.

FILE ID: LLRW.DBF

FILE NAME: Low-Level radioactive waste file (Section B-1 and F of the questionnaire)

DESCRIPTION:

This file contains information on the total volume of LLRW shipped for disposal during the survey year by the facility. It also contains any information given on specific actions or procedures taken to minimize the generation of mixed waste at the facility.

FULE ID: LLRW_GS.DBF

FILE NAME: LLRW Generating and Storage file (Section B-2, B-3, C-1, C-2, C-3, C-4 of the questionnaire)

DESCRIPTION:

This file contains information on the type of LowLevel Radioactive Waste generated and/or stored at the facility. It also includes information on LLRW generating practices and storage; states when the LLRW is considered hazardous.

FIIE ID: MIX_WAST.DBF

FILE NAME: Mixed Waste file (Section D-1 of the questionnaire)

DESCRIPTION:

This file contains information on each LLRW stream which is considered hazardous. Information is given on the waste stream number, physical form, basis for documenting the information, hazardous component, source, and total volume of the LLRW stream generated. 


\section{Subfile Description}

FIIE ID: TREATMEN.DBF

FILE NAME: Mised Waste treatment file (Section D-2 of the questionnaire)

DESCRIPTION:

This file contains information on each LLRW stream listed in the mixed waste file. It includes the major radionuclides, the RAD waste classification, the cumulative activity, treatment site, type of treatment, and the volume treated during the year.

FILE ID: TREA_WAS.DBF

FILE NAME: Treated Mixed Waste file (Section D=3 of the questionnaire)

DESCRIPTION:

This file contains information on the results of the treatment of each LLRW stream listed in the mixed waste file. It includes the after treatment volume, activity, and effect on the hazardous component, and the volume of the LLRW stream requiring ultimate disposal.

FIIE ID: STOR_WAS.DBF

FILE NAME: Stored Mired Waste file (Section E-1 of the questionnaire)

DESCRIPTION:

This file contains information on stored mixed waste streams. Information includes the physical form and the basis for that judgement, the hazardous component and its source, and the cumulative amount in storage at the end of the reporting year.

FILE ID: RADIOACT.DBF

FILE NAME: Radioactivity of stored Mixed Waste file (Section E-2 of the questionnaire)

DESCRIPTION:

This file contains information on the major radionuclides in the stored mixed waste. It includes the major radionuclides, RAD waste classification, cumulative activity, and reason for storage. 


\section{Data Field Descriptions}

FILE ID: FACILITY.DBF

FILE NAME: Mixed Waste facility file (Section A of the questionnaire)

DESCRIPTION:

FIELD ID FIEID NAME

IDNUMBER Identification number

FACILITY Name of facility

ADDRESS Address of facility

CITY City of facility

STATE State of facility

ZIP

FACCATEG Facility Category

SICNUM Standard Industrial

Classification Number

NRCSTATE NRC/Agreement

State license \#

EPAIDNO EPA identification number

EPACLASS EPA facility classification

NAME Name
This file organizes identification information and includes the name and address of the facility returning the questionnaire, the name and title of the individual completing the questionnaire along with numbers identifying the facility.

\section{FIEILD DESCRIPTION}

An assigned identifier to unify the parts of the questionnaire. The first position identifies the type of facility, the second a source list, and the next four the sequence. (See Attachment 1)

Name of university, company, or plant where waste is generated or stored.

Mailing address of facility.

City of facility location.

Two letter abbreviation of state location.

U.S. zip code, 5 or 9 digit.

Categories are nuclear reactor, medical, academic, industrial or government, entered as a code. (See Attachment 2)
Rated large, small, or conditionally exempt small quantity generator, entered as a code. (See Attachment 3)

Name of person completing form. 


\section{Data Field Descriptions}

TITLE Title Title of person completing form.

PHONENO Telephone number Telephone number of person completing form.

YEAR Year of questionnaire The year (2 digits) for which data were reported.

COMMENT Comment Field for information found in the first two pages of the questionnaire not fitting one of the above fields.

FILE D: LLRW.DBF

FILE NAME: Low-level radioactive waste (LLRW) file (Section B-1 and F of the questionnaire)

DESCRIPTION:

FIELD ID FIELD NAME

IDNUMBER Identification number

FACCATEG Facility Category

STATE State of facility

EPACLASS EPA facility classification

LLRWCLA LLRW Class A

LLRWCLB LLRW Class B

LLRWCLC LLRW Class C
This file contains information on the total volume of LLRW shipped for disposal during the survey year by the facility. It also contains any information given on specific actions or procedures taken to minimize the generation of mixed waste at the facility.

\section{FIEID DESCRIPTION}

Original assigned identifier.

Categories are nuclear reactor, medical, academic, industrial or government, entered as a code (See Attachment 2).

Two letter abbreviation of state location.

Rated large, small, or conditionally exempt small quantity generator, entered as a code. (See Attachment 3)

Volume of Low-Level Radioactive Waste Class A shipped for disposal during the year, reported in cubic feet/year.

Volume of Low-Level Radioactive Waste Class B shipped for disposal during the year, reported in cubic feet/year.

Volume of Low-Level Radioactive Waste Class C shipped for disposal during the year, reported in cubic 


\section{Data Field Descriptions}

$\begin{array}{llll}\text { LLRWTOTL } & \text { Total LLRW Shipped } & \begin{array}{l}\text { feet/year. } \\ \text { Total volume of Low-Level Radioactive Waste } \\ \text { shipped for disposal during the year, reported in cubic } \\ \text { feet/year. }\end{array} \\ \text { YEAR } & \text { Year of questionnaire } & \begin{array}{l}\text { The year (2 digits) for which data were reported. } \\ \text { COMMENT }\end{array} \quad \text { Comment } & \begin{array}{l}\text { Field for information found in the low-level } \\ \text { radioac, ive waste section of the questionnaire not } \\ \text { fitting one of the above fields. }\end{array} \\ \text { MWMINIM } & \text { Mixed waste minimization } & \begin{array}{l}\text { Specific action or procedures used to minimize the } \\ \text { generation of mixed waste at the facility. (See section }\end{array} \\ \text { F-1 of the questionnaire) }\end{array}$

FILE ID: LLRW_GS.DBF

FILE NAME: LLRW Generating and Storage file (Section B-2, B-3, C-1, C-2, C-3, C-4 of the questionnaire)

DESCRIPTION:

FIELD ID FIEID NAME FIEID DESCRIPTION

IDNUMBER Identification number Original assigned identifier.

FACCATEG Facility Category Categories are nuclear reactor, medical, academic, industrial or government entered as a code. (See Attachment 2)

COUNTNO Repeat for IDNUMBER A sequential number assigned to indicate the record number for a common ID number questionnaire. Numbers are $\mathrm{G} 01, \mathrm{G} 02$, etc. for generated waste information and $\mathrm{S} 01, \mathrm{SO2}$, etc. for stored waste information.

LLRWCODE LLRW waste stream code

A number from Attachment 1 of the questionnaire identifying the LLRW waste stream being generated. 


\section{Data Field Descriptions}

LLRWNAME LLRW waste stream name A name from Attachment 1 of the questicnnaire identifying the LLRW waste stream being generated.

GENOSTOR LLRW generated or store Single letter G (generated) or S (stored) indicating type of waste streamed described.

LGENPRAC LLRW generating practice Practices at the facility generating the listed LLRW.

LSTORINF LLRW storage information Reason for storage of the listed LLRW.

HAZWASTE Hazardous waste Indicates if any of the facility's LLRW waste is considered hazardous. ( $\mathrm{Y}$ or $\mathrm{N}$ )

YEAR Year of ques'ionnaire The year (2 digits) for which data were reported.

COMMENT Comment Field for information found in the LLRW generating or storage sections of the questionnaire not fitting one of the above fields.

FILE ID: MIX_WAST.DBF

FILE NAME: Mixed Waste $\mathrm{L} \cdot$ (Section D-1 of the questionnaire)

DESCRIPTION:

This file contains information on each LLRW stream which is considered hazardous. Information is given on the waste stream number, physical form, basis for documenting the information, hazardous component, source, and total volume of the LLRW stream generated.

FIELD ID FIEID NAME FIELD DESCRIPTION

IDNUMBER Identification number Original assigned identifier.

FACCATEG Facility Category Categories are nuclear reactor, medical, academic, industrial or gojernment entered as a code. (See Attachment 2)

COUNTNO Repeat for IDNUMBER A sequential number assigned to indicate the waste stream line number for a common ID number questionnaire. (Each waste stream will be numbered. 101,102 , etc.) 


\section{Data Field Descriptions}

\begin{tabular}{|c|c|}
\hline LLRWCODE & LLRW waste stream \\
\hline PHYSFORM & Physical form \\
\hline BASIS & Basis \\
\hline $\begin{array}{l}\text { HAZNAME } \\
\text { name }\end{array}$ & $\begin{array}{l}\text { Name of hazardous } \\
\text { component }\end{array}$ \\
\hline $\begin{array}{l}\text { SOURCE } \\
\cdot\end{array}$ & $\begin{array}{l}\text { Source of hazardous } \\
\text { component }\end{array}$ \\
\hline
\end{tabular}

TOTVOLGN Total volume generated

ESUPVLGN Estimated upper volume generated

$\begin{array}{ll}\text { ESLOVLGN } & \begin{array}{l}\text { Estimated lower } \\ \text { volume generated }\end{array}\end{array}$

MIXTPURE Mixture or Pure

YEAR Year of questionnaire

GROUPID Group identification

COMMENT Comment
A number from Attachment 1 of the questionnaire identifying the LLRW waste stream containing hazardous materials.

The physical form of the waste (aqueous, bulk liquid, compacted solid, etc.).

Basis for judgement of constituents and characteristics of waste. Choices are tested ( $\mathrm{T}$ ) or process knowledge (PK).

Names as they appear in the hazardous component section of the questionnaire without the EPA HAZNO

Total volume of waste stream generated during the year reported in cubic feet/year. This value includes only the reported firm values.

The upper estimate of the total volume of waste stream generated during the year reported in cubic feet/year. This value includes either the firm value, the upper values for less than estimates or the upper values for range estimates.

The lower estimate of the total volume of waste stream generated during the year reported in cubic feet/year. This value includes either the firm value or the lower values for range estimates.

Indicates whether the hazardous component is pure (P) or part of a mixture (M).

The year (2 digits) for which data vere reported.

An identification assigned by the ORNL committee.

Field for information found in the Mixed Waste section of the questionnaire not fitting one of the above fields. 


\section{Data Field Descriptions}

Three fields that would normally be found in the above file along with an internal and external counting number assigned in sequence and the identification number are in a subfile to the above file. This subfile will have a record for each chemical that is listed in the Hazardous name field.

SUB FILE ID: MIX_SUB.DBF

IDNUMBER Identification number Original assigned identifier.

COUNTNO Repeat for IDNUMBER A sequential number assigned to indicate the waste stream line number for a common ID number questionnaire. (Each waste stream line is numbered 101,102 , etc.)

HAZCHEM Name of hazardous chemical

CASRN CAS Registry number of chemical

EPAHAZNO EPA Hazardous Waste No. COUNTER Repeat for COUNTNO
Chemical name of one of the components of the hazardous component name (if only one is found in the above field it will repeated here)

Chemical Abstract Service Registry number for the preceding chemical.

FILE ID: TREATMEN.DBF

FILE NAME: Mired Waste treatment file (Section D-2 of the questionnaire)

DESCRIPTION:

FIEID ID FIEID NAME

IDNUMBER Identification number

FACCATEG Facility Category
This file contains information on each LLRW stream listed in the mixed waste file. It includes the major radionuclides, the $\mathrm{RAD}$ waste classification, the cumulative activity, treatment site, type of treatment, and the volume treated during the year.

\section{FIEID DESCRIPTION}

Original assigned identifier.

Categories are nuclear reactor, medica!, academic, industrial or government, entered as a code. (See Attachment 2) 


\section{Data Field Descriptions}

COUNTNO Repeat for IDNUMBER A sequential number assigned to indicate the record number for a common ID number questionnaire. (Lines of information are numbered 101, 102, etc.)

LLRWCODE LLRW waste stream code

MAJNUCLI Major radionuclides

$3 \mathrm{H}$

$14 \mathrm{C}$

$32 \mathrm{P}$

$59 \mathrm{NI}$

$63 \mathrm{NI}$

9OSR

$137 \mathrm{CS}$

$134 \mathrm{CS}$

$60 \mathrm{CO}$

$35 S$

$125 I$

51CR
Hydrogen-3

Carbon-14

Phosphorus-32

Nickel-59

Nickel-63

Strontium-90

Cesium-137

Cesium-134

Cobalt-60

Sulfur-35

Iodine-125

Chromium-51
A number found in Attachment 1 of the questionnaire identifying the LLRW waste stream containing hazardous materials.

Major radionuclides found in the LLRW waste stream.

True or false: the hydrogen-3 isotope is found in the waste stream.

True or false: the carbon-14 isotope is found in the waste stream.

True or false: the phosphorus-32 isotope is found in the waste stream.

True or false: the nickel-59 isotope is found in the waste stream.

True or false: the nickel-63 isotope is found in the waste stream.

True or false: the strontium-90 isotope is found in the waste stream.

True or false: the cesium-137 isotope is found in the waste stream.

True or false: the cesium-134 isotope is found in the waste stream.

True or false: the cobalt -60 isotope is found in the waste stream.

True or false: the sulfur-35 isotope is found in the waste stream.

True or false: the iodine-125 isotope is found in the waste stream.

True or false: the chromium-51 isotope is found in the waste stream. 


\section{Data Field Descriptions}

22NA Sodium-22

36CL Chlorine-36

$235 \mathrm{U}$

$239 U$

$65 \mathrm{ZN}$

207BI

$54 \mathrm{MN}$

59FE

133BA

CLASS Classification

MIXTPURE Mixture or Pure

CUMACTIV Cumulative Activity

ESUPCUAC Estimated upper cumulative activity

ESLOCUAC Estimated lower cumulative activity
True or false: the sodium-22 isotope is found in the waste stream.

True or false: the chlorine-36 isotope is found in the waste stream.

True or false: the uranium-235 isotope is found in the waste stream.

True or false: the uranium-239 isotope is found in the waste stream.

True or false: the zinc- 65 isotope is found in the waste stream.

True or false: the bismuth-207 isotope is found in the waste stream.

True or false: the manganese-54 isotope is found in the waste stream.

True or false: the iron-59 isotope is found in the waste stream.

True or false: the barium-133 isotope is found in the waste stream.

The radioactive waste classification $(A, B, C)$.

Indicates whether the radioactive component is pure (P) or part of a mixture (M).

Cumulative activity in millicuries for each waste during year reported. This value includes firm values, the upper values for less than estimates, and the upper values for range estimates.

Upper estimate of the cumulative activity in millicuries for each waste during year reported. This value includes the upper values for less than estimates and the upper values for range estimates.

Lower estimate of the cumulative activity in millicuries for each waste during year reported. This value includes only the lower value for range estimates. 


\section{Data Field Descriptions}

$\begin{array}{ll}\text { TREATSIT } & \text { Treatment On-Si } \\ \text { TREATTYP } & \text { Treatment type } \\ \text { VOLTREAT } & \text { Volume treated } \\ \text { ESUPVLTR } & \begin{array}{l}\text { Estimated upper } \\ \text { volume treated }\end{array}\end{array}$

ESLOVLTR Estimated lower volume treated

YEAR Year of questionnaire

GROUPID Group identification

COMMENT Comment
True or false: the waste was treated onsite.

Waste treatment, burned for energy, storage for decay, etc., entered as a code. (See Attachment 4)

Volume of mixed waste treated during the year reported in cubic feet. This value includes only the reported firm values.

Upper estimate for the volume of mixed waste treated during the year reported in cubic feet. This value includes the reported firm values, the upper values for less than estimates or the upper values for range estimates.

Lower estimate for the volume of mixed waste treated during the year reported in cubic feet. This value includes either the firm values or the lower values for range estimates.

Year (2 digits) for which data were reported.

An identification assigned by the ORNL committee.

Field for information found in the Mixed Waste radioactivity section of the questionnaire not fitting one of the above fields.

FIIE ID: TREA_WAS.DBF

FILE PJAME: Treated Mixed Waste file (Section D-3 of the questionnaire)

DESCRIPTION:

FIEID ID

FIELD NAME

IDNUMBER Identification numoer
This file contains information on the results of the treatment of each LLRW stream listed in the mixed waste file. It includes the after treatment volume, activity, and effect on the hazardous component, and the volume of the LLRW stream requiring ultimate disposal.

\section{FIEIDD DESCRIPTION}

Original assigned identifier. 


\section{Data Field Descriptions}

FACCATEG Facility Category

COUNTNO Repeat for IDNUMBER

LLRWCODE LLRW waste stream code

TREATVOL After treatment volume

MIXTPURE Mixture or Pure

ESUPTRVL Estimated upper after treat volume

ESLOTRVL Estimated lower after treat volume

TREATACT After treatment activity

ESUPTRAC Estimated upper after treat activity

ESLOTRAC Estimated lower after treat activity

TRTHAZCO Hazardous component
Categories are nuclear reactor, medical, academic, industrial or government, entered as a code. (See Attachment 2)

A sequential number assigned to indicate the record number for a common ID number questionnaire. (Lines of information will be 101, 102, etc.)

A number from Attachment 1 of the questionnaire identifying the LLRW waste stream containing hazardous materials.

The volume (cubic feet) of the mixed waste after treatment. This value includes only the reported firm values.

Indicates whether the hazardous component is pure (P) or part of a mixture (M).

Upper estimate of the volume (cubic feet) of the mixed waste after treatment. This value includes the reported firm value, the upper values for less than estimates or the upper values for range estimates.

Lower estimate of the volume (cubic feet) of the mixed waste after treatment. This value includes the firm values or the lower values for range estimates.

Radioactivity of the mixed waste after treatment. This value includes firm values, the upper values for less than estimates, and the upper values for range, estimates.

Upper estimate of the radioactivity of the mixed waste after treatment. This value includes the upper values for greater than estrastes and the upper values for range estimates.

Lower estimate of the radioactivity of the mixed waste after treatment. This value includes only the lower value for range estimates.

Efitw of the trastinent on the hazardous component in the mined wate. 


\section{Data Field Descriptions}

VOLDISPO Volume for disposal

ESUPVLDS Estimated upper volume for disposal

ESLOVLDS Estimated lower volume for disposal

YEAR Year of questionnaire

GROUPID Group identification

COMMENT Comment
Volume (cubic feet) of the mixed waste remaining after treatment requiring ultimate disposal. This value includes only the firm values.

Upper estimate of the volume (cubic feet) of the mixed waste remaining after treatment requiring ultimate disposal. This value includes the firm values, the upper values for greater than estimates or the upper values for range estimates.

Lower estimate of the volume (cubic feet) of the mixed waste remaining after treatment requiring ultimate disposal. This value includes either the firm values or the lower values for range estimates.

Year (2 digits) for which data were reported.

An identification assigned by the ORNL committee.

Field for information found in the treated Mixed Waste section of the questionnaire not fitting one of the above fields.

FILE ID: STOR_WAS.DBF

FILE NAME: Stored Mixed Waste file (Section E-1 of the questionnaire)

DESCRIPTION:

FIELD ID FIELD NAME

IDNUMBER Identification number

FACCATEG Facility Category
This file contains information on stored mixed waste streams. Information includes the physical form and the basis for that judgement, the hazardous component and its source, and the cumulative amount in storage at the end of the reporting year.

\section{FIEID DESCRIPTION}

Original assigned identifier.

Categories are nuclear reactor, medical, academic, industrial or government, entered as a code. (See Attachment 2) 


\section{Data Field Descriptions}

COUNTNO Repeat for IDNUMBER

LLRWCODE LLRW waste stream code

PHYSFORM Physical form

BASIS Basis

HAZNAME Name of hazardous component

SOURCE Source of hazardous component

AMTSTORD Amount stored

MIXTPURE Mixture or Pure

ESUPAMST Upper estimate of amount stored

ESLOAMST Lower estimate of amount stored

YEAR Year of questionnaire

GROUPID Group identification

COMMENT Comment
A sequential number assigned to indicate the waste stream line number for a common ID number questionnaire. (Each waste stream line will be numbered 501, 502, etc.))

Number from Attachment 1 of the questionnaire identifying the LLRW waste stream containing hazardous materials.

Physical form of the waste (aqueous, bulk liquid, compacted solid, etc.).

Basis for judgement of constituents and characteristics of waste. Choices are tested (T) or process knowledge (PK).

Names as they appear in the hazardous component name section of the questionnaire without the EPA HAZ NO

Cumulative amount (cubic feet/year) of mixed waste in storage as of December 31 of reporting year. This value includes firm values only.

Indicates whether the hazardous component is pure (P) or part of a mixture (M).

Upper estimate of the cuinulative amount (cubic feet/year) of mixed waste in storage as of December 31 of the reporting year. This value includes the firm values, the upper values for less than estimates or the upper values for range estimates.

Lower estimate of the cumulative amount (cubic feet/year) of mixed waste in storage as of December 31 of the reporting year. This value includes either the firm value or the lower values for range estimates.

Year (2 digits) for which data were reported.

An identification assigned by the ORNL committee.

Field for information found in the stored Mixed Waste 


\section{Data Field Descriptions}

section of the questionnaire not fitting one of the above fields.

Three fields that would normally be found in the above file along with an internal and external counting number assigned in sequence and the identification number are in a subfile to the above file. This subfile will have a record for each chemical that is listed in the Hazardous name field.

\section{SUB FILE ID: STOR_SUB.DBF}

IDNUMBER Identification number Original assigned identifier.

COUNTNO Repeat for IDNUMBER A sequential number assigned to indicate the waste stream line number for a common ID number questionnaire. (Each waste stream line will be numbered 501, 502, etc.))

HAZCHEM Name of hazardous chemical

Chemical name of one of the components of the hazardous component name (if only one component is found in the above field it will repeated here)

CASRN CAS Registry number of chemical

Chemical Abstract Service Registry number for the preceding chemical.

EPAHAZNO EPA Hazardous Waste No. This number from Attachment 2 of the questionnaire. It should be selected by using the chemical name listed above.

COUNTER Repeat for COUNTNO

A sequential number assigned to identify each individual chemical contained in the hazardous mixture. (Numbers will be $1,2,3$, etc.)

FILE ID: RADIOACT.DBF

FILE NAMiE: Radioactivity of stored Mixed Waste file (Section E-2 of the questionnaire) DESCRIPTION:

This file contains information on the major radionuclides in the stored mixed waste. Ii iricludes the major radionuclides, RAD waste classification, cumulative activity, and reason for storage.

FIELD ID FIELD NAME FIELD DESCRIPTION

IDNUMBER Identification number Original assigned identifier. 


\section{Data Field Descriptions}

FACCATEG Facility Category

COUNTNO Repeat for IDNUMBER

LLRWCODE LLRW waste stream code

MAJNUCLI Major radionuclides

$3 \mathrm{H}$

$14 \mathrm{C}$

32P

$59 \mathrm{~N}$

$63 \mathrm{NI}$

9OSR

$137 \mathrm{CS}$

$134 \mathrm{CS}$

$60 \mathrm{CO}$

$35 S$

$$
\text { Hydrogen-3 }
$$

Carbon-14

Phosphorus-32

Nickel-59

Nickel-63

Strontium-90

Cesium-137

Cesium-134

Cobalt- 60

Sulfur-35
Categories are nuclear reactor, medical, academic, industrial or government, entered as a code. (See Attachment 2)

A sequential number assigned to indicate the record number for a common ID number questionnaire. (Lines of information will be numbered 101, 102, etc.)

A number from Attachment 1 of the questionnaire which identifies the LLRW waste stream containing hazardous materials.

List of the major radionuclides found in the LLRW waste stream.

True or false: the hydrogen- 3 isotope is found in the waste stream.

True or false: the carbon-14 isotope is found in the waste stream.

True or false: the phosphorus-32 isotope is found in the waste stream.

True or fulse: the nickel-59 isotope is found in the waste stream.

True or false: the nickel-63 isotope is found in the waste stream.

True or false: the strontium-90 isotope is found in the waste stream.

True or false: the cesium-137 isotope is found in the waste stream.

True or false: the cesium-134 isotope is found in the waste stream.

True or false: the cobalt-60 isotope is found in the waste stream.

True or false: the sulfur-35 isotope is found in the waste stream. 


\section{Data Field Descriptions}

$125 I$

51CR

22NA

$36 \mathrm{CL}$

$235 \mathrm{U}$

$239 U$

$65 Z N$

207BI

$54 \mathrm{MN}$

59FE

133BA

CLASS

CUMACTIV Cumulative Activity

MIXTPURE Mixture or Pure

ESUPCUAC Upper estimate of cumulative activity
True or false: the iodine-12S isotope is found in the waste stream.

True or false: the chromium-51 isotope is found in the waste stream.

True or false: the sodium-22 isotope is found in the waste stream.

True or false: the chlorine-36 isotope is found in the waste stream.

True or false: the uranium-235 isotope is found in the waste stream.

True or false: the uranium-239 isotope is found in the waste stream.

True or false: the zinc-65 isotope is found in the waste stream.

True or false: the bismuth-207 isotope is found in the waste stream.

True or false: the manganese-54 isotope is found in the waste stream.

True or false: the iron-59 isotope is found in the waste stream.

True or false: the barium-133 isotope is found in the waste stream.

Radioactive waste classification (A, B, C).

Cumulative activity in millicuries for each mixed waste as of December 31 of the reporting year. This value includes firm values, the upper values for less than estimates, and the upper values for range estimates.

Indicates whether the radioactive component is pure (P) or part of a mixture (M).

Upper estimate of the cumulative activity in millicuries for each mixed waste as of December 31 of the reporting year. This value includes the upper values 


\section{Data Field Descriptions}

for less than estimates and for range estimates.

ESLOCUAC $\begin{aligned} & \text { Lower estimate of } \\ & \text { cumulative activity }\end{aligned}$

REASSTOR Reason stored

YEAR Year of questionnaire

GROUPID Group identification

COMMENT Comment
Lower estimate of the cumulative activity in millicuries for each mixed waste as of December 31 of the reporting year. This value includes only the lower values for range estimates.

Reason for the mixed waste storage (storage for decay, unable to treat, unable to ship, etc.). (See Attachment 5)

Year (2 digits) for which data were reported.

An identification assigned by the ORNL committee.

Field for information found in the radioactivity of stored Mixed Waste section of the questionnaire not fitting one of the above fields. 


\section{ATTACHMENT 1}

\section{Decode for IDNUMBER}

This field will be a 6 character alphanumeric field as follows:

1st position: $\quad \mathbf{U}$ - Utilities

M - Medical

A - Academic

I - Industrial

G - Government

2nd position: 1 - ORNL list

2 - Shippers List Excluding ORNL list

3 - NRC with EPA permit

4 - NRC without EPA Permit

3rd, 4th, 5th, 6th position: 1 to 9999, assigned by ORNL committee and is the sample number. 


\section{ATTACHMENT 2}

\section{IACILITY CATEGORY DECODE FILE (FACCATEG)}

$\begin{array}{cc}\text { Nuclear Reactor Facility } & 100 \\ \text { Boiling Water Reactor } & 110 \\ \text { Pressurized Water Reactor } & 120 \\ \text { Research \& Test Reactors } & 130 \\ & \\ \text { Medical (non-Federal) } & 200 \\ \text { Hospital } & 210 \\ <250 \text { beds } & 211 \\ 250-750 \text { beds } & 212 \\ >750 \text { beds } & 213 \\ \text { Medical college/hospital } & 220 \\ \text { Laboratory } & 230 \\ \text { Research } & 240\end{array}$

Academic $\quad 300$

$<10,000$ students $\quad 310$

$10,000-20,000$ students $\quad 320$

$>20,000$ students $\quad 330$

Industrial $\quad 400$

Manufacturing $\quad 410$

$<50$ employees on site $\quad 411$

50-200 employees on site 412

$>200$ employees on site $\quad 413$

Research and Development $\quad 420$

Decontamination facility \& waste

reduction 430

Sealed source/gauge/instrument
user

Waste broker/processor $\quad 450$

Nuclear fuel cycle other than power reactors $\quad 460$

Commercial radiopharmacy $\quad 470$

Government $\quad 500$

Federal $\quad 510$

Hospital 511

Research \& Development 512

Military 513

State $\quad 520$

Other 530*

* 530 is for any type of facility which appears frequently in the questionnaires and does not have a category listed. 


\section{ATTACHMENT 3}

\section{DECODE FOR EPA FACILITY CLASSIFICATION(EPACLASS)}

Large quantity generator $(>1000 \mathrm{Kg} /$ month $) \quad$ LQ

Small quantity generator $(100-1000 \mathrm{Kg} /$ month $) \quad$ SQ

Conditionally exempt small quantity generator ( $<100 \mathrm{Kg} /$ month) $\quad$ CON

No EPA Calssification NO 


\section{ATTACHMENT 4 \\ TREATMENT TYPE DECODE FILE}

Burned for energy 1

Evaporation 2

Incineration 3

Not treated

Radioactive contaminant removal 5

Solidification 6

$\begin{array}{ll}\text { Storage for decay } & 7\end{array}$

$\begin{array}{ll}\text { Compaction } & 8\end{array}$

$\begin{array}{ll}\text { Neutralization } & 9\end{array}$

$\begin{array}{ll}\text { Filtration } & 10\end{array}$ 


\section{ATTACHMENT 5 \\ REASON STORED DECODE FILE}

Accumulation

10

Evaluating options

20

Holding for deregulation

30

Storage for decay

40

Unable to treat

50

Unable to ship

60

Using as a shield

70 
APPENDIX D

DETAIIED "AS REPORTED" DATA TABLES 
Table D.1 Mixed waste generated in 1990 [As reported $\left(\mathrm{ft}^{3}\right)$ ]

\begin{tabular}{|c|c|c|c|c|c|c|}
\hline & \multicolumn{6}{|c|}{ Facility categary } \\
\hline & Academic & Government & Industrial & Medical & $\begin{array}{l}\text { Nuctear } \\
\text { utilities }\end{array}$ & Total \\
\hline Northeast Compact $(7 y)^{1}$ & 283 & 4 & 1,216 & 217 & 62 & 1,782 \\
\hline Appalachian Compact (136) ${ }^{1}$ & 1,882 & 11,989 & 3,148 & 474 & 1,388 & 18,881 \\
\hline Southeast Compact (131) ${ }^{1}$ & 3,284 & 3,566 & 5,896 & 2,923 & 2,687 & 18,356 \\
\hline Central States Compact $(30)^{1}$ & 352 & 42 & 8 & 54 & 232 & 688 \\
\hline Midwest Compact $(166)^{1}$ & 6,359 & 448 & 4,614 & 201 & 860 & 12,482 \\
\hline Central Midwest Compact (47) & 1,531 & 787 & 640 & 770 & 2,610 & 6,338 \\
\hline Rocky Mountain Compact (11) ${ }^{1}$ & 135 & 9 & 120 & $0^{2}$ & $0^{3}$ & 264 \\
\hline Northwest Compact (48) ${ }^{1}$ & 781 & 469 & 42 & 384 & 30 & 1,706 \\
\hline Southwestern Compact (125) ${ }^{1}$ & 2,547 & 160 & 2,143 & 2,401 & 5,010 & 12,261 \\
\hline \multicolumn{7}{|l|}{ Unaligned } \\
\hline$D C(11)^{1}$ & 140 & 533 & $0^{2}$ & 4 & $0^{4}$ & 677 \\
\hline $\operatorname{ME}(7)^{1}$ & 10 & $0^{2}$ & $0^{3}$ & $0^{3}$ & 112 & 122 \\
\hline MA $(77)^{1}$ & 1,666 & 23 & 637 & 599 & 70 & 2,995 \\
\hline $\mathrm{NH}(3)^{1}$ & $0^{2}$ & $0^{3}$ & $0^{2}$ & $0^{2}$ & $0^{3}$ & $0^{3}$ \\
\hline NY $(110)^{1}$ & 982 & 249 & 575 & 1,109 & 160 & 3,075 \\
\hline $\operatorname{PR}(0)^{1}$ & $0^{5}$ & $0^{5}$ & $0^{5}$ & $9^{2}$ & $0^{4}$ & $0^{3}$ \\
\hline RI (1) ${ }^{1}$ & $0^{2}$ & $0^{2}$ & $0^{2}$ & $0^{3}$ & $0^{4}$ & $0^{3}$ \\
\hline $\operatorname{TX}(27)^{1}$ & 269 & 45 & 17 & 1,015 & 27 & 1,373 \\
\hline VT $(5)^{1}$ & 200 & $0^{2}$ & $0^{3}$ & $0^{2}$ & 27 & 227 \\
\hline TOTAL $(1,014)^{1}$ & 20,421 & 18,324 & 19,056 & 10,151 & 13,275 & 81,227 \\
\hline
\end{tabular}

${ }^{1}$ Numbers in ( ) represent the number of facilites returning questionnaires within this compact/atate.

${ }^{2}$ No facilities were surveyed in this particular category (e.g., no industrial facilities were surveyed in New Hampahire).

${ }^{3}$ At least one facility in this category within the compact/state returned a MW survey and all facilitics returning surveys in this caicgory and within the compact/state reported generating no mixed waste.

No facilities are present in this category within the compact/state (i.e., nuclear reactor in DC, PR, \& RD).

${ }^{5}$ Facilities were surveyed in this category, but none of theac facilities returned their surveye. 


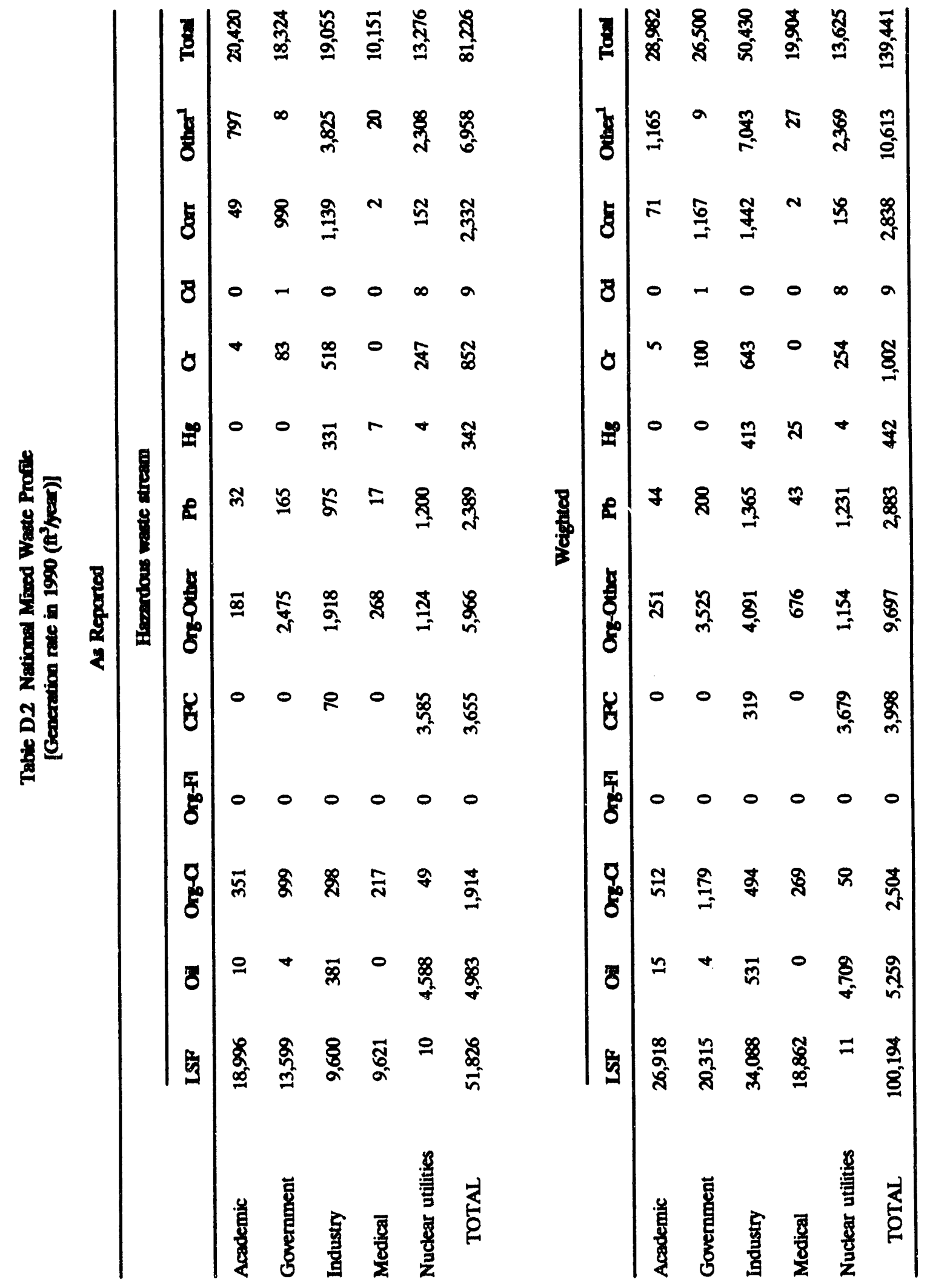




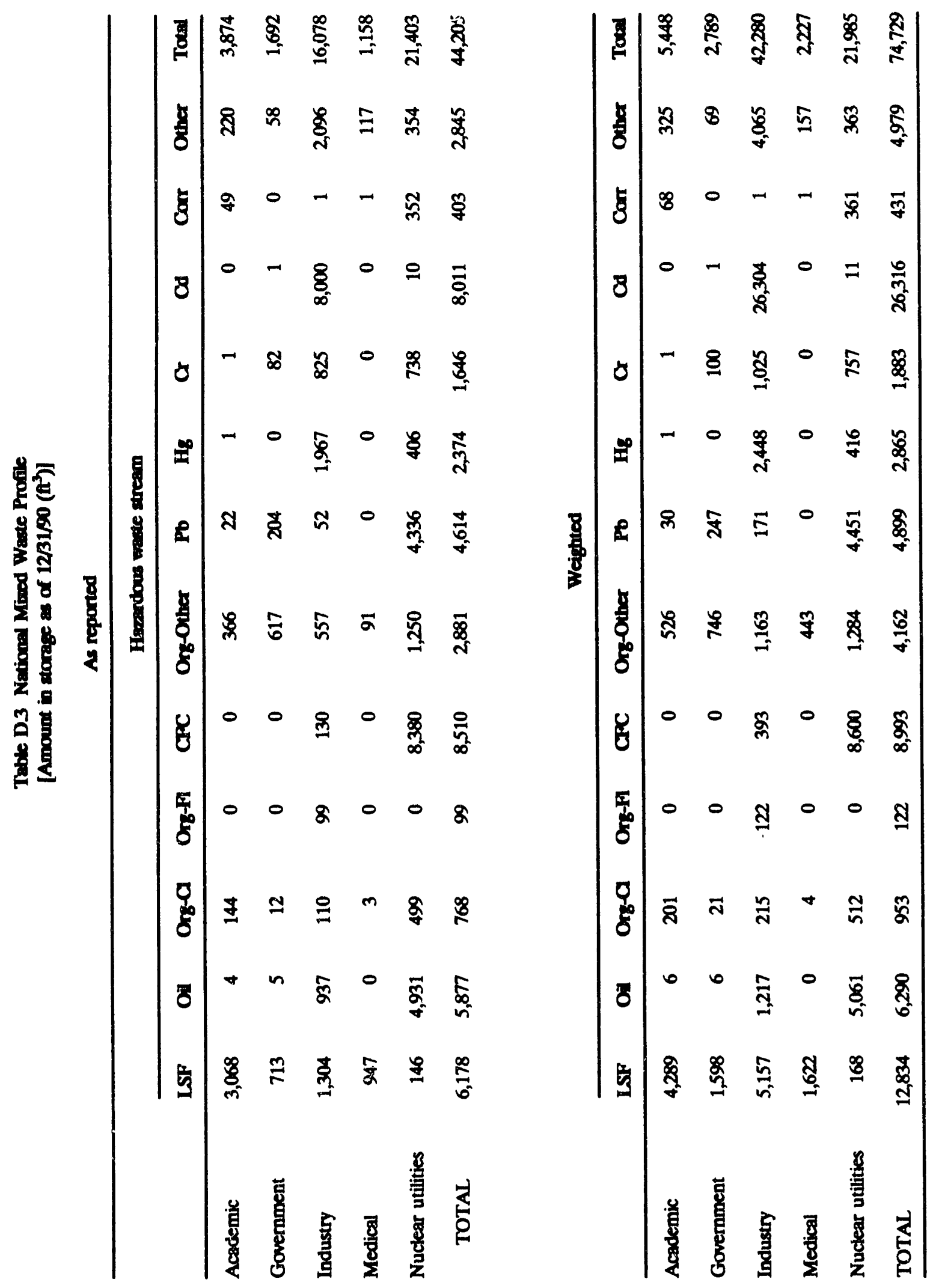




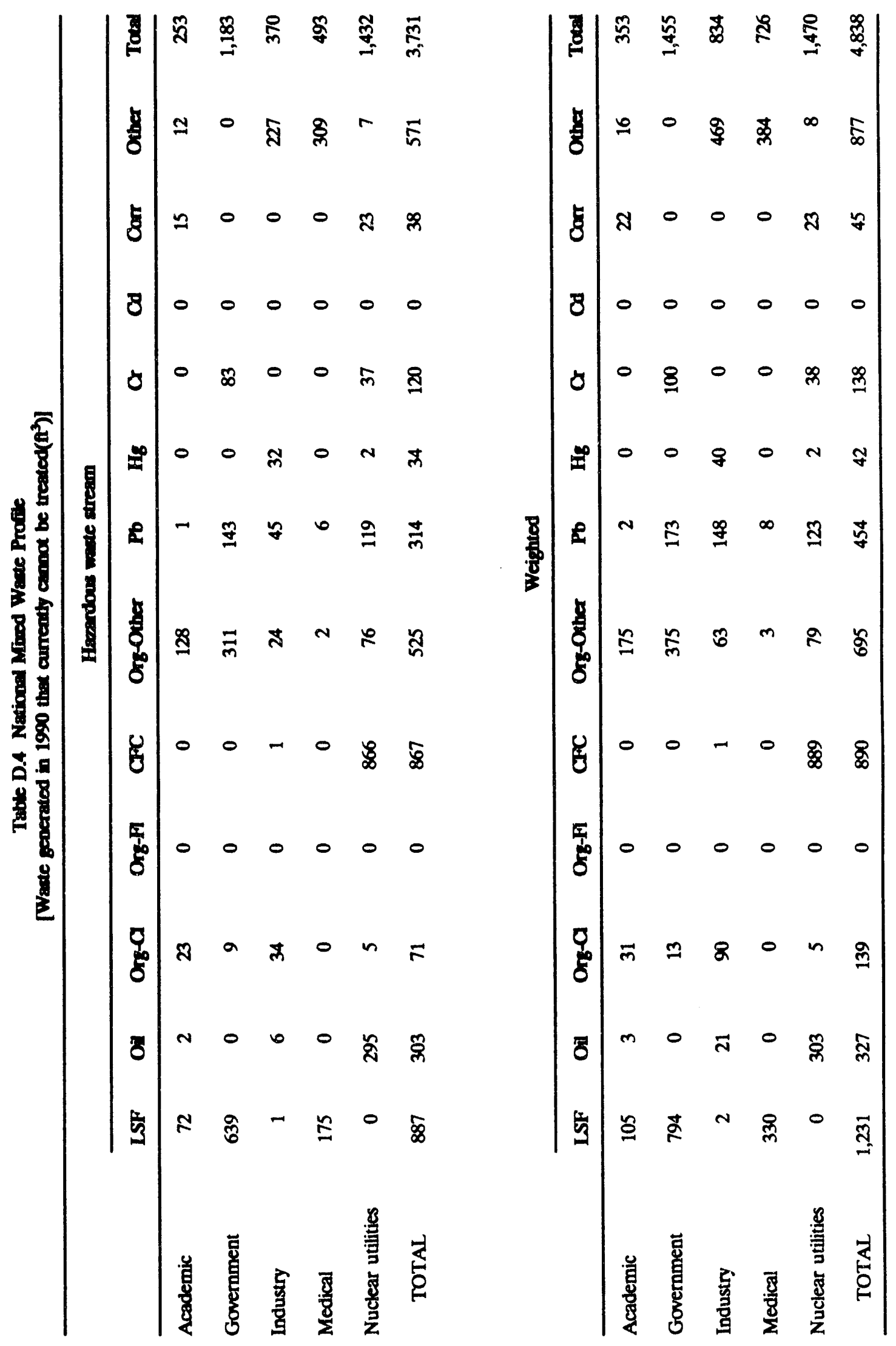




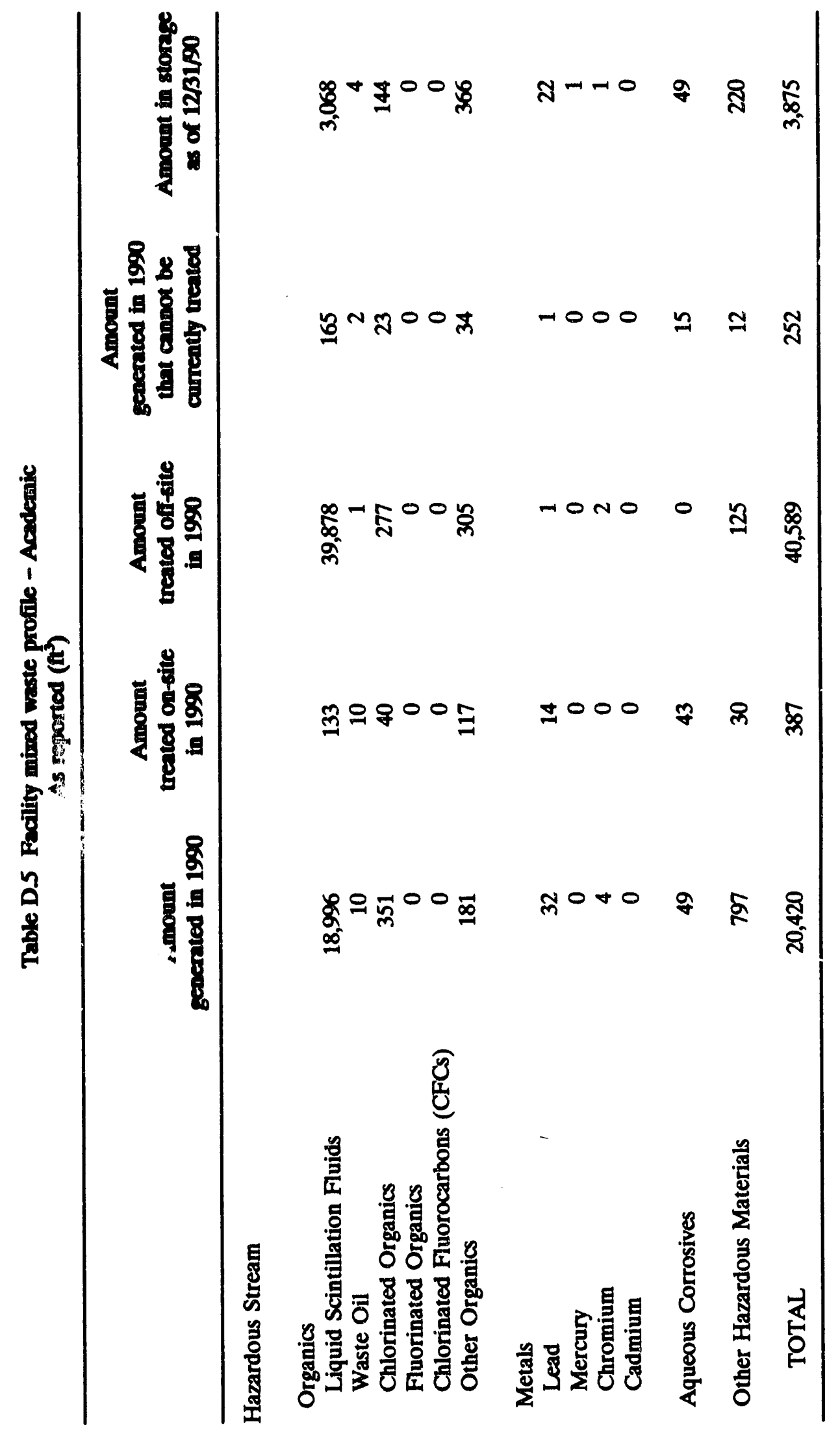




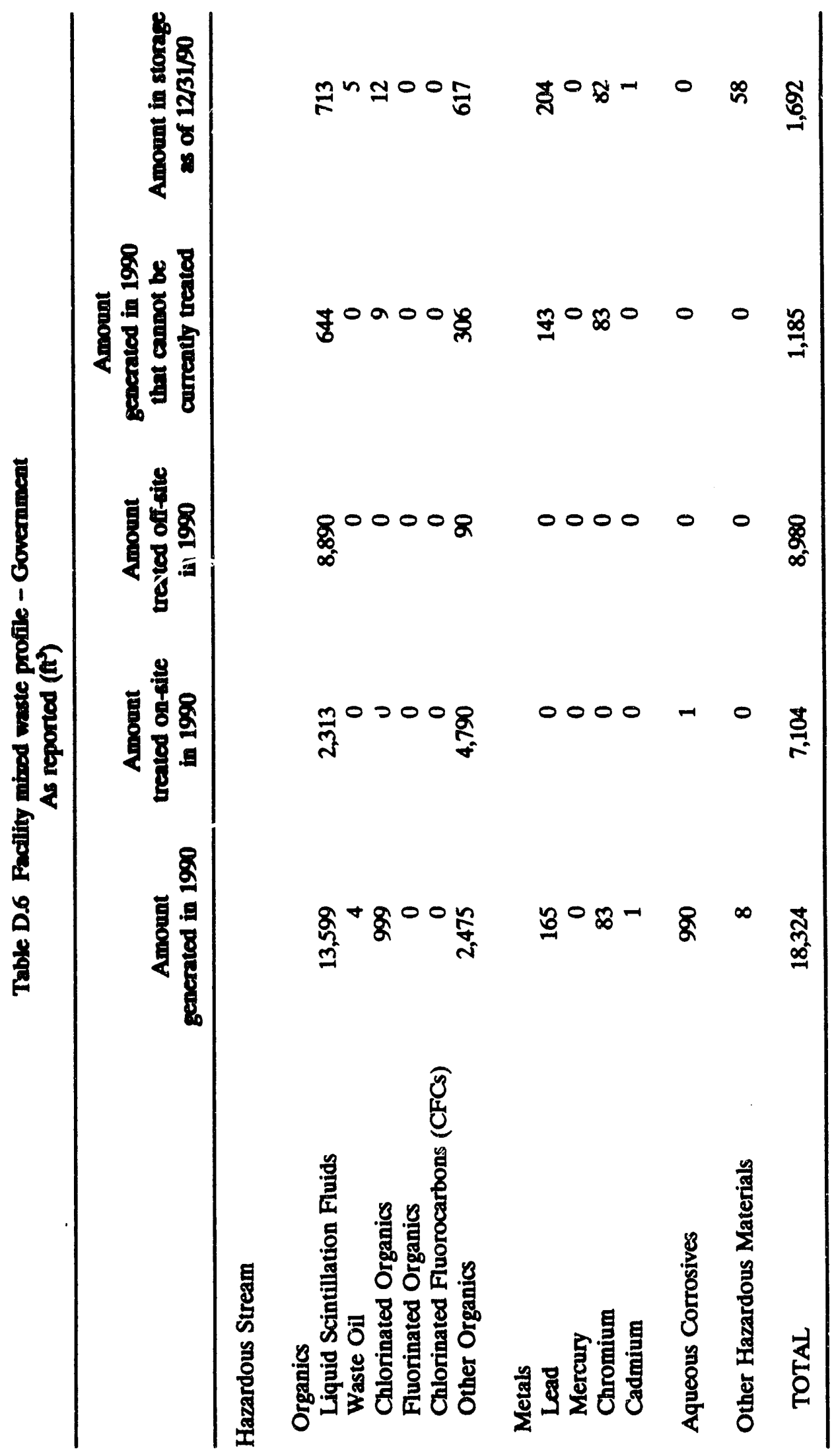




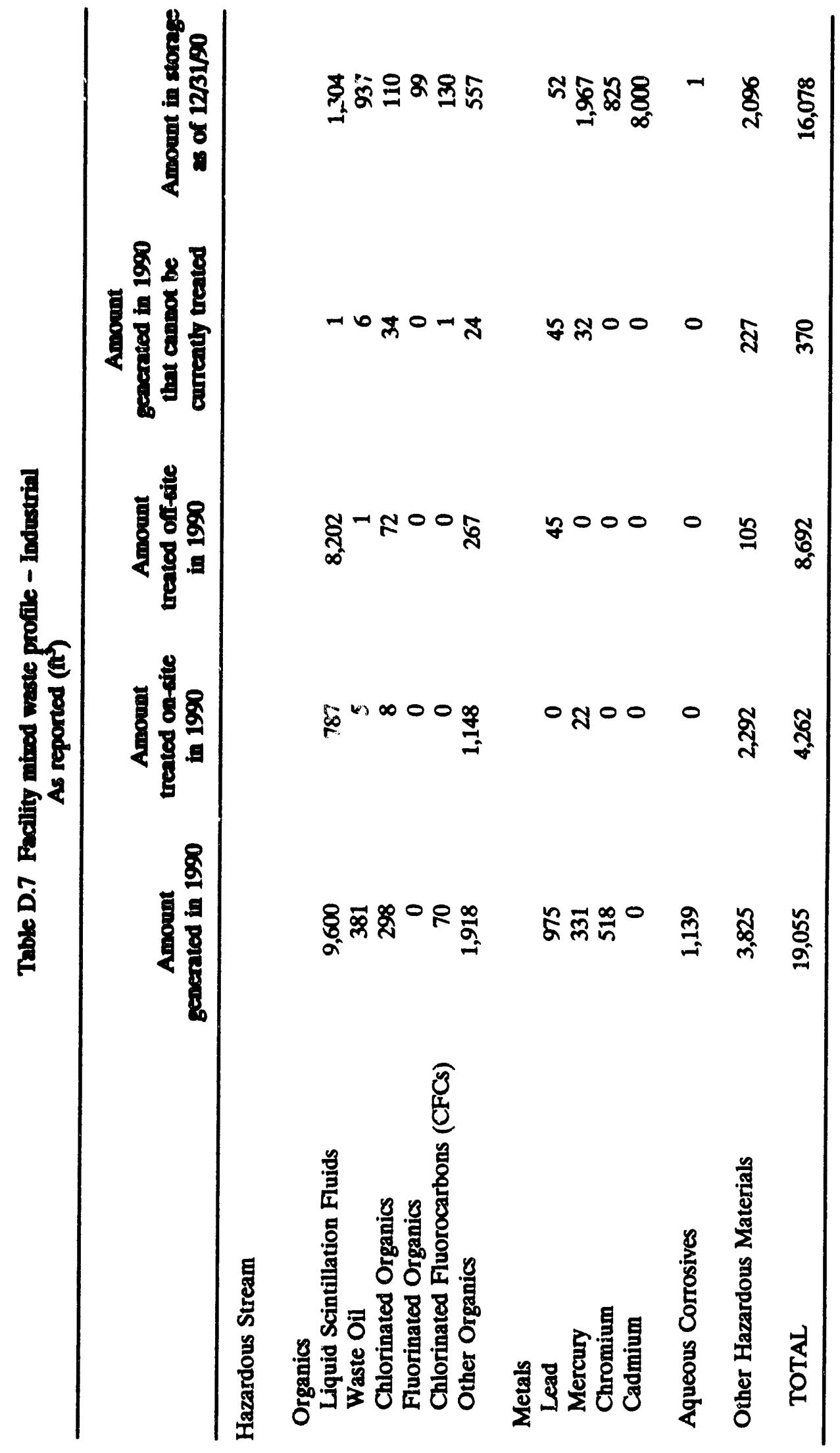




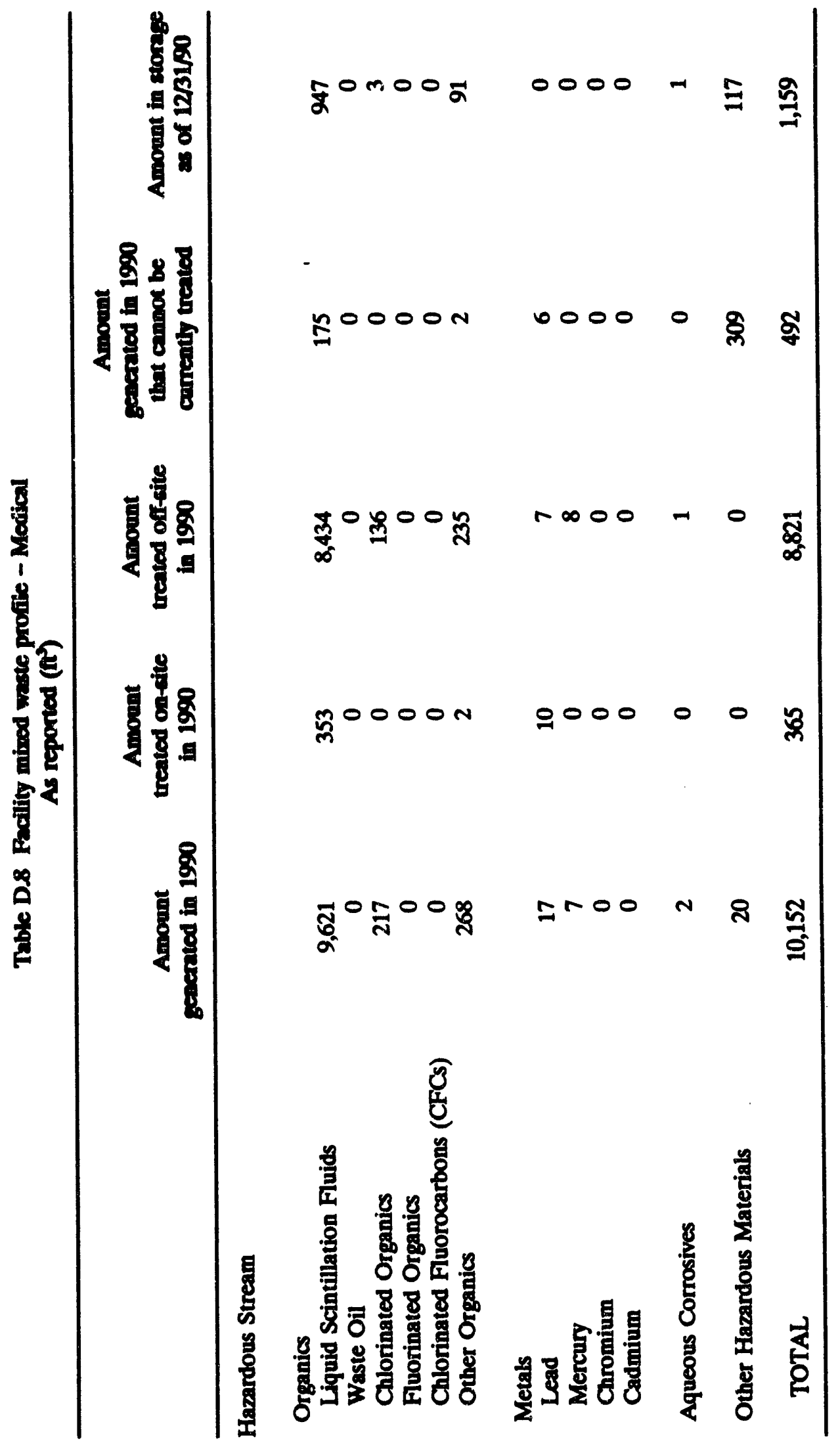




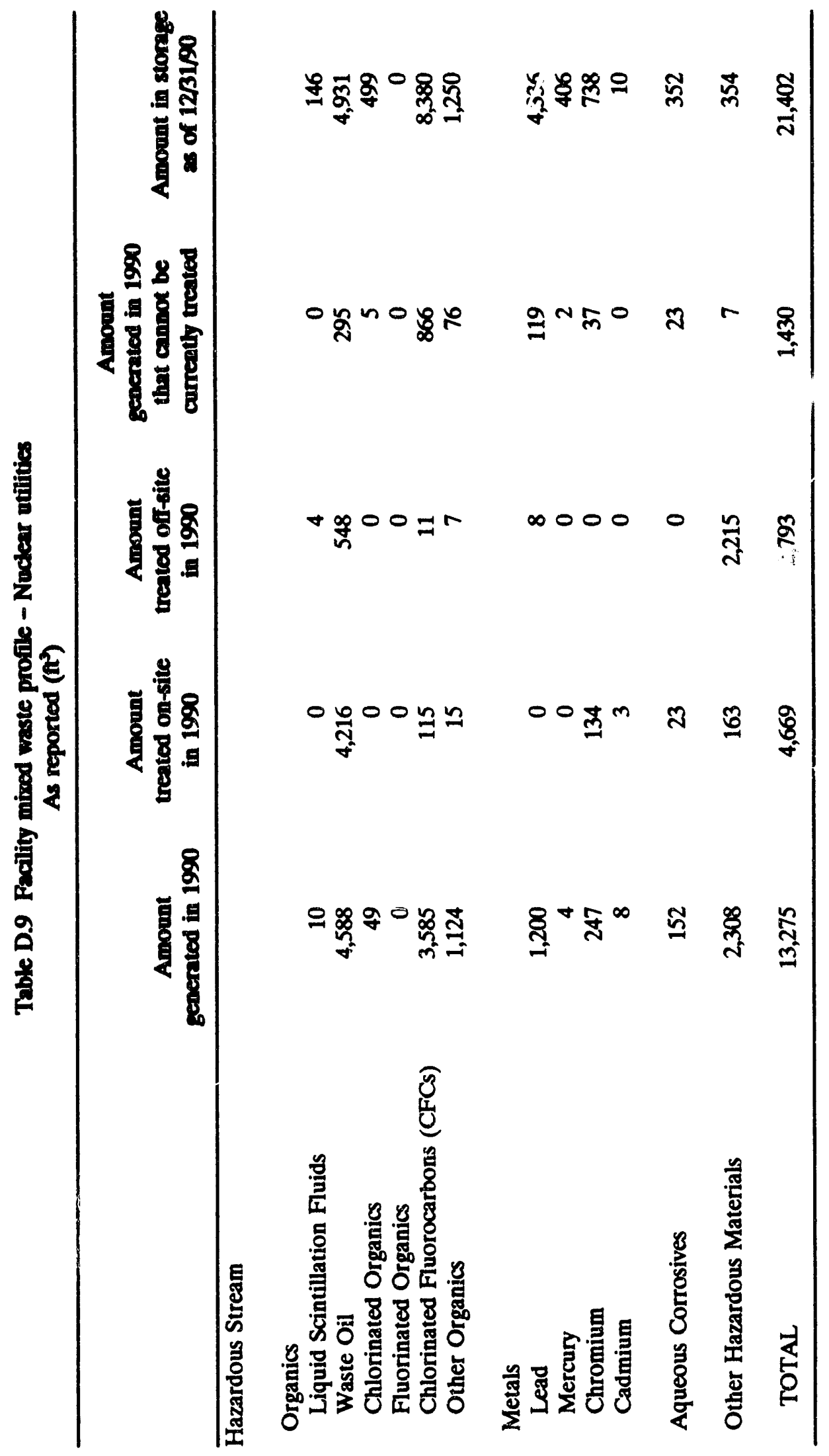




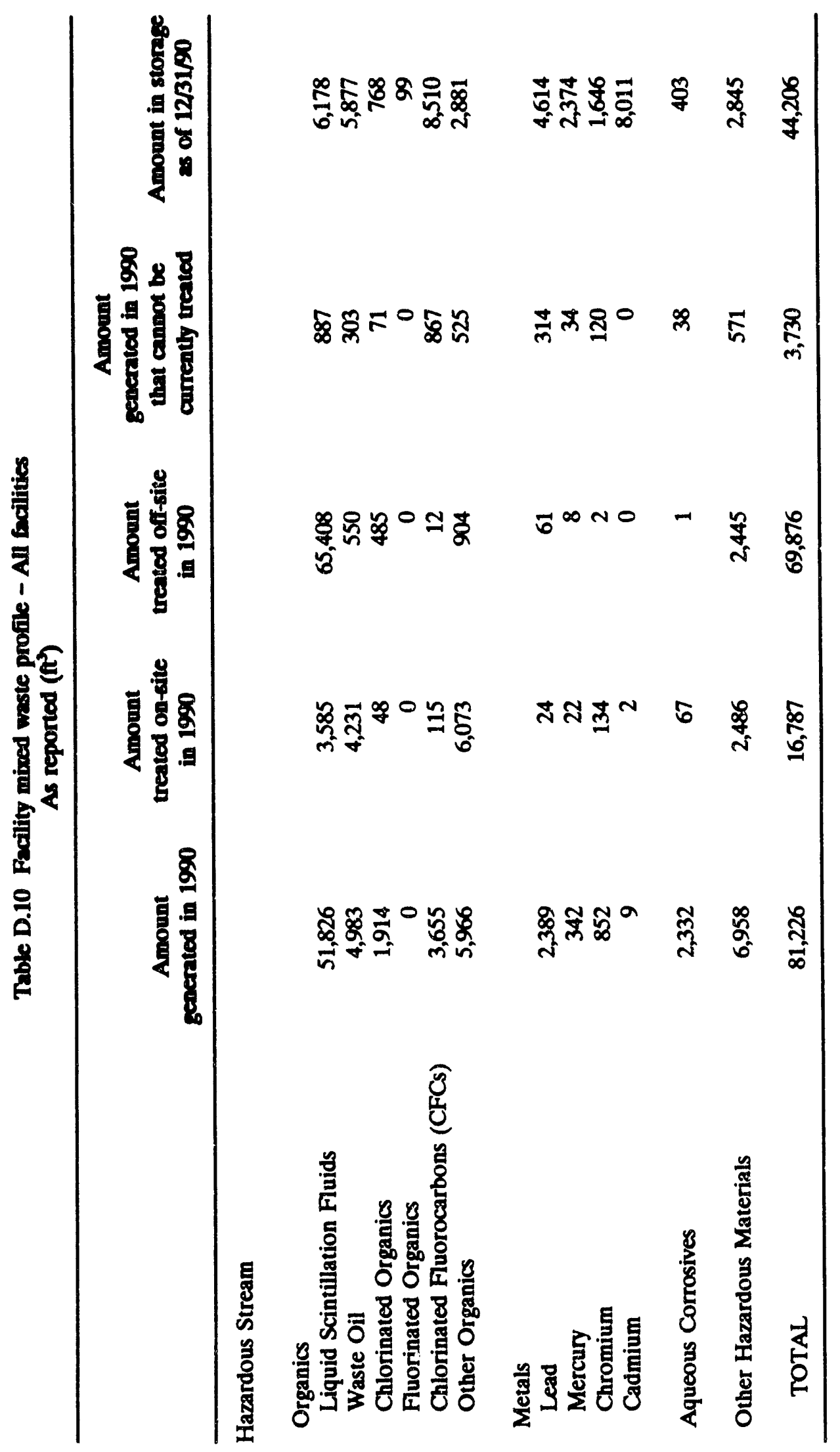


Table D.11 National Mired Waste Profile

[Amount generated in 1990 (F)]

Hamrous stream = other

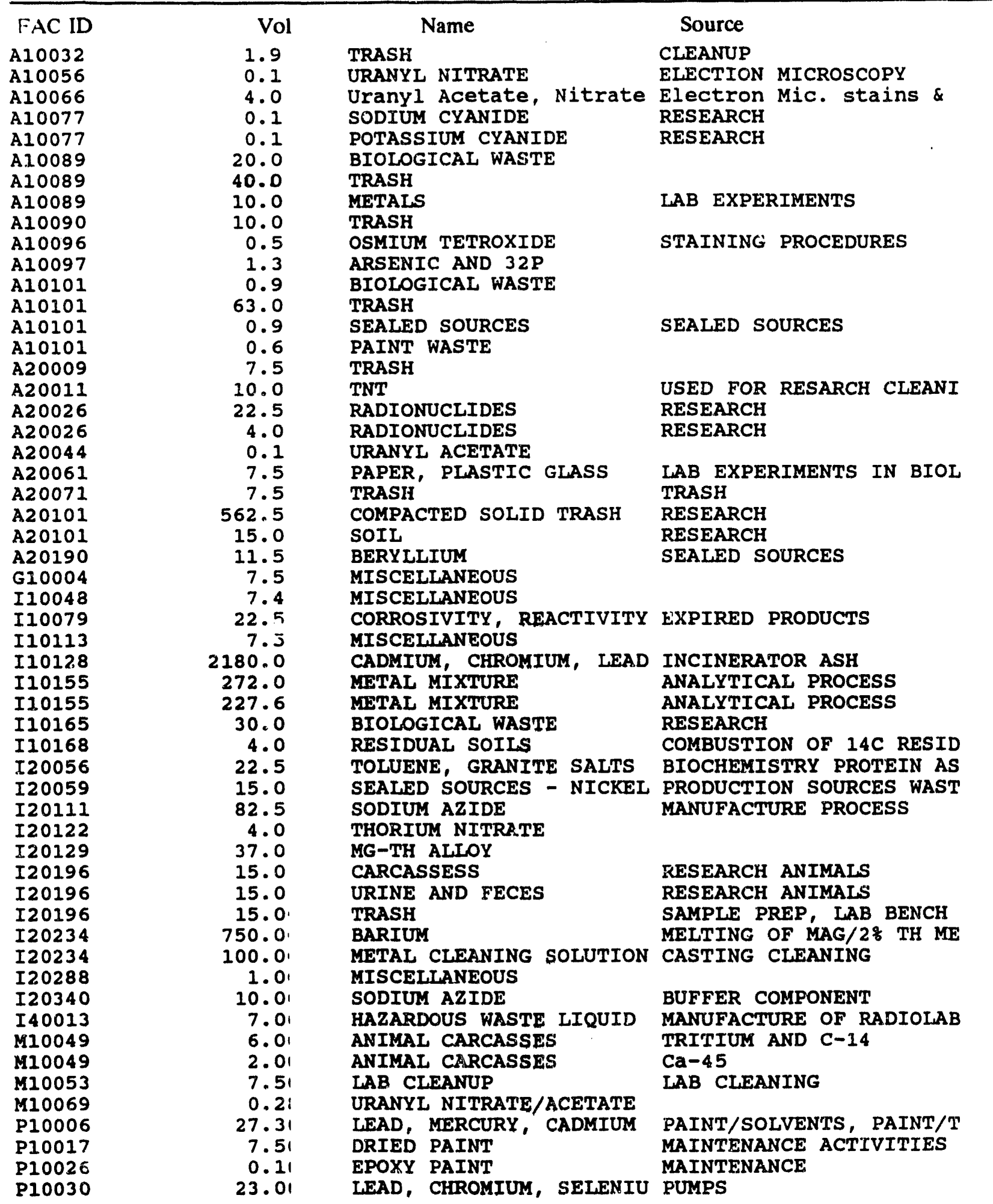


Table D.11 (continued)

\begin{tabular}{|c|c|c|c|}
\hline FAC ID & Vol & Name & Source \\
\hline $\begin{array}{l}\text { PI0040 } \\
\text { P10042 } \\
\text { P10042 } \\
\text { P10045 } \\
\text { P10048 } \\
\text { P10048 }\end{array}$ & $\begin{aligned} & 15 \cdot 0 \\
& 2188 \cdot 0 \\
& 7 \cdot 5 \\
& 5 \cdot 0 \\
& 10.0 \\
& 25 \cdot 0\end{aligned}$ & $\begin{array}{l}\text { LEAD, CADMIUM, CARBON T } \\
\text { LEAD, OII, SOLVENTS AND } \\
\text { PROCESSING USED OIL/ ILEA } \\
\text { CCRROSIVE LIQUID, CADMI } \\
\text { LEAD, MERCURY, BARIUM, } \\
\text { IGNITABLE, MERCURY, BAR }\end{array}$ & $\begin{array}{l}\text { SPENT SOLVENTS - DEGREA } \\
\text { EQUIPMENT MAINTENANCE } \\
\text { FILTER BAGS } \\
\text { EQUIPMENT REPAIR/REPLAC } \\
\text { DECONTAMINATION } \\
\text { MAINTENANCE ACTIVITIES }\end{array}$ \\
\hline
\end{tabular}

Total $\quad 6,958$

Notes:

The first column is the facility ID Number: $A=$ Academic, $G=$ Government, $I=$ Industrial, $M=$ Medical, $\mathrm{P}=$ Nuclear Power Facilities.

The second column is the amount of this type waste generated in 1990. The decision to place a particular waste stream in the "Other " category was made by ORNL, based on information provided in the next two columns and on other information contained in the completed questionnaire.

The third and fourth column contain abbreviated comments on the hazardous name and source that give some indication of the type of material present in this stream. 
APPENDIX E

ESTIMATION PROCEDURES 


\section{ESTIMATION PROCEDURES \\ National Proffle on Commercially Generated \\ Low-Level Radioactive Mixed Waste}

The steps for estimation of volumes related to the National Profile on Commercially Generated Low-Level Radioactive Mixed Wastes and consistent with stratified random sampling as presented in Appendix A of "Technical Letter Report for Task Three FIN L-16470," September 30, 1991, and in Appendix A of this report, are as follows.

Step 1. Assume that the original frame construction placed each facility in its correct stratum $i j$ as indicated in Table 1. At this point, the extent to which this assumption is false is believed to be negligible.

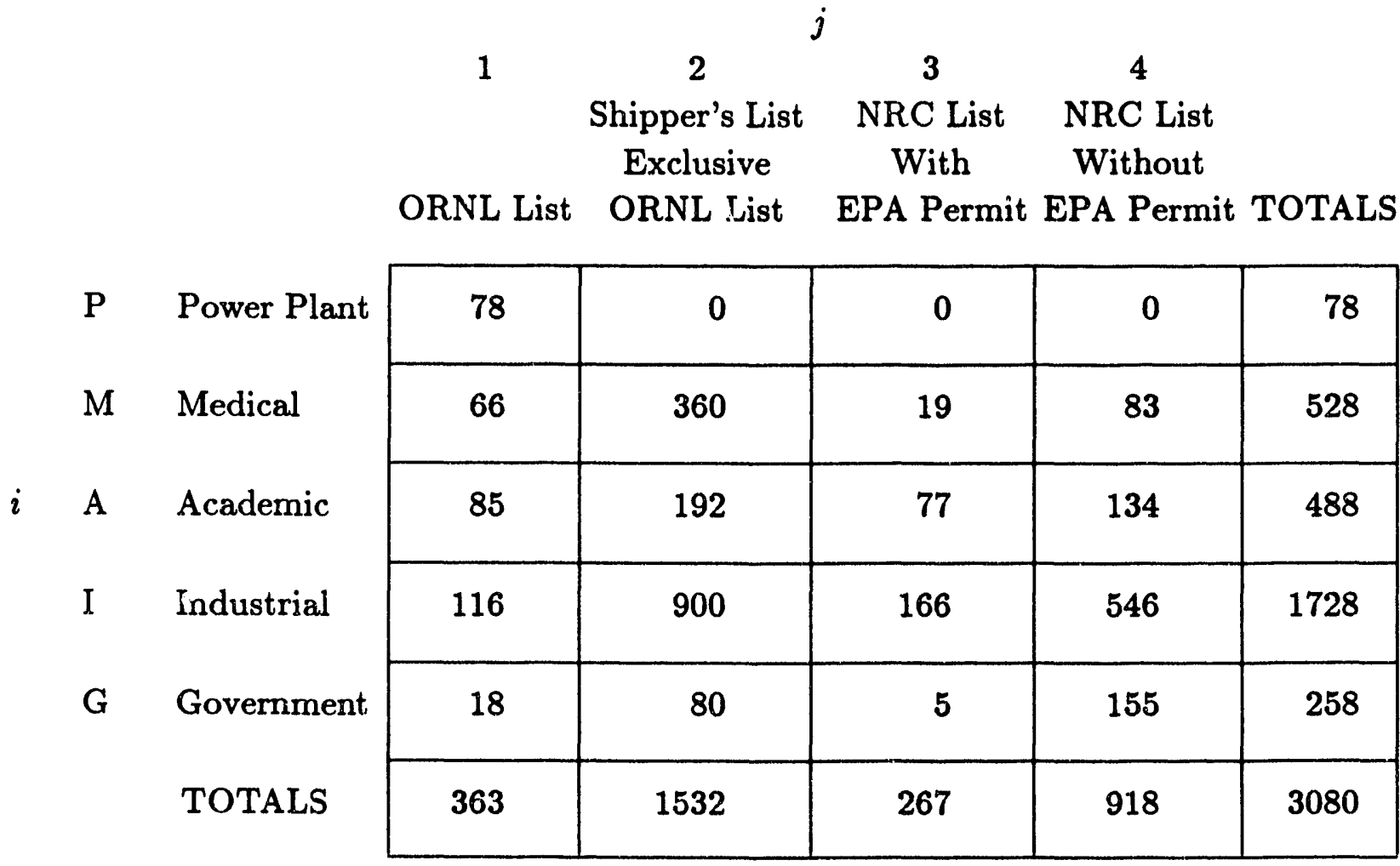

TABLE 1. Original (Sampled) Universe Sizes 
Step 2. A stratified random sample of size 1334 was selected (i.e., a simple random sample was selected within each stratum and independently of the other strata) as shown in Table 2.

\begin{tabular}{|c|c|c|c|c|c|c|}
\hline & & & & & & \\
\hline & & 1 & 2 & 3 & 4 & \\
\hline & & & Shipper's List & NRC List & NRC List & \\
\hline & & & Exclusive & With & Without & \\
\hline & & ORNL List & ORNL List & EPA Permit & EPA Permit & TOTALS \\
\hline$P$ & Power Plant & 78 & 0 & 0 & 0 & 78 \\
\hline M & Medical & 66 & 95 & 1 & 4 & 166 \\
\hline A & Academic & 85 & 192 & 77 & 44 & 398 \\
\hline I & Industrial & 116 & 355 & 24 & 39 & 534 \\
\hline G & Government & 18 & 30 & 5 & 55 & 158 \\
\hline & TOTALS & 363 & 722 & 107 & 142 & 1334 \\
\hline
\end{tabular}

TABLE 2. Original Stratified Random Sample Size Distribution 
Step 3. Following Step 2, 95 additional facilities were identified from late submittals from various states and included in the sample with certainty with the following distribution assignments. Note that no attempt was made to identify and eliminate possible duplicates among the 95 that might have already been in the universe or sample.

\begin{tabular}{|c|c|c|c|c|c|}
\hline \multicolumn{6}{|r|}{ TOTA T } \\
\hline & 1 & 2 & 3 & 4 & TOTALS \\
\hline$P$ & 0 & 0 & 0 & 0 & 0 \\
\hline M & 13 & 0 & 0 & 0 & 13 \\
\hline A & 26 & 0 & 0 & 0 & 26 \\
\hline I & 53 & 0 & 0 & 0 & 53 \\
\hline G & 3 & 0 & 0 & 0 & 3 \\
\hline TOTALS & 95 & 0 & 0 & $\mathbf{0}$ & 95 \\
\hline
\end{tabular}

TABLE 3. Additional Sample Sizes 
Step 4. Combining the results of Tables 1, 2, and 3 yields,

\begin{tabular}{|c|c|c|c|c|c|}
\hline & & & & & \\
\hline & 1 & 2 & 3 & 4 & TOTALS \\
\hline $\mathrm{P}$ & $\begin{array}{l}78+0=78 \\
78+0=78\end{array}$ & $\begin{array}{l}0+0=0 \\
0+0=0\end{array}$ & $\begin{array}{l}0+0=0 \\
0+0=0\end{array}$ & $\begin{array}{l}0+0=0 \\
0+0=0\end{array}$ & $\begin{array}{l}78 \\
78\end{array}$ \\
\hline M & $\begin{array}{l}66+13=79 \\
66+13=79\end{array}$ & $\begin{array}{r}360+0=360 \\
95+0=95\end{array}$ & $\begin{array}{r}19+0=19 \\
1+0=1\end{array}$ & $\begin{array}{r}83+0=83 \\
4+0=4\end{array}$ & $\begin{array}{l}541 \\
179\end{array}$ \\
\hline $\mathrm{A}$ & $\begin{array}{l}85+26=111 \\
85+26=111\end{array}$ & $\begin{array}{l}192+0=192 \\
192+0=192\end{array}$ & $\begin{array}{l}77+0=77 \\
77+0=77\end{array}$ & $\begin{array}{r}134+0=134 \\
44+0=44\end{array}$ & $\begin{array}{l}514 \\
424\end{array}$ \\
\hline I & $\begin{array}{l}116+53=169 \\
116+53=169\end{array}$ & $\begin{array}{l}900+0=900 \\
355+0=355\end{array}$ & $\begin{array}{r}166+0=166 \\
24+0=24\end{array}$ & $\begin{array}{r}546+0=546 \\
39+0=39\end{array}$ & $\begin{array}{r}1781 \\
587\end{array}$ \\
\hline G & $\begin{array}{l}18+3=21 \\
18+3=21\end{array}$ & $\begin{array}{l}80+0=80 \\
80+0=80\end{array}$ & $\begin{array}{l}5+0=5 \\
5+0=5\end{array}$ & $\begin{aligned} 155+0 & =155 \\
55+0 & =55\end{aligned}$ & $\begin{array}{l}261 \\
161\end{array}$ \\
\hline TOTALS & $\begin{array}{l}458 \\
458\end{array}$ & $\begin{array}{r}1532 \\
722\end{array}$ & $\begin{array}{l}267 \\
107\end{array}$ & $\begin{array}{l}918 \\
142\end{array}$ & $\begin{array}{l}3175 \\
1429\end{array}$ \\
\hline
\end{tabular}

TABLE 4. Preliminary Universe and Sample Sizes

where within stratum $i j$ the top number is the preliminary number of facilities in the sampling frame and the bottom number is the preliminary number of facilities in the sample. 
Step 5. Following a review (based on matching) of all sample facilities during data collection, duplicates were discovered as follows.

\begin{tabular}{|c|c|c|c|c|}
\hline Case & $\begin{array}{c}\text { First } \\
\text { Stratum }\end{array}$ & $\begin{array}{l}\text { Second } \\
\text { Stratum } \\
\end{array}$ & $\begin{array}{c}\text { Number of } \\
\text { Duplicates }\end{array}$ & $\begin{array}{l}\text { Recommended Action for } \\
\text { Identified Sample Duplicates }\end{array}$ \\
\hline 1 & A1 & A1 & 1 & Delete 1 from A1 sample \\
\hline 2 & A1 & A2 & 22 & Delete 22 from A2 sample \\
\hline 3 & A1 & A3 & 1 & Delete 1 from A3 sample \\
\hline 4 & A1 & A4 & 3 & Delete 3 from A4 sample \\
\hline 5 & A1 & M2 & 2 & Delete 2 from A1 sample \\
\hline 6 & A2 & A2 & 3 & Delete 3 from A2 sample \\
\hline 7 & A2 & A3 & 3 & Delete 3 from A3 sample \\
\hline 8 & A2 & A4 & 11 & Delete 11 from A4 sample \\
\hline 9 & A2 & I2 & 1 & Delete 1 from A2 sample \\
\hline 10 & A2 & M1 & 1 & Delete 1 from A2 sample \\
\hline 11 & A2 & M4 & 1 & Delete 1 from M4 sample \\
\hline 12 & A3 & M1 & 1 & Delete 1 from M1 sample \\
\hline 13 & G1 & G2 & 4 & Delete 4 from G2 sample \\
\hline 14 & G1 & G4 & 1 & Delete 1 from G4 sample \\
\hline 15 & G1 & M1 & 2 & Delete 2 from M1 sample \\
\hline 16 & G1 & P1 & 1 & Delete 1 from G1 sample \\
\hline 17 & G2 & G2 & 1 & Delete 1 from G2 sample \\
\hline 18 & G2 & G3 & 1 & Delete 1 from G3 sample \\
\hline 19 & G2 & G4 & 2 & Delete 2 from G4 sample \\
\hline 20 & G2 & P1 & 1 & Delete 1 from G2 sample \\
\hline 21 & G3 & I2 & 1 & Delete 1 from I2 sample \\
\hline 22 & G4 & I2 & 1 & Delete 1 from I2 sample \\
\hline 23 & G4 & M1 & 1 & Delete 1 from M 1 sample \\
\hline 24 & I1 & I1 & 2 & Delete 2 from I1 sample \\
\hline 25 & I1 & $\mathrm{I} 2$ & 16 & Delete 16 from 12 sample \\
\hline 26 & I1 & M1 & 1 & Delete 1 from II sample \\
\hline 27 & I1 & P1 & 2 & Delete 2 from I1 sample \\
\hline 28 & I2 & I2 & 9 & Delete 9 from I2 sample \\
\hline 29 & $\mathrm{I} 2$ & $\mathrm{I} 4$ & 1 & Delete 1 from I4 sample \\
\hline 30 & I2 & P1 & 4 & Delete 4 from I2 sample \\
\hline 31 & I4 & $\mathrm{P} 1$ & 1 & Delete 1 from I4 sample \\
\hline 32 & M1 & M1 & 1 & Delete 1 from M1 sample \\
\hline 33 & M1 & M2 & 2 & Delete 2 from M2 sample \\
\hline \multirow[t]{2}{*}{34} & M2 & M2 & 1 & Delete 1 from M2 sample \\
\hline & & & $\overline{106}$ & $\overline{106}$ \\
\hline
\end{tabular}

TABLE 5. Identified Duplicates in the Sample

In the last column of Table 5, each duplicate was deleted from the stratum sample for which it was least appropriate. The total number in each stratum (frame) was reduced proportionally by the number of sample deletions from that stratum. 
Step 6. Thus, using the results of Tables 4 and 5 , the following table gives the STATE OF THE DATA BASE used in the estimation procedures.

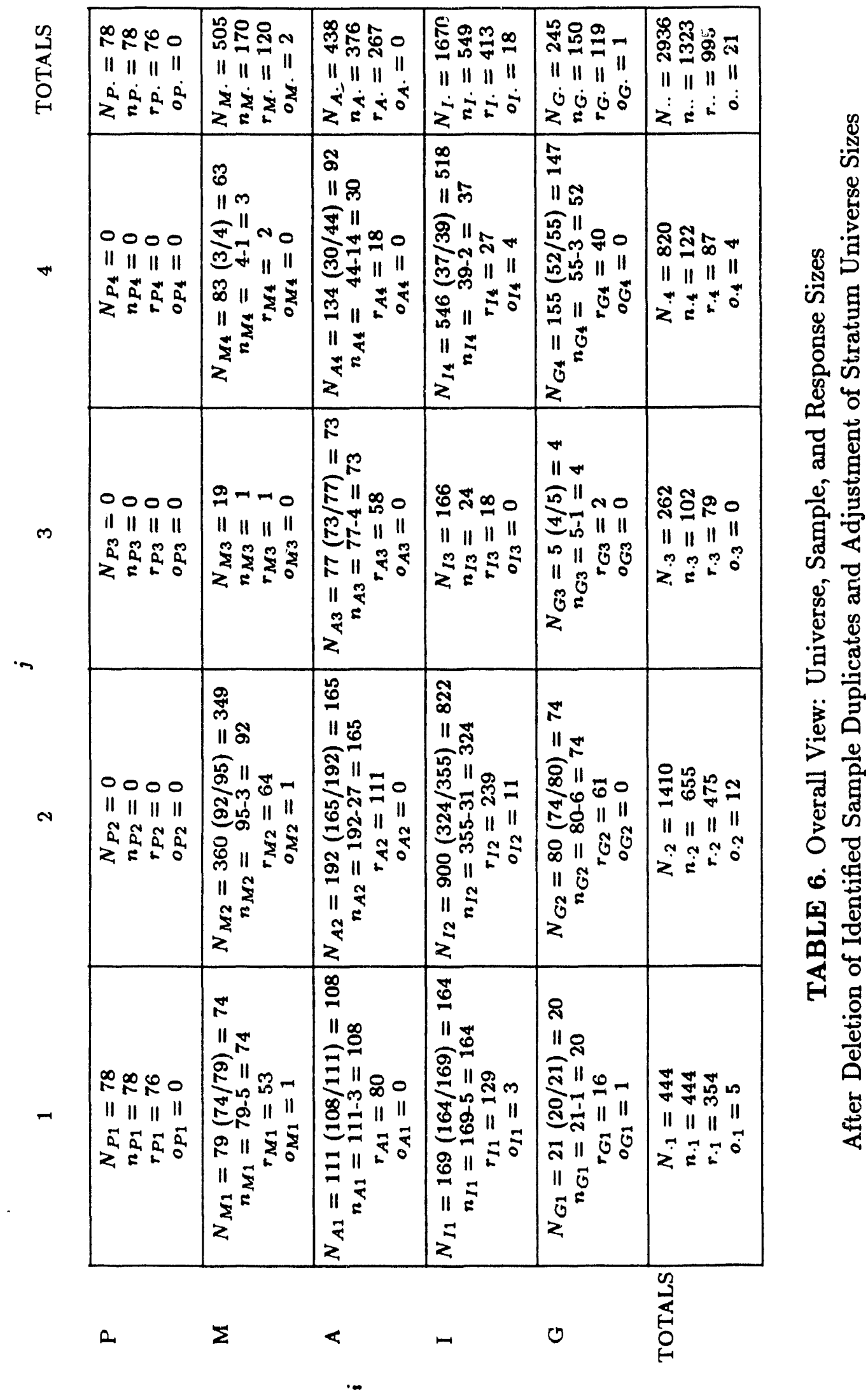


where in stratum $i j$,

$$
\begin{aligned}
N_{i j}= & \text { the estimated total universe size for stratum } i j . \\
n_{i j}= & \text { the total sample size for stratum } i j . \\
r_{i j}= & \text { the number out of } n_{i j} \text { sample facilities that responded with data, including zeros } \\
& \text { reported over the telephone, and that were still in business at the time of the survey. } \\
o_{i j}= & \text { the number out of } n_{i j} \text { sample facilities that responded but were not still in business at } \\
& \text { the time of the survey. }
\end{aligned}
$$

NOTE that the total number of respondents in stratum $i j$ is $r_{i j}+o_{i j}$.

\section{Step 7. Estimation}

The fundamental setting for sample selection was stratum $i j$. Thus, the fundamental setting for estimation is also stratum $i j$. We consider two cases. Actually, Case 2 includes Case 1.

\section{CASE 1: Estimation Consistent With (Along) Stratum Boundaries}

Parameters To be specific, let $W S T_{i j 1}, W S T_{i j 2}, \ldots, W S T_{i j N_{i j}}$ be the volumes of low level mixed wastes $(l l m w)$ generated during 1990 by the $N_{i j}$ facilities in stratum $i j$. Then

- the total volume of $l l m w W S T$ generated during 1990 by the $N_{i j}$ facilities in stratum $i j$ is

$$
T_{W S T(i j)}=\sum_{k=1}^{N_{i j}} W S T_{i j k}
$$

and

- the total volume of $l l m w W S T$ generated during 1990 by all of the facilities in category $i$ (i.e., $i 1, i 2, i 3$, and $i 4$ ) is

$$
T_{W S T(i \cdot)}=T_{W S T(i 1)}+T_{W S T(i 2)}+T_{W S T(i 3)}+T_{W S T(i 4)}
$$

for $i=\mathrm{A}, \mathrm{G}, \mathrm{I}, \mathrm{M}$, and $\mathrm{P}$.

The desire is to estimate $T_{W S T(i .)}$ for $i=\mathrm{A}, \mathrm{G}, \mathrm{I}, \mathrm{M}$, and P. Parameters similar to $T_{W S T(i j)}$ and $T_{W S T(i \cdot)}$ can be defined for other specific $l l m w$ substances such as SCINT LIQUID, LEADWASTE, etc. 


\section{Estimation of $T_{W S T(i j)}$ and $T_{W S T(i)}$}

We focus on the substance llmw WST. Estimators of total volumes for other substances would be similar.

Within stratum $i j$, we assume that the $n_{i j}-\left(r_{i j}+o_{i j}\right)$ sample nonrespondents are "missing at random" (Little and Rubin, 1983). According to Little and Rubin (1983), "if the process leading to missing (WST) values (and in particular, the probability that a particular value of (WST) is missing) does not depend on the values of ... (WST), then the missing data are called missing at random and the observed data are observed at random." In such cases, it is appropriate (Oh and Scheuren, 1983; Rubin, 1983; Cochran, 1983; and NAS Panel on Incomplete Data, 1983) to assign sampling weights as follows:

$$
w_{i j}=\frac{N_{i j}}{r_{i j}+o_{i j}}=\frac{N_{i j}}{n_{i j}}\left(\frac{n_{i j}}{r_{i j}+o_{i j}}\right)
$$

for each of the $r_{i j}+o_{i j}$ respondents.

The sampling weights used are given below in Table 7.

$$
\begin{array}{llll}
w_{P 1}=\frac{78}{76+0}=1.0263 & w_{P 2}=0.0000 & w_{P 3}=0.0000 & w_{P 4}=0.0000 \\
w_{M 1}=\frac{74}{53+1}=1.3704 & w_{M 2}=\frac{349}{64+1}=5.3692 & w_{M 3}=\frac{19}{1+0}=19.0000 & w_{M 4}=\frac{63}{2+0}=31.5000 \\
w_{A 1}=\frac{108}{80+0}=1.3500 & w_{A 2}=\frac{165}{111+0}=1.4865 w_{A 3}=\frac{73}{58+0}=1.2586 & w_{A 4}=\frac{92}{18+0}=5.1111 \\
w_{I 1}=\frac{164}{129+3}=1.2424 & w_{I 2}=\frac{822}{239+11}=3.2880 w_{I 3}=\frac{166}{18+0}=9.2222 & w_{I 4}=\frac{518}{27+4}=16.7097 \\
w_{G 1}=\frac{20}{16+1}=1.1765 & w_{G 2}=\frac{74}{61+0}=1.2131 & w_{G 3}=\frac{4}{2+0}=2.0000 & w_{G 4}=\frac{147}{40+0}=3.6750
\end{array}
$$

TABLE 7. Sampling Weights 
Within stratum $i j$, assume the raw sample data values are

\begin{tabular}{c}
$r_{i j}$ sample values \\
\hline$W S T_{i j 1}$ \\
$W S T_{i j 2}$ \\
$\cdot$ \\
$\cdot$ \\
$\cdot$ \\
$W S T_{i j r_{i j}}$
\end{tabular}

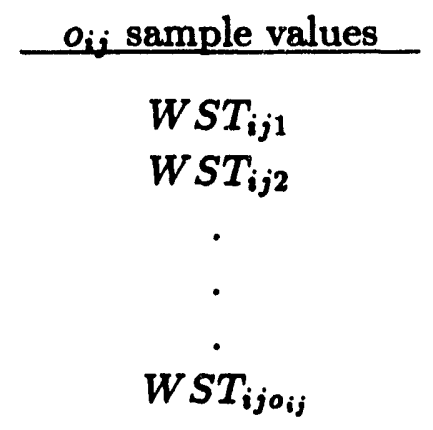

NOTE: We take all sample values for the $o_{i j}$ respondents to be zeros. (This assumption s' sms ok if we think "domain estimation" for facilities that are "still in business.")

An estimator for $T_{W S T(i j)}$ is

$$
\hat{T}_{W S T(i j)}=\sum_{k=1}^{r_{i j}+o_{i j}} W S T_{i j k} \cdot w_{i j}
$$

The estimator $\hat{T}_{W S T(i j)}$ is a random variable whose value depends on which sample is selected (and which facilities respond). Thus, $\hat{T}_{W S T(i j)}$ has a variance which can be denoted by $\operatorname{Var}\left(\hat{T}_{W S T(i j)}\right)$.

An estimator of $\operatorname{Var}\left(\hat{T}_{W S T(i j)}\right)$ is

$$
\hat{\operatorname{Var}}\left(\hat{T}_{W S T(i j)}\right)=N_{i j}\left(N_{i j}-r_{i j}-o_{i j}\right) \frac{S_{W S T(i j)}^{2}}{r_{i j}+o_{i j}}
$$

where

$$
S_{W S T(i j)}^{2}=\frac{\sum_{k=1}^{r_{i j}+o_{i j}}\left[W S T_{i j k}-W S T_{i j}\right]^{2}}{r_{i j}+o_{i j}-1}
$$

and

$$
W S T_{(i j)}=\frac{\sum_{k=1}^{r_{i j}+o_{i j}} W S T_{i j k}}{r_{i j}+o_{i j}}
$$

NOTE: Again, all sample values for the $o_{i j}$ respondents are zeros. This can be viewed as making estimates of volumes generated in 1990 for facilities still in business at the time of the survey. This changes the definition of the total being estimated slightly. 
Hence, an estimator of the standard error of $\hat{T}_{W S T(i j)}$ is

$$
\text { s.e. }\left(\hat{T}_{W S T(i j)}\right)=\sqrt{\operatorname{Var}\left(\hat{T}_{W S T(i j)}\right)} \text {. }
$$

It follows that an estimator of $T_{W S T(i .)}$, for the $i^{\text {th }}$ category facilities, is

$$
\hat{T}_{W S T(i)}=\hat{T}_{W S T(i 1)}+\hat{T}_{W S T(i 2)}+\hat{T}_{W S T(i 3)}+\hat{T}_{W S T(i 4)},
$$

and an estimator of the standard error of $\hat{T}_{W S T(i \cdot)}$ is

$$
\text { s.e. }\left(\hat{T}_{W S T(i \cdot)}\right)=\sqrt{\left.\hat{\operatorname{Var}}\left(\hat{T}_{W S T(i 1)}\right)+\hat{\operatorname{Var}}\left(\hat{T}_{W S T(i 2)}\right)+\hat{\operatorname{Var}}\left(\hat{T}_{W S T(i 3)}\right)+\hat{\operatorname{Var}}\left(\hat{T}_{W S T(i 4)}\right)\right)}
$$

Also, an estimator of $T_{W S T(\cdot)}=\sum_{i} T_{W S T(i .)}$, for all facilities is

$$
\hat{T}_{W S T(\cdot)}=\sum_{i} \hat{T}_{W S T(i \cdot)}
$$

and an estimator of the standard error of $\hat{T}_{W S T(. .)}$ is

$$
\text { s.e. }\left(\hat{T}_{W S T(\cdot .)}\right)=\sqrt{\sum_{i}\left[\text { s.e. }\left(\hat{T}_{W S T(i .)}\right)\right]^{2}}
$$


CASE 2: Estimation Not Necessarily Consistent With (Along) Stratum Boundaries: Domain Estimation

It may be of interest to estimate the total volume of $1 / m w W S T$ generated during 1990 by a subuniverse (domain) of facilities which does not coincide with the sampling stratum boundaries. For example, if $D$ is the collection of Academic Institutions or the collection of all facilities in the Southeastern Compact, then one may want to proceed as follows to estimate $T_{W S T(D)}$ which would be the total $l l m w W S T$ generated in 1990 by all facilities in domain $D$, say Academic Institutions (that were still in business during the time of the survey). This method of estimation is also important if there is concern about the extent to which facilities were assigned to incorrect strata in the frame. As under Case 1, we should first work within stratum $i j$. An estimator of the total portion of $T_{W S T(D)}$ which is in stratum $i j$ is

$$
\hat{T}_{W S T(D, i j)}=\sum_{\substack{\text { over all } \\ \text { D facilities } \\ \text { in stratum } \\ i j \text { among the } \\ \text { rijtoij } \\ \text { respondents }}}\left(W S T_{D(i j k)}\right)\left(w_{i j}\right) .
$$

(See e.g. Cochran (1977), Section 2.13.)

NOTE: Once again, taking all $W S T_{D(i j k)}$ sample values for the $o_{i j}$ respondents as zeros, changes the definition of the estimated total volume to those still in business at the time of the survey.

An estimator of the variance (see Cochran (1977), Section 2.13) of $\hat{T}_{W S T(D, i j)}$ is

$$
\hat{\operatorname{Var}}\left(\hat{T}_{W S T(D, i j)}\right)=N_{i j}\left(N_{i j}-r_{i j}-o_{i j}\right) \frac{S_{W S T(D, i j)}^{2}}{r_{i j}+o_{i j}}
$$

where $S_{W S T(D, i j)}^{2}=$

$$
\frac{\sum_{\substack{k \text { over all } \\ \text { p facilities } \\ \text { in stratum } \\ i j \text { among the } \\ r_{i j+o i j}+o_{i j}}}\left[W S T_{D(i j k)}\right]^{2}-\left(r_{i j}+o_{i j}\right)\left[\sum_{\substack{\text { over all } \\ \text { p facilities } \\ \text { in stratum } \\ \text { ij among the } \\ \text { rijtij }}} W S T_{D(i j k)} /\left(r_{i j}+o_{i j}\right)\right]^{2}}{r_{i j}+o_{i j}-1} .
$$

The estimator of the standard error of $\hat{T}_{W S T(D, i j)}$ is

$$
\text { s.e. }\left(\hat{T}_{W S T(D, i j)}\right)=\sqrt{\hat{\operatorname{Var}\left(\hat{T}_{W S T(D, i j)}\right)}} \text {. }
$$


Thus, our estimator of $T_{W S T(D)}$ is

$$
\hat{T}_{W S T(D)}=\sum_{i} \sum_{j} \hat{T}_{W S T(D, i j)}
$$

and our estimator of the standard error of $\hat{T}_{W S T(D)}$ is

$$
\text { s.e. }\left(\hat{T}_{W S T(D)}\right)=\sqrt{\sum_{i} \sum_{j} \hat{\operatorname{Var}}\left(\hat{T}_{W S T(D, i j)}\right)} .
$$

From Table 4.3, $\hat{T}_{(D)}=28,982$ and s.e. $\left(\hat{T}_{(D)}\right)=3,055$ where $D=$ Academic.

\section{NOTES:}

- Actually, all estimators of total volumes can be obtained as described under Case 2. Case 1 was presented first mainly to help the presentation of Case 2.

- If one is only interested in estimating totals such as with $\hat{T}_{W S T(D)}$ and not in estimating standard errors such as s.e. $\left(\hat{T}_{W S T(D)}\right)$, then an easy way to view the process in general is to take each respondent's sample value for $l l m w W S T$ and multiply it by its sampling weight and sum all of these products for those sample units in domain $D$. This gives the same $\hat{T}_{W S T(D)}$ described under (14); and when $D$ coincides with strata boundaries, it gives the same result for estimation of a total as would be obtained under Case 1. Recall that taking all sample values for $o_{i j}$ respondents as zeros changes the definition of the total being estimated slightly to the estimate of total volume generated in 1990 by those facilities still in business at the time of the survey.

- One may only want to estimate standard errors only for estimated total volumes at the category level ( $i=\mathrm{A}, \mathrm{G}, \mathrm{I}, \mathrm{M}$, and $\mathrm{P}$ ) or higher due to possibly small sample sizes at lower levels and hence less reliable estimators of standard error. See Table 4.3.

- Assuming that the general estimator $\hat{T}_{X(D)}$ has an approximate normal distribution, then an approximate, say $95 \%$, confidence interval for $T_{X(D)}$, the total volume generated for substance $X$ for some domain $D$, is given by

$$
\hat{T}_{X(D)}-1.96\left[\text { s.e. }\left(\hat{T}_{X(D)}\right)\right], \hat{T}_{X(D)}+1.96\left[\text { s.e. }\left(\hat{T}_{X(D)}\right)\right] \text {. }
$$




\section{References}

1. Cochran, W. G. (1977). Sampling Techniques ( $\left.g^{r d} E d\right)$, Wiley and Sons, New York.

2. Cochran, W. G. (1983). "Historical Perspective," pp. 20-21, in Incomplete Data in Sample Surveys, Vol. 2, (W. G. Madow, I. Olkin, and D. R. Rubin, eds.), Academic Press, New York.

3. Little, R. J. A. and Rubin, D. B. (1983). "Missing Data in Large Data Sets," in Statistical Methods and the Improvement of Data Quality, (T. Wright, ed.), Academic Press, New York.

4. NAS Panel on Incomplete Data (1983). "Review of Theory," Chapter 5, in Incomplete Data in Sample Surveys, Vol. 1, (W. G. Madow, H. Nisselson, and I. Olkin, eds.), Academic Press, New York.

5. Oh, H. L. and Scheuren, F. J. (1983). "Weighting Adjustment for Unit Nonresponse," in Incomplete Data in Sample Surveys, Vol. 2, (W. G. Madow, I. Olkin, and D. R. Rubin, eds.), Academic Press, New York.

6. Rubin, D. B. (1983). "Conceptual Issues in the Presence of Nonresponse," in Incomplete Data for Sample Surveys, Vol. 2, (W. G. Madow, I. Olkin, and D. R. Rubin, eds.), Academic Press, New York. 


\section{APPENDIX F \\ RECOMMENDATION FOR CHANGES TO SURVEY QUESTIONNAIRE}




\section{RECOMMENDATION FOR CHANGES TO SURVEY QUESTIONNAIRE}

As outlined in Sect. 1.2.4, twenty members of Appalachian Compact Users of Radioactive Isotopes (ACURI), the association of radioactive licensees within the Appalachian Compact agreed to cooperate in the initial test phase of the national mixed waste survey. Based on the data collected, comments received, and various discussions among the mixed waste profile team members, the pretest survey questionnaire was modified to enhance its usefulness. The final survey questionnaire is included in Appendix B.

However, after receiving over 1,000 responses to the mixed waste questionnaire, we still found that respondents to the questionnaire were able to interpret some of the questions in ways we felt were impossible.

The following are comments or suggestions that the mixed waste profile team are making if any reissuance of the survey is attempted.

GENERAL:

An additional note defining scintillation fluids needs to be added. 'Scintillation fluids with activity both above and below the $0.05 \mu \mathrm{Ci} / \mathrm{g}$ level for carbon-14 and tritium are requested. Only information on scintillation fluids containing RCRA hazardous materials such as toluene or xylene is requested.' This clarification could possibly be added under the definition of "Mixed" waste on page $i$ of the questionnaire.

\section{SECTION C}

Need to add a statement that a positive answer to $\mathrm{C}-1$, for one or more wastes, should not preclude testing the other LLRW by answering C-2, C-3, and C-4.

\section{SECTION D-1}

Add; 'Source - Process or procedure that produced the waste'.

\section{SECTION D-2}

Volume Treated During 1990; Should be worded to indicate the 'amount of the 1990 generated waste that has been treated to date'. also "treated (on-site/off-site)" in the directions should be changed to 'treated (indicate on-site or off-site)'.

\section{SECTION D-3}

Need to add a statement that emphasized that the information requested 'included treatment already carried out or expected to be carried out under current conditions'. Should also read "For each mixed waste stream shown as being generated in D-1,.

Need to add a statement that in general, volume, activity, and effect on the hazard component for incineration are respectively 0,0 , destroyed.

\section{SECTION E-1}

Need to add a statement that 'This waste may or may not have been actually generated in 1990.'

\section{SECTION E-1}

Add; 'Source - Process or procedure that produced the waste'. 
APPENDIX G

PERMITS AND LICENSES FOR COMPANIES

TREATING MIXED WASTES 


\section{Appendix G \\ Permits, Licenses, or Authorizations for Companies Treating Mixed Waste}

Exhibit A List of current and potential future commercial mixed waste treatment facilities.

Exhibit B1 List of permits, licenses, or authorizations pertaining to DSSI.

Exhibit B2 Radioactive materials license for DSSI.

Exhibit B3 Treatment, storage, and disposal permit for DSSI.

Exhibit B4 Air Pollution Control Permit for DSSI.

Exhibit B5 National Emissions Standards for Hazardous Air Pollution Permit for DSSI.

Exhibit B6 Hazardous wastes acceptable for receipt at DSSI.

Exhibit C1 List of permits, licenses, or authorizations pertaining to NSSI.

Exhibit C2 Hazardous waste permit for NSSI.

Exhibit C3 RCRA Part B Permit for NSSI.

Exhibit C4 Radioactive materials license for NSSI.

Exhibit D1 List of permits, licenses, or authorizations pertaining to Quadrex.

Exhibit D2 RCRA hazardous waste permit for Quadrex.

Exhibit D3 RCRA Part B Permit for Quadrex.

Exhibit D4 Radioactive materials license for Quadrex.

Exhibit D5 FDER Used Oil Registration for Quadrex.

Exhibit E1 List of permits, licenses, or authorizations pertaining to RAMP.

Exhibit E2 Radioactive materials license for RAMP.

Exhibit E3 RCRA Part B Permit for RAMP.

Exhibit E4 Hazardous wastes acceptable for receipt at RAMP.

Exhibit F1 List of permits, licenses, or authorizations pertaining to Envirocare.

Exhibit F2 Radioactive materials for license for Envirocar:

Exhibit F3 RCR/A permit for Envirocare.

Exhibit F4 Hazardous wastes acceptable for disposal at Envirocare.

Exhibit G Acceptance limits and criteria for contaminated oils at SEG. 
Exhibit A

G-3 


\section{Current and Potential Future Commercial Industries Treating Mixed Wastes}

\section{Company Name and Location}

DSSI

P.O. Box 863

Kingston, TN 37763

NSSI

P.O. Box 34042

Houston, TX 77234

Quadrex Corp.

1940 NW 67th Place

Gainesville, FL 32606-1649

RAMP Industries

1127 W. 46th Ave.

Denver, CO 80211

Envirocare

Salt Lake City, UT 84111

SEG

P.O. Box 2530

1560 Bear Creek Rd.

Oak Ridge, TN 37830

\section{Status of Mired Waste}

Treatment Capability

Current

Phone Number

615-376-0084

Current

713-641-0391

Current

904-373-6066

Current

$303-480-1481$

Planned for future

801-532-1330

Planned for future

$615-481-0222$ 
Exhibit B1

LIST OF PERMITS, LICENSES, OR AUTHORIZATIONS PERTAINING TO DSSI 


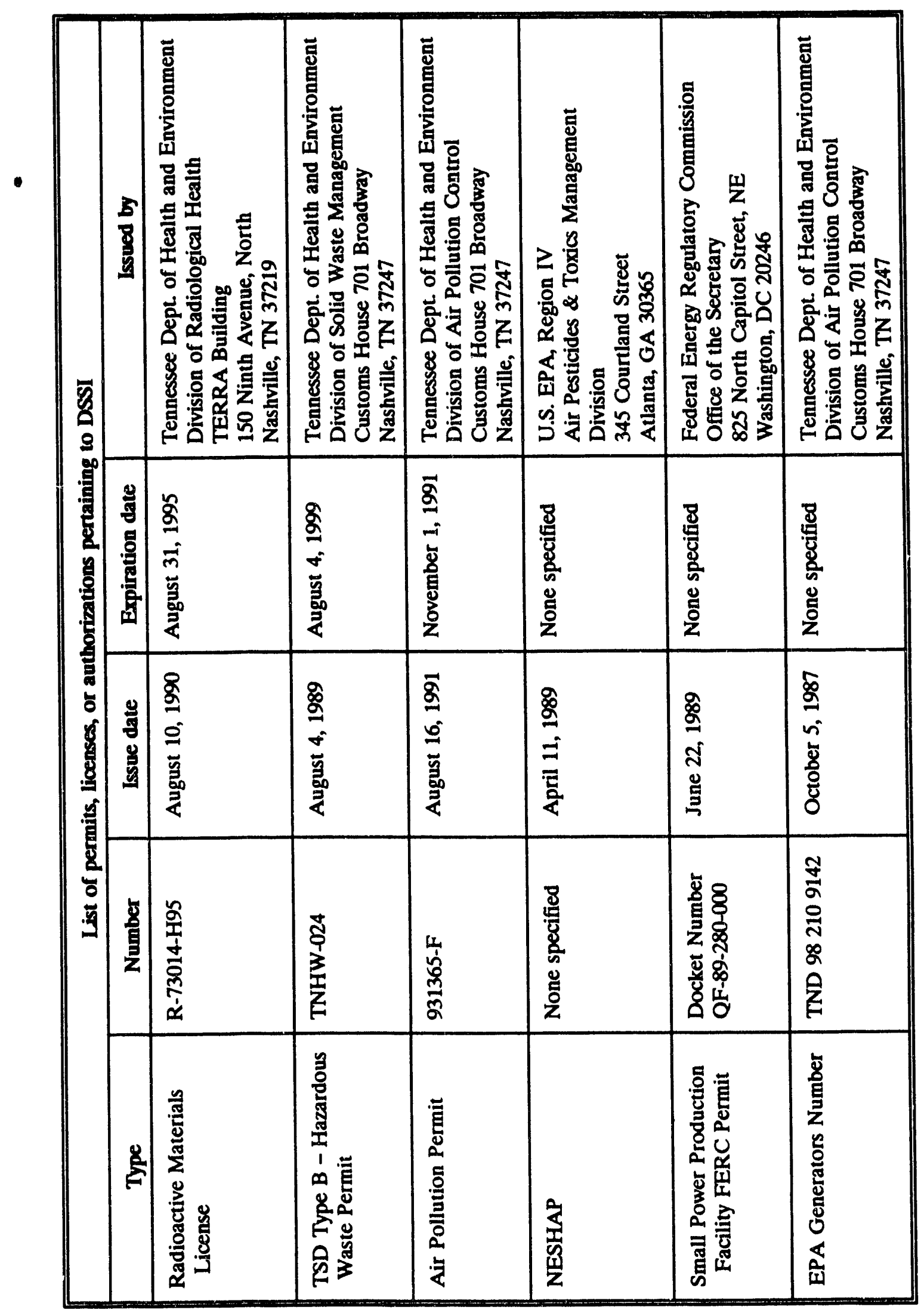


Exhibit B2

RADIOACTIVE MATERIALS LICENSE FOR DSSI

G-11 
August 10,1990

STATE OF TENNESSEE

DEPARTMENT OF HEALTH AND ENVIRONMENT

CORDELL HULL BUILDING

NASHVILLE, TENNESSEE 37219.5402

Diversified Scientific Services, Inc.

$508 \mathrm{~N}$. Kentucky Street

Kingston, TN 37763

Attention: James $T$. McVey, RSO

Gentlemen:

Attached to this letter is your Tennessea Radoactive Material License numbered R-73014-H95 issued to expire or August 31, 1295 .

A copy of 'State Regulations fcr Protection Against Radiacion' referred to in Condition 12 of the license conditions is being sent to you hy a separate mailing. Your attention is directed to State Regulations and to specific license Conditions 11 through 27 which are to be followed in the use of this license.

Also attached to this letter are several copies of Form RHS 8-3 for posting as notet on that form.

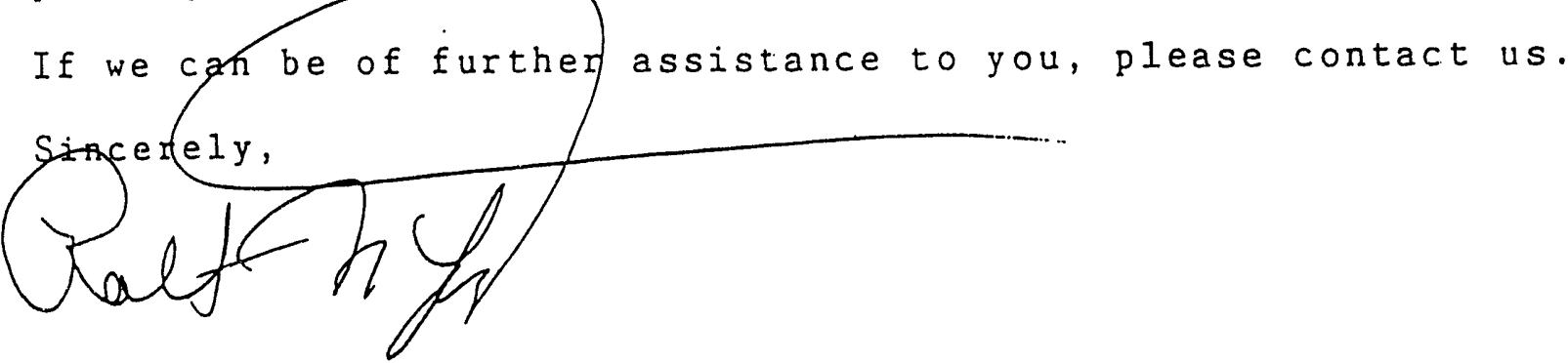

Robert $N$. Young

Health Physicist

Division of Radiological Health

Attachments:

RNY / ry 
TENNESSEE DEPARTMENT OF HEALTH AND ENVIRONMENT

DIVISION OF FIADIOLOGICAL HEALTH

\section{FADIDACTIVE MATEFIAL LICENSE}

SUFPLEMENTAFY SHEET

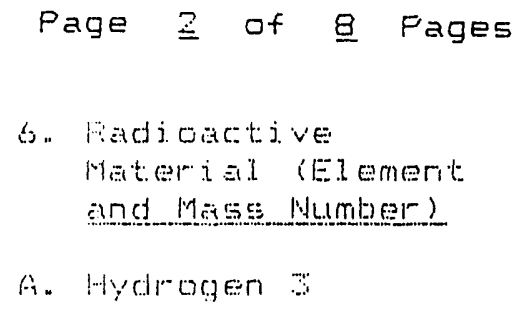

8. Chemi cast arrolor vysical rom

A. Any as associdated witith li is gut it

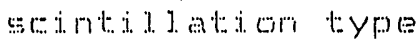

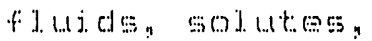

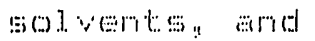
a

B.

…

1)

E.

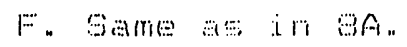

ดั

H. Gente

I.

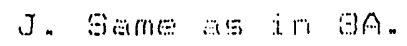

भ.

L. G

M. Same as jo BA.

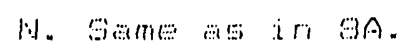

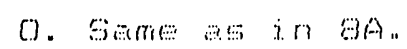

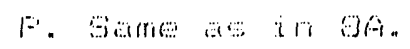

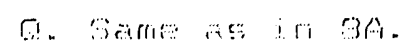

License Number Ei-73014-H95

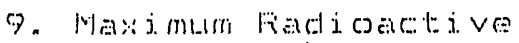
Mater jal. Which L.tichsen May Fossesto at Any Ore Time

An The total combinged isotopic activitiss

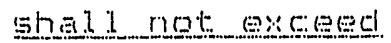

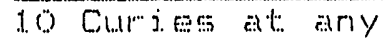
one time.

EI. Sien Item gA.

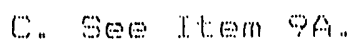

I.)

E. ⿹ㅃ Item 9A.

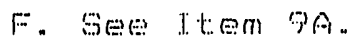

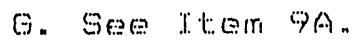

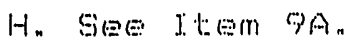

I. SeE It:em 94 .

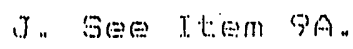

$\therefore$ 今日e It

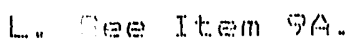

M. SEE IHEM JA.

N. GळE THEm \%A.

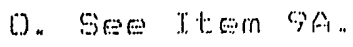

F

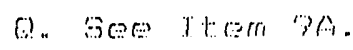


rorm RHS 8-7A

$(10-85)$

\section{TENNESSEE DEPARTMENT OF HEALTH AND ENVIRONMENT \\ DIVISION OF RADIOLOGICAL HEALTH}

\section{FADIDACTIUE MATERIAL LICENSE}

\begin{abstract}
Page 3 of 9 Pages
\end{abstract}
Fi. Mercury 20:3

5. T. Indiullin 1.11

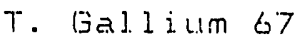

U. Manganese 54

V. Sc andium 46

W. Selenium 75

X. Cacimilum 1.0\%

Y. N:LE: 6I

i. Copper 64

AA. Tin 1.13

EE. Tin $119 \mathrm{~m}$

Cic. I Galines 1.25

IDD. Iodine 1:1

EEE. EH sinuth :20\%

FF. Cerrium 14.1.

GG. GoI 195

Hit. Any Fiadjoact.jve Materiall with Atomic numbers 1. through 55 : inclusive (except (.)-3.5, 1. -255 , and any isotope of

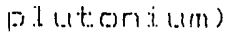

B. Nicted to

License Number R-73014-H95

Fi. Same as in 8 A

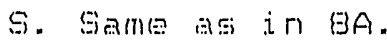

T. Same as in $8 A$.

1. Same as in $\theta A$.

V. SRाE as j. BA.

W. Game as in $8 A$.

X. Same as in BA.

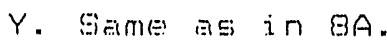

Z. Same as j.

AA. Game as in $B A$.

EE. Same? as j.

CC. Same a! jn BA.

DD. Siamer diej jin BA.

EE. Same! as in BA.

FF. Same as jn 8A.

QG. Some as in BA.

HH. Şea] exd Source in plated encapsul. ated, embedisecl, or fl ame gen l kd (1. i glui (d) form.
Fi. See Item gA.

S. See Jtem $9 A$.

7. See j.tem $\Rightarrow A$.

1.). See Item SA.

v. See jitem $9 A$.

W. ge日 Item GA.

X. See Itiem 9A.

Y. Sne Item 9 A.

7. See Iterm \%A.

AA. set ltem अa.

EB. SeE Itrem $7 \mathrm{~A}$.

(C. See Item gA.

DD. See Itam $9 A$.

EE. Seอ It.m ЭA.

FF. See Item $9 A$.

GG. GEe J ter GA.

HH. No single source to excensil 100 miceroculuses. Tostal not to exesed one (1) mj. J. . j. c...1 je.
II. Siended Solume (New Erral and Nue) par Mode! MEM-atona)
II. Threes (S) solltres not to anders: n. $111 \div 1.1 \% 1 \mathrm{mon}$

G-16 


\section{FADIDACTIVE MATEFIAL LICEMSE}

\section{SUPFLEMENTARY SHEET}

\section{Page 4 of 8 Fages License Number Ri-73014-H95}

\section{Authorized use}

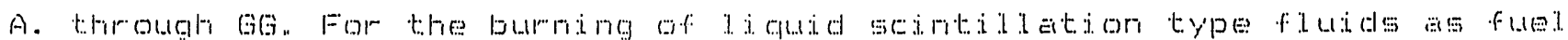
i.

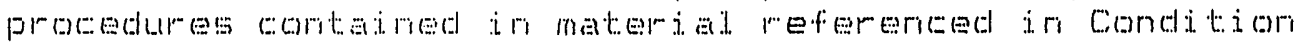
27.0 .

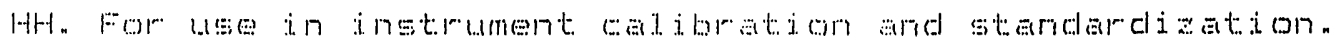

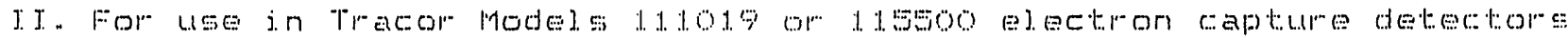
as part of Tracor

Conditions (:ontionted)

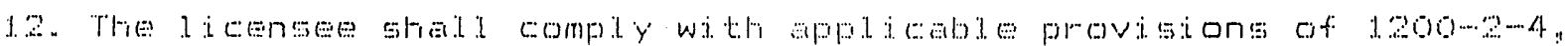
$1200-2-5$, and $1200-2 \cdots 0$ of Fiarcili at is in".

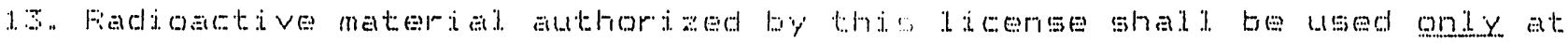

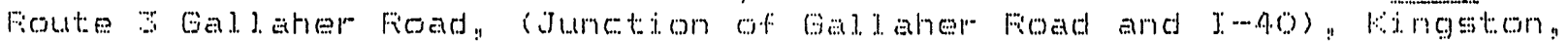
Tenreseses

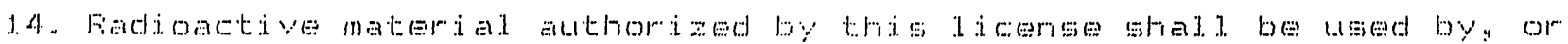

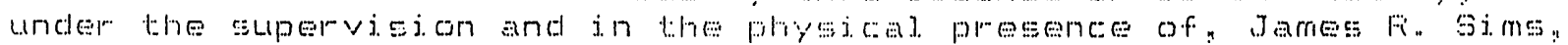

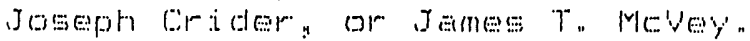

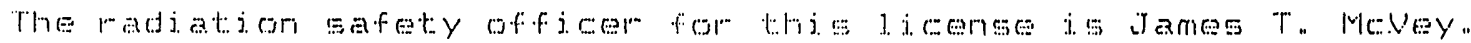

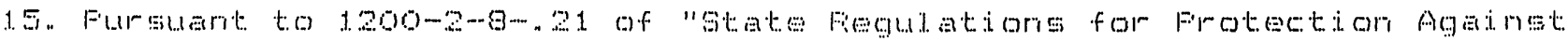

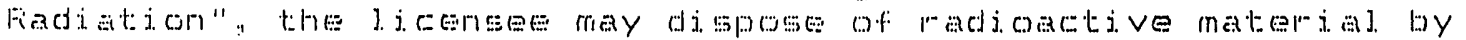

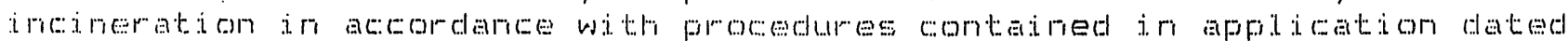

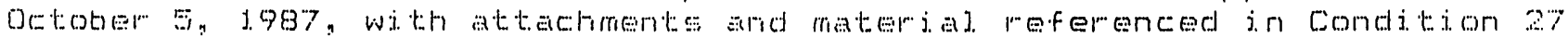

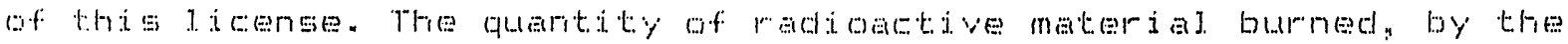

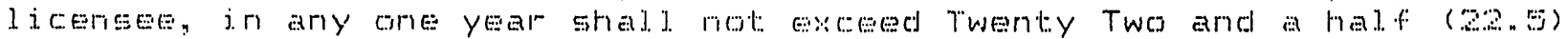

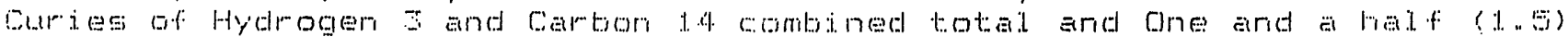

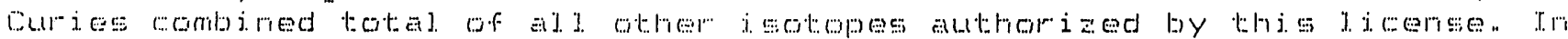

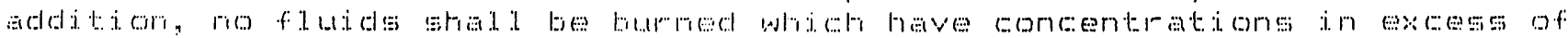

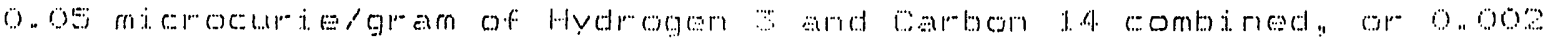

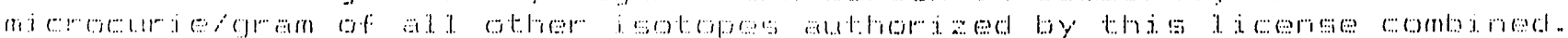


rurin nas a-1h

$(10-85)$

TENNESSEE DEFARTMENT OF HEALTH AND ENVIFONMENT

DIVISION OF FIADIULOGJCAL HEALTH

\section{FADIDACTIVE MATEFIAL LICENSE}

\section{SUFFLEMENTAFIY SHEET}

\section{Fage $\underline{5}$ of $\underline{B}$ Pages}

\section{License Number R-73014-H95}

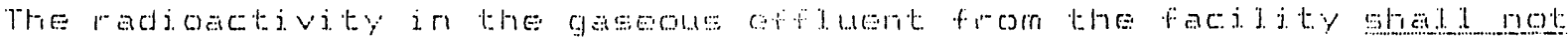

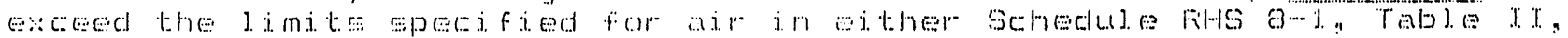

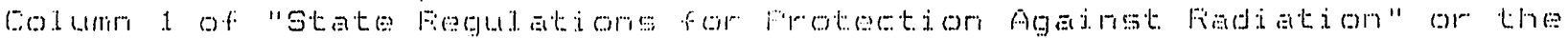

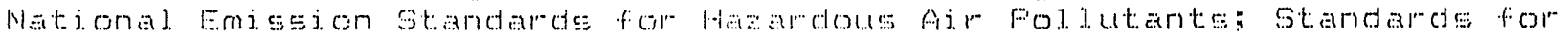

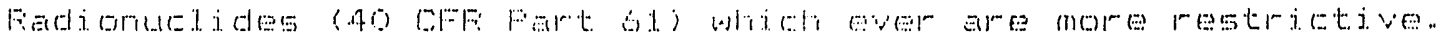

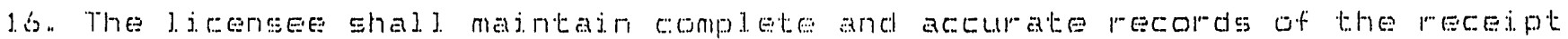

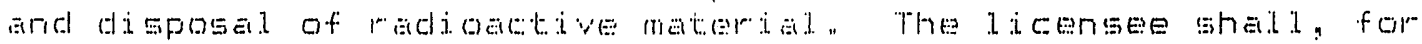

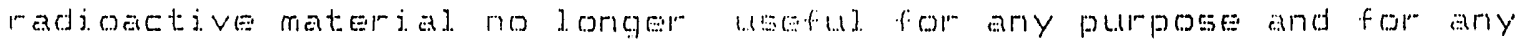

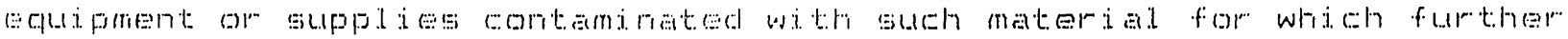

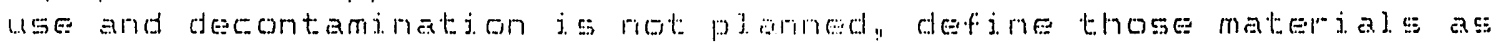

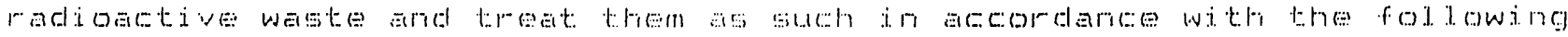
provi. s. allo:

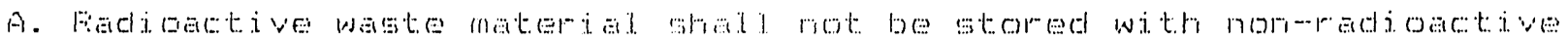
w

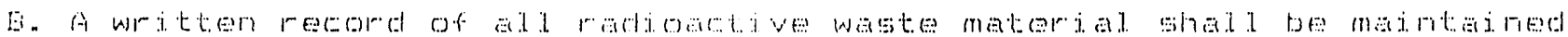

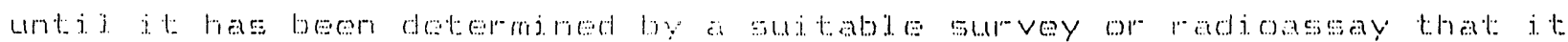

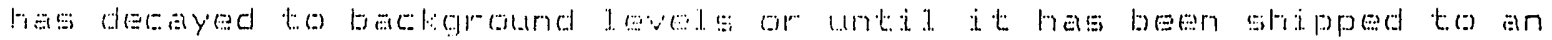

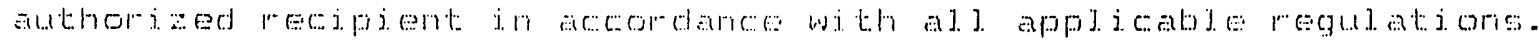

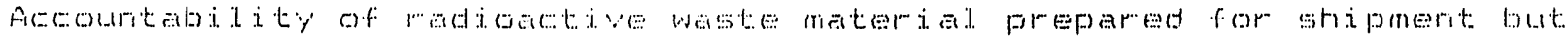

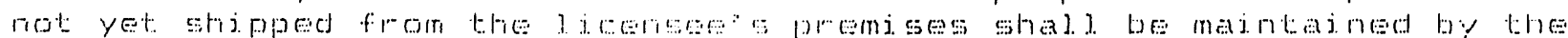

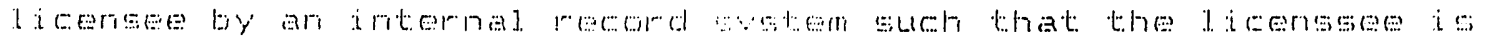

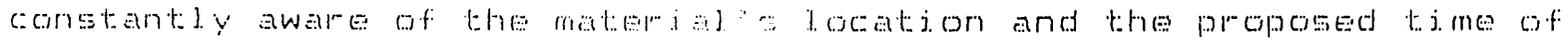

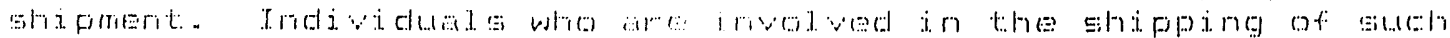

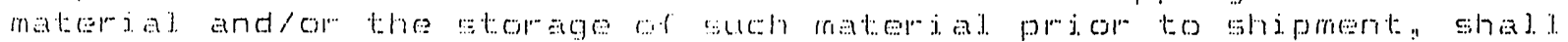

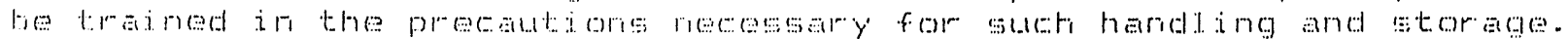

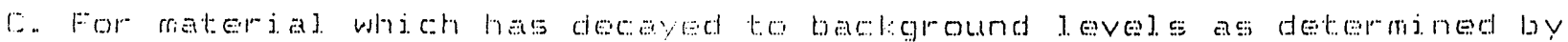

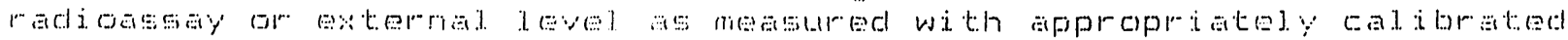

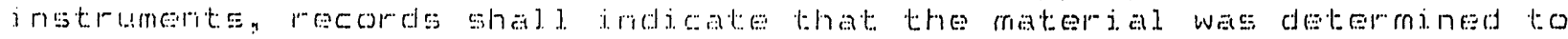

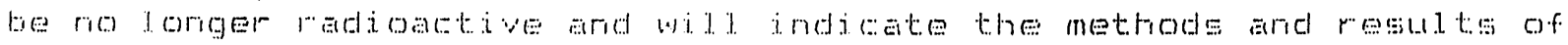
thie survey or arialysis.

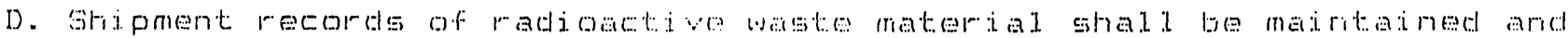

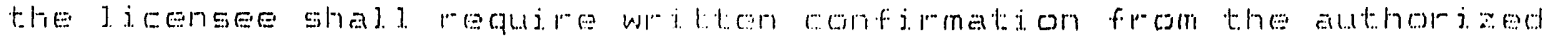

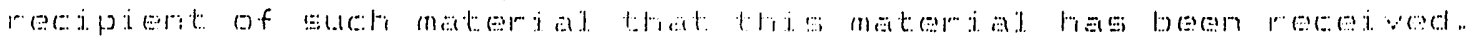

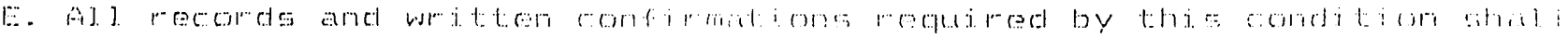

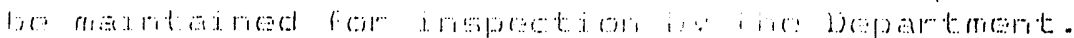


FOrm FiHS $8-7 \mathrm{~A}$

$(10-85)$

TENNESSEE DEPARTMENT OF HEALTH AND ENVIRONMENT

DIVISION OF RADIOLOGICAL HEALTH

\section{FADIDACTIVE MATEFIAL LILENSE}

\section{SUFPLEMENTARY SHEET}

\section{F'age $\underline{b}$ of $\underline{B}$ Fages License Number R-73014-H95}

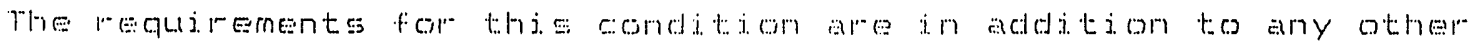

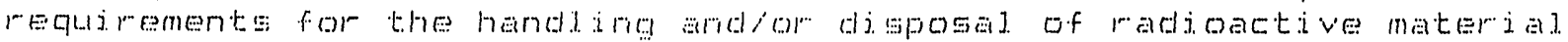

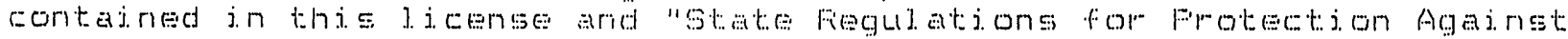
Fiacli ation".

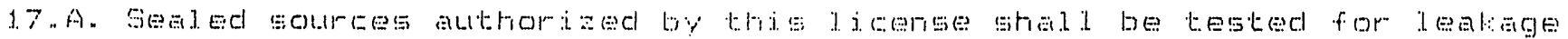

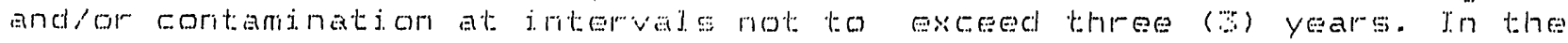

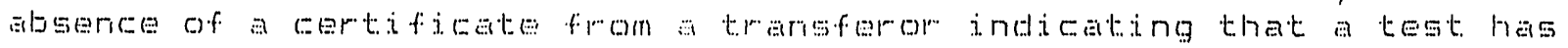

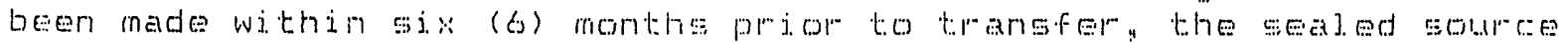

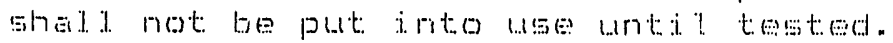

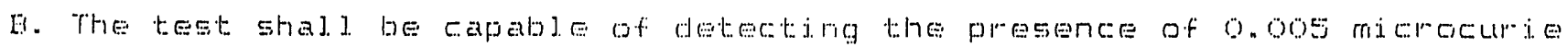

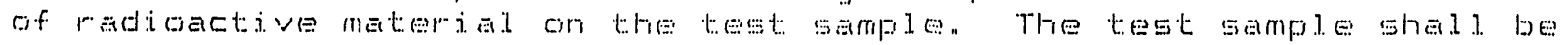

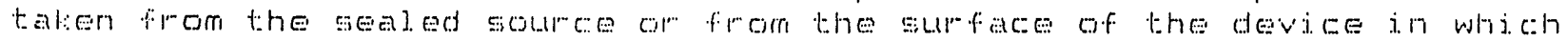

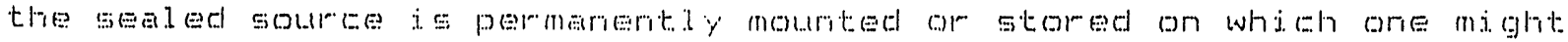

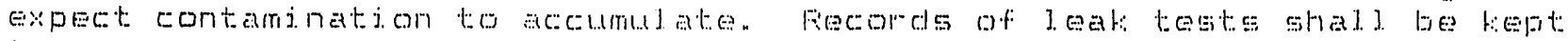
in

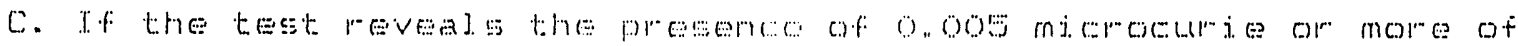

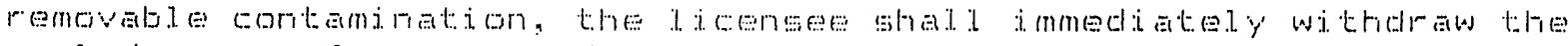

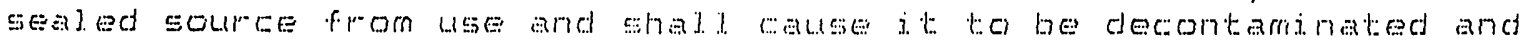

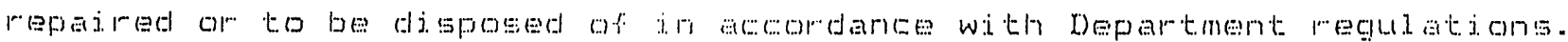
A report shad. be filed within five (g) days of the teset with the

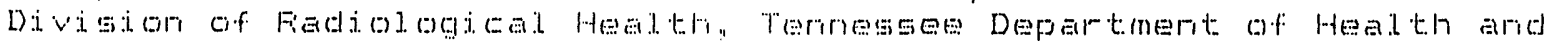

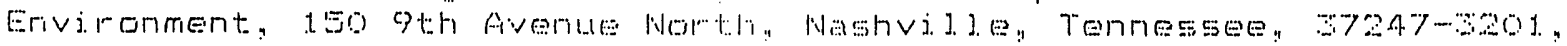

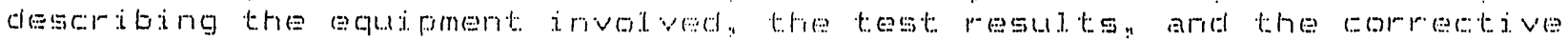
act tion tat:en.

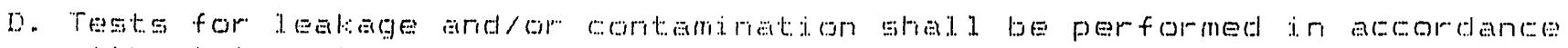

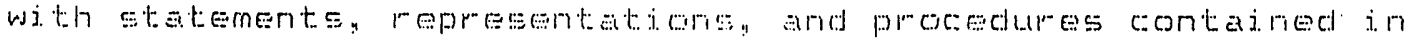

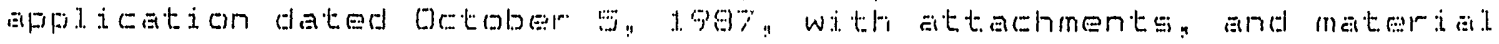

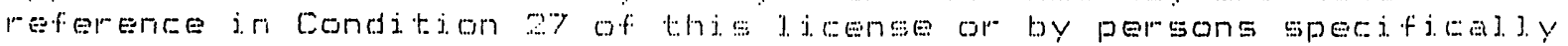

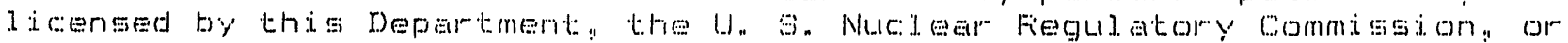
ancther Acgreement state to per form such services.

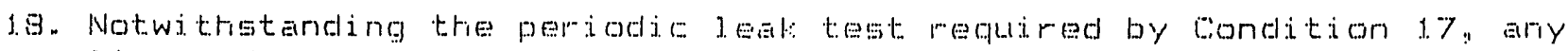

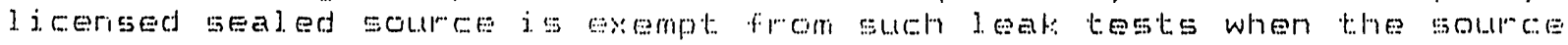

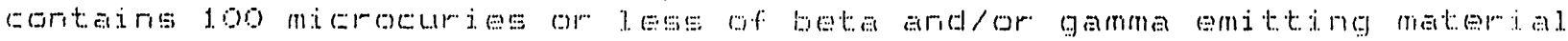

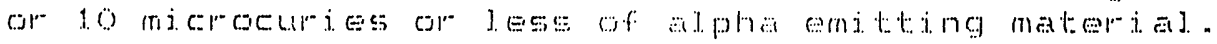

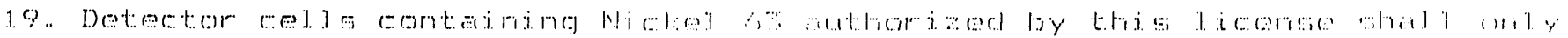

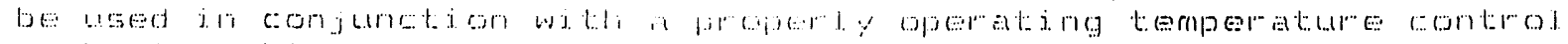

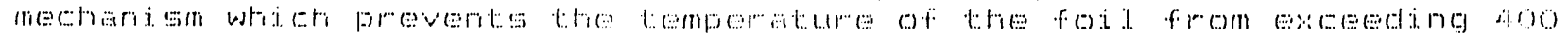

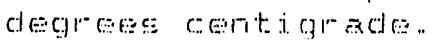


-m RHS $8-7 A$

$(10-85)$

TENNESSEE DEFARTMENT OF HEALTH AND ENVIRONMENT

DIVISION OF RADIOLOGICAL HEALTH

\title{
FADIQACTIVE MATEFIAL LICENSE
}

\author{
SUPFLEMENTAFIY SHEET
}

\author{
Fage $Z$ of $g$ Pages License Number R-7jo14-H95
}

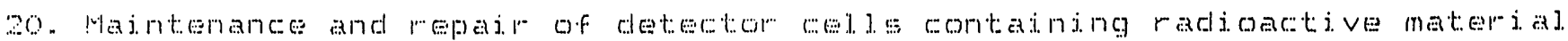

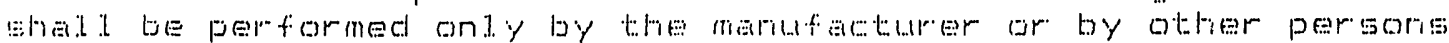

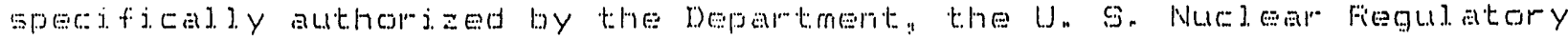

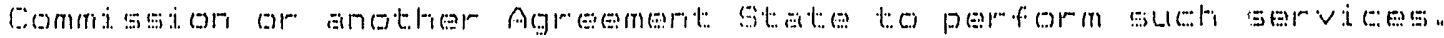

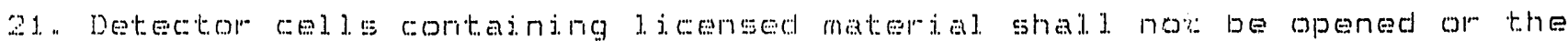

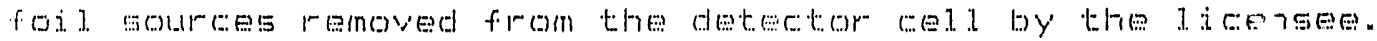

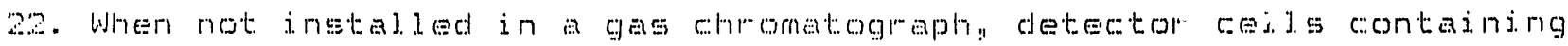

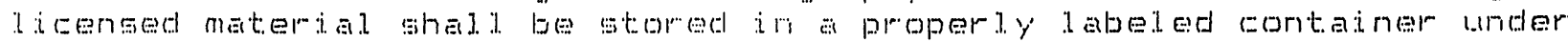

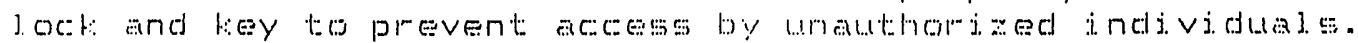

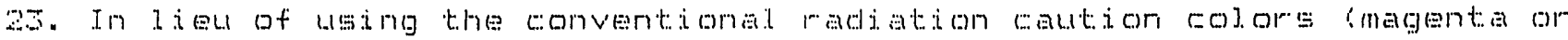

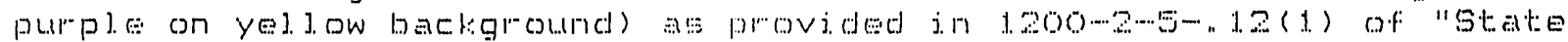

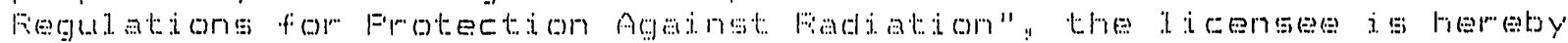

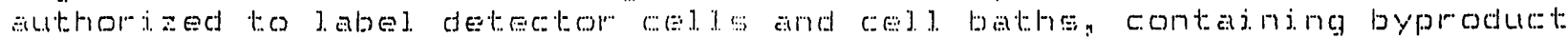

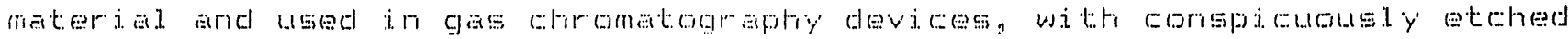

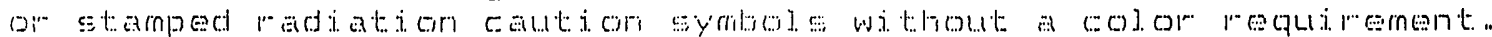

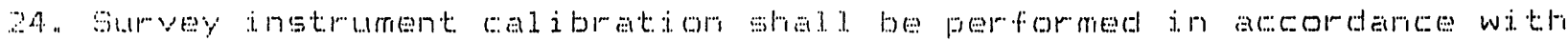

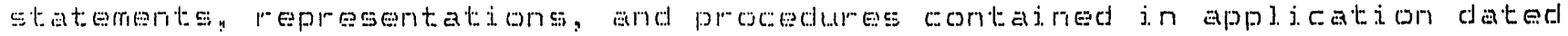

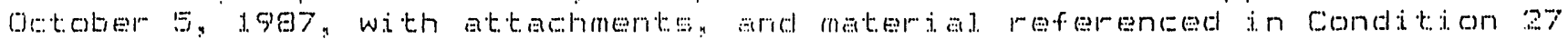
cof thi.s J. i.

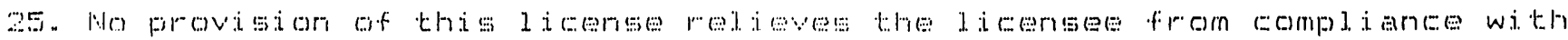

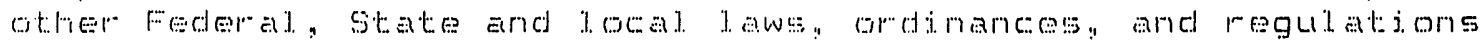

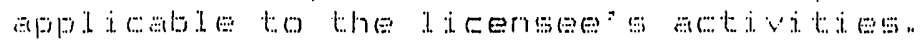

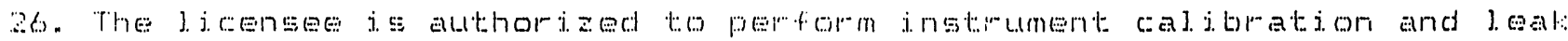

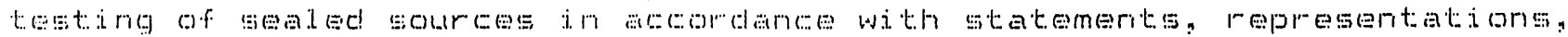

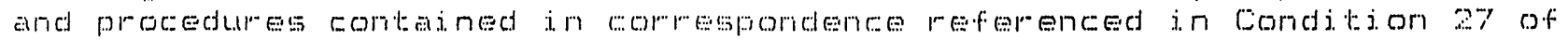
t. Hi is i. i.

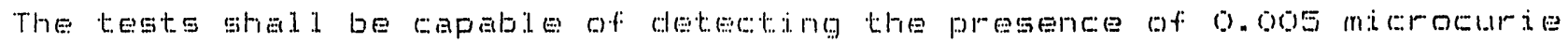

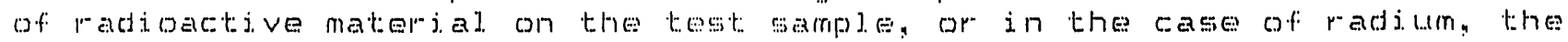

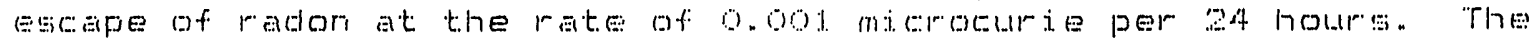

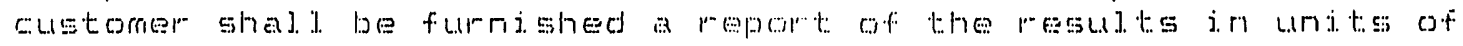
inicirocuries.

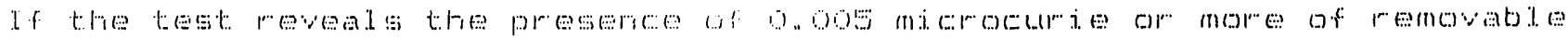

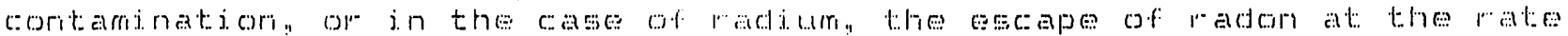

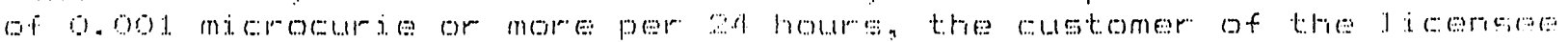

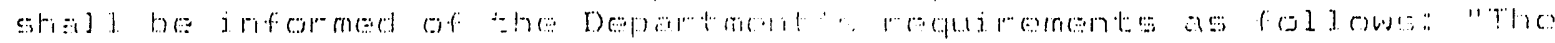


rorm RIHS $8-7 A$

$(10-85)$

TENNESSEE DEPARTMENT OF HEALTH AND ENVIFONMENT

DIVISION OF FADIOLOGICAL HEALTH

FADIDACTIVE MATEFIAL LICENSE

\section{SUFPLEMENTARY SHEET}

\section{Page $\underline{8}$ of $\underline{g}$ Pages License Number R-73014-H95}

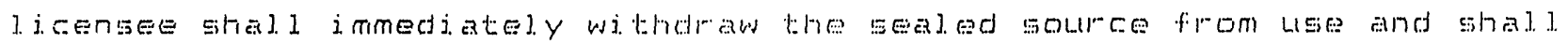

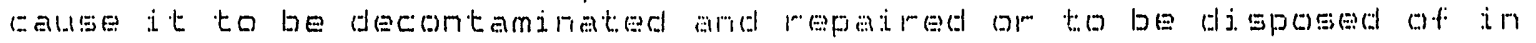

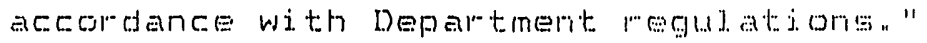

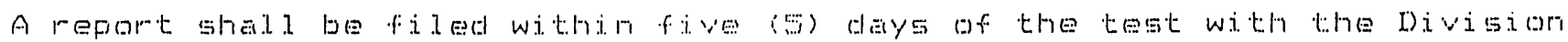

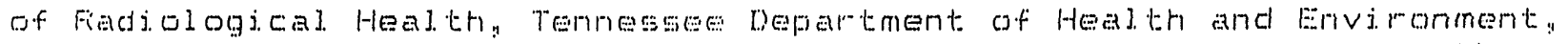

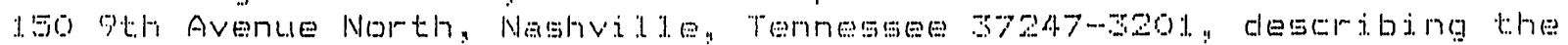

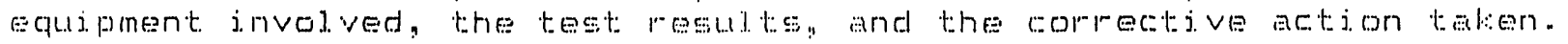

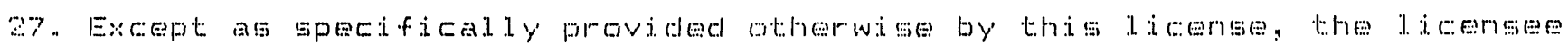

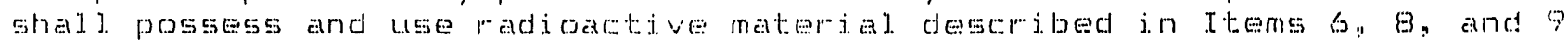

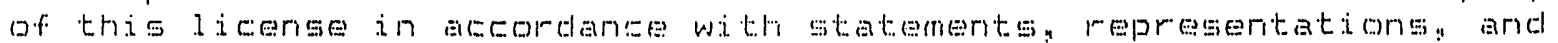

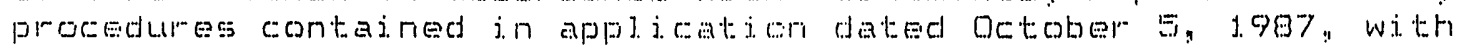

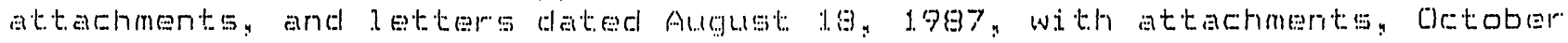

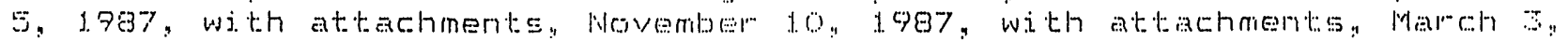

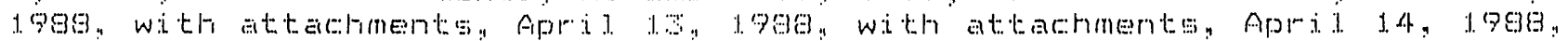

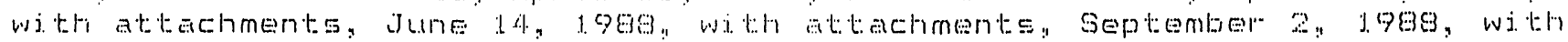

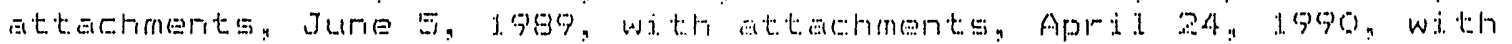

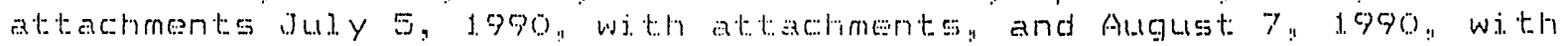
at achments. 


\section{TENNESSEE DEPARTMENT OF HEALTH AND ENVIRONMENT \\ DIVISION OF RADIOLOGTCAL HEALTH}

FADIEAETIVE WATEFIAL LIEEN:E

Ameridment $\underline{\underline{1}}$

Page 1 of $\underline{3}$ Pages

License Number $R-73014-H 9 S_{1}$

Diversified Scientific Services, Inc.

P.O. Box 363

Kingston, TN 37763

Attention: James T. MeVey, Executive Vice President

\section{Gent lemen:}

As requested by James T. McVey and in accordance with his letters dated December 10, 1990, January 17, 1991, Fetruary 25 , 1991 with attachments, March, 5,7991 with attachments, Mareh 14 , 1997 with attachments (tiwo letter $\equiv$ ), and Mareh la; ; 991 , your Tennesseg Radioactive Material license is amended as follows:

To $\exists d d:$

6. Radioactive Material

(E) Ement and

Mass Number)
3 Chemical andior
Fhysical Form

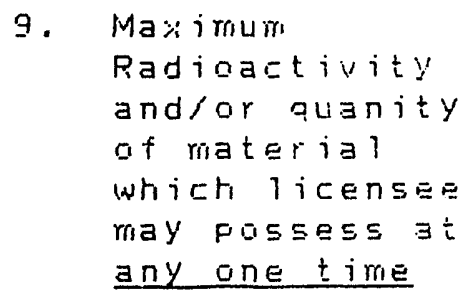

9. Maæimum Radioactivity andfor auanity of material which licenses may possess $3 \hbar$ any one time

1.3. Any radiagctive 13. Same a in BA. 3. material with atomic numbers 1 through 33 , inclusive, except as in $A$. through II, and lik. through TT.

kK. Cr $\quad$ C -51

kK. Same as in $B A$.

kk.

2 Curies

LL. C. C. -134

LL. Same as in GA.

LL.

2 Curies

MM. TC- T⿱
MM. Same as in 3A. MM. 2 Curies 
TENNESSEE DEPARTMENT OF HEALTH AND ENVIRONMENT DIVISION OF RADIOLOGICAL HEALTH

FA口I曰A口TIVE MATEFIAL LIE: Amendment 1

Page 2 of $\underline{3}$ Pages

License Number R-73014-H95

NN. Ge-68

0. Uranilum inot $U-233$ or $U-235)$

PP. Thorium

QQ. Radium

RR. Uranium 235

S5. Uranium 233

TT. Plutonium
NN. Same as in $8 A$.

oo. Same as in $8 A$. Same as in $8 A$.

o.

NN. 2 Curies

Total quantity authorized in Items 00 . and PP. is 200 t:i lograms PP. Same as in 8A. PP. See Item 00. QQ. Same as in BA. QQ. 10 mililcuries RR. Same as in BA. RR. 175 grams* S5. Same as in BA. SS. 100 grams* TT. Same as in BA. TT. 100 grams*

* For each tind of special nuclear material, determine the ratio between the quantity of that special nuclear material and the quantity specified here for the same kind of special nuclear material. The sums of such ratios for all kinds of special nuclear material in combination shall not exceed " 1 " (i.e., unity). In accordance with letter dated January 17,1991 and signed by James $T$. McVey, the amount of special nuclear material allowed under this license is one-half of the amount defined in "State Regulations for Protection Against Radiation" 1200-2-4-.04(00).

10. Authorized Use

JJ. through TT. Same as A. through GG.

To change Condition 27 . This condition will now read as follows:

27. Except as specifically provided otherwise by this license, the licensee shall possess and Lise radioactive material described in Items $s, 8$, and 7 of this license $n$ accordance with statements, mepresentations, and procedures contained in application dated october 5, 1987 with attachments and letters dated Aligust 18,1987 with attachments, october 5, 1997 with attachments, November 1 , 


\title{
TENNESSEE DEPARTIENT OF HEALTH AND ENUIRONMENT
}

DIVISION OF FADIOLOGICAL HEALTH

\author{
FA口 \\ Amendmient $\underline{1}$ \\ Page 3 of 3 Pages \\ License Number R-73014-H9S \\ 1987 with attachments, March 3, 1988 with attactiments, Apri1 \\ 13, 1988 with attartimeits, April 14, 1988 with attachments, \\ June 14, 1988 with attaliments, September 2,1988 with \\ attactiments, June 5,1989 with attachments, Aprill 24,1990 \\ with attachments, July 5, 1990 with attachments, August 7 , \\ 1990 with attachments, December 10, 1990, January 17, 1991, \\ February 25, 1991 with attachrients, March, 5,1991 with \\ attachments, March 14, 1991 with attachments (two letters), \\ and March 18, 1991 .
}

This amendment authorizes by reference the design and installation of air sampling probes in accordance with letters signed bu James T. McVey dated Fetruary 25,1991 with attactuments, March S, ig̣1 with attacliments, and Marcis 14,1991 witri attachments.

All other parts of this license remain unchanged.

Date: March 19,1991

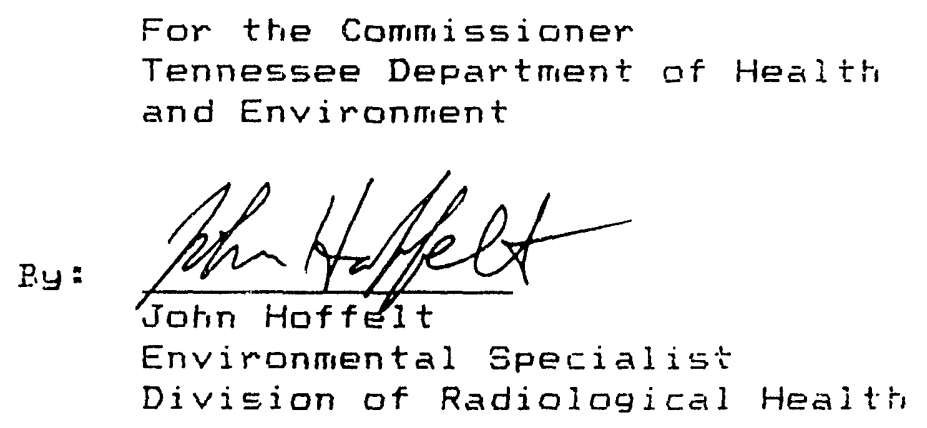




\section{TENNESSEE DEPARTMENT OF HEALTH AND ENVIRONMENT} DIVISION OF RADIOLOGICAL HEALTH

FADIGAETIVE MATEFIAL LIEEMEE Amendment 2

Page 1 of 2 Pages

Diversified Scientific Services! Inc.

P.O. Bo\% 363

Kingston, TN 37763

Attentian: James T. McVey, Executive Vice President

Gent lemen:

As requested ty lames T. Mcvey and in accordance with his letter dated April 15, 1991, your Tennessee Radicactive Material License number F-73014-HSS is amended as follows:

To add condition 2s. This condition shall read as follows:

28. The licensee is autharized ta stare drumis of materials described in letter dated Aprit 15,1991 in excess of iso day not ta exceed June 1, 1991.

To change Condition 27. This canditian will now read as foilows:

27. Except as specifically provided atherwise ty this license, the licensee shall possess and use radiagctive material described in Items $\varepsilon, B$, and 9 of this license in accordance with statements, representations, and procedures contained in application dated october 5,1987 with attachments and letters dated August 13,1937 with at achments, October 5, 1937 with at tachments, Navember 10 , 1937 with attachments, March 3,1933 with attachments, Apri\} 13, 1933 with attactiments, Apri7 14, 1938 with attachments, June 14, 1938 with attachments, September 2, 1983 with attachments, June 5,1939 with attachments, April 24, 1990 with attachments, July 5,1990 with attachments, August 7 , 1990 with attachments, December 10, 1990, January 17, i991, Fetruary 25,1991 with attachments, March 5,1991 with attachments, March 14, 1991 with attachments (twa letters), March 18, 1991, and April 15, 1991 .

All other parts of this license remain unchanged. 


\title{
TENNESSEE DEPARTMENT OF HEALTH AND ENVIRONMENT DIVISION OF RADIOLOGICAL HEALTH
}

FADIGAETIVE MATEFIAL LIEEMEE Amendment $\underline{2}$

Page $\underline{\underline{Z}}$ of 2 Pages

License Number R-73014-H95

Date: April 17, 1991

\begin{abstract}
For the Commissioner
Tennessee Department of Health and Environment
\end{abstract}

B.y :

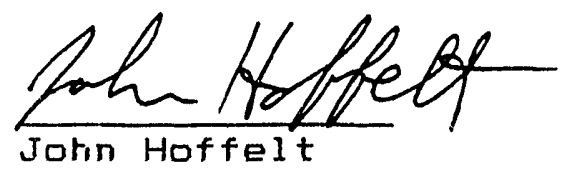

Envimonmental Specialist

Division of Radiological Health 
Exhibit B3

TREATMENT, STORAGE, AND DISPOSAL PERMIT FOR DSSI 
State of Tennessee

Department of Health and Environment

Division of Solid Waste Management
Hazardous Waste Management Program 4 th Floor, Customs House

701 Broadway

Nashville, Tennessee 37219-5403

(615) $741-3424$

\section{PERMIT}

Permittee: Diversified Scientific Services Incorporated

Route 3, Gallaher Road

P.O. Box 863

Kingston, Tennessee 37763

Installation Identification Number: TND 982109142

Permit Number: TNHW-024

Pursuant to the Tennessee Hazardous Waste Management Act, as amended (Tennessee Code Annotated 68-46-101 et seg), and regulations (Chapter 1200-1-11) promulgated thereunder by the Tennessee Solid Waste Disposal Control Board, a permit is issued to Diversified Scientific Services Incorporated (her inafter called the Permittee or DSSI), to construct and operate a hazardous waste storage facility to be located at Gallaher Road near Interstate 40 just outside Kingston, Tennessee, Roane county at latitude $35^{\circ} 52^{\prime} 05^{\prime \prime}$ and longitude $84^{\circ} 27^{\prime}$ 10". The Permittee will be allowed to store and recycle hazardous waste subject to the terms of this permit.

The Permittee must comply with all terms and conditions of this permit. This permit consises of the conditions contained herein (including those in any attachments) and the applicable regulations contained in Rule Chapter 1200-1-11, as specified in the permit. Applicabie regulations are those which are in effect on the date of issuance of the permit, except for the applicable fee requirements of Rule 1200-1-11-.08, applicable land disposal restriction requirements of Rule 1200-1-11-:10, and the permit continuation, transfer, modification, revocation and reissuance, and termination provisions at Rule 1200-1-11-.07(9). Any lawfully promulgated modification made to these excepted regulations during the effective life of this permit shall be considered applicable regulations.

Continuation, Transfer, Modification, Reviocation and Reissuance, arid Termination of this permit must comply with and conform to Rule 1200-1-11-.07(9).

This permit is based on the assumption that the information subnitted in the original permit application and subsequent modifications thereto (hereinafter referred to as the application) is accurate aris that the facility will be constructed, operated, maintained, and closed as specified in the application. The Permittee's failure in the application to disclose fully all relevant facts. or the Permittee's misrepresentation of a:y relevant facts at any time may be grounds for termination of this permit and futentlal enforcement action. The Commissioner may modify this permit if infornation is received which was not available at the time of permit 1ssuance and which justifies the application of different permit conditions at the time of 1ssuance. The Permittee must inforin the Tennessee Department of Health and Environment, Division of Solid Waste 
Management, of any deviation from or changes in the information in the application which would affect the Permittee's ability to comply with the applicable regulations or permit conditions.

This permit is effective as of August 4,1989 , and shall remain in effect until August 4, 1999, unless revoked and reissued, or terminated, or continued.

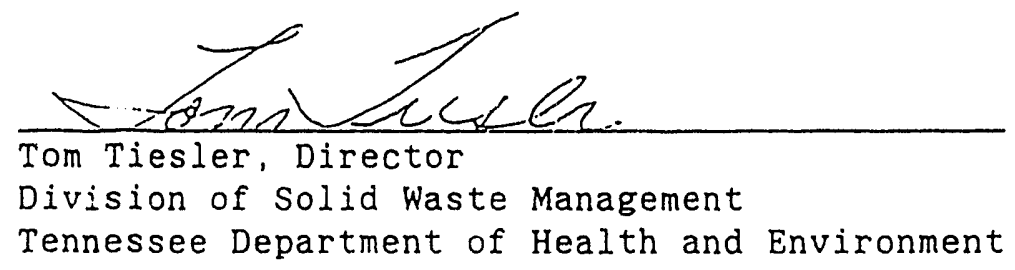

JTT/kl 


\section{STATE OF TENNESSEE \\ CUSTOMS HOUSE \\ 701 BROADWAY \\ DEPARTMENT OF HEALTH AND ENVIRONMENT \\ NASHVILLE, TENNESSEE 37247}

January 23,1991

Mr. Jamen T. MeVay

Diveratiled Scientific Services, Inc.

P.O. Box 863

K1ngeton, TN 37763

Dear Mr. McVey:

The. Tenmessed D1vision of Solld Waste Management acknowledged your request of December 14, 1990 for a major modification pursuant to the rules governing Tepnessoe Rule Chapter $1200-1-11-.07(9)(c)(5)(x 111)(I)$ to add the addit1onal EPA wabe codar (Attachmant 1).

The modiflcation to your permit will be processed under the now pending regulations dealing with the new TCLP and modiflcation classifications by March 1, 1991.

Th1s letter serves as notice that the faclilty can handle the new waste codes unt1l the flnal modification is made to the facility permit No. TNHW-024.

If there are any additional concerns, please feel free to contact Ms. Hymelia Norras of my staft at (615) $741-3424$.

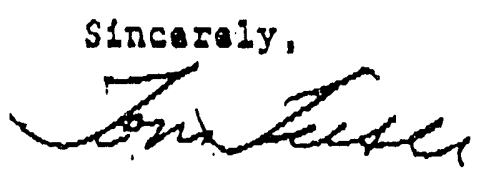

Tom Tiesler, Director

Division of Sol1d Waste Management

ITT/F5081022

CC: James Scarbrough, EPA, Reg10n IV

Dala Dzlar

Jack Crabtrea, Knoxville F.O.

R1ck Brown, Knoxville F.O.

Jacqueline Okorebh-Baah, Chlef Hazardous Permitting 


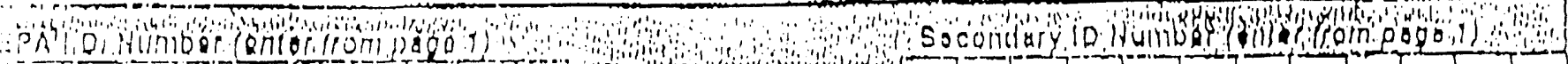

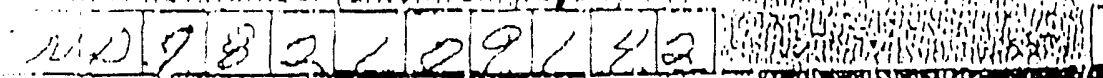

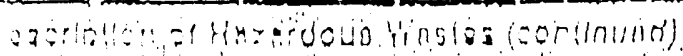

vold of

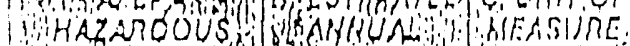

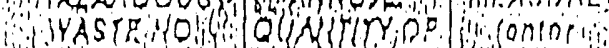

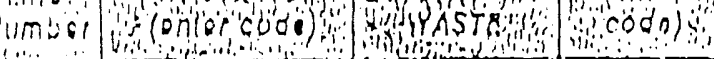

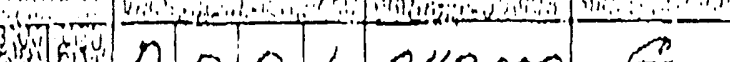

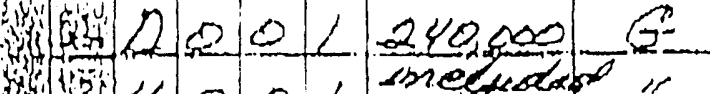

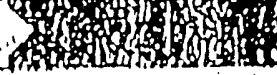

渵

Z04 151502 riseluded abees

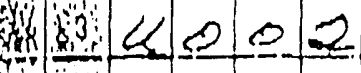

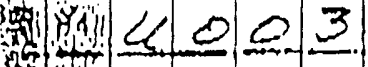

4 ine 4

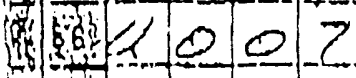

wit $40<2$

(3) $<$ < $<2$

441827

4029

a 1031

40.40 .37

(2) 4044

140.52

040.53

4055

Y

40,56

V

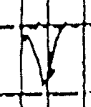

y

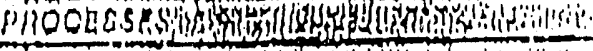
政

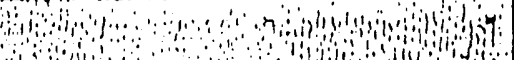

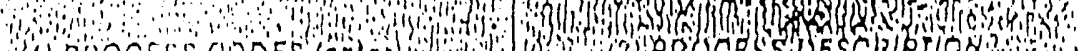

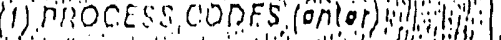

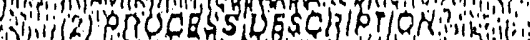
(1) 


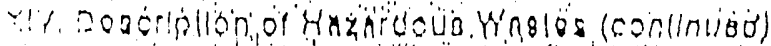

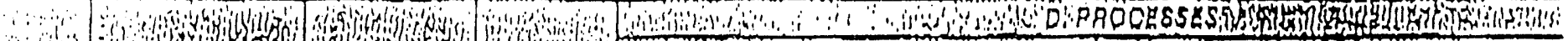
U.

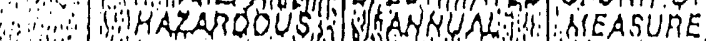

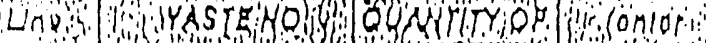

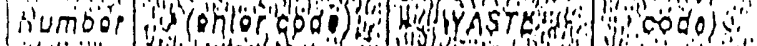

-

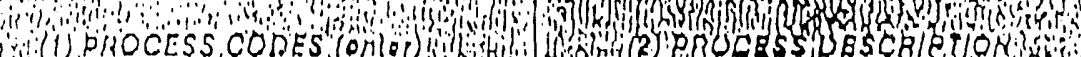
a

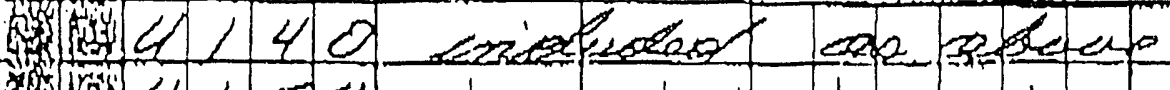
(y) $4<54$ s 자에

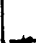

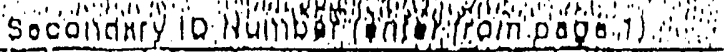


Exhibit B4

AIR POLLUTION CONTROL PERMIT FOR DSSI 
Permit to Construct or Modify an Air Contaminant Source Issued Pursuant to Tennessee Air Quality Act

Date Issued: AUG 1 : 6.1991

Permit Number:

Date Expires:

November 1,1991

$931365 \mathrm{~F}$

Issued To:

Installation Address:

Diversified Scientific Services, Inc.

I-40 \& Gallaher Road

Kingston

Installation Description:

Emission Source Reference No:

Dual Fuel Boller: Modification to Expand From

$73-0137-01$

D001 Solvent to D001, F001 thru F005 Solvents;

Dry Baghouse Scrubber and Packed Tower Control

PES 01

The holder of this permit shall comply with the conditions contained in this permit as well as all applicable provisions of the Tennessee Air Pollution Control Regulations.

This is not a permit to operate.

CONDITIONS:

1. This permit does not cover any air contaminant source that does not conform to the conditions of this permit and the information given in the approved application. This includes compliance with the following operating parameters:

The rated heat input for this source shall not exceed 14.5 million Btu per hour.

2. Particulate matter emitted from this source shall not exceed 0.48 pounds per mllion Btu heat Input ( 6.96 pounds per hour).

3. Hydiogen chloride emitted from this source shall not exceed 5.0 pounds per hour.

4. Chlorine gas emitted from this source shall not exceed 0.029 pounds per hour.

5. Gaseous fluoride (as hydrogen fluoride) emitted from this source shall not exceed 0.0124 pounds per hour.

(continued on the next page)

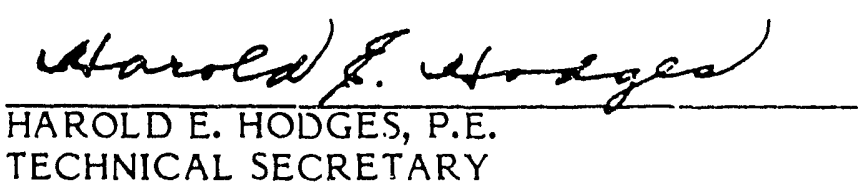

No Authority is Granted by this Perinit to Operate, Construct, or Maintain any Installation 10221225
of any Law, Statute, Code, Ordinance, Rule or Regulation of the State of Tennessee or any of its Political Subdivisions. 
AUG 161991

\section{$931365 \mathrm{~F}$}

6. Visible emissions shall not exceed 208 opacity as specified in Rule 1200-3-5-.01 of the Tennessee Air Pollution Control Regulations (aggregate count). Visible emissions from stacks will be determined by. Tennessee Visible Emission Evaluation Method 2 as adopted by the Tennessee Air Pollution Control Board on August 24, 1984 .

7. This permit shall serve as a temporary operating permit from initial start-up to the receipt of a standard operating permit, (regardless of the expiration date), provided the operating permit is applied for within thirty (30) days of initial start-up and the conditions of this permit and any applicable emission standards are met.

8. The Technical secretary shall be notified in writing at least ten (10) days prior to start-up of the source.

9. Liquid propane gas, and the following solvents D001,F001 thru F005 only shall be used as fuel(s) for this source.

10. The boiler shall be operated at a temperature of at least $1,800^{\circ} \mathrm{F}$.

11. This permit is valid only for the storage tank(s) listed below:

Tank I.D. Contents

Capacity

Turnovers/year

$01,02,03$

D001, F001-F005 (mixture)

10,000 gallons (each)

$55($ each)

12. A $\log$ of the boiler operating temperature and solvents burned (amount and type) on a daily basis must be maintained at the source location and kept available for inspection by the Technical secretary or his representative. This log must be retained for a period of not less than two years.

13. Within 90 days after the issued date of this permit, a source test for chloride shall be conducted. The owner or operator shall furnish the Technical secretary a written report of the results of this emissions performance test within 45 days of testing. Chloride emissions shall be determined utilizing EPA Method 26 as promulgated in the Federal Register, Volume 56; Number 30, February 13, 1991,

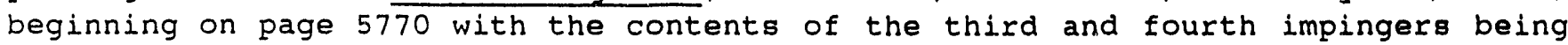
analyzed for chlorine utilizing ion chromatography.

(continued on the next page)

F5221225 
14. Within 90 days after the issued date of this permit, a source test for gaseous fluorides shall be conducted. The owner or operator shall furnish the Technical secretary a written report of the results. of this emissions performance test. within 45 days of testing. Gaseous fluoride emissions shall be determined utilizing either EPA Method 13A or 13B as published in the Federal Register, Vol. 45, No. 121, June 20, 1990, and subsequent amendments. For purpose of compliance with the gaseous fluoride emission standard contained in condition 5 only the fluoride catch in the impingers will be considered. In conducting this testing the filter is to be placed between the probe and first impinger and the probe and filter shall be recovered and analyzed separately from the impingers.

15. The Technical secretary shall be notified in writing at least 20 days prior to performing these compliance tests so that his representative may be present.

16. The chlorine and fluorine mass content of the fuel burned shall not exceed that which is equivalent to the contents in the fuel burned during the source tests required in conditions 13 and 14 of this permit. 
Exhibit B5

NATIONAL EMISSIONS STANDARDS FOR HAZARDOUS AIR POLLUTION PERMIT FOR DSSI

G-41 


\title{
UNITED STATES ENVIRONMENTAL PROTECTION AGENCY
}

\author{
REGION IV \\ 343 COURTLAND STREET \\ ATLANTA, GEORGIA 30363
}

APR 111989

4APT - AC

Mr. James T. McVey

Executive Vice President

Diversified Scient.ific Services, Inc.

P.O. Box 863

Kingston, Tennessee 37763

Subject: NESHAP Construction/Operation Approval Letter for Diversified Scientific Services, Incorporated (DSSI) Scintillation Fluid Burning System

Dear Mr. McVey:

In accordance with the provisions of 40 CFR 61 , we have reviewed information submitted on June 16, 1988; October 13, 1988; January 20, 1989; and March 9, 1989, to detemine the ability of the referenced facility to comply with the NESHAP radionuclide emission standards promulgated at 40 CFR 61, subpart I. Based upon this review, approval is hereby given for the construction and operation of the scintillation fluid burning system at DSSI's Kingston site, based upon tine regulations currently in effect, i.e. those promulgated at 50 FR 5195 on February 5, 1985.

Although approval cor the burner is being issued on the basis of it being able to comply with the regulations currently in effect, you should be aware of the potential impact that recently proposed revisions to $40 \mathrm{CFR} 61$, Subpart I may have on your facility. For your information, we have enclosed the full text of the revisions proposed on March 7, 1989. The portions of the package which are of primary importance to you are the regulations in $\$ 61.100$ to $\$ 61.108$ and the compliance demonstration procedures outlined in Appendices $B, D$ and $E$. One important fact you should keep in mind is that EPA is proposing dose standards that correspond to four different control approaches and that:, based upon which of the four approaches is chosen at promulgation, the dose standard for NRC-licensed facilities could range anywhere from $0.03 \mathrm{mrem} / \mathrm{yr}$ to $1.0 \mathrm{mrem} / \mathrm{yr}$ effective dose equivalent (ede).

The dose standards for the proposed regulations are calculated differently than the whole body and critical organ dose standards in the current regulation. Since the $10 \mathrm{mrem} / \mathrm{Yr}$ ede standard under approaches $A$ and $B$ in the proposed regulation is roughly equivalent to the $25 \mathrm{mrem} / \mathrm{yr}$ whole body standard in the exj.sting regulation, we would not anticipate you having any trouble complyjing with the emission standard in approaches $A$ or $B$ if the burner is constructed and operated as described in the Application. If the standards iri approaches $C$ or $D$ are chosen for the promulgated standards, then you would either have to reduce the quantity of radionuclides processed in the burner or would have to install additional pollution controls. Since construction of the bumer will begin after proposal of the subpart I revisions, the burrer wijl be considered to be a new source under the new regulations also. Therefore, the revised standards 
will apply to your facility upon promulgation and you will not be eligible for a corpliance waiver under the provisions of 40 CFR \$61.10 and \$61.11.

In addition to the provisions of $40 \mathrm{CFR}$ 61, Subparts $A$ and I, approval to construct and operate the burner j.s also contingent upon compliance with the following additional terms and condj.tions:

1. The facility shaill be designed, constructed, and operated as described in the NESHAP application dated October 13, 1988, and additional information dated June 16, 1.988; January 20, 1989; and March 9, 1989, (hereinafter referred to as the Application), unless superseded by a more stringent condition below.

2. All flue gas fran the burner shall pass through an air pollution control system consisting of a prefilter, HEPA filter, and carbon adsorber.

3. The Applicant shall maintain a log of all radioactive receipts for the facility and shail include the following information in the log: the date of shipment, the radionuclide inventory at the time of shipment, the date of receipt, verification results when conducted, and comparison of the verification results with the reported inventory. A separate log shall be maintained and shall include a cumulative inventory for each radionuclide received and treated. In addition, the Applicant shall notify the Agency whenever the cumulative inventory of radionuclides in the waste burned in a calender year exceeds either of the quantities listed below:

a. Total tritium and cartbon-14:22.5 Ci

b. Total for radionuclides other than tritium and carbon- $14: 1.5 \mathrm{Ci}$

4. For any radionuclide not listed in the Application, the Applicant shall establish a Maximum Acceptable Quantity (MAQ) of the radionuclide to be treated each year if that quantity is likely to exceed a minimum amount. The minimm amount is based on the quantity of the radionuclide that would result in a calculated effective dose equivalent of $1 / 100$ of the NESHAP standards. Upon receiving a request for disposal of a radionuclide for which a MAQ has not been established and which is greater than the minimum amount, the Applicant shall perform a dose equivalent assessment for the radionuclide prior to establishing a MAQ. The dose equivalent assessment shall be conducted using the same techniques and data bases as outlined in the Application, with the exception that assessment must be performed only at the previously established point of maximum impact. Concurrent with the notification to the generator of waste acceptance, and prior to receiving the first shipment for a new radionuclide, which exceeds the minimum amount, the Applicant shall notify the Agency in writing of its intent to receive a waste containing a radionuclide not originally analyzed in the Application. The notification shall include the MAQ established for the new radionuclide, the 
composition of the waste, the expected quantity of waste to be received annually, and the estimated dose resulting from treating the waste in combination with all other doses associated with activities at DSSI's Kingston site.

5. The exhaust stack shall be provided with testing facilities as follows:
a. Sampling ports adequate for test methods applicable to such facility.
b. Safe sampling platform(s).
c. Safe access to sampling platform(s).
d. Utilities for sampling and testing equipment.

6. Procedures in $\$ 61.107$ of the subpart I revisions to be promulgated on or about August 31, 1989, shall be used for determining radionuclide emissions from the burner. If the burner starts lip prior to August 31, 1989, procedures in the version of $\$ 61.107$ proposed on March 7, 1989, shall be used to determine the burner's radionuclide emissions in the period of time between proposal and promulgation ol: the revisions. The Applicant shall maintain a record of all radionuclides emitted and shall notify the Agency whenever the cumlative emissions during a calendar year exceed either of the quantities listed below:
a. Total tritium and carbon-14:22.5 Ci
b. Total for radionuclides other than tritium and carbon-14:1.5 $\mathrm{Ci}$

7. Within 90 days after the effective date of the subpart I revisions to be promulgated on or about August 31, 1989, the Applicant shall notify the Agency as to whether or not the burner will be capable of conplying with the offsite dose standard in the promulgated regulation. Details of this notification appear at 40 CFR 61.10.

8. Thirty (30) days after the end of each calendar quarter, the Applicant shall report the radionuclide release rate from the facility (expressed as curies per month for each radionuclide emitted) during each of the previous three months.

9. No condition presented herein precludes the Applicant from adhererce to additional or more stringent conditions or requirements of any uther Federal, State, or local approval or permit.

10. Failure to comply with the conditions of this approval may result in revocation of the approval and/or enforcement action by. the Agency.

11. At all times, including periods of startup, shutdown, and malfunction, the burner shall be maintained and operated in a manner consistent with good air pollution control practices for minimizing emissions. 
12. All notifications, reports, and correspondence shall be submitted to the Chief, Air Compliance Branch, Air, Pesticides and Toxics Management Division, U.S. EPA, 345 Courtland Street, Atlanta, Georgia 30365 with copies to the Director, Tennessee Division of Radiological Health; and Director, Tennessee Division of Air Pollution Control.

This approval is granted solely under Section 112 of the Clean Air Act and implementing regulations at 40 C.F.R. 61 and in no way affects approvals under other Federal or State regulatory authorities.

If you have questions concerning this approval, please contact me at 404/347-3043.

Sincerelỳ yours,

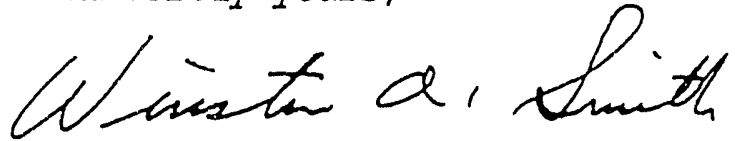

Winston A. Smith, Director

Air, Pesticides and Toxics

Management Division

Enclosure

cc: Mr. Harold Hodyes, Director

Division of Air. Pollution Control

Tennessee Department of Public Health

Customs House, 4th Floor

701 Broadway

Nashville, Tenuessee 37219-5403

Mr. Michael Mobley, Director

Division of Radiological Health

Tennessee Department of Health and Environment

150 9th Avenue, North

TERRA Building

Nashville, Tennessee 37219-5404 
Exhibit B6

HAZARDOUS WASTES ACCEPTABLE FOR RECEIPT AT DSSI 


\section{CHEMICALS ACCEPTABLE FOR RECEIPT AT DIVERSIFIED SCIENTIFIC SERVICES, INC.}

\section{Chemical Name}

1,1 Dichloroethane

1,2 Dichloroethane

1,1,1-Trichloroethane

1,1,2-Trichloroethane

1,1,2-Trichlorotrifluorethane

1,2-Dichlorobenzene

1,4-Dioxane

2-butenal

2-ethoxyethanol (ethylene glycol monethyl

ether)

2-Nitropropane

Acetaldehyde

Acetone

Acetonitrile

Acetophenone

Aniline

Acrylamide

Benzene

n-Butyl alcohol

Carbon Disulfide

Carbon Tetrachloride

Chlorobenzene

Chloroform

m-Cresol

o-Cresol

p-Cresol

Cresylic acid

Cumene

Cyclohexane

Cyclohexanone

o-Dichlorobenzene

m-Dichlorobenzene

p-Dichlorobenzene

Dichloroisopropyl ether

Dipropylamine

Ethanol

Ethyl Acetate

Ethyl Benzene

Ethyl Ether

Ethylene glycol

Formaldehyde

Furan
Hazardous Waste Code Number

U076

U077

F001/F002/U226

F002/U227

F001/F002

F002/U070

U108/D001

U053

F005/U359

F005/U171

U001

F003/U002

$\mathrm{U} 003$

UD04

U012

UC107

FC05/U019

F003/U031

F005/P002

F001/U211

F002/U037

U044

F004/U052

F004/U052

F004/U052

FO04

U055

U056

F003/U057

F002/U070

F002/U071

F002/U072

U027

U110

D001

F003/U112

F003

F003/U117

D001

U122

U124 


\section{Chemical Name}

Heptane

Hexane

Isoamyl alcohol

Isobutyl alcohol

Isoctane/2,2,4-Trimethylpentane

Methane, bromo-

Methane, dibromo

Methane, trichloro

Methanol

Methylene Chloride

Methyl Ethyl Ketone

Methyl Isobutyl Ketone

Methyl Pyrrole

Mineral Spirits

Naphthalene

Nitrobenzene

Nonane

Octane

Propanol

Pentane

Propane, 1,2-dichloro

2-Propenal

Propylene glycol

Pyridine

Tetrahydrofuran

1,1,2,2-Tetrachloroethane

1,1,1,2-Tetrachloroethane

Tetrachloroethylene

Toluene

o-Toluidine

m-Toluidine

p-Toluidine

Trichloroethylene

Trichlorofluoromethane

Trichloromethane

m-Xylene

o-Xylene

p-Xylene

Unlisted Ignitable Waste

Spent Solvents

Spent Solvents

Spent Solvents

Spent Solvents

Spent Solvents

Arsenic

Barium
Hazardous Waste Code Number

D001

D001

D001

F005/U140

D001

U029

U068

U044

F003/U154

F002/U080

F005/U159

F003/U161

D001

D001

U165

F004/U169

D001

D001

D001

D001

U083

$\mathrm{P} 003$

D001

F005/P075/U196

U213

U209

U208

F001/F002/U210

F005/U220/D001

D001/U328

D001

D001/U353

F001/F002/U228

F002/U121

U044/D001

F003/U239/D001

F003/U239/D001

F003/U239/D001

D001

FOO1

$\mathrm{F} 002$

$\mathrm{FOO3}$

F004

F005

D004

D005 


\begin{tabular}{ll} 
Cadmium & $\mathrm{D} 006$ \\
Chromium & $\mathrm{D} 007$ \\
Lead & $\mathrm{D} 008$ \\
Mercury & $\mathrm{D} 009$ \\
Selinium & $\mathrm{D} 010$ \\
Silver & $\mathrm{D} 011$ \\
Endrin & $\mathrm{D} 012$ \\
Lindane & $\mathrm{D} 013$ \\
Methoxychlor & $\mathrm{D} 014$ \\
Toxaphene & $\mathrm{D} 015$ \\
2,4-D & $\mathrm{D} 016$ \\
2,4,5-TP (silvex) & $\mathrm{D} 017$ \\
Benzene & $\mathrm{D} 018$ \\
Carbon Tetrachloride & $\mathrm{D} 019$ \\
Chlordane & $\mathrm{D} 020$ \\
Chlorobenzene & $\mathrm{D} 021$ \\
Chloroform & $\mathrm{D} 022$ \\
o-Cresol & $\mathrm{D} 023$ \\
m-Cresol & $\mathrm{D} 024$ \\
p-Cresol & $\mathrm{D} 025$ \\
Cresol & $\mathrm{D} 026$ \\
1,4-Dichlorobenzene & $\mathrm{D} 027$ \\
1,2-Dichloroethane & $\mathrm{D} 028$ \\
1,1-Dichloroethylene & $\mathrm{D} 029$ \\
2,4-Dinitrotoluene & $\mathrm{D} 030$ \\
Heptachlor (and its epoxide) & $\mathrm{D} 031$ \\
Hexachlorobenzene & $\mathrm{D} 032$ \\
Hexachlorobutadiene & $\mathrm{D} 033$ \\
Hexachloroethane & $\mathrm{D} 034$ \\
Methyl ethyl Ketone & $\mathrm{D} 035$ \\
Nitrobenezene & $\mathrm{D} 036$ \\
Pentachlorophenol & $\mathrm{D} 037$ \\
Pyridine & $\mathrm{D} 038$ \\
Tetrachloroethylene & $\mathrm{D} 039$ \\
Trichloroethylene & $\mathrm{D} 040$ \\
2,4,5-Trichlorophenol & $\mathrm{D} 041$ \\
2,4,6-Trichlorophenol & $\mathrm{D} 042$ \\
Vinyl Chloride & \\
\hline & $\mathrm{D} 043$
\end{tabular}


Exhibit C1

LIST OF PERMITS, LICENSES, OR AUTHORIZATIONS PERTAINING TO NSSI 


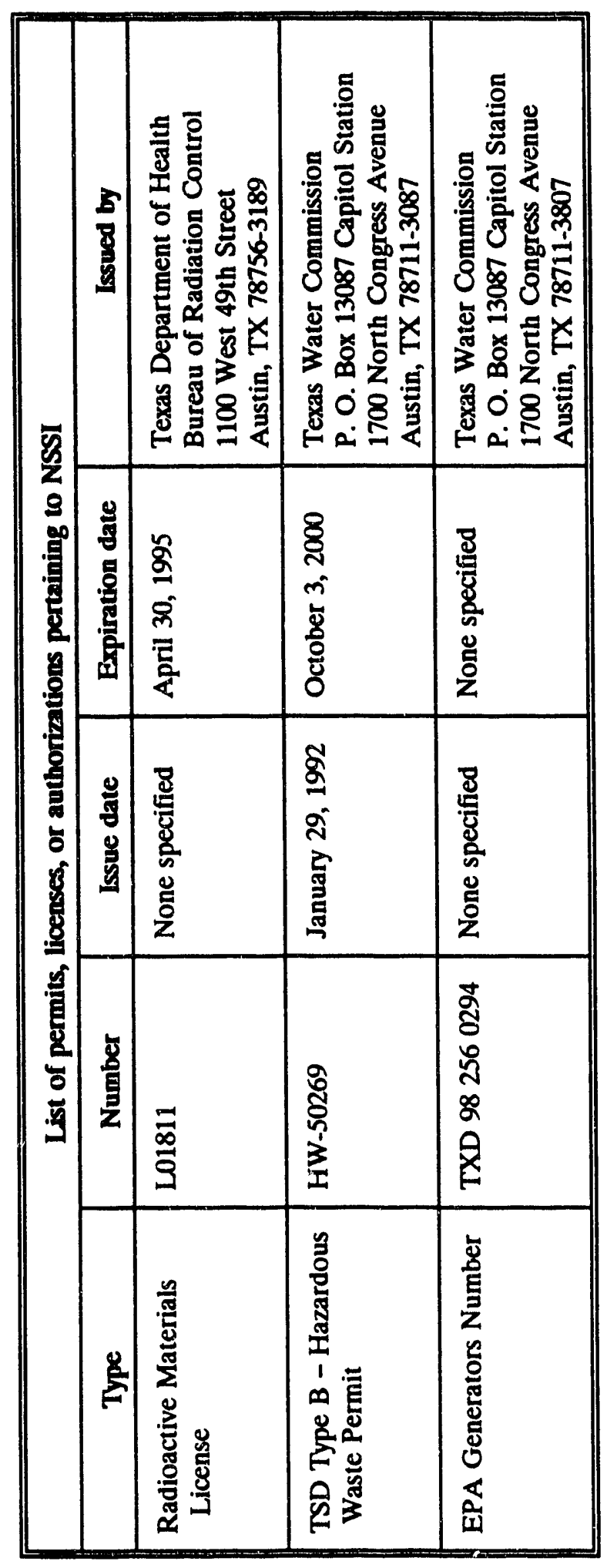


Exhibit C2

HAZARDOUS WASTE PERMIT FOR NSSI 


\section{Texas Water Commission}

\section{INTEROFFICE MEMORANDUM}

TO

: Texas Water Commission

DATE:

$8-2-90$

THRU : Michael E. Field, Chief Hearings Examiner

FROM : Carl $\dot{x}$. Forrester, Senior Administrative Law Judge

SUBJECT: NSSI/Recovery Services, Inc.; Proposed Permit No. HW-50269

NSSI/Recovery Services, Inc. of Houston, Texas, has applied to the Texas Water Commission for proposed Permit No. HW-50269 which would authorize NSSI/Recovery Services, Inc., to operate a commercial hazardous waste storage and processing facility in east Harris County, Texas. The facility will store and process wastes in 20 tanks totaling 58,530 gallons capacity and four container storage areas totaling 114,620 gallons capacity. The facility site is located on eighteen city lots in a mixed commercial, residential and industrial aree located at 5711 Etheridge, Houston, Texas. The site is located in Segment No. 1006 of the San Jacinto River Basin.

Carl X. Forrester, Attorney, a Commission Senior hdministrative Lä̈ Judge (ALJ), conducted an adjudicative public hearing in Houston, Texas on May 15, 1990 after proper notice of the hearing was given pursuant to Section 26.022 of the Texas Hater Code, as amended, and Section 361.082 of the rexas Health and Safety Code.

The hiJ desigrated the joliowing as parties to the hearing: the applicant (represented by Tom Buckle, Attorney); the Commission's Executive Director (represented by Bob Renbarger, Attorney); the Commissicn's public Interest Coursel (represented by Leslie Sachanowicz, httorney): Treatment One/SET Environmental, inc. (represented by Reith Hopson, Attorney); and Harris County (represented by David Kelasky, Attorney). Six employees of the City of Houston were present but did not seek party status anc offered ro puizic coment.

Prior to the start of the trial of the issues, the parties negotiated a complete settlement of the issues. As a result of that settlement, the attached proposed permit has been modified to include the regulatory provisions regarding air pollution control which were agreed to by the parties. As a result of that agreement and inclusion of the air pollution control provisions in the permit, the protests of this application have been dropped and this application has become uncontested. 
Memorandum to the Commission NSSI/Recovery Services, Inc.

The AlJ belleves that $1 \mathrm{t}$ is in the public lnterest and the interest of this agency to support negotiated settlements of parties to contested hearings whenever possible. Therefore, the Judge recommends that the Commission approve this application and issue the attached Permit No. HW-50269 which includes the agreed provisions of the parties.

Because the application is now uncontested, no Order with Findinys of Fact and Conclusions of Law contained therein has been prepared.

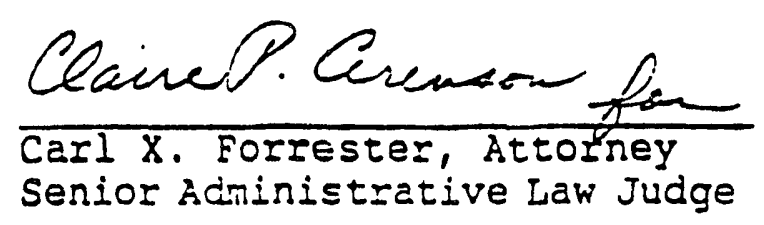




\section{TEXAS WATER COMMISSION}

B. J. W'ynne, Ill, Chaiman

John O. Houchins, Commissioner

John E. Birdwell, Commissioner

October 11, 1990

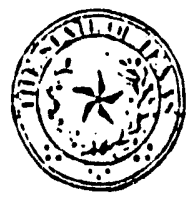

Allen Beinke. Executive Director
John J. Vay, General Counsel

Michael E Field, Chief Hearings Examiner

Brenda W. Foster, Chiel Clerk

RE: NSSI/RECOVERY SERVICES, INC.: PeImit NO. HW-50269

\section{Dear Permittee:}

Enclosed is a copy of:

$x$ 1. Permit for a wastewater treainent facility issued pursuant to chapter 26 of the Texas Water Coce. In order that you may comply with monitoring requirements of your permit, self-reporting forms and instructions will be forwarded to you from the Water Quality Division at an early date. If your fasility is not yet operaing, please use the attached liotification of completion of tacilities scr... to advise this ageney and our district office o: the completion or placement in operaison of proposed facilities in accordance with the speeial provision incorporated into the permit.

2. imenced permit for a wastewater treatment facility issued pursuant :o Chapter 26 of the Texas Water Code. Please continue using the self-reporting forms you have on hand until new fers are fozwarded by the water quality Division. If your sacility is not yer operatiss, please use the attached Netification of completion of Facilities form to advise this agency and our district office of the completion or placement in operation of proposes Eacilities in ecsoriance wisth the speciel provision incorporated into tus per...it.

3. Renewal of a pemit for a wastewater treatment facility issued Finjuart tc Chapter $2 E$ of the Texes rieter code. Is your fasility is not ye: operating, please use the attached totification of Completion of Facilities form to advise this agency and our distzict cffice of the completion o: zlecement in operetion of proposed sacilities $i n$ ascordanse with the specij: provision incerporsted into the perit:

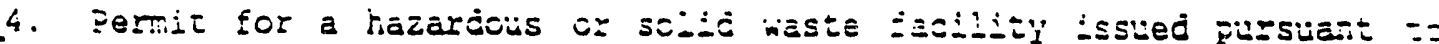
Fit. 4477-7, Texas Revised Civil s:atutes. Yo:z attentior. is directed $=$

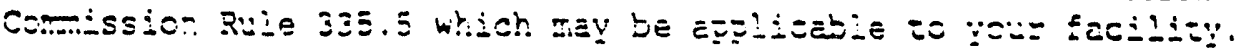

5. Permit or anended permit for a waste disposal weli or an injecti=s weil issued pursuant to Chapter 27 of the Texas Water Code. In accordarc with the Texas hater Code, you must $f i$ ie a copy of the persit with the ci: $\because$ and county health authorities.

If there are any questions concerning this permit, please let us know.

$\cdot$

cc w/enclosures

TWC Distriet No.

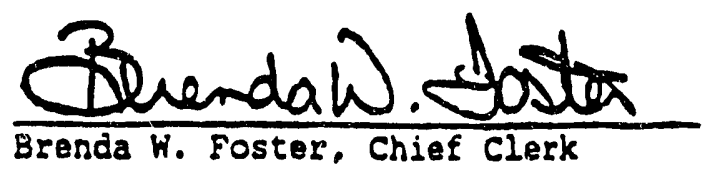

G-61

P. O. Box 13087 Capitol Station • 1700 North Congress Áve. - Austin. Tixas 78711.3087 • Area Code 512!463.7830 


ACKNOWLEDGEMENT OF NOTIFICATION
OF HAZARDOUS WASTE ACTIVITY


Jobiun Ilall, Chairman

Pam Recd, Conmaissioner

'Peggy Garner, Conmissioner

JAN $3 ! 1992$

\section{TEXAS WATER COMMISSION}

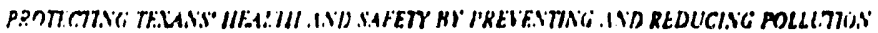

NSSI/Recovery Services, Inc.

Atten: Robert D. Gallagher, Pres

P. O. Box 34042

Houston, Texas 77234

RE: NSSI/RECOVERY SERVICES, INC. CIASS 2 !OD ; Permit HW50269

Erclosec is a copy of:

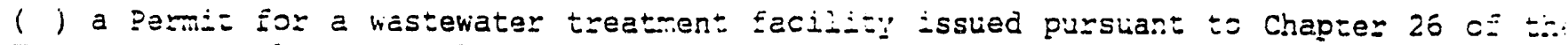
Texas hater Code. In order that you may compi $\ddot{y}$ with moritoring requirements for $\because 0:$ waste iischarge permi=, self-reportinc forms ard instructions will be forwarced to yc from the Water quality Division at ar early jate. If you have these forms on ha:c please continue using them untii new forms are sent. (NOTE: If your permit is Ec disposal only, self-reporting foras are not applicabie.) If your facility is not ye operaring, please use the attached "Report of progress of Construction of Wastaiare Treetrent Easilities" form. This form will ajvise this agency and cur district cfE:

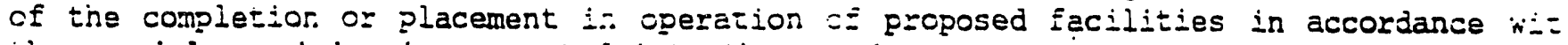
the special provision incorporated into the parnit.

(W a permit for a hazardous or solid waste Eacility issued pursuant to Axt. 447i-7 Texas Revised Civil Statutes. Your attention is Cizected to Comission Rlie 335.5 wit:L may se applizaisle tc your facility.

( ; a Permil for a weste disposai liell or an irjection well issued pursuant to chepze 27 of the Mexas Water Code. In eccorcance with the Texas Water Code, you biust file

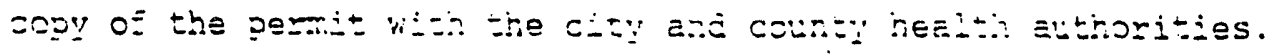

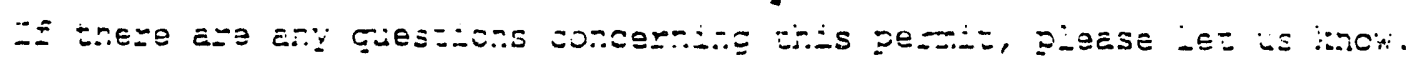

\section{Sincerely,}

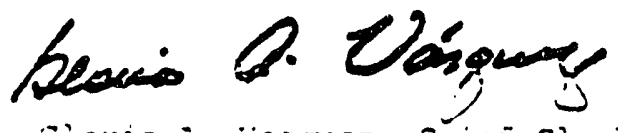

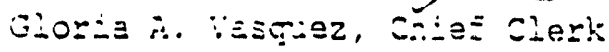

GAV: SD

En:Los:-e

crinersicsuso:

Yio liseret defice 


\section{TEXAS WATER COMMISSION \\ FIELD OPERATIONS DIVISION AREA OFFICES}

DISTAICT 1

3918 Canyon Drive

Amarillo, Texas $79109-4996$

806/353.9251 (TEX-AN 8-862.0071)

Don Manning. District Manager

DISTRICT 2

530350 in Sireel, Suite 306-4

Lubbock, Texas 79414-1875

8067796.7092 (TEX.AN 8.840.1067)

Lamy L. Smith, District Manager

\section{DISTRICT 3}

14000 Woodway Drive

Waco, Texas 76712-3193

$8177751-0335$ (TEX-AN 8-820-1465)

Larry Fergusson. District Manager

\section{DISTRICT \&}

1019 N. Duncanville Rd.

Duncanville, Texas 75116-2201

214298-6171 (TEX-AN 8-831-5650)

Chartes D. GIII, District Manager

\section{DISTRICT 5}

2916 Teague Dive

Tyler, Texas 75701.3734

903/595-5468 (TEX-AN 8-834-5256)

John Witherspocon. District Manager

\section{DISTRICT 6}

4820 Ward Drive

Beaumont, Texas $77705-0328$

409842-9413 (TEX-AN 8-850-1383)

Keith Anderson, District Manager

DISTAICT 7

5144 East Sam Houston Pahyay North

Houston, Texas 77015

713/457.5191 (TEX-AN 8-730-0200 or 0300)

William F. Bowles, District Marager

TWC LABORATORY

5144 East Sam Houston Parkway North

Houston, Texas 77015

713/457-5229 (TEX.AN 8.730.0200 or 0300)

Jim Busceme, Lab Manager
DISTRICT \&

140 Heimer Road, Suite 360

San Antonio, Texas 78232.5042

$512 / 490.3096$ (TEX-AN 8.820-1308

Billy Boggs, District Manager and 820.1314 )

DISTRICT 9

102 Canyon Road

San Angelo, Texas 76904

915/655-9479 or 655-1336

Kenneth W. Knueger, District Manager

DISTRICT 10

2626 J.B. Shepperd Parkway Blvd.

Bldg. B-129

Odessa, Texas 79761

915/362-6997 (TEX-AN 8-840-1432)

William F. Lockey, District Manager

DISTRICT 11

813 E. Pike Blvd.

Weslaco, Texas 78596-4935

512968-3165 (TEX-AN 8-820-1825)

John Sturgis, District Manager

DISTAICT 12

4410 Dimon Lane. Suite 47

Corpus Christi, Texas 78415-5326

512/851-8484 (TEX-AN 8-820-1682)

Chip Volz, District Manager

DISTRICT 14

1700 South Lamar, Eldg. 1, No. i01

Austin, Texas $78704-3300$

512/463-7800 (TEX-AN 8-255-7803:

iv. John Young, District Manager

DISTRICT 15

7500 Viscound Bind. Suite 147

E! Paso, Texas 79925

9157778-9534 (TEX-AN 8-846-8183)

Hector Villa, Districa Managor

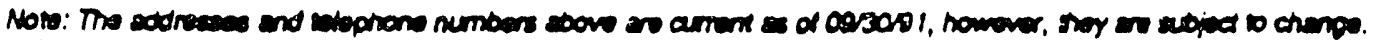

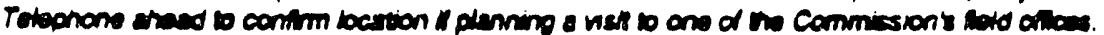




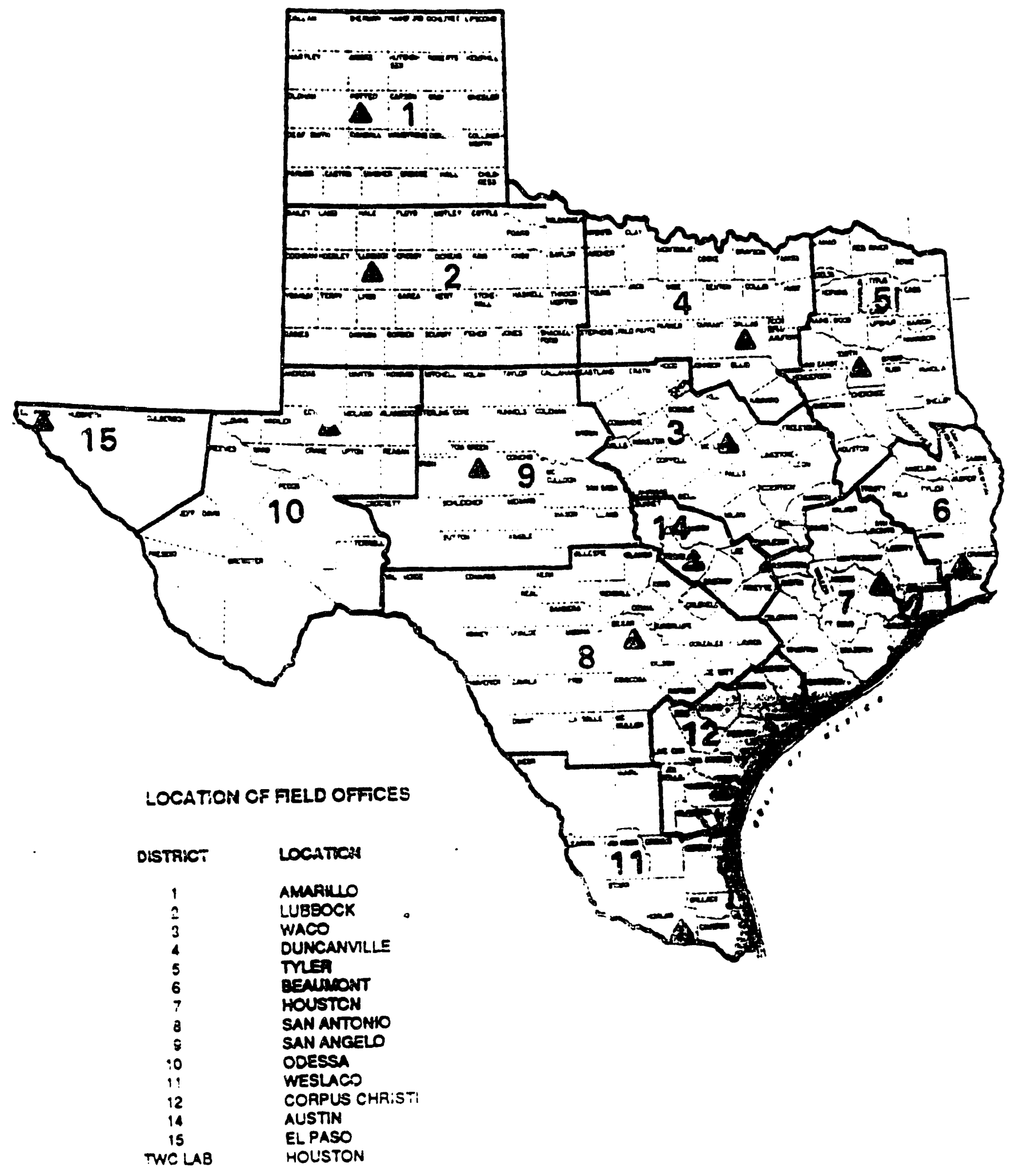




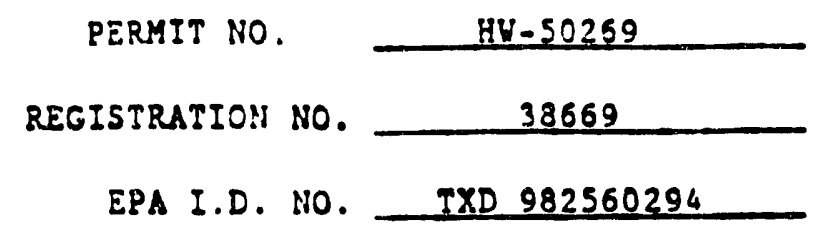

TEXAS WATER COMMISSION

Stephen F. Austin State Offlce Bullding

Austin, Texas

PERMIT FOR INDUSTRLAL SOLID WASTE MANAGEMENT SITE Issued under provisions of TEX. HEALTH \& SAFETY CODE ANN. Chapter 361 (Vernon)

Name of Peraitiee:

Site Omner:

Registered Agent for Service:

Classification of Site:
NSSIiRecovery Servises, Inc.

2.0. 30x 34042

Houston, Texas 77234

Rober: D. Gallage:

c/O NSSI/Recovery Services, In.c.

?.0. Box $3 \div 042$

ت̈oustor, Te:as $7: 234$

Robert D. Gallage:

C/O $\mathrm{HSSI} /$ Recovery Sergices, Ir.s.

?.). $30 x 34342$

:Custon, ?ex.3s 77234

Hazardous waste storage and processing, commercial

The permittee is authorized to stoze and process wastes $i=$ accordanse with limitations, requirerents and othe = condicions set forth terein. This perait is granted subject to the rules of the Cocmission and other orders of the Conaissi:s: and lays of the state of lexas. Nothing in this perzit exempts the permittee

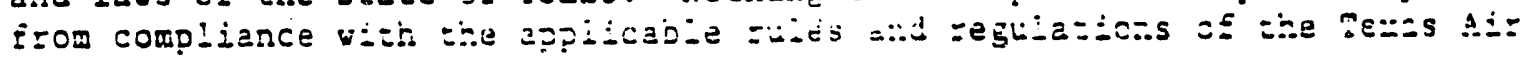
cortrol Board.

This permit vill be valid until carcelied, amended or revoked by the Commission. Authorization to store anc process vastes siall expize midnight, octobez $3,20{ }^{2}$.

The provisions in this perzi: ste $f=0=$ joth state ar.d Eeceral autrority. Tase

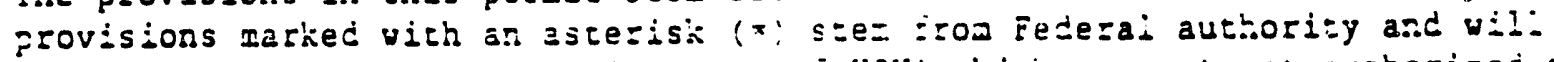

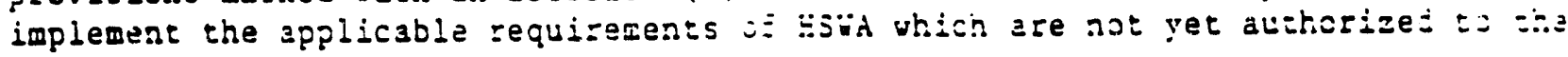
state of Texas. APPROVED, ISSUED, AND EFFECTIVE this $20+1$ day of
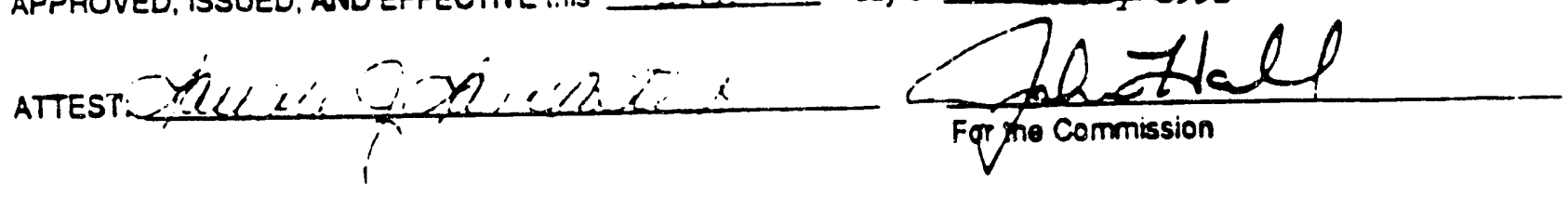
Table of Contents

NSSI/Recovery Services, Inc.

Section

I. Size and Location of Facility

II. Units and Operations Authorized
A. Wastes Authorlzed
B. Units Authorlzed
C. Processing Functions Authorized

III. Facilley Design, Construction, and Operation

A. General Design, Construction, and Operazion

B. General Operational Requizewents

C. Tank Design, Construction, and Operarion Requirezents

D. Conzalner Storage Area Design, Conszruction and Operation Requirements

IV. Closure

A. Genera: Closure Reçuizements

B. Lazardous waste Management ir: = Ciosure Reguizer.enzs

$\because$ Standazo Pezmie Condizicris

iI. Incorpozased Regularcri Resuirements

VI. Incorporated Appilicarion Maseriais

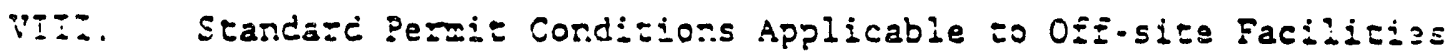

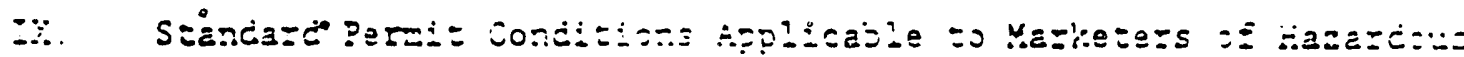
Waste Elue:

X. RCRA Fac1i: =y Investigation

XI. AlE Qua?izy ?:ovisior.s 
PERMIT NO. HW -50269

NAME: NSSI/Recovery Services, Inc.

I. Size and Lecacion of Facility

A. The hazardous waste management facility is located on 18 city lots in a mixed commercial. residential and industrial area at 5712 Etheridge. Houston. Harris Councy. Texas. The location is described as being in vatershed area 1006 of the San Jacinto River Basin (North Latikude $29^{\circ}$ $40^{\prime} 32^{\prime \prime}$. Vest Longitude $95^{\circ} 18^{\prime} 24^{\prime \prime}$ ).

B. The legal description and site plan subaitted in the application for Permit No. th-50269 are hereby made parts of this permit as Attachmerts $A$ and $B$.

II. Units and Operations Authorized

A. Wastes Authorized:

The permittee is authorized to aarage tazardous and iriustrial so:id waste listed in the application and described hezeir., subject to the limitations provided herein.

Wastes irclude those generaced $a=$ tris izcility and Ezon off-site

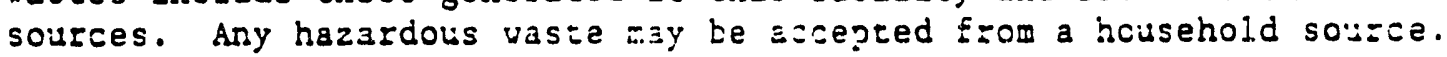

Hazardous and iadustrial soidd rastes authorized to be managed urde: this permit are limized as follows:

i. Hazard Code Group Codes las prosczibed by U. S. Envirar.mentai Protection Agency regulations; is effect ipon date of permit approva 1:

\begin{tabular}{l}
$\frac{x}{x}$ Ignitabie (I) $\quad \frac{x}{x}$ icios bazardous Waste (H) \\
$\frac{x}{x}$ Toxicity Characteristic (I) \\
\hline
\end{tabular}

2. Nasto Descziptiors
a. Spert Haiogenaced soïEn:3
b. Spent Non-Halozeraeed Solve:s:s
c. Acetone
d. Benzene
e. .-Butgl slcohol
E. Cunene
8. Cyclohexare
h. Cyclohexanone
i. 1,4 Dioxane
j. Ethyl Acetate
k. Ethy: Ether
1. Formaldehyde

\begin{tabular}{|c|c|}
\hline $\begin{array}{c}\text { Tho } \\
\text { ines:e CIass }\end{array}$ & Hazarci Codes \\
\hline تِّتّ & $\tau, E$ \\
\hline I'U & $I, T, E$ \\
\hline İ & I \\
\hline 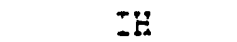 & $I, I, \Sigma$ \\
\hline$I \ddot{F}$ & $I$ \\
\hline$i \ddot{i}$ & $I$ \\
\hline EH & $I$ \\
\hline$\because \ddot{8}$ & $I$ \\
\hline IE & $I$ \\
\hline โร & I \\
\hline . & $z$ \\
\hline$I: !$ & $?$ \\
\hline
\end{tabular}


PERMIT NO. HW-50269

CONTINUATION SHEET 3 OF 28

NAME : NSSI/Recovery Services, Inc.

[II.A.2.]

Waste Descriptions

m. Isobutanol

n. Methanol

o. Methyl Ethyl Ketone

p. Kethyl Isobutyl Ketone

q. Naphthalene

r. Pyridene

s. Toluene

t. Xylene

u. Eapty Containezs

v. Misc. Chemicai-contaminezed Katerials

w. Iabpacks and Containers $=0$ be Consoiidated into labpacks

$x$. $0 \vdots 1$ and Solvents

$y$. Paint Sludge

z. Paine Sludge containing Ohlo:inated Solvents

22. Cyanides

bb. Wastewater contairing Organics, Yatals, and Oil

sc. Orgaric Liguids

dd. Sludge from Oxidation, Reduatio:

ea. Solids from Solveat Still

Ef. Stabilized Vaste

gg. Sllige from Blending/Separation: Stc=age Tanks

hi. Waste Carbon Adsorftirr. Media and Solids

¿i. Haste Ion Exchange Yecia and Soi ids

jj. Filser Soldds and Media

ki. Lazazdaus solid Mazez:三:

$\because \therefore$ Corsoijiazad :

a]. Consolidatad Hazarciolis Soilds

$s=$ blended Hazardous Viste Fuel

co. Compressed Hazardcus Waste Gas
THC

Vaste Class Hazard Codes

IH

IH

IH

IH

IH

IH

IH

IE

I

IH

IS

Iit

$\because \ddot{7}$

IH

IH

$\underline{x}$

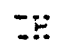

Iii

IE

IE

$I \ddot{*}$

I3

$=5$

$\mathrm{IH}$

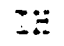

$\because$

I.

Iis

IE:

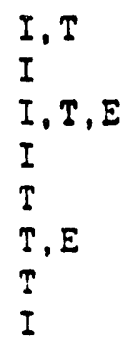

$I, C, R, E, Z, ?$

$I, C, R, \Xi, \Xi, T$

I.T, $\mathrm{I}$

I, C, E, H, T

$I, C, \Xi, \ddot{H}, I$

R, :

$\Xi, \Xi, T$

I, E,

$Z, C, \Xi, \ddot{B},=$

I,E, $, T, T$

E,, T

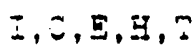

I, E, В, T

C, E, H, T

I, $, E, E, \mathrm{H}$, ?

$\bar{Z}, \Sigma, \bar{E}, \vec{E}, T . \bar{I}$

$\Xi, \sigma, R, \Xi, \ddot{\Xi}, Z$

I, $, \bar{E}, \Xi, \Xi, Z$

$I, C, E, R$

I, C, E, R, H, I

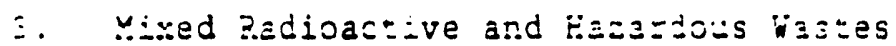

So iong as the pezticee streil hold and asicie the restricticns s:

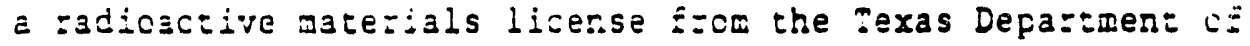
Heaith, radicacrive or nuclear waste racerials ii..e., vaste ataerial bich eciss ionizing radiation sponcaneously) which asso bt itie vaste descripticns in provision. II.A.2. above nay be seceived frou off-site and annaged is accosdance with the frovisions of this permit. 
NAME: NSSI/Recovery Services, Inc.

[II.A.]

4. Prohibited Wastes and Haste Limitations:

Explosive material as defined by the Department of Transportation (DOT) under 49 CFR 173.

5. Prior to accepting any additional wastes with chemical characteristics similar to those authorized by provision. II.A.2., the permittee shall satisfy the following reguizemens:
a. Notify the Execurive Director;
b. Provide a characterization of the vaste deaonitrating i:s sinilari=y;
c. Submit, upor. request of the Executive Dizector, sufficte:: information to ascertain similarity of the waste material. If the Executive Dizecto: determines the meteriai is no: similar, the permittee sust obtain a permit amendaent befoze accepting the waste.
j. Receive written response frcs the Executive Direcsor informing the permittee that the material is similar to stose materials authorized by Provision II.A.2. and that a perzit

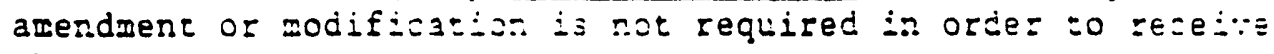 the vaste.

巴. Units Authorized:

The permittee is authorized to opezate the folloving units for s:0:az= and processing gubject to the iixitstisss contained hereiz. ill vas:e mansgement actirities subject to fermiting are to be confized to ihe Eollowing units:

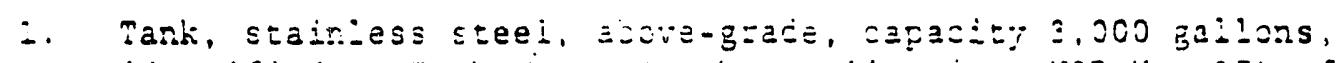

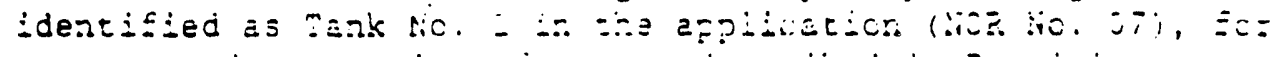
storage ard processi=.e ci wastes descrílec in Eroyisions II.A.2.a.-t., x., cC., II., E..d na.

2. Tank, stainless steel, above-grade, capacif; 3.000 sillons, ¿dentified as mank No. 2 ir :ho application (HOR Ho. $37 \%$, Ea=

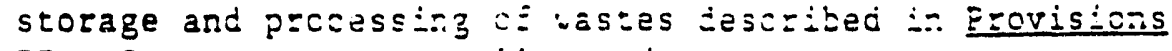

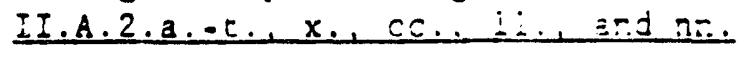

3. Tank, stainless steel, ajove-brais, capacity 3,000 gajions, identified as lank lio. j :- the jfpiication (NOR No. 07), Ea: storage and jucessing je wastes desizibed ir provisions

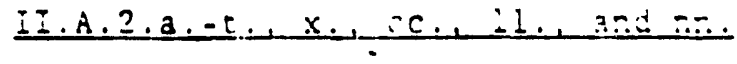


NAME: NSSI/Recovery Services, Inc.

[II.B.]

4. Tank, stainless steel, above-gzade, capacity 3,000 gallons, identified as Tank No. 4 in the application (NOR No. 07), for storage and processing of vastes described in Provisions II.A.2.a. -t., x., CC., II., and $n n$.

5. Tank, stainless steel, above-gzade, capacity 1,700 gallons, identified as Tank No. 5 in the application (NOR No. 07), for storage and processing of wastes described in Provisions II.A.2.a. -t., x., Ce., i. . and nn.

6. Tank, stainless steel, ebove-grade, capacity 1,700 gallons. identified as Tank Mo. 5 in the application (NOR No. 07), for storage and processing of vastes described in Provisions

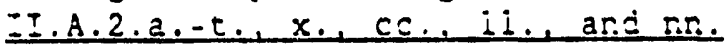

7. Tank, stainless steel, Ebove-grade, capacity 1,200 galions, identified as Tank No. 7 in tise application (NOS. No. C7), E0: storage and processing of vastes described in provision.s I.A.2.a.-t., X., CE., 1., and n.n.

8. Tank, stainless steel, abcve-grade, capacity 1,-jo gailcss, identified as Tank No. $\delta$ in the application (NOR No. 0T), fo: storage and processing of vastes described in Provisions

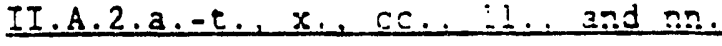

9. Tank, stainless steel, above-grade, capacity i,100 gallons, identified as Tank No. 9 in the application (NOR No. 07), for storage and processing of wastes descrited in Provisions II.A.2.B.-t., $x ., C C ., 1, \ldots$ and $\mathrm{r.R}$.

iv. Tank, stainless steel, acove-grade, capacity 900 gallons, identified as Tank tho. 0 in the appiicaticn (NOR No. 07), io: storage and processing of wastes described in provisions

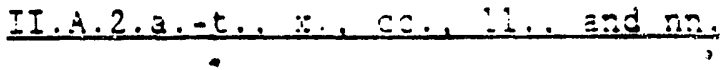

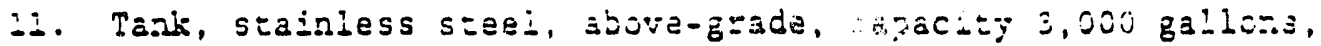
identified as Tani: No. 11 in the apptation (NOE No. 07), Io: storage and processing of vasces derrybed in provisions II.A.2.a.t., X., CC., I., and na.

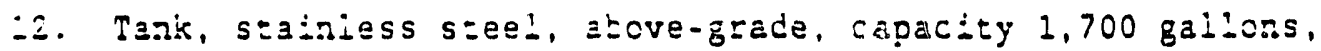

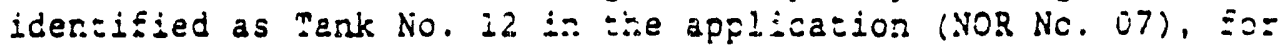
storage and processing os wasies dascribed in provisiors

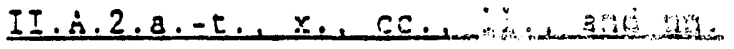




\section{NAME: NSSI/Recovery Services, Inc.}

[II.B.]

13. Tank, stainless steel, above-grade, capacity 10,000 gallons, identified as Tank No. 13 in the application (NOR No. 07), for storage and processing of wastes described in provisions II. A. 2, Bb.

14. Tank, staindess steel, above-gFade, capacity 10,000 galluns, identified as Tank No. 14 in the applicacion (NOR No. 07), fo: storage and processing of wastes described in provisions II.A.2.a.- t., X., cC., II., and nn.

25. Tank, stainless steel, above-grade, capacity 10,000 gallons, identified as Tank No. 15 in the application (NOR No. 07), fc: storage and processing 0 ₹ wastes described in Provisicrs

II.A.2.bb.

15. Tank, stairless steel, above-grade, capacity -.300 gallons. identified as Acid-Base tievtralization Tank in the applicatic: (NOR No. 03), for storage and processing of all authorized aciss and bases.

37. Tank, carbon steei, glass-iined, above-grade, capacity 650 gallons, identified as the 600-gallon Oridation-Reduction Taris in the application (IIOR. No. 04 ), for processing of al! authorizes $\because$ astes.

19. Tank, carbcr steel, Elass-1ined, above-grade, capacity 360 gallons, identified as the 400-gallon Oxidation-Reduction Tasis is the application (NOR No. $0 \dot{4}$ ), Eor processing of ali authorized wastes.

19. Tank, stainless steel, avove-grade, capacity 960 gallons, idj:: fied as Grinder Tank No. 1 in the application (NOR No. 16). Es storage and processing $0 \equiv$ wastes sescribed in Provisions

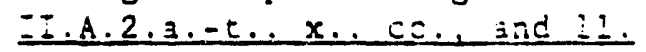

20. Tark, stainless sceel, acove-zraje, capacity gija galioss, iż:::fied as Grinder Tank No. 2 in the applicasion (NOR No. 25), Ec= storage and processing of vastes described in Provisions II.A.2.8.-t., X., CC.. and 11 .

2:. Contairer storage arez, ¿-osed or all sicies, saximum capacis:" 79.860 gallons: identiziec as the suilding 1 containez storase Area in the application (NJa No. 03), Sor storage and process of wastes described ir. Ezovisions II.A.2.a.-nr. 
NAME: NSSI/Recovery Services, Ine.

[II.B.]

22. Container storage area, closed on all sides, maximum capacity 29.700 gallons, identified as the Building 2 Cortainer Storage Area in the application (NOR No. 17), for storage and processing of all authorized vastes which are not reactive and not ignitable.

23. Container storage area, contairing two "explosive" storage buildings, each closed on all sides, maximum capacity 500 gallons. identified as the Reactive Container storage Area in the application (NOR No. 22 ), for storage of all authorized reacrive wastes.

24. Containe: storage area, closed or all sides, maximum capacity 33,2:5 gailons, identified as the Builcing 3 Container stozage area in the application (NOR NO. _), for storage of all authorized rastes.

2. Functiors Authozized:

The perrittee is authorized to perform the following functions, sujjec: to the lizitations contained herein:

1. Blending of wastes to fora a fuel for use off-site;

2. Consolidaricn of waste contairezs into lab facks;

3. Breaking down lab packs for ze-consolidation for off-site disposa: or cr.-site processing;

4. Helizaiizarion, oxidation, reduction, and other chemical reactiors to zender wastes less hazardous or noze suizable for off-site disposal or on-site processing;

E. Res:-iting of solvents;

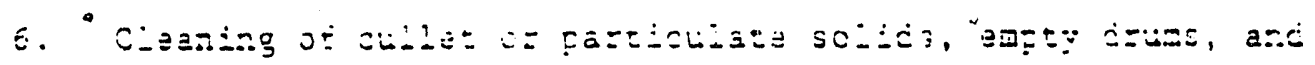
eq̨uдpэes: :

7. Cenerifugation, filtration, and ion exchange in portabie equipmen: iithin an authorizej contairer scorage area;

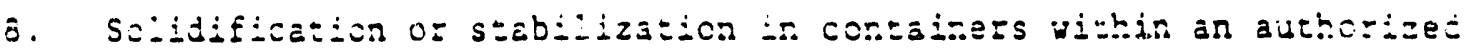
cor:aine: sto:3ge area;

9. Shrejding of contairers for recovery of contents;

10. Consoijdatizn of Jisielareous comparible hazazdous vastes; 
NAME: NSSI/Recovery Services, Inc.

[II.C.]

11. Chemical and/or mechanical treatment to accomplish separation. settling. or clarification in portable equipoent vithin an authorized container storage area:

12. Removal of hazardous constituents by absorpeion on solid media in portable equipment within an authorized container storage area;

13. Dryirg of solids to meet off-site disposal criteria for release 0 : vater only; as.d

14. Recovery of waste chericals and other material for re-lise or resale.

D. Authorization to operate these unizs is contingent upon maintenarce os firancial assurance pursuant to Provision IV.A.1. and maintenance $0 \equiv$ liability coverage in conpliance with the requirements of, and $i n a$ form outlined in, $40 \mathrm{CER}$ Part 264, Subpart 4 . Authorizztion to begin operation of new uri:s is coneingent upon compliance with provisions IV.A.1. and V.C. The permittee may not store or process waste unless comp'iant vith 3 il financial assurance requirements and liability requirements, to inciude all selated financial assurance instrufents and liability coverage instzunents being in full force and effes:.

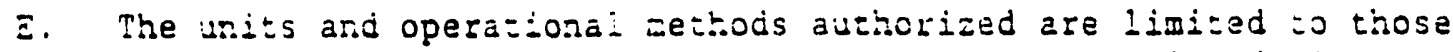
described both herein and by the appicazion and related plans a.ac specifications whici vere included in the permit application submi=5ais dated November 4, 1988; June 29, 1989; August 24, 1989, March 15. 199: and Seprember 5, 1991. $P=i 0=$ to constructing or operating eng unit: i.. a manzer which differs $f r a=€$ ther the related plans and specifina: or the limitations of this peraiz, itse permittee is sequired to

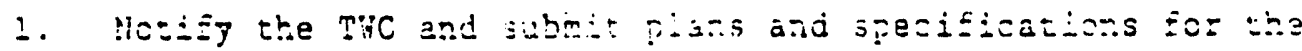
zeoposed changes: $3.2:$

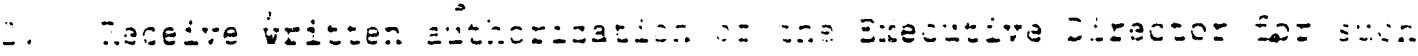

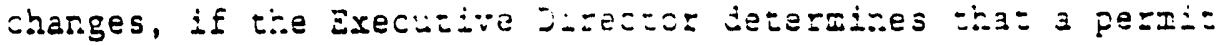
amendrent or godiE icacion is roc required by Thic ruies.

E. Aag prcposed unit changes, additicr cf loits, or expansion in capact:y which has r.ot been adizessec by the tercs of this pezat must te

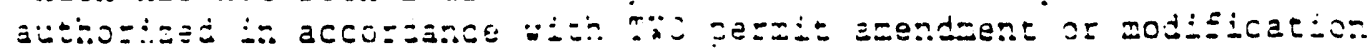
z:ㅇs. 


\section{NAME: NSSI/Recovery Services, Inc.}

III. Facility Design, Construction, and Operation

A. General Design, Construction, and Certification Requirements:

1. Facility design, construction, and operation must comply with this permit. Texas hater Commission (THC) Rules, and be in accordance with the plans and specifications for design, construction and operation approved herein. All plans submitted with the application da:ed November 4, 1988; June 29, 1989; August 24, 1989; March 15, 1991 and September 5. 1991 are approved, subject to the teras of ihls permit and any other orders of the Texas Water Commission which are rereby incozporated by reference and made a part cí this permit.

2. The entize hazazdous waste managexent facilizy shall be desigred, constructed, operazed, and aaintsined to prevent the release and/or migzation of any hazacdols waste beyond the zone of engineering control and to prevent inundation of and discharga fron the areas surrounding the facility components. Each rezeipt, storage, and processing arsa, including unloacir.g areas, sha!l be provided with a secondary containment system which will meet its requirements $0 \equiv 40 \mathrm{CER} 264.193$ and which vill collect spills ani incident precipitation in sush a manner as to:

a. Preclude ine reiease frow the syscem of any coilected saills, leaks, oz precipization, except as provided in provision III.8.2. This requirement shall be met by, at a minimua, providing a base and sides which are free of cracks or gaps and are sufficiently impersious to contain leaks, spills, o: precipitation until the collected material is removed, as: providing curbs or sides designed to rithstand a full hycrost3tic teadi

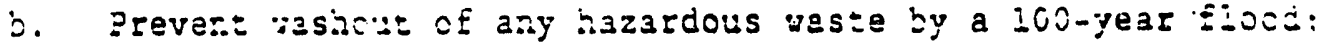

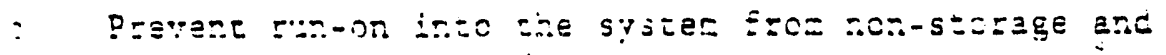

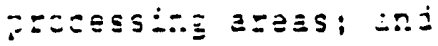

d. Save sufficient sapacity to costais the volume of the lazges: tank or 10: of the total tank and/or container Eree liquid capacieg, whichever is greater, plis (for uncovered areas) the vollue ci rainwater which woulj be collected by the 2s-yeer, zi-hour zair.zill evert ig.z is...

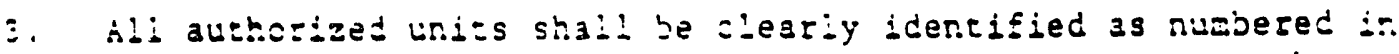
Provision. II.3. At a minimum, the container azeas aze to bave signs, and tiee anks are to have pairced labels indizatirg "riv

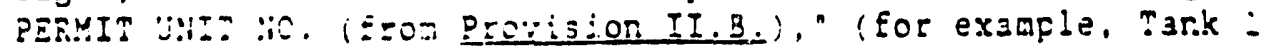

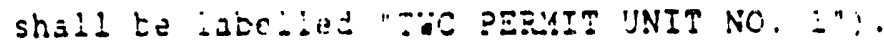


NAME: NSSI/Recovery Services, Inc.

[III.A.]

4. Within seven months of October 3, 1990, or 60 days prior to use, the permittee shall construct and submit to the Executive Director and to the TUC District 7 Office as-built dravings and certifications prepared in accordance vith provision V.C. for Tanks 1-15, two Grinder Tanks, the Building 2 Container Storage Area, and the Buildirg 3 Container Storage Area.

B. General Operational Req̨uigements:

1. Incompatible wastes shall not be comingied in ary storage or processing facility compcner:, unless the permittee takes precautions to prevert the adverse reactions icentified in 40 CEE 264.17 (b). The persittee shall comply with tihe requiremens 0 E $-J$ CER 264.17(a) for ignisabie iastes.

3. Collected spilis, Leaks, claan-up residues, anc ccntazinated zairfall runot: including stormater from all waste management areas shall be rasoved within 24 hours atter the spillage andior rainfall event by a nettoc(s) in provision III.B.4.

3. The permittee shall Eanage al: wastes within the facility usis in a manner in which partioulate emissions of waste to the air weet Texas Air Contzo: Ecazd and Texas irater Commission zequirexer:s.

4. dill contaminated vate: as isentified by provision III.B.5... provision IV.B.2. and Erovision IV. B. 3. shall be managed by the folloring me: jd(s):

a. Remcval tc an on-sise, autrozized industzisi solid waste unit:

b. Eischarge to the santaz:y sewer, after sazisfyirg aj:

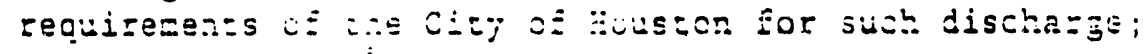

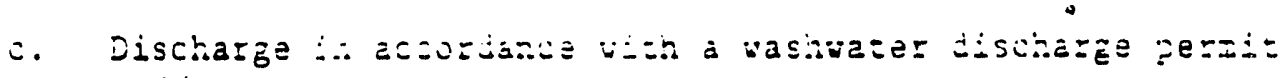
and/or;

d. Remoral off-size to an authozized industzial sojid waste aaragemer: $\vdots \equiv c \vdots i \leq: y$.

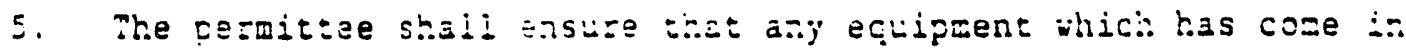
conzact with hazazdods wisse tas been decontazinsted frio= $=0$

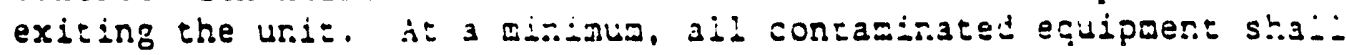
be vashed sufficier:ly to remove vaste residies, ill wash water

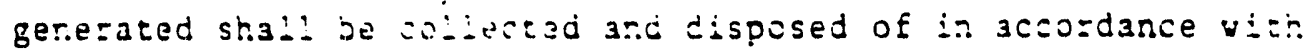
provisicn IZI.Z.... 
NAME: NSSI/Recovery Services, Ine.

[III.B.]

6. The annual site activity report required by provision V.F. shall be submitted to the THC Central Office and District 7 Office by January 25 of each year for the preceding year's activities. This annual report shall include, at a minimum, the following Information:
a. All information and records requized by 31 Texas Admiris:za- tive Code (TAC) 335.:54;
b. Volume of fuel-froz-vaste shipped;
c. Amounts of non-fuel naterias received as waste and soid Without processing;
d. Volume of all vastes storec at the facility lint althorized in Erovision II.B.; ar.d
e. Summary oE the arusuai cost estimate adjustments for faci-i:y closure.

7. The permitree shall ensure that all waste analyses utilized Eoz waste identification or verification have been performed in accordance with methods specified in the current editions of ?: Methods for Chemical analysis of Water and Wastes" or "Test Methods for the Evaluation of Solid Vaste" (S\$-846) or other wethods which are officiaily approved by the EPA. The permittea shall utllize only labcratories which follow a quality cortro:, quality essurance program conforming to the program specifie $1:-$ "Test Methods for the Evaluation of Sclid Maste" (SH-846).

8. The peroittee shall deveiop and use inspection forcs which iaciude a:1 units to be inspected and a list cf all items to be insfected ot each.unit. Any rewedial acsions teken in responsa to uni:

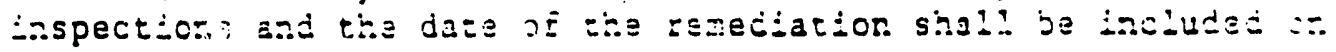
the inspection fores.

9. The permittee shail ensize that all facility personnel banding hazardous waste successfully complete a program of classroom instrucion and on-the-job tzairirg that teaches them to pe:fost their duties in a way witich ensures the faciilty's compilasoe wi=t: chis permit. The permitsee shall coaply viti 4 C CF? 264.10.

10. All tanks, sumps, pumps, fire and spill contro! equipment, deccntamination equipmen:, and all other equipment and sirul:ures authorized or requized by this perait shall be raintaired in gios Eunctions: condision. 


\section{NAME: NSSI/Recovery Services, Inc.}

[III.B.]

11. The permittee shall comply with the security requirements of 40 CER 264.14.

C. Tank Design, Construction, and Operation Requizements:

The permittee shall comply with the following minimum requirements fo: the tanks authorized by provision II.B.:

The tanks shall be constructed and operated in such a way as to comply with the standards presented in 40 CFR 264.192-264.199.

D. Cortainez Storage Area Design, Conszuction and Opezatior. Requiregents:

1. The contairez storage azeas stail be constructed and operased ir. such a way as to comply with it.e stardards presented is 40 CFk $264.171-264-178$.

2. In addition, within 30 days of axendzent issuance by the rhic, tha perzitiee shail saxply with tiae foiloving rinimus requizements f: the container storage sreas authorized by Provis:on II.B.
a. The persittee shail proride a nominal 30" aisle spacing

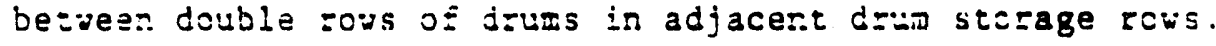

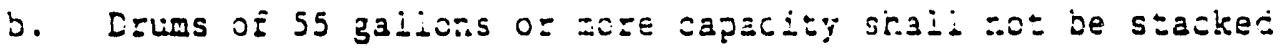 vore than three high;
c. Pailess shali be usec beiween layers of stacked dzums; and
d. Erums of ircompatibie wases shall be ueperazed jy a:: imperaestle barzier.

$\because \because$ Closica

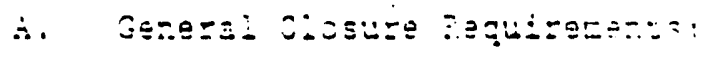

1. The permittee shall provide inascial assurarce for closure in accordance with the form outlined in 40 CFP Part 264, Subpart it i:: an initial snount not less thas $\$ 692.091$ in 1988 dollars plus an addicional \$104,205 is 1991 toilars. This firancial assurance amour: sha!: be adjusted annizaly as specified in provision IV.A.2.a. Eiraraial assizance shali be secured and maintained :compliance vith Commission regulasicns sa hazardous vaste financial requirements (3? ?.: Sectica 335.252 and if CFE Past 264, Subpart :).

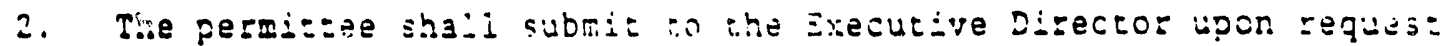
such inforacion as may be necessary to deterwine the adequas; $0:$ financial assurance. 


\section{NAME: NSSI/Recorery Services, Inc.}

[IV.A.2.]

a. Within 60 days prior to the anniversary date of the financial assurance documents, or vithin 30 days after the firm's fiscal year for firms lising the firancial test or corporate guarantee, the facility's closure cost estimate shall be updated for inflation and submitted to the Executive Dizector. The adjustment shall be made by recalculating costs in currest doliars, or by using an inflation factor derived from the most recent Inplicit Price Deflator. Pursuane to 31 TAC 335.178 , the cost estimate for clostice shall be based on off-site disposal du=ing closure of all waste and wasta residue for all urits not required to ciose as landfills.

b. If changes in the cicsure plan bill inczease the cos= of closuze, then the cost estimate shall be revised within 30 days after approval of the pian by the Exec:itive Direc:o=. The revised cost shail also be adjusted as specisted i: Provision IV.A.2.3.

3. Eacility ciosure shail comence:

a. Upon direction of the Texas Yater Comission or the Executive

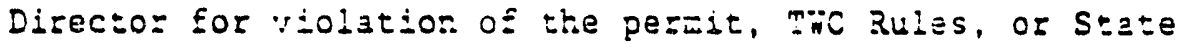
Statuzes;

b. Jpor suspension, cancellation, or revocation of the terms and conditions of this permit conceraing the authorization to store, process, or discose of waste daterisls;

c. Jyon abandoneant of ina size;

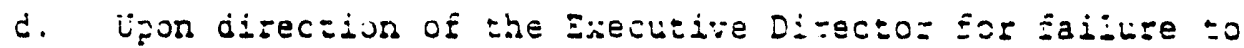
seciure and maintain sn adequate bcrod or otser financia:

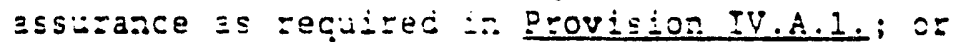

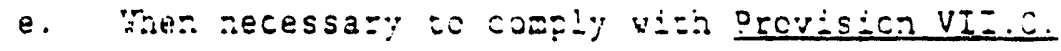

4. The permilitee shail submit a vritten request for a permit amerdaen: or zudification to austorize a charge ir operating plars, unit design, 0 s the appzored closuze pian in accordance vith tie tife frazes of Provisions $\because \ddot{v}$ A.5.a.-i. The written zeques shal: iaclide a copy oi the amendej clostre p-a.t for appooval by the Execuitue Directoz. Tree pezait see shall submit a writcen zecues כor a permit ameriment or codification so atricrize 3 change in the afproved closure plan uhenever:

3. Changes in operatiag pians ci tacilizy desiga afject sha approved closure plar: 
NAME: NSSI/Recovery Services, Inc.

$[$ [V.A.4.]

b. There is a change in the expected year of firal closure, if applicable:

c. In conducting partial or Einal closure activities, unexpected events require amendment of the apprcved closure plan; or

d. Requested by the Execuitve Director Li:ier the conditions described in P=ovisions IV.A.4.a.-C.

5. The perwittee shall sucril a vaitten reques: for a perait awer.tment or modification:

a. At least 60 days $p: \leq 0=: 2$ the propcses change in init design cr opezation vhic: :

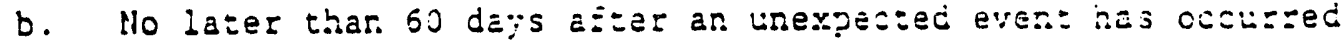
which has aftected the ciosize plan;

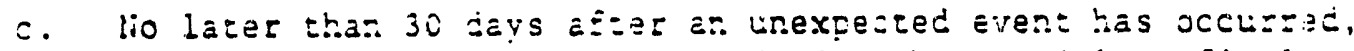
if the unexpected event occuss during the fastial or finai slostre period; or

c. Hichin 60 days of the Executive Directoz's gegiest pursuant

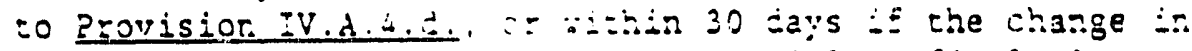
facility conditions ocadzs juring partiai or fisal closlize.

5. The perwittee sha1l rotify the Executive Difector in vriting at least 45 daps prior to tae sate ca which be expects to begis 5i-aj closuze of the facility. A zopy of the sotice siball be subsiz=ed to the Texas Vater Commissis. (To) Distr:at 7 nffice.

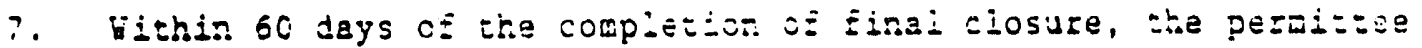
shall suimit to the Exacution Director by registered mail, wit: a

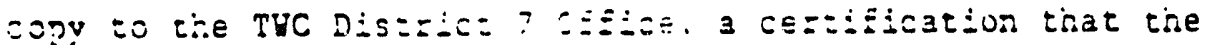
tuzzar:0us iast.e mar.

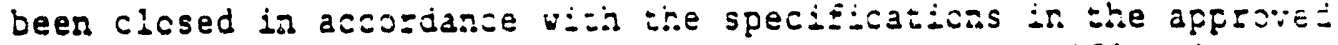
closure plan and the terms af this permit. The certification shall be signed ty it:e perzictee and by an independert registered $p$ cofessional engineer. Addicional documentation supporting the

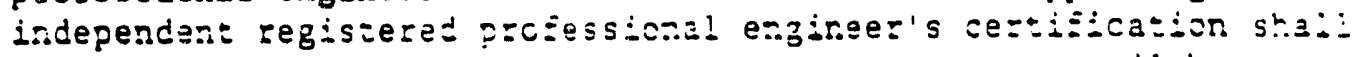

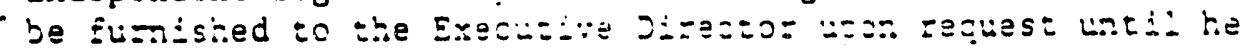

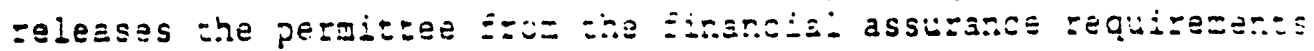
Sor ciosure unjez 40 CES $20-1.63(\vdots)$. 
NAME: NSSI/Regovery Services, Inc.

[IV.]

B. Hazardous Haste Management Unit Closure Requirements:

1. All tanks, pumps, piping, and any other equipment or structures which have come in contact with vaste shall either be decontaninated by removing all vaste or disposed of at an authorized facility.

2. All wash vater generated during decortamination activities shall be collected and disposed of in accordance with provision III.B.4.

3. All hard-surfaced area within tho hazardous waste management uni: areas shall be decontamirated and the wash water gererated shall be collected and disposed of in accordance vith p=ovisicn III.3.4.

4. Verification of decontaminasion shall be performed by analyzing wash vater for the waste constituents which have been wost recently in contact with the particular item being dacontaminated.

\section{v. Standard Pernit Conditions}

The permittee has a duty to comply with the Standard Permit Conditions under mitle 31 TAC 305.125 . Moreover, the permittee has a duty to comply with the following permit conditions:

A. In order to continue a permitsed activity after the expiration date of the permit the permittee shail submit a new permle applicstion at least 180 days before the expiration date of the effective permit, ualess permission for a later date has been granted by the Executive Director. Authorization to continue such activity will terminate upon the effective derial of said application.

3. The permittee need rot comply vith the conditions of this permi: to the extent and for the duration such noncompliance is autborized in $2:$ s=e-qen:-; ozier issued by the commission.

C. For 3 nev unit, the permittae shall not comence storage, processing or disposal of solid waste; and for a unit being wodified, the permittee shall not process, store or dispose of solid waste in the modified portion of the unit, lutil the Eolloving requiremencs have been satistied:

2. The perxiztee has notified the jocal THC District office a:d submitted to the Executive Director by certified mail or hard Jelivery a letter signed by the permittee and a texas registered professional engineer certifying that the facillty has been constructed or modified in compliance with the fertit. Reguized

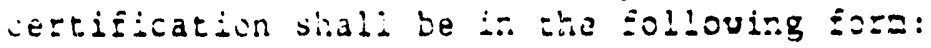


NAME: NSSI/Rec * 'FY Services, Inc.

[V.C.1.)

This is to certify that the construction of the following facility components authorized or required by TWC Pezait No. HH-50269 has been completed, and that construction of said facility component has been performed in accordance with and in compliance with the design and construction specifications of Perait No. Hy-50269. (Descriftion of facility units and confonen:s vith reference to applicable permit provisions), and

2. The Executive Director has inspected the modisied or neviy constructed unit and finds it is in complia.ce with the conditions of the permit; or within 15 days of submitting the letter required by Provision V.C.2., the permitsee has not received notice from the Executive Dizector of an ircent to inspecs, prior irspecsion is vaived ard the percictee may comrence frcoessing, storage $=$ disposal of solid waste.

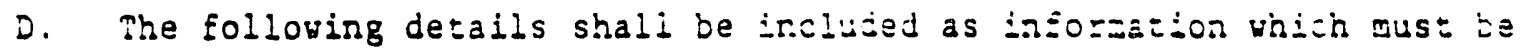
reported orally winis 24 hours pursuant to Tilie 3: TAC 305.225(5):

$\therefore \quad$ Information concerring release of any solit iaste that jay caise an endangezment to pubiic drinkir.g vate: supplises.

2. Ary information o: a release or ischarge oßsolid waste, or of $\equiv$

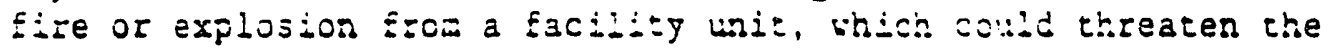
environment or human heaith outs de the faci-ity. The descripticr. of the occurrence and its cause shall irclude the folloring information:

a. name, addzass, ard telephore nuaber as tho owner or operato::

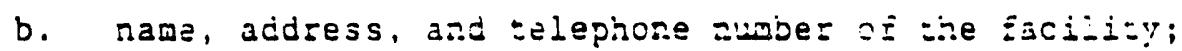

c. tz:e, time, ard zjpe of inciders:

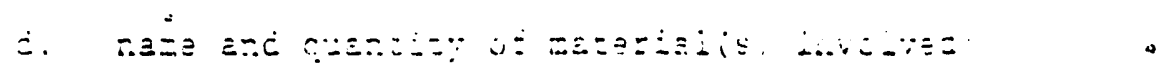

e. the exter: c: injuries, iz asy;

I. an assessment of actual o= poter:izi nazarcis to the envizor.-

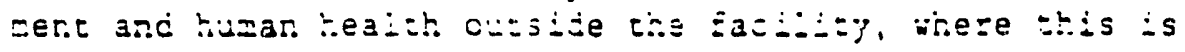
appiscabie; anc

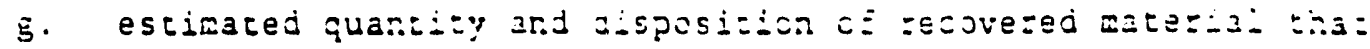
resuized from tree incident. 


\section{NAME: NSSI/Recovery Services, Ina.}

$[\mathrm{V} \cdot]$

E. The Executive Director may vaive the Eive-day writsen notice requi=ement as specified in Title 31 TAC $305.125(9)$ in favor of a written report submitted to the Commisston vithin 15 days of the time the permittee becomes aware of the noncompliance or condition.

F. An annual repore wust be submitted covering facility activities during the previous calendar year.

G. Emissions fzom this faciitey must rot cause or contribute to a condition of "ait pollution" as defined in section 382.003 of the Texas Clean Ais Act or violate Section 382.085 of the Texas Clean Air Act. If the Executive Dilector of the Texas Air Contzoi soazd determires that such cordition or violation cciurs, the perxistee shall inei isent additional abarement meastures as recessary to cor:s=ol oz prevent ::ee condition o: vioiation.

f. The provisiors or this permit are severable, and if any provisicr. of this permit or the application of any provision c E this permit to any circustance, is teld invalid, the application 0 such provisicn $=0$ other circumstances, and the remainder of this perait shail not be affected thereby.

I. The permittee shail notify the Commission in writirg within 10 da:s cf discciery of any zelease to the ervironment of hazedous vaste 0 z hazardous constituents that may have occurred from any soild waste mansgerent untt at the facility regardless of when the release occu=zo $c$ or may have occurred, and regardlegs of when wasts ves placed in any unit. Release of hazardous waste or hazardous vaste constituen:s from ang solid vaste management unit regardless of when vaste gas placed in that lait or when the release occurred, will constituse grounds sor (I) a major permit amendment or modification pursuant to the Texas Solid Waste Disposal Act, TERAS GEAiTy AND SAFETY CODE, Chapter 361 (Veracr). as recessazy to incozporate irto the permit appropriate correcivive

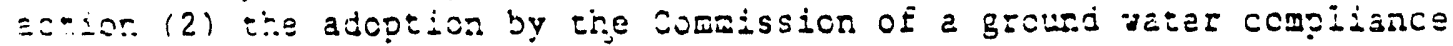

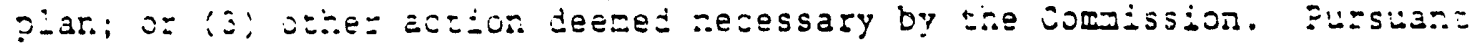
to such perzit anendment or modification, grousd-wates complias=e piza, or other order or action, the permittee shall ther tike timels corrective acticn for such releases.

With: sorty-fire (45) ¿3ys of becowing avare of 3 sclid waste

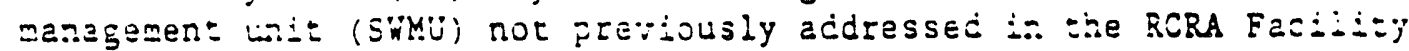
Assessient, the pertizee shali subsi: a prelizirary assessment. The freitminary assessmene shali incilde information segardirg the siry : deteraine if there has been or is currently a release of hazardous waste or hazaztows constituents jrom the unit. Sased lipon this

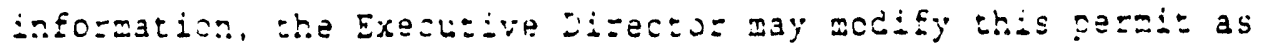
r.écesisizy. 
NAME: NSSI/Recovery Services, Inc.

[V.]

*If the release involves off-site contamination, the Director of the Hazardous Haste Division of Region VI of the U.S. Envizonmental Protection Agency must be included in all of the required activities specified in this provision.

\section{J. Waste Minimization}

The peraitcee shall certify annually by October 1 Eor the prerious year endirg August 31 , that the permittee

1. has a program in place to reduse the volume and soxicity of a: hazardous wastes which are gererated oy the peraitree's faciliz? cpezation to the degree deterwined to be ecoromicaliy fracticaj:e:

2. that the prcposed method ot tzeatment, storage, or disposij is that practicable method currenty available to the permittee it:ich. wirimizes the presert and Euture threat to himan tealih and the environment. The waste mirimization certificstion is to be included in she cperatir.z recosds; and

3. Cas surveyed its plant processes and other sources of hazardous waste and has identified those that are listed on the THC hni:us:

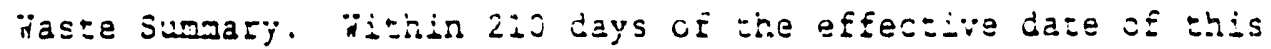
permit, the permiteee shall subwit to the Executive ilisctor a list of hazarcious wastes generated, together with a list of bastoc Minioizarion Projects ("MMPs") that it has determinad through $t t$, vaste miaimization seviey $c=c g r a n$ car. be implezerted vithin the rezt Eive yesrs.

Anrially thereatter, the permitiee shall subrit to tha Execusive zirecto:, on cz jefore the anniversary date ct the furrittee's

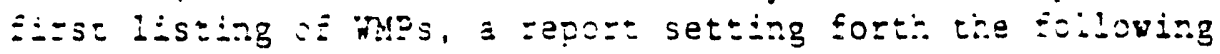

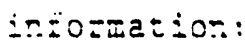

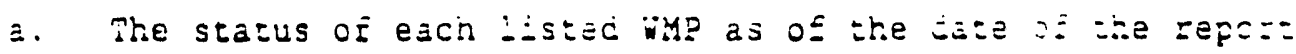
including the quantity of each hazardous vaste asd the percertage of reduction together with a frojection conceri.ing the expected work or rascurces that can be devoted to each. issed lis? duzing the rexz sue ive montis;

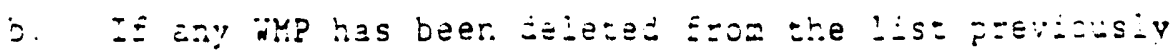
subaitzed, ste reason Es: such detericr; ar.d

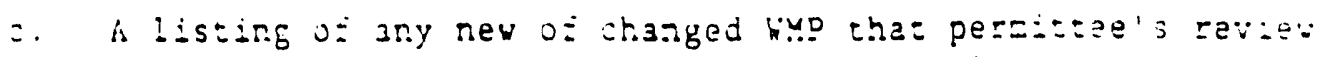

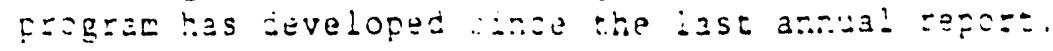




\section{NAME: NSSI/Recovery Services, Inc.}

$[$ [V.J.3.C.]

The Executive Director may require the permittee to submit a more detailed Status report for a specific WMP if it is ur.clear to the Executive Director the reasons the permittee has taken a particular action in regard to such WMP.

K. The permittee shall comply with 40 CFR $266.23(\mathrm{~b})$.

i. The permittee is required to meet all perfornance standards in this permit, regardless of whether the permit also contains a specific design or other requirement relating to the performance standard.

* $\quad M$. The permittee shall comply with the land disposal restrictions as four.: i: 40 CFR 268 LFed. Reg. November 7, 1986; June 4, 2987; July 8, :987; August 27,1988 ; June 23, 1989; Jure 1 , 1990 and ang subsequent applicable promulgations). Requirements inciude modifying the permittee's waste analysis plar, as necessary, to include analyses to determine compliance with applicable treatment standazds or probihitis: levels, pursiant to 40 CFR 268.7 (c) and $264.13(a)$.

The folloving provision V.N. is not a part of the TWC permit. It is included as $p \equiv r t$ of the EPA permit, and is to be enfozced only by EPA.

* $\quad$ N. The Permittee muse comply with the requirements of 40 CER 264 Subpa:t

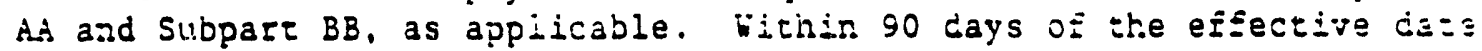
of this modification, the Permittee shall submit to the Director of it.e Hazardous vaste Management Division, EPA, Ragion $\sigma$, a repczt which mLs: contain, at the minimum, the folloving information:

1. An equipment list which includes all of the informatics required under Part 264.1064 (b)(1) for equipment that contains or contacts hazardous waste vith organic concentrations of at least 10 percsnt by yeigit, and a : $\vdots s:$ cE all process vents associazed with distillation, E-acticnption, thin-file evapozation, solyent extracsica, c=

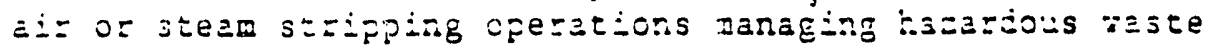
with organic concenczasions of at lease io parcere by yeigis.

2. For the frocess vents listed above, the amount of vent emissions in $\mathrm{lb} / \mathrm{hr}$ or $\mathrm{kg} / \mathrm{hr}$, and $\mathrm{in} \mathrm{lb} / \mathrm{yr}$ cr $\mathrm{kg} / \mathrm{yr}$.

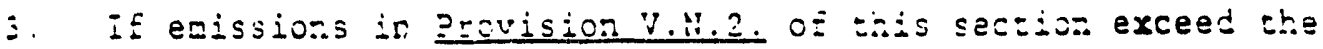
exissior limits cised in Bart 254.:032 (a) (1), the report zist detail the manner in which compliarce vili be obiaises, i.e., by the reduction of toral organic emissions to the limits in Part 264.1032 (a)(1), or reduction by weans of a contro: device per Part 204.2032 (3) (2). 
NAME: NSSI,'Recovery Services, Inc.

$[$ V.N.]

4. If a closed vent system and control device is installed to comply vith the requirements in Part 254.1032 (a)(2), provide the following:

a. An implementation schedule that includes dates by which the closed venc system and control device vill be installed and in operation (Part 254.1033 (a)(2)).

b. The type of control device under Part 264.1033 to be installed (e.g., vapor recovery, Eiaze, etc...).

5. If ihe Fermittee Eeels any of the requirements of plovision V.ri, or cf 40 CZR ?are 264 Sutfa:ts AA a:S 33 , are not applicable to this Eacility, the ?ezoittee rust frovide justificarion sur this decisior as part o Ele report.

\section{Irccrnorarec Fegulatorv Recuiregerts}

A. The follouing taxas water Comaission regulatiors are rereby made provisicas and conditions of this permit. Issuance os this permit $\because i$ it incorporated rules in no way exempts the permittee frog compisarse itit: any other ap?liçble state sratute and/or Commission R:-le.

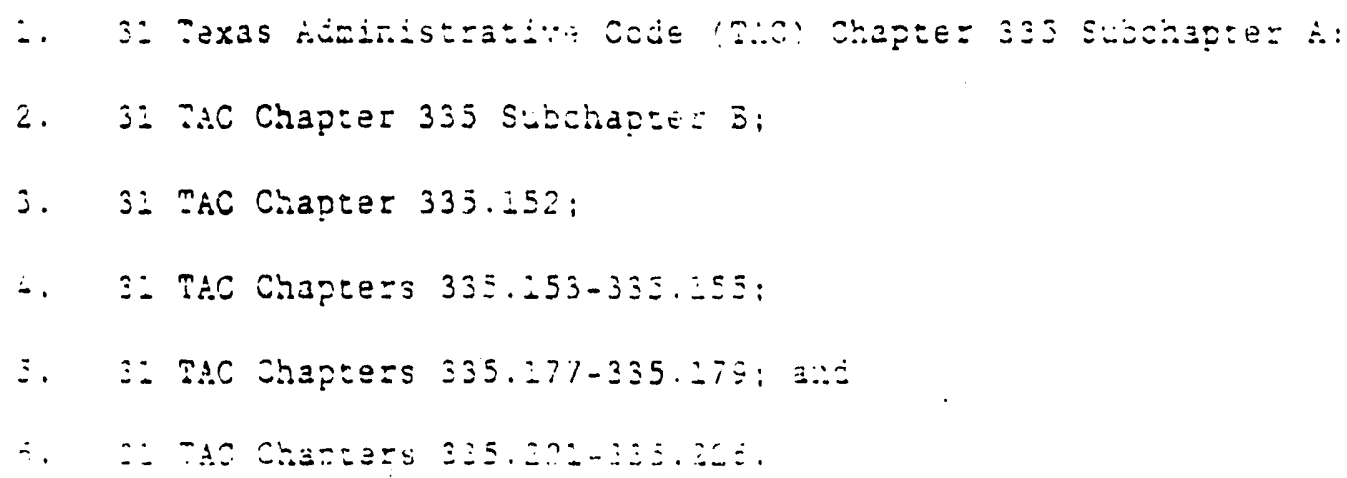

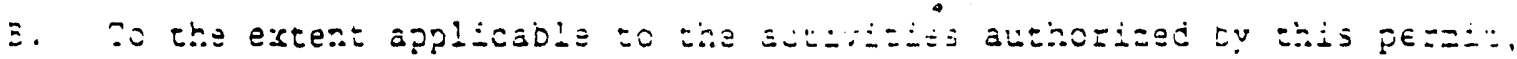
the following p.uvisiors of io Code oz Ederal Regulazions Part zil, adopted by raference by $3:$ TAC Secticn 335.152, are hereby rade provisions and concitions of this perdit:

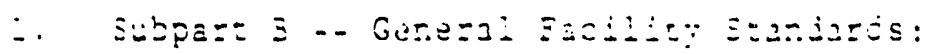

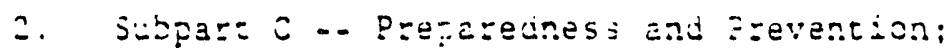

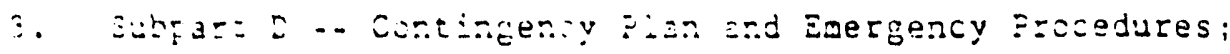

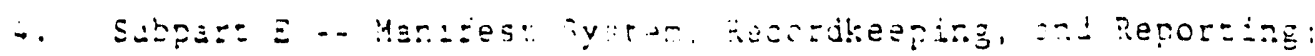


NAME: NSSI/Recovery Services, Inc.

[VI.B.]

$$
\begin{aligned}
& \text { 5. Subpart G -- Closure and Post-closure; } \\
& \text { 6. Subpazt H -- Financial Requirements; } \\
& \text { 7. Subpart I -- Use and Managerent of Containers: and } \\
& \text { 8. Subpart J -. Tank Systems. }
\end{aligned}
$$

\section{Incordorated Apolication Materiais}

The perititee shali maintain the following documents at the facilisy and make thes available for inspection by regulatory personsel.

A. Contingency Plan

The permittee shall follow the contingercy pian, developed in accasjance with 40 CFR Part 264, Subpart D, dared November 1, 1989, and revised July 1, 1989; Auguse 10, 1989 and August 2, 1991, which is hereby approved subject to the teras of this permit and any otber orders of the Tezas Vate Commission. The contingency plan is herejy incorporated into this permit by reference as if set out fuily hereir. Ang and sll revisions to the pian shall becone provisions and conditicns of this permit upon the date s: approval by the commissicr.

\section{Ispection Schedule}

The peraitree shall follow the inspection scheduie, developed in accordarce yith 40 CFR 264.15, dated Norember 1, 1989, and revised ILis $\therefore 1989$ 3rd August 2, 1991, vinich is hereby approved subject to the terms of this fermit and any otine orders of the Texas Vater Conmission. The lnspection schedule is hereby incorporated into this perait by refezance as if set out tuliy bezeis. Any and ail ravisions to tha schedula shall become provisicas and conditicrs of this perait upon tiae ¿ase ois approvel by tise Coraissisr.

\section{c. Closure Plan}

Facility closure stall be completed in accordance with the requirements of 31 IAC Section 335.152 and 40 CER Part 264 Subpart $G$ and the closu=e plas. dated Novenber i, 1939, and zevised Juiy 1, 1989: August 1C, 1989 and August 2, 1991, which is tereby approved stuject to the ter=s o: in:s perzit and any vether orders 0 : the Texas Hater comission. The clostize plan is hereby incorporated. into this peroit by reference as : set oli fully herein. Any and 3 i: revisiors to the pian shall become frovisions and concitions of the perate uron the date of approva: by the cuezissior. 
NAME: NSSI/Recovery Services, Inc.

[VII.]

\section{Vaste Analysis Plan}

The permittee shall follow the waste analysis plan developed in accordance with 40 CFR 264.13, dated November 1, 1989, and revised July 1, 1989; August 10, 1989 and August 2, 1991, which is hereby approved subject to the terms of this permit and any orher orders of the Texas Water Comission. The waste analys is pian is hereby incorporated in:o this permit by refererce as if set out fully herein. Any and ali revisions to the plan shall become provisions and conditions of this permit upon the dace of appsoval by the Comission.

\section{Standard Permit Conditions Aodicable to Off-site Facilities}

The following reporss sirali be subui:ted:

A. Manifest discreparcy : $\equiv p \circ r::$ IE a sigrificant discreparoy in a manifest is discoverei, the pezaitege rust attempt to reconcile tie discrepancy. If not resolved witinin 15 days, the pezittee must suba: a lettar report irojuding a copy $c$ E the manifest to the Executive Direc $=$ or.

3. Unmanifested waste repo:t: hust te suboitted to the Executive gizes:or

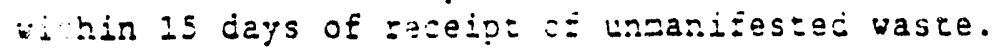

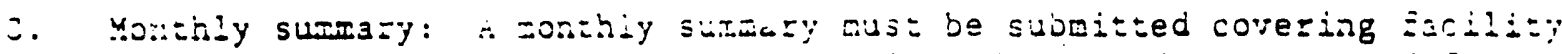
activities during ine gzevious acnih, including produc: produced frem waste and shipped.

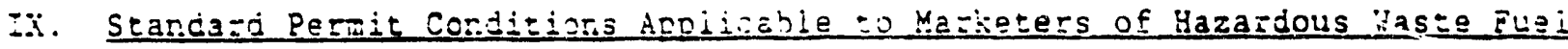

A. Before engaging in the watketirg ol hazartous waste fuel, tha fe:=it:e=

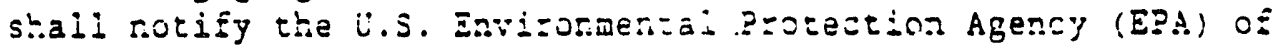
¿azazdous wasta Euei warketing activicies.

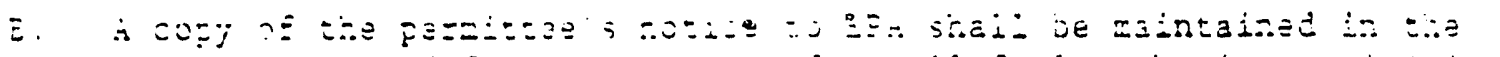
operasing record fc: croee y have been stopped.

0. Pernitzee shail rot ship hazarcous waste fuei vithouit a written and

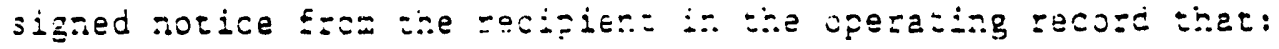

2. The burner o: =3rkeze bas ac: wasce-as-fwei aczivit:es; ar:

2. If the recipient is a burrez, the turner vili burn tige razarobus waste fuel only in an indistrial Eurnaze or boilez idereifiad in 31 TAC $335.222(0)$. 
NAME: NSSI/Recovery Services, Inc.

$[$ [X.]

D. A copy of the notice from each recipient to the permittee shall be maintained in the operating record sor three years after the last shipment to the recipient.

E. Dioxins, F020, F021, F023, F026, F027, and F028 shall not be blended into fuel.

F. Prior to selecting any waste streas for use in a fuel blend, a representative sample of the waste stream shall be collected and analyzed for heat content using ASmy D240 or D2015. The sample shail not be considered appropriase for tuel blending and the waste streat from which the sample was collected stall not be used in a fuel blend, uriless the sample exhibits a so:al hea content of at least 5,000 BTU/lb. No waste stream uith a to:ai PCB contert of 50 ppm or gzazer shall be used in a fuel blend.

o. Following final blescing, i.e. jefize sale, a zepresentative sample cE the resultant hazazdous iaste ixture shall be collected and analyzej for heat content using ASTY $2240=22015$ and PCB content lising SH8468080. The restitant hazardows waste mixture shall not be labelled $0=$ othervige represented as fuel unless the mixture exhibirs the follori: criteria:

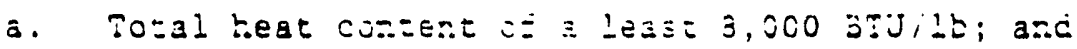

$$
\begin{aligned}
& \text { 3. Total PCB content less than } 50 \mathrm{ppq} \text {. }
\end{aligned}
$$

ti. Ail sampling and analyses that aze performed in orcer to ensure

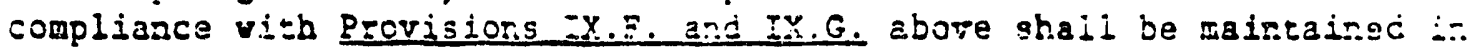
the facility operatirg records.

$x$. This Section is not used.

\section{Si. Air Cualizer p=ousions}

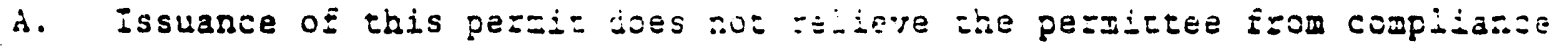
with the Tezas Clean Ais ACt (ICAA; as amended (TEXAS HEALTH AND SAIE?: CODE, Chafter 382) or any applicasie Rule, Regulatice or Order of the Texas Aiz Control Board (TACB).

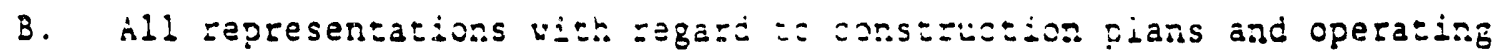

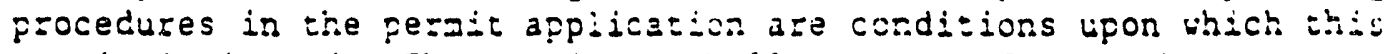
perrit is issued. The peraitsee siall rot vary from stich epresentations if the change vi:- result in a significant ircrease :the discharge of any aiz contaminant, waless prior notification is rise

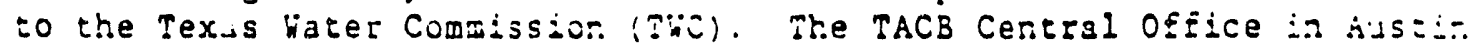

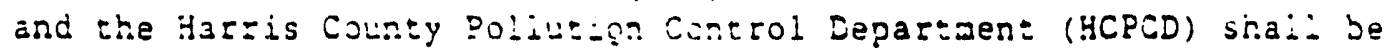
rotified at the time of such notizication to the Tir. 
NAME: NSSI/Recovery Services, Inc.

[XI.]

C. The appropriate regiona! of ice of the TACB and HCPCD shall be notified prior to the seart of any governmentally required air monitoring of the facility units althorized by this permit in such a manner that a represencative of the TACB and HCPCD may be present during monitoring.

D. The facility units covered by this permit shall not be operated unless all assoeiated ais poliution abatement equipment which is required $=0$ be in place is mainteired in. good vorking order and is operating properly diring rormal iac:itity operations.

E. A copy of this permit shal: be kep: at the plant site and made available at the request of persorsel tron the TACB, TWC, or HCPCD.

F. The perritzes shall ainta:- a duplicate zecozo of a currert inver.tory of materials regulatec und $=$ this permit at an off-site location.

$G$ Containers of hazavious vasie cr solid waste shail je opened only Eaz the purposes auth $: \vdots z d$ by $i t a$ teras and conditions of this pernit.

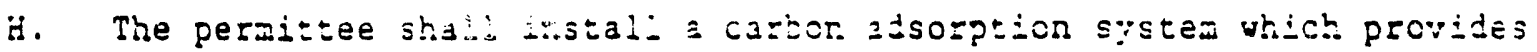
the following:

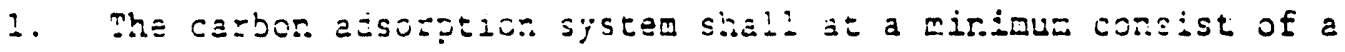

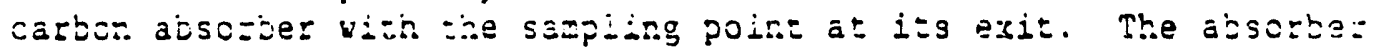
exi: shali be zonito:三 on a veeily hasis to detersine braakthrough of orgasic corpouncs. If breakthrough is determined to have occurred as syecified in provisions XI.J.2.-3., the absorber shail be zep aced by a second absorber cr the abs z=je: shali be rezenes

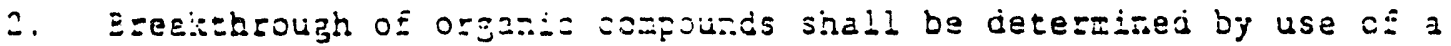
ptosoicnization :

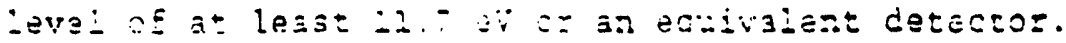

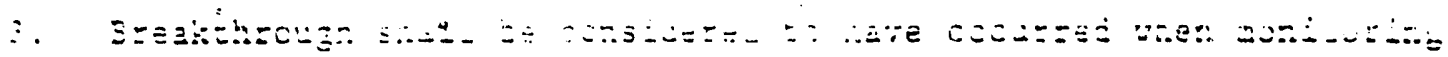

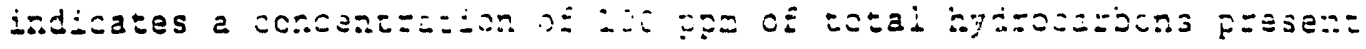

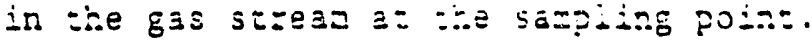

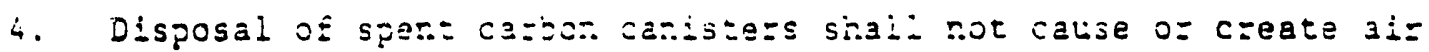
eaissions.

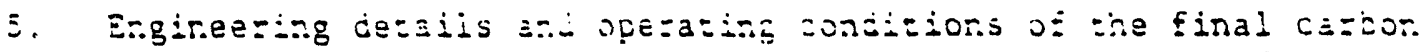

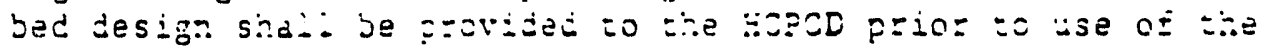
systez.

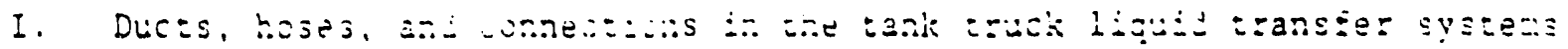

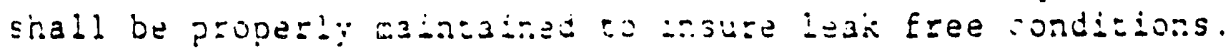


NAME: NSSI/Recovery Services, Inc.

[XI.]

J. Within 60 days of tober 3, 1990, or sixty $(60)$ days prior to use, whichever is later, the Permittee shall provide to HCPCD diagrams of the scrubber systems, including alt manifolds, ductuork, and dampers.

K. All storage tanks in Building No. 2 containing volatile organic liquid shall be vented to the condenser carbon absorber system.

L. Storage tank and process vessels in Building No. 1 shall be vented to caustic scrubber prior to the condenser/carbon absorber system, unless there are no particulates or acid gases in the vaste siream.

M. Vapors from tank trucks containirg vor shall be vented into the carbor absorber unit.

N. Vapors from tank trucks witid ac is igulds sinall be vented to a calstic scrubber system.

0. The caustic scrubber shall neet t:e foidowing criteria:

1. The coustic scrubber will be designed by the Permitcee.

2. The scrubbing liquid to be ised is no less than 0.1 : caustic.

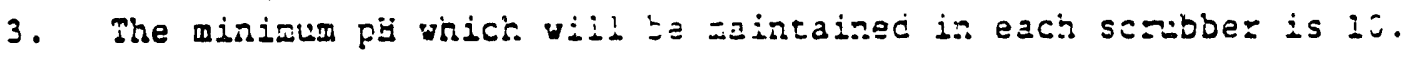

4. The type of packing will be prorided after the writ is designed.

P. The handling of hydrochiorlic aci $i\left(24^{\circ}\right.$ ) shall not exceed $10 z$ of tise total acid handled at this facility. Handling of bydzcchloric acid (35\%) shall not exceed $7.5 \%$ of the cotal acid handled at this facility.

Q. Sulfuric acids (985) shall hot exceed 13: of the tocal asid handled $a:$ inis facility.

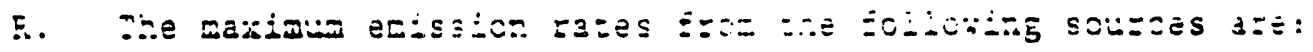

i. The scrubber

(1) VOC: 2.9913 polnds per sour or one ton per gear

(2) Acid gases: 0.8452 pojeds per hour or 0.17 ton per gear

2. Th.e absorbe:

(1) VCC: 0.4759 poinds je: tour or 0.25 ecn pez yeaz

(2) Acid gases: 0.2527 pour:ss per hou or 0.30 :0: ter year 
PERMIT NO. HW-50269

NAME: NSSI/Recovery Services, Inc.

\section{Moritoring of Commercial Hazazdous Haste Manazement Facilizy Operations}

A. Within the first year after commission action on the modification the facility ouner or operatcr shall provide rotice to affected persons of intent to have an independent anrual environmental audit of the facility performed. The notice shall be issued in accordance vith the following procedure.

1. The notice shall siate the nazes o: at least three : wependert inspectors nominated by the jacilisy orner or operator to perform the exvironmental aldi: and shali be fuibished in the nevspaper of the largest general cirsuiz:ion shat is pliblished in the cous:y in which. the Eacibity is icsatej. Ti: Eac:-isy outer or ofezasoz shail not

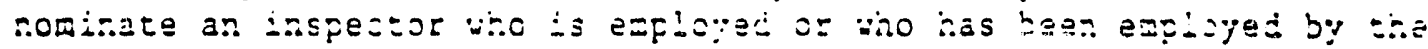
sac $\vdots 1 \leq \pm y$.

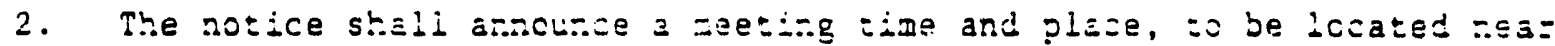
the Eacility iocation, ja heid yitis. 15 days of the publisied notice ia order for the fuci:ity io sezeive cocments Ezom and allow for participation by iaterestec ajfected persons in the seiection of the independert inspector. The iaterested affected persors nay either agrae to one of the nocinated independene inspector cr nominate other indeperdent inspector if they do $: 0$ a afprove of the raxinee list. The selection of the indepenten: inspector shall be agreec to by tra

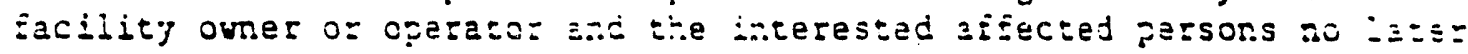
than 30 days frod the date of the setting. The name of the selecsed independent inspector shall be subattted to the comoission no latez than 15 days frow the da:e oz seisz:ion for tre comission's apf =cra:. The commission shall approve tie independen: irspector after it has jetermined that t.:e indepercier: inspecror has the resessary expertise to perform the aldit ar:d does not tave a conflict oz interest with $2: y$ of the parties irroived in the isseectcr seisttior.

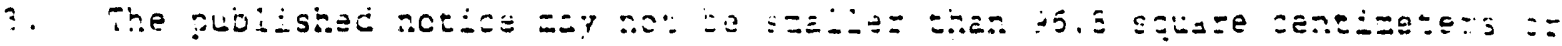

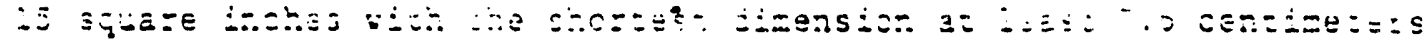

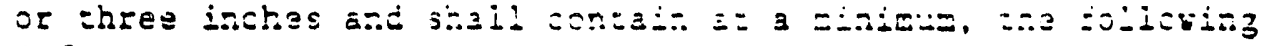
information:

a. Lhe fazility orne:'s o: opeza:va's rasue:

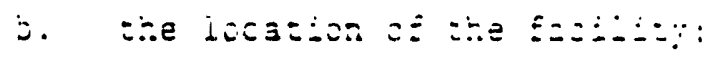

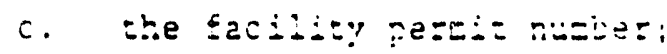

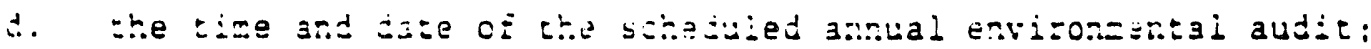

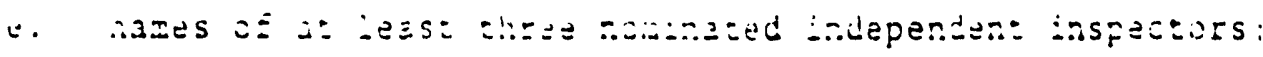


NAME: NSSI/Recovery Services, Inc.

$[X I I . A \cdot 3 \cdot]$

f. the dace and time and location of the selection meeting; and

g. The nawe and telephone number of a facilicy contact person.

4. The facility owner or operator shall provide a copy of the published notice to local jurisdictions where the facilley is located.

j. The facility ouner or operator shall provide the condission with an affidavit including a newspaper tear sheet of the published notice and svorm statement of the edito: or publisher certifying that the notice vas given as required by this section. Acseptance of the affidavit creates a rebuttable presuption that tha applicart has complied with this requirements.

B. If the facility orrer or operator and interested affected persons cannot agree on the selection of an independent inspector wishin the time frame specified in Provision XII.A.2. the comission shall salact an independent inspector. The commission's selection, however, shal: rot be limited to either the facility owner or operato:'s nominee list or the interested affected persons' nominee list. The comission shall take sieps necessary to assure that the independent isspector or entity selecred to perform the audit has the necessary expertise to perform the audit, is not a business competitor of the faci: $1=y$, and does rot have a conflict of interest vith ang of the parties inrorved in the inspector selectica.

C. The facilitg owner or operator shill pay the cost of notice requized to be provided.

2. The facility owner operator shult be zesponside for the costs of an independent annual envizonoentai aucie. The facility orner or operator shall also maintais responsibility for procuring the selected indepenoient isspector. The comisision shail not be a party to such procuregent not waz:3a: the workmanship of the selected inspestor.

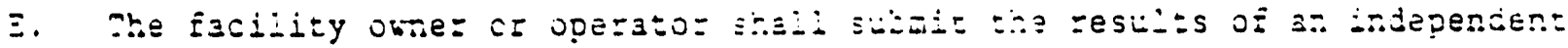
arnual environgental audit in vriting to jie Execlitive Direcsor.

$\vec{F}$ The scope of the independens ansial exvironmencal audit may encompass any and all provisicns of environmertal permits required for the facility and ai: zelevent satutes and gegilations gegarding the anagerent of the Esciíz:y.

3. The facility is ro: required to persosa the annual independert environmenta: audit if the facility does not receive any comments from affected persons. If the facility perforss the independent audit despitc lack of response, the Ecility must obtain the comsission's sforova: of the seiected independen: isspector prior to ihe audit. 
PERMIT NO. HW-50269

NAME: NSSI/Recovery Services, Inc.

[XII.]

H. An affected person is any person who is a resident of a county of any councry adjacent or contiguous to the courisy in which a hazardous vaste management facility is to be locaced including any pezson who is doing business or owns land in the county or adjacent or contiguous county and any local govermment. Such person affected shall also demonstrate to the comaission that he has suffered or vill suffer actual injury or economis damage.

at:ashmens

$\therefore$ - Legal Deserifeion

s -. Sice rla: 


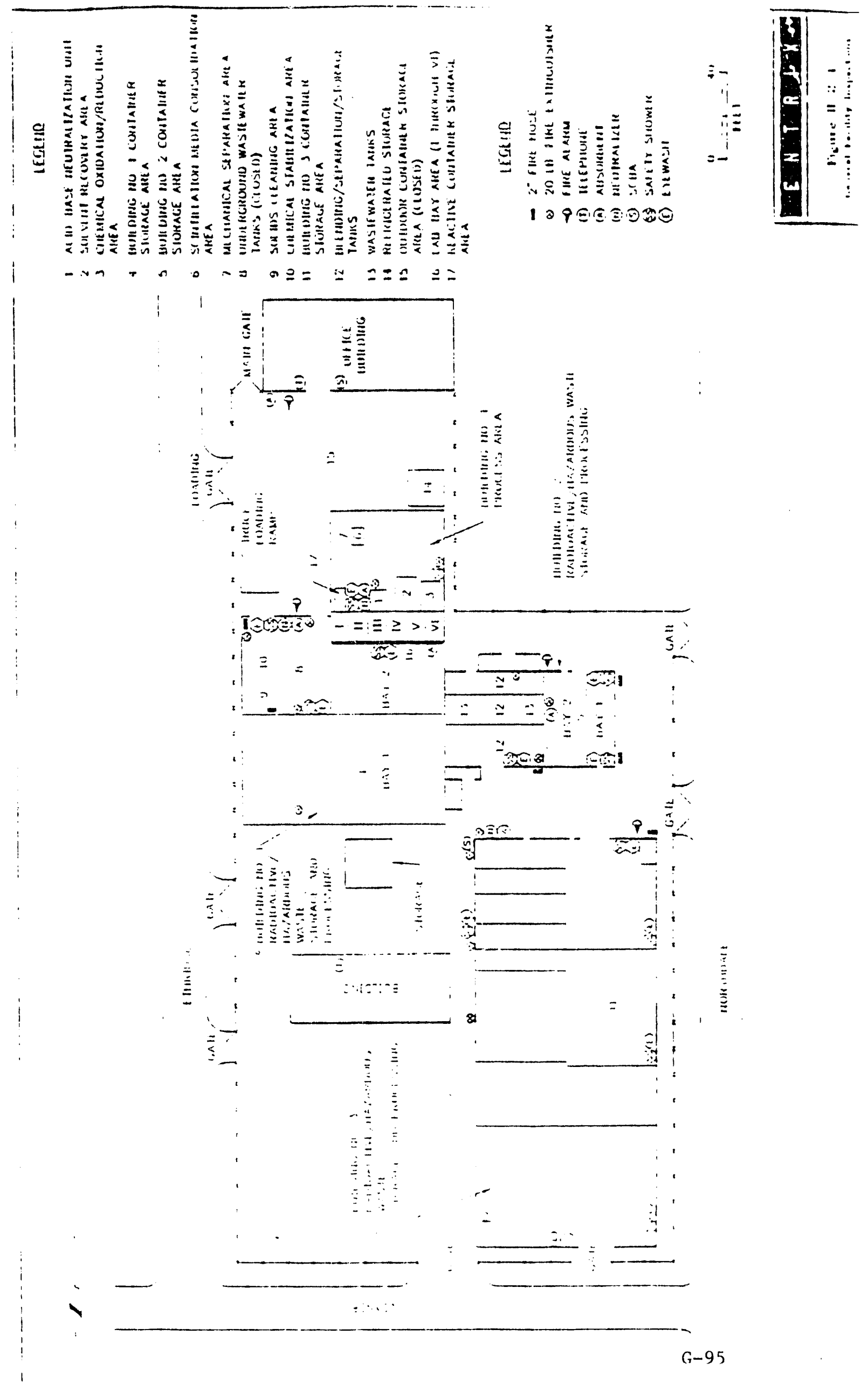


Exhibit C3

RCRA PART B PERMIT FOR NSSI 
UNITED STATES ENVIRONMENTAL PROTECTION AGENCY REGION VI

IA4S ROSS AVENUE. SUITE 1200

DALLAS. TEXAS 75202

April 17, 1989

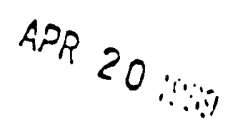

Hs. Janet Greenberg

Project Manager

NSSI/Recovery Services, Inc. Project Team

ENSR Consulting and Engineering

3000 Richmond Avenue

Houston, Texes 77098

Dear lis. Gresnberg:

Your March 2Ē, 1989, letter to Mr. Lee Haze of this Agency, raquested sore information on permitting requirements for facflities that handle radioactive gixed waste. It is our understanding that your facility has

both $P a \cdot t A$ and $B$ applications on file with the Texas Hater Commission.

The State of Texas, through the Texas Water Commission, has applied for approval of some State regulatory revisions. The Environmental Protection Agency has proposed in a February 3, 1989, notice in the Federal Register (54 FR 5500) the approval of these revistons. Included in she application was the State's request to regulate radioactive mixed waste.

EPA will soon publish a final decision on the Texas application in the Federal Recister. However, the notice will not be published until a statutory asendment that affects the State's RCRA permitting program is acted upon by the Texas legislature.

We recomenes that you continue to work with the Texas Water Comission $s^{:}:$: $:$they will have the authority to issue the required perait. If this Agency can provide any further assistance, please contact re or have your staff call بs. Lynn Prince, Regional Authorization Coordinator, at (214) $655-5750$.

\section{Sincereiy yours,}

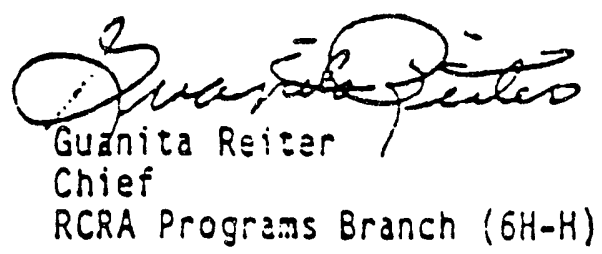


DALLAS. TEXAS 19202

APRIL 21, 1989

Ms. Janet Greenberg

Project Manager

NSSI/Recovery Services, Inc. Project Tean

ENSR Consulting and Engineering

3000 Richmond Avenue

Houston, Texas 77098

Re: NSSI/Recovery Sezvices, Inc.

Industrial Solid Waste Registration No. 38659

EPA I.D. NO. TXD982560294

Dear Ms. Greenberg:

Thank you for the opportunity to answer your question concerning the subject facility. As you are aware, the state of Texas is authorized to administer the RCRA hazardous waste progran; however, Texas is not authorized to regulate the radioactive mixed waste portion of the RCPA progran.

Therefore, NSSI/Recovery Services, In:., 's not subject to RCRA regulation of radioactive mixed wastes "...until the state program is revised and authorized to issue RCRA pemits for radioactive mixed waste." Once- the State of Texas is authorized to regulate radioactive mixed wastes, " $(m)$ ixed waste TSDE's [treatnent, storage, or disposal facilities] in states with base progran authorization mast comply with applicable state reguirements and deadines for obtaining interin status as prescribed in authorized state law.

Texas has made application to recive authorization fo: the radioactive mixed waste groxram. The application is currently being reviewed by the U.S. Envirormental protection Agency (EPA). A final decision is expected to be made in a few months. If you have any further grestions regarding the effective dates and/or specifics of the new Texas statites implementing the mixed haste program, you should adiress your grestions to the Texas Water Comission $(M, C)$.

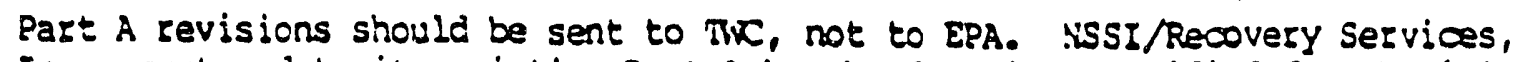
Inc., must update its existing Part $A$ by the deadline specified for obtaining interim status in the Texas law authorizing the radiosctive mixed waste program. However, NSSI/Recovery Services, Inc., may sulmit its revised Part A to ThC before that deadine if it is convenient to do so.

sinserely yours,<smiles>CCNCCOCC</smiles>

Willlam K. Honker, Chilef

RCRA Parmits Branch

cc: Susan Farguson

Texas hater Camission 


\section{TEXAS WATER COMMISSION}

B. J. Wynne, III. Charniun

Paui Hopkins. Cumnussiuter

John O. Houchins, Connnissioncer

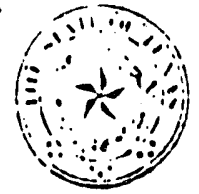

July 24, 1989

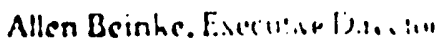

Michael E. Field, Gu:.ti.: Cow....

Brenda W. Foster. Chucl Cistin

Mr. William K. Honker, Chief

RCRA Permits Branch

U. S. Environmental Protection igency

Region VI - 6H-PT

1445 Ross Avenue

Dallas, Texas 75202-2733

Re: Transmittal os an RCRA Facility Assessment

NSSI/Recovery Service, Inc. - Houston, Texas

Solid Waste Registration No. 38669

EPA I.D. NO. TXD 932560294

Dear Mr. Honker:

Consonant with the agreement made between the state of rexas and the U.S. Environmental protection Agency (EPA) this letter and enclosures constitute the RCRA Facility Assessment (RFA) for ISSI/Recovery Service, Inc. - Houston, Texas. We understand that EPA has committed to a 30-day review and comment period for RFA documents so that the Texas Water Comnission can proceed with permitting.

The Preliminary Review (PR), copy enclosed, presents information about all units managing waste materials as well as information about waste materlals managed. The $\mathrm{PR}$ has been merged into the attached Visual site Inspection (VSI) report so that, for each unit, the VSI pages and the PR pages are adjacent. The units at the factlity are classified into one of the following five categories:

\section{RCR:-Regulated Units}

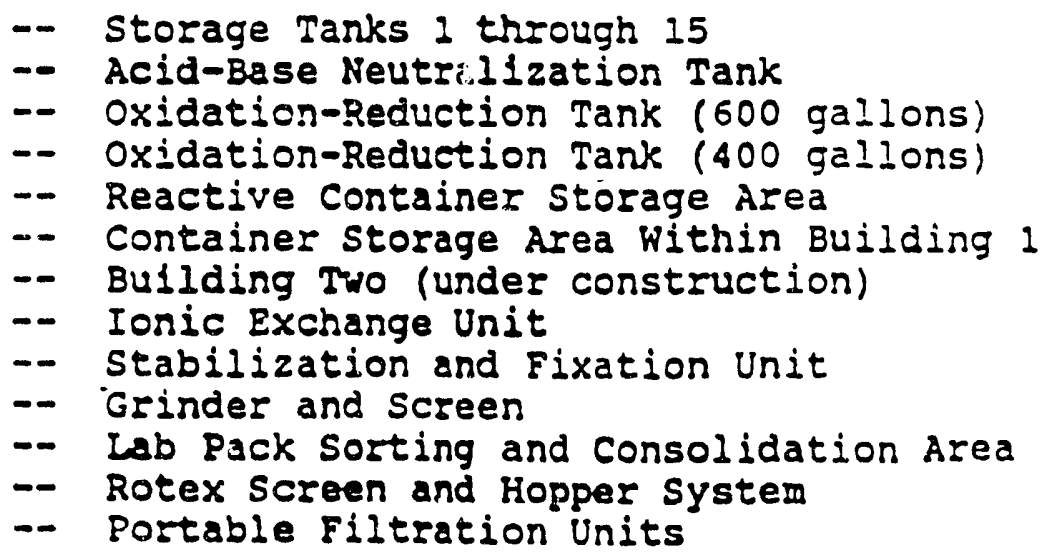


Mr. Williaro K. Honker, Chief

July 24, 1989

Page 2

RCRA Units Being closed

-- Wastewater Tanks

-- Grinder Tanks

-- Open-Air Container Storage Area

Mixed Waste Management Unit

-- Mixed Waste Compaction and Sorting Area

Solid Waste Management linit

- Cullet Dumpster

"Other" Units

- Carbon Adsorption tinit

-- Vapor Scrubbers

All units on-site are of such design and status as to justify a recommendation of "no furtice action".

In conclusion there is insufficient evidence to warrarit an RFI for any unit on this facility site.

Questions or coments on the RFA should be directed within 30 days from the date of this letter to Alan P. Church, P.E. at AC512/463-8559.

sincerely,

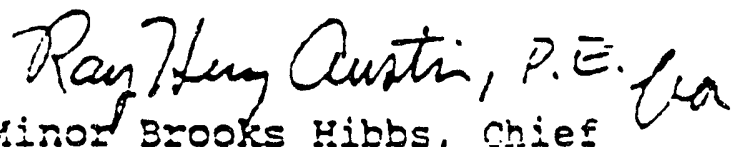

peruits section

Hazardous ard Sclic Haste pivision

$A P C: b b$

Enclosure: $P R$ and VSI

xC: : Robert D. Gallagher, NSSI - Houstor. (with VSI)

Shirley Workman, EPA - Dallas

TWC Southeast Region Office - Deer Park (with VSI)

Paul Lewis, TWC Enforcement Section - Austin 

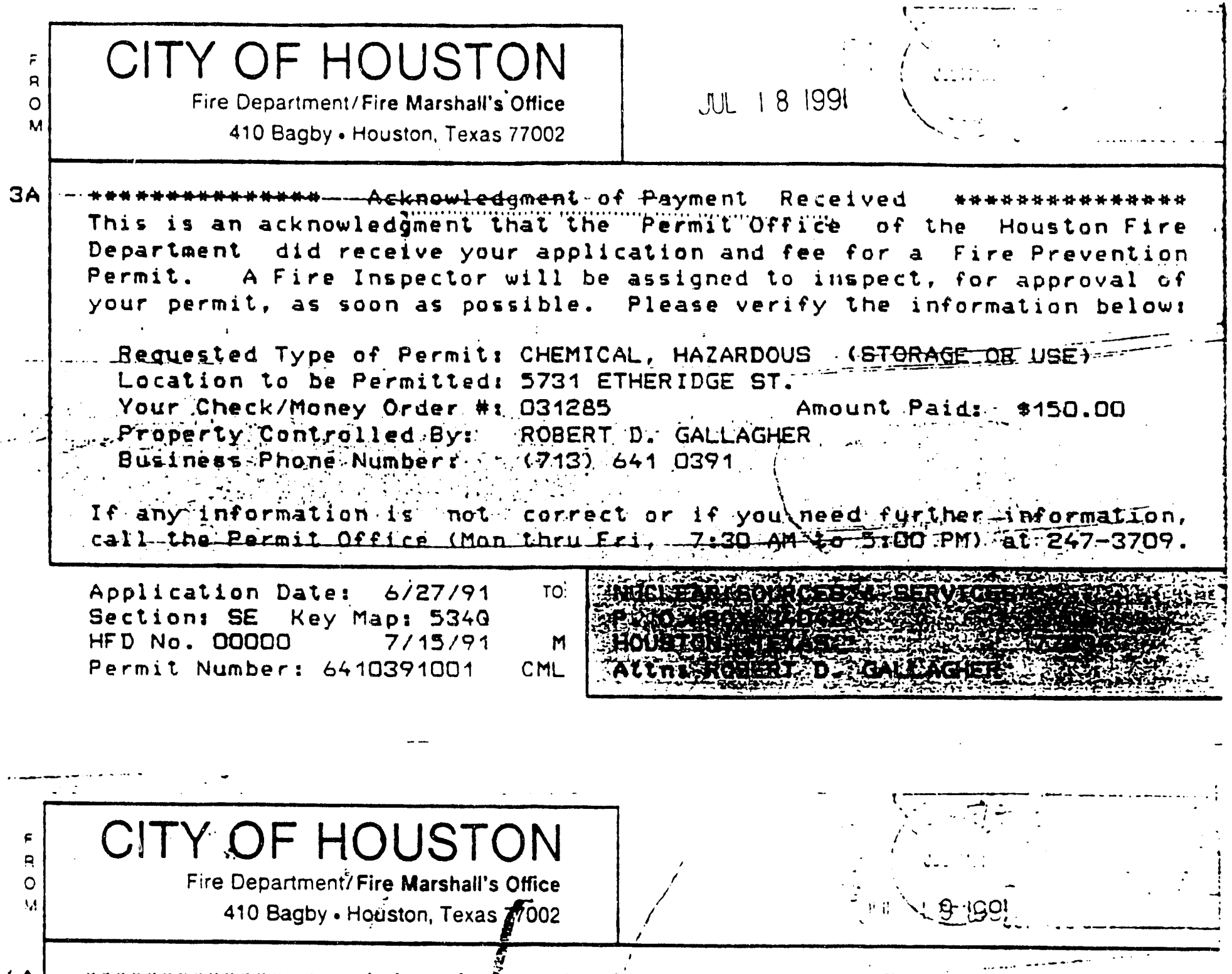

*********\#*** Acknowledgrant of Rayment Received

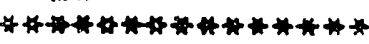

Tris is an acknowledgment hhat..then...permit..office of the Houston fire Department did recefve yourapplication and fee for a fireprovention Permit. A Fire Inspector will be assigned to inspect. for approval of your permit, as soon as possible. Please verify the information below:

Requested Type of Permit: FLAMM. /COMB. LIQUID STORAGEZ-YSE GEN-..... Location-to be:Permitied: 5731 ETHERTDGE ST.

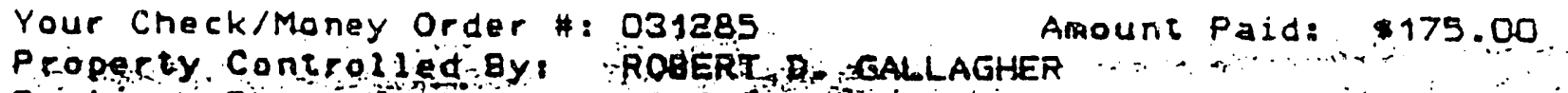

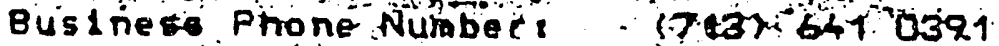

If any information ig not correct or if you need further information, call the Permit office (Mon thrufri,..7:30_AM.to-5.00.P4) 3t 247-3709.

Applicalion Date: 6/27/91 To

Section: SE Key Map: 5340 HFD No. $00000 \quad 7 / 15 / 91$

Permit Number: 6410391000
$M$

CNIL

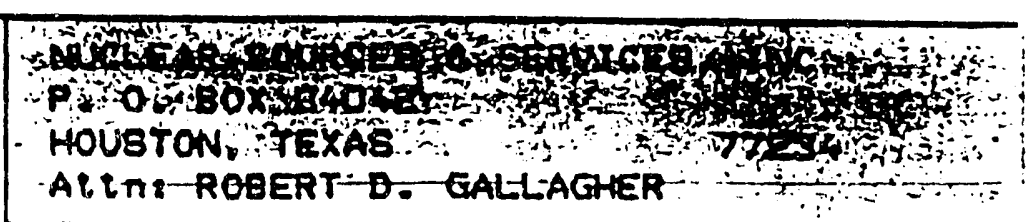


THIS IS NOT A PERMIT AND DOES NOT CONSTITUTE AUTHORIZATION OF ANY WASTE MANAGEMENT ACTIVITIES OR FACILITIES LISTED BELOW. REQUIREMENTS FOR SOLIO WASTE MANAGEMENT ARE PROVIDED BY TEXAS ADMINISTRATIVE CODE SECTION 335 OF THE RULES OF THE TEXAS WATER COMMISSION (TWC). CHANGES OR ADDITIONS TO WASTE MANAGEMENT METHODS REFERRED TO IN THIS NOTICE REQUIRE WRITTEN NOTIFICATION TO THE TWC.

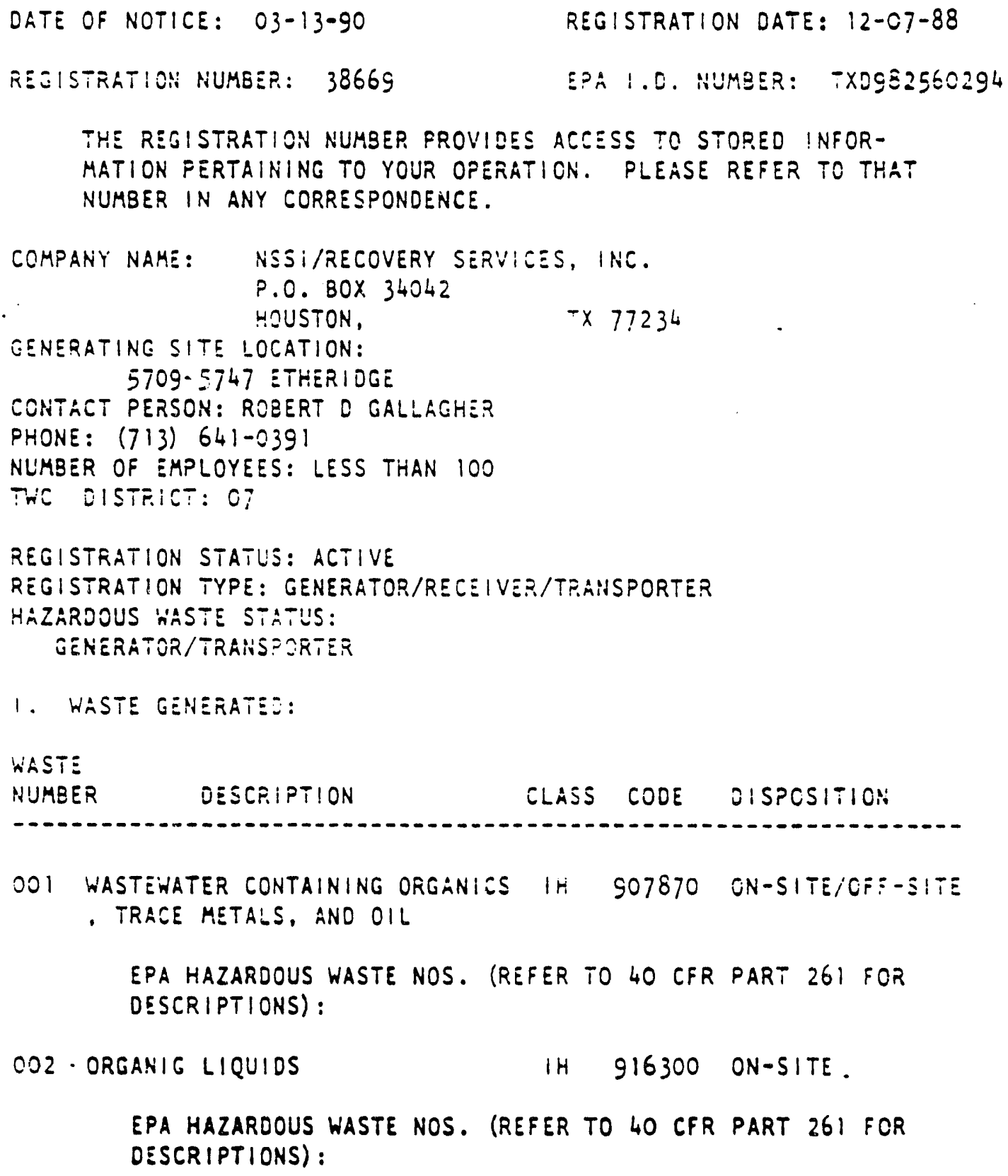


EPA HAZARDOUS WASTE NOS. (REFER TO 40 CFR PART 26I FOR DESCRIPTIONS):

004 STILL BOTTOMS. SOLVENT RECOVER IH 950240 ON-SITE/OFF-SITE Y

EPA HAZARDOUS WASTE NOS. (REFER TO 40 CFR PART 261 FOR DESCRIPTIONS) :

OO5 CON.RETE ANO/OR METAL. MISC. C IH 979230 ON-SITE/OFF-SITE HEMICAL CONTAMINATED

EPA HAZARDOUS WASTE NOS. IREFER TO HO GFR PART 261 TOR DESCRIPTIONS):

006 TANK BOTTOMS IHY 952100 ON-S1TE

EPA HAZARDOUS WASTE NOS. (REFER. TO 40 GFR PART Z6I FOR UESCRIFTIONS):

007 CARBON, ACTIVATED, SPENT IH S81730 ON-SITE/OFF-SITE

EPA HAZARDOUS WASTE NOS. (REFER TO LC TFR FLET 2SI FOR OESCRIPTIONS) :

OOR ION EXCHANGE RES!N :H QLGQSO ON-SITE/OFF-SITE

EPA HAZARCOUS WASTE NOS. (REFER TO LO GFR FART 26! TOR DESCRIPTIONS):

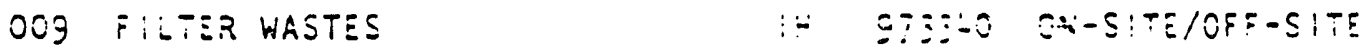

EPA HAZARDOUS WASTE NOS. (REEER TO LO GFR FLRT 261 FOR QESCP!DT! QNS! :

OIO DUST, GRINDING IR STS-SO ER-S,TEIOFT-S:TE

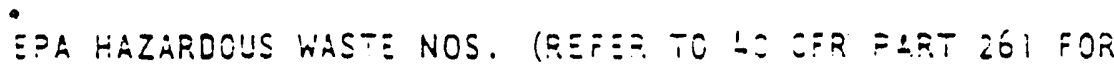
BESCRIFTIONS: :

O11 TRASH AND DEBRIS I I8ZISO ENTSITE/OFF-SITE

012 CHEMICAL CONTAMINATED WASTE, L IH QICISI ON-SITE/OFF-SITE IOUID

EPA HAZARDOUS WASTE NOS. (REFER TO LO CFR =ART 26.1 FOR DESCRIPTIONS):

013 CHEMICAL CONTAMINATED WASTE, S IH $98 E 000$ ON-SITE/OFF-SITE OLIO

EPA HAZARDOUS WASTE NOS. (REFER TO 40 CFR FART 261 FOR OESCRIPTIONS): 


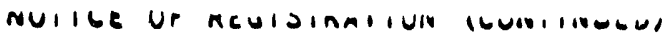

REGISTRATION NUMBER: 38669

COMPANY NAME: NSSI/RECOVERY SERVICES, ING.

11. Shipping/Reporting: Pursuant to Section 335 of the Texas Administrative Code of the rules of the TWC pertaining to Hazardous Waste management, issuance of manifests and annual reporting are required for off-site 5 torage/Processing/Disposal of the following wastes listed in Part 1. All manifested wastes should be reported on the annual waste summary report and submitted to the TWC by the $25 \mathrm{th}$ of each January for the prior calendar year.

001907870 WASTEWATER CONTAINING ORGANICS
. TRACE METALS. AND OIL

003951850 SIUNGES, HAZARDOUS

004950240 STILL BOTTOMS. SOLVENT RECOVER Y

005979250 CONCRETE ANO/OR METAL, MISC. C HEMICAL CONTAMINATED

007981730 CARBON, ACTIVATED, SPENT

008 94999O ION EXCHANGE FEEIN

OO9 973340 FILTER WASTES

OIC EIZ-SO CUST, GPIMOINE

O!1 183780 TRASH ANO OEERIS

C12 :10191 CHEMICAL CONTAMIMATED WIASTE, L IQUIO

013 S88000 CHEMICAL CONTAMINATED HASTE, S $\therefore ! ! ?$

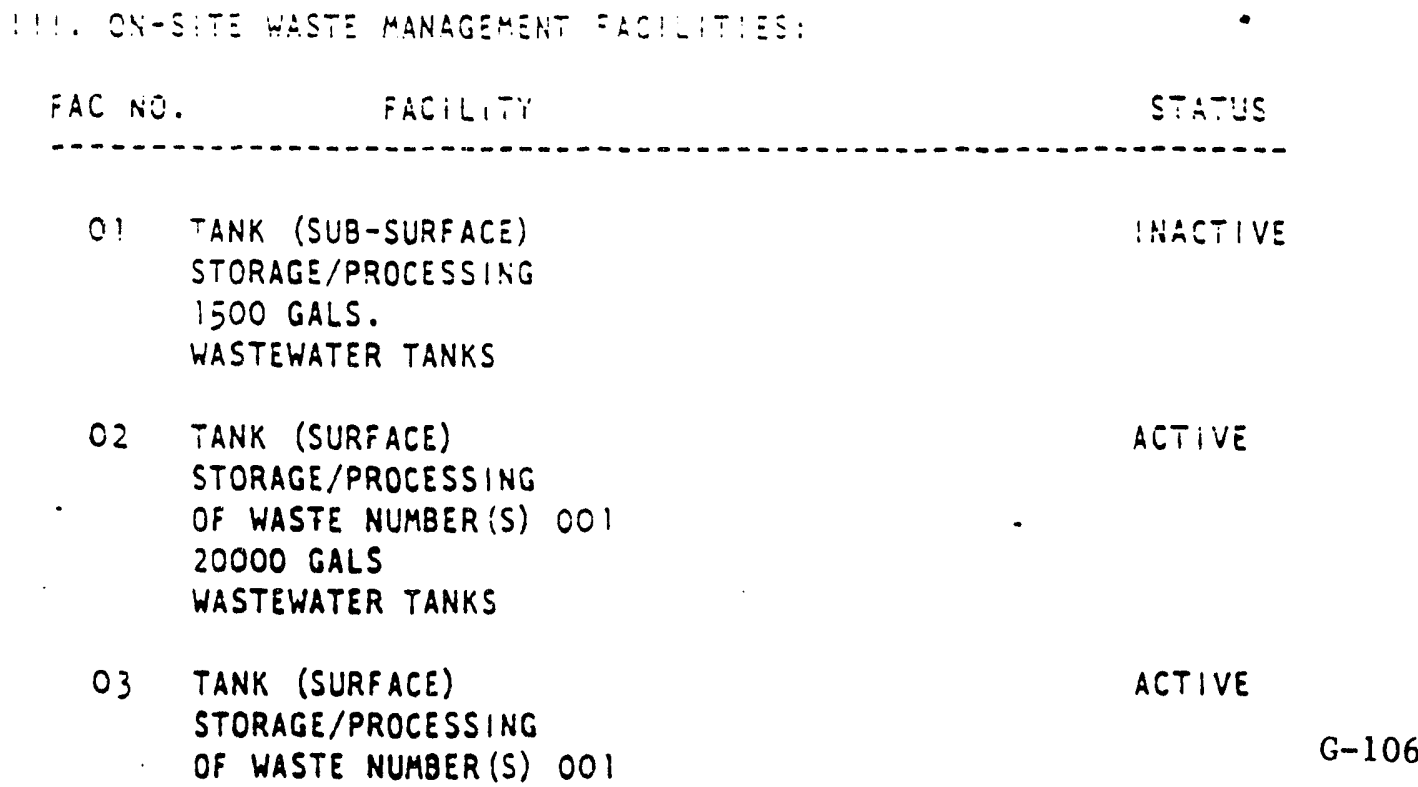




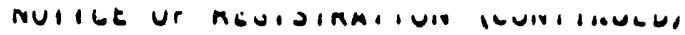

REGISTRATION NUMBER: 38669

COMPANY NAME: NSSI/RECOVERY SERVICES, INC.

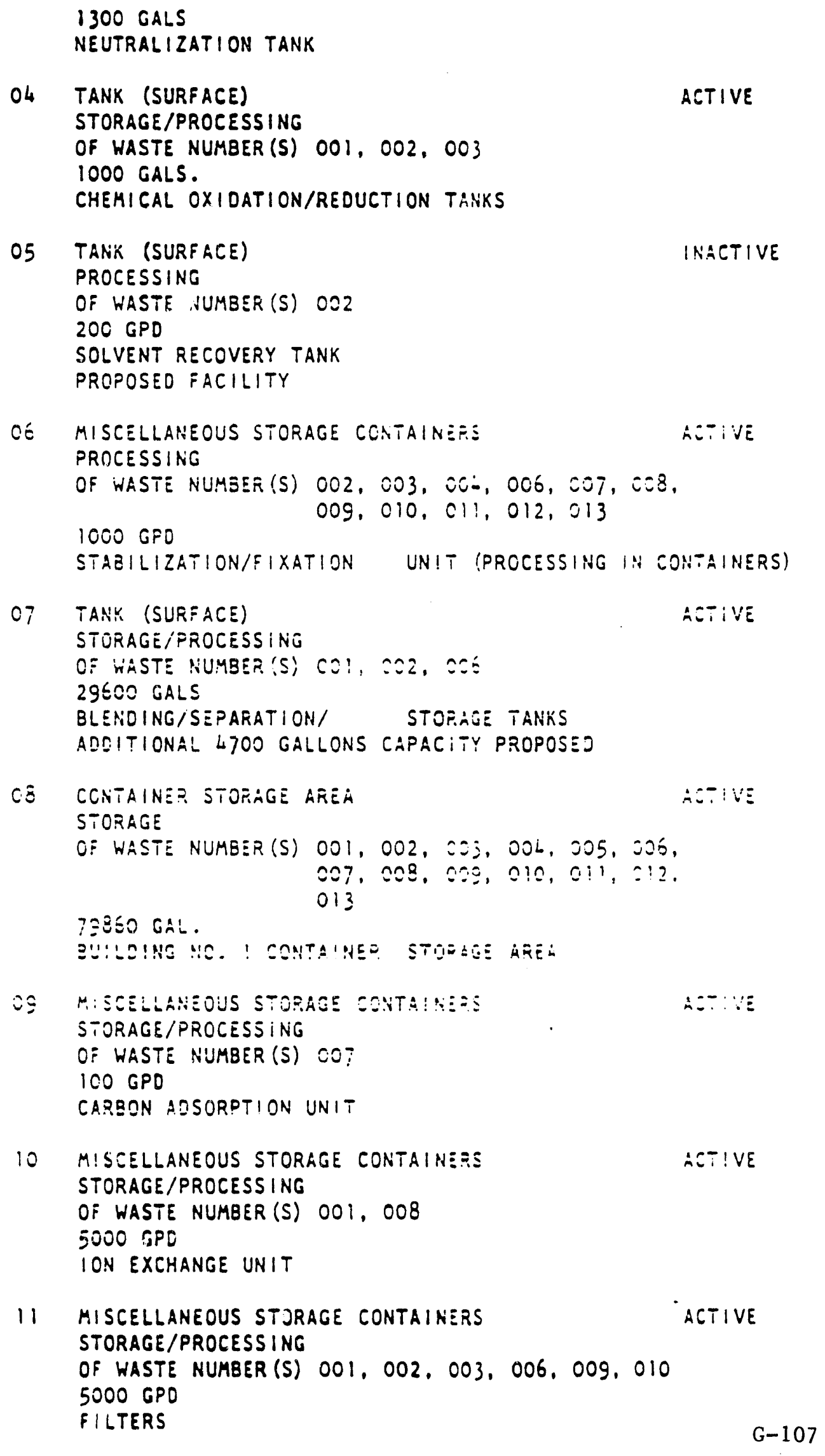




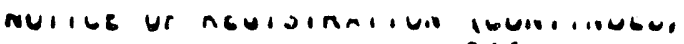

RECISTRATION NUMBER: 38669

COMPANY HAME: HSSI/RECOVERY SERVICES, INC.

12 CONTAINER STORAGE AREA

ACTIVE

STORAGE

OF WASTE NUMBER (S) 012,013

500 GALS.

REACTIVE CONTAINER STORAGE AREA

13 MISCELLANEOUS STORAGE CONTAINERS

ACTIVE

STORAGE

OF WASTE NUMBER(S) OII

10000 PPE

DUMPSTER

IL MISCELLANEOUS STORAGE CONTAINERS RCTIVE

PROCESSING

OF WASTE NUMBER(S) 003,004, 006, 007, 008, 0CE,

220000 PPM

010.013

SOLIDS CLEANING AREA

(PROCESSINE AREA)

16 TANK (SURFAEE)

INACTIVE

STORAGE

OF WASTE NUMEER(S) 002

128 CU.FT.

SRINDER TANIS

IT CONTAIAIE STORAEE AREA

STORACE

SF WASTE NUMBER(S) 001, 002,003, 004, 005, COE, $007,008,009,010,011,0: 2$.

29700 04:5

013

EUILDINE NO. 2 CONTAIPIER STORAEE ARER

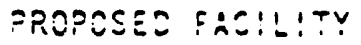

IS CONTAIUE? STCRAGE AREA

STOPAES

O? WASTE RUMEE?!S! 0!2, Q !3

$\xi i 20$ SALS.

iE TANK (SURE:EE)

STORAGE

QF WASTE NUMBER (S) 002

2000 GAL.

2-GRINESR TANKS OF 1000 GALS. EACH

INACTIVE 
MUIIL UR KEUIJINAIIUIN ILUIVIIUUEN

REGISTRATION NUMBER: 38669

COMPANY NAME: NSSI/RECOVERY SERVICES. INC.

A. FOR PURPOSES OF FILING ANNUAL REPORTS PURSUANT TO TEXAS ADMINISTRATIVE CODE SECTION 335 OF THE RULES OF THE TWC PERTAINING TO INOUSTRIAL SOL 10 WASTE MANAGEMENT, RECORDS SHOULD BE MAINTAINED FOR STORAGE. PROCESSING ANO/OR DISPOSAL OF THE FOLLOWING WASTE (S) LISTED IN PART I:

001907870 WASTEWATER CONTAINING ORGANICS

- trace metals, and oIl

CO2 916300 ORGANIC LIQUIOS

CO3 951850 SLUDGES, HAZARDOUS

004950240 STILL BOTTOMS, SOLVENT RECOVER Y

OO5 979250 CONCRETE ANO/OR METAL, MISC. C HEMICAL CONTAMINATED

006952180 TANK BOTTOMS

007981730 CAFEON, ACTIVATED, SPENT

OO8 949990 !ON EXCHANEE RESIN

:DS GT3jLO EILTES H'ASTES

010973460 DUST, GRINDING

OiI 183780 TRASH AND DEBRIS

012 910191 CHEMICAL CONTAMINATED WASTE, : IQUID

O! S g80000 CHEMICAL CONTAMINATEU WHSTE, S OLIO 
Exhibit C4

RADIOACTIVE MATERIALS LICENSE FOR NSSI

G-111 


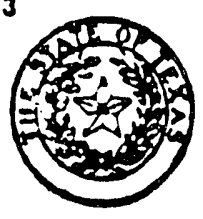

\section{TEXAS DEPARTMENT OF HEALTH \\ RADIOACTIVE MATERIAL LICENSE}

Page 1. or 13 Pages

Pursuant to the Texas Radiation Control Act and Texas Departmeat of Health reculations on radiation, and in reliance on staternents and representatoons heretofore made by the licenere, a license is hereby issued authorizing the lleensee to receive, acquire, posseas and transfer radloactive material listed below; and to use such radloactive material for the purpose(s) and at the place(a) designated below. This license is subject to all applicable rulea, regulations and arders of the Texas Department of Health now or hereafter in effect and to any conditions specified below.

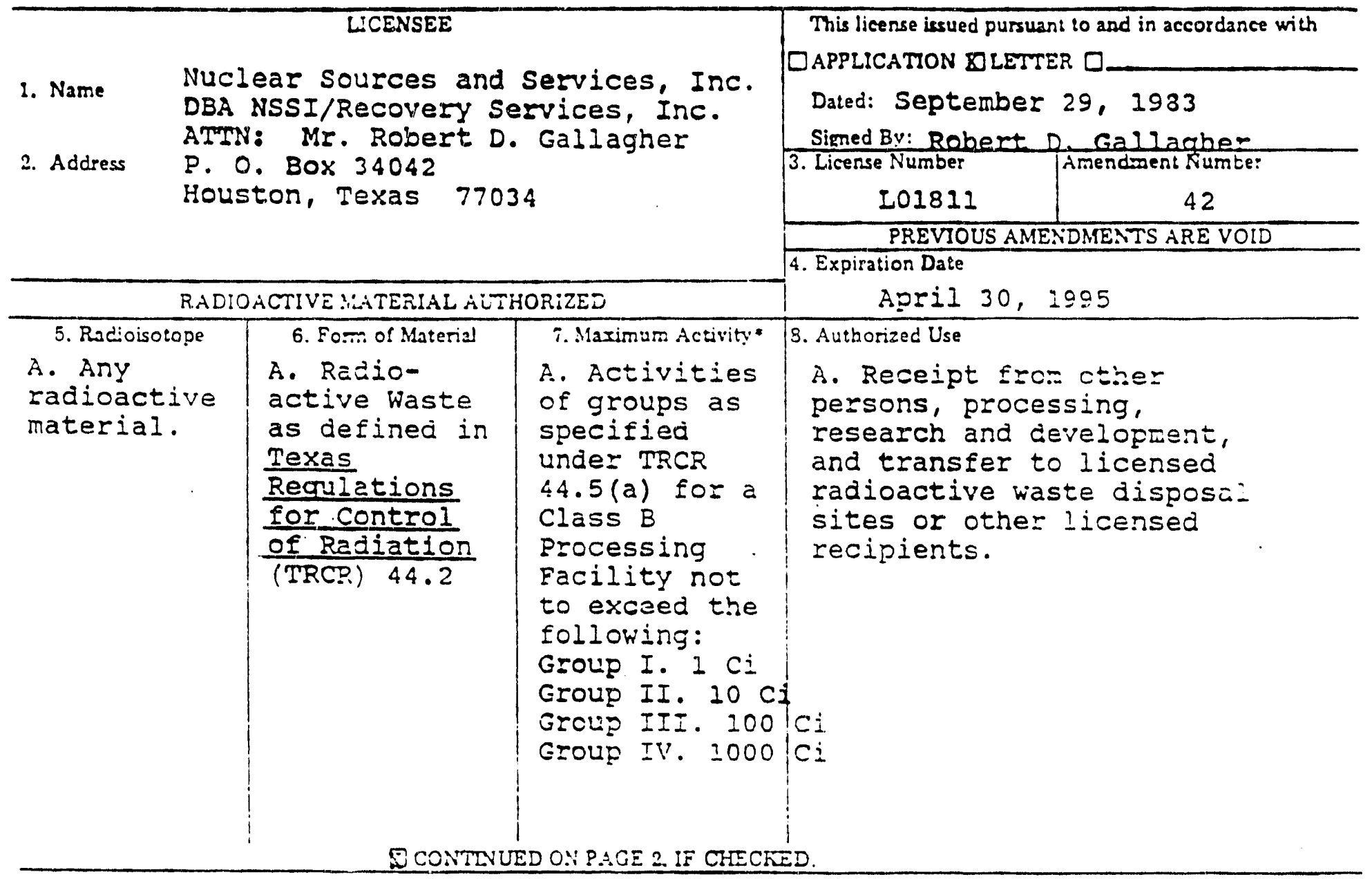

CONDITIONS

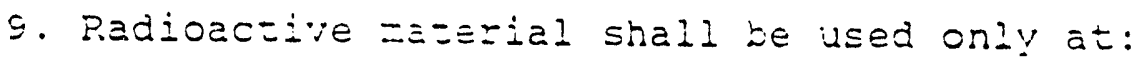

Subsite Numbe: 000

\section{Location} Houston - 5711 Etheridge (this address shall consist of all properties operated by the licensee within an area bounded on the north by Moline street, on the south by Joyne: street, on the east by Northale street, 
TEXAS DEPARTMENT OF HEALTH

RADIOACTIVE MATERIAL LICENSE

Supplementary Sheet

\begin{tabular}{|c|c|}
\hline WCENSE NUMBER & AMENDAENT NUMAER \\
L01811 & 42 \\
\hline
\end{tabular}

Page_2 or 13 Pages

26237 c. Any radio-
active
material

D. Special

iivclea:

Material

\begin{abstract}
6. Form of Material
\end{abstract}

B. Radioactive Waste as defined in TRCR 44.2 .

C. Sealed sources received as radioactive waste

$$
\begin{aligned}
& \text { D. Any } \\
& \text { received as } \\
& \text { radioactive } \\
& \text { iaste }
\end{aligned}
$$

\section{Maximum Activity}

B. Activities of groups as specifled under TRCR 44.5 (a) for a Class $B$ Storage Facility not to exceed the following: Group I. $2 \mathrm{Ci}$ Group II. $20 \mathrm{CI}$ Group III. $200 \mathrm{Ci}$

Group IV. $2000 \mathrm{Ci}$

c. Total activity not to exceed 2000 $\mathrm{Ci}$

D. As specified in TRCR 11.2 "Special Nuclear Material in Quantities not Sufficiert to Form a Critical rass"

\section{Authorized Use}

B. Receipt from other persons, storage, and transfer to iicensed radioactive waste disposa! sites or other licensed recipients. c. Receift from other persons, storage, processing and transfer to licensed radioactive waste disposal sites or other licensed recipients.

D. Receipt from other persons, storage, processing and transfer to licensed radioactive waste disposal sites or other licersed recipients. 
TEXAS DEPARTMENT OF HEALTH

RADIOACITVE MATERIAL LICENSE

Supglementary Sheet
Page 3 3 ol 13 Pafes

26238

LICENSE NUMBER AMENDMENT NUMBER 42

CONDITIONS CONTINUED:

9. (continued)

and on the west by cheswood street, and is further identified as Block 37 lots 3,4 , $5,6,7,8,9,10,11,12, \frac{17}{17}$ and 18 , and Block 38 , lots $4,5,7,8,9,10,11,12$, $13,14,15,16,17$, and 18 in Houston, Texas as inaicated in Attachsent 1 , visich is attached hereto and is made a part herect).

10. The licensee sha! compl: litth the provisions of TRCR Parts 11, 12, 12, $21,22,41$, and 44 .

11. The activities authorized by this license shall only be performed by individuals designated by the iicensee's Radiation Safety Committee or by persons working under the direct supervision of persons designater by the licensee's Radiation Safety Comittee.

12. The individual designated to perform the functions of Radiation Safety officer (RSO) for activities covered by this license is Robert $D$. Gallagher.

i3. The licensee is authorized to possess special nuclear material onl $\because$ in quantities not to exceed that specified in TRCR 11.2. The total amount of special nuclear material possessed under all licenses issued by this figency at the licensee's facility described in Condition No. 9 siall rot exceed the TRCR 11.2 Iimits.

¿f. $\therefore$. The licensee is autborized to coliect and repackage radioactive waste at custoner sites throughout Texas and transport the radioactive waste in containers that comply with united states Department of Transportation (USDOT) specifications to the licensee's or other properly licensed facility.

B. Waste processing under this license is linited to that as defines by the TRCR and the following:

(1) Receipt and survey in accordance with procedures contained in the application dated september 29,1983 and letter dated

$\because$ September 14, 1984; 


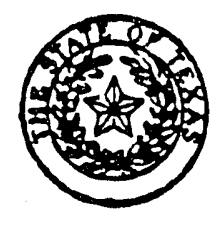

TEXAS DEPARTMENT OF HEALTH

RADIO`CTIVE MATERIAL LICENSE

Supplementary Sbeet
Page 4 of 13 Pares

26264

LICENSE NUMBER ANENDYENT NUMBER 42

\section{CONDITIONS CONTINUED:}

14. B. (continued)

(2) Repackaging in accordance with procedures contained in the application dated september 29, 1983;

(3) Compaction and consolidation in accordance with procedures contained in the application dated september 29, 1983:

(4) Separation and frocessing of liquid scintillation Eedia, containers, and other bulk liquid and solid waste into: (a) liquid fractions; (b) solid fractions; and (c) rinses in. accordance with procedures contained in the application dated september 29, 1983 and letter dated september 14, 1984 .

(5) Solidification of liquid radioactive waste using nedia acceptable to low-level waste disposal sites.

15. Empty or processed liquid scintillation vials may be disposed of in accordance with TRCR $2 \bar{i} .307$ (a) without regard to their radioactivity if: (1) concentrations of carbon-14, hydrogen-3, or iodine-325. do not exceed .05 microcuries per gram; or (2) for any other radionucliide, concentrations which do not exceed TRCR Appenaix 2i-n̈, Tabie Ti, Colum... 2 lirits.

The determination of concentration shail he maie with at ieast a ioj gram sampie collected from each process batch.

Is. While on site, waste wili remain physically identifiable as radioactive waste and traceable to waste receipt records until sinipment Eo= disgosal.

17. A. Waste inventory shall be computed in units of, or equivalent to the volume of 55 -galion drums (7.35 cubic feet). When computing the total inventory, any drum or container not equal to the volume of a 55-galion drun shall be included in the inventory as its 55-gallon drum equivalent (e.g., a 30-galion container has a volume equal to $30 / 55$ of a 55-galion drum).

B. Any container that contains any quantity of radioactive waste shall be counted as a full container in the drua equivalent inventory. unless it can be readily verified as enpty. 
TEXAS DEPARTMENT OF HEALTH RADIOACTIVE MATERLAL LICENSE

Supplewentary Sheet
Page 5 _ol 13 Pages

26239
42

\section{CONDITIONS CONTINUED:}

17. (continued)

C. By January 15, April 15, July 15 and october 15 of each year the licensee shall submit a written report to the Agency which includes the following information about the preceding calendar quarter:

(1) The number of drus equivalents and activity on hand at the beginning and end of the guarter:

(2) The number of drum equivaients and activity received during the quarter:

(2) The number of drum equivalents and activity processed during the quarter:

(4) The number of druas or drum equivalents disposed of at a licensed low-level radioactive waste disposal site; and

(5) Volume and activity of waste disposed of in accordance with TRCR 21.307 (a) and the icientity of the disposal site (e.g., the rame of the municipal landfili, incinerator, etc.) and the date of each disposal.

D. No more than 4000 55-galion drum equivalents of radioactive haste shall be possessed at any one time.

io. A. The outer surfaces of each container shall be wipe tested for removable contamination upon receipt or reparkaging and just prior to transfer. Any container with removable contamination in excess of $2200 \mathrm{dpm} / 100 \mathrm{~cm}^{2}$ (alpha) or $22000 \mathrm{dpm} / 100 \mathrm{~cm}^{2}$ (beta-gamma) shall be decontaminated. Dru storage area floors shall be wipe-tested at least quarterly to confirm that containers are not lealing radioactive materials.

B. Containers shall be visualiy inspected at least quarterly. in: container showing signs of rusting, physical damage, leaking materials, or other deterioration shall be repackaged as soon as practicable, but not later than ten days.

c. Upon receipt, the surface of each container shall be surveyed individually to assess the external radiation fields present and a record made of the highest surface reading noted. 


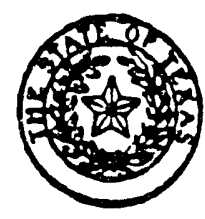

TEXAS DEPARTMENT OF HEALTH RADIOACIIVE MATERLAL LICENSE

Supplementary Sheet
Page 6 _ol 13 Pages

26240

LICENSE NUASEE APENDMENT NUABEA

L01811

42

CONDITIONS CONTINUED:

19. Records of all environmental sampling resultsi visuai and physical inspections: radiation surveys; bioassay; personnel monitoring: personnel contamination surveys; radioactive material receipt, transfers, and disposals; managenent safety audits; biweekly wipe surveys of any restricted and unrestricted areas; area surveys anc other records required by $T R C R$ and this license shall be maintained by the licensee, in accordance with the time limits specified by the TRCR, for inspection by the Agency.

20. $\dot{0}$. Shipments of racioactive vaste by the licensee shall meet the requirements of the U.S. DOT, as specified in Title 49 . Code 0 f Federal Regulations and the requirements of the waste disposal sits to which they are being shipped.

B. The licensee is authorized to store any package prepared. for shipment containing waste byproduct, source or special nuclear material in truck trailers at the licensee's facility for periocs not to exceed ten working days prior to transport to a disposa: site.

21. The licensee shall naintain for inspection by the Agency an inventor: of all radicactive waste possessed under this Iicense. The inventor: shall show the radionuclide, date received, from whom received, amourit of activity, physical form, date processed, original and reassignea drum or containez-number, and the date transferred for disposal. In: addition, the licensee shall at least monthly generate a cumulative inventory, by radionuclide, which demonstrates compliance with tiss appropriate processing group limits of Trop 44.5 .

22. A. The clotring and skin of ali employees (includirg permanent $\equiv .:$ contract workers) working in a radiation restricted area shall $i e$ monitored with radiation detecting instrumentation for contamination prior to departure from the facility. Confamination exceeding 20 dpm/100 c=2 (alpha) and/or 1,000 dpm/100 $\mathrm{cm}^{2}$ (beta-gamma) shal? be removed prior to an individual departing the radiation restricted area. 
TEXAS DEPARTMENT OF HEALTH RADIOACTIVE MATERIAL LICENSE

Supplerpentury Sheet

$$
\text { Page } 7 \text { or } 13 \text { Pages }
$$

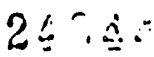

WCENSE NUMBER AMENDMENT NUMBER
42

\section{CONDITIONS CONTINUED:}

22. (continued)

B. Areas found to possess contanination in excess of $2200 \mathrm{dpm} / 100 \mathrm{~cm}^{2}$ (removable alpha) and/or $22,000 \mathrm{dpm} / 100 \mathrm{~cm}^{2}$ (removable beta-gamma) shall be decontaminated and resurveyed to assure that removable contamination is below the aforementioned limits. The limits do not apply to the contents of properly packaged waste materials, to waste materials during processing, or to the inner surfaces of processing equipment and air handling, sampling, or exhausting equipment.

23. A. Radiation safety training shall be given to radiation workers and radiation safety technicians in accordance with the licensee's letter dated september 14, 1984. All permanent radiation workers shall attend the "Radiation Workers Training Program" within 30 days of employment and shall attend the "Respirator Training Program" prior to working in areas requiring respiratory protection.

3. Contract or temporary workers working in any radiation restricted area will work only under the direct supervision of a Radiation Safety Techrician and shall not work in any radiation restricted area alone.

C. All female employees who enter any radiation restricted irea will be given instruction concerning prenatal radiation exposure.

D. All training will be documented. Documentation of the training shall be made available for Agency inspection.

24. The Iicensee shall provide appropriate respiratory protection ior persons working in areas where airborne contamination at concentrations above the limits specified in TRCR Appendix 21-i, Table I, Column I is possible. A physical inspection to include wipe testing of the respirator shall be performed before each use, but not less frequently than quarterly. Persons working in those areas shall be-tested for proper fit of respirators at least once each year. Records of the physical inspection, fit test and training given to employees shall be maintained for inspection by the Agency. 


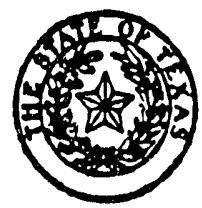

TEXAS DEPARTMENT OF HEALTH RADIOACTIVE MATERLAL LICENSE

Supplementary Sheel
Page_8_or 13 Pages

26241 \begin{tabular}{|l|l|}
\hline LICENSE NUMBER & ANRENDWENT NUMBER \\
\hline
\end{tabular}
42

CONDITIONS CONTINUED:

25. Respirators made available for use must show no removable alpha contamination in excess of $22 \mathrm{dpm} / 100 \mathrm{~cm}^{2}$, no removable beta-gamma contamination in excess of $220 \mathrm{dpm} / 100 \mathrm{~cm}^{2}$, no fixed alpha contamination in excess of $100 \mathrm{dpm} / 100 \mathrm{~cm}{ }^{2}$, or no fixed beta-gamma contamination in excess of $1,000 \mathrm{dpm} / 100 \mathrm{~cm}^{2}$.

26. Individuals involved in operations which utilize, during any 24-hour period, more than 50 millicuries of iodine-125 (I-125) and/or iodine131 (I-131) or unvented operations involving 10 millicuries of I-125 and/or I-I3I in a noncontained form shall have bioassays performed within one week. If the use of I-125 and/or I-131 is on a continual basis, bioassays shall be performed once every two weeks. The action points listed below shall be observed:

A. Whenever the thyroid burden at the time of measurement exceeds 0.12 microcuries of I-125 or 0.04 microcuries of I-131, the following actions shall be taken:

(1) An investigation of the operations involved, including ventilation surveys, shall be carriedjout immediately to determine the cautses of exposure and to evaluate the ipotential for further exposures.

(2) If the investigation indicates a potential for -excessive inorker exposure, access:=will be controlled until the source of exposure is discovered and =comrected.

(3) Corrective actions that -will meliminate or lower the potential for further-exposures shall be implemented.

(4) A repeat bioassay -shall be taken within one week of -the-previous measurement in order to confirm the effectiveness of the corrective action taken.

(5) Reports or notification shall be provided as required by TRCR 21.405 and 21.408 .

B. If the thyroid burden at any time exceeds 0.5 microcuries of I- 125 or 0.14 microcuries of I-131, the following actions shall be taken:

(1) Prevent the individual from any further handing of I-125 or I131 until the thyroid burden is below the above limits.

(2) Carry out all steps described above. 
TEXAS DEPARTMENT OF HEALTH

RADIOACTIVE MATERIAL LICENSE

Supplementary Stoet
Page 9 ol 13 Page

26242

LCENSE NUMAER AMENDMENT NUNBER

L01811 42

CONDITIONS CONTINUED:

26. B. (continued)

(3) As soon as possible, refer the case to appropriate medical consultation for recommendations regarding therapeutic procedures that may be carried out to accelerate removal of radioactive iodine from the body. This should be done within 23 hours after exposure when the time of exposure is known so that any prescribed thyroid blocking agent would be effective.

(4) Carry out repeated measurements at approximately one-week intervals at least until the thyroid burden is less than 0.12 microcuries of I-125 or 0.04 microcuries of I-131.

27. A. Individuals involved in operations which utilize, at any one time, more than 100 millicuries of hydrogen-3 in a noncontained form, other-thañ-metallic foil, outside of a glovebox shall have-biöassays performed within one week following a single operation and at weekly intervals for continuing operations.

B. Hydrogen-3 shall not be used in such a manner as to cause any individual to receive a radiation exposure such that iurinary excretion rates exceed 28 microcurles of hydrogen-3 per-iiter winer: averaged over a calendar quarter.

c. i report of an average concentration-inexcess of-the imit specified in=Part $B$-of-this -condition-for-any-individual-shall be

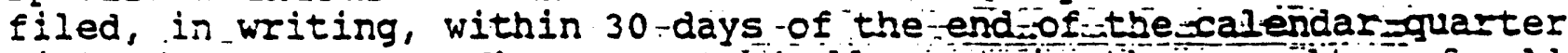
with the Agency. The report shal-contain-the-resultsof all urinalysis for the individual during the calendar quarter, the cause of the excessive concentrations, and the corrective steps taken: or planned to assure against a recurrence.

D. Any single urinalysis which discioses a concentration of greater. than 50 microcuries per liter shall be reported, in writing, within seven days of the licensee's receipt of the results. 
TEXAS DEPARTMENT OF HEALTH

\section{RADIOACITVE MATERLAL LICENSE}

Supplementary Sheet
Page 10 _ol 13 Pages

26243

\begin{tabular}{|c|c|}
\hline WCENSE NUMAER & AMENDMENT NUMBER \\
LO1811 & 42 \\
\hline
\end{tabular}

\section{CONDITIONS CONTINUED:}

28. A. If air sample results indicate that an airborne release in excess of ten times the limits of TRCR Appendix 21-A, Table I, Colunn 1 occurred to the restricted area or to any portion of the restricted area, the licensee shall immediately perform bioassays on all individuals who were present. If the bioassay results indicate that the maximum permissible body burden was exceeded for any individual:; the individual shall have a whole body count performed to determine the uptake, if appropriate for the radionuclide. Appropriate measures to enhance elimination shall be made in consultation with the licensee's consulting physician.

B. If any air sample results indicate that an airborne release to the unrestricted area in excess of the limits of TRCR Appendix 21-A, Table II, Column 2 has occurred, the licersee shall take appropriate measures to determine the dose to the maximaliy exposed member of the pablic downwlind of the plume and notify the Agency in writing within five working days of the sampie analysis and the dose assessment.

29. Records of bioassays, thyroid counts, whole-body exposures, any dose to employees or -members of : the $=$ public and any corrective actions taken shal be maintañ for Agency inspection:

$\because \because-$.

30. The -licensee =shali conduct-the radiation suriey - and area. monitoring program as described in =sections .5. . 5.3, and 5.4 - of the document entitled noperating procedures foi the Radioactive Waste processing and Storage Facilities at Houston, Harris County" cated september 1983, at the locations indicated in Drawirg to. $100-33023-B$, nsite-Plan Nuclear Sources and Services Inc." dated August 10, 1983. The monitoring program will be reviewed at least semiannually by the Radiation Safety Committee to assure its adecuacy for the size and scope of operations at the facility. A report of its analyses shall be kept for Agency inspection.

31. Once each calendar quarter the licensee sinall collect three environmental soil samples from the following locations:

A. South of the NSSI office building, west of 5747 Etheridge, just west of the fence on the east side of Etheridge, on the south side of the driveway, in the low drainage area; 


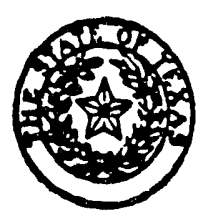

\begin{tabular}{|c|c|}
\hline $\begin{array}{c}\text { WCENSE NUMBER } \\
\text { LO }\end{array}$ AMENDLENT NUMBER & 42 \\
\hline
\end{tabular}

CONDITIONS CONTINUED:

31. (continued)

B. Southwest of the NSSI office building, just west of the fence on the east side of Etheridge, just south of the main gate drive where the slab drainage exists at the site.

c. Southwest of the NSSI office building, just west of the fence on the east side of Etheridge, on the south side of the driveway to the drum storage area and waste storage and processing buildir.j, in the low drainage area.

32. The RSO and the Radiation Safety Comaittee shail review the following areas of the radiation safety program at least semiannualiy:

A. health physics authority anc responsibility;

B. operating procedurws (involving the handling, processing and/or storage of radioactive materinis):

C. audits, frspeictions, and timeliness and the resolution of any proble s);

D. radiation protection including employee exposure records; bioassay procodures and results, quartarly, semiannül, or annual surveys and lispectons; cadlologiful survey and sainpling data; and any

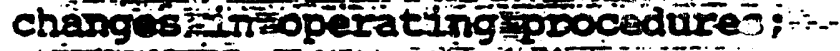

E. radration safety traturting

F. respiratory protection-program:

G. facility Eand =equipment fdesign including ventilation rates witin various portions of the $=$ facility and sire control;

H. cortiol of aliborne radioactive materials;

I. compliance with applicable fed ral and state regulations and the conditions of this license; "and

$\mathrm{J}$. the audit of drum inspection and receipt procedures.

A copy of this report shall be maintained for review by the Agency.

33. Modifications of existing facilities or construction of a new facility requiring a change in the operating procedures or the use of new radioisotope handing facilities shall be approved by the Agency prio: to the intiation of their use on a commercial scale. 


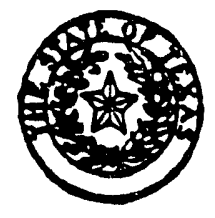

TEXAS DËPARTMENT OF HEALTH RADIOACTIVE MATERIAL LICENSE

Supplementary Stuest
Page 12 ol 13 Pages

26244

\begin{tabular}{|c|c|}
\hline LICWNE NGMBER & AMENDAENT NUMBER \\
LO1811 & 42 \\
\hline
\end{tabular}

\section{CONDITIONS CONTINUED:}

34. A. The licensee shall post and maintain financial security.

B. Financial security shall be in the form of a preapproved trust agreement with the Agency designated as the beneficiary.

c. Th: amount of financial security shall be based on the average number of drum-equivalents of radioactive waste, as determined from a count obtained during the two inspections made during the prior year. The amount of financial security required shall be reviewed on a yearly basis and adjusted to reflect the average number of drums as determined during the two semi-annual inspections. No adjustment shall be made downward unless the total amount of security equals the total amount required by the Agency based on the preceding year's average drum count.

D. The initial amount of financial security is $\$ 225,000$, based upon $\$ 300$ per a rumpequivalent of radioactive waste counted onssite aduring the two inspections conducted prior to issuance of Amenament No. 42 of this license. This amount is to be paid as provided in parts $E$ anci $F$ of this condition.

E. The initial payment to the trust fund shall be in the amount of $\$ 56,250$.

F. Payments to the trust fund shall be made on a semi-annual basis (June $I$ and December I) until the total amount-of financial-security required is attained. The semi-annual payments shall-be-in the amount of $\$ 2.00$ for every cubic foot of radioactive waste received during the six =onth period.

6. In no event shall the anount of the security be less than $\$ 56,250$. This amount may be reviewed annually.

35. The licensee shall provide the Agency a Certificate of Insurance which indicates that the requirements of TRCR 44.30 (c) have been fulfilled. Should the licensee be unable to obtain such insurance coverage, every six months the licensee shall submit documentation of attempts to obtain the liability insurance and a request for exemption from TRCR $44.30(c)$. 


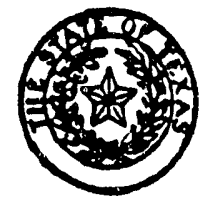

\section{TEXAS DEPARTMENT OF HEALTH \\ RADIOACTIVE MATERIAL LICENSE}

Supplomentary Sheet

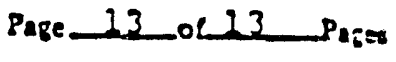

26248

\begin{tabular}{|l|c|}
\hline LICENSE NUMAER & ANENDMENT NUMBE? \\
LO1811 & 42 \\
\hline
\end{tabular}

CONDITIONS CONTINUED:

36. The licensee shall notify the Agency in writing or via telephone at least 48 hours in advance of shipping its low-level radioactive waste, including the shipment of TRCR 21.307 (a) waste, to a commercial treatment, storage, or disposal site.

37. All containers of radioactive waste shall be stored within enclosed buildings with the following exceptions:

A. Containers may be stored outside temporarily (i.e., not to exceed one week) while being received or being prepared for shipment.

B. Bulk flammable liquids shall be stored in accordance with local applicable fire safety regulations.

38. For research and development of waste processing techniques, the licensee is authorized to process up to 15 drum equivalents at any one time using new procedures, equipment, facilities, and technology without prior approval from the Agency. ill research and development studies must be approved by the Radiation safety Committee, and a summary report of such activities provided to the Agency at least annually.

29. Except as specifically provided ctherwise by this license, the licensee shall possess and use the radioactive material authorized by this license in accordance with staterents, representations, and procedures contained in the following:

application dated september 29,1983 ,

letter dated September 14, 1984:

The Texas Requlations for control of Radiation shall prevail over statements contained in the above documents unless such statements are more restrictive than the regulations. 


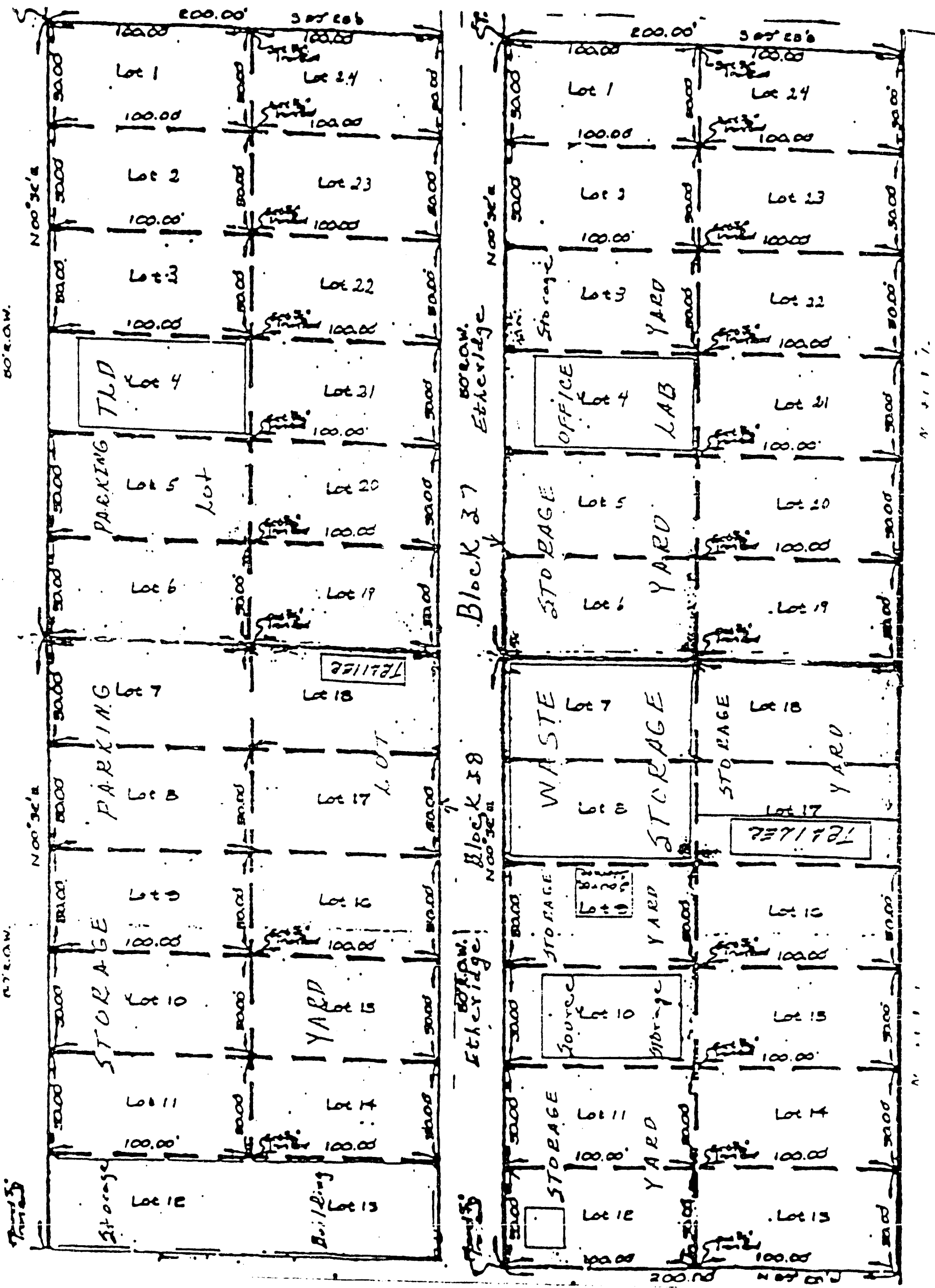




\section{造) \\ Texas Department of Health}

Robert Bernstein, M.D., F.A.C.P. Commissioner
1100 West 49 th Street

Austin, Texas 78756.3189

(512) $458-7111$

Radiation Control

(512) 835-7000
Roberi A. MacLean, M.D.

Depury Commissioner

Professional Services

Hermas L. Miller

Deputy Commissioner

Management and Administration

February 6, !985

Nuclear sources and services, inc. fit:n: Rob

F.U. BOX 340́千 2

Hous:on, Texas $\$ 7034$
Ke:: Compliance No. Losislo

License No. $1 !-i \varepsilon \bar{\varepsilon}: i$

Inspection oE Dez. 14, $\ 988$

By i.rthur Flozes

A: 5711 Etheridge

Houston, Texas

Dear Mr. Galiagt:

inter reviewing the report of in: inspestior. conducted by Mr. ristir Elores

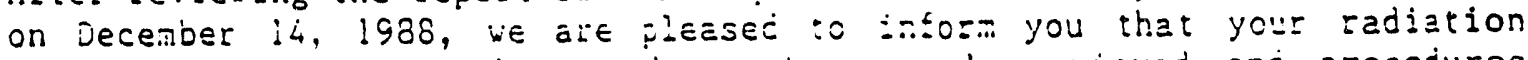

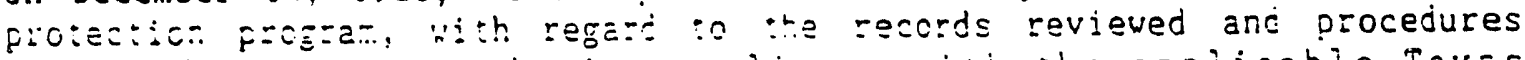
observed, apf三ers to be in corplisnce $\because$ ith the appliceble texas Regulations for Control of Radieition anj/oz Conditions peztaisiag to the above references License.

Thank you jor ine cooperaijon ans ass inspection.

Sincereli.

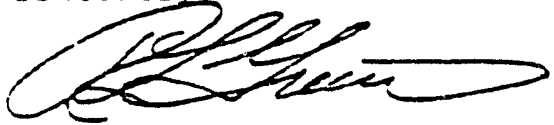

Rober: L. Grees. iz.

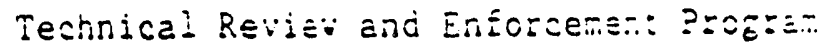

Radioactive Material Inspectio: and

Enforcement E:anch.

Division of Cozpliance and Inspection

Buresi of Redia:ion Control 


\section{Exhibit D1}

LIST OF PERMITS, LICENSES, OR AUTHORIZATIONS

PERTAINING TO QUADREX 


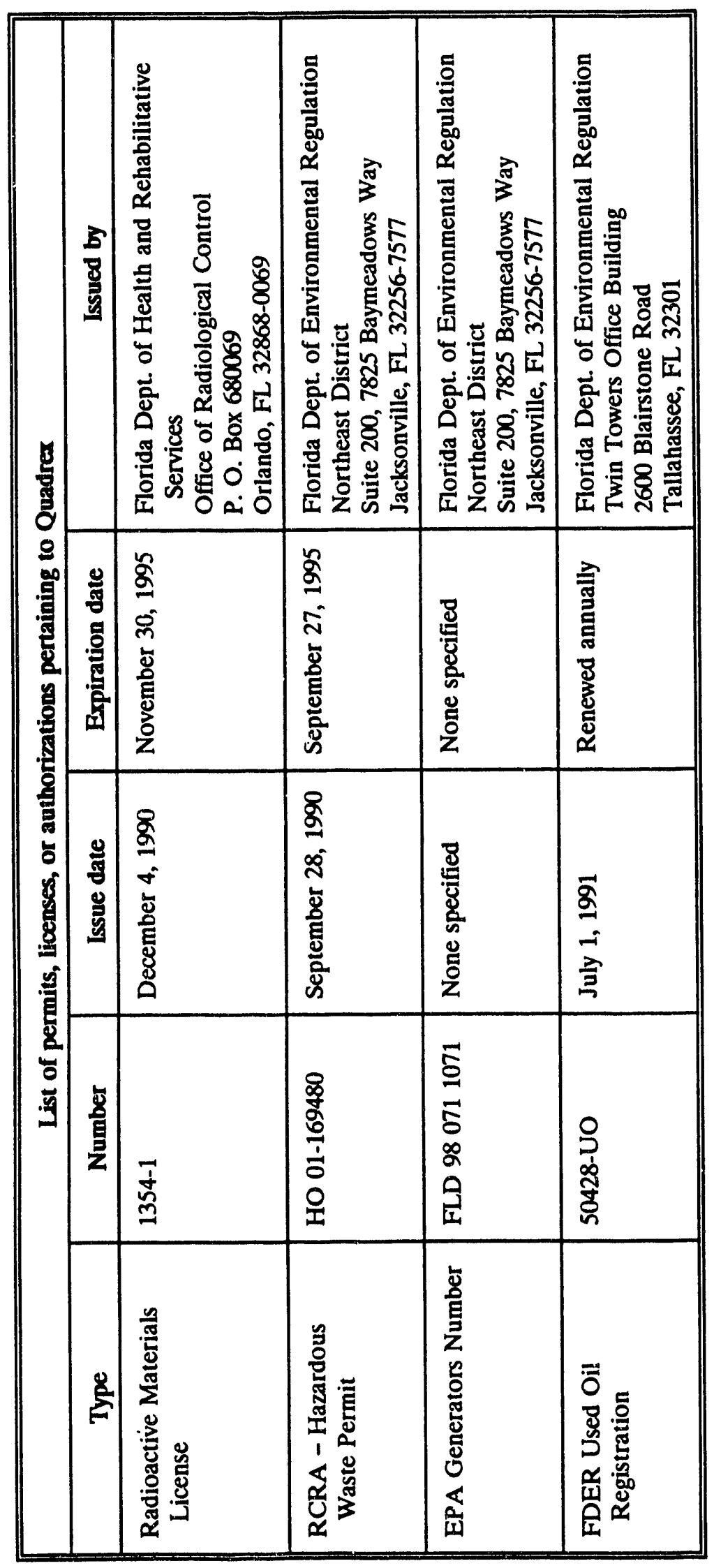


Exhibit D2

RCRA HAZARDOUS WASTE PERMIT FOR QUADREX 
RCRA Hazardous Waste Permit

Date of Issuance:

Date of Expiration:

EPA Permit Number:

EPA I.D. Number:
September 28, 1990

September 27, 1995

HO 01-169480

FLD 980711071

NPDES/Pretreatment

Quadrex does not discharge any material and is not subject to NPDES/Pretreatment permit requirements.

\section{Storm Water Permit}

Although a storm water permit is not required at this time, Quadrex is seeking a general permit to ensure compliance with Section 402(p) of the Clean Water Act.

RCRA Notification

EPA was renotified of Quadrex's hazardous waste and used oil marketing activities on May 24, 1991.

FDER Used Oll Registration

Date of Issuance: $\quad$ July 1, 1991

Date of Expiration: Renewed Annually

Registration Number: $\quad$ 50428-uO

Radioactive Materials Lcense

Date of Issuance: December 4, 1990

Date of Expiration: November 30, 1995

License Number: $\quad$ 1354-1 
Exhibit D3

RCRA PART B PERMIT FOR QUADREX 


\section{Florida Department of Environmental Regulation}

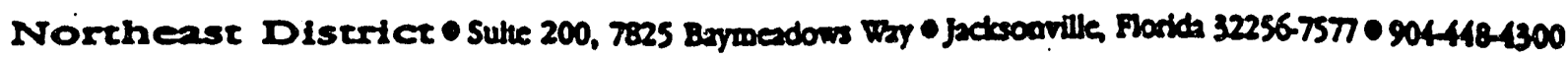

Dot Mardacer Governor

P:H:TETIER:

Attention: Mr. Bernherdt C. Warren quadrex anvirominated compans

1940 Hostburest 67th Place

Giniovil1e. Floride 32606-2649

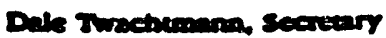

I.D. Mumber: FTD 980711071

Permit/Cortification Eo. 80 01-169480

Date of Issue: September 28, 1990

Expiration Date: September 27, 1995

County: Nacbua

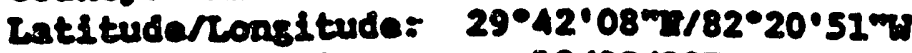

sect Lon/Township/Ranse: 18/9s/202

Project: "Oparation. of a tank and a containar storage area and closure of a secondary containar storage aras.

Inis permit is issued under the provisions of Chapter 403 . Florida Statutes, and Florida Administrative Code Pules $17-4$ ind 17-730. The abovo-named parmittee is haraby - authorized to perform the work or operate the facility shown on the application and approved drawing (s). plans, and other documents attached herete or on flle with the Department and made a part hereof and specifleally. described as follows:

To close a secondary container storage area with diwensions of fifty feet square and maximus storage eapacity of 480 fifty-five (55) gallon drums. Ihis storage area is described in Figures 10 and 11 of the closure plan dated sugust 8, 1990.

To operate the following two (2) hazardous waste storage units at quadrex Bnvirormantal

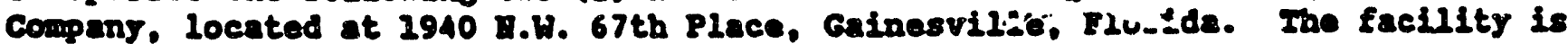
deseribed in Figure 10 of the permit application dated spptember 1, 1989, and rovised Figure 11 dsted April 2, 1990:

A. A container storage area as described in Figure 11 contains three (3) zones to store haxardous inste in containers ransing fron $\mathrm{x}$ gallon to Elfty-five (55) gallon drums and other D.O.I. approved containers. The storage area is allowed to store a maximim volume of 72,100 gallons of hazardous waste.

B. A 3,000 gallon aboveground storage tank, Installed on Saptembar 1, 1983, is constructed of $\mathrm{K}^{\prime \prime}$ carbon stoel.

The hazardous wates and hazardous wastes pixed with low level radiosctive waste storsd at this faclilty and theis designated hasardous wate codes are as Ilsted in Attaebupt $\Lambda$.

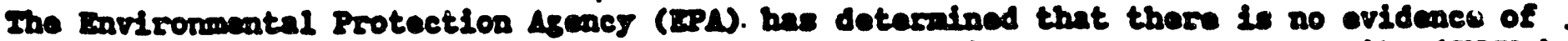

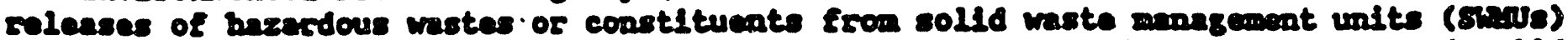
at this facility. Inarafors, ot this tswo. sectlon 3004 (u) of the Harardous and $8011 d$

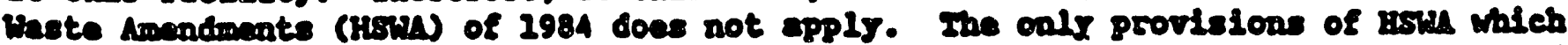
apply to the facility are the $80 c t i o n 3005(h)$ wate winlisiration certification and section 3004 (d) iand Disposei Restriction requirements, whlch have been incorpornted into the proposed state pernit. since thare sre no other provisions. of Hsw which affect this facility, the final state permit, if lesued, will conatitute the full 2012 permit required by DER and EPA. 


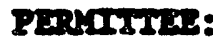

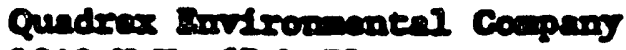
1940 A.D. . 67th Place

Calbavilie, Forida 32606-1649
I.D. Answar: $720980721 \cdot 071$

Perite/Cartlflention muber: HO 01-169480

Date of Iscus: soptembar 28, 1990

Ixplration Date: . Septaber 27, 1995

Operation of thase unite will be in accordace itth the operation peralt appllention dated septanber 1, 2989, and the supplowantal information dated AprL1 10, 1990, Julj 6. 1990. Juily 28, 1990 and Angunt 3. $1990^{\circ}$. 
PERMIIIEE:

Quadrex Emolromenten Compary

1940 N.W. 67th Place

Gainesville, Florida 32606-1649
I.D. Number: FLD 980711071

Permit/Certifscation Limber: HO 01-169480

Date of Issue: Septamber 28, 1990

Dxpiration Date: Soptenber 27, 2995

\section{GENERAL CONDITIONS:}

1. The tarnis, conditions, requirements, Intentons, and restrictions set forth herein are "Pexnit Cooditelons" and as ouch are binding upon the parnitten and enforceable purrevent to the wethorfts of 8ectlons 403.161 . $403.72 \%$. or 403.859

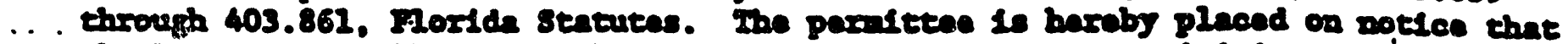

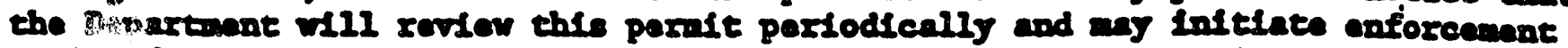
actiwg; for ary Violation of the "Parnit Condfelons" by the parmitees, Its azonte. aplosees, sesventes or zeprescontutives.

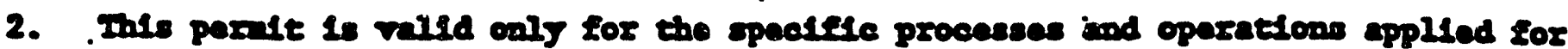

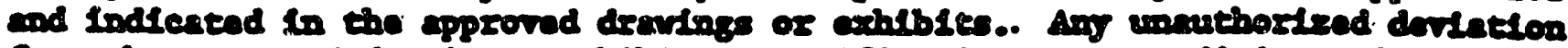

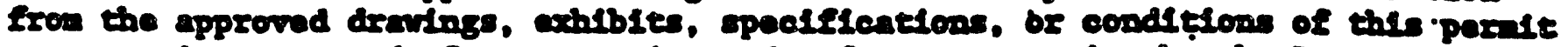
any coostitute grounds. for revocation and anforcunont action by the Dapartant.

3. As providad is Subsectons $403.087(6)$ and $403.722(5)$. Flortde statures, the

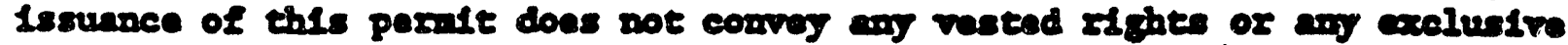

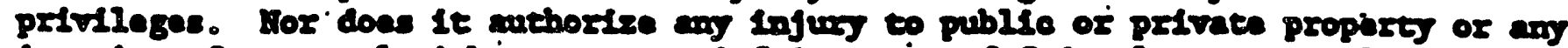

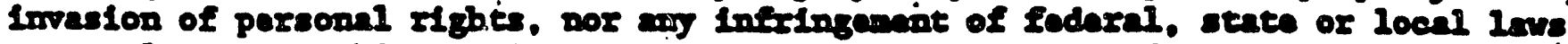
or regulations. Inls pasalt does not constitute a valver of or approval of any other Department pariult that may be required for othar aspecte of the totnl profect which are not addressed in the pormit.

4. This pernit couveys no.t1tle to land or water, does not constltute state recognition or acknouledgenent of title, and does not construte authority for the

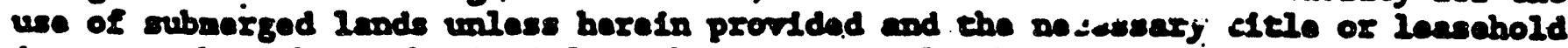
Interese hwe beon obtainad fron the state.. Oaly the Irustans of the Intarmal Improvenent Ixust Fund any axpress etate oplotion as to efele.

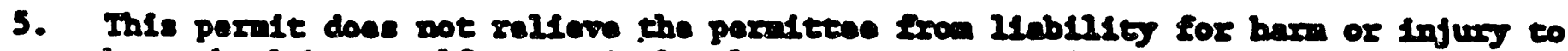
buman health or valfere, animal, plent or aquatele llfe or property. and ponaleles therefore cauned by the conetruction or operation of this perrittad source, nor

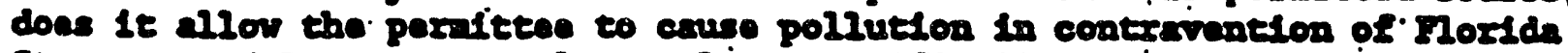

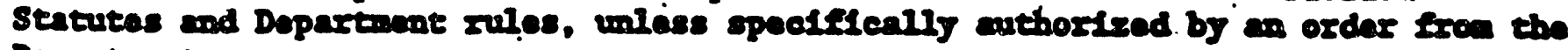
Departient.

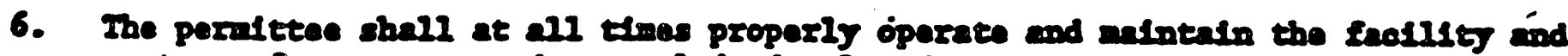

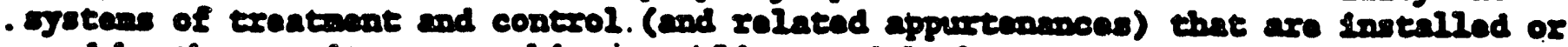

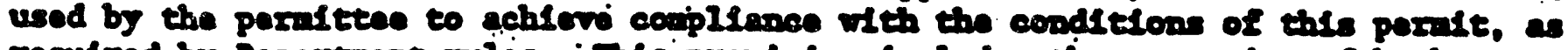

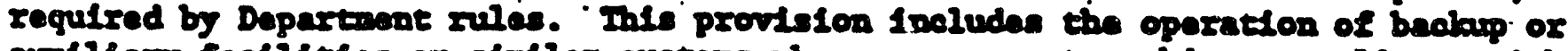

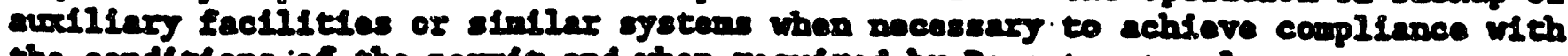

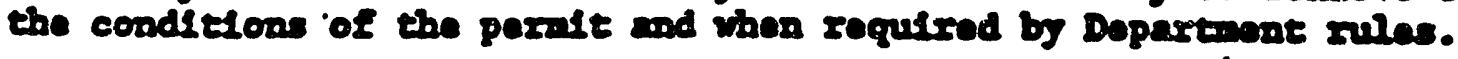

7. . The pormittee, by accopting this porift, opeetfically agroes to allow authortsed

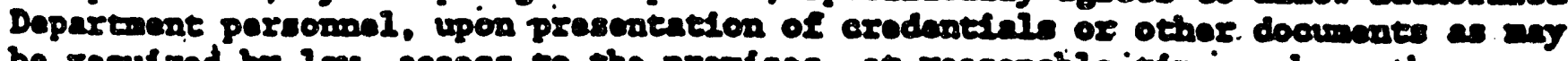
be required by $19 x$, access to the prentses, at reasonable thais, where the permitted activity is located or conducted for the purpose of:

a. Having access to and copylng any records that nast be kept undar the conditions of the pernit; 
PERrorye:

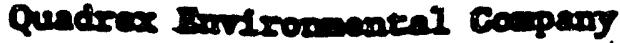

1940 B. 1. 67th Place

Gelneoville, Florida 32606-1649
I.D. Haber: FLD 980711071

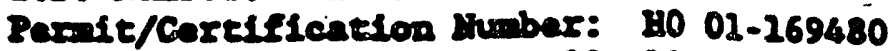

Date of Issua: Septamber 28, 2990

Explration Dace: Soptabar 27, 1995.

7. (contsoned)

b. Iropecting the Eacll15, equipant, prectices, or operations ragulated or requlred undar this parist; and

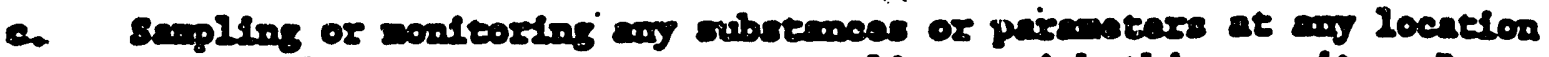

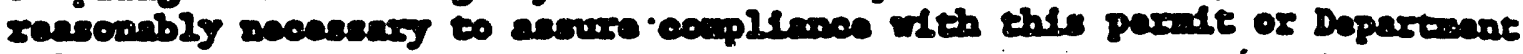
2010.

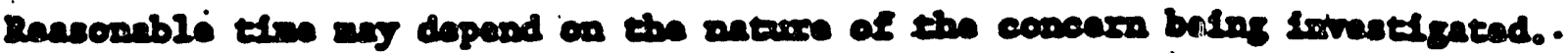

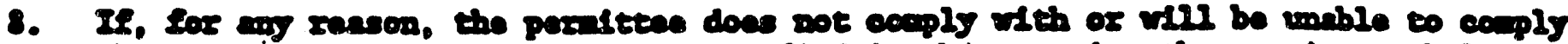

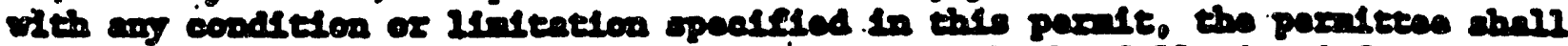

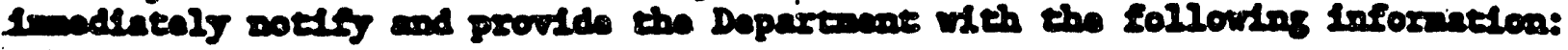

a. a dascription of and emue of novecmpilmoe: and

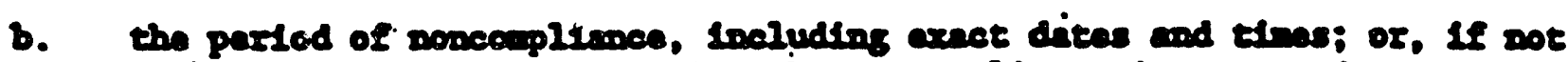

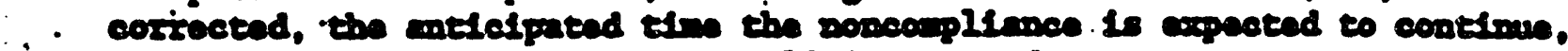

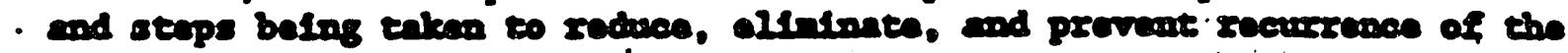
sosecuplines.

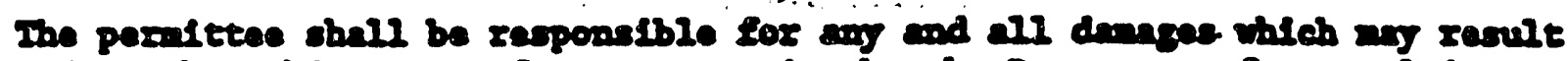
and nas be rubject to onforcenant action by the Departinent for pernalefes or revocation of this perait.

9. In sccoptelng this paredt, the pizaltece undaratonds and acreas that all records.

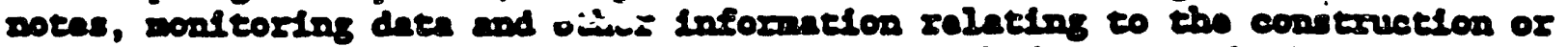
operation of this perifted source, which are subafted to the Dopartment, any be used by the Dapartinent as ovidance in am enforcanent case arising undar tho Ilorlde statcutes or Dopartmant rulas, axcopt whare such use is proserlbed by secelons 403.73 and 403.211 , Mortde stratens.

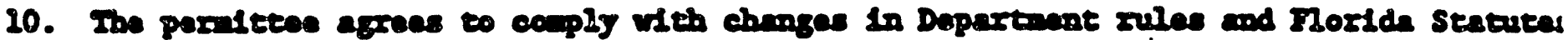

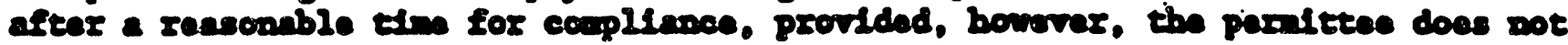
watve an other righte granted by Florida statutes or Departinent sules.

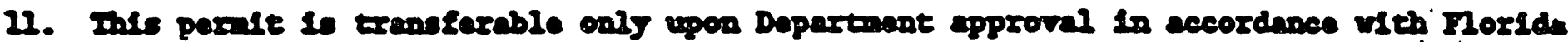

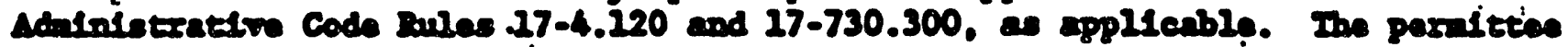

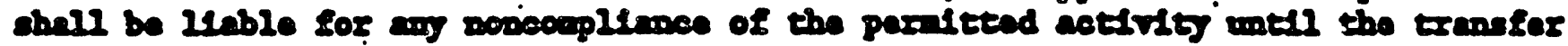
is epproved by the Dopartanent.

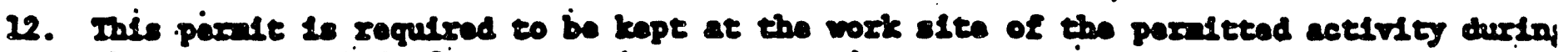
the entire period of construction or operation.

23. This parist also consteltutes:

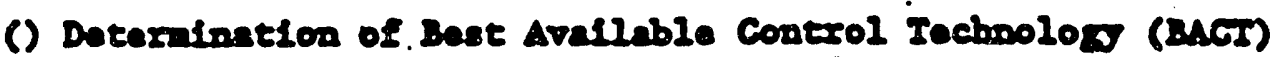

() Determination of Prevention of 81 golflamt Doterloration (PSD)

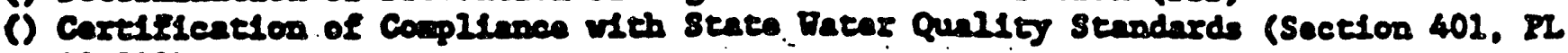
92-500)

() Compliance with Hew Source Performance Srandards 
PERYIITER:

Quadrex Exvilromentel Coupany

1940 N.W. 67th Place

Gainesville, Floride 32606-1649
I.D. Number: FLD $980711071^{\circ}$

Perait/Certification Nimber: 80 01-169480

Date of Issue: Soptember 28, 1990

- Dxplization Date: Soptamber 27, 1995

14. Tive permittee shall couply with the following monitoring and recordkeeping requiremantes:

a. Opon zequest, the pezoittei shall furaish all rocoxids and plens required

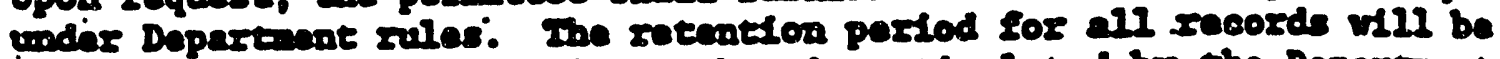

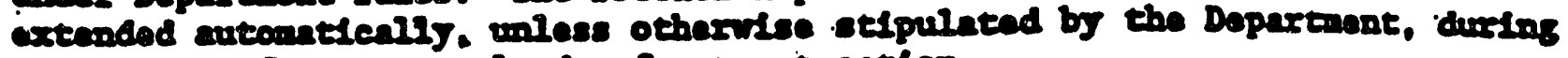
the course of ang unsesolved onforcunent acton.

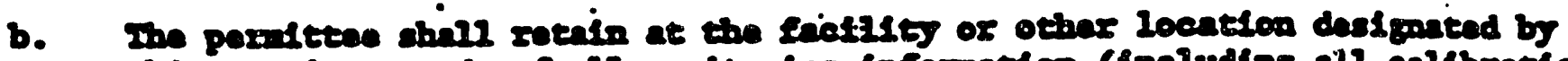

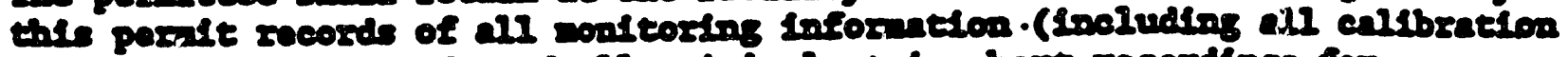

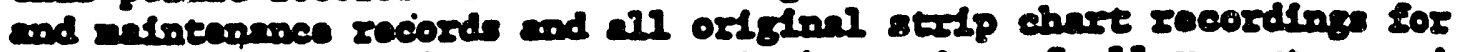

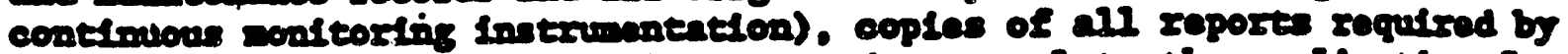
this porite, and records of all date used to gonplete the appllestion for

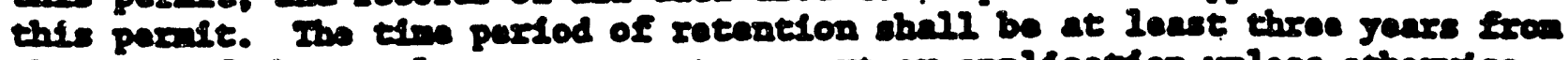

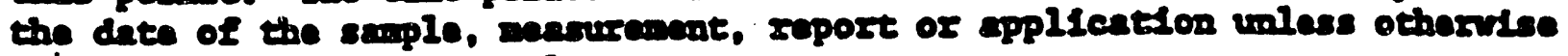
opeclelad by Depdrtiont sule.

c. Records of monitoring information shall includa:

- the date, usect place, and tine of sapling or mentrrenents:

- the parson responslble for perforning the supling or acasrrements:

- the date (s) conlyses were periformad:

- the parson responsible for performing the annjans:

- the annirtical techniquas or netbods used; and

- the resultes of such ennigses.

15. When requested by the Department, the pernittee shall, within a reasonable period of

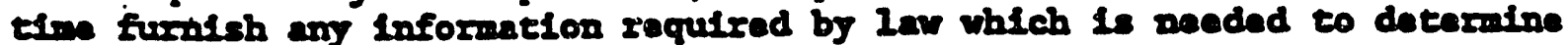
complinnce with the percilt. If the perpittee becoines aware that relevant facts were not subalted or were incorrect is the pernit applicatefon or in am report to the Department, subl facts or information shall be subalteed or corrected proipty.

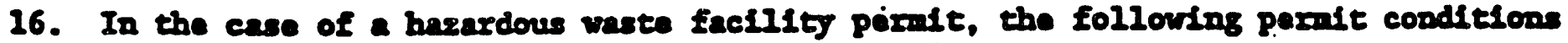
shall also apply:

a. The permittae ofll subalt the following roports to the Departant:

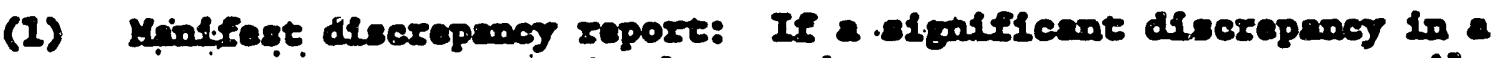
initifest is discovered, the permitee must atterpt to roconclle the discropancy. If not resolved within 15 dags after receiving the waste. the pornttee shall imodintely oubnit a letter report including a copy of the andfest to the Dopartaent.

(2) Drmanifosted waste report: Pernittee shall submit an umanifested waste report to the Dopartuant withlo 15 dajs of recolpt of unontfested waste.

(3) Amoul report: An amual roport covering faclifty activities durlas the previous calendar year muet be subnttend in accordance with Florida Aduinistrative Code Rule 17-730. 
Katrerge:

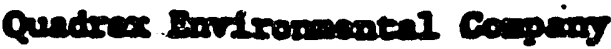

1940 H.D. 67th Rlace

Gainaville. Foride 32606-1649
I.D. Rimber: $720980^{\circ} 711071$

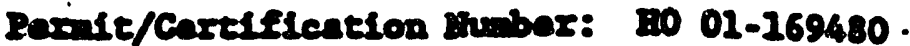

Date of Issua: Saptembex 28, 1990

Inplritelon.Date: Soptabar 27. 1995

16. (conesmind)

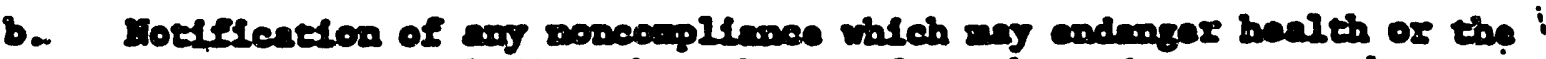

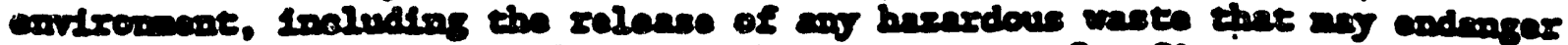

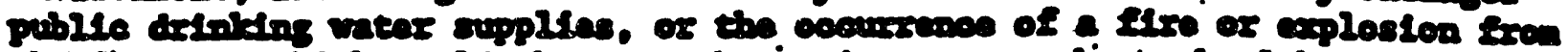

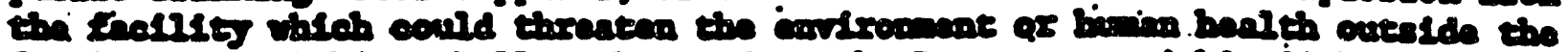

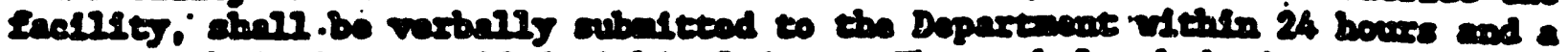

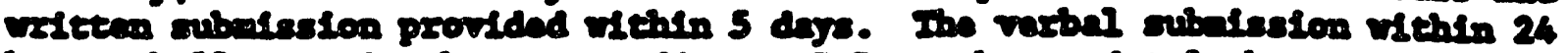

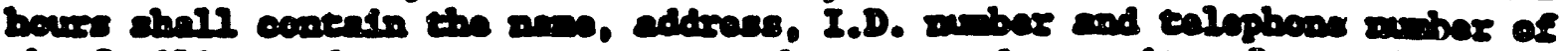

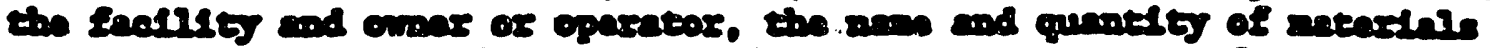

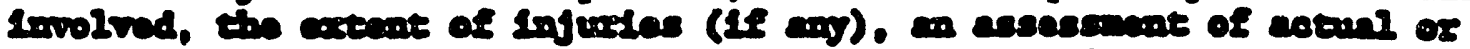

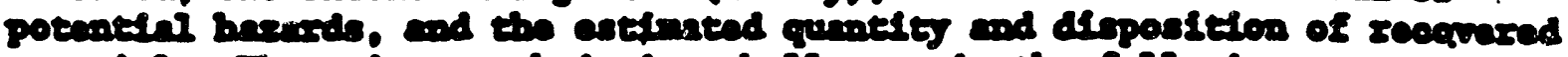

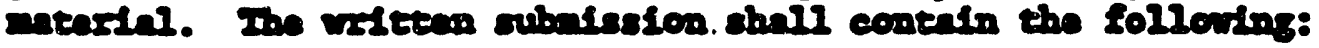

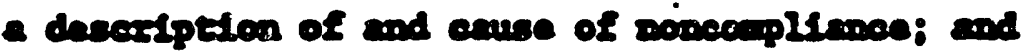

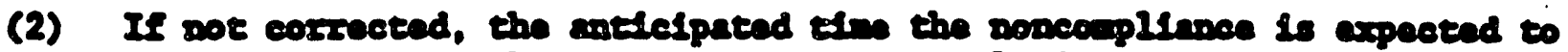

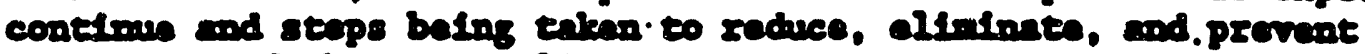
recurremen of the someonplimes.

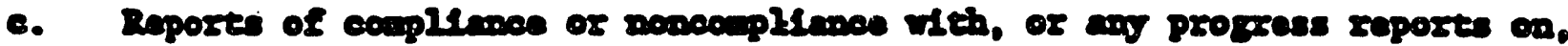

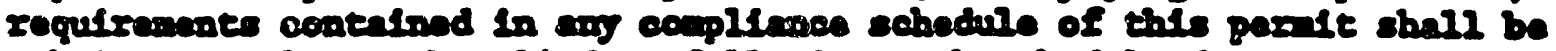
subelted no lates than 14 dage following ench sehedule date.

d. All reports or Information requirad to bo subatted to the Dopartant by a

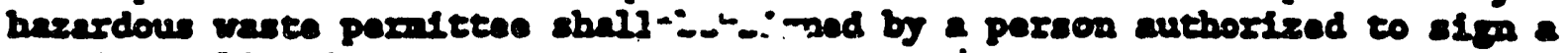
perist application. 
PERMITISE:

Quadrex Ervilrormentel Comping

1940 N.W. . 67th Place

Gainesil11e, Forlde $32606-1649$
I.D. Number: FID 980711071

Pesult/Cartification liumber: HO 01-169480

Date of Issue: September 28, 1990

Explration Date: Soptamber 27, 1995

SPECIETC CONDITTONS:

\section{PerteI - Gentenl Operating Requirements}

1. The permittee shall anintaln and oparate the facllity to aininize the possibillty of fire, explosion, or ary urplemed sudden or non-sudden reloase of hezardous

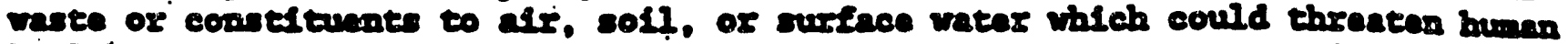
health or the exrodroment. [ [40 GrR 264.31]

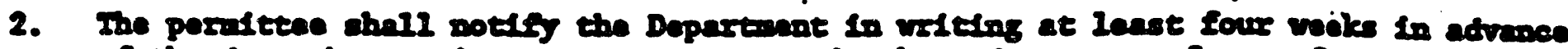
of the date the pernittee cuppects to recalve harardous vast from a forel gn source, In accordence with 40 CrR 264.12. Rot1es of subsequent shipandes of the san waste

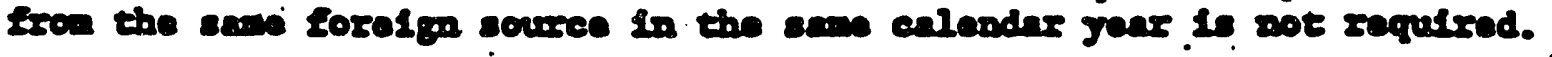

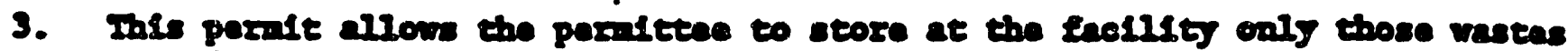
speclfled in Attachnont A. Prlor to aceoptence of now hasardous vantas, the - permittae shall subnit. to the Depertwent, for approvel, a vaste malysis of the proposed now valte strean. This anelyele mest be lpeorporated in the genaral waste anclysis plan and rotained on-site. [40 CKR 264.13]

4. The permittee shall follor, the procechures described in the vaste sanlyals plan, Section A-6. Purt II of the permit application. [40 GTR 264.13(b)]

5. The pernettee shall comply whth the secursty provisions of 40 GR2 264.14(b)(2) and ". (c).

6. The parmitttee shall inopect the facllity operating, anargency and safot equipuent In accordance with the schedulle approved in Sectlon A-4.d.. Part II of the peralt= application. The pernittee sball ranady any deterforation or anlfunction discovered by an inpection in accordance with the requirenents of 40 GFK 264.25(c). Changes, additions, or delettons to the schadule merst be approved in writing by the Dapartwent. The schodile muet be malntalned as part of the operating record of the facility. [40 Gr2 264.15]

7. Faclilty porsomel must successfirly complete the approved training progran Indfeated In Section A-4.e.. Part II of the pernitt applleation within 6 sonths of ouploywent or assignent to a faclilty or to a now position at the facllity. Vorlfication of this tratning must be knpt with the persomel trafning recorde and malntalned on-alte. Porsormal shell pot work inoupervised untll trafnirg bas been

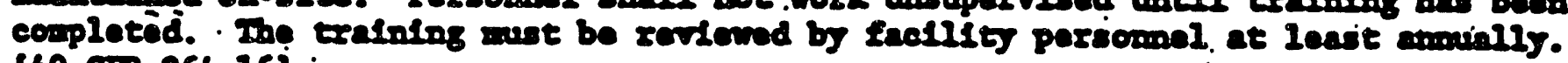
[40 GR2 264.16]

8. The pernittee shall couply with the goneral requiremonte of 40 GrR 264.27 (a) and (B). and the location requirenonte of 40 Grs 264.276 and.264.198.

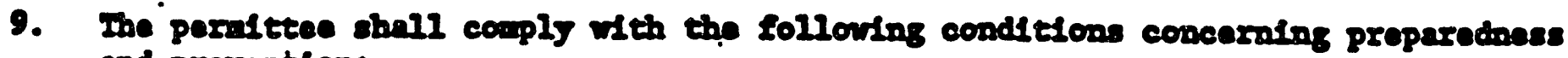
and prevention:

a. At a aininm, thic porniteic shall equip the faclilty wh the equipant doscribed in the contingeney plan, section A-4.b.. Part II of the perult application, as required by $40 \mathrm{CDR} 264: 32$. 
Prowares:

Qundrex Bovirominteal Compary

1940 A.H. 67th Place

Calnesille. Mortda 32606-1649
I.D. Lhmber: FLD 980721071

Paralt/Cartifleation nmbar: $1001-269480$

. Date of Isrue: Sepramber 28, 1990

Ixplration Date: Septambar 27. 1995

\section{9. (costimed)}

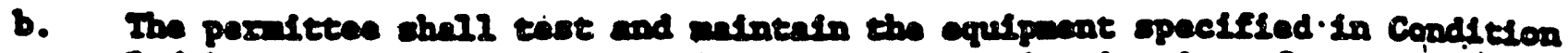

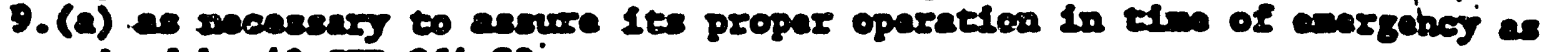
requered bs $40 \mathrm{cr} 264.33^{\circ}$.

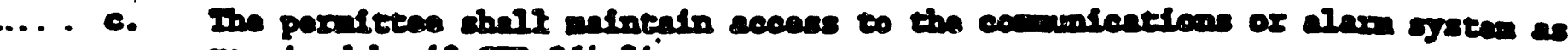
required by $40 \mathrm{GrR} 264.34$.

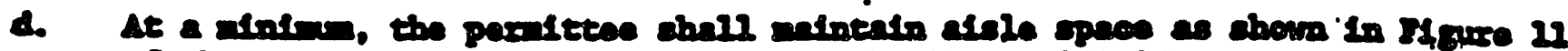
of the partit application, as required by $40 \mathrm{Gr} 264.35$.

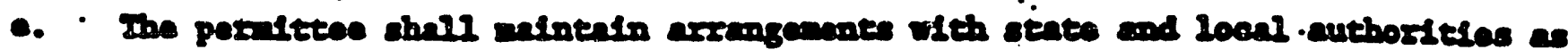
regialred by $40 \mathrm{GL}$ 264.37. If sente or loenl offlolals zafuse. to cater into

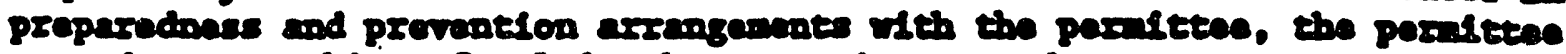

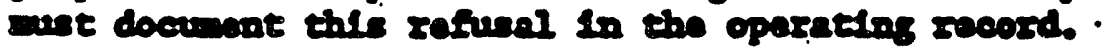

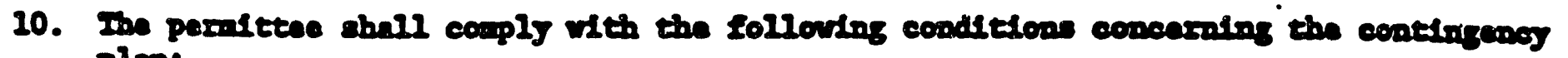
plon:

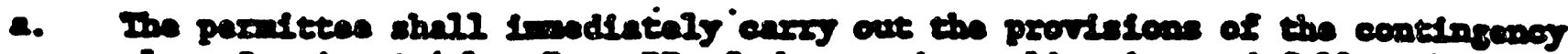
plan, 8ecton A-4.b., Part II of the parite appllenter and follow the anerganey procadures described by 40 GFA 264.56, whanover there is a Llye.

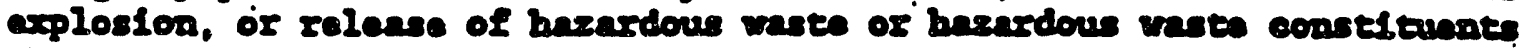
whleb threatens or corlld threaten human bealth or the exvirosmant. Ithe permitese shall give proper notiflention if . Vergeney altuation arlses and

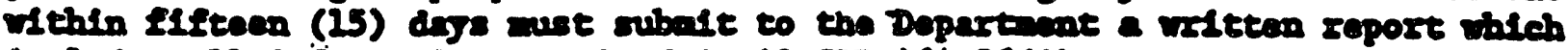
includes all informetion required in $40 \mathrm{GrR}$ ¿öi.s6(j).

b. The permitene shall comply with the requiranants of 40 CT2 264.53.

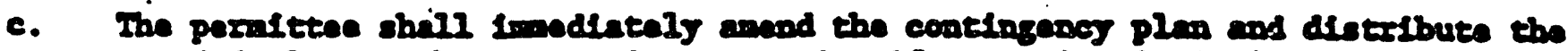
anandad plen to the appropriate agancles if amy erfterin in 40 CFR 264.54 are act. Amandinantes to the plan unet be approved in veltelng by the Dapartiant.

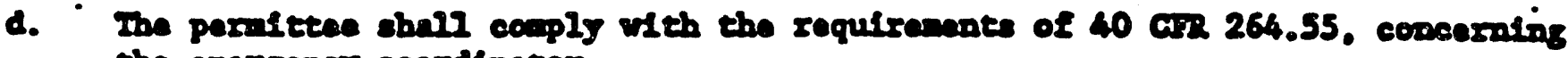
the anergency coordinntor.

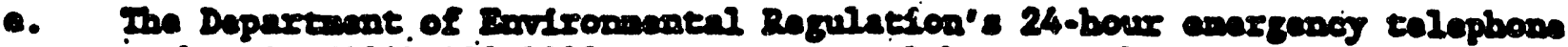

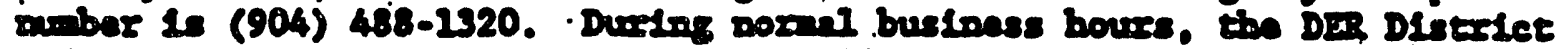
Offlce any be contracted at (904) 798-4200.

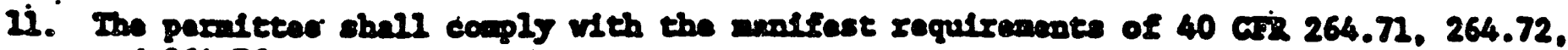
and 264.76.

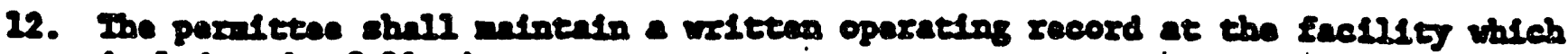
Includes the Lollowing:

- the descriptfon and guratity of ach harardous waste recelved

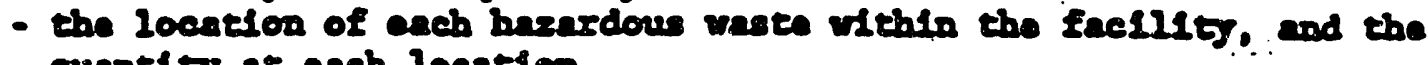
quantity at each location

- the results of the waste analyses 
PERMITIEE:

Quadrex Ervitrormentel Company

1940 N.W. 67th Place

Gainesville, Florida 32606-1649
I.D. Lumber: FLD 980711071

Pertit/Certification Shimber: HO 01-169480.

Date of Issue: September 28, 1990

Expiration Date: Soptamber 27. 1995

12. (continued)

- a sumary report and detalls of incidents that require implanentated of the contingency plan

- andfest mimbers

- the renules of inpoctions (for 3 years)

- aminal cextiflcation of waste afolinization

- the closure plan and closure cost estinates

These record wet be minteninad at the faclilty untell couplotion and certiflention of closwe. [40 GrR 264.73]

13. The permiten shall antutals and operate the tricllity in aceordance whth sectlon D-2. Part I of the parite applicnefon (Including FLgures 6, 9, 10, and 11).

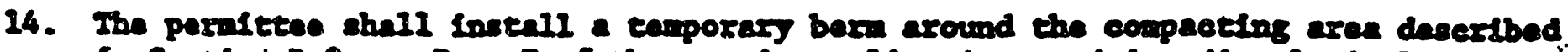
is Sectlon D-2.C.. Part I of the parmt application, and Imadinealy implamat

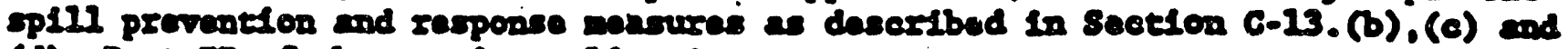
(d). Part II of the parilt application.

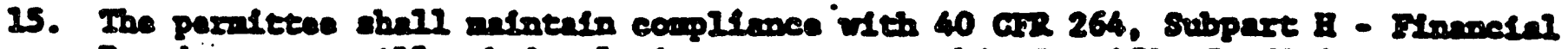

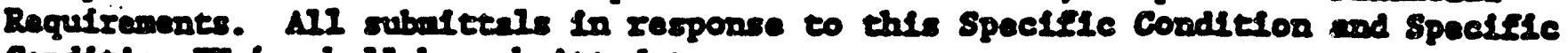
Condltion IV.4. shall be subnitted to:

Finneial Coordinntor

Barardous Waste Regulation Section

Dopartment of Buviromental Rogulatson

2600 Blalr Stome Road

Tallabresee, Florida 32399-2400

16. All subnittals in reoponse to thls pexntt (except Speclfle Conditelons I.IS. and IV.4.) shall be subalteed in quadruplicate to:

Bnzardous Dante Superviser

Dopartant of Eusiromentel Regulation

3426 B1118 Road

Jacksouville, Morida 32207

17. Purcume to 40 GR $264.73(\mathrm{~b})(9)$, and section 3005(h) of RGRA, 42 v.s.C. 6925(h).

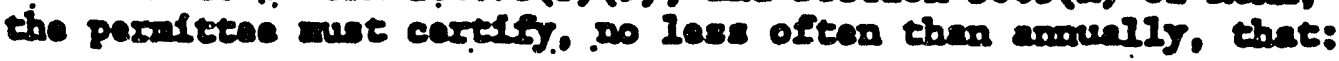

a. The pernittee has a progran in placie to reduce the volume and coxiclty of barardores wiste to the degree determingd by the permitece to be ecopouleally practicable: and

b. The proposed nothod of terentane, itorage or disposal is the nost practleable pethod avaliable to the pornitee which alninizus the present and future

- threat to buman bealth and the exviroment.

c. The perattece ahall also nifitinin coples of certifleation in the facllst operating record as required by $40 \mathrm{crR} \cdot 264.73(\mathrm{~b})(9)$. 
PERHIITEE:

puadrex Dovirowental company

1940 B.H. 67 th Place

Galnewille. Floride 32606-2649

Permit/Certification inmber: THO 01-169A80

Date of Issue: September 28, 1990

Dopiration Date: Soptember 27, 2995

18. The Waste uinimization prosrem required under specific condition I.17.e. and b. above should as a minimin address the following topics:

a. Identify each hasardous waste strean with the source of generztion.

b. Iypes and exounts of hasardous wete that are genarated at the facillty.

c. Present and proposed athod of treatment, storage or diposal that is avallable to the perritten.

d. Description of techniques implemented in the past for hasardous waste roduction and thals affectiveness.

-. In craluation of teemieally and ceononically fiasible hazardous wasto rocuetion toebniquas.

f. - A progten and sebodule for lmplementing the selected hazardous waste reduction techalque.

19. 10 Gr Part 268 1diatifles hasardous wistes that are restrieted from lond disposal and-deflines those ilnited cireunstances which on otharwise problbited waste any continue to be pleced on or in a land treatment, storase or disposel unit. The

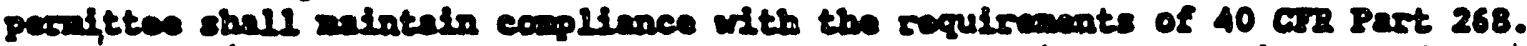
Whare the permitteo has applied for en cxtension, walver or vaslance under $10 \mathrm{Gr}$ Part 268 the perrittee shall comply with all restrictions on land disposel under this part once the offective date for the waste has been reached peading final approval of auch application.

20. A restricted waste 1dentified in 40 CFR Part' 268 subpart $C$ an: ... $:$ he placed in a land disposal unit without further treataent unless the requirements of 40 CrR Part 268 subparts $C$ and/or $D$ are ant.

21: The storage of hazardous wastes restrdeted from land difposal under 40 CrR Part 268 is prohiblted unless the requitrenents of $40 \mathrm{CrR}$ Part 268 subpart $\mathrm{I}$ are ant.

22. All subrittals sodifylng major cosincering features of the hazardous viste storage areas stoll be worded. slened and certifled by a qualifled, professional casineer registered in the state of Florida in aceordance ifith 27-730,220(5), TLC.

\section{Rart II - contalinere}

2. The permittee is allowed to store in the approved storage area only the hazardous wastas 1isted in $\Delta t$ tachent $A$. Containers must conform to DOT speclflestion and be amaged in accordsnee with the approved operation plan. Containgrs shall be kopt closed coceept when addins or rewovine waste and shall be bandied is a manner that wlll aot illow the containirs to rupture or lenk, in accordance with 10 GR 264.173. If a contalner boldins hazerdous wate Lo not in $800 d$ condition, or begins to leak, the waste shall be transfersed to anothar contalner is $800 d$. condition, in accordence with $40 \mathrm{GLR} 284.172$.

2. The permittee shall use only those contalners ande of or lined with materials which will not resct with and are otberwhe cospatible with the waste to be stored in them, as iridicated in section B-3. Past II of the pernit application. [40 CER 264.172] 


\section{PERMITIEE:}

Qundrex Enviromentel Corpary

1940 N.W. 67th Place

Gainesuille, Florida 32606-1649
T.D. Number: FUD 980711071

Permit/Certiflcation Number: HO 01-169480

Date of Issue: September 28, 1990

Expiration Date: Septembar 27, 1995

3. The peraitee shall conduct reekly visual inspections in accordance with Section B-5, Part II of the perult appllcat1on (the Inopection schodule), to datact. Ieakage in the besardou waste conteniner storage aren or its assoclated loading/unloading zones. [40 CRR 264.174] IE. In splte of. the weekly Inspections, a sonteleant deterforation of the pervanont (due to occaslonel splils) is soted, the noed for a resurfacing/seal vaterisi shall be. ireoveluated.

4. The pernitece shall store a aximm of 72,100 gallons of vaste in containers in sizes ranging frov $1 / 2$ gellon to flfty-five gailon or other D.0. T. approved containers. In the container storage area as shown in FIgure 11 of the permit application (revised April 2, 1990).

5. The permitice shall notify the Departiont when the capacity of the container storage erea reaches 90 percent, 1.e. volume of 64,900 gallons.

6. For storage of drums larger than flfty-flve gallons, the permittee shall not place more than four drums per pallet and shall not stack them more than two hlgh.

7. The permittee shall comply with the waste compatibility requirenents of $40 \mathrm{CFR}$ 264.177, as Indicated in Section B-3, Part II of the permit application.

\section{Part III: Tanks}

1. The pernittee is allowed to store in the tank only those hazardous wastes specified In Attachment A.

2. The permittee shall store a maximin of 3,000 gallons of waste In the storage tank.

3. The permittee shall notify the Department when the volume of waste stored in the tank reaches ninety-five (95) percent capacity of the tank, 1.e.. 2,850 gallons.

4. The permitece shall not place 1gnitable or reactive waste in tank systems unless the vaste is stored in such a way that it is protected from any material or conditlons that any cause the waste to. Igatte or react. [40 CFR 264.198(a)]

5. The permittee shall comply with the protective distance requirements for the tank placemant as set forth in Tables 2-1 through 2-6 of the National Fire Protection Association's "Flammable and Combustible Ifquids Code" (1977. or 1981), as required. by 40 CFR $264.198(b)$.

6. The permittee shall handle incompatible wastes in accordance with Section C-10, Part II, of the permit application and 40 GF 264.199. by not introducing tazardous waste Into unwashed tank system which previously held incompatible waste or material.

7. For new tank components which may be required by the repair options of 40 CFR 264.196(f), the permittee must submit a written assessment, reviewed and certified by an Independent registered professional engineer, which attests to the component's stuctural integrity. This assessment shall include the requirements of 40 CFR 264.192. As required in 40 CFR 264.192(b), an independent qualified inspector or independent registered professional engineer must inspect the installation. 
PERHITIER:

Qundrex Borviromantel Company

1940 N. H. 67th Place

Galnesolile, Florida 32606-1649
I.D. Number: FID 980711071

Permit/Certification Number: HO 01-169480

Date of Issue: September 28, 1990

Explrat10r Date: September 27, 1995

8. The permitte shall prevent the release of hazardous vaste or hazardous

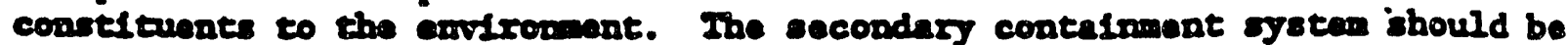
malntained according to sections C-7, Part II of the application and shall comply with the requiramente of $40 \mathrm{GrR} 264.193$. Including the requiranents set forth below:

a. 111 new componants shall bave sacopdary covitalment as raqulred by parts (b) and (c) of thls condition prior to beling put lato service.

b. The secondary contalment oystan shill soet the requiranonts of $40 \mathrm{CFR}$ 264.193 and shall be:

(1) Updated to provent ang algration of wastes or accumulated 11quid to the so11. groumdwater or surface waters.

(2) Capable of detecting and collecting releases and run-on unt1l the collected material is renoved.

(3) Lned with materials compatible wth the waste to be stored and heve sufficlent structural strength to sustain the stresses linduced by a. fallure of the primary contalment system as well as other seresses which may be induced by the emviroment.

(4). Placed on a foundation or base capable of providing support to the secondary contaiment system.

(5) Provlded with leak detection equipment designed and operated to datcet fallure of elther the primary or secondary contalment structuid: =r the presence of any release within 24 hours.

(6) Sloped or otherrise designed and operated to drain or remove 11quids resulting from leaks, spills, or precipleation.

(7) Designed and operated, with the exception of double walled tank containmant, to contaln 1008 of the capacity of the largest tank within 1te boundary and also contaln the preciplention due to a 25-year. 24-hour ralnfall event, if rum-on control is not provided.

c. Ancillary equipment shall be provlded with recondary contalment, except as provldad for In 40 CTR $264.193(E)$.

9. The permittee shall, as part of the general operating requiranents of 40 CFR 264.194:

a. Hot placs hazardous wastes or treatnent reagents in a tank systen if the possibillty existe that this may cause the tank system to fall.

b. Ose appropriate controls and practices to prevent apills and overflows, and

c. Comply with the requirements of $40 \mathrm{CFR} 264.196$ if a leak or splil occurs. 
PERTITIEE:

Qundrex Eoviromental Coupamy

1940 N.W. 67th Place

Galnesville, Florida $32606-1649$
I.A. Number: FUD 980711071

Permit/Certification limber: HO 01-169480

Date of Isisue: September 28, 1990

Expiration Date: September 27, 1995

10. The peraltee shall inspect the tank systen in accordance with Section C-11, Part II of the permit application and as required by $40 \mathrm{CFR} 264.195$. Thise requirements Include:
a. Developing and following a schedule and procedure for inspecting overfilling controls, and

b. Inspecting at least once each operating day the aboveground portlons of the tank systam, date fron leak detection or monitoring equiprent, and the construction anterials and area lmadiately surrounding the tank.

c. The resultes of the Inspactions in (a) and (b), of this condition shall be antntalned in the operating record of the facility.

11. The permitsuie shall follow the procedures outlined in section C-11. Part II, of the permit application, whon a tank systan or secondary contalnment systen produces a leak or spill, or is determined to be unflt for use. These requirements include, as they are made applicable by $40 \mathrm{CFR} 264.196$ :

a. Cassation of use; prevention of flow or addition of waste.

b. Ramoval of waste from the tank system or secondary containment system.

c. Containment of visible releases to the emvironment.

d. Notifications, reports.

- Provision of secondary contalment, repair or closure, and

f. Certification of major repalrs.

\section{Part IV - Closure}

1. The permitte shall comply with the following conditions concerming closire:

a. The permittee shall close the faclilty as required by $40 \mathrm{CFR} 264.111$, and in accordance with the closure plan in Section B-6, C-12, and K, Part II of the permit application.

b. The permittee shall anend the closure plan In accordance with 40 CFR 264.112(b) whenever necessary.

c. In sccordance with $40 \mathrm{CFR} 264.112$ (d)(1). the permitte shall notify the Departwent at least forty-five (45) days prior to the date he expects to begin closure and submit a complete closure permit application. [17-730.260(1), FAC]

d. Within 90 days after recelving the final volume of hazardous waste, the permitcee shall treat or remova all hazardous waste from the site in accordance with the schedule spicified in the closure plan, Sections B-6. C-12 and $K$, Part II, of the permit application, and in accordance with 40 CFR 264.113(a). 
PERYITIEE:

Qundrex Doviromental Company

1940 N.W. 67th Place

Gainesville, Florida 32606-1649.
I.D. Number: FLD 980711071

Peritt/Certificetion limber: HO 01-169480

Date of Issue: September 28, 1990

Expiration Date: Soptamber 27, 1995

\section{1. (contimed)}

- The pernittee aball decontanimate and/or diopose of all faclilty oquipment as requirsed by 40 C22 264.114, 264.197, and the elosure plan, Sections B-6,

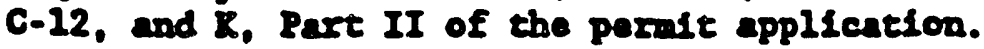

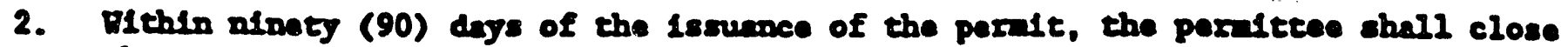
the secondary storage area in accordance with the closure plan dited August 8, 1990 and $40 \operatorname{CrR} 264.111$.

3. Dithin thirty (30) days from coupletion of any closure, the perattec shall subult

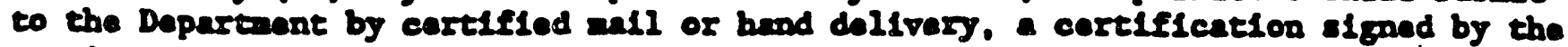
permittee and an 1ndepandant professional anginecr regletered in the state of Florida that the faclilty has been closed in accordance with the pernit and specifleations of the closure plan. [17-730.220(5) FAC]

4. In addition to the requirements of Speclfic Condition I.15.. the pernittee shall revise the closure cost estimate required by 40 CFR 264.142 whenever there is:

- a change in disposal cost due to changes in the regulations, or

- change in the disposal factilty.

\section{- Part V - Permit Modiffeation/Reneval}

1. The Department may nodify, revoke and reissue, or terminate for cause, this permit in accordance with the provisions of 17-730.290. FAC. The filing of a request for a permit modification, revocation and reissunce, or termination, or the notffication of planned changes or anticipated noncompliance on the part of the permittee does not stay the applicability or enforcenbility of any permit condition. The permitee may subsit any subsequent revislons to the Department for departmentel approval. Should these revislons contitute a major modification to the permit, the permitece shall neet the requirements of $17-730.290$, FAC.

2. This permit nay be reopened if additional Information becomes avallable Indicating that the provleions of Section $3004(u)$ of the Hazardous and Solid Waste Amendments (HSWA) of 1984 apply to this faclilty. At that time, this pernit any be modified to address the requirenente of Section $3004(u)$ of HSTh if the state bas been authorized for the provisions, or altermetely, the Exviromental.Protection Agency (EPA) would Iseund a separate federal pernit addressing Section $3004(u)$ requirenents. 
PERITITEE:

Quadrex Erolromientel Company

1940 N.W. 67th Place

Galnesville, Florida 32606-1649
I.D. Number: IUD 980711071

Permit/Cartification limber: HO 01-169480

Date of Issue: September 28, 1990

ExpIration Date: Saptember 27. 1995

3. Prfor to 135 days before the explration of this pernit, the parnitece shall subnit a complete application for runowal of the pernit on forms and in a inmor; preserlbed by the Departant, unless the factifty is to be closed prior to the explration date of this parnit par the requirenante of FAC 17-730.300(1).

Executed in Jackouvilie, Morlda.

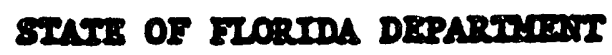

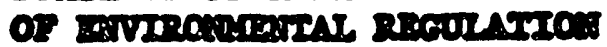

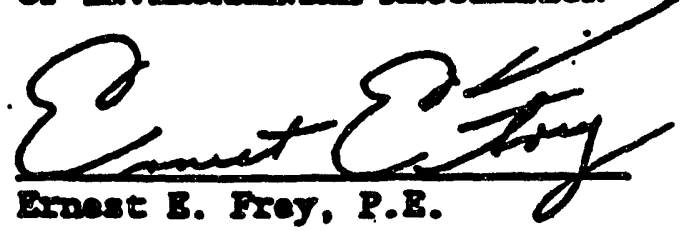

Doputy Aselseant Secretary

Mortheast District

3426 Bl1Is Rosd

Jacksomville, Florida 3220 ?

Rage 15 of 15 
Anne

1.1 Diehloroethane

1.2 DLehlorocthem.

1,1,1-Ir1 chloroethmi

1,1,2-Ir1ehloroethene

..1,1,2-IrLchlorotrifluoroethes:

1,2-Dichlorobenzene

1,4-Dlexene

2-butencl

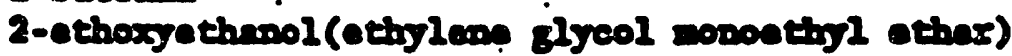

2-112xopropeno

scetaldabyde

scotowe

scetoniterile.

Acetophenone

Ansilino

Benzone

n-Butgl alcohol

Carbon Disulfide

Carbon Tetrachloride

Chlorobenzene

Chloroform

m-Cresol

- Cresol

p-Cresol

Cumere

Cyclohexane

Cyclohexanone

o-Dichlorobenzene

-Dichlorobenzene

P-Dlehlorobenzene

Diehlorolsopropyl ether

Dipropylamine

Ethanol

Ethyl Acetate

Ethyl Benzone

Ethyl Ether

Ethylene glycol

Formaldobyde

Puran

Hoptane

Hoxeme

Isomyl alcohol

Isobutyl alcobol

Isoctana/2,2,4-Trifiethylpentime

Hetheme, bromo:

Methase, dibrowo

Mothane, Erlchloro.

Kethanol

Yiethylene Chloride

Methyl Ethyl Ketone

Methyl Isobutyl Kerone

Methy Pyrxole
Hezardous Waste

Code Nimber

0076

0077

$5001 / 2002 / 0226$

$5002 / 0227$

2001

$5002 / 0070$

$0108 / 0001$

0.053

r005/0358

$2005 / 0171$

0001

$5003 / 0002$

0003

0004

0012

5005/0019

$5003 / 0031$

$2005 / 2022$

$5001 / 0211$

$5002 / 0037$

0044

$5004 / 0052$

$5004 / 0052$

$5004 / 0052$

0055

0056

$5003 / 0057$

0070

0071

0072

0027

D1io

D001

$5003 / 0112$

5003

2003/0117

D001

0122

0124

D001

D001

0001

$5005 / 0140$

D001

0029

0068

0044

$5003 / 0154$

$5002 / 0080$

$5005 / 0159$

5003/0161.

D001 
Attachment A

Page ewo

Mineral Splxits

D001

Naphthalene

U165

Nierobenzene

5004/0169

Nonane

D001

Octane

D001

Propanol

D001

Pancane

Pxopane,1,2-Alchloro

D001

2-Propenal

Propylene elycol

0083

2003

Bysidine

Totrahydrofuran

0001

8005/2075/0196

0223

1,1,2,2-Tetrachloroethane

U209

0208

Tetrachloroethylene

$5002 / 5002 / 0210$

Toluene

- Toluldine

$5005 / 0220$

m-Toluidine

0328

D001

p-Toluidine

0353

Irlehloroethylene

Irichlorofluoromethane

F001/5002/0228

$5002 / 0121$

IrIchloromethane

a-Xylene

o-xylene

p-Xylene

Unlisted I gnibLiod" "iste

$0044 / 10001$

5003/0239

$5003 / 0239$

5003/0239

Spent Solvents

D001

5001

Spent Solvents

F002

Spent Solvents

5003

Spent Solvents

5004

Spent Solvents.

5005

Arsenic

D004

Barium

D005

Cadmiun

D006

Chromium

D007

Laed

D008

Maxcury

D009

Selenium

D010

Silver

D011

Endrin

D012

Indane

D013

Mothoxychlor

D014

Toxaphene

D015

2.4-D

D016

2,4,5-IP S1Ivex $\quad 0017$

Banzene

D018

Carbon Tetrachlorida

D019

Chlordane

DO20

Chlorobenzene

D021

Chloroform

D022

0-Cresol

D023

M-Cresol

D024

P-Cresol

D025

Cresol

D026 
Aterchnont A

Page three

1,4 DIchloroberziene

D027

1,2 Dichloroethane

DO28

1,1 Dichloroethylene

D029

2.4 Dinitrotoluene

D030

Heptachlor

Hexachlorobenzene

D031

Hexachlorobuterdsene

DO32

D033

Hexechloroethane

DO34

Hethylethylketone

D035

N1Erobenrene

D036

Pentachlorophenol

D037

Pyridise

D038

Tetrachloroethylon

D039

Irlehloroethylene

DO4O

2,4,5 Irichlorophenol

D041

2,4,6 Trichlorophenol

$D 042$

vinylchloride

D043 
Exhibit D4

\section{RADIOACTIVE MATERIALS LICENSE FOR QUADREX}




\title{
STATE OF FLORIDA DEPARTMENT OF HEALTH AND REHABILITATIVE SERVICES OFFICE OF RADIATION CONTROL
}

RADIOACTIVE MATERIALS LICENSE

Page 1 of $\frac{8}{\text { AMENDMT }}$. Pages 28

\begin{abstract}
Pursuant to Chapter 404, Florida Statutes, and Chapter 100-91, Florida Administrative Code, and in reliance on statements and representations heretofore made by the licensee designated below, a license is hereby issued authorizing such licensee to receive, acquire, possess and transfer the radioactive material(s) designated below and to use such radioactive material(s) for the purpose(s) and at the place(s) designated below. This license is subject to all applicable rules, regulations and orders of the State of Florida. Department of Health and Rehabilitative Services now or hereafter in effect and to any conditions specified below.
\end{abstract}

Licensee

1. Name:

\section{QUADREX ENVIRONMENTAL COMPANY}

2. Address: 1940 N.W. 67 th Place Gainesville, FI 32606
With reference to correspondence dated 11/15/91, State of Florida Radioactive Materials

3. License Number. 1354-1 is hereby amended in its entirety to read as follows:

4. Expiration date: November 30,1995

5. Category:

$4 \mathrm{C}$
6. Radioactive material (element and mass number)

A. Any radioactive material with an atomic number 1 through 83.

B. Any radioactive material with an atomic number 84 through 95.

C. Carbon 14

c. Iiquid scintillation materials.

D. Hydrogen 3

D. Liquid scintillation materials.

B. Any sealed source ment state.
8. Maximum quantity licensee may possess at any one time

A. 250 microcuries total; no single source to exceed 10 microcuries each. that has been approved for distribution.by the U.S. Nuclear Regulatory Commission or an.Agree-

B. 250 microcuries total; no single source to exceed 10 microcuries each.

C. See Condition 15 , below.

D. See Condition 15 , below.

(See Page 2! 
STATE OF FLORIDA

DEPARTMENT OF HEALTH AND REHABILITATIVE SERVICES

OFFICE OF RADIATION CONTROL

RADIOACTIVE MATERIALS LICENSE SUPPLEMENTARY SHEET

$$
\begin{aligned}
& \text { Page } \frac{2}{2} \text { of } \frac{8}{1354-1} \text { Pages } \\
& \text { AMEND Number No. } 28 \\
& \text { (4C) (K95) }
\end{aligned}
$$

6. Radioactive material 7. Chemical and/or

(element and mass

physical form

8. Maximum quantity licensee may number) possess at any one time

E. Iodine 125

Chromium 51

E. Liquid scintillation materials.

E. See Condition 15 , Iron 59

Sulfur 35

Phosphorus 32

Calcium 45

Sodium 22

Cobalt 57

Zinc 65

Rubidium 86

Gallium 67

Indium 111

Chlorine 36

Mercury 203

Iodine 131

Selenium 75

Germanium 68

Cadium 109

Cerium 141

Scandium 46

Copper 64

Gold 195

Technetium 99

Gadolinium 153

Tin 119

Tin 113

Phosphorus 33

F. Radon 222 and its daughter products.

F. Iiquid scintillation material contained in radon detection kits only.
F. See Condition 15 , below.

9. Authorized Use.

A. and B. To be used as calibration or reference standards.

C. through F. Liquid scintillation materials shall be received, processed, stored and disposed of in accordance with Condition 15 of this license.

(See Page 3) 
STATE OF FLORIDA

DEPARTMENT OF HEALTH AND REHABILITATIVE SERVICES

OFFICE OF RADIATION CONTROL

RADIOACTIVE MATERIALS LICENSE

SUPPLEMENTARY SHEET

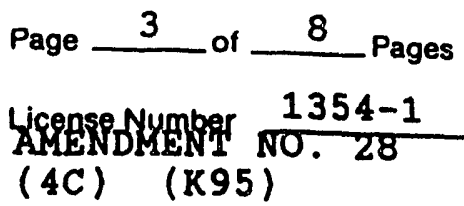

\section{CONDITIONS}

10. A. The authorized place of receipt, storage, use and processing shall be the licensee's facility located at 1940 N.W. 67th Place, Gainesville, Florida 32606.

B. Liquid scintillation fluids may be transported to oldover Corporation's rotary kiln located at Green Cove Springs, Florida, where they are mixed with the kiln!s fuel.

11. Failure to comply with the provisions of this license is a felony of the third degree pursuant to section 404.161 , Florida statutes. Also, violations may warrant an administrative fine of up to $\$ 1,000.00$ per violation per day, pursuant to section 404.162 , Florida statutes.

12. A. Licensed material shall be used by or under the supervision of and in the physical presence, at the license facility listed in Item 2 , above, of Raymond Thomas, Joseph Owens, Bernhardt Warren, Jack Flaacke, Raymond Whittle, David Gardner, Orin Pelto, Thomas Owens, or Russell. Pendleton.

B. The Radiation Safety Officer is Bernhardt C. Warren.

13. The licensee shall comply with the provisions of Chapter 10D-91, Florida Administrative Code, Part $X$, "Notices, Instructions and Reports to Workers; Inspections" and Part IV, "standards for Protection Against Radiation."

14. Sealed sources described in Items 6, 7, 8 and 9 , subitems $A$ and $B$ containing licensed material shall not be opened.

15. A. Receipt, possession, storage, processing and disposal of licensed material described in Items 6, 7, 8 and 9, subitems $C$ and $D$ must satisfy the following:

1. Be received and processed in concentrations no greater than 0.05 microcuries per gram of medium;

2. Be transported for disposal to Oldover's Corporation rotary kiln located at Green Cove Springs, Florida in concentratione no greater than 0.05 microcuries per gram of medium.

(see Page 4) 


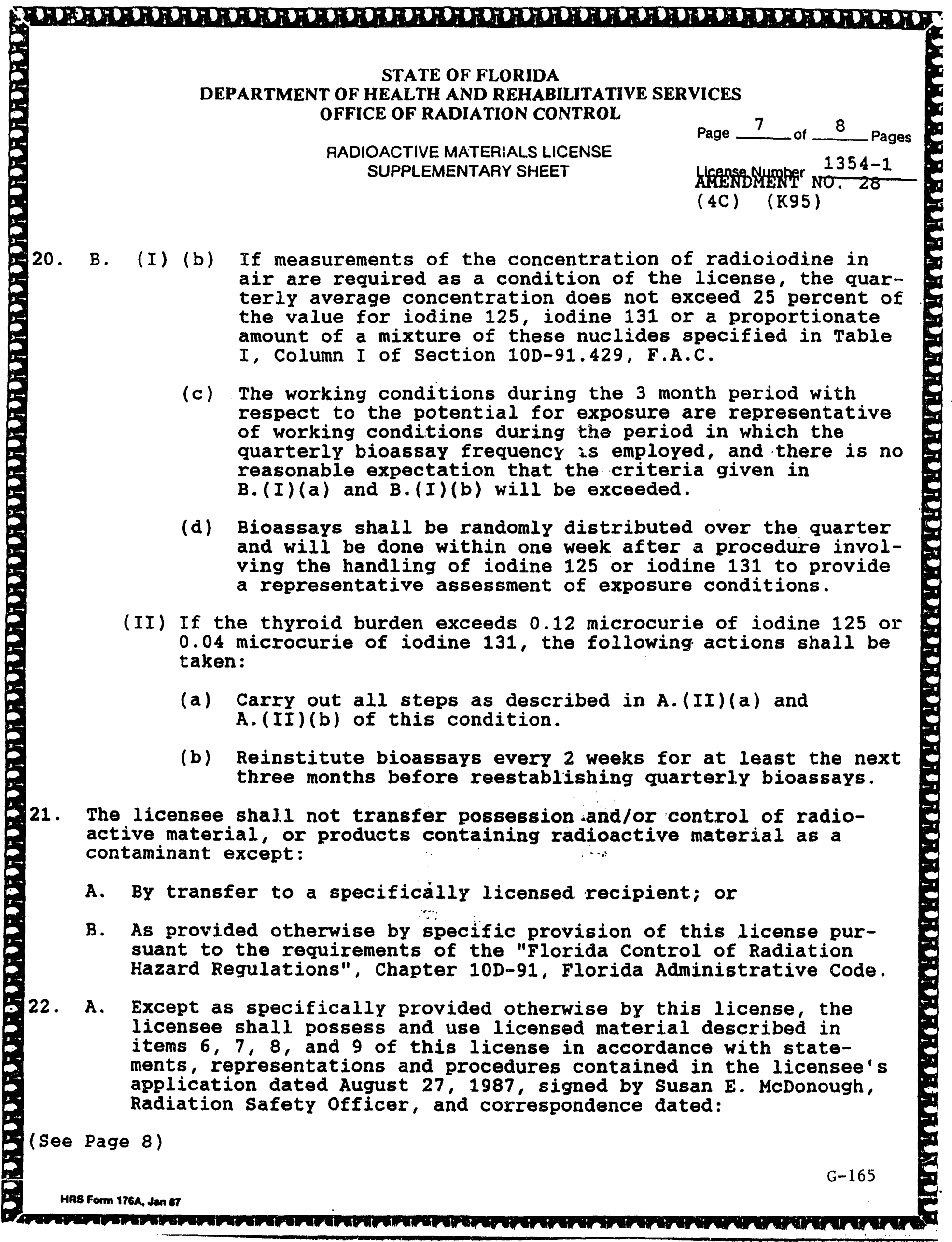


Exhibit D5

FDER USED OIL REGISTRATION FOR QUADREX 


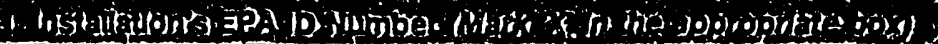

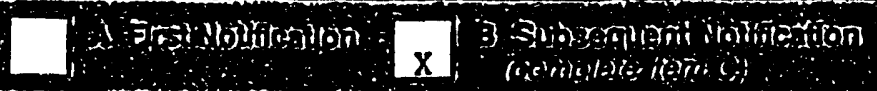

$$
\begin{array}{|l|l|l|l|l|l|l|l|l|l|l|l|}
\hline \text { F } & \text { L } & \text { D } & 9 & 8 & 0 & 7 & 1 & 1 & 0 & 7 & 1 \\
\hline
\end{array}
$$

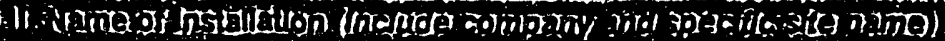

\begin{tabular}{l|l|l|l|l|l|l|l|l|l|l|l|l|l|l|l|l|l|l|l|l|l|l|l|l|l|l|l|l|}
\hline Q & U & A & D & B & E & X & & E & N & V & I & R & O & N & M & E & N & T & A & L & & C & O & M & P & A & N & $Y$ \\
\hline
\end{tabular}

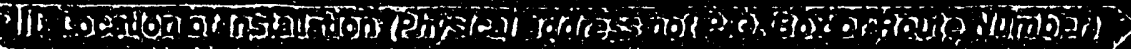

\begin{tabular}{|l|l|l|l|l|l|l|l|l|l|l|l|l|l|l|l|l|l|}
\hline 1 & 9 & 4 & 0 & & N & W & & 6 & 7 & $t$ & $h$ & & P & L & A & C & E \\
\hline
\end{tabular}

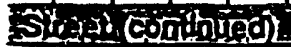

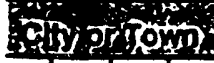

\begin{tabular}{l|l|l|l|l|l|l|l|l|l|l|l}
\hline S & A & I & N & E & S & V & I & L & L & E \\
\hline
\end{tabular}

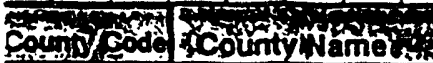

(1)

\begin{tabular}{|l|l|l|l|l|l|l|l|l|l|}
\hline A & L & A & C & H & U & A & & & \\
\hline
\end{tabular}

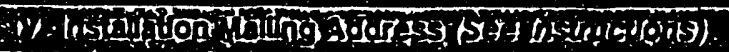

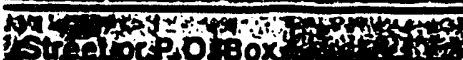

\begin{tabular}{l|l|l|l|l|l|l|l|l|l|}
\hline P & 0 & B & O & X & & 4 & 1 & 0 & 0 \\
\hline
\end{tabular}

ais or phe

\begin{tabular}{l|l|l|l|l|l|l|l|l|l|l|} 
G & A & I & N & E & S & V & I & L & L & E \\
\hline
\end{tabular}

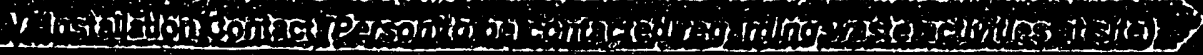

artition:

\begin{tabular}{|l|l|l|l|l|l|l|l|l|l|l|l|l|l|l|l|l|l|l|l|l|}
\hline F & L & E & E & T & W & O & O & D & & & & & & & D & E & N & N & I & S \\
\hline
\end{tabular}

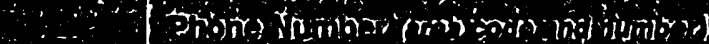

\begin{tabular}{l|l|l|l|l|l|l|l|l|l|l|l|l|l|l|l|l|l|l|l|l|l|l|l|l|l|l|}
\hline M & G & R & & R & E & G & & C & O & M & P & L & I & A & 9 & O & 4 & - & 3 & 7 & 3 & - & 6 & 0 & 6 & 6 \\
\hline
\end{tabular}

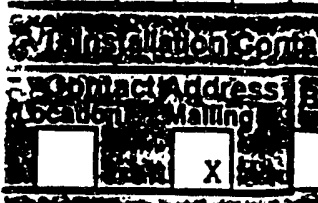

Eis ditotustis

$\sin$

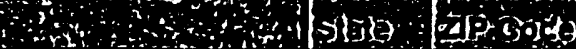

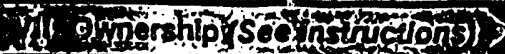

A Name of Instailation's Legal owners \begin{tabular}{l|l|l|l|l|l|l|l|l|l|l|l|l|l|l|l|l|l|l|l|l|l|l|l|l|l|l|l|l|l|l} 
P & U & B & L & I & C & & C & O & & N & O & R & M & & D & U & D & E & Y & & P & R & E & S & I & D & E & N & T \\
\hline
\end{tabular}

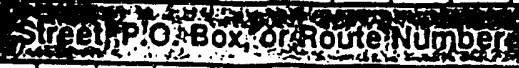

\begin{tabular}{l|l|l|l|l|l|l}
\hline$S$ & $A$ & $M$ & $E$
\end{tabular}

Chy or Town
State ZIP Code

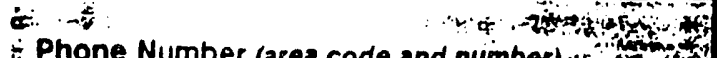
\begin{tabular}{l|l|l|l|l|l|l|l|l|l|l|l|}
\hline 9 & 0 & 4 & - & 3 & 7 & 3 & - & 6 & 0 & 6 & 6 \\
\hline
\end{tabular}

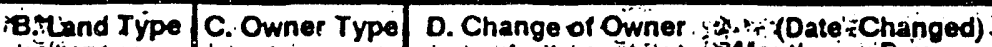

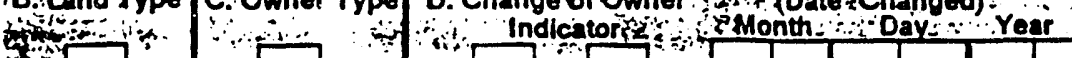




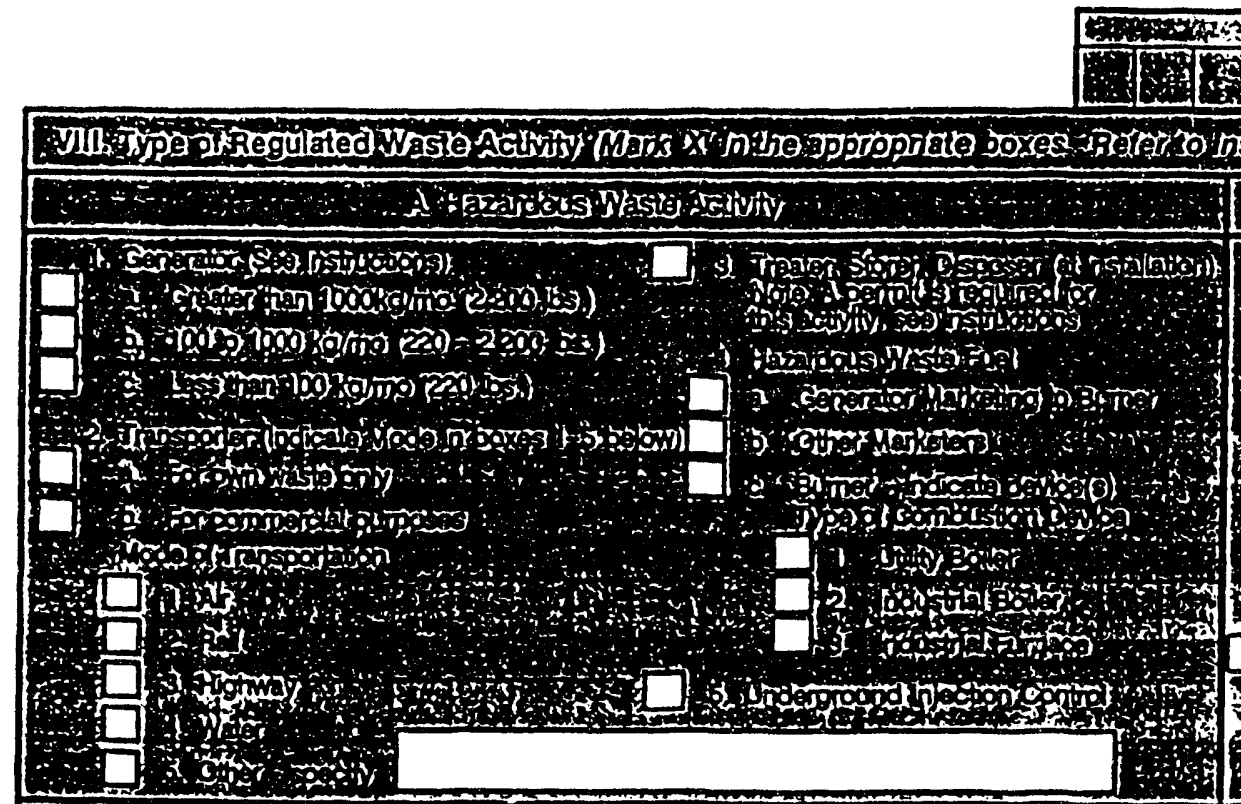

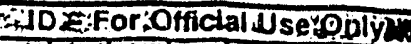
$+3$

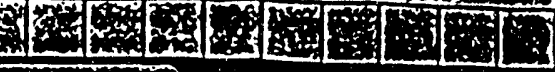
VIILType

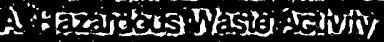

$\square^{0}$

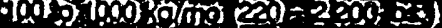

(1)

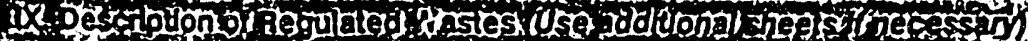

A. Charectertedes of Nonlistod Hezardous Wastes. Mark $X$ in tho boxes corresponding to the characteristics of nonlisted haznerdous waste your instalution handles. (Se0 40 CFR Parts 261.20 - 261.24)

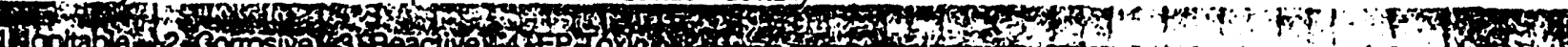

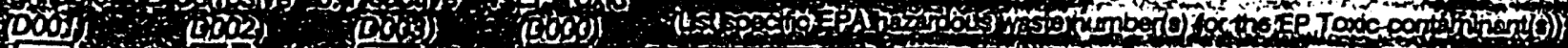
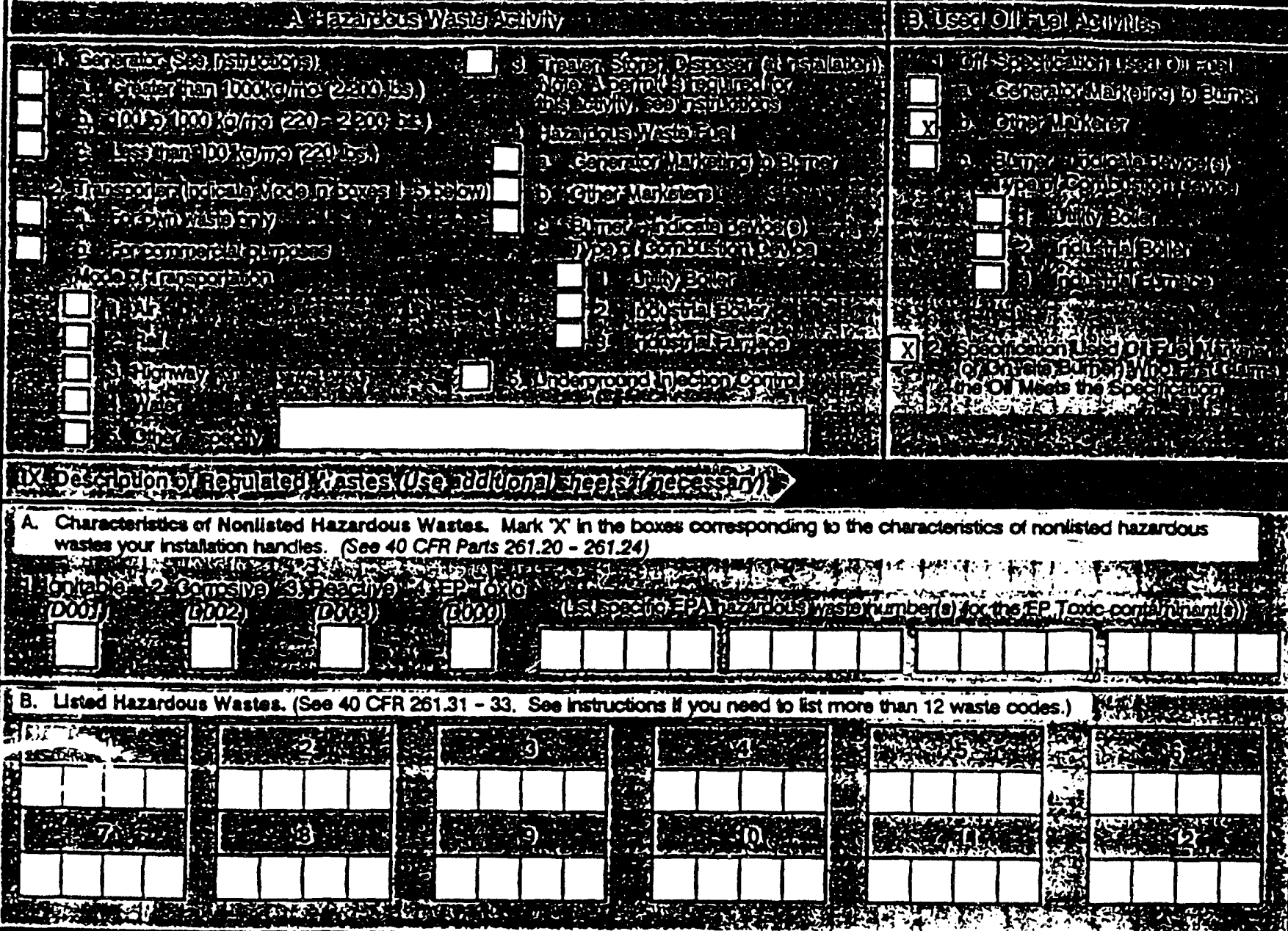

L. Other Wastos. (State or other wastes reguining an I.D. mumber. See instructions.)
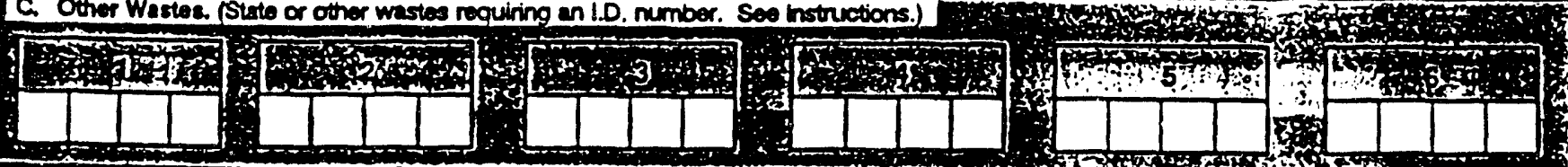

gerigiting

I certify under penalty of law that I have personally examined and am famlliar with the information submitted In thls and all attached documents, and that based on my inquiry of those Individuals immedlately responsible for obtaining the Information, I belleve that the submitted Information is true, accurate, and complete. I am aware that there are significant penalties for submitting false information, including the possibility of fines and Imprisonment.

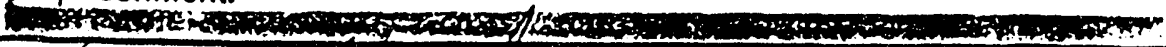

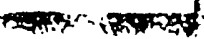

\begin{tabular}{|l|l|l|}
\hline Signerire & Date Signed \\
\hline
\end{tabular}

yifoomments

* Company name changed from Quadrex HPS to Quadrex Environmencal Compan.

Note: Mall completed form to the appropriare EPA Regional or State Omice. (See Section lll of the booklet lor addresses.) 


\section{Florida Department of Environmental Regulation}

Twin Towers Office Bldg. 2600 Blair Stone Road - Tlllahassee, Florida 32399-2400

Ben C. Warren

Quadrex Corporation

P.O. Box 4100

Gainsville, FI 32613

July 20, 1991

BE IT XNOWN THAT

Quadrex Corporation

IS HEREBY REGISTERED AS A USED OIL

COLIECTION FACIIITY

in compliance with Chapter 17-710, Florida Administrative Code (F.A.C.).

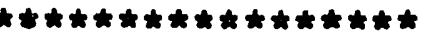

- The Department of Environmental Regulation hereby issues registration number 50428-00 on July 1, 1991. This registration will expire June 30, 1992 .

This certificate documents receipt of your annual registration and annual report. It shall be displayed in a prominent place at your facility. This certificate and your cancelled check are your receipts.

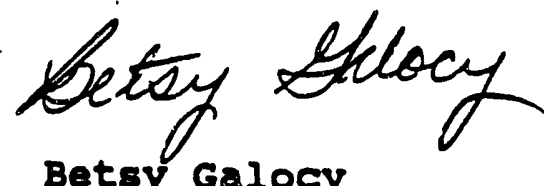

Betsy Galocy

Used Oil Recycling Manager

Hazardous Waste Reduction \& Management Section 
Exhibit E1

LIST OF PERMITS, LICENSES, OR AUTHORIZATIONS PERTAINING TO RAMP 


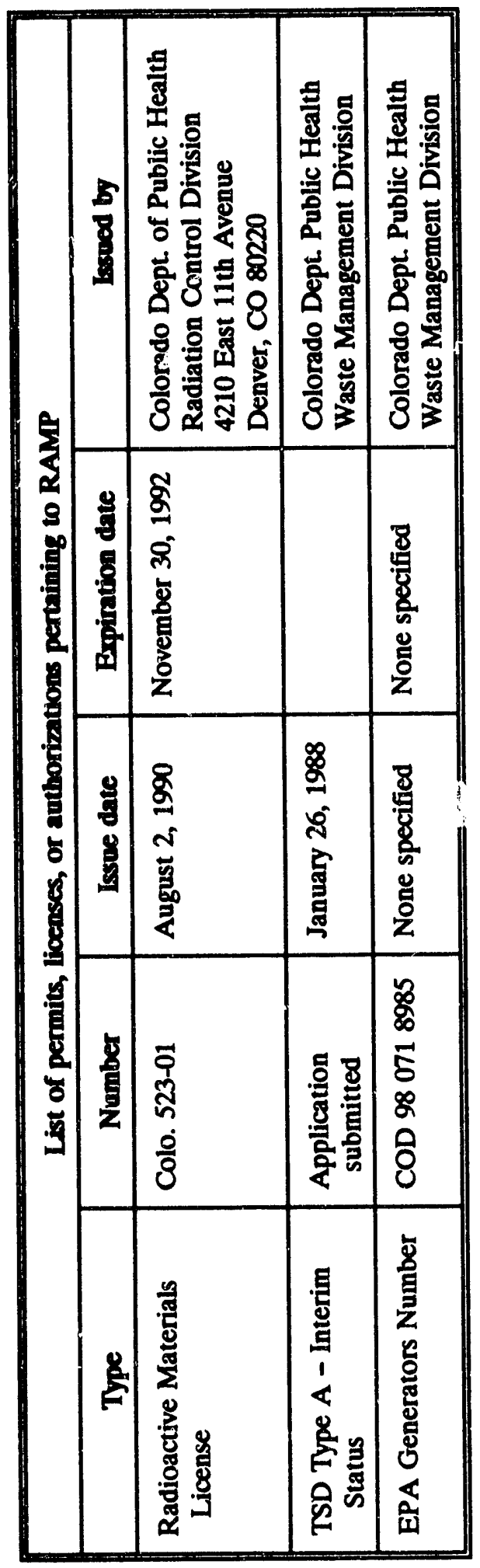


Exhibit E2

RADIOACTIVE MATERIALS LICENSE FOR RAMP 


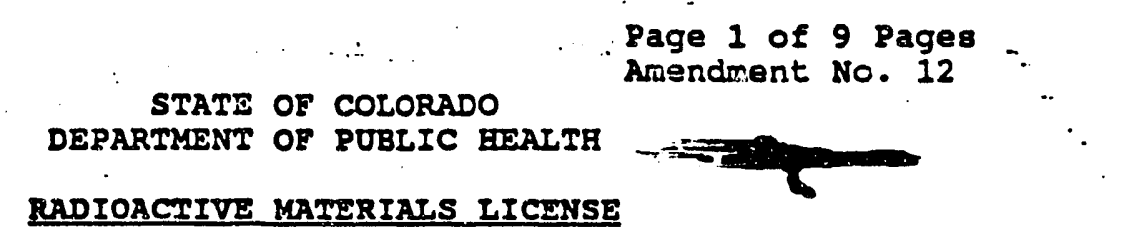

Pursuant to the Radiation Control Act Title 25, Article 11, CRs 1989, Replacement Volume, as amended, and the Radiation Control Regulations, Part 3 , and in reliance on statements and representations heretofore made by the licensee designated below; a license is hereby issued authorizing such licensee to transfer, receive, possess and use the radioactive material(s) designated below; and to use such radioactive material(s) for the purpose(s) and at the place(s) designated below. This license is subject to ail applicable rules, regulations, and orders now or hereafter in effect of the colorado Department of Health and to any conditions specified below.

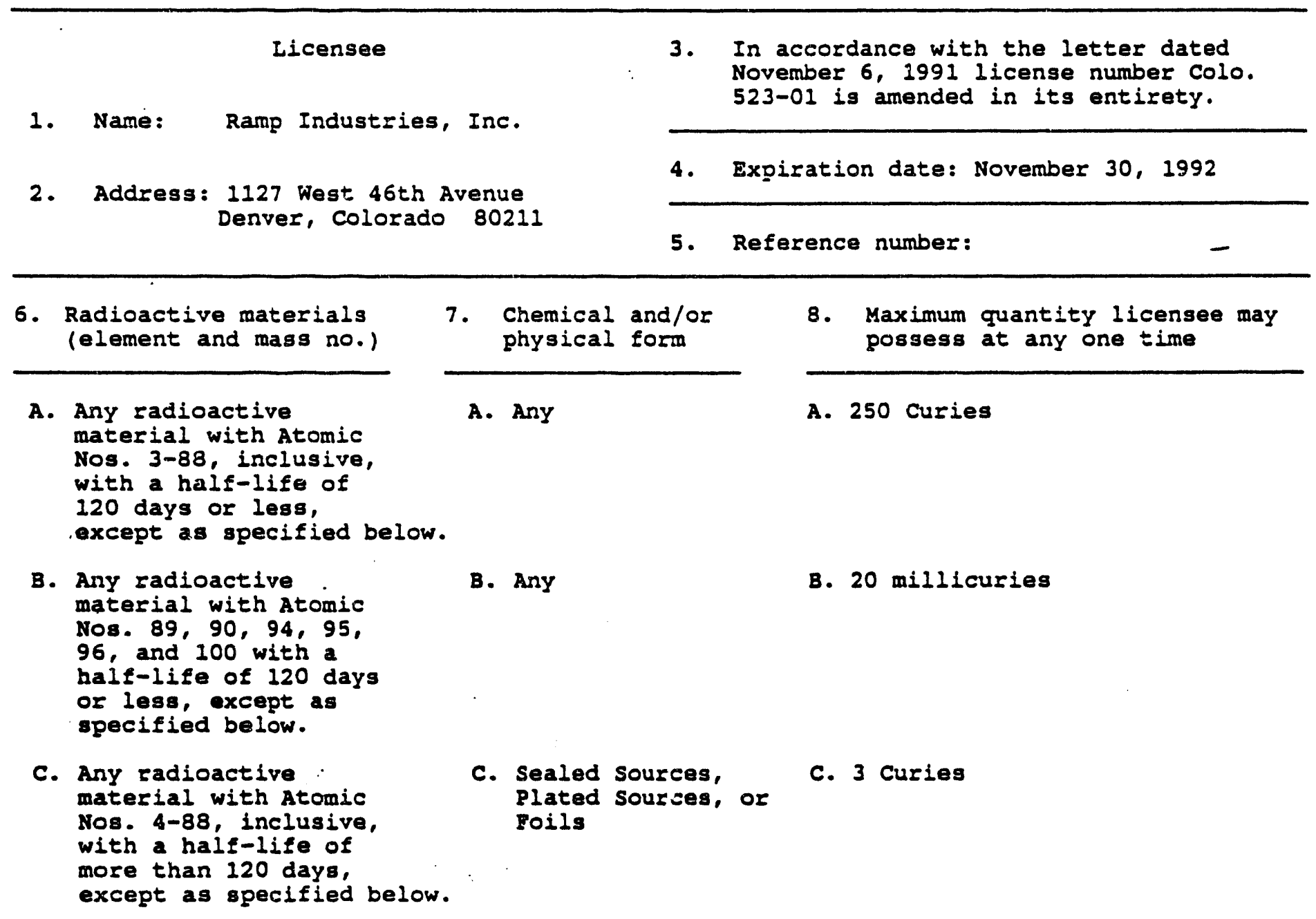




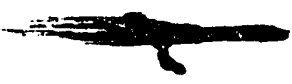

STATE OF COLORADO

DEPARTMENT OF PUBLIC HEALTH

RADICACTIVE MATERIALS LICENSE

Iicense Number Colo. 523-01

(Expiration Date: November 30, 1992)

Amendment No. 12

6. Radioactive materials (element and mass no.)

D. Any radioactive material with Atomic Nos. 3-89 inclusive, and 91 , with a

half-life of more than 120 days, except as specified below.

E. Any radioactive material having atomic nos. 93, $95,96,97,98$, and 99 with a half-life greater than 120 days.

F. Special nuclear material

G. Source Material

B. Natural and Depleted Uranium.

I. Bydrogen 3

J. Bydrogen 3

R. Carbon 14

I. Cobalt 57

M. Cobalt 60

N. Nickel 63

. O. Zine 65

\section{Chemical and/or} physical form

D. Any

E. Any

F. AnY

G. Any

B. Any

I. Any

J. Sealed Sources, foils, and exit signg

R. AnY

I. Any

M. Sealed Sources

N. Sealed Sources

o. Sealed sources plated sources or foils $\because$
8. Maximum quantity license may possess at any one tine

D. 3 Curies

E. 20 microcuries

E. 10 grams

G. 250 kilograms

B. 500 kilograms

I. 10 curies

J. 150 curies

R. 500 millicuries

I. 200 millicuries

M. 10 curies

N. 2 curies

0. 100 millicuries

OR-RR-18 


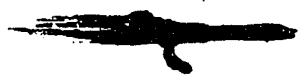

STATE OF COLORADO

DEPARTMENT OF PUBLIC BEALTH

RADIOACTIUE MATERIALS LICENSE

Iicense Number Colo. 523-01

(Expiration Date: November 30, 1992)

Amendment No. 12

D. Radioactive materials
(element and mass no.)
P. Strontium 90
Q. Cadmium 109
R. Silver $110 \mathrm{~m}$

S. Iodine 129

T. Cesium 137

0. Promethium 147

v. Gadolinium 153

พ. Polonium 210

x. Lead 210

צ. Radium 226

z. Radium 226

AA. Americium 241

BB. Cesium 137
7. Chemical and/cr physical form

P. Sealed sources

2. Sealed sources

R. Sealed Sources plated sources or foils

s. Sealed sources

T. Sealed sourceg

0. Sealed sources

v. Sealed sources

W. Sealed Sources plated sources or foils

X. Sealed sources plated sources or foils

Y. Any

2. Sealed sources

AA. Sealed sources plated sources or foils

BB. Sealed sources
8. Maximum quantity licensee may possess at any one time

P. 3 curies

Q. 100 millicuries

R. 50 millicuries

s. 10 millicuries

T. 5 curies

0. 10 curies

v. 3 curies

ฟ. 500 millicuries

x. 350 millicuries

Y. 100 millicuries

2. 900 millicuries

AA. 500 millicuries

BB. 1 source, not to exceed 1.2 curies 


\author{
STATE OF COLORADO \\ DEPARTMENT OF PUBLIC GEALTH
}

RADIOACTIVE MATERIALS LICENSE

Iicense Number Colo. 523-01

(Expiration Date: November 30, 1992)

Amendment No. 12

$=$

\title{
CONDITIONS
}

9.A. The licensee may receive, pick-up, transport, store, solidify, subject to absorption and/or compaction, consolidate, package, and refackage radioactive material authorized in Items 6.A., 6.C., 6.D., 6.G., 6.H., 6.I., 6.K., 6.I., and 6.Y. as waste, in approved Department of Transportation (D.O.T.) shipping containers. Disposal of waste shall be made by transfer to authorized recipients.

B. Radioactive material authorized in Items 6.B., 6.5., and 6.F. shall be received, solidified, packaged, and transferred to authorized recipients for disposal. Prior approval must be granted by the Radiation Control Division for any processing of special nuclear material.

C. Radioactive material authorizec in Items 6.J., 6.M. through 6.X., 6.2., and 6.AA. shall be received, packaged, and transferred to authorized recipients for disposal.

D. Radioactive material authorized in Item 6.BB. shall be used for survey instrument calibration.

10. Radioactive material shall be used only at 1031, 1107, and 1127 West 46th Avenue, Denver, Colorado, 80211 .

11. The licensee shall comply with the provisions of the State of Colorado Rules and Regulations Pertaining to Radiation Control, Part 10, "Notices, Instructions and Reports to Workers; Inspections" and Part 4, "Standards for Protection Againgt

. Radiation".

12. Radioactive material shall be used by, or under the supervision of John E. Iucas, Ray Allen, Gregory D. Smith, or Jack F. Patterson.

13.A. The designated Radiation Safety officer is John E. Lucas.

B. The designated Alternate Radiation Safety officer is Ray Allen.

14. Radioactive material authorized by Item 6 . of this license shall be stored and used in a manner that will preclude use by unauthorized personnel.

15. A total volume of 6375 cubic feet or 850 55-gallon drume of radioactive material may be possessed by RAMP Industries, Inc. This volume includes processed waste, unprocessed waste, waste in storage for decay, f'zgulated scintillation fluids, and a.l other radioactive materials.

\section{OR-RB-18}




\section{STATE OF COLORADO \\ DEPARTMENT OF PUBLIC MEATTH \\ RADIOACTIVE MATERIALS LICENSE}

License Number Colo. 523-01

(Expiration Date: November 30, 1992) Amendment No. 12

$$
=
$$

16. No radioactive waste may be received for which there is no current disposal option.

17. Any radioactive waste must be returned to the generator if:

A. it is determined to be a mixed waste which cannot be stored for decay to background; or

B. it is not acceptable at a commercial low level waste disposal site.

18. The licensee is authorized to perform tests for leakage and/or contamination upon sealed scurces containing radioactive material and upon devices which contain such sealed sources.

19.A. (1) Radioactive material authorized in Item 6.3B. shall be tested for leakage and/or contamination at intervals not to exceed six (6) months.

(2) In the absence of a certificate from a transferor indicating that a test has been made within six months prior to the transfer, a sealed source received from another person shall not be put into use until tested.

B. The test shall be capable of detecting the presence of 0.005 mierocurie of radioactive material on the test sample. The test sample shall be taken from the sealed source or from the surfaces of the device in which the sealed source is permanently mounted or stored on which one might expect contamination to accumulate. Records of leak test results shall be kept in units of microcuries and maintained for inspection by the Department.

C. If the test reveals the presence of 0.005 microcurie or more of removable contamination, the licensee shall immediately withdraw the sealed source from use and shall cause it to be decontaminated and repaired or to be disposed of in accordance with Department regulations. A report shall be filed within 5 days of the test with the Director, Radiation Control Division, Colorado Department of Health, 4210 East 11th Avenue, Denver, Colorado 80220, describing the equipment involved, the test results, and the corrective action tiken.

D. Tests for leakage and/or contamination shall be performed thy the licensee or by other persons. specifically authorized by the U.S. Nucletis hegulatory Commission or an Agreement state to perform such services.

20. Sealed sources containing radioactive material shall not je opened.

21.A. Radioactive material authorized in Item 6.A. shall not be stored for a period exceeding 42 months.

OR-i் -18 


\section{STATE OF COLORADO \\ DEPARTMENT OF PUBIIC HEAITH \\ RPDIOACTIVE MATERIAIS LICENSE}

License Number Colo. 523-01

(Expiration Date: November 30, 1992) Amendment No. 12

21.B. (1) Radioactive material authorized in Items 6.B. through 6.H. and Items 6.N. through 6.0. (except Iridium 192 sealed sources) shail not be in the licensee's possession for a period greater than twenty-four (24) months from the date of pick-up or receipt.

(2) Sealed sources containing Iridium 192 shall not be in the licensee's possession for a period greater than thinty-six (36) months from the date of pick-up or receipt.

c. The licensee may also hold unsealed radioactive material for in-gtorage decay for a period of thirty-six (36) months from the date of receipt or 10 half-Iives of the longest-lived radioactive material, whichever is shorter.

22.A. Individuals involved in operations which utilize, at any one time, more than 50 millicuries of I-125 and/or I-131 or unvented laboratory operations involving 10 mCi of I-125 and/or I-13I in a noncontained form shall have bioassays performed within one week following a single operation. Records of the bioassays shall be maintained for inspection by the Department and the action points listed below shall be observed.

B. Whenever the thyroid burden at the time of measurement exceeds $0.12 \mathrm{microcuries}$ of I- 125 or 0.04 microcuzies of $I .131$, the following actions shall be taken:

(1) An investigation of the operations involved, including ventilation surveys shall be carried out to determine the causes of exposure and to evaluate the potential for further exposures.

(2) If the investigation indicates that further work in the area might result in exposure of a worker to concentrations that are excessive, the licensee shall restrict the worker from further exposure until the source of exposure is discovered and corrected.

(3) Corrective actions that will eliminate or lower the potential for further exposures shall be implemented.

(4) A repeat bioassay shall be taken within 1 week of the previous measurement in order to confirm the effectiveness of the corrective action taken or to verify internal radioiodines present.

(5) Reports or notification shall be provided as required by RH 4.29 and 4.34 of the state of Colorado Rules and Regulations Pertaining to Radiation Control. 


\author{
STATE OE COLORADC \\ DEPARTMENT OF PUBLIC HEALTH \\ RADTOACTIVE MATERIALS LICENSE
}

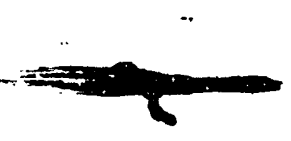

Iicense Number Colo. 523-01

Expiration Date: November 30, 1992)

Amendment No. 12

22.C. If the thyroid burden at any time exceeds 0.5 microcuries of $I-125$ or 0.24 microcuries of I-131, the following actions shall be taken:

(1) Erevent the individual from any further handing of I-125 or I-131 unti the thyroid burden is below the above limits.

(2) As soon as possible, refer the case to appropriate medical consultation for recommendations regarding therapeutic procedures that may be carried out to accelerate removal of radioactive iodine from the body. This should be done within 2-3 hours after exposure when the time of exposure is known so that any prescribed thyroid blocking agent would be effactive.

(3) Carry out repeated measurements at approximately 1-week intervals at least until the thyroid burden is less than 0.12 microcuries of I-125 or 0.04 microcuries of $I-131$.

23.A. Individuals involved in operations which utilize, at any one time, more than 100 millicuries of Hydrogen $3^{3}$ in a non-contained form, other than metallic foil, shall have bioassays performed within one week following a single operation and at weekly intervals for continuing operations. Records of the bioassays ghall be maintained for inspection by the Department and the action points listed below shall be observed.

B. (1) Tritium shall not be used in such a manner as to cause any individual to receive a radiation exposure such that urinary excretion rates exceed 28 microcurieg of tritium per liter when averaged over a calendar quarter.

(2) Orinalysis shall be performed at weekly intervals on all individuals who work in the restricted areas of facilities in which tritium is used. If the average concentration of tritium in urine for any single individual during a calendar quarter is less than 10 microcuries per liter, urinalysis may be performed on that individual at monthly intervals for the following calendar quarter and may continue at monthly intervals so long as the average concentration in the calendar quarter remains below 10 microcuries per liter. The urine specimen shall be collected on the same day of the week insofar as possible.

(3) A report of an average concentration in excess of the limit specified in $B$. (1) above for any individual shall be filed, in writing, within thirty (30) days of the and of the calendar quarter with the Director, Radiation Control Division, Colorado Department of Health, 4210 East 11th Avenue, Denver, Colorado 80220. The report shall contain the results of all urinalyses for the individual during the calendar quarter, the cause of the excessive concentrations, and the corrective steps taken or planned to assure against a recurrence.

(4) Any single urinalysis which discloses a concentration of greater than 50 microcuries per liter shall be reported, in writing, within seven (7) days of the licensee's receipt of the results, to the Director, Radiation Control Division, Colorado Department of Bealth, 4210 East 11th Avenue, Denver, Colorado 80220.

OR-RE-18 


\author{
STATE OF COLORAEO \\ DEPARTMENT, OF PUBLIC HEALTH \\ RADIOACTIVE MATERIAIS LICENSE
}

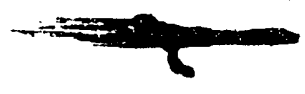

Iicense Number colo. 523-01

(Expiration Date: November 30, 1992)

Amendment No. 12

24.A. The licensee may transport radioactive material or deliver radioactive material to a carrier for transport, in accordance with the provisions of RH 17.5 of the State of Colorado RuIes and Requlations pertaining to Radiation Control, "Transportation of Iicensed Material".

B. The licensee is authorized to transport radioactive material for eventual transfer to persons licensed by the U.S. Nuclear Regulatory Commission or an Agreement Stato to perform radioactive waste disposal services, and that are transported in accordance with $R H 17.5$ of the state of Colorado Rules and Requlations pertaining to Radiation Control.

c. The transportation of Colorado radioactive materials shall be subject to all applicable regulations of the colorado Public Utilities Commission, Colorado Department of Highways, Colorado Department of Public Safety, Colorado Department of Revenue (Port of Entry), U.S. Department of Transportation, and other agencies of the United States having jurisdiction. When the U.S. Departinent of Transportation Regulations (Title 49, Chapter I, Code of Federal Regulations) are not applicable to shipments by land of colorado radioactive material by reason of the fact that the transportation does not occur in interstate or foreign commerce, the licensee must be in compliance with the requirements relating to packaging of the radioactive material, marking and labeling of the package, placarding of the transport vehicle, and accident reporting set forth in the regulations of the $0 . S$. Department of Transportation.

25.A. The licensee shall maintain in force a surety pursuant to RH 3.9 .5 .1 of the Regulations for the decommigsioning and decontamination at the site and buildings at the storage area. This surety is subject to yearly review for adequacy by the Department.

B. The decommissioning and decontamination surety shall be maintained sufficient to fully comply with all conditions of this License, the Regulations, and 6 CCR 1007-1. The Surety Agreement entered into between the licensee and the state is hereby incorporated by reference as a condition of the license.

C. As of April 30, 1992, a surety of $\$ 11,654.37$ must be on deposit for Rakp Industries in a trust account with Central Bank National Association.

D. As of June 30, ig91 a surety of $\$ 92,588.56$ must be on deposit with the Department for RAMP Industries.

D. Additions to the surety account in the amount of $\$ 5,000,00$ shall be made by RAMP Industries on a quarterly basis.

$O R-R H-18$ 


\section{STATE OF COLORADO \\ DEPARTMENT OF PUBLIC HEALTH \\ RADIOACTIVE MATERIAIS LICENSE}

License Number Colo. 523-01

(Expiration Date: November 30, 1992) Amendment No. 12

26. The transportation of radioactive materials within the DOT specification 20 WC packaging shall be in accordance with the limitations and reçuirements specified in the DOT-E 9581 exemption.

27. Within three months of the igsuance of this license or amendment the licensee must furnish this Division evidence of the licensee's ability to lawfully dispose of the Radium source(s) possessed by the licensee. The evidence must include the name and address of the company/licensee to which the source(s) would be sent for disposal during the period of time this license is valid. The evidence must also include the ability of the receiving company/licensee to receive such source(s). The ability to dispose of the Radium source(s), and documents supporting that ability, must be maintained by the licensee until lawful disposal of the Radium source(s) has been completed.

28. All low-level radioactive waste, which was generated outside the Rocky Mountain Compact Region and was imported into the Compact Region by Ramp Industzies, Inc., shall be removed from the Compact Region prior to Januar. 1, 1993.

29. Prior to the use of licensed materials outside the state of colorado the licensee shall comply with the applicable provisions of $10 \mathrm{CrR} 150.20$ or if the use shall take place in an Agreement State the licensee shall comply with the applicable provisions of that state's reciprocity requiremencs.

30. Except as specifically provided otherwise by this license, the licensee shall possess and use radioactive materials described in Items $6 ., 7 .$, and 8 . of this ilcense in accordance with statements, representations, and procedures contained in:

A. The applications and attachments dated october 28, 1987; November 25, 1987 (mR services); and

B. The license correspondence and attachments dated November 15, 1982; June 8, 1983; November 6, 1984; December 10, 1985; February 16, 1988; and February 17, 1988; March 9, 1990; March 15, 1990; April 5, 1990; August 2, 1990; August 22, 1990; January 31, 1991; March 14, 1991; November 6, 1991; Deceriber 10, 1991; December 19, 1991; January 9, 1992; and February 28, 1992; and

c. The Ramp Industrieg Contingency Plan (received November 27, 1987).

The State of Colorado RuIes and Regulations Pertaining to Radiation Control shall govern the licensee's statements in applications or letters, unless the statements are more restrictive than the regulations.

\section{FOR THE COLORADO DEPARTYENT OF BEALTH}
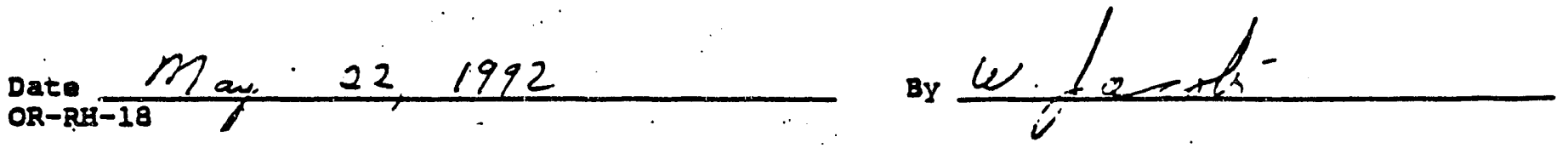
Exhibit E3

RCRA PART A PERMIT FOR RAMP 

it in the designated soce. Aeview the intor ation carriully: if any of it is incorrect. o through it and onter the corroct data in uppropriare fill-in arv bulow. Also, if any the prepnnted deta is abent lahe ares to latt of the label epace lists the informat ther should appeori. plense provide it in proper fill-in arealst batow. If the labe complete and correct, you need not compl Items I. III. V. and VI lexcept Vl-a m must be completed regerdlesel. Complete items if no lobel has been provided. Reter the instructions for derailed ltem dese tions and for the legal wthorizations us which this dare is collected. :

II. POLLUTANT CHARACTERISTICS R

INST RUCTIONS: : Compione A througn $d$ to determine whether you need to submit any permit applieation forms to the EPA. If you answer "Yes" to an questions, you must submit this. form and the supplemental form listed in the parenthesis following the question. Mark " $X$ " in the box in the third colum if the supplemental. form is atrached. If you answar "no" to ech question, you need not submit any of these forms Your may answer "no" if your activit is excluded from ponnit nquirements; sese Section $C$ of the instructions See also. Section D of the instructions for dafinitions of bold-faced turms

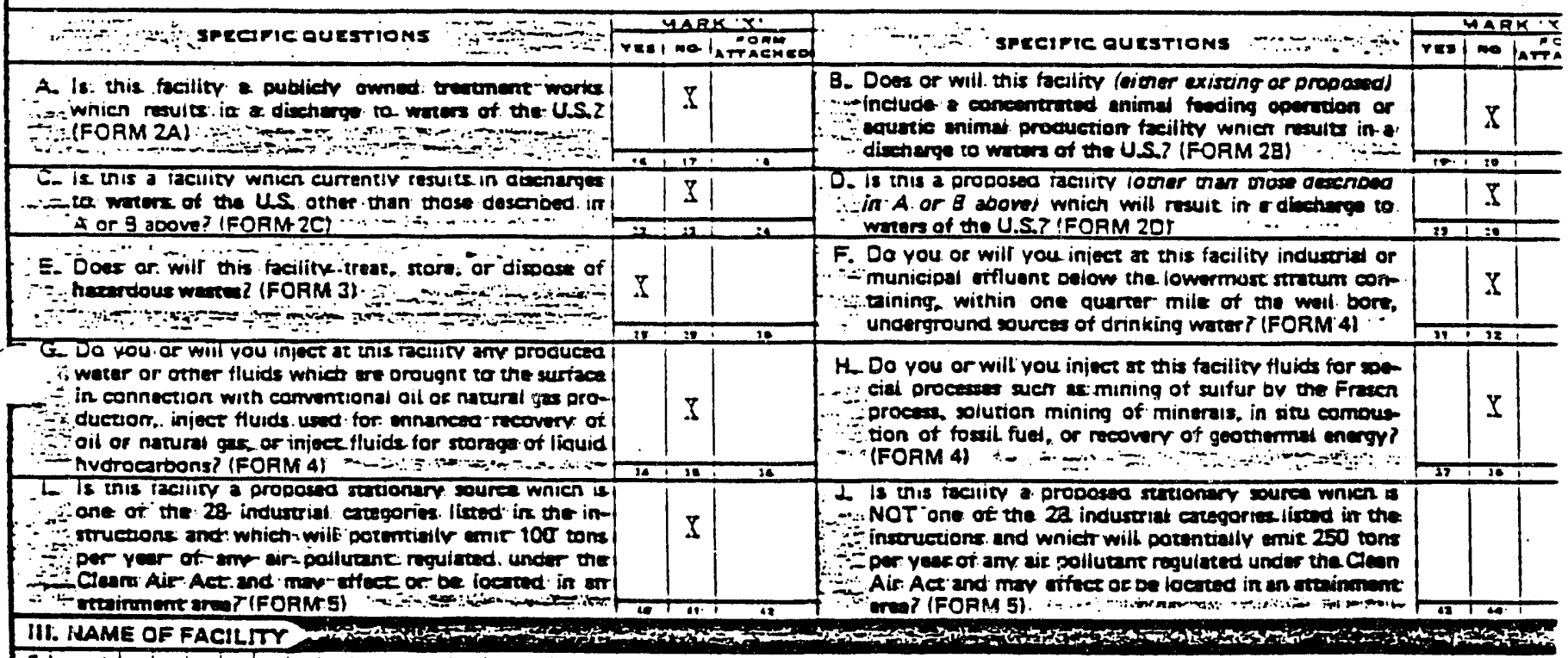

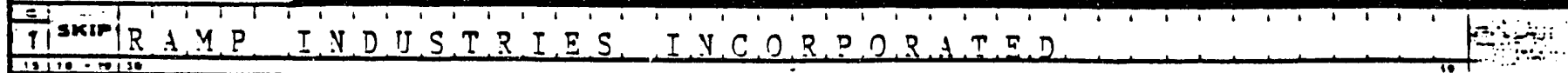

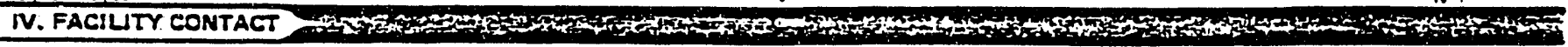

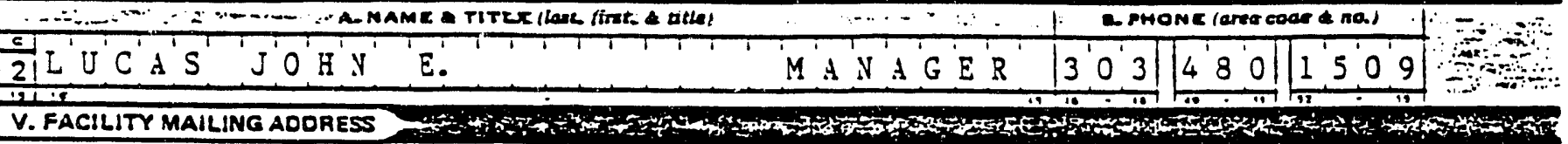

V. FACILIT

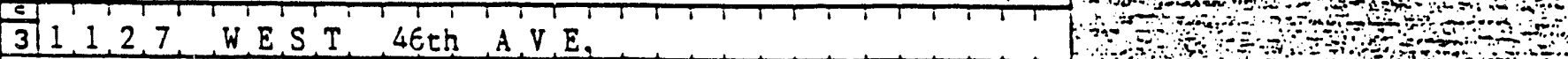
ज|DENVER

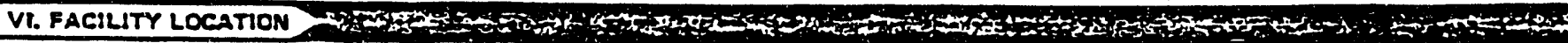

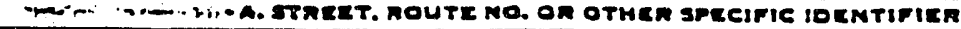

511127 WES T 46 th A V E.

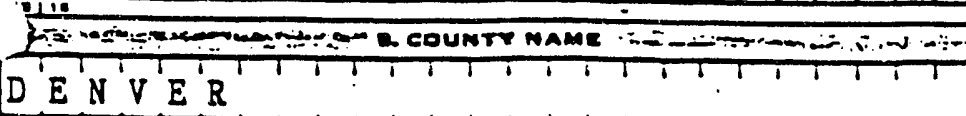

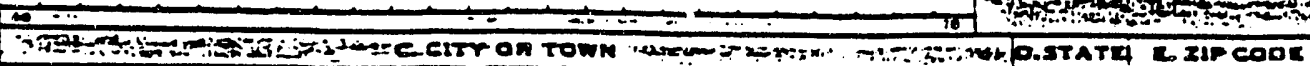

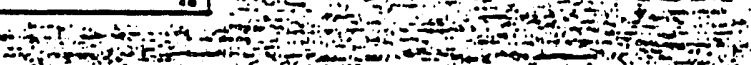

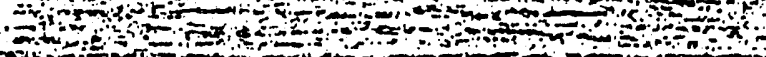
GD EN V E R

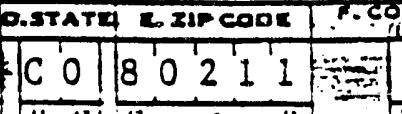
oun ris CONTINUE ON RE 


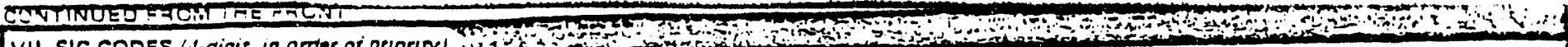

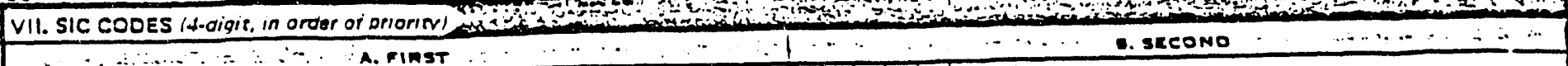

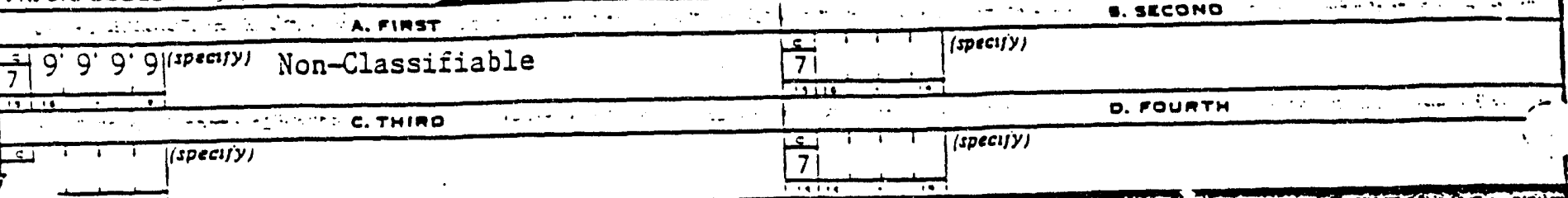

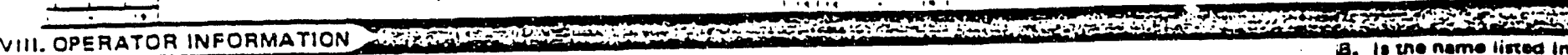

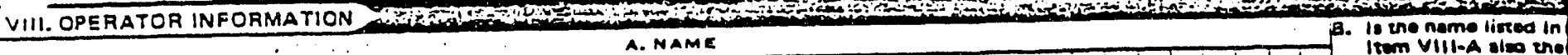

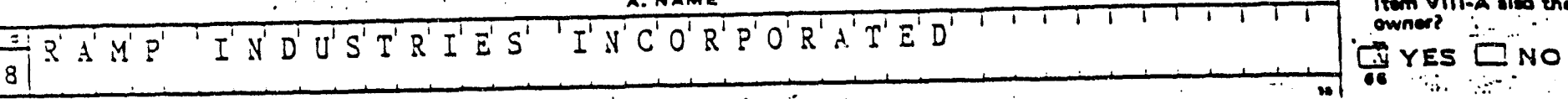

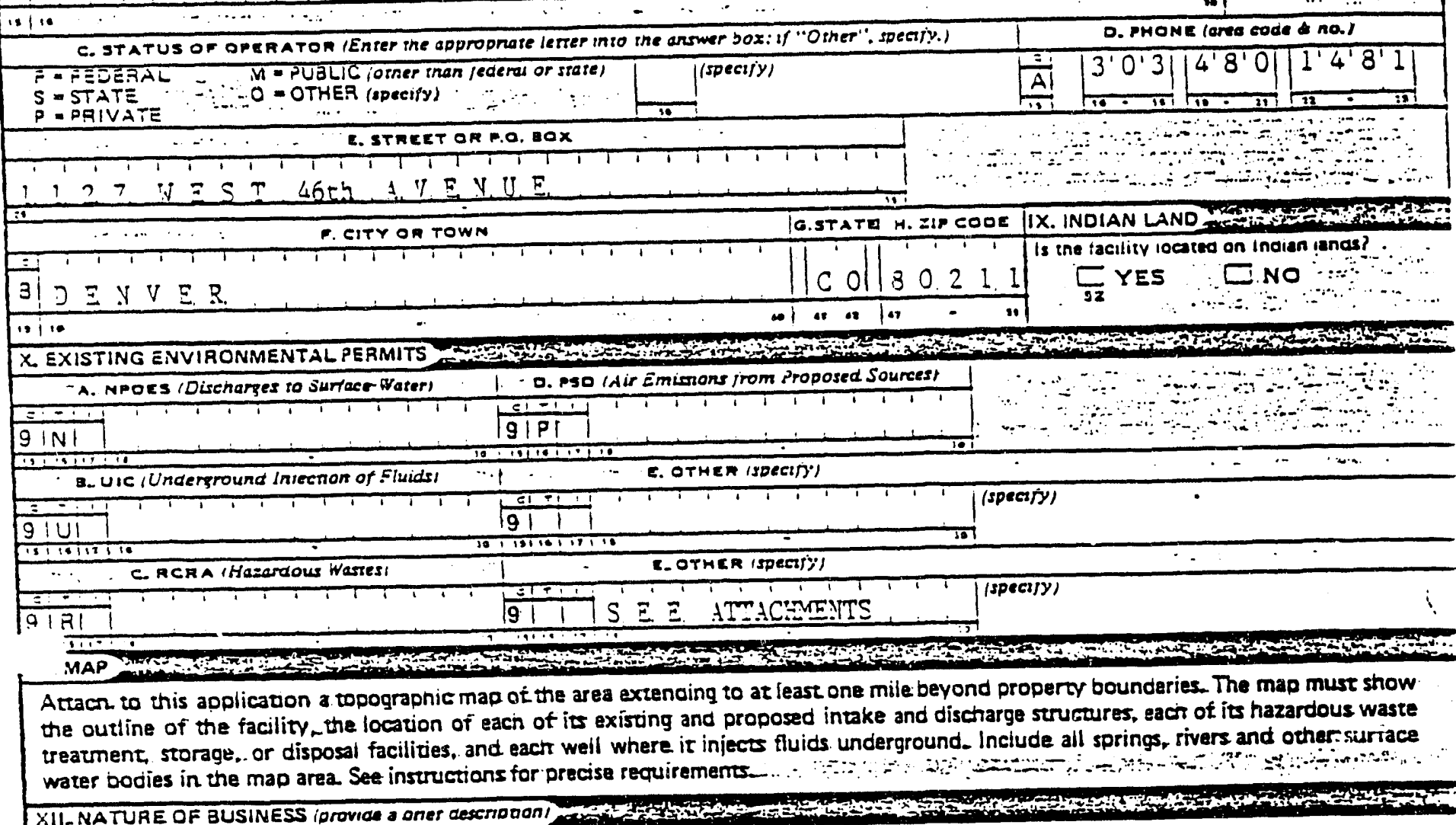
See Attachments

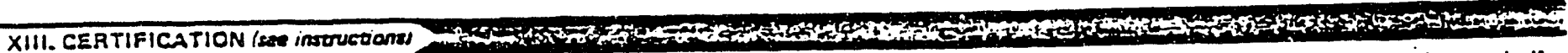
I cercity under penalty of law thas I have personally examined and am familiar with the information submitted in this application and all attaciments and that, based on my inquiby of those persons immediately responsible for obtaining the intormation concained in the apolication, / believe that the information is true, accurate and complete / am aware that there are significamt penalties for submitting false information, including the possibility of fine and imprisonment. A. MAMC OFPICIAL TITLE (rype or pinnt)

Daniel E. Caulk President Naviul .... $\because . .$. - 


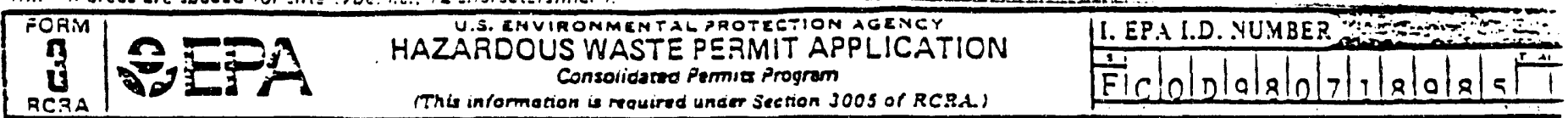

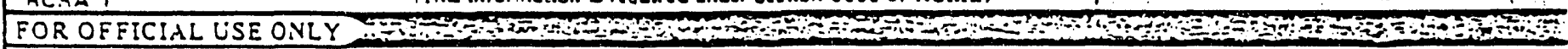
appication OATERECEIVEDI

COMMENTS

II. FIRST OR REVISED APPIICATION

$P !$ ace an " $X$ " in the aoprodriate cox in $A$ or 3 Eelow imarx one sox oniyl to incicate wnerner enis is ine rirst adolication you are suamitring for your iacility or

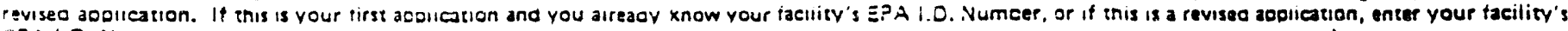
$=$ PA I.D. Numoer in Item I aoove.

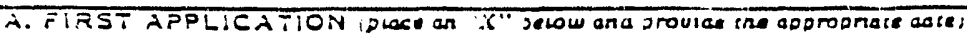

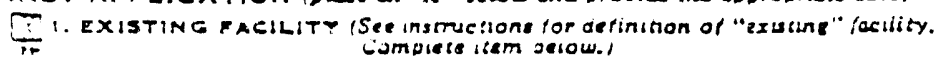

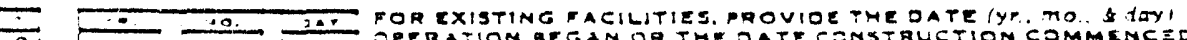

3 OI OIO OI OPERATION BEGAN OR THE DATE CONSTRUCTION COMMENCED

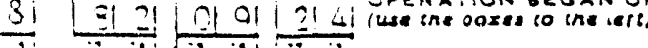

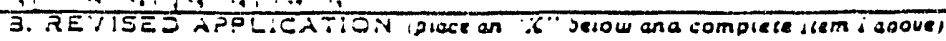

Fi. Macility Mas INTERIM STATUS

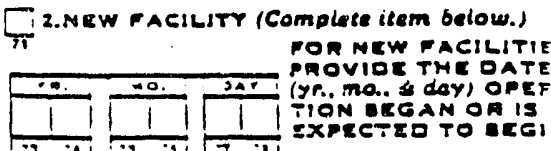

III. PROCESSES - CODES AVD DESIGN CAPACITIES -

A. PRCCESS COCE - Enter the code from the list of Jrocess coces velow that best describes each orocses to be used at jhe iacilitv. Ten lines are orovided fo entering coces. If more lines are neeced. anter ine coceiss in ine soaca grovided. If a orocess will be ised istat is not inciuced in the list or coces oelown the

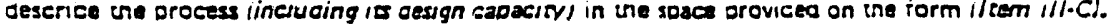

8. PROCESS DESIGN CAPACITY - For exen code entered in column $\lambda$ enter the Goacity of the process.

1. AMCUNT - Enter Gie amoune.

2. UNIT OF MEASURE - For saen amount entered in column 3 (1), enter the cece irom the list or unit measure coces delow that deseribes the unit of measure usea. Oniy the units or measure that are listed betow snowa be usseo.

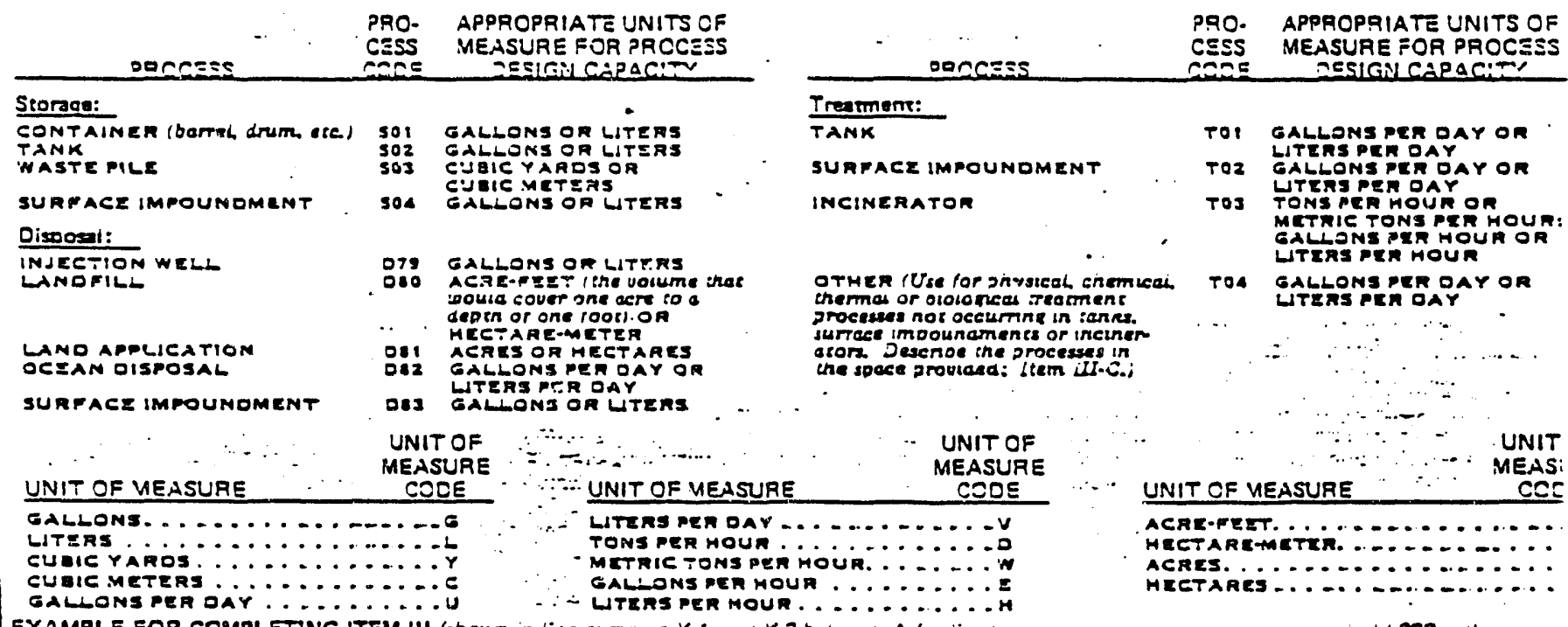

EXAMPLE FOR COMPLETING ITEM III (shown in line numoers X.1 ano X.2 below): A tacilitv nas two storage anks, one ank can nold 200 gallons ana otner can nold 100 gallons. The tacsity also has an inctnerator that an oum uo to 20 gallons cer nour.

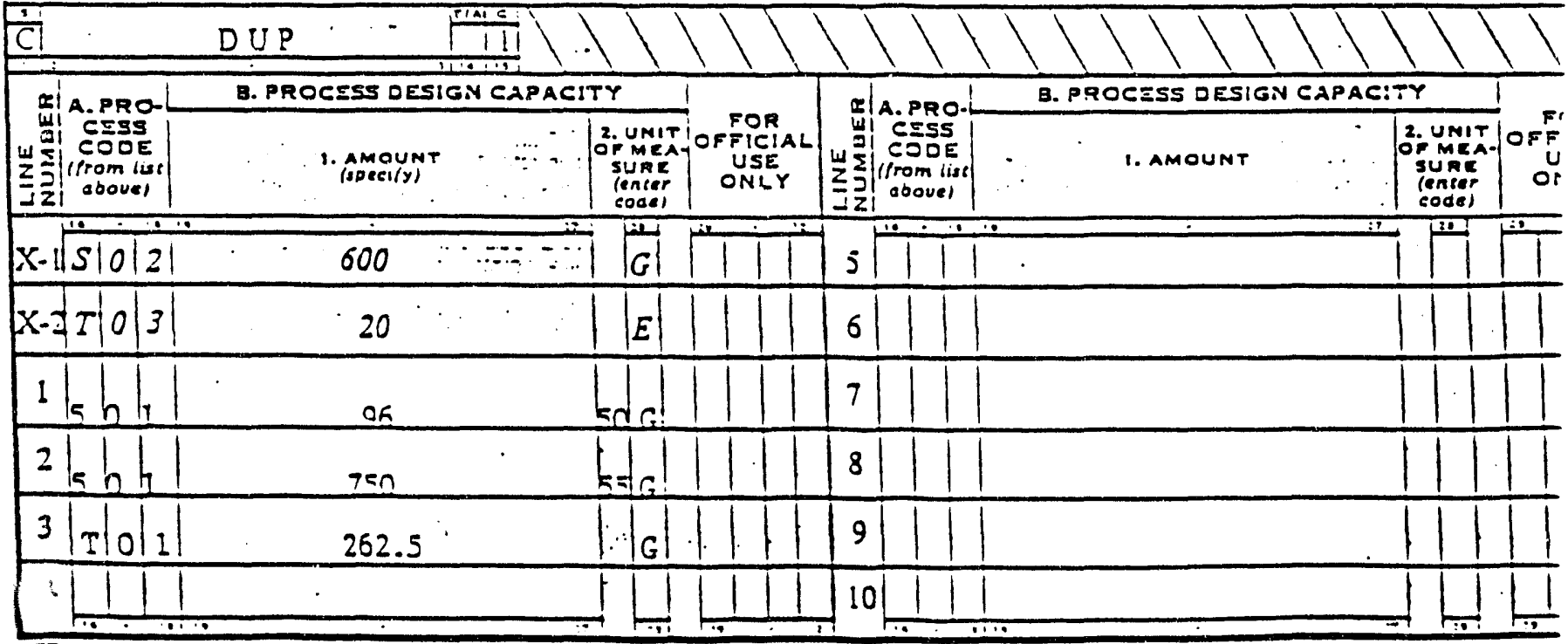




\section{SEE ATISCNEVTS}

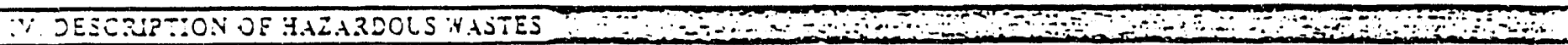

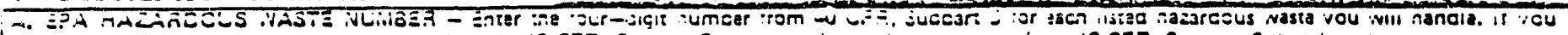

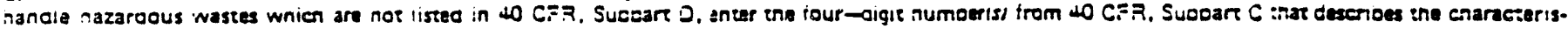
iles anolor ine toxic sontaminand or those nazarcous wastes.

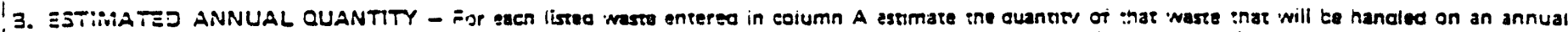

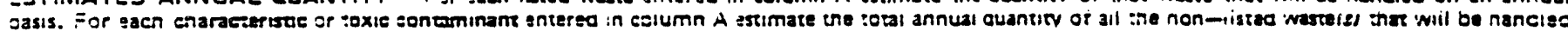
wnich sossess inat characserisste se contaminant.

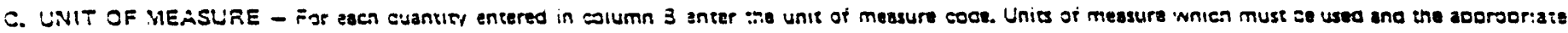
seces are:
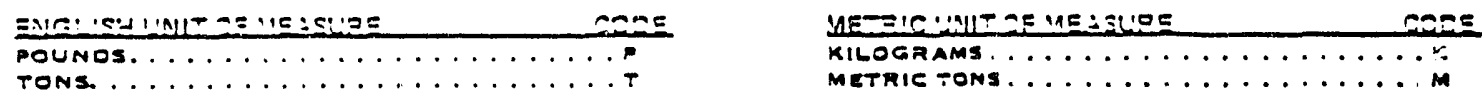

If Se:lis, iecores use anv orner unit ji neasure for guantitv, the units or measure must ze converted into one of tise recuireo units of measure taking inso acseune ine accreoriate censity or sceciric gravioy or she waste.

D. PRCCESSES

1. PQCCESS CE:SS:

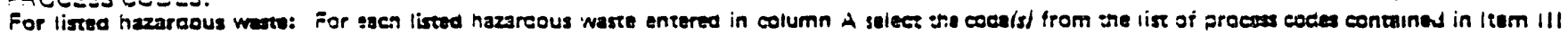

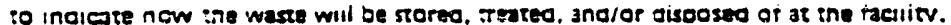

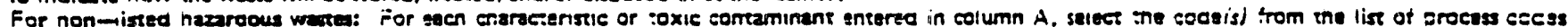

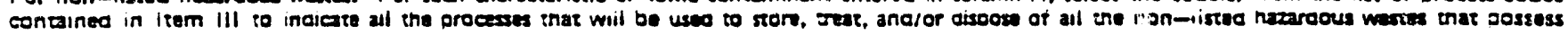
That $=$ רaracentistic or toxic =omtaminant.

Now: Four soaces are sroviced for entenna srocass ceces. If more an needed: (1) Ezrer ine tirss inres as Cescribue above: (2) Enter "YCO" in ine

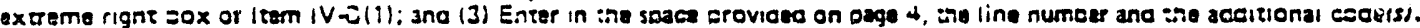

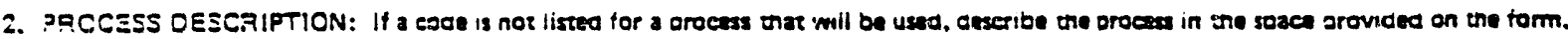

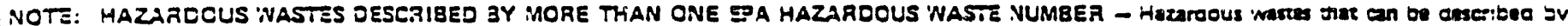
more inan one EPA Haxaroous Warte Numeer snall de aescrioed on ene rorm as follows:

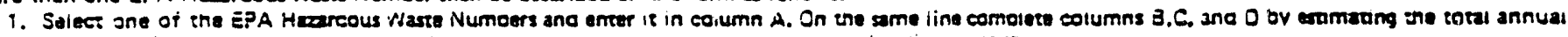
ouantiov oi the waste and cescreing all the oroeeses to ce usec to treat. store. 3na/or oisoose or ine wasts.

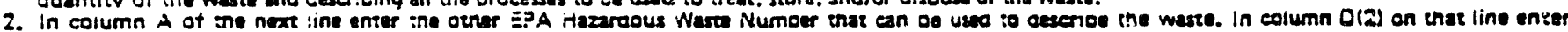
mevoed with asove" and maxe no orner entnes on that line.

3. Reoeat steo 2 for ecen otner E?A Hazarcous Wast Numoor that en on used to describe the hamerdous warte.

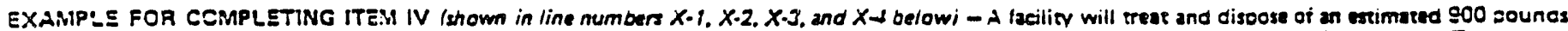
aes year of etrome snavings from leather :anning and finisining ooeration. In acdition, the tac:lity will treat ano disoose of three non-listed wastas. Two wass are esprosive oniy and there wit be an eszimareg 200 souncs ser year of each waste. The otner waste is corrosive and ignicable and inere will te an estirtia:ec 100 oouncs ser vear of that warte. Treatmene will be in an incinerator and disoosal wili be in a landill.

\begin{tabular}{|c|c|c|c|c|c|c|c|}
\hline & A. EPA & & C. UNIT & & & & sses \\
\hline$\equiv$ & $\begin{array}{l}\text { HAZARD } \\
\text { WASTEIN } \\
\text { lenter code }\end{array}$ & $\begin{array}{l}\text { B. ESTIMATED ANNUAL } \\
\text { OUANTITY OF WNASTE }\end{array}$ & $\left|\begin{array}{c}\text { sung } \\
\text { concer } \\
\text { coesi }\end{array}\right|$ & $\begin{array}{l}\text { 1. Pnocess } \\
\text { loni }\end{array}$ & coors & & 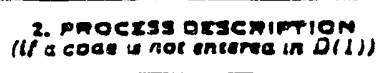 \\
\hline$X-1$ & $K 1015$ & 900 & $P$ & $\left.\begin{array}{lll|lll}I & 0 & 3 & 0 & 8 & 0\end{array}\right)$ & & & \\
\hline 2 & $|D| 0|0|$ & 400 & $P !$ & \begin{tabular}{lll|lll}
$T^{\prime}$ & $0^{\prime}$ & 3 & $D^{\prime}$ & 8 & 0
\end{tabular} & 11 & ' & \\
\hline$Y-3$ & $D ! 0 ! 0$ & 100 & $p$ & $\left|T^{\prime} 0^{\prime} 3\right| D^{\prime} 8^{\prime} 0$ & & & $\cdot$ \\
\hline$\times 1$ & D|O|l|o| & & & & 11 & & included with above \\
\hline
\end{tabular}




\begin{tabular}{|c|c|c|c|c|c|}
\hline & EPA I.D. NUME & BER (enter from page () & & FOR OFFICIA & \\
\hline Wi & a 1 गो al & 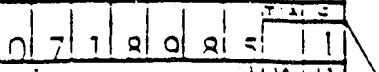 & 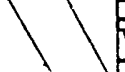 & $D U P$ & $\mathrm{DUP}$ \\
\hline IV. & JESCRIPTIO & N OF HAZARDOUS WAS & C UMUT & & $55=5$ \\
\hline$\stackrel{j}{2}$ & $\begin{array}{l}\text { HAZARD. } \\
\text { WASTENOI } \\
\text { lencer codel }\end{array}$ & $\begin{array}{l}\text { B. ESTIMATED ANNUAL } \\
\text { QUANTITY OF WNASTE }\end{array}$ & $\left|\begin{array}{c}\text { OFMEA- } \\
\text { SURE } \\
\text { (encer } \\
\text { COOC) }\end{array}\right|$ & $\begin{array}{l}\text { 1. PROCESS COOES } \\
\text { (encer) }\end{array}$ & $\begin{array}{l}\text { 2. PROCEss OEsCRIPTION } \\
\text { (if a code w not encerea in } D(d) \text { ) }\end{array}$ \\
\hline
\end{tabular}

$1 \longdiv { 5 }$ ol ol 3120,000

- El ol ol st Included in above ||$G||$\begin{tabular}{lll}
\hline & 0 & 1
\end{tabular}

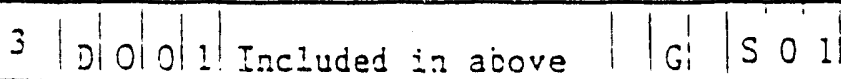

4

5

$6: 11$

7

8

9

10

11

12

13

14

151111

15

171111

18

19

20

21

221111

2311111

24

25

26 


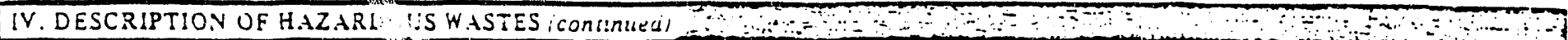
E. USE THIS SPACE TOLISTA: "TIONAL PROCESSCODESFROM ITEM OIION PAGE J.

$$
\text { - }
$$$$
-
$$

\begin{tabular}{|c|}
\hline \\
\hline $\begin{array}{l}1 \\
1\end{array}$ \\
\hline
\end{tabular}

V. F.ACILITY DRAWING

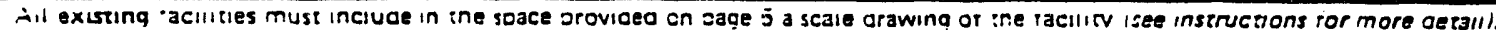

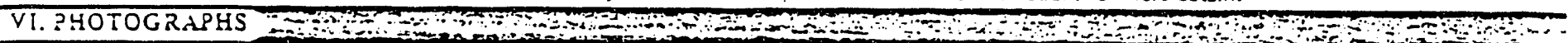

All existing iacilities must inc:uce pnotograons (aeriai or groung-,evel) that cieariv deiineate all existing structures: existing storage, ireatment and disoosal areas: and sites of future storage. treztment or disoosal areas (see instruc:ions ior more detaill.

${ }^{\prime} \quad$ TCILITY GEOGR.APHC LOCATION

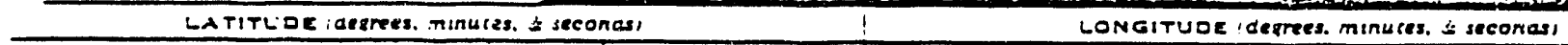

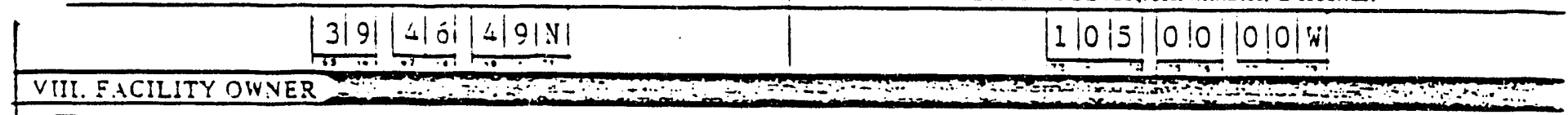

-A. If the facilitv owner is also the factiov operator as listed in Section VIll on Form 1, "General Iniormation". place an " $X$ " in the oox to the leit ano skip to Section $1 \times$ beiow.

3. If the racility owner is not the factitiv oderator as listed in Section VIII on Form 1, complete the fotlowing items:

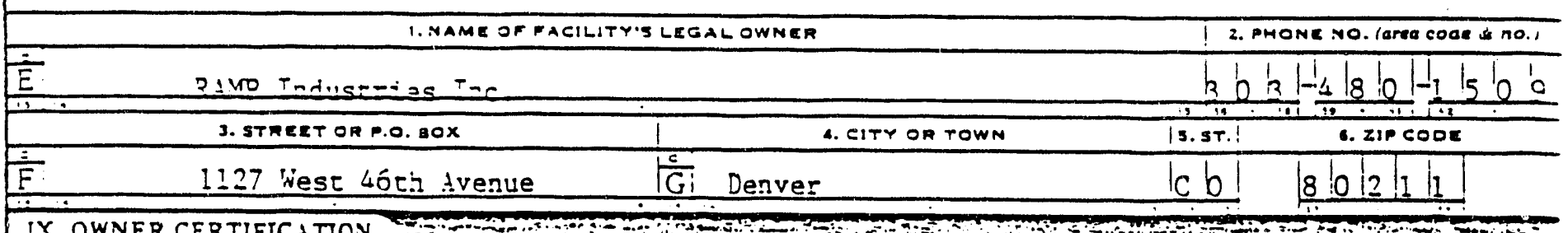

LX. OWNER CERIIFIC.ATION

I certify uncer penalty of law that I have personaily examined and am ramiiiar with the iniormation suomitred in tnis and all attacnea documents, and that based on my innuiry of those individuals immediately responsible for obtaining the iniormation, I believe that une suivmitted iniormation is true, accurate, and complete. I am aware that there are significant penalties for submitting false information, including the possibility of fine and imprisonment.
A. NAME (DTRZ OP CYPE)
Daniel E. Caulk

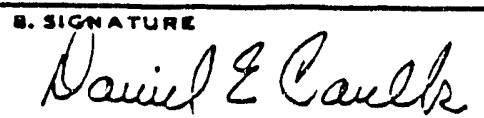
President
C. JATE SIGNEO
$1-26-88$

.. OPERATOR CERIIFICAIION

I cerify under penaity of law that I have personally examined and am familiar with the information suomitred in this and all atracned - 'Iments. and that based on my inquiry of those incividuals immediately resoonsibie for obtaining the information. I believe that the aitred information is tue, accurate, and complete. I am aware that there are significant penaities for submitting falso intormation. including the possubility of fine and imprisanment.
A. Name idnnc or roel
Daniel E. Coulk
A. Name ipnnc or ropl
Daniel E. Coulk
- spomatuna
C. DATE SIGNED
$1-26-88$

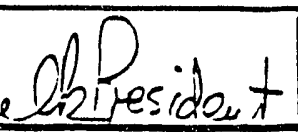

PAGE' \& OF
는 


\section{Exhibit E4}

HAZARDOUS WASTES ACCEPTABLE FOR RECEIPT AT RAMP 


\subsection{EPA Waste Codes Accepted}

The RAMP facility receives RCRA waste in the following EPA waste codes:

D001 Wastes meeting ignitability criteria per Section 251.21.

F003 Spent nonhalogenated solvents (xylene, acetone, ethyl acetate, ethyl ben 2 ene, ethyl ether, methyl isobutyl ketone, n-butyl alcohol, cyclohaexanone, and methanol) and still bottoms from their recovery.

F005 Spent nonhalogenated solvents (toluene, methyl ethyl ketone, carbon disulfide, isobutanol, and pyridine) and still bottoms from recovery. 


\section{Exhibit F1}

LIST OF PERMITS, LICENSES, OR AUTHORIZATIONS

PERTAINING TO ENVIROCARE 


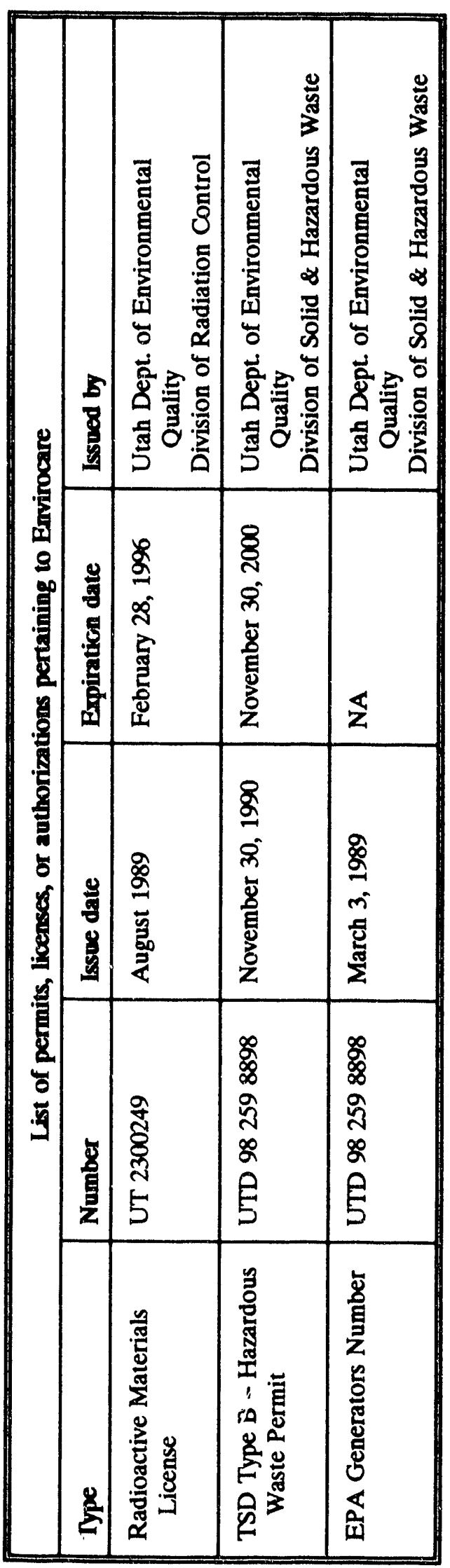


Exhibit F2

RADIOACTIVE MATERIAIS FOR LICENSE FOR ENVIROCARE 
DRC-03

August 1989

\section{UTAH DEPARTMENT OF ENVIRONMENTAL QUALITY \\ DIVISION OF RADIATION CONTROL \\ RADIOACTIVE MATERIAL LICENSE}

Pursuant to Section 19-3-104 of the Utah Code Annotated 1953, and the Utah Department of Environmental Quality Rules for the Control of Ionizing Radiation, and in reliance of statements and representations heretofore made by the licensee designated below, a license is hereby issued authorizing such licensee to transfer, receive, possess and use the radioactive material designated below; and to use such radioactive material for the purpose(s) and at the place(s), designated below. This license is subject to all applicable rules, and orders now or hereafter in effect and to any conditions specified below.

\section{LICENSEE}

1. Name Envirocare of Utah, Inc.

2. Address

Suite 1160

Salt Lake City, Utah 84111

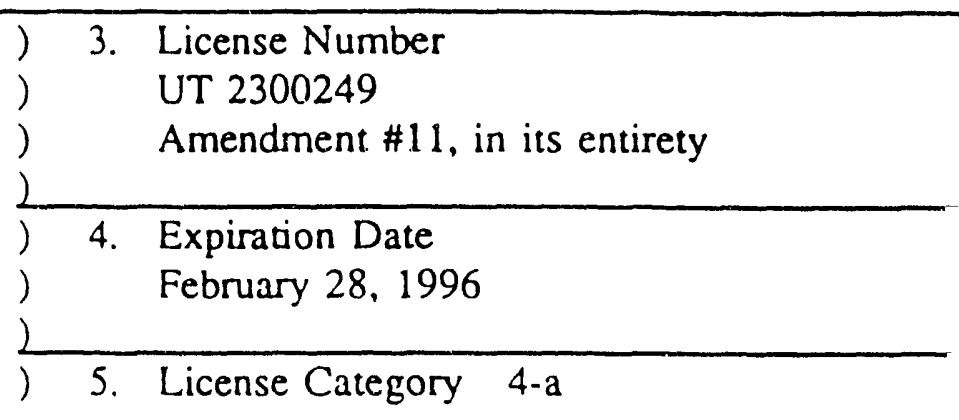

6. Radioactive Material (Element and Mass Number)

A. Silver-11917

B. Americium-241

C. Americium-243

D. Beryllium-7

¿. Calcium-45

F. Cadmium-109

G. Cobalt -56

H. Cobalt -57
7. Chemical and/or Physical Form

A. Volumetric bulky materials or structural debris

B. Volumetric bulky materials or structural debris

C. Volumetric bulky materials or suructural debris

D. Volumetric bulky materials or structural debris

E. Volumetric bulky materials or structural debris

F. Volumetric bulky materials or structural debris

G. Volumetric bulky materials or structural debris

H. Volumetric bulky materials or suructural debris
8. Maximum Concentration in Waste for Disposal

A. $5.6 \mathrm{E}+02 \mathrm{pCi} / \mathrm{g}$

B. $2.3 \mathrm{E}+02 \mathrm{pCi} / \mathrm{g}$

C. $\quad 1.7 \mathrm{E}+03 \mathrm{pCi} / \mathrm{g}$

D. $3.8 \mathrm{E}+04 \mathrm{pCi} / \mathrm{g}$

E. $\quad 4.0 \mathrm{E}+08 \mathrm{pCi}^{\prime} \tilde{\varepsilon}$

F. $\quad 4.6 \mathrm{E}+04 \mathrm{pCi} / \mathrm{g}$

G. $\quad 3.6 \mathrm{E}+02 \mathrm{pCi} / \mathrm{g}$

H. $\quad 1.9 \mathrm{E}+04 \mathrm{pCi} / \mathrm{g}$

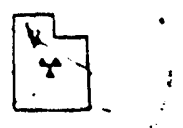


DRC-03

August 1989

UTAH DIVISION OF RADIATICN CONTROL

Page 2 of 12

RADIOACTIVE MATERIAL I ICENSE

SUPPLEMENTARY SHEET

License \# UT 2300249

6. Radioactive Material

(Element and Mass Number)

I. Cobalt -58

J. Cobalt -60

K. Chromium-51

L. Cesium-134

M. Cesium-137

N. Europium-152

O. Europium-154

P. Iron-55

Q. Mercury-203

R. Potassium-40

S. Iridium-192

T. Manganese-54
7. Chemical and/or Physical Form

I. Volumetric bulky materials or structural debris

J. Volumetric bulky materials or structural debris

K. Volumetric bulky materials or structural debris

L. Volumetric bulky materials or structural debris

M. Volumetric bulky materials or structural debris

N. Volumetric bulky materials or structural debris

O. Volumetric bulky materials or structural debris

P. Volumetric bulky materials or structural debris

Q. Volumetric bulky materials or structural debris

R. Volumetric bulky materials or structural debris

S. Volumetric bulky materials or structural debris

T. Volumetric bulky materials or structural debris
8. Maximum Concentration In

Waste for Disposal

I. $\quad 1.6 \mathrm{E}+03 \mathrm{pCi} / \mathrm{g}$

J. $\quad 3.6 \mathrm{E}+02 \mathrm{pCi} / \mathrm{g}$

K. $\quad 6.8 \mathrm{E}+04 \mathrm{pCi} / \mathrm{g}$

L. $\quad 1.2 \mathrm{E}+03 \mathrm{pCi} / \mathrm{g}$

M. $\quad 5.6 \mathrm{E}+02 \mathrm{pCi} / \mathrm{g}$

N. $\quad 1.7 \mathrm{E}+03 \mathrm{pCi} / \mathrm{g}$

O. $\quad 1.4 \mathrm{E}+03 \mathrm{pCi} / \mathrm{g}$

P. $\quad 1.8 \mathrm{E}+06 \mathrm{pCi} / \mathrm{g}$

Q. $\quad 1.0 \mathrm{E}+04 \mathrm{pCi} / \mathrm{g}$

R. $\quad 1.0 \mathrm{E}+04 \mathrm{pCi} / \mathrm{g}$

S. $\quad 2.5 \mathrm{E}+03 \mathrm{pCi} / \mathrm{g}$

T. $\quad 5.6 \mathrm{E}+03 \mathrm{pCi} / \mathrm{g}$

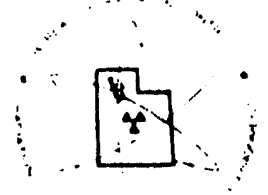

G-205 
DRC-03

August 1989

Page 3 of 12

UTAH DIVISION OF RADIATION CONTROL RADICACTIVE MATERIAL LICENSE

SUPPLEMENTARY SHEET

License \# UT 2300249

6. Radioactive Material

(Element and Mass Number)

U. Niobium-94

V. Nickel-59

W. Nickel-63

X. Lead-210

Y. Polonium-210

Z. Radium-226

AA. Radium-228

BB. Radium-228

1 year

CC. Radium-228

5 years

DD. Radium-228

10 years

EE. Ruthenium-106

FF. Antimony-124
7. Chemical and/or Physical Form

U. Volumetric bulky materials or structural debris

V. Volumetric bulky materials or structural debris

W. Volumetric bulky materiais or structural debris

$\therefore \quad$ Volumetric bulky materials or structural debris

Y. Volumetric bulky materials or structural debris

Z. Volumetric bulky materials or structural debris

AA. Volumetric bulky materials or structural debris

BB. Volumetric bulky materials or structural debris

CC. Volumetric bulky materials or structural debris

DD. Volumetric bulky materials or structural debris

EE. Volumetric bulky materials or structural debris

FF. Volumetric bulky materials or structural debris

\section{Maximum Concentration in} Waste for Disposal

U. $\quad 1.6 \mathrm{E}+02 \mathrm{pCi} / \mathrm{g}$

V. $\quad 7.0 \mathrm{E}+02 \mathrm{pCi} / \mathrm{g}$

W. $\quad 2.0 \mathrm{E}+06 \mathrm{pCi} / \mathrm{g}$

X. $2.3 \mathrm{E}+05 \mathrm{pCi} / \mathrm{g}^{*}$

Y. 2.0E $+04 \mathrm{pCi} / \mathrm{g}$

Z. $2.0 \mathrm{E}+03 \mathrm{pCi} / \mathrm{g}^{*}$

AA. $\quad 1.8 \mathrm{E}+03 \mathrm{pCi} / \mathrm{g}$

BB. 1.2E+03 pCi/g*

CC. $6.7 \mathrm{E}+02 \mathrm{pCi} / \mathrm{g}^{*}$

DD. $\quad 5.6 \mathrm{E}+02 \mathrm{pCi} / \mathrm{g}^{*}$

EE. $\quad 1.9 \mathrm{E}+04 \mathrm{pCi} / \mathrm{g} *$

FF. $\quad 7.9 \mathrm{E}+02 \mathrm{pCi} / \mathrm{g}$

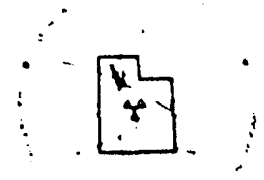


DRC-03

August 1989

UTAH DIVISION OF RADIATION CONTROL

Page 4 of 12

RADIOACTIVE MATERIAL LICENSE

SUPPLEMENTARY SHEET

License \# UT 2300249

6. Radioacuve Material

(Element and Mass Number)

GG. Antimony-125

HH. Tin-113

II. Strontium-90

JJ. Thorium-230

KK. Thorium-232

LL. Uranium-234

MM. Uranium-23.5

NN. Uranium-236

OO. Uranium-238

PP. Uranium-natural

QQ. Uranium-depleted

RR. Zinc-65
7. Chemical and/or Physical Form

GG. Volumetric bulky materials or structural debris

HH. Volumetric bulky materials or structural debris

II. Volumetric bulky materials or structural debris

JJ. Volumetric bulky materials or structural debris

KK. Volumetric bulky materials or structural debris

LL. Volumetric bulky materials or structural debris

MM. Volumetric bulky materials or structural debris

NN. Volumetric bulky materials or structural debris

00. Volumetric bulky materials or structural debris

PP. Volumetric bulky materials or structural debris

QQ. Volumetric bulky materials or structural debris

RR. Volumetric bulky materials or suructural debris
8. Maximum Concentration In

Waste for Disposal

GG. $\quad 5.3 \mathrm{E}+03 \mathrm{pCi} / \mathrm{g}$

HH. 7.3E+0.5 pCi/g

II. $\quad 2.0 \mathrm{E}+04 \mathrm{pCi} / \mathrm{g}$

JJ. $\quad 1.5 \mathrm{E}+04 \mathrm{pCi} / \mathrm{g}$

KK. $\quad 6.8 E+02 \mathrm{pCi} / \mathrm{g}^{*}$

LL. $\quad 3.7 \mathrm{E}+04 \mathrm{pCi} / \mathrm{g}$

MM. 7.7E+02 pCi/g

NN. $\quad 3.6 \mathrm{E}+04 \mathrm{pCig}$

OO. 2.8E+04 pCi/g

PP. $\quad 1.8 \mathrm{E}+04 \mathrm{pCi} / \mathrm{g}$

QQ. $\quad 1.1 \mathrm{E}+05 \mathrm{pCi} / \mathrm{g}$

RR. 1.1E+04 fCi/g

* Daughters are assumed to be present at same concentrations in equilibrium.

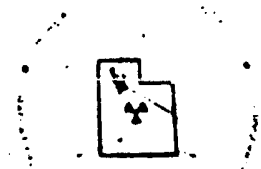




\section{AUTHORIZED USE}

Radioactive material as radioactive waste may be received, stored and disposed of by land burial. The licensee shall not accept low-level radioactive waste generated outside the region comprised of the party states to the Northwest Interstate Compact on Low-Level Radioactive Waste Managemen ( Compact") namely Alaska, Hawaii, Idaho, Montana, Oregon, Utah and Washington, unless the provisions of Articles IV and $V$ of the Compact are met. Prior to receiving any such shipments, the licensee shall subrait to the Utah Division of Radiation Control documentation evidencing compliance with these Compact provisions.

\section{CONDITIONS}

10. Licensed material shall be used at the licensee's facility located in Section 32 of Township 1 South and Range 11 West, Tooele County, Utah.

11. The licensee shall not possess at any time, more than 300,000 cubic yards of radioactive waste material which is not disposed of in accordance with the finished design requirements. This includes all wastes in storage or active processing.

12. Pursuant to R447-12-54(1), the licensee is granted as exemption to R447-25-9, as it relates to land ownership and assumption of ownership.

13. The maximum quantity of special nuclear material which the licensee may possess, undisposed of, at any one time shall not exceed 350 grams of Li-235.

14. Licensed maisrial specified in Item 6.A through 6.RR shall not be placed in a disposal cell unless it has been determined that the concentration of radionuclides is appropriately homogeneous within the physical form of the waste. This does not pertain to structural debris superficially contaminated with licensed materials.

15. A. If a mixture of radionuclides $a, b$, and $c$ are present in the waste in the concentrations $C_{a}, C_{b}$, and $C_{c}$ and if the applicable maximum waste concentrations from Item 8 of this license are $\mathrm{MWC}_{\mathbf{a}}, \mathrm{MWC}_{\mathrm{b}}$ and $\mathrm{MWC}_{\mathrm{c}}$ respectively, then the concentration in the waste shall be limited so that the following relationship existi.

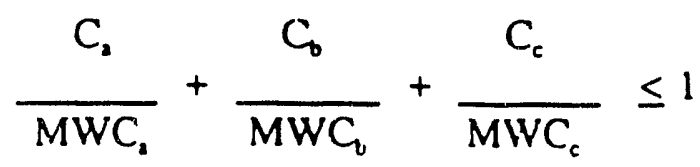

B. If a single radionuclide is present in the waste, the concentration shall not exceed the applicable value found in Item 8 of this license.

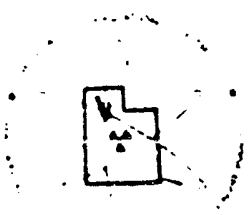




\section{UTAH DIVISION OF RADIATION CONTROL RADIOACTIVE MATERIAL LICENSE SUPPLEMENTARY SHEET}

16. A. The licensee may receive for treatment, storage, and disposal any radioactive waste as authorized by this license that contains hazardous constituents as permitted by the "RCRA Hazardous Waste Operations Permit" issued by the Executive Secretary, Utah Solid and Hazardous Waste Committee and "HWSA Permit" issued by the U.S. Environmental Protection Agency.

B. The licensee shall dispose of these wastes in the "mixed waste" disposal embankment only.

17. Sealed sources as defined in R447-12-3(64) shall not be accepted for disposal.

18. Radioactive waste containing liquid, shall not be accepted for disposal except as provided by the Ground Water Discharge Permit, number UGW 450005, issued by the Executive Secretary of the IJtah Water Quality Board.

19. The licensee shall comply with the provisions of Chapter R447-18, "Notices, Instructions and Reports to Workers by Licensees or Registrants, Inspections" and Chapter R447-15, "Standards for Protection Against Radiation".

20. The licensee may transport licensed material or deliver licensed material to a carrier for transport in accordance with the frovisions of R447-19-100 "Transportation".

21. W'ritten procedures shall be maintained and available at the disposal facility for operations involving radioactive materials. The procedures shall incorporate operating instructions and appropriate safety precautions for the work. The employee training program shall include detailed review of the operating procedures applicable to the employee's assignments. The requirement for written procedures shall include establishment of procedures for conduct of the radiation safety and environmental monitoring programs, including analytical procedures and instrument calibration requirements. Written procedures and subsequent changes to the procedure shail be reviewed and approved by the Corporate Radiation Safety Officer and the Project Manager. At least annually. all procedures shall be reviewed to assure continued applicability.

2:2. The Corporation Radiation Safety Officer shall perform and document weekly inspections of the facility and report any findings of non-compliance, affecting radiological safety, to the Project Manager. Iterns for inspection include: operating procedures, license requirements and safety practices.

23. The licensee shall conduct contamination surveys in accordance with Table 7.2 of the license amendment application dated September 20, 1990.

24. The licensee shall conduct a bioassay and occupational airborne radioactive contamination monitoring program in accordance with Section 7.4.8.3 of the license amendment appl:cation dated September 20, 1990. 
DRC-03

August 1989

\section{UTAH DIVISION OF RADIATION CONTROL RADIOACTIVE MATERIAL LICENSE SUPPLEMENTARY SHEET}

Page 7 of 12

License \# UT 2300249

25. The use of respirators shall be controlled by a respiratory protection program as stipulated in R447-15-103.

26. The licensee shall calibrate air sampling equipment at intervals not to exceed six months.

27. The operational environmental monitoring program shall be conducted in accordance with Section 4.5. Table 4.7 and Figure 4.6 of the license amendment application dated September 20, 1990.

28. Vehicles, facilities, equipment or other items for unrestricted use shall not be released from the licensee's control if contamination measurements exceed the following limits:

\begin{tabular}{|c|c|c|c|}
\hline Nuclide" & $\begin{array}{l}\text { Column I } \\
\text { Average }{ }^{b, s .1}\end{array}$ & $\begin{array}{l}\text { Column II } \\
\text { Maximum b.as }\end{array}$ & $\begin{array}{l}\text { Column III } \\
\text { Removable bes }\end{array}$ \\
\hline $\begin{array}{l}\text { U-nal, U-235. U-238. and associated } \\
\text { decay products }\end{array}$ & $\begin{array}{l}5.000 \mathrm{dpm} \text { alpha/ } \\
100 \mathrm{~cm}^{2}\end{array}$ & $\begin{array}{l}15,000 \mathrm{dpm} \text { alpha/ } \\
100 \mathrm{~cm}^{2}\end{array}$ & $\begin{array}{l}1,000 \mathrm{dpm} \text { alpha/ } \\
100 \mathrm{~cm}^{2}\end{array}$ \\
\hline $\begin{array}{l}\text { Transuranics, Ra-226, Ra-228. Th-230. } \\
\text { Th-228. Pa-231, Ac-227, 1-125, 1-129 }\end{array}$ & $100 \mathrm{dpm} / 100 \mathrm{~cm}^{2}$ & $300 \mathrm{dpm} / 100 \mathrm{~cm}^{2}$ & $20 \mathrm{dpm} / 100 \mathrm{~cm}^{2}$ \\
\hline $\begin{array}{l}\text { Th-naL. Th-232. Sr. 90. Ra-223. Ra-224, } \\
\text { U-232, } 1-126,1-131.1-133\end{array}$ & $1,000 \mathrm{dpm} / 100 \mathrm{~cm}^{2}$ & $3.000 \mathrm{cpm} / 100 \mathrm{~cm}^{2}$ & $200 \mathrm{dpm} / 100 \mathrm{~cm}^{2}$ \\
\hline $\begin{array}{l}\text { Beta-gamma emitters (nuclides with decay } \\
\text { mocies other than alpha emissions or }\end{array}$ & $\begin{array}{l}5.00 \times 1 \mathrm{dpm} \text { beta, } \\
\text { gamma/100 } \mathrm{cm}^{2}\end{array}$ & $\begin{array}{l}15,000 \mathrm{dpm} \text { beta- } \\
\text { gamma/ } 100 \mathrm{~cm}^{2}\end{array}$ & $\begin{array}{l}1,000 \mathrm{dpm} \text { beta. } \\
\text { gamma/10 } \mathrm{cra}^{2}\end{array}$ \\
\hline
\end{tabular}
spontaneous fission) except $\mathrm{Sr}-90$ and other noted above.

3. Where surface contamination by both alpha- and beta-gamma cmitting nuclides exists, the limits established for alpha- and beta-gamma cmitting nuclides should apply independenuly.

b. As used in this table, dpm (disintegrations per minute) means the rate of emission by radioactive material as determined by correcting the counts per minute observed by an appropriate detector for background, efficiency, and geometric factors associated with the instrumentation.

c. Measurements of average contaminant should not be averaged over more than one square meter. For objects of iess surface area. the average should be derived for each such object.

d. The maximurn contamination level applies to an area of not more than $100 \mathrm{~cm}^{2}$.

e. The amount of removable radioactive material per $100 \mathrm{~cm}^{2}$ of surface area should be determined by wiping the area with dry filter or sof ahsorbent paper, applying moderate pressure, and assessing the amount of radioactive material on the wipe with an appropriate instrument of know efficiency. When removable contamination on objects of less surface area is determined. the peninent levels should be reductal properionally and tine entire suriace should be wipers.

i. The average and maximum radiation levels associated with surface contamination resulting from beta-gamma emitters shall not exceed 0.2 $\mathrm{mrad} / \mathrm{hr}$ at $1 \mathrm{~cm}$ and $1.0 \mathrm{mrad} / \mathrm{hr}$ at $1 \mathrm{~cm}$. respectively, measured through not more than 7 milligrams per square centimeter of total absorter. 
DRC-03

August 1989

\section{UTAH DIVISION OF RADIATION CONTROL RADIOACTIVE MATERIAL LICENSE SUPPLEMENTARY SHEET}

License \# UT 2300249

29. A quarterly report shall be prepared by the Corporate Radiation Safety Officer for the Project Manager and Company President evaluating employee exposures, effluent releases and environmental data to determine:

A. If there are any upward trends in personnel exposures for identifiable categories of workers or types of operations or in effluent releases;

B. If exposures and effluents might be lowered under the concept of maintaining exposures and effluents as low as reasonably achievable; and

C. If equipment for exposure and effluent control is being properly used and maintained.

30. In accordance with R447-25-33, the licensee shall submit annual reports to the Division of Radiation Control by the end of the furst calendar quarter of each year for the preceding year. The reports shall include:

A. Specification of the quantity of each of the principal contaminants released to unrestricted areas in liquid and in airborne effluents during the preceding year.

B. The results of the environmental monitoring program:

C. A summary of licensee disposal unit survey and maintenance activities; and

D. A summary of the volume, radioisotopes and their activities for materials disposed of.

31. Except as provided by this condition, the licensee shall maintain the results of sampling, analyses, surveys, and instrument calibration, reports on inspections and audits, employee training records as well as any related reviews, investigations and corrective actions, for five (5) years. The licensee shall maintain personnel exposure records in accordance with R447-15-401.

32. Operations shall be conducted by or under the supervision of Vernon E. Andrews, Corporate Radiation Safety Officer, or other individuals designated by the Corporate Radiation Safety Officer upon successful completion of the licensee's training program.

33. The licensee shall staff the operations of the facility in accordance with the organization char (Figure 8.1) of the license amendment application dated September 20, 1990.

34. The licensee staff shall meet the qualifications as described in Section 8.2 and shall have the responsibilities as described in Section 8.1.2 of the license amendment application dated September 20, 1990. 


\section{UTAH DIVISION OF RADIATION CONTROL RADIOACTIVE MATERIAL LICENSE SUPPLEMENTARY SHEET}

35. The licensee shall not initiate disposal operations in newly excavated areas until the Division of Radiation Control has inspected and approved the cell/embankment liner.

36. The licensee shall provide "as built drawings" of the facility, at intervals not to exceed six (6) months. Drawings shall be submitted by February 1 and August 1 of each year. The drawings shall show conditions on the site as they existed no earlier than thirty (30) days prior to the submittal of the drawings to the Division of Radiation Control. Drawings submitted as, "as built drawings" will be marked as such, and will be marked in the same place on each drawing. Record drawings showing approved future designs, final or finished conditions at the site may be included in the "as built drawings", but shall be marked as "record drawings".

37. Radioactive waste which have been off loaded shall be placed in the appropriate disposal embankment and stored in a manner approved by the Division of Radiation Control.

38. For the purpose of this license, debris is defined as any radioactive waste for disposal other than soils. Compactible debris is defined as: (A) having a gradation that will pass through a four inch (4") grizzly and; (B) as having a density greater than seventy pounds per cubic foot dry weight in accordance with ASHTO T-99. Contaminated materials, other than soil, not meeting these criteria are defined as noncompactible debris.

39. The licensee shall place bulk radionctive materials in twelve inch (12") uncompacted lifts.

40. In-place bulk radioactive waste shall be compacted at a moisture content of zero percent (0\%) in three percent (3\%) of optimum as determined by the Standard Proctor Method ASTM D-698.

41. The licensee shall compact each lift to not less than ninety percent $(90 \%)$ of optimum density as determined by Standard Proctor Method ASTM D-698. Sampling points for compaction testing shall include locations immediately adjacent to debris when debris is included in the lift.

42. All debris shall be less than ten inches (10") in at least one (1) dimension, and no longer than eight feet ( $\left.8^{\prime}\right)$ in any dimension.

43. The final 24 inches of the radioactive waste material embankment, within the side slopes and the top surface, shall be free of debris.

44. A lift or any portion of a lift shall be limited to less than ten percent (10\%) by volume of noncompactible debris and the debris shall be uniformly distributed throughout the lift. However, noncompactible debris in the form of concrete, stone or solid metal may be placed in the lift up to twenty-five percent (25\%) by volume, of the total lift if uniformly distributed throughout the lift.

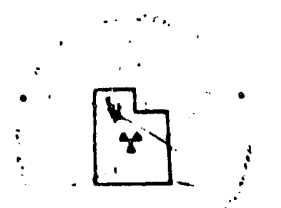


DRC-03

August 1989

\section{UTAH DIVISION OF RADIATION CONTROL RADIOACTIVE MATERIAL LICENSE SUPPLEMENTARY SIIEET}

License \# UT 2300249

45. The licensee shall excavate the disposal cell liner, consisting of native materiais, to a depth of twenty-four inches $\left(24^{\prime \prime}\right)$ and replace it with imported clay in six inch (6") uncompacted lifts. Each lift shall be compacted to not less than ninety-five percent (95\%) optimum density as determined by ASTM D-698 and field permeability of $1.0 \times 10^{-7} \mathrm{~cm} / \mathrm{sec}$.

46. The licensee shall not place, compactible nor non-compactible debris, in the first lift.

47. The disposal cell liner and radon barrier shall be consuructed with a moisture content of zero percent (0\%) to three percent $(3 \%)$ of optimum moisture as determined by Standard Proctor Method ASTM D-698.

48. The licensee shall compact the radon barrier to not less than 95 percent of optimum density as determined by Standard Proctor Method ASTM D-698 and a field permeability of $1.0 \times 10^{-7} \mathrm{~cm} / \mathrm{sec}$.

49. The licensee shall record, at the time of acceptance, the date and time of day that any lift or portion of a lift has been accepted by the licensee as finished in accordance with all specifications and license conditions.

50. The licensee shall use rock filter zone and rock erosion barrier that has been sized and graded in accordance with Section 3.1.1.2 and 9.2.5 of the license amendment application dated September 20, 1990.

51. The licensee shall test rock erosion barrier and filter zone rock in accordance with the provisions found in Section 9 of the license amendment application dated September 20, 1990.

52. The licensee sha!l utilize a manifest ("Radioactive Waste Shipment and Disposal Record," Envirocare Form E100) $\mathrm{Cc}$ aini.ig the information required in R447-15-311(2) and (3) including:.

A. Specification of any solidification agents utilized;

B. Identification of wastes containing more than $0.1 \%$ by weight of chelating agents. Chelating agents means amine polycarboxylic acids, hydroxyl-carboxylic acids, gluconic acids and polycarboxylic acids;

C. An estimate of the weight percentage of any chelating agents in waste.

53. The licensee shall not accept radioactive waste for storage and disposal unless the licensee has received a complete "Radioactive Waste Shipment and Disposal Record" (Form \#E-100) from the shipper.

54. The licensee shall mainiain copies of complete manifests or equivalent documentation until the Division of Radiation Control authorizes their disposition.

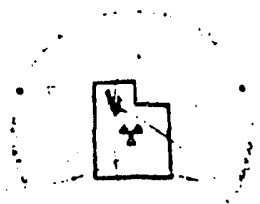


55. The licensee shall immediately notify the Division of Radiation Control or the Division's on-site representative of any waste shipment where a violation of applicable regulations or license conditions has been found.

56. The licensee shall require anyone who transfers radioactive waste to the facility comply with the requirements in R447-15-311(4)(a) through (h).

57. The licensee shall acknowledge receipt of the waste within one (1) week of receipt by returning a signed copy of the manifest or equivalent documentation to the shipper. The shipper to be notified is the licensee who last possessed the waste and transferred the waste to the licensee. The returned copy of the manifest or equivalent documentation shall indicate any discrepancies between materials listed on the manifest and materials received.

58. The licensee shall notify the shipper (i.e., the generator, the collector, or processor) and the Division of Radiation Control when any shipment or part of a shipment has not arrived within 60 days after the advance manifest was received.

50. The licensee shall maintain a record for each shipment of waste disposed of at the site. As a minimum, the record shall include:
A. The date of disposal of the waste;
B. The location of waste in the disposal site;
C. The condition of the waste packages received;
D. Any discrepancy between the waste listed on the shipment manifest or shipping papers and the waste received in the shipment.

E. A description of any evidence of leaking or damaged packages or radiation or contamination in excess of applicable regulatory limits; and

D. A description of any repackaging operations of any of the waste packages in the shipment.

60. In accordance with R447-25-31 the licensee shall maintain a Utah Division of Radiation Control Surety ('Trust) Agteement adequate to fund the decommissioning and reclamation of the grounds, equipment and facilities. These costs, identified in Section 10 of the license amendment application dated September 20, 1990, shall be reviewed and updated annually and a report submitted to the Utah Division of Radiation Control within 60 days after July 1. of each year. The survey arrangement shall be updated as necessary to reflect decommissioning and reclamation costs. 


\section{UTAH DIVISION OF RADIATION CONTROL RADIOACTIVE MATERIAL LICENSE SUPPLEMENTARY SHEET}

j1. Truck, railcar, waste hauling and other earth moving equipment washdown (decontamination) facilities, including evaporation ponds, shall be controlled and fenced to prevent intrusion.

52. All burial embankments and waste storage areas, including immediately adjacent drainage structures, shall be controlled areas, surrounder by a six foot (6') high, chain link fence, topped with twisted selvedge. All permanent fence shall be chain link, six feet (6) high, topped with three strand barbed wire, top terision wire and twisted selvedge.

33. The licensee shall fulfill and maintain compliance with all conditions and shall meet all compliance schedules stipulated in the Ground Water Discharge Permit, number UGW 450005, issued by the Executive Secretary of the Utah Water Quality Board.

54. One (1) year prior to the anticipated closure of the site, the licensee shall submit a final version of the site closure, decontamination and decommissioning plan. As part of this plan, the licensee shall demonstrate by measurements and/or modeling that concentrations of radioactive materials which may be released to the general environment, after site closure, will not result in an annual dose exceeding 25 millirems to the whole body, 75 millirems to the thyroid, and 25 millirems to any other organ of any member of the public.

35. Except as specifically provided otherwise by this license, the 'icensee shall possess and use radioactive material described in Item 6, 7, and 8 of this license and conduct site operations in accordance with statements, representations, operating procedures, and disposal criteria, heretofore made by the licensee or his authorized representative in application for and subseguent to issuance of Utah Radioactive Material License No. UT 2300249 and amendments thereto.

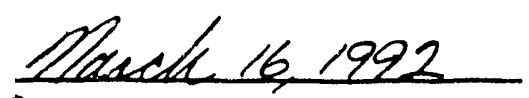

Jate
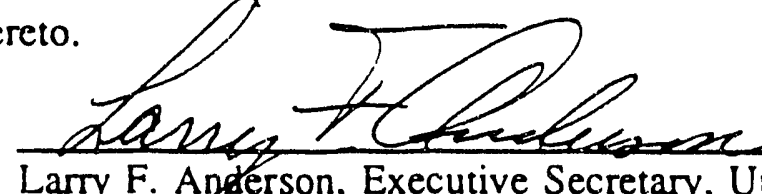

Larry F. Anderson, Executive Secretary, Utah Radiation Cuntrol Board 
Exhibit F3

RCRA PERMIT FOR ENVIROCARE 


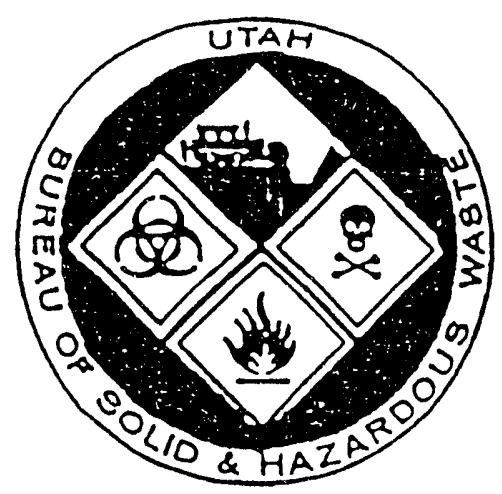

\section{STATE OF UTAH PLAN APPROVAL}

Permittee:

Envirocare of Utah, Inc.

Troele County, Utah

EPA Identification Number UTD982598898

Pursuant to the Utah Solid and Hazardous Waste Act, (the Act), 26-14-1, et. seq., Utah Code Annotated 1953, as amended and the Utah Administrative Code (UAC) (R450-1 through R450-13 and R45050) as adopted by the Utah Solid and Hazardous Waste Committec, (the Committee), a plan approval (herein after called "permit") is issued to Envirocare of Utah, Ino. (hereafter ca]jed the "permittee"), to operate a hazardous waste treatment and storage facility in Tooele County, Utah, at latitude $40041^{\prime}$. 000 " Horth and longitude $113006^{\prime}$ "030" West. The U.S. Environmental Protection figency (U.S. EPA) has authorized the Executjure Secretary to issue such a permit under Section 3006 ibj of the Resource Conservation and Recovery ACt (KCRA).

The permittee must comply with ail the terms and conditions of this permit. The permit consists of the conditions sontaired herein (including the portions of the application attaches and incorporated by refereice;, and the applicable portions of $\mathrm{x} 450$ 1 through R450-13, R.550-50, and R450-101 contained in trie pexmit. Applicable rules are those which are in effect on the date of issuance of this permit.

This permit is based on the premise that the information sibmitted in the application dated July 22, 1987 as mocificid by subsequent amendments dated April 25, 1986 and July 25, Igg9 (hereaftcr referred to as the application), is accurate and that the facility will be operated as specified in the referenced portions of the application, except as modified by the conditions herein. Portions of the application are attached and incorporated herein by reference, wherever noted, as part of this permit. Any inaccuracies or misrepresentations found in the application may be grounds for tise tejmination or modification of this permit lsee $5 \leq 50-3-9$.$) The Fermittee must inforn the$ Executive Secretary of any deviation frcm, or changes in the information in tlie application which would affect the permittee's ability to comply with the applicable regulations or permit conditions. 


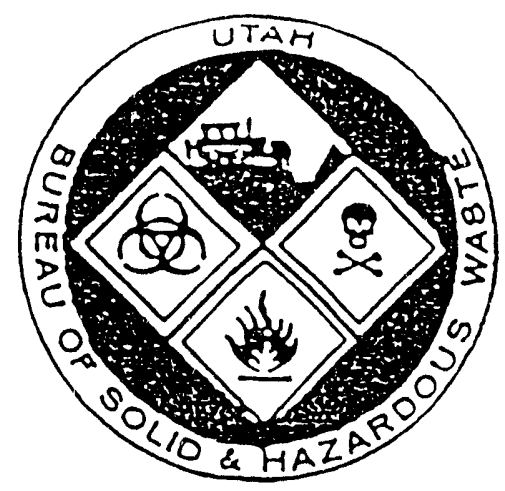

This permit is effective as of November 30,1990 and shall remain in effect until November 30, 2000, unless revoked and reissued (R450-3-9.1(a) (b) (c)) or terminated (R450-3-9.2.), or continued in accordance with R450-3-5(d).

Signäture:

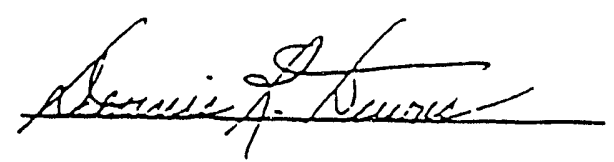

Date: $\frac{11 / 30 / 90}{1 / 1}$

Dennis R. Downs

Executive Secretary

Utah Solid and Hazardous wastes committee 


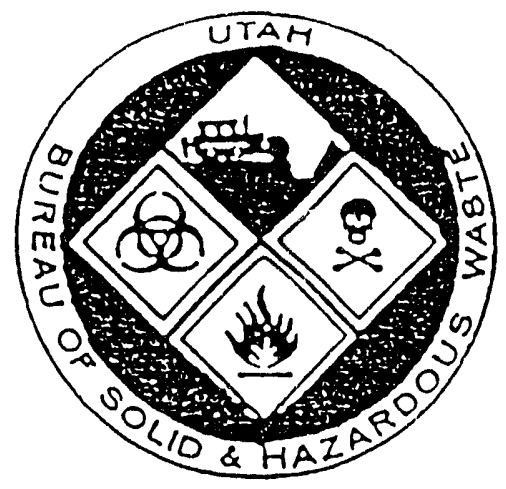

NOTE TO ENVIROCARE'S PART B PERMIT CERTIFICATE:

The Envirocare site is licensed by the Utah Bureau of Radiation Control ior disposal of radioactive waste. The site is also licersed by the Utah Bureau of Radiation Control and pernit:ed by the Utah Bureau of Solid and Hazardous Waste ior djsposal of "mixed" (hazardousiradioastive) waste.

Any one wishing to visit the site should contact the pernittee to make irrangoments for a site tour and to determirie that all safety requirements are met prior to entering tins site.

Inspectors who will have extensive contact with the site should contact both the Utah Bureau of Radiation Control and the Urah Bureau of Solid and Hazardous Waste to determine that alu. safety requirements i.e. satety equipment, safety training, andior physical, are met prior to entering the site. 
Exhibit F4

HAZARDOUS WASTES ACCEPTABLE FOR DISPOSAL AT ENVIROCARE 
APFROVED HAZARDOUS WASTE NUMBERS ENVIROCARE OF UTAH, INC. 
RCRA Wastes

APPROVED HAZARDOUS WASTE NUMBERS

ENVIROCARE OF UTAK, INC.

EPA Waste No.

Hazard

Code

\begin{tabular}{llr}
\hline D001 & Ignitability & (I) \\
D002 & Corrosivity & (C) \\
D003 & Reactivity & (R) \\
D004 & Arsenic & (E) \\
D005 & Barium & (E) \\
D006 & Cadmium & (E) \\
D007 & Chromium & (E) \\
D008 & Lead & (E) \\
D009 & Mercury & (E) \\
D010 & Selenium & (E) \\
D011 & Silver & (E) \\
D012 & Endrin & (E)
\end{tabular}

$(1,2,3,4,10,10$-hexachloro-1,7, epoxy-1,4,4a,5,6,;7,8,8a-0 octahydro-1,4, endo, endo-5,8-dimeth-ano-naphthal ene) D013

$(1,2,3,4,5,6$, hexa-chloro-cyclohexane, garmo isomer)

DO14

Lindane

(E)

(1,1,1-Trichloro-2,2-bis [p-methoxypheny(] ethane)

D015

Methoxychlor

(E)

$\left(\mathrm{C}_{10} \mathrm{H}_{10} \mathrm{Cl}_{8}\right.$, technical chlorinated camphene, 67-69 percent chlorine)

D016

(2,4 dichlorophenoxyacetic acid)

$2,4-D$

( $E)$

D017

(2,4,5-trichloro-ihenoxypropionic acid)

D018

D019

D020

$\mathrm{D} 021$

D022

D023

D024

D025

D026

D027

D028

D029

D030

$\mathrm{D} 031$

$\mathrm{D} 032$

$\mathrm{D} 033$

D034

D035

D036

D037

D038

D039

D040

D041

D042

D043

$2,4,5-\mathrm{TP}$ silvex

Benzene

Carbon Tetrachloride

Chlordane

(C)

Chlorobenzene

(R)

Chloroform

(E)

o-Cresol

(E)

m-Cresol

(E)

p-Cresol

(E)

Cresol

(E)

1,4-Dichlorobenzene

(E)

1,2-Dichloroethane

(E)

1,1-Dichloroethylene

(E)

2,4-Dinitrotoluene

(E)

Heptachlor (and its epoxide)

(R)

Hexachlorobenzene

(E)

Hexachlorobutadiene

(E)

Hexachloroethane

(E)

Methyl Ethyl Ketone

(E)

Nitrobenzene

(E)

Pentachlorophenol

(E)

Pyridine

(E)

Tetrachloroethylene

(E)

Trichloroethylene

(E)

$2,4,5-\operatorname{Trich}$ lorophenol

(R)

$2,4,6$-Trichlorophenol

(E)

Vinyl Chloride

(E)

(E) 


\section{APPROVED HAZARDOUS WASTE NUMBERS \\ ENVIROCARE OF UTAH, INC. \\ (continued)}

\section{HAZARDOUS WASTE FROM NON-SPECIFIC SOURCES:}

F001 The following spent halogenated solvents used in degreasing:

Tetrachloroethylene, trichloroethylene, methylene chloride, 1,1,1trichloroethane, carbon tetrachloride, and chlorinated fluorocarbons; all spent solvent mixtures/blends used in degreasing containing, before use, a total of ten percent or more (by volume) of one or more of the above halogenated solvents or those solvents listed in F002, F004 and F005; and still bottoms from the recovery of these spent solvents and spent solvent mixtures.

F002 The following spent halogenated solvents:

Tetrachloroethylene, methylene chloride, trichloroethylene, 1,1,1trichloroethane, chlorobenzene, 1.1.2-trichloro-1,2,2-triflouroethane, ortho-dichlorobenzene, trichlorof luoromethane, and 1, 1,2-trichloroethane; and all spent. solvent mixtures/ blends containing, before use, a total of one or more of the above halogenated solvents or those listed in F001, F004, or FOO5; and still bottoms from the recovery of these spent solvents and spent solvent mixtures.

F003 The following spent non-halogenated solvents:

Xylene, acetone, ethyl acetate, ethyl benzene, ethyl ether, methyl isobutyl ketone, n-butyl alcohol, cyclohexanone, and methanol; all spent solvent mixtures/blends containing, before use, only the above non-halogenated solvents; and all spent solvent mixtures/blends containing, before use, one or more of the above non-halogenated solvents, and, a total of ten percent or more (by volume) of one or more of those solvents listed in F001, F004, and F005; and still bottoms from the recovery of these spent solvents and spent solvent mixtures.

F004 The following spent non-halogenated solvents:

Cresols and cresylic acid, nitrobenzene; all spent solvent mixtures/blends containing, before use, a total of ten percent of more (by volume) of one or more of the above non-halogenated solvents or those solvents listed in F001, FOO2, and F005; and still bottoms from the recovery of these spent solvents and spent solvent mixtures.

F005 The following spent non-halogenated solvents:

Toluene, methyl ethyl ketone, carbon disulfide, isobutanol, and pyridine; benzene, 2-ethoxyethanol, and 2-nitropropane; all spent solvent mixtures/blends containing, before use, a total of ten percent or more (by volume) of one or more of the above non-halogenated solvents or those solvents listed in F001, F002, or F004; and still bottoms from the recovery of these spent solvents and spent solvent mixtures. 


\section{APPROVED HAZARDOUS WASTE NUMBERE ENVIROCARE OF UTAH, INC. (continued)}

\section{HAZARDOUS WASTE FROM NON-GPECIFIC SOURCES (continued):}

F006 Waste-water treatment sludges form electroplating operations except from the following processed: (1) sulfuric acid anodizing for aluminum; (2) tin plating on carbon steel; (3) zinc plating (segregated basis on carbon steel; (4) aluminum or zinc-aluminum plating on carbon steel; (5) cleaning/stripping associated with tin, zinc and aluminum plating on carbon steel; and (6) chemical etching an milling o aluminum.

F007 Spent cyanide plating bath solutions from electroplating operations.

F008 Plating bath residues from the bottom of plating baths from electroplating operations where cyanides are used in the process.

F009 Spent stripping and cleaning bath solutions from electroplating operations where cyanides are used in the process.

F010 Quenching bath residues from oil baths from metal heat treating operations where cyanides are used in the process.

F011 Spent cyanide solutions from salt bath pot cleaning from metal heat treating operations.

F012 Quenching waste water treatment sludges from metal heat treating operations where cyanides are used in the process.

F019 Waste-water treatment sludges from the chemical conversion coating of aluminum.

F028 Residues resulting from the incineration or thermal treatment of soil contaminated with EPA Hazardous Waste Nos. F020, F021, F022, F023, F026 and r027.

\section{HAZARDOUS WASTE FROM SPECIFIC SOURCES:}

K011 Bottom stream from the wastewater stripper in the production of acrylonitrile.

K013 Bottom stream from the acetonitrile column in the proluction of acrylonitrile.

K050 Heat Exchanger Bundle Cleaning Sludge from the petroleum refining industry.

K051 API separator sludge from the petroleum refining industry.

K052 Tank bottoms (leaded) from the petroleum refining industry. 


\section{APPROVED HAZARDOUS WASTE NUMBERS \\ ENVIROCARE OF UTAH, INC. \\ (continued)}

HAZARDOUS WASTE FROM SPECIFIC SOURCES (cOntinued):

K061 Emission control dust/sludge from the primary production of steel in electric furnaces.

K069 Emission control dust/sludge from the secondary lead smelting.

\section{DISCARDED COMMERCIAL CHEMICAL PRODUCTS, OFF-SPECIFICATION SPECIES, CONTAINER RESIDUES, AND SPILL RESIDUES THEREOF:}

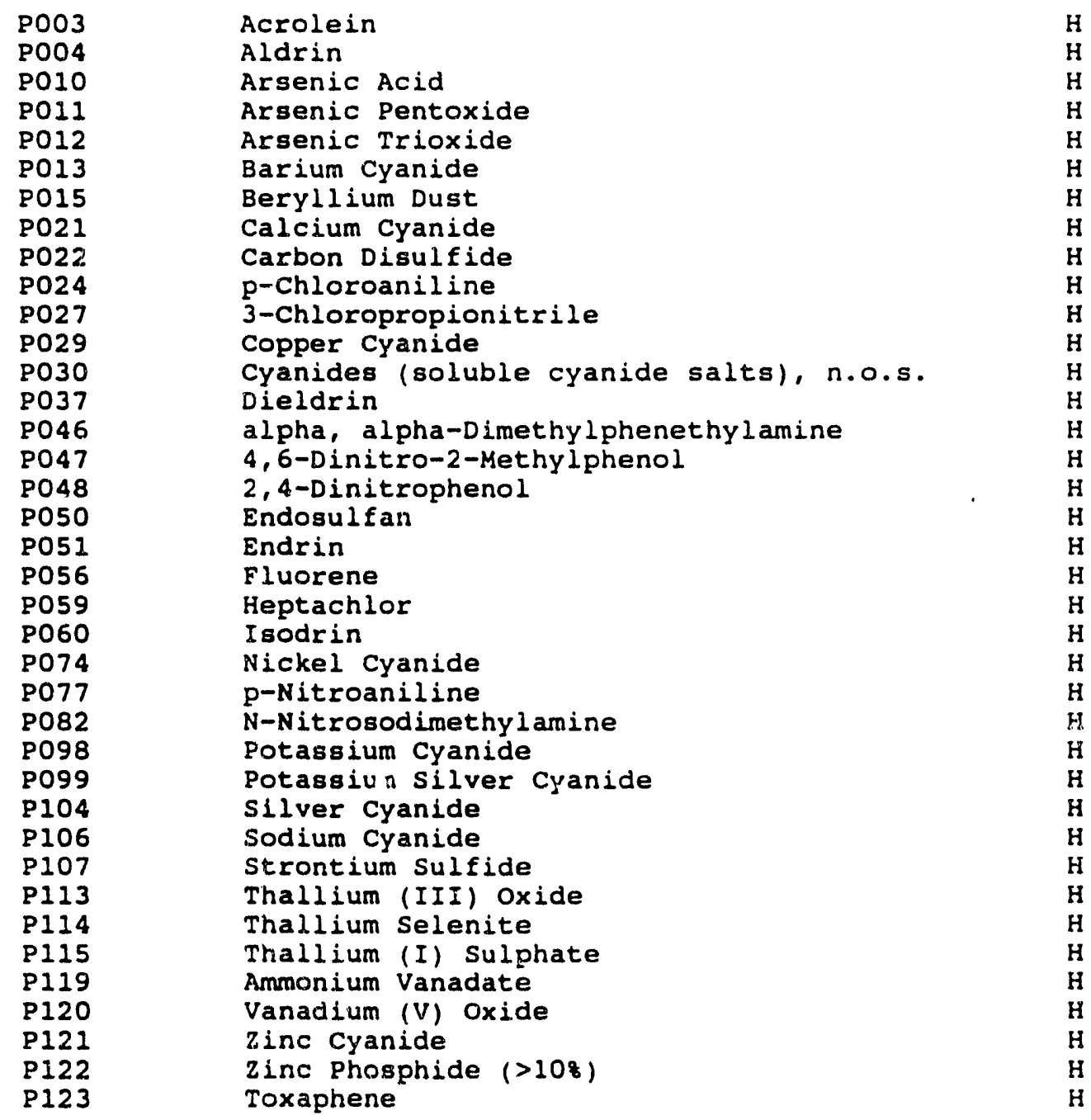




\section{APPROVED HAZARDOUS WASTE NUMBERS \\ ENVIROCARE OF UTAH, INC. (continued)}

COMAERCIAL CHEMICAL PRODUCTS, MANUFACTURING CHEMICAL
INTERMEDIATES, OR OFF-SPECIFICATION COMMERCIAL CHEMICAL
PRODOCTS:

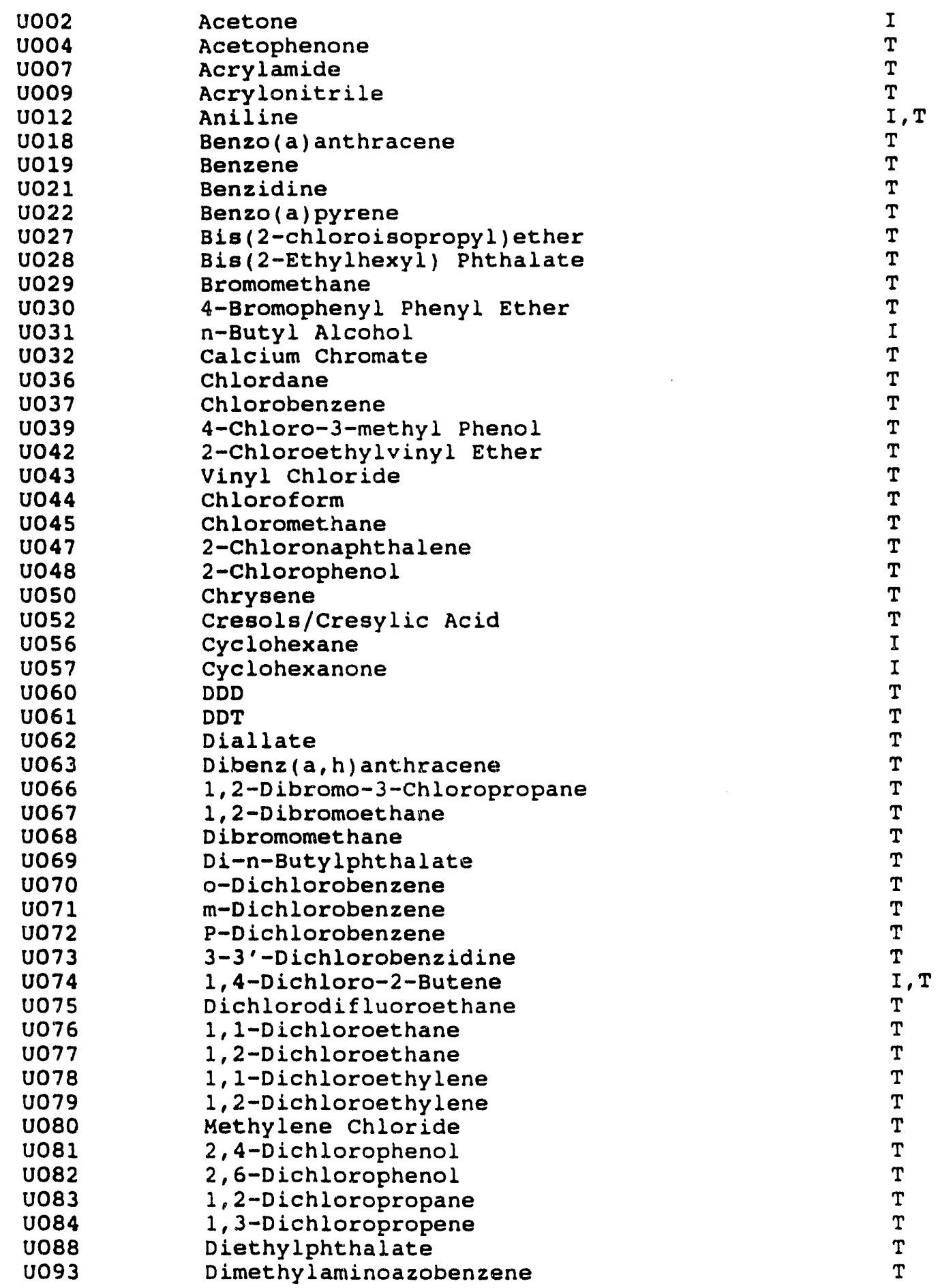




\section{APPROVED HAZARDOUS WASTE NUMBERS ENYIROCARE OF UTAH, INC. (continued)}

\section{COMMERCIAL CHEMICAL PRODUCTS, MANOFACTURING CHEMICAL INTERMEDIATES, OR OFF-SPECIFICATION COMMERCIAL CHEMICAL PRODUCTS (continued):}

U094

บ095

U101

U102

U105

U106

U107

U109

U112

U117

U119

U120

U121

U127

U128

U129

U130

U131

U132

U135

U137

U138

U140

U142

U144

U145

U146

U151

U154

U157

U158

U159

U161

U165

U167

U168

U169

U170

U171

U172

U179

U182

U183

U184

U185

U187

U188

U191

U192

U196

U204

U205

U207
7, 12-Dimethylbenz (a) anthracene

$3,3^{\prime}-$ Dimethylbenzidine

2, 4-Dimethyl phenol

Dimethylphthalate

2,4-Dinitrotoluene

2,6-Dinitrotoluene

Di-n-Octyl Phthalate

1,2-Diphenylhydrazine

Ethyl Acetate

Ethyl Ether

Ethyl Methanesulfonate

Fluoranthene

Trichlorofluoromethane

Hexachlorobenzene

Hexachlorobutadiene

Lindane (Hexachlorocyclohexane)

Hexachlorocyclopentadiene

Hexachloroethane

Hexachlorophene

Hydrogen sulfide

Indeno $(1,2,3-c d)$ pyrene

Iodomethane

Isobutyl Alcohol

Kepone

Lead Acetate

Lead Phosphate

Lead Subacetate

Mercury

Methanol

3-Methylcholanthrene

4, 4'-Methylene Bis(2-Chloroaniline)

Methyl Ethyl Ketone

Methyl Isobutyl Ketone

Naphthalene

1-Naphthalenamine

2-Naphthalenamine

Nitrobenzene

4-Nitrophenol

2-Nitropropane

$\mathrm{N}$-Nitroso-di-n-butylamine

$\mathrm{N}$-Nitrosopiperidine

Paraldehyde

Pentachlorobenzene

Pentachloroethane

Pentachloronitrobenzene

Phenacetin

Phenol

2-Picoline

Pronamide

Pyridine

Selenium Dioxide

Selenium sulfide

$1,2,4,5$-Tetrachlorobenzene

$T$
$T$
$T$
$T$
$T$
$T$
$T$
$T$
$T$
$I$
$T$
$T$
$T$
$T$
$T$
$T$
$T$
$T$
$T$
$T$
$T$
$T$
$T$
$T$
$T$
$T$
$T$
$T$
$T$
$T$
$T$
$T$
$T$
$T$
$T$
$T$
$T$
$T$
$T$
$T$
$T$
$T$
$T$
$T$
$T$
$T$
$T$
$T$
$T$
$T$
$T$
$T$
$T$
$T$
$T$
$T$
$T$
$T$
$T$
$T$
$T$
$T$
$T$
$T$
$T$
$T$
$T$




\section{APPROVED HAZARDOUS WASTE NUMBERS}

ENVIROCARE OF UTAH, INC.

(continued)

\section{COMMERCIAL CHEMICAL PRODUCTS, MANUFACTURING CHEMICAL INTERMEDIATES, OR OFF-SPECIFICATION COMMERCIAL CHEMICAL PRODUCTS (continued):}

\begin{tabular}{|c|c|}
\hline $\begin{array}{l}\text { U208 } \\
\text { U209 } \\
\text { U210 } \\
\text { U211 } \\
\text { U212 } \\
\text { U214 } \\
\text { U215 } \\
\text { U216 } \\
\text { U217 } \\
\text { U220 } \\
\text { U225 } \\
\text { U226 } \\
\text { U227 } \\
\text { U228 } \\
\text { U230 } \\
\text { U231 } \\
\text { U232 } \\
\text { U233 } \\
\text { U235 } \\
\text { U237 } \\
\text { U239 } \\
\text { U240 } \\
\text { U242 } \\
\text { U2 } 233 \\
\text { U247 } \\
\text { U249 } \\
\text { U359 }\end{array}$ & 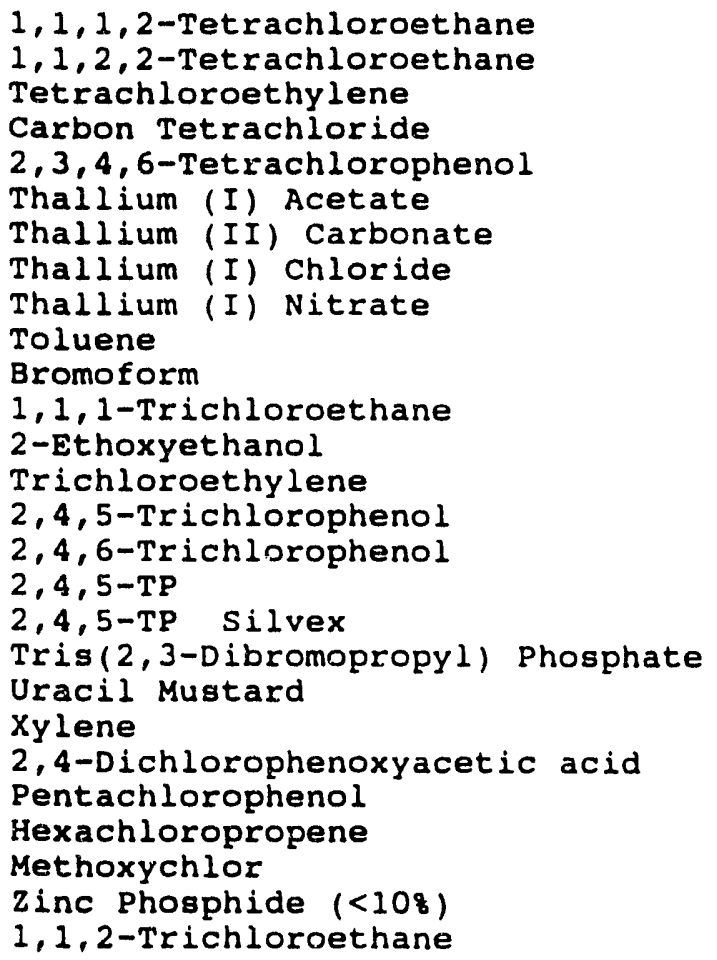 \\
\hline
\end{tabular}

\section{Other Wastes}

- Chemical Waste from the Envirocare Laboratory: Laboratory waste which can be landfilled on site will be disposed of at Envirocare. Other wastes will be sent off-site for hazardous waste management.

- On-site Generated Waste: Wastes generated at the facility can generally be characterized adequately as to the composition of the waste.

(Note: Non-radioactive hazardous wastes must not be mixed with radioactive wastes to avoid or circumvent the land disposal restrictions.) 
Exhibit G

ACCEPTANCE LIMITS AND CRITERIA FOR CONTAMINATED OILS AT SEG 


\section{WASTE ACCEPTANCE POLICY}

PURPOSE: The purpose of this policy is to provide a uniform plan and procedure for the acceptance of low level radioactive waste for processing.

POLICY: SEG will accept waste which meets our waste acceptance criteria, can be safely processed, and meets the SEG license criteria. Waste which does not meet the general acceptance criteria may be accepted after evaluation and approval of the pertinent waste information provided on a Non-standard Waste Acceptance Form (NWAF).

ACCEPTANCE OF NORMAL WASTE:

Normal waste is defined as any radioactive waste which meets the waste acceptance criteria listed below:

1. Low Level Waste Acceptance Criteria

2. Oil Acceptance Criteria

3. Metal Acceptance Criteria

4. TRU (Transuranic) Criteria

5. Liquid Waste/Bldg 3 Criteria (to be added later)

Waste which meets these criteria will be accepted if SEG has sufficient "financially assured storage space", if its licensed radionuclide inventory will not be exceeded, and can be processed within the allowed license time frame. Other business and/or process related factors may cause otherwise acceptable waste to be refused or delayed.

RESPONSIBILITIES :

REGULATORY SERVICES: Shall be responsible for the folluwing:

1. Assist in determining that the material would meet DOT and burial site criteria.

2. Accepting the advanced waste shipment notification and assuring that the proposed shipment complies with the SEG Waste Acceptance Criteria.

3. Determining that the proposed shipment can be stored on "financially assured storage space".

4. Determining that the proposed shipment will not cause SEG to exceed its licensed radionuclide concentrations on any license. 
BEAR CREEK AND GALLAHER OPERATIONS DEPARTMENT: Shall be responsible for the following:

1. Providing the Regulatory Service Department with regular information regarding the storage space available.

2. Determining that the proposed shipment will not cause any fence-line dose to be exceeded when stored awaiting processing.

3. Determining how the waste can be safely processed.

4. If the waste is approved using the NWAF form, the operations department will provide information to the sales department regarding the method of processing, the estimated manpower, and the equipment required to process the waste. In addition, a processing schedule shall be provided.

DATA SYSTEMS: Shall be responsible for the following:

1. Providing a weekly radionuclide inventory and/or updates to the inventory when requested.

ACCEPTANCE OF NON-STANDARD WASTE:

SEG may accept waste which does not meet our standard waste acceptance criteria using the following procedure:

SALES DEPARTMENT: The customer service department shall work with the customer to determine and document the following information on the Non-standard Waste Acceptance Form (NWAF):

1. Generator's company name \& facility

2. Contact name and phone number

3. Waste description

4. Radionuclide and activity information

5. Size, weight and volume data

6. Biological activity

7. Special characteristics

8. Desired date of shipment

9. Method of shipment 
10. Planned packaging

11. Special disposal instructions

12. Amount of free-standing water

13. Material requiring quick processing

NOTE: Operations to generate cost figures for additional processes required. This cost figure shall be on a separate page.

After completing the NWAF and depending on the waste type, the Customer Service Department shall work with the appropriate manager to determine the acceptability of the waste form. The appropriate manager shall indicate his agreement in writing on the NWAF. He should consider the following:

1. Can the waste be processed in a time period which meets our license condition,

2. Can the waste be safely processed in the planned manner,

Pricing for Non-Standard waste shall be developed by the Marketing Manager with the assistance of the appropriate manager.

When the appropriate Processing Manager approves the waste for processing, then the Customer service Department shall obtain the written approval of the Manager of Regulatory Services, or his designee, concerning the acceptability of the waste meeting our license and permit requirements. Factors to be considered by the Manager of Regulatory Services will include:

1. Can the waste be safely shipped, received, and effectively processed for burial,

2. Can the radionuclide concentrations be accepted without exceeding our license permit limitations,

3. Can the waste be processed in a manner which meets our ALARA and safety plan objectives, 
After the NWAF has been completed and the appropriate signatures have been obtained, a copy of the NWAF shall be provided to the following:

1. Cognizant Production Manager

2. Regulatory Services Department

3. Incomingl Shipment Coordinator

4. Customer Service Department

5. Invoicing Department

6. Fax copy of completed form to the client and document to the files. 


\title{
LOW LEVEL WASTE ACCEPTANCE CRITERIA \\ ATTACHMENT 2 \\ THE SCIENTIFIC ECOLOGY GROUP, INC.
}

\author{
SOLID/NON-METAL \\ RADIOACTIVE WASTE DESCRIPTION
}

The Scientific Ecology Group, Inc. (SEG) defines Radioactive Waste as radioactive materials and their containers described, identified, marked, and labeled in compliance with applicable Federal, state and local regulations which meet the ACCEPTANCE CRITERIA listed below. The waste consists of any solid material meeting these ACCEPTAICE CRITERIA.

\section{ACCEPTANCE CRITERIA}

The following are general criteria for waste acceptance at SEG. Different criteria are available depending on client needs.

*Radiation Level per Package - $<200 \mathrm{mR} / \mathrm{hr}$ at contact (1 cm).

*DAW waste with radiation levels higher than $200 \mathrm{mR} / \mathrm{hr}$ should be packaged in 55 gallon drums or SEG supplied innerpack boxes. This waste category requires SEG approval prior to shipment.

Removable External Contamination - $<2200 \mathrm{dpm}$ beta-gamma/100 sq cm. $<220 \mathrm{dpm}$ alpha/100 sq cm.

Radionuclide Content per Package: *

$$
\begin{array}{ll}
\text { Mixed F\&AP }(Z<84) & -<25 \mathrm{mCi} / \mathrm{cf} \\
\mathrm{Ra}-226 & -<0.1 \mathrm{mCi} / \mathrm{cf} \text { and }<10 \mathrm{nCi} / \mathrm{gm} \\
\mathrm{Th}-232 & -<5 \mathrm{mCi} / \mathrm{cf}(100 \mathrm{~m} \mathrm{Th} / \mathrm{cf} \text { waste) } \\
\mathrm{U}-238 \text { as metal or oxide } & -<15 \mathrm{mCi} / \mathrm{Cf}(100 \mathrm{~b} \mathrm{U} / \mathrm{cf} \text { waste) } \\
\mathrm{U}-233, \mathrm{U}-235 & -<0.1 \mathrm{gm} / \mathrm{cf} \\
\text { Transuranics } & -<10 \mathrm{nCi} / \mathrm{gm}
\end{array}
$$

*Acceptance criteria for incineration may be more restrictive for certain radionuclides; primarily, H-3, C-14, TC-99, I-129, Sr90. Other radionuclides may also be affected based on incinerator permit limits. Your SEG representative will be happy to assist you if you have any other questions.

client is required to pre-notify (by telephone or fax) SEG to approve shipment prior to transport. Generator must maintain an active disposal site permit. 
Package Volume Determination:

$$
\begin{aligned}
& \text { 55-Gallon Drums - } 7.5 \text { cf } \\
& \text { Other Containers - Based on External Dimensions }
\end{aligned}
$$

Physical and Chemical Composition - No gases, biological materials, chelating agents, hazardous chemicals, pyrophorics, nor explosives. Solid wastes must not contain any significant free standing liquids. SEG will only accept waste materials which are acceptable at the destination burial ground.

Contact SEG for special materials which require processing for them to become acceptable at the destination burial ground.

FILTERS - Activity less than $0.1 \mathrm{uCi} / \mathrm{cc}$ nf those isotopes with half-life greater than five years. Please call an SEG representative for activity levels greater than $0.1 \mathrm{ici} / \mathrm{cc}$.

ASBESTOS WASTE - All asbestos will be properly manifested, identifying number of bags, boxes, etc. Containers are to be properly identified (Labeled) on the primary containers as well as the secondary or individual containers. SFr does not have an abatement program, therefore, material should ve sized and packaged to allow repackaging for compact: on without breaching the primary container (i.e.. double plastic wrapping).

CONDENSER TUBES - Tubes to be relatively straight (some curvature is permissible) and the tubes are not to be pinshed closed or grooved during removal. Interior buildup of scale to be less than $2 \%$ of the total weight of the tube. Condenser tubes to be removed in such a manner that will not gr and contamination into the tube; that will segregate the stainless steel tubes from the brass tubing; that the inside of the tubes are dry or will be drained prior to loading. In addition, if any beveled ends exist, the beveled ends to be loaded toward the front of the container. 
$11 / 92$

\section{SEG ACCEPTANCE IIMITS FOR CONTAMINATED OILS}

NOTE: This is a general guideline used for interfacing analytical results in client's oil with SEG's acceptance criteria for oil. SEG's acceptance criteria is based upon EPA regulations contained in 40 CFR 261/266, Tennessee Valley Authority requirements and the state of Tennessee regulations, where appropriate.

TYPE OF ANALYSIS

SEG ACCEPTANCE CRITERIA

1. Toxicity Characteristic (TCLP)

Heavy Metals (40 CFR 261.24)

Arsenic

Barium

Cadmium

Chromium

Lead

Mercury

Selenium

silver
$<5.00 \mathrm{mg} / \mathrm{I}$

$<100.00 \mathrm{mg} / \mathrm{l}$

$<1.00 \mathrm{mg} / \mathrm{I}$

$<5.00 \mathrm{mg} / \mathrm{I}$

$<5.00 \mathrm{mg} / \mathrm{I}$

$<0.2 \mathrm{mg} / \mathrm{l}$

$<1.00 \mathrm{mg} / \mathrm{l}$

$<5.00 \mathrm{mg} / \mathrm{I}$

Organics

See list of 31 organic compounds and their respective regulatory levels listed under 40 CFR 261.24. Any compound which cannot be certified by the generator to be absent from the oil must be tested for under TCLP standards.

2. Total Halogens (TOX)

(ASTM Method D808-81)

Equal to or less than 1000 ppm Unless rebutted *

* EPA has specified $1000 \mathrm{ppm}$ total halogens as the level at which they presume mixing with spent halogenated solvents has occurred. The oil can contain up to $4000 \mathrm{ppm}$ total halogens if the presumption of mixing can be successfully rebutted. To successfully rebut the mixing presumption, you must be able to show that the oil contains less than $100 \mathrm{ppm}$ of any individual halogenated solvent listed as an F001 or F002 waste and certify that there has been no additional mixing of hazardous constituents with the oil. Additional volatile organic analysis (EPA method 8240 ) would be required to analyze for these individual halogenated compounds. 
3. Polychlorinated Biphenyls

$$
<2.00 \mathrm{ppm}
$$

Limits based upon request by the Tennessee Valley Authority and EPA regulations contained in 40 CFR 761 .

4. Flashpoint

5. Viscosity

6. Solids Content

7. Aqueous Liquid Content

8. Radiological Analyses:

A. Maximum total concentration of radionuclides less than $1 \mathrm{E}-4(\mathrm{uCi} / \mathrm{ml})$ averaged over truckload lot.

B. Uranium at less than $1 E-5$ (uCi/ml) averaged over truckload lot.

C. No other alpha emitters comprising $>10 \%$ of the total amount in a single container (prior arrangements/rad. license).

9. Maximum Individual Isotope Activities
A. $\mathrm{H}-3$
$1.9 \mathrm{microci} / \mathrm{gal}$ lon or $0.5 \mathrm{nanoci} / \mathrm{ml}$
B. $\mathrm{C}-14$
$0.1 \mathrm{microci} /$ gallon or 0.026 nanoci $/ \mathrm{ml}$
C. TC-99
$0.4 \mathrm{microci} /$ gallon or 0.1 nanoci $/ \mathrm{ml}$
D. $I-129$
$0.01 \mathrm{microci} /$ gallon or $0.0026 \mathrm{nanoci} / \mathrm{ml}$

NOTE: Oil which exceeds any of the above radiological limits will require prior approval by SEG. SEG will review these requests on a case-by-case basis. 


\section{ATTACHEENT 2 \\ TO EEG'S RADIOACTIVE WASTE SERVICEB AGREEMEWT \\ BURNING OF RADIOACTIVE OILS}

PART 2. 1 SEG RADIOACTJVELY CONTAYINATED OIL ACCEPTANCE CRITERIA

SEG standard oil pricing is based upon oil acceptable for burning with the following specifications:

1. Oil with grades less than 40 weight.

2. Specific oil history should be identified if possible.

3. Solids content less than $10 \%$ by volume.

4. Aqueous liquid content less than $10 \%$ by volume.

5. Certified to be free of listed and characteristic hazardous waste as defined by RCRA or the Toxic Substances Control Act (TSCA). Oil which contains detectable levels of PCB's (2 ppm or greater) as regulated by the Toxic substance control Act (TSCA) would not be acceptable by SEG.

6. Shipped in leak-tight containers.

7. Maximum Radionuclide concentration less than $1 \times 10^{-4} \mathrm{uCi} / \mathrm{ml}$ with Uranium at $<1 \times 10^{-5} \mathrm{uCi} / \mathrm{ml}$ both averaged over a truckload lot and with no other significant alpha emitters comprising $>10 \%$ of the total amount of any single container may be taken, but prior notification and approval is required.

Normal oils and heating oils, including kerosene, hydraulic oil, diesel, and other flammable oils are acceptable if they are not listed hazardous wastes or characteristic wastes. Alcohol or gasolines or highly flammable solvents that comprise <1\% of total are acceptable. Call a SEG representative for pricing on alcohols, gasolines, and highly flammable solvents that exceed 1\%. If you have questions about your specific oil mixture, contact your SEG representative for a determination.

SEG can also analyze your oils and provide you with necessary certification for suspect oils. Analytical costs vary, depending upon extent and nature of the analysis. contact an SEG representative for details. SEG will work with you to determine what is required to qualify your oil for disposal. Radioactive or commingled oils which cannot be burned will be solidified and buried according to the regulations at the time. In addition, a waste burial allocation will be required for any nuclear power plant oil or sludge which cannot be burned and must be solidified and buried. 
Surcharges over and above the price for burning oils may be applied for higher solid content or nonflammable liquids, or any oils that may require solidification for burial or oils that require certification to allow burial. SEG will perform additional tasks on a time and material basis with labor charged at 3.0 times direct salary and other costs billed at cost plus $20 \%$. 


\section{ATTACHENT 2 SEG'S RADIOACTIVE WASTE GERVICES AGREEMENT BURNING OF RADIOACTIVE OILS}

\section{PART 2.2 DISCUSSION OF SEG OIL ACCEPTANCE CRITERIA}

1. OII VIscosITY: The viscosity of the oil is important since we are planning to burn the oil in a specific burner. SEG's original guidance on oil viscosity was to specify a grade of 40 or less. A second way of looking at our acceptance criteria is that SEG will accept oil that has a viscosity of 3000 ssu units or less. Alternately, we will accept oil which has a viscosity of 3000 ssu units or less when the oil is diluted with kerosene in a ratio of 1 part kerosene to 2 parts oil. As you can see from this discussion, SEG accepts oil with a wide range of viscosities. If the oil will flow when poured, SEG will probably be able to prepare it for burning. When you have a question on your oil's grade or viscosity, send a sample to SEG for analysis and acceptance. SEG will also take grease if it can be dissolved with kerosene to meet our viscosity requirements. In the case of grease, the charge will be made on the basis of the diluted volume.

2. ANALYSIS SERVICE: At the request of the customer, SEG will perform necessary analyses of the oil to determine that it meets our license criteria. The client can ship oil samples to SEG and SEG will analyze the oil for a fee as determined by SEG's Radioactive Waste Services Agreement (Attachment 3 Burning Radioactive Contaminated oil.). Results of sampling will be provided to the customer. The analyses that may be required will depend on the history of the oil. Some of the typical tests that might be used and the approximate prices associated with those tests (without markup) are attached. Reference Attachment 3 for SEG's fee for pass through services.

3. OIL SHIPPING CONTAINERS: SEG will provide "double containment with absorbent" shipping boxes to the customer. These containers are generally of two types. The first type is an approximate $4^{\prime} \times 4^{\prime} \times 6^{\prime}$ ISA container loaded with internal 79 galion drum overpacks. The client's 55-galion drums can then be contained inside of the 79 gallon drums. Absorbent is added around outer 79-galion drums. The second type container supplied by SEG is more appropriate for those customers that wish to ship oil to SEG in bulk. This container is a double containment sea-land container with absorbent, a sea land container with a full drip pan inside of the container for possible spill. The approximate oil carrying capacity of the box is 210 gallons (4 each 55-galion drums) and of the sea land is 2500 gallons. Transportation of the containers from SEG to the customer and return will be done at the rates quoted in the fee schedule (see Attachment 3). 
4. SOLIDIFICATION EERVICES: Oil which contains unacceptable contents for burning will be returned to the customer or at the customers option, be solidified by SEG. Oil which must be solidified will be processed for an extra charge in accordance with Attachment 3. This charge should be less than twice the charge of SEG's standard oil burning fee schedule rate, plus the cost of any sampling and laboratory analysis costs and transportation charges to disposal. SEG will solidify the oil using approved procedures for the selected burial grounds, package the solidified oil, arrange for transportation, and pay for burial. The customer will provide a waste allocation and a burial permit for the selected burial ground.

5. WASTE EXPORT PERMIT: SEG will take the lead and arrange for a permit to export solidified oil from the southeast compact Region with the assistance of the customer required.

6. TITLE AND POSSESSION OF WASTE: SEG will take title and possession of the oil when it is delivered at our facility. SEG will be responsible for all burial ground fines and violations which relate to the packaging, method of solidification, quality of the solidified material, or other violations which SEG was directly responsible for. The utility will be responsible for the accuracy and certification of the oil, as being non-hazardous under RCRA and TSCA regulations.

7. RADIONOCLIDE CONCENTRATION: Oil with concentrations of radionuclides equal to or less than $1 \times 10^{-4}$ microcuries per $\mathrm{ml}$ for fission products and $1 \times 10^{-5}$ microcuries per ml for uranium when averaged over the entire batch or shipment and with no other significant alpha emitters comprising $>10 \%$ of the total amount of the activity may be taken. If higher oil concentrations apply, contact SEG for permission to ship the oil.

8. TRANSPORTATION SERVICES: SEG will provide transportation in accordance with Attachment 3 (SEG's Radioactive Waste Services Agreement). The charges are summarized on the applicable fee schedule titled - Transportation.

9. OIL DISPOSAI FEES: SEG will burn and/or solidify radioactive oil on a per gallon basis based upon Attachment 3.. The Attachment is based upon a per gallon price plus the cost of transportation and any sampling and laboratory analysis costs. A discount is usually provided to those clients that provide substantial DAW business to SEG (drums, boxes or sea lands).

10. SEG IIMITS: SEG will work with our client to quickly remove oils from their site to SEG for processing. The total of all oil backlogged at utilities exceeds on the short term the capacity of SEG to receive all of this oil at the same time. SEG will work with our client to schedule the burning of their oils or transfer of their oils to SEG's site for our backlog purposes. 


\section{ATTACKMENT 2 \\ TO SEG'S RADIOACTIVE TASTE SERVICES AGREEMENT BURNING OF RADIOACTIVE OILB}

\section{PART 2.3 SUMQYARY OF HAZARDOUS WASTE REGULATIONS RELATED TO OIL ACCEPTANCE CRITERIA}

\section{GENERAL STATEMENT}

SEG is NOT a hazardous waste treatment, storage, or disposal facility. Therefore, SEG is NOT permitted to receive, accept, store, or process any client's regulated listed or characteristic hazardous waste.

In regard to specific regulations on used oil, SEG will accept nonhazardous oil as defined in the Resource Conservation Recovery Act (RCRA) 40 CFR, part 261. This part sets specific constituents/properties and the allowable levels. Additionally, used oil which contains PCBs as regulated by the Toxic substance Control Act (TSCA), 40 CFR, part 761, would not be acceptable by SEG.

The term "hazardous" means that the material is regulated as such by a governing authority and has no reference to whether or not the material is "dangerous". For example, kerosene is dangerous but it is not hazardous since it is not defined as such by regulations. Furthermore, a waste is not necessarily "hazardous" by regulation even if tests show that the waste contains materials typically regulated as hazardous; it often depends on how the waste was generated. Thus, it is literally possible to have two identical containers of waste with one regulated as hazardous and the other not.

The discussion below is not intended to make the issue more complex than it obviously is; rather, its purpose is to provide SEG clients with the maximum flexibility allowed by law for the shipment to SEG of oil and similar materials contaminated with radioactive material. None of the comments below are special license or permit conditions at SEG. Rather, they are restatements of the current RCRA regulations as of February $1,1988$.

DEFINITION OF NONHAZARDOUS "OIL"

The following nonhazardous material may be accepted in pure form or as mixtures with each other or as mixtures with other nonhazardous (by regulation) materials; motor oil, hydraulic oil, transmission and power steering fluids, lubricating oils, kerosene, turpentine, most cutting oils, diesel fuel, and similar nonhazardous materials. Any such similar liquid material having a flash point above $140^{\circ} \mathrm{F}$ $\left(60^{\circ} \mathrm{C}\right)$ and which is not listed or otherwise hazardous by regulation is acceptable. Generally, scintillation fluids are not accepted unless one of the exemptions below is met. 


\section{CHARACTERISTICALLY HAZARDOUS MATERIALS}

IGNITABLE - Liquid materials not otherwise hazardous except for the characteristic of ignitability (flash point less than $140^{\circ} \mathrm{F}$ ) are acceptable if the generator unintentionally or accidentally mixes it with the nonhazardous materials listed above. Thus, gasoline, mineral spirits, or other similar ignitable material mixed with oil is acceptable if the mixture flash point is greater than $140^{\circ} \mathrm{F}$. However, a container of pure gasoline, mineral spirits, or other similar ignitable material (FP less than $140^{\circ} \mathrm{F}$ ) is not acceptable at SEG.

CORROSIVE, REACTIVE, TOXIC CHARACTERISTIC (TC) - Oil containing a material which would cause it to exhibit one or more of these characteristics (e.g., a toxic characteristic metal such as hexavalent chromium or lead), as defined by regulation, is not acceptable. Oil containing small quantities of hazardous constituents is acceptable if the final mixture does not exhibit the characteristic and is also not a listed waste.

\section{OIL CONTAMINATED WITH EMPTY-CONTAINER RESIDUES}

The release left in "empty" containers as defined by regulation are not hazardous. Therefore, oils contaminated by such residues may be accepted as long as they do not exhibit a characteristic of a hazardous waste. An example is the toluene residue in an "empty" container. Even though toluene is a listed constituent, it is not regulated as hazardous under these conditions. Furthermore, a nonhazardous waste stored in that container and which becomes contaminated with the toluene residue does not become a hazardous waste even though it now contains a constituent which is regulated as a "listed" waste under certain conditions. It is important that the regulatory definition of "empty" be met; simply "emptying" a container may not qualify the container as "empty", especially with acute hazardous wastes, which require triple rinsing to qualify as "empty".

\section{SPECIAL RULES FOR HALOGENATED SOLVENTS (FOO1-F002)}

Mixtures of hazardous waste and used oil ordinarily are classified as hazardous waste. However, both used oil and hazardous halogenated solvents are frequently generated by the same facility, and some incidental contamination is inevitable. Therefore, some specific rules exist for halogenated solvents in used oil.

Any used oil containing more than 1,000 ppm and up to 4,000 ppm of total halogens is presumed to be a hazardous waste because it was mixed with halogenated hazardous waste. Persons may rebut this presumption by demonstrating that the used oil does not contain significant concentrations of halogenated hazardous constituents. Some possible examples of rebuttal are: 
1. Show that the used oil contains less than 100 ppm of any individual hazardous halogenated component listed as a hazardous spent solvent.

2. Show that the hazardous const:tuents could have been added or formed during use of the oil.

There are possible other rebuttable presumptions depending on the circumstances specific to individual cases. If you have any questions regarding the acceptability of your used oil, contact you SEG representative.

\section{ACCEPTABILITY OF OTHER HAZARDOUS WASTES}

Any listed or characteristic hazardous waste not exempt above is, most likely, not acceptable to SEG. In summary, to determine if used oil may or may not be accepted by SEG, many factors such as the generating process, mixing characteristics, etc., may to be reviewed to determine acceptance. Please contact your SEG representative. 


\section{METAI ACCEPTANCE}

1. Size

Weight

2. Rad Level
Maximum is a piece or a combination of pieces that can be placed in a 20 foot sealand.

A. Shield Material

B. Volume Reduction for Burial 51 - $200 \mathrm{mr} / \mathrm{hr}$

Note: Any material $>200$ requires prior permission from SEG, and no single piece to exceed $1000 \mathrm{MR}$ on contact. The standard Radwaste surcharge shall apply.

Special Nuclear Materials* (U233-U235) . $1 \mathrm{gm} / \mathrm{cf}$ Transuranic* (Including Pu241) Activated Metal <1. nanoci/gm

Ra 226 (DOE only)

$0.1 \mathrm{mr} / \mathrm{hr}$ on contact

Ra 226 (Commercial) requires special permission.

* Subject to pre-verification approval. Materials which are not metal will be billed by the appropriate rate. Asbestos materials require special permission. 


\section{APPENDIX H \\ OPEN LITERATURE CITATIONS FOR \\ SELECTED MIXED WASTE TREATMENT TECHNOLOGIES}

$\mathrm{H}-1$ 


\title{
APPENDIX H \\ OPEN LITERATURE CITATIONS \\ FOR SELECTED MIXED WASTE TREATMENT TECHNOLOGIES
}

A search of the open literature publications from October 1990 to June 1992 for waste treatment technologies resulted in 902 citations. The data bases searched included: Biotechnology Abstracts, DOE Energy, Enviroline, Fede ! Register, Federal Reasearch in Progress, National Technical Information Service, Pollution Abstracts, and Envisonmental Bibliography. The search included mixed, hazardous, and low-level radioactive waste and treatment categories listed in Tables 5.2 and 5.3 of Sect. 5, The Treatability of Mixed Waste. The treatment categories and number of citations are summarized below:

\begin{tabular}{|c|c|}
\hline \multicolumn{2}{|r|}{299 citations; } \\
\hline Thermal Recovery & 9 citations; \\
\hline Vitrification . & 234 citations; \\
\hline Solidification & 173 citations; \\
\hline Stabilization & 139 citations; \\
\hline Acid Leaching & 10 citation \\
\hline Chemical Treatment & 13 citation \\
\hline Neutralization $\ldots$ & 25 citation \\
\hline
\end{tabular}

Examples of the citations, which are arranged chronologically according to treatment category along with annotated abstracts and citation information, are presented in this appendix. The entire citation database can be obtained by submitting a request and a blank $3.5 \mathrm{in}$. floppy disk (1.4 Mb size) to:

\author{
OAK RIDGE NATIONAL LABORATORY \\ Attention: Dr. J. A. Klein \\ Nuclear Waste Studies and Applications \\ P.O. Box 2008, MS 6495 \\ Oak Ridge, Tennessee 37831-9984 \\ Telephone No. (615) 574-6823
}

Although grouped according to major treatment category, many citations will include information about other treatment technologies. Thus, in lieu of an index, reading of the citations (or a computer search) is recommended in order to make greater use of the citation data. (Because of their length, generally only titles and citation information are included for Federal Register citations.)

A previously conducted search for the 1987 to 1990 time period resulted in 412 citations. This database is also available on request from Dr. Klein, arranged according to treatment categories. 
INCINERATION

$\mathrm{H}-5$ 
10/725 (Item 25 from file: 103)

03253282 JPN-91-011202; EDB-92-016039

Title: Overall reaction rate analysis of ion-exchange resins incineration by fluidized bed

Author(s): Kinoshita, Koki; Hirata, Masaru; Yahata, Taneaki (Japan Atomic Energy Research Inst., Oarai, Ibaraki (Japan). Oarai Research

Establishment)

Source: Journal of Nuclear Science and Technology (Tokyo) (Japan) $~ 28: 8$.

Coden: JNSTA ISSN: 0022-3131

Publication Date: Aug 1991 p 739-747

Language: In English

Abstract: A kinetic study on the incineration of ion-exchange resins was conducted using fluidized bed. In the experiment, cation or anion exchange resins with known quantities were fed into the fluidized bed maintained at a constant temperature from 550 to $750 \mathrm{degC}$. The apparent reaction rate constants $k$ \{sub ap\} could be evaluated by the time for completion of combustion derived from the continuous measurement of $\mathrm{CO}$ \{sub 2 \} concentration in the off-gas. It was confirmed that the reaction of the ion-exchange resins proceeded with the shrinking particle model forming no solid product layer and the rate of disappearance of the resins could be expressed by the surface chemical ricaction. Most preferable conditions for incinerating the ion-exchange resins were found to be about $650 \mathrm{deg} C$ for temperature and more than $4.91 \times 10$ \{sup -2$\} \mathrm{m}$ \{center dot\}s \{sup -1 \} for the air velocities at fluidized bed $u$ \{sub $B$ \}. Also, $k$ \{sub ap\} for cation and anion exchange resins were found to be $1.25 \times 10$ \{sup -2 \} and $1.51 \times 10$ \{sup -2 \}s \{sup -1 \}, respectively, at $650 \mathrm{deg} C$ and $u\{$ sub $B\}$ of $5.45 \times 10$ \{sup -2$\} m$ \{center dot\}s \{sup -1\}. (author).

10/7/26 (Item 26 from file: 103)

03252039 NTS-92-008675; EDB-92-014796

Title: Safety in the ARIES-III D- sup 3 He tokamak reactor design Author(s)/Editor(s): Herring, J.S.; Dolan, T.J. Corporate Source: EG and G Idaho, Inc., Idaho Falls, ID (United States) Sponsoring Organization: DOE USDOE, Washington, DC (United States) Conference Title: 14 . IEEE symposium on fusion engineering Conference Location: San Diego, CA (United States) Conference Date: 30 Sep - 3 Oct 1991

Publication Date: 1991 (5 p)

Report Number(s): EGG-M-91280 CONF-910968--40

Order Number: DE92003289

Contract Number (DOE): AC07-76ID01570

Language: In English

Availability: OSTI; NTIS; INIS; GPO Dep.

Abstract: The ARIES-3 reactor study is an extensive examination of the viability of a D-\{sup 3\}He-fueled commercial tokamak power reactor. Because neutrons are produced only through side reactions, the reactor has the significant advantages of reduced activation of the first wall and shield, low afterheat and Class $A$ or $C$ low level waste disposal. Since no tritium is required for operation, no lithium-containing breeding blanket is necessary. A ferritic steel shield behind the first wall protects the magnets from gamma and neutron heating and from radiation damage. The ARIES-3 reactor uses an organic coolant to cool the first wall, shiclu and divertor. The organic coolant has a loy 
efficiency. Radiation damage requires processing the coolant to remove and crack radiolytic products that would otherwise foul cooling surfaces. The cracking process produces waste, which must be disposed of through incineration or burial. We estimated the offsite doses due to incineration at five candidate locations. The plasma confinement requirements for a $D$ - $\{$ sup 3$\}$ He reactor are much more challenging than those for a D-T reactor. Thus, the demands on the divertor are more severe, particularly during a disruption. We explored the potential for isotopically tailoring the $4 \mathrm{~mm}$ tungsten layer on the divertor in order to reduce the offsite doses should a tungsten aerosol be released from the reactor after an accident. We also modeled a loss-of-cooling accident in which the organic coolant was burning in order to estimate the amount of radionuclides released from the first wall. We analyzed the disposition of the $20 \mathrm{~g} /$ day of tritium that is produced by D-D reactions and removed by the vacuum pumps. For our reference design, the tritium will be burned in the plasma. These results re-emphasize the need for low activation materials and advanced divertor designs, even in reactors using advanced fuels.

10/7/27 (Item 27 from file: 103)

03249963 GRA-91-91879; EDB-92-012720

Title: Waste-minimization assessment for a manufacturer of speed-reduction equipment. Environmental Research Brief Author(s)/Editor(s): Kirsch, F.W.; Maginn, J.C.

Corporate Source: University City Science Center, Philadelphia, PA (United States)

Publication Date: Oct 1991 (5 p)

Report Number(s): PB-92-104363/XAB

Contract Number (Non-DOE): EPA-R814903

Note: Sponsored by Environmental Protection Agency, Cincinnati, OH. Risk Reduction Engineering Lab.

Language: In Euglish

Availability: NTIS

Abstract: The U.S. Environmental Protection Agency (EPA) has funded a pilot project to assist small- and medium-size manufacturers who want to minimize their generation of hazardous waste but who lack the expertise to do so. Waste Minimization Assessment Centers (WMACs) were established at selected universities and procedures were adapted from the EPA Waste Minimization Opportunity Assessment Manual (EPA/625/7-88/003, July 1988). The WMAC team at Colorado State University performed an assessment at a plant manufacturing speed reduction equipment -- approximately 110,000 speed reduction units/yr. Plant operations include machining and assembling parts for worn gear shafts and other shafts, worn gear bodies, hubs and housings, bearings and seals. Keyed and threaded shafts are case-hardened, ground with a thread grinder, and deburred. Component parts are washed with an aqueous cleaner before assembly, and finished assemblies are spray painted with solvent-based paints and lacquer thinner. Spent cutting fluid and sludge, including turnings, and spent wash water are shipped offsite for disposal. Spent hydraulic oil and non-aqueous cutting fluid are shipped to a recycler. Waste paint and spent lacquer thinner are shipped offsite for incineration. The team's report, detailing findings and recommendations, indicated that most waste consists of spent aqueous cutting fluid, and that the greatest savings could be obtained by ultrafiltration and recycle of spent wash water. 


\section{THERMAL RECOVERY}

H-9 
9/9/2 (Item 2 from file: 103 )

03283988 NOV-92-014231; EDB-92-046745

Title: Environmental aspects of heavy-oil recovery by thermal EOR processes

Author(s): Sarathi, P. (National Inst. for Petroleum and Energy Research (US))

Source: Journal of Petroleum Technology (United States) v 43:6. Coden:

JPTJA ISSN: 0022-3522

Publication Date: Jun 1991 p 662-667

Document Type: Journal Article

Language: In English

Journal Announcement: EDB9208

Subfile: ETD (Energy Technology Data Exchange); INS (US Atomindex input). NOV (DOE contractor)

US DOE Project/NonDOE Project: NP

Country of Origin: United States

Country of Publication: United States

Abstract: This paper summarizes the major U.S. and State of California environmental regulations relevant to thermal EOR processes and assesses their impact on the process. The environmental laws that have the greatest impact on thermal EOR processes pertain to air quality, water quality, hazardous wastes, and environmental quality. This paper also identifies the source and type of pollutant likely to be generated in a typical thermal EOR facility.

Major Descriptors: *ENVIRONMENTAL POLICY -- THERMAL RECOVERY; *THERMAL RECOVERY -ENVIRONMENTAL POLICY; *THERMAL RECOVERY -- POLLUTION SOURCES

Descriptors: AIR QUALITY; CALIFORNIA; ENHANCED RECOVERY; HAZARDOUS MATERIALS; POLLUTANTS; REGULATIONS; USA; WASTES; WATER QUALITY

Broader Terms: DEVELOPED COUNTRIES; ENHANCED RECOVERY; ENVIRONMENTAL QUALITY; GOVERNMENT POLICIES; MATERIALS; NORTH AMERICA; RECOVERY; USA

Subject Categories: 021000* -- Petroleum -- Legislation \& Regulations

020900 -- Petroleum -- Environmental Aspects

INIS Subject Categories: C5612* .- Environmental aspects of petroleum -(1992-)

9/9/3 (Item 3 from file: 103)

03283967 NOV-92-014230; EDB-92-046724

Title: Control of waste gas from a thermal EOR operation

Author(s): Peavy, M.A.; Braun, J.E. (Oryx Energy Co. (US))

Source: Journal of Petroleum Technology (United States) v 43:6. Coden:

JPTJA ISSN: 0022-3522

Publication Date: Jun 1991 p 656-661

Document Type: Journal Article

Language: In English

Journal Announcement: EDB9208

Subfile: ETD (Energy Technology Data Exchange). NOV (DOE contractor)

US DOE Project/NonDOE Project: NP

Country of Origin: United States

Country of Publication: United States

Abstract: This paper summarizes a waste-gas treatment system designed to control emissions from thermal EOR wells. This case study discusses the need, design, installation, and operation of the system.

Major Descriptors: *GASEOUS WASTES -- WASTE PROCESSING; *THERMAL RECOVERY .- GASEOUS WASTES

Descriptors: AIR POLLUTION CONTROL; DESIGN; EMISSION; ENHANCED RECOVERY; INSTALLATION; OPERATION

Broader Terms: CONTROL; ENHANCED RECOVERY; MANAGEMENT; POLLUTION CONTROL; PROCESSING; RECOVERY; WASTE MANAGEMENT; WASTES 
Subject Categories: 020800* -- Petroleum -- Waste Management

9/9/4 (Item 4 from file: 103)

02931389 GRA-90-72630; EDB-90-148633; ERA-15-049524

Title: Final response to BDAT related comments document. D009, K044, K045,

K047, D011, P119, P120, and P and U wastes. Volume 1-I

Author(s)/Editor(s): Rosengrant, L;; Craig, R.

Corporate Source: Environmental Protection Agency, Washington, DC (USA).

Office of Solid Waste (Code: 9513743)

Publication Date: May 1990 (246 p)

Report Number(s): PB-90-234584/XAB EPA--530/SW-90/061K

Contract Number (Non-DOE): EPA-68-W9-0068

Note: See also Volume 1-H, PB--90-234576 and Volume 1-J, PB--90-234592.

Also available in set of 19 reports PC E99/MF E99, PB--90-234477

Document Type: Report

Language: In English

Journal Announcement: EDB9020

Availability: NTIS, PC A11/MF A02

Distribution: (Report):9 (MF):6 ND-00

Subfile: EPA (Energy Abstracts for Policy Analysis); ERA (Energy Research

Abstracts); ETD (Energy Technology Data Exchange). GRA (NTIS NTS)

US DOE Project/NonDOE Project: NP

Country of Origin: United States

Country of Publication: United States

Abstract: The contents of this article include the following:

characteristic wastes for mercury $p$ and $u$ wastes containing mercury

(data submission only, thermal recovery standard-demonstrability,

establishment of bdat standard level below the characteristic level, stabilization as bdat or sulfide precipitated d009 as bdat, alternative treatment for debris and other wastes, reconsideration of the retort cutoff level, treatment standard mixed waste, and indigenous waste); wastes from the manufacturing and processing of explosives (treatment standard); characteristic wastes for silver (treatment standards, precipiation, and concentration-based standards vs. recovery or stabilization); vanadium containing wastes (treatment technology, waste classification, treatment standards, and data submission); and $p$ and $u$ wastes containing thallium (data submission).

Major Descriptors: *MERCURY -- STANDARDS

Descriptors: COMPLIANCE; DATA PROCESSING; EXPLOSIVES; GROUND DISPOSAL; HAZARDOUS MATERIALS; INDUSTRIAL WASTES; LEACHING; POLLUTION REGULATIONS ; REMEDIAL ACTION; SILVER; STABILIZATION; SULFIDES; TECHNOLOGY UTILIZATION; THALLIUM; VANADIUM; WASTE PROCESSING; WASTE WATER

Broader Terms: CHALCOGENIDES; DISSOLUTION; ELEMENTS; HYDROGEN COMPOUNDS; LIQUID WASTES; MANAGEMENT; MATERIALS; METALS; OXYGEN COMPOUNDS; PROCESSING; REGULATIONS; SEPARATION PROCESSES; SULFUR COMPOUNDS; TRANSITION ELEMENTS; WASTE DISPOSAL; WASTE MANAGEMENT; WASTES; WATER

Subject Categories: 540120* -- Environment, Atmospheric .- Chemicals Monitoring \& Transport -. (1990-)

540220 -- Environment, Terrestrial -- Chemicals Monitoring \& Transport $-(1990-)$

540320 .- Environment, Aquatic -- Chemicals Monitoring \& Transport -(1990-)

290300 -- Energy Planning \& Policy -- Environment, Health, \& Safety 


\section{VITRIFICATION}

H- 13 
$19 / 7 / 3$ (Item 3 from file: 103 )

03294907 EDB-92-057664

Title: The Hanford Waste Vitrification Plant Project Technology Exchange program

Author(s)/Editor(s): Woodcock, G.; Westphal, L.O.

Corporate Source: Westinghouse Hanford Co., Richland, WA (United States)

Sponsoring Organization: DOE USDOE, Washington, DC (United States)

Conference Title: American Nuclear Society annual meeting

Conference Location: Boston, MA (United States) Conference Date: 7-12 Jun 1992

Publication Date: Jan 1992 (6 p)

Report Number(s): WHC-SA-1427 CONF-920606-10

Order Number: DE92008081

Contract Number (DOE): ACO6-87RL10930

Language: In English

Availability: OSTI; NTIS; INIS; GPO Dep.

Abstract: The status of the Hanford Waste Vitrification Plant (HWVP) Project is

discussed, with its relationship to other waste vitrification efforts in the

United States and abroad. The focus of this paper is on the benefits of the

Technical Exchange program as a vehicle for making scientific, technical, and

engineering data developed at a given site available to all organizations with

interest in waste vitrification.

19/7/4 (Item 4 from file: 103 )

03293700 EDB-92-056457

Title: Analyses of SRS waste glass buried in granite in Sweden and salt in the United States

Author(s)/Editor(s): Williams, J.P. (Tuskegee Inst., AL (United States));

Wicks, G.G. (Westinghouse Savannah River Co., Aiken, SC (United

States)); Clark, D.E. (Florida Univ., Gainesville, FL (United States))

; Lodding, A.R. (Chalmers Tekniska Hoegskola, Goeteborg (Sweden))

Corporate Source: Westinghouse Savannah River Co., Aiken, SC (United States)

Sponsoring Organization: DOE USDOE, Washington, DC (United States)

Conference Title: 5 . international symposium on ceramics in nuclear and hazardous waste management

Conference Location: Cincinnati, OH (United States) Conference Date: 29 Apr - 3 May 1991

Publication Date: 1991 (13 p)

Report Number(s): WSRC-MS-90-370 CONF-9104261--6

Order Number: DE92009419

Contract Number (DOE): AC09-89SR18035

Language: In English

Availability: OSTI; NTIS; INIS; GPO Dep.

Abstract: Simulated Savannah River Site (SRS) waste glass forms have been buried in the granite geology of the Stirpa mine in Sweden for two years. Analyses of glass surfaces provided a measure of the performance of the waste glasses as a function of time. Similar SRS waste glass compositions have also been buried in salt at the WIPP facility in Carlsbad, New Mexico for a similar time period. Analyses of the SRS waste glasses buried in-situ in granite will be presented and compared to the performance of these same compositions buried in salt at WIPP.

197/5 (Item 5 from file: 103)

03293699 EDB-92-056456

Title: The DWPF product composition control system at Savannah River:

Statistical process control algorithm

Author(s)/Editor(s): Postles, R.L.; Brown, K.G.

Corporate Source: Westinghouse Savannah River Co., Aiken, SC (United States)

Sponsoring Organization: DOE USDOE, Washington, DC (United States)

Conference Title: Symposium on nuclear waste management

Conference Location: Cincinnati, OH (United States) Conference Date: 28 Apr - 2 May 1991

Publication Date: 1991 (11 p)

Report Number(s): WSRC-MS-91-104 CONF-9104256--15 
Order Number: DE92009804

Contract Number (DOE): AC09-89SR18035

Language: In English

Availability: OSTI; NTIS; GPO Dep.

Abstract: The DWPF Process batch-blends aqueous radwaste (PHA) with solid radwaste (Sludge)

in a waste receipt vessel (the SRAT). The resulting SRAT-Batch is transferred to the next process vessel (the SME) and there blended with ground glass (Frit) to produce a batch of feed slurry. The SME-Batch is passed to a subsequent hold tank (the MFT) which feeds a Melter continuously. The Melter produces a molten glass wasteform which is poured into stainless steel canisters for cooling and, ultimately, shipment to and storage in a geologic Repository. The Repository will require that the glass wasteform be resistant to leaching by any underground water that might contact it. In addition, there are processing constraints on Viscosity and Liquidus Temperature of the melt. The Product Composition Control System (PCCS) is the system intended to ensure that the melt will be Processible and that the glass wasteform will be Acceptable. Within the PCCS, the SPC Algorithm is the device which guides control of the DWPF process. The SPC Algorithm is needed to control the multivariate DWPF process in the face of uncertainties (variances and covariances) whicil arise from this process and its supply, sampling, modeling, and measurement systems.

19/7/6 (Item 6 from file: 103)

03293697 EDB-92-056454

Title: Numerical simulation of high-level radioactive nuclear waste glass production Author(s)/Editor(s): Choi, I.G. (Westinghouse Savannah River Co., Aiken, SC (United States)); Ungan, A. (Purdue Univ., Indianapolis, IN (United States). Dept. of Mechanical Engineering)

Corporate Source: Westinghouse Savannah River Co., Aiken, SC (United States)

Sponsoring Organization: DOE USDOE, Washington, DC (United States)

Conference Title: International waste management conference

Conference Location: Seoul (Korea, Republic of) Conference Date: 21-26 Oct 1991

Publication Date: 1991 (10 p)

Report Number(s): WSRC-MS-91-099 CONF-911040-13

Order Number: DE92009901

Contrac! Number (DOE): AC09-89SR18035

Language: In English

Availability: OSTI; NTIS; INIS; GPO Dep.

Abstract: Vitrification of radioactive waste has become an international approach for converting highly radioactive wastes into a durable solid prior to placing them in a permanent disposal repository. The technology for the process is not new. The conversion melter is a direct descendant of all electric melters used for manufacturing of some commercial glass types. Therefore, the vitrification process of radioactive wastes inherits typical problems of all electric furnaces and creates some other specific problems such as noble metal sedimentation. The noble metals and nickel sulfides in the melter are heavier than molten glass and have a low solubility. In a reducing condition, these metals amalgamate and tend to settle on the melter floor. The metal deposit resulting from this settling has a potential to short circuit the melter. The objective of this paper is to identify the typical problems that have been encountered in the waste melter operations and to address how these problems can be tackled using state-of-the-art numerical simulation techniques. It is believed that the large amount of pilot-scale melter experience throughout the world, combined with the knowledge gained from state-of-the-art computer modeling techniques would give assurance that the existing and future radioactive wastes can be effectively converted into a durable glass material and safely placed in a permanent repository. 
SOLIDIFICATION 
15/7/3 (Item 3 from file: 103)

03293671 EDB-92-056428

Title: Choosing solidification or vitrification for low-level radioactive and mixed waste treatment

Author(s)/Editor(s): Gimpel, R.F.

Corporate Source: Westinghouse Environmental Management Co. of Ohio, Cincinnati, OH (United States).

Fernald Environmental Management Project

Sponsoring Organization: DOE USDOE, Washington, DC (United States)

Conference Title: Annual meeting of the Air and Waste Management Association (AWMA)

Conference Location: Kansas City, MO (United States) Conference Date: 21-26 Jun 1992

Publication Date: 14 Feb 1992 (16 p)

Report Number(s): FEMP-2256 CONF-9206114--2

Order Number: DE92009077

Contract Number (DOE): AC05-86OR21600

Language: In English

Availability: OSTI; NTIS; INIS; GPO Dep.

Abstract: Solidification (making concrete) and vitrification (making glass) are frequently the treatment methods recommended for treating inorganic or radioactive wastes. Solidification is generally perceived as the most economical treatment method. Whereas, vitrification is considered (by many) as the most effective of all treatment methods. Unfortunately, vitrification has acquired the stigma that it is too expensive to receive further consideration as an alternative to solidification in high volume treatment applications. Ironically, economic studies, as presented in this paper, show that vitrification may be more competitive in some high volume applications. Ex-situ solidification and vitrification are the competing methods for treating in excess of $450,000 \mathrm{~m}$ \{sup 3$\}$ of low-level radioactive and mixed waste at the Fernald Environmental Management Project (FEMP or simply, Fernald) located near Cincinnati, Ohio. This paper summarizes how Fernald is choosing between solidification and vitrification as the primary waste treatment method.

15/7/4 (Item 4 from file: 103 )

03293659 EDB-92-056416

Title: Polyethylene encapsulation of mixed wastes: Scale-up feasibility

Author(s)/Editor(s): Kalb, P.D.; Heiser, J.H.; Colombo, P.

Corporate Source: Brookhaven National Lab., Upton, NY (United States)

Sponsoring Organization: DOE USDOE, Washington, DC (United States)

Conference Title: Waste management ' 92

Conference Location: Tucson, AZ (United States) Conference Date: 1-5 Mar 1992

Publication Date: 1991 (9 p)

Report Number(s): BNL-47122 CONF-920307--46

Order Number: DE92010046

Contract Number (DOE): AC02-76CH00016

Language: In English

Availability: OSTI; NTIS; INIS; GPO Dep.

Abstract: A polyethylene process for the improved encapsulation of radioactive, hazardous, and mixed wastes have been developed at Brookhaven National Laboratory (BNL). Improvements in waste loading and waste form performance have been demonstrated through bench-scale development and testing. Maximum waste loadings of up to 70 dry wt \% mixed waste nitrate salt were achieved, compared with 13--20 dry wt \% using conventional cement processes. Stability under anticipated storage and disposal conditions and compliance with applicable hazardous waste regulations were demonstrated through a series of lab-scale waste form performance tests. Full-scale demonstration of this process using actual or surrogate waste is currently planned. A scale-up feasibility test was successfully conducted, demonstrating the ability to process nitrate salts at production rates (up to $450 \mathrm{~kg} / \mathrm{hr}$ ) and the close agreement between bench- and full-scale process parameters. Cored samples from the resulting pilot-scale (114 liter) waste form were used to verify homogeneity and to provide additional specimens for confirmatory performance testing.

$15 / 7 / 5$ (Item 5 from file: 103 )

03293635 EDB-92-056392

Title: Initial demonstration of DWPF process and product control strategy using actıal radioactive waste 
Author(s)/Editor(s): Andrews, M.K.; Bibler, N.E.; Jantzen, C.M.; Beam, D.C. Corporate Source: Westinghouse Savannah River Co., Aiken, SC (United States)

Sponsoring Organization: DOE USDOE, Washington, DC (United States)

Conference Title: 93. annual meeting and exposition of the American Ceramic Society (ACerS)

Conference Location: Cincinnati, OH (United States) Conference Date: 28 Apr - 2 May 1991

Publication Date: 1991 (14 p)

Report Number(s): WSRC-MS-91-012 CONF-910430--23

Order Number: DE92009635

Contract Number (DOE): AC09-89SR18035

Language: In English

Availability: OSTI; NTIS; INIS; GPO Dep.

Abstract: The Defense Waste Processing Facility at the Savannah River Site (SRS) will vitrify high-level nuclear waste into borosilicate glass. The waste will be mixed with properly formulated glass-making frit and fed to a melter at 1150 \{degrees\} C. Process control and product quality are ensured by proper control of the melter feed composition. Algorithms have been developed to predict the processability of the melt and the durability of the final glass based on this feed composition. To test these algorithms, an actual radioactive waste contained in a shielded facility at SRS was analyzed and a frit composition formulated using a simple computer spreadsheet which contained the algorithms. This frit was then mixed with the waste and the resulting slurry fed to a research scale, joule-heated melter operated remotely. Approximately $24 \mathrm{~kg}$ of glass were successfully prepared. This paper will describe the frit formulation, the vitrification process, and the glass durability.

$15 / 7 / 6 \quad$ (Item 6 from file: 103 )

03287805 AIX-23-024974; EDB-92-050562

Title: Polymers in the nuclear power industry

Author(s): Phillips, D.C.; Burnay, S.G. (AEA Industrial Technology, Harwell (United Kingdom))

Title: Irradiation effects on polymers

Author(s)/Editor(s): Clegg, D.W.; Collyer, A.A. (Sheffield Polytechnic (United Kingdom)) (eds.)

Publisher: London (United Kingdom) Elsevier Applied Science

Publication Date: 1991 p 345-381 (460 p)

ISBN: 1-85166-563-3

Language: In English

Abstract: This chapter is concerned with practical uses of organic polymers in the nuclear industry in applications where they are subjected to high energy radiation. Materials based on organic polymers are used as widely in the nuclear industry because of their versatility, low cost, ease of manufacture, corrosion resistance, and many other advantages which make them attractive for a wide range of applications. They are used for coatings, seals, cables containers, gloveboxes for example. However, these materials are susceptible to damage by ionising radiation with resulting changes in properties. The following have been looked at in detail: coatings and liners, plastic surfaces, seals and cables. Polymeric materials have also been considered for the immobilisation of intermediate level radioactive waste. (author). 
STABILIZATION

H-21 
11/7/12 (Item 12 from file: 103 )

03275974 EDR-92-038731

Title: Fiscal year 1992 program plan for evaluation and remediation of the generation and release of flammable gases in Hanford Site waste tanks

Author(s)/Editor(s): Johnson, G.D.

Corporate Source: Westinghouse Hanford Co., Richland, WA (United States)

Sponsoring Organization: DOE USDOE, Washington, DC (United States)

Publication Date: Jan 1992 (85 p)

Report Number(s): WHC-EP-0537

Order Number: DE92008383

Contract Number (DOE): AC06-87RL10930

Language: In English

Availability: OSTI; NTIS; INIS; GPO Dep.

Abstract: The Waste Tank Flammable Gas Stabilization Program was established in 1990 to provide for resolution of a major safety issue identified for 23 of the high-level waste tanks at the Hanford Site. This safety issue involves flammable gas mixtures, consisting mainly of $h \% d r o g e n$, nitrous oxide, and nitrogen, that are generated and periodically released in concentrations that exceed the lower flammability limit. Initial activities of the program have been directed at Tank 241-SY-101 because it exhibits the largest risk. The purpose of this document is to provide a brief description of the FY 1992 priorities, logic, work breakdown structure (WBS) and task descriptions for the Waste Tank Flammable Gas Stabilization Program. A major change for FY 1992 involves the core sampling and sample analyses. All activities associated with these tasks will be conducted under the Tank Waste Characterization Program (1N4). Resource requirements for the Waste Tank Flammable Gas Stabilization Program for fiscal years beyond 1)are given in the Waste Tank Safety Program Overview Plant (Gasper 1991).

11/7/9 (Item 9 from file: 103 )

03284437 EDb-92-047194

Title: Technology needs for treatment of DOE's low-level mixed wastes

Author(s)/Editor(s): Harmon, L.H.; Rhoderick, J.E. (USDOE Office of Environmental Restoration and Waste Management, Washington, DC (United States). Office of Waste Operations); Borduin, L.C. (Los Alamos National Lab., NM (United States)); Musgrave, B.C. (Lawrence Livermore National Lab., CA (United States)); Ross, W.A. (Pacific Northwest Lab., Richland, WA (United States))

Corporate Source: Los Alamos National Lab., NM (United States)

Sponsoring Organization: DOE USDOE, Washington, DC (United States)

Conference Title: Waste management ' 92

Conference Location: Tucson, AZ (United States) Conference Date: 1-5 Mar 1992

Publication Date: 1992 (17 p)

Report Number(s): LA-UR-92-644 CONF-920307--30

Order Number: DE92008481

Contract Number (DOE): W-7405-ENG-36

Language: In English

Availability: OSTI; NTIS; INIS; GPO Dep.

Abstract: The US Department of Energy (DOE) stores and generates

significant amounts of low-level mixed wastes (LLMW) consisting of

radioactive materials mixed with hazardous chemical substances. Many of

these wastes are regulated under the US Environmental Protection Agency

(EPA) Land Disposal Restrictions and must be treated and disposed in

compliance with applicable state and federal requirements. In general, treatment requirements include elimination of organic hazardous

constituents and stabilization of inorganic hazardous constituents.

Final waste forms must meet both EPA leach testing and DOE disposal

acceptance criteria. The DOE currently does not have an adequate

capability to ineet these treatment objectives. The Mixed Waste

Treatment Project has been established by the DOE to define needed LLMW 
treatment capabilities as a basis for either a prototype plant design or an existing facility modifications. Existing DOE mixed waste data bases were analyzed to identify the range of waste quantities and types and to define broad treatment categories needed to bring these wastes into compliance. Using these treatment categories as a starting point, we constructed a baseline flow sheet defining process steps from receipt through final form. From this baseline flow sheet, we developed functional and operational requirements ( $F$ ORs) for each process train. An initial set of near-term technologies was identified for each process step, and alternative near- and long-term options were listed. Based on these analyses, we identified technology gaps and improvement needs in the areas of characterization, waste handling, segregation and sorting, size reduction, decontamination, materials recycle, primary and secondary treatment for RCRA compliance, offgas treatment, and final waste forms.

11/7/6 (Item 6 from file: 103)

03293611 EDB-92-056368

Title: ISV of a simulated seepage trench: A Radioactive Field Test at ORNL Author(s)/Editor(s): Tixier, J.S.; Powell, T.D. (Pacific Northwest Lab.,

Richland, WA (United States)); Jacobs, G.K.; Spalding, B.P. (Oak Ridge National Lab., TN (United States))

Corporate Source: Oak Ridge National Lab., TN (United States)

Sponsoring Organization: DOE USDOE, Washington, DC (United States)

Conference Title: American Nuclear Society annual meeting

Conference Location: Boston, MA (United States) Conference Date: 7-12 Jun 1992

Publication Date: 1992 (6 p)

Report Number(s): CONF-920606-8

Order Number: DE92007832

Contract Number (DOE): AC05-84OR21400; AC06-76RL01830

Language: In English

Availability: OSTI; NTIS; INIS; GPO Dep.

Abstract: The pits and trenches used at Oak Ridge National Laboratory (ORNL) from 1951 through 1966 to dispose of over a million curies of radioactive liquid wastes are currently undergoing remedial investigations/feasibility studies to identify potential technologies for cleanup and/or stabilization. In situ vitrification (ISV) is a leading technology candidate because of the high risks associated with options requiring retrieval, and because of the high-quality waste form produced by ISV. The Radioactive Field Test, conducted on a simulated ORNL seepage trench, in May 1991, is the second step in evaluating ISV as a remedial action at these sites. This document discusses this field test. 


\section{ACID LEACHING}


6/7/6 (Item 6 from file: 103 )

02897784 GRA-90-01940; EDB-90-115025; ERA-15-040389; INS-90-029266

Title: Uranium ore treatment. June 1981-March 1990 (A Bibliography from the

COMPENDEX data base). Report for June 1981-March 1990

Corporate Source: National Technical Information Service, Springfield, VA (USA)

Publication Date: May 1990 (110 p)

Report Number(s): PB-90-869785/XAB

Note: Supersedes PB--81-864290. See also PB--90-869777

Language: In English

Availability: NTISPC N01/MF N01

Abstract: The treatment of uranium ores is reviewed with emphasis placed on acid leaching as the primary step in the process. Tailing disposal and proper handling of radioactive materials is emphasized. Primary treatment procedures include ion-exchange, sulfuric acid leaching, solvent extraction, and sedimentation. Environmental aspects of uranium milling and mining are examined in a related published bibliography. (This updated bibliography contains 265 citations, all of which are new entries to the previous edition.)

$6 / 7 / 7$ (Item 7 from file: 103)

02897783 GRA-90-01939; EDB-90-115024; ERA-15-040388; INS-90-029265

Title: Uranium ore treatment. January 1970-May 1981 (A Bibliography from the COMPENDEX data base). Report for January 1970-May 1981

Corporate Source: National Technical Information Service, Springfield, VA (USA)

Publication Date: May 1990 (267 p)

Report Number(s): PB-90-869777/XAB

Note: See also PB--90-869785

Language: In English

Availability: NTISPC N01/MF N01

Abstract: The treatment of uranium ores is reviewed with emphasis placed on acid leaching as the primary step in the process. Tailing disposal and proper handling of radioactive materials is emphasized. Primary treatment procedures include ion-exchange, sulfuric acid leaching, solvent extraction, and sedimentation. Environmental aspects of uranium milling and mining are examined in a related published bibliography. (This updated bibliography contains 300 citations, none of which are new entries to the previous edition.)

6/78 (Item 1 from file: 6 )

1475987 NTIS Accession Number: PB90-234618/XAB

Final Response to BDAT Related Comments Document. K071 and K106: Mercury Cell Process Wastes K086:

Residues from Ink Production Wastes Containing Cyanide. Volume 1-L

Rosengrant, L. ; Craig, R.

Environmental Protection Agency, Washington, DC. Office of Solid Waste Corp.

Source Codes: 031287518

Report No.: EPA/530/SW-90/061N May 90 251p

Languages: English

Journal Announcement: GRAI9020

See also Volume 1-K, PB90-234600 and Volume 1-M, PB90-234626.

Also available in set of 19 reports PC E99/MF E99, PB90-234477.

NTIS Prices: PC A12/MF A02

Country of Publication: United States

Contents: Mercury cell process wastes (data submission only, thermal recovery standard-demonstrability, treatment standard for K071 and K106 wastewater, multimedia impacts, stabilization as BDAT option, retain existing BDAT standard for $\mathrm{K} 071$ nonwastewater, reconsideration of retort cutoff level, and indigenous waste); Chlorinated hydrocarbon wastes (no comments were received for this waste code); Residues from ink production (treatment standards, subcategories, total chromium vs hexavalent chromium, mixture and derived-from rule, and soft hammer); Waste leaching solution from acid leaching of emission control dust/sludge from secondary lead smelting (no comments were received for this issue); Wastes containing cyanide (analytical methodology, BDAT, treatment standards, and soil/debris). 
6/7/9 (Item 2 from file: 6 )

1475939 NTIS Accession Number: PB90-234121/XAB

Final Treatment Standards for Nonwastewater and Wastewater Forms of K100. Volume 12 (Memorandum rept)

Paintal, A. S.

Versar, Inc., Springfield, VA.

Corp. Source Codes: 060372000

Sponsor: Environmental Protection Agency, Washington, DC. Office of Solid Waste.

Report No.: EPA/530/SW-90/059L 8 May 90 38p

Languages: English

Journal Announcement: GRA19020

See also Volume 11, PB90-234113 and Volume 13, PB90-234139. Sponsored by

Environmental Protection Agency, Washington, DC. Office of Solid Waste.

Also available in set of 25 reports PC E99/MF E99, PB90-234006.

NTIS Prices: PC A03/MF A01

Country of Publication: United States

Contract No.: EPA-68-W9-0068

Contents: The memorandum presents the technical support and rationale for the development of treatment standards for nonwastewater and wastewater forms of K100. According to $40 \mathrm{CFR}$ Part 261.32 (hazardous wastes from specific sources), waste code $\mathrm{K} 100$ is listed as waste leaching solution from acid leaching of emission control dust/sludge from secondary lead smelting. Treatment standards for K100 wastes were originally scheduled to be promulgated as part of the Third Third rulemaking. However, a treatment standard of 'No Land Disposal Based on No Generation' for K100 nonwastewaters was promulgated on August 8, 1988, and was subsequently revised on May 1, 1989, (54 FR 18836) to be applicable only to nonwastewater forms of these wastes generated by the process described in the listing description and disposed after August 17, 1988, and not generated in the course of treating wastewater forms of these wastes (Based on No Generation).

6/7/10 (Item 1 from file: 41 )

179043 92-00992

Treated waste/soil interactions and long-term metal mobility under acid rainwater leaching conditions

Donahoe, R.J.; Gong, Chang-Rui; Chasse, J.L.

Dep. Geol., Univ. Alabama, Box 870338, Tuscaloosa, AL 35487, USA

3. Annu. Symp. of the GCHSRC on Bioremediation, Fundamental and Effective Application Beaumont, TX (USA) 21-22 Feb 1991

J. HAZARDOUS MATER VOL. 28, NO. 1-2, pp. 236-237, Publ.Yr: 1991

SUMMARY LANGUAGE - ENGLISH

Languages: ENGLISH

Journal Announcement: V23N1

Contents: Column flow-through experiments have been conducted in which a treated municipal waste effluent has been reacted with two silty loam and two sandy loam soil samples having different TOC values, clay contents, and densities to study the attenuation of waste solution metals on soil columns. 
CHEMICAL TREATMENT

$H-29$ 
$5 / 7 / 1 \quad$ (Item 1 from file: 103 )

03258380 NOV-91-026152; EDB-92-021137

Title: Chemical basis for pyrochemical reprocessing of nuclear fuel

Author(s): Ackerman, J.P. (Chemical Technology Div., Argonne National Lab., Argonne, IL (US))

Source: Industrial and Engineering Chemistry Research (United States) v 30:1. Coden: IECRE ISSN: 0888-5885

Publication Date: Jan 1991 p 141-145

Language: In English

Abstract: The integral fast reactor (IFR) is an advanced breeder reactor concept that includes on-site reprocessing of spent fuel and wastes. Spent metallic fuel from the IFR is separated from fission products and cladding, and wastes are put into acceptable forms by use of a compact pyrochemical process based on partition of fuel and wastes between molten salt and liquid metal. To minimize reagent usage and, consequently, waste volume, electrotransport between metal phases is used extensively for feed dissolution and product recovery, but chemical oxidation and reduction are required for some operations. This paper describes the processes that are used and presents the chemical theory that was developed for quantitatively predicting the results of both chemical and electrotransport operations.

$5 / 7 / 2 \quad$ (Item 2 from file: 103 )

03242544 INS-91-033168; EDB-92-005301

Title Mediated electrochemical hazardous waste destruction Author(s)/Editor(s): Hickman, R.G.; Farmer, J.C.; Wang, F.T.

Corporate Source: Lawrence Livermore National Lab., CA (United States)

Sponsoring Organization: DOE USDOE, Washington, DC (United States)

Conference Title: I EC special symposium of the American Chemical Society

Conference Location: Atlanta, GA (United States) Conference Date: 1-3 Oct 1991

Publication Date: Aug 1991 (14 p)

Report Number(s): UCRL-JC-106676 CONF-9110158--2

Order Number: DE92001819

Contract Number (DOE): W-7405-ENG-48

Language: In English

Availability: OSTI; NTIS; INIS; GPO Dep.

Abstract: There are few permitted processes for mixed waste (radioactive plus chemically hazardous) treatment. We are developing electrochemical processes that convert the toxic organic components of mixed waste to water, carbon dioxide, and innocuous anions such as chloride. Aggressive oxidizer ions such as $\mathrm{Ag}\{\sup 2+\}$ or $\mathrm{Ce}\{\sup +4\}$ are produced at an anode. These can attack the organic molecules directly. They can also attack water which yields hydroxyl free radicals that in turn attack the organic molecules. The condensed (i.e., solid and/or liquid) effluent streams contain the inorganic radionuclide forms. These may be treated with existing technology and prepared for final disposal. Kinetics and the extent of destruction of some toxic organics have been measured. Depending on how the process is operated, coulombic efficiency can be nearly $100 \%$. In addition, hazardous organic materials are becoming very expensive to dispose of and when they are combined with transuranic radioactive elements no processes are presently permitted. Mediated electrochemical oxidation is an ambient-temperature aqueous-phase process that can be used to oxidize organic components of mixed wastes. Problems associated with incineration, such as high-temperature volatilization of radionuclides, are avoided. Historically, $\mathrm{Ag}(2)$ has been used as a mediator in this process. $\mathrm{Fe}(6)$ and $\mathrm{Co}(3)$ are attractive alternatives to $\mathrm{Ag}(2)$ since they form soluble chlorides during the destruction of chlorinated solvents. Furthermore, silver itself is a toxic heavy meta! Quantitative data has been obtained for the complete oxidation of ethylene glycol by $\mathrm{Fe}(6)$ and $\mathrm{Co}$, wagh ethylene glycol is a nonhalogenated organic, this data has enabled us to make direct comparisons of vities of $\mathrm{Fe}(6)$ and $\mathrm{Co}(3)$ with $\mathrm{Ag}(2)$. Very good quantitative data for the oxidation of ethylene glycol by $\mathrm{Ag}(2)$ had already been collected. 4 refs., 6 figs. 
Title: Review of treatment for hazardous-waste streams (Chapter 21). Book chapter

Author(s)/Editor(s): Grosse, D.W.

Corporate Source: Environmental Protection Agency, Cincinnati, OH (United States). Hazardous Waste Engineering

Research Lab.

Publication Date: 1991 (74 p)

Report Number(s): PB-91-191163/XAB EPA--600/D-91/088

Note: Pub. in Library of Environmental Science, v3 Aug 90 and Advances in

Environmental Technology and Management, Mar 90.

Language: In English

Availability: NTIS

Abstract: The publication will examine some of the practices being used or considered for use at on-site or commercial hazardous waste treatment, storage and disposal facilities (TSDF). Options for managing hazardous wastes containing heavy metals and/or cyanide compounds involve conventional treatment processes, recycle/reuse applications and waste minimization. Some of the technologies to be reviewed in this section include: precipitation applications such as hydroxide (e.g. lime, magnesium and iron oxyhydroxide), sulfide and carbonate systems; reduction techniques employing chromium, mercury and selenium reducing agents; adsorption/selection techniques using activated carbon ion exchange and hydrous solids; stabilization/fixation with discussion on applications, interferences and landfill design; cyanide destruction, including chemical oxidation (e.g. alkaline chlorination, ozonation/photolysis), electrolytic decompostion and incineration; and pollution prevention measures such as source reduction, recycling and reuse. Each of these options will be described in terms of effectiveness of treatment in removing the hazardous constituents of interest and characterization of the generated treatment residuals or in the case of waste minimization practices, the degree to which the constituents of concern are eliminated at the point of waste generation.

$5 / 7 / 4 \quad$ (Item 1 from file: 6 )

1538508 NTIS Accession Number: PB91-191163/XAB

Review of Treatment for Hazardous Waste Streams (Chapter 21) (Book chapter)

Grosse, D. W.

Environmental Protection Agency, Cincinnati, $\mathrm{OH}$. Hazardous Waste

Engineering Research Lab.

Corp. Source Codes: 034122080

Report No.: EPAV600/D-91/088 $199174 p$

Languages: English Document Type: Journal article

Journal Announcement: GRAI9116

Pub. in Library of Environmental Science, v3 Aug 90 and Advances in

Environmental Technology and Management, Mar 90.

NTIS Prices: PC A04/MF A01

Country of Publication: United States

Contents: The publication will examine some of the practices being used or considered for use at on-site or commercial hazardous waste treatment, storage and disposal facilities (TSDF). Options for managing hazardous wastes containing heavy metals and/or cyanide compounds involve conventional treatment processes, recycle/reuse applications and waste minimization. Some of the technologies to be reviewed in this section include: precipitation applications such as hydroxide (e.g. lime, magnesium and iron oxyhydroxide), sulfide and carbonate systems; reduction techniques employing chromium, mercury and selenium reducing agents; adsorption/selection techniques using activated carbon ion exchange and hydrolysis. 
NEUTRALIZATION 
10/7/1 (Item 1 from file: 103 )

03289054 DE-92-003559; EDB-92-051811

Title: Application of UASB-reactors to industrial waste-water treatment; performance data and results in granulation control

Author(s): Morvai, L.; Mihaltz, P.; Czako, L.; Hollo, J. (Technical

Univ., Budapest (Hungary). Inst. of Agricultural Chemical Technology)

Source: Acta Biotechnologia (Germany) v 11:5. Coden: ACBTD ISSN: 0138-4988

Publication Date: 1991 p 409-418

Language: In English

Abstract: Several types of high organic matter polutants containing (COD-range: 3-50 kg.m \{sup -3\}) industrial waste waters were treated in laboratory scale $(1.2-23 \mathrm{dm}$ \{sup 3\}) sludge blanket (UASB) and UASB-fixed bed hybrid (UBF) reactors. In most cases higher than $80 \%$ of COD-removal efficiency has been attained. The $\mathrm{CO}\{$ sub 2$\}$ content of the biogas developed was mainly influenced by the neutralization (base to acid) ratio related to feed $\mathrm{pH}$. Cell immobilization by granule formation was considered as a change in microbial population: Enrichment and aggregate formation of Methanotrix-like filamentous microorganisms. Based on physiological and physical indexes of microbial selection and with regard to the different sensitivities of microorganisms to substrate inhibition, a new start-up method was developed for rapid (40-45 days) granulation of raw digested sludge. (orig.).

10/72 (Item 2 from file: 103 )

03285898 EDB-92-048655

Title: Waste knowledge: The key to waste minimization

Author(s): Noskin, H.A. (Idaho National Engineering Lab., Idaho Falls (United States))

Title: DOE model conference on waste management and environmental restoration. Proceedings

Corporate Source: USDOE, Washington, DC (United States)

Conference Title: 6. annual Department of Energy model conference on waste management and environmental restoration

Conference Lucation: Oak Ridge, TN (United States) Conference Date: 29 Oct - 2 Nov 1990

Publication Date: 1990 p 1, Paper 12 (343 p)

Report Number(s): CONF-9010166--

Order Number: DE91010951

Language: In English

Availability: OSTI; NTIS; INIS

Abstract: Waste minimization is an important aspect of waste management. One very simple way to reduce or minimize waste is through good housekeeping. In this case segregation, and knowing what kind of waste you truly have. A key problem to waste management is the ultra-conservative approach GOCO's have taken. In a time when the contractors are playing catch-up, many decisions have been made without a common sense justification. These kinds of decisions are making a bad problem worse and at the same time confusing employees. Approximately $240,000 \mathrm{~kg}$ of hazardous waste is generated in the US annually. There are only about 250 operating hazardous waste landfills, and those are closing at a very fast rate. In addition, soon most hazardous waste will fall under the Land Disposal Restriction requirements. Segregation, neutralization, and sampling are important ingredients to solving waste problems. Make sure that the waste is characterized properly. Anti-c clothing should be visually inspected for hazardous waste contamination; if it hasn't been contaminated, it shouldn't be disposed of as hazardous waste. Non-listed acids and basics can be neutralized and removed. These good housekeeping measures, among other common sense ideas, can reduce waste generated at the source and give employees a clear understanding of good waste management.

$10 / 7 / 3$ (Item 3 from file: 103)

03284549 EDB-92-047306

Title: Effluent testing for the Oak Ridge Toxic Substances Control Act mixed waste incinerator emissions tests of January 16 and 18, 1991

Author(s)/Editor(s): Shor, J.T. (Oak Ridge National Lab., TN (United States)); Bostick, W.D.; Coroneos, A.C.; Bunch, D.H.; Gibson, L.V.; Hoffmann, D.P.; Shoemaker, J.L. (Oak Ridge K-25 Site, TN (United States))

Corporate Scurce: Oak Ridge K-25 Site, TN (United States)

Sponsoring Organization: DOE USDOE, Washington, DC (United States)

Publication Date: Feb 1992 (52 p)

Report Number(s): K/QT-407 
Order Number: DE92008519

Contract Number (DOE): AC05-84OT21400

Language: In English

Availability: OSTI; NTIS; INIS; GPO Dep.

Abstract: On January 16 and 18, 1991, special emissions tests were conducted at the Oak Ridge, K-25 Site

Toxic Substances Control Act (TSCA) Incinerator. Both tests were approximately $6 \mathrm{~h}$ long and were performed at TSCA temperatures (1200\{degrees\} C, secondary combustion chamber (SSC)). Liquid feed and effluent samples were collected every $30 \mathrm{~min}$. A filter was used to collect particles from stack gases to study morphology and composition during the first test. Isokinetic air samples were also taken during the second test. Metals emissions from the second test were evaluated using the Environmental Protection Agency (EPA) Method 5 sampling train. The aqueous waste was collected and fed in batches to the Central Neutralization Facility (CNF), where it was treated by iron coprecipitation and polymer flocculation and data were collected. In the first test (1-16-91), the aqueous and organic wastes were fed directly to the kiln or primary combustion chamber (PCC). In the second test (1-18-91), the remaining organic waste from the first test was fed into the SSC, and other organic waste was fed into the PCC. One objective of the two tests was to determine if feeding the same organic waste into the two combustion chambers made a difference in a partitioning of uranium and other metals. No evaluation of radionuclides other than uranium was made. The partition coefficient of uranium to the quench water was 0.3 on January 16 and 0.35 on January 18; so directing Tank 306A to the feed to the primary vs the secondary combustion chamber appears to have made little difference. The partition coefficient of uranium to the stack on January 18 was 0.0039 .5 refs., 15 figs., 26 tabs.

10/7/4 (Item 4 from file: 103 )

03275905 FRD-92-000131; EDB-92-038662

Title: Solidification of TRU wastes in a ceramic matrix

Original Title: Verfestigung TRU-haltiger abfaelle in keramischer matrix

Author(s)/Editor(s): Loida, A.; Schubert, G. (Kernforschungszentrum

Karlsruhe $\mathrm{GmbH}(\mathrm{DE})$. Inst. fuer nukleare Entsorgungstechnik)

Corporate Source: Commission of the European Communities, Luxembourg (Luxembourg)

Publication Date: 1991 (86 p)

Report Number(s): EUR-13509

Order Number: TI92772855

Contract Number (Non-DOE): Fl1W-0021-D (B)

Language: In German

Availability: OSTI; NTIS (US Sales Only)

Abstract: Aluminumsilicate based ceramic materials have been evaluated as an alternative waste form for the incorporation of TRU wastes. These waste forms are free of water and - cannot generate hydrogen radiolyticly, - they show good compatibility between the compounds of the waste and the matrix, - they are resistent against aqueous solutions, heat and radiation. $R$ and $D$-work has been performed to demonstrate the suitability of this waste form for the immobilization of TRU-wastes. Four kinds of original TRU-waste streams and a mixture of all of them have been immobilized by ceramization, using glove box and remote operation technique as well. Clay minerals, (kaolinite, bentonite) and reactive corundum were selected as ceramic raw materials (KAB 78 ) in an appropriate ratio yielding $78 \mathrm{wt} \% \mathrm{Al}$ \{sub 2\} $\mathrm{O}$ \{sub 3 \} and $22 \mathrm{wt} \% \mathrm{SiO}$ \{sub 2\}. The main process steps are (i) pretreatment of the liquid waste (concentration, denitration, neutralization, solid- liquid separation), (ii) mixing with ceramic raw materials and forming, (iii) heat treatment with $\mathrm{T}$ max. of 1300 \{sup 0 \} $\mathrm{C}$ for 15 minutes. The waste load of the ceramic matrix has been increased gradually from 20 to 50 , in some cases to $60 \mathrm{wt} . \%$. 


\section{INTERNAL DISTRIBUTION}

1. J. M. Begovich

2. A. G. Croff

3. A. A. Francis

4. R. L. Jolley

5-8. J. A. Klein

9. J. E. Mrochek

10. I. W. Osborne-Lee
11-12. C. E. Pugh
13. T. Wright
14. ORNL Patent Section
15. Central Research Library
16. Document Reference Section
17-18. Laboratory Records
19. Laboratory Records (RC)

\section{EXTERNAL DISTRIBUTION}

20. B. Arrowsmith, SEG, P.O. Box 2530, 1560 Bear Creek Rd., Oak Ridge, TN 37830

21. R. Gallagher, NSSI, P.O. Box 34042, Houston, TX 77234

22. A. Greenland, David C. Cox \& Associates, 5501 Cherokee Ave., Suite 111, Alexandria, VA 22312

23. K. Higgins, Envirocare, Salt Lake City, UT 84111

24-28. S. Jones, Office of Solid Waste, U.S. Environmental Protection Agency, Washington, DC 20460

29. J. Lucas, RAMP Industries, 1127 W. 46th Ave., Denver CO 80211

30. J. McVey, DSSI, P.O. Box 863, Kingston, TN 37763

31. B. Warren, Quadrex Corp., 1940 NW 67th Place, Gainesville, FL 32606-1649

32. Office of Assistant Manager for Energy Research and Development, U.S. Department of Energy, Oak Ridge Field Office, P.O. Box 2001, Oak Ridge, TN 37831-8600

33-35. Office of Scientific and Technical Information, U.S. Department of Energy, P.O. Box 62, Oak Ridge, TN 37831

36- . Given distribution as shown in NRC categories ... 
DATE

FILMED

$4 / 12 / 93$ 
